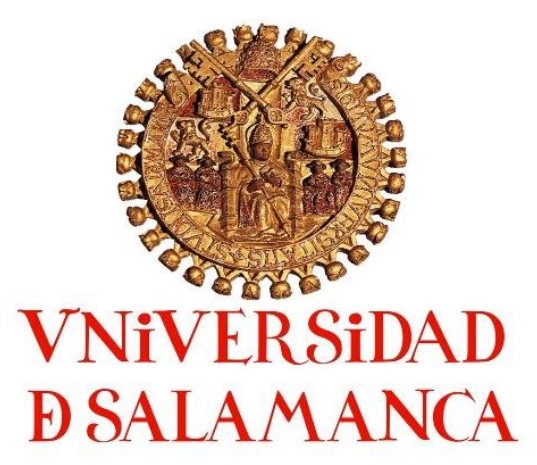

FACULTAD DE DERECHO

DEPARTAMENTO DE DERECHO PÚBLICO GENERAL

DOCTORADO EN PROCESOS POLÍTICOS CONTEMPORÁNEOS

IMPACTOS DE LOS MOVIMIENTOS SOCIALES: UNA SÍNTESIS DE LA PERSPECTIVA INTEGRADORA Y LOS MECANISMOS DE LA CONTIENDA POLÍTICA A PARTIR DEL ESTUDIO DE DOS MOVIMIENTOS SOCIALES EN COLOMBIA

TESIS DOCTORAL

VERA XIOMARA SAMUDIO REYES

DIRECTOR

SALVADOR MARTII I PUIG

SALAMANCA, 2015 


\section{IMPACTOS DE LOS MOVIMIENTOS SOCIALES: \\ UNA SÍNTESIS DE LA PERSPECTIVA INTEGRADORA Y LOS \\ MECANISMOS DE LA CONTIENDA POLÍTICA A PARTIR DEL ESTUDIO \\ DE DOS MOVIMIENTOS SOCIALES EN COLOMBIA}

TESIS DOCTORAL

VERA XIOMARA SAMUDIO REYES

DIRECTOR

SALVADOR MARTÍ I PUIG

VISADO 


\section{Índice de Contenido}

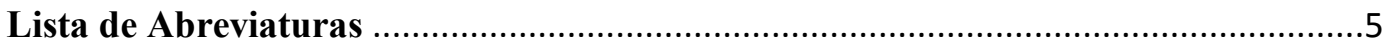

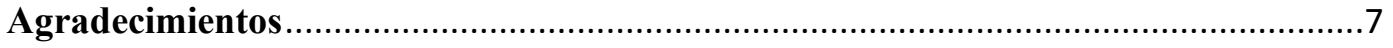

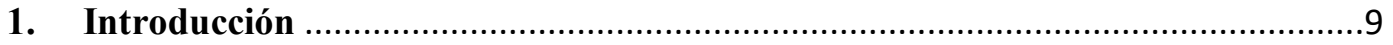

1.1. Estudio de dos Movimientos Sociales en Colombia ..........................................

1.2. Las teorías para el estudio de los Movimientos Sociales .................................13

1.2.1. Las teorías sobre el Comportamiento Colectivo ......................................14

1.2.2. La Agenda Clásica sobre los Movimientos Sociales................................16

1.2.3. Los Nuevos Movimientos Sociales........................................................19

1.2.4. Las Agendas Contemporáneas .................................................................20

1.2.5. Impactos de los Movimientos Sociales ..................................................22

1.3. El Marco Teórico de esta investigación.............................................................24

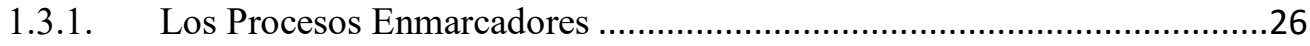

1.3.2. Estructuras de Movilización ................................................................28

1.3.4. Estructuras de Oportunidades Políticas....................................................34

1.3.5. Los Mecanismos de la contienda política ..............................................38

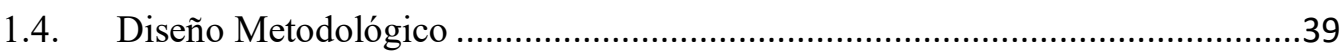

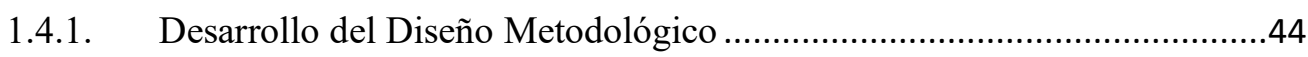

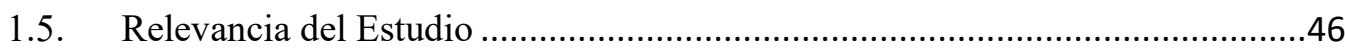

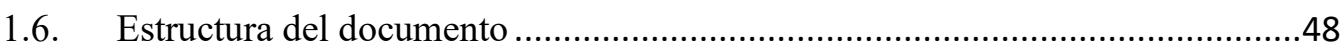

2. El Contexto del Conflicto Político, Social y Armado en Colombia ......................51

2.1. El Estado Colombiano ……………...........................................................

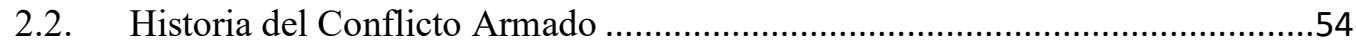

3. Primera Parte. La Ruta Pacífica de las Mujeres...............................................59

3.1. Capítulo 1. Eı Surgimiento de la Ruta Pacífica de las Mujeres ...................59

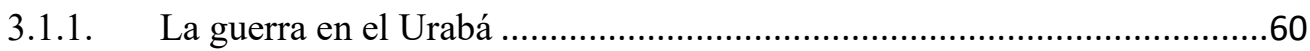

3.1.2. Violencia contra las Mujeres ...............................................................64

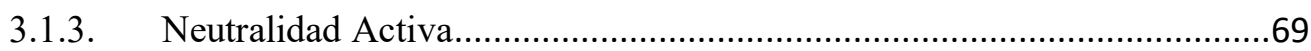

3.1.4. La década de los 90 para el feminismo en Colombia ................................71

3.1.5. El nacimiento de la Ruta Pacífica de las Mujeres .....................................75 


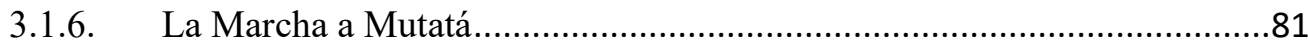

3.2. Capítulo 2: El Desarrollo de la Ruta Pacífica de las Mujeres ......................86

3.2.1. Primeras movilizaciones y nuevos repertorios ...........................................86

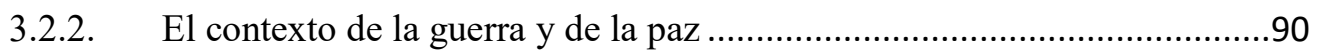

3.2.3. El Desarrollo de la Ruta Pacífica de las Mujeres .......................................98

3.2.4. El Movimiento de Mujeres contra la Guerra.........................................100

3.2.5. La persistencia de la violencia contra las mujeres .................................103

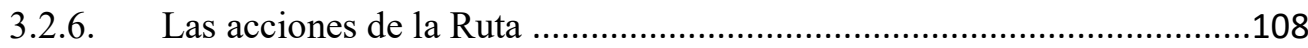

3.2.7. La Ruta Pacífica de las Mujeres contra la impunidad .............................114

3.2.8. La lucha contra el desplazamiento forzado y sus consecuencias.............117

3.3. Capítulo 3: Análisis de los Elementos Descriptivos de la Ruta ..................120

3.3.1. Los Marcos Cognitivos de la Ruta.........................................................122

3.3.2. Organización y Repertorios de la Ruta Pacífica de las Mujeres...............142

3.3.3. Una mirada Cuantitativa ......................................................................165

3.4. Capítulo 4: Los efectos de la movilización de la Ruta Pacífica de las

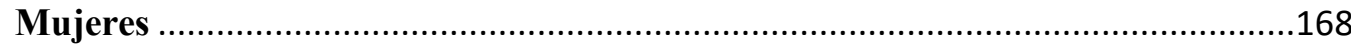

3.4.1. Y comienza a "cocinarse" el hito ..........................................................169

3.4.2. La Ruta en la preparación de la Audiencia ............................................176

3.4.3. La expedición del Auto 092 de 2008 ...................................................180

3.5. Capítulo 5: La influencia de la Ruta Pacífica de las Mujeres en la expedición del Auto 092 de 2008 de la Corte Constitucional ...............................189

3.5.1. La Estructura de Oportunidades Políticas ...............................................190

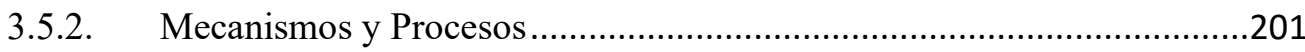

3.5.3. Algunas Conclusiones ....................................................................212

4. Segunda Parte: El Movimiento Nacional de Víctimas de Crímenes de Estado en

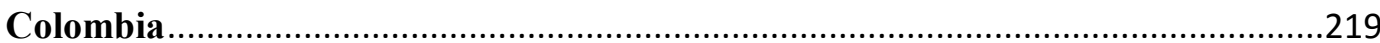

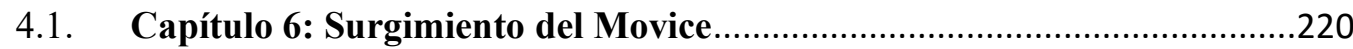

4.1.1. El paramilitarismo de Estado en el conflicto colombiano .......................220

4.1.2. La Legalidad y la Impunidad del paramilitarismo: la historia de los crímenes de Estado vista por el Movice .............................................................222

4.1.3. El monólogo entre el gobierno y los paramilitares ................................227

4.1.4. Resistencia civil y lucha contra la impunidad .........................................229

4.1.5. Las víctimas del Estado perseveran en su lucha ....................................235

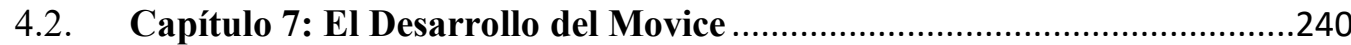


4.2.1. La Ley 975 en el centro de la contienda ...........................................241

4.2.2. Las víctimas del Estado se reúnen y se visibilizan..................................246

4.2.3. Las estrategias para la movilización ...................................................249

4.2.4. El contexto de la "Seguridad Democrática": estigmatización y re

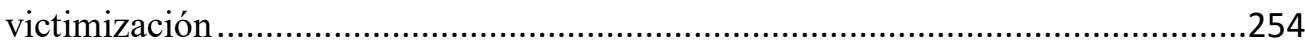

4.2.5. La movilización de las víctimas del Estado por sus derechos ..................257

4.2.6. Se cierra un círculo criminal en torno al gobierno ..................................262

4.3. Capítulo 8: Análisis de los Elementos Descriptivos del Movice ................264

4.3.1. Los marcos cognitivos del Movice …………………………….........266

4.3.2. Organización y Repertorios del Movice ..............................................288

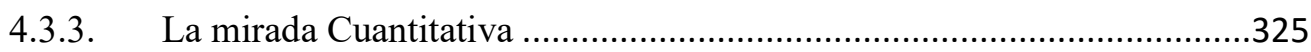

4.4. Capítulo 9: Los Efectos de la Movilización del Movice ..............................327

4.4.1. Las voces de las Víctimas llegan al Congreso .......................................328

4.4.2. Primer Proyecto de Ley …………….....................................................330

4.4.3. Y "tumban” la Ley...............................................................................339

4.4.4. El Gobierno Santos y la bancada de Unidad Nacional .............................340

4.4.5. Segundo Proyecto de Ley ...................................................................

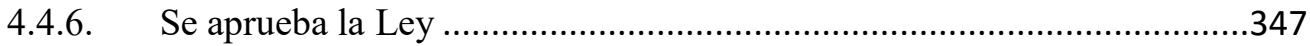

4.5. Capítulo 10: La Influencia del Movice en la Ley 1448 de 2011 .................349

4.5.1. Estructura de Oportunidades Políticas ....................................................350

4.5.2. Los Mecanismos y los Procesos .................................................................366

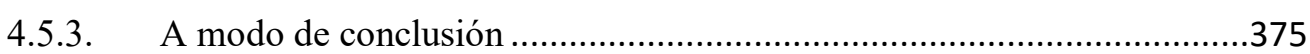

5. Conclusiones Comparadas y Perspectivas de Investigación...............................383

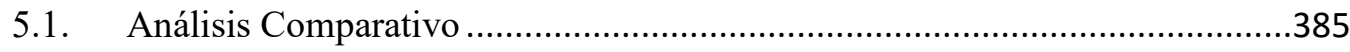

5.1.1. Cuadro Comparativo ……….............................................................387

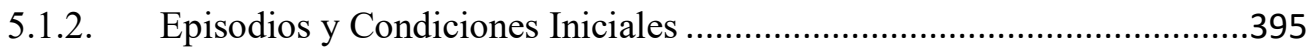

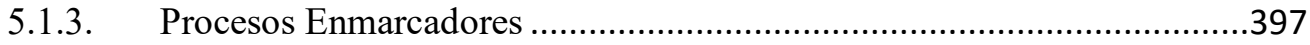

5.1.4. Estructuras de Movilización ................................................................400

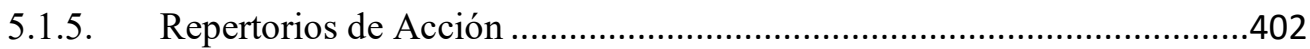

5.1.6. Estructura de Oportunidades Políticas ...................................................405

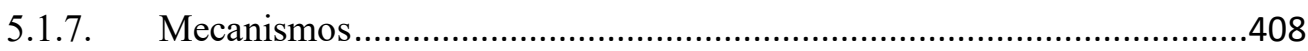

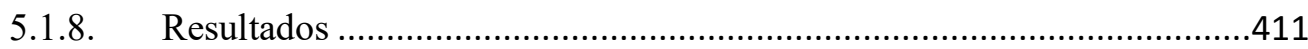

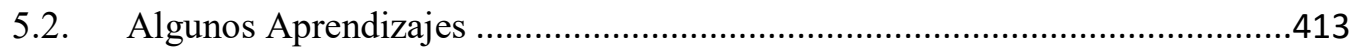




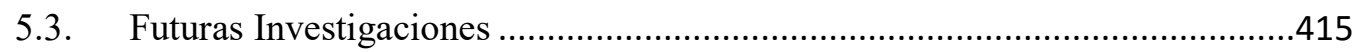

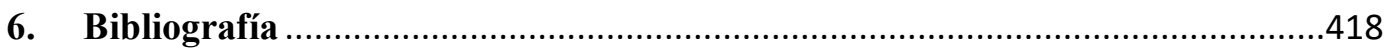

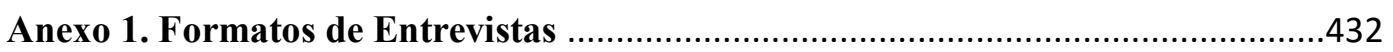

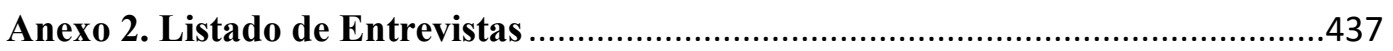

Anexo 3. Esquema de Codificación para Análisis en Atlas Ti .................................439

Anexo 4. Cifras de Victimización por Año y por Departamento ……......................443

\section{Índice de Ilustraciones}

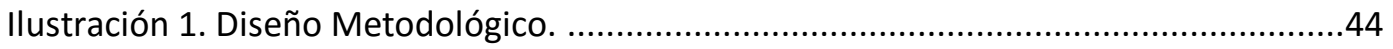

Ilustración 2. Mapeo de la evolución de la victimización por el conflicto en Colombia. ..58

Ilustración 3. Presencia regional de la Ruta Pacífica de las Mujeres. .............................145

Ilustración 4. Movilizaciones Ruta Pacífica entre 1996 y 2011 ......................................166

Ilustración 5. Modelo de explicación del Hito en el Episodio de Contienda ....................218

Ilustración 6. Presencia regional del Movice ...............................................................290

Ilustración 7. Movilizaciones de Víctimas por año entre 1986 y 2013 ..........................326

Ilustración 8. Modelo de explicación del Hito en el Episodio de Contienda ....................382

\section{Índice de Tablas}

Tabla 1. Análisis de la incidencia de la Ruta en el número y el tipo de movilizaciones de mujeres entre 1975 y 2013

Tabla 2. Análisis de la incidencia de MOVICE en el número y el tipo de movilizaciones de

Víctimas entre 1986 y 2013 


\section{Lista de Abreviaturas}

$\mathrm{ACCU}$

ACNUR

ADESCOP

AECID

ANDAS

ASONAL

AUC

CAJAR

CCEEU

CCJ

CEDAW

CINEP-PPP

CODHES

CONVIVIR

$\mathrm{CPDH}$

CREDHOS

Humanos

CRIC

CUT

DAS

DINEM

DNP

DOC

ELN
Autodefensas Campesinas de Córdoba y Urabá Agencia de Naciones Unidas para los Refugiados Asociación de Desplazados y Desplazadas por la Convivencia Pacífica

Agencia Española de Cooperación Internacional para el Desarrollo

Asociación Nacional de Ayuda Solidaria

La Asociación Nacional de Trabajadores del Sistema

Judicial Colombiano

Autodefensas Unidas de Colombia

Colectivo de Abogados José Alvear Restrepo

Coordinación Colombia, Europa, Estados Unidos

Comisión Colombiana de Juristas

Convención para la eliminación de todas las formas de discriminación contra la mujer

Centro de Investigación y Educación Popular

Consultoría para los Derechos Humanos y el

Desplazamiento Forzado

Cooperativas de Vigilancia y Seguridad Privada para la autodefensa agraria

Comité permanente por la defensa de derechos humanos

Corporación Regional para la Defensa de los Derechos

Consejo Regional Indígena del Cauca

Central Unitaria de Trabajadores

Departamento Administrativo de Seguridad

Dirección Nacional para la Equidad de la Mujer

Departamento Nacional de Planeación

Dinamics Of Contention

Ejército de Liberación Nacional 
EPL

FARC-EP

FUNSAREP

GMH

ICBF

IMP

INSTRAW

M-19

MAS

MORENA

MOVICE

OACNUDH

Humanos

OEA

OFP

OIA

OMCT

ONG

ONU

PROFAMILIA

RUV

SENA

SNAIPD

Desplazada

SUIPPCOL

Colombia

UNIFEM
Ejército Popular de Liberación

Fuerzas Armadas Revolucionarias de Colombia

Fundación Santa Rita para la Educación y la Promoción

Grupo de Memoria Histórica

Instituto Colombiano de Bienestar Familiar

Iniciativa de Mujeres por la Paz

Instituto Internacional de Investigaciones y

Capacitación para la Promoción para la Mujer

Movimiento 19 de Abril

Muerte a Secuestradores

Movimiento de Renovación Nacional

Movimiento de Víctimas de Crímenes de Estado

Oficina del Alto Comisionado para los Derechos

Organización de Estados Americanos

Organización Femenina Popular

Organización Indígena de Antioquia

Organización Mundial contra la Tortura

Organización No Gubernamental

Organización de Naciones Unidas

Asociación Probienestar de la Familia Colombiana

Registro Único de Víctimas

Servicio Nacional de Aprendizaje

Sistema Nacional de Atención a la Población

Programa Suizo para la Promoción de la Paz en

Fondo de Desarrollo de las Naciones Unidas para la Mujer 


\section{Agradecimientos}

La identificación de una temática, la estructuración de unas preguntas e hipótesis y, en general, el desarrollo de una investigación doctoral, suele estar profundamente imbricado por la experiencia personal y cotidiana de quien acomete la tarea. La decisión de adentrarse en el estudio de los Movimientos Sociales y la Acción Colectiva en Colombia como tema de investigación en esta Tesis Doctoral, refleja por sí misma la curiosidad y admiración que siento por la determinación y valentía de miles de personas que optaron por la defensa de los derechos humanos en un contexto abiertamente hostil y degradado como el que nos ha impuesto la guerra. Por eso, mi primer y más sentido agradecimiento es para la Ruta Pacífica de las Mujeres y el Movimiento Nacional de Víctimas de Crímenes de Estado, por abrirme sus puertas y permitirme entrar en sus recintos para preguntar, indagar y analizar sobre sus trayectorias, decisiones y apuestas de futuro. Gracias a las mujeres y hombres que hicieron pausas en sus trabajos para dedicar tiempo y energía a responder con paciencia una a una mis preguntas y mis correos, a contarme y a mostrarme sus realidades y sus experiencias de lucha más allá de los imaginarios y concepciones pre construidas.

Agradezco también a Salvador Martí i Puig, mi director, por mostrarme hace varios años las posibilidades inmensas de los estudios sobre Movimientos Sociales y lo mucho que podemos aprender a través de ellos. Por su confianza, apertura y paciencia para recomponer el camino durante estos años de investigación cuando por momentos me encontré perdida y por ayudarme a ver que siempre es posible hacerlo mejor.

Gracias al Servicio Jesuita a Refugiados y a mis compañeras de trabajo porque siempre estuvieron allí para apoyarme y acompañarme cuando esta investigación me exigió invertir tiempo y energías que fueron arrebatadas a las actividades laborales. Porque escucharon con paciencia mis cavilaciones, mis angustias, mis hallazgos y me brindaron su respaldo permanente. Gracias por su generosidad, actuante de su propia misión. 
Y por supuesto, a mi familia. Un agradecimiento especial a Italia Reyes, mi madre, y a Mónica Arabella e Italia Isadora, mis hermanas, quienes desde el primer día hasta el último fueron mis cómplices incondicionales; Financiadoras de Sueños.

Por último, un agradecimiento infinito a Andrés Rivera, que por ser mi compañero de vida terminó convirtiéndose en mi compañero de Tesis. Lector, corrector, comentarista, auxiliar, tutor y hasta contradictor; todos esos fueron los roles que jugó durante estos años, todos ellos realizados con inmenso amor. A esta altura y contra todos los pronósticos podría decir, confiada y feliz, que un matrimonio sí es capaz de soportar una Tesis Doctoral. 


\section{Introducción}

\subsection{Estudio de dos Movimientos Sociales en Colombia}

En más de 50 años de conflicto armado en Colombia se han producido millones de víctimas por toda la geografía nacional. El Estado colombiano ha reconocido desde 1985 hasta la actualidad a cerca de 7 millones de personas afectadas directamente por los actores armados legales e ilegales ${ }^{1}$. Son personas, en su inmensa mayoría civiles, que no lograron escapar a la barbarie generada por los distintos actores armados en los diversos ciclos de violencia que se han producido. Se trata del 15\% de la población nacional entre quienes se cuentan varios sectores que han conformado importantes procesos de movilización y acción colectiva generando redes de defensa y denuncia de los atropellos y de las violaciones a los derechos humanos.

De esta forma, durante varias décadas, grupos interesados en la defensa de los derechos humanos han creado las bases de fuertes movimientos sociales que aún, hoy por hoy, se encuentran imponiendo significativos desafíos al Estado nacional. Movimientos que entraron a la contienda en medio de un conflicto armado que les exigía ponerse en acción, al tiempo que les condicionaba fuertemente el camino a recorrer. El contexto del conflicto armado que ha originado y condicionado el surgimiento de estos movimientos también ha influido en el contexto general de las arenas, de los actores y de los procesos de toma de decisiones políticas, conformándose estrechos márgenes de acción para estos sectores que no traían consigo ningún tipo de ascendencia política, económica o electoral.

Con el tiempo estos movimientos comenzaron a ser significativos en la vida política del país y a generar discusiones acerca de la guerra y sus consecuencias, de las

\footnotetext{
${ }^{1}$ Cifra consultada el 7 de agosto de 2015 en la página web de la Red Nacional de Información de la Unidad para la Atención y Reparación Integral a las Víctimas http://rni.unidadvictimas.gov.co/. La UNARIV es la entidad oficial encargada de coordinar el sistema de registro y atención a las víctimas a partir de la expedición de la Ley 1448 de 2011 conocida como Ley de Víctimas y Restitución de Tierras.
} 
víctimas y sus derechos; empezaron a poner cortapisas a los guerreros de todos los bandos y a denunciar enérgicamente los atropellos y continuas violaciones a los Derechos Humanos e infracciones al Derecho Internacional Humanitario, las cuales se ocultaban en los emotivos devaneos ideológicos de las pugnas por el poder expresados dramáticamente por las balas y las bombas. Cientos de personas se aglutinaron para reclamar, exigir y evidenciar que la guerra en Colombia se estaba haciendo contra los civiles y que los intereses que se ponían en juego iban más allá de unos supuestos ideológicos y la defensa de la seguridad interna de una nación. Sin embargo, la sensación de injusticia no cedía al paso de la contienda y la frustración por la impunidad servía de alimento permanente a los movilizados que no encontraban salidas a sus reclamaciones ni veían producirse los cambios por los cuales realizaban su lucha.

Aunque parecería que las acciones colectivas no violentas de los movimientos sociales resultaran vanas en medio una guerra sin cuartel y sin memoria, y que incluso muchos de sus militantes han llegado a considerar inútiles los esfuerzos y las energías invertidas en sus procesos reivindicativos cayendo en el escepticismo, y pese a que el conflicto armado se ha perpetuado en la cotidianidad y en la forma de varias generaciones de colombianos, hoy por hoy, en medio de la esperanza que ha traído un nuevo intento de poner fin a la guerra y de llevar a cabo importantes transformaciones sociales y políticas, resulta importante y pertinente preguntarnos: ¿Han logrado generar impactos los Movimientos sociales en la política colombiana? ¿Qué características tienen estos impactos? ¿Es posible explicar de qué manera los Movimientos sociales intervienen en la toma de decisiones de un Estado al que están enfrentados? ¿Qué eventos explican que estos impactos se produzcan? ¿Es posible asociar cambios en los planteamientos del Estado por la acción de los movimientos? ¿Qué elementos intervienen en la producción de estos impactos?

Esas son algunas de las preguntas que motivan esta investigación y que determinan el carácter y la metodología escogida para adelantarla. En este orden de ideas, nuestro objetivo es: identificar, describir, analizar y comparar los elementos que 
intervinieron durante dos episodios de contienda generados por dos movimientos sociales en Colombia, que han traído como resultado la introducción de temáticas propias de las reivindicaciones de esos movimientos en políticas públicas concretas.

Nuestra hipótesis general de partida es que: La toma de decisiones sobre políticas públicas es un proceso complejo en el que intervienen mecanismos que van configurando cadenas causales de eventos, las cuales pueden llegar a ser influidas, entre otros factores, por las acciones y las interacciones que los movimientos sociales como actores políticos generan en sus procesos de contienda con otros actores, introduciendo y transformando marcos de interpretación, creando y apropiando estructuras de movilización y atribuyendo y generando oportunidades o amenazas políticas.

Para ello hemos escogido dos movimientos sociales ampliamente reconocidos en Colombia y que representan dos versiones distintas de los movimientos sociales que se han fraguado en el marco de las reivindicaciones resultantes a partir de la introducción y la incorporación del discurso de derechos humanos desde la década de los años 80s en el país, tales son, la Ruta de las Mujeres y el Movimiento Nacional de Víctimas de Crímenes de Estado - Movice.

El primero de ellos, un movimiento de carácter feminista, pacifista y antimilitarista, hunde sus raíces en los primeros años de la década de los 90s cuando un grupo de mujeres, activistas feministas y con profundas convicciones políticas y sociales, optan por demandar una salida negociada al conflicto armado mientras denuncian las afectaciones particulares que genera la guerra en la vida y en el cuerpo de las mujeres. La Ruta Pacífica de las Mujeres (en adelante Ruta), que logró su consolidación muy poco tiempo después de su primera acción movilizadora, comenzó un largo proceso de visibilización de los efectos de la guerra en las mujeres para lo cual desplegó diversos repertorios y activó varios episodios de contienda. Uno de ellos fue la participación en el proceso que conllevó a la expedición de la orden más importante que se ha producido desde el poder judicial 
sobre esta temática: el Auto 092 de $2008^{2}$ sobre la protección de los derechos fundamentales de las mujeres víctimas del desplazamiento forzado por causa del conflicto armado. Este Auto se convirtió con el tiempo, en una de las herramientas más poderosas para los procesos de exigibilidad de derechos de las mujeres desplazadas forzosamente en el país.

El segundo es un movimiento surgido como reacción al proceso de desmovilización de los grupos paramilitares que promovió el gobierno del presidente Álvaro Uribe (2002-2010), está compuesto por múltiples organizaciones jurídicas y políticas de oposición, que en aquel momento plantearon el repudio a este proceso interpretándolo como continuación de las políticas de impunidad y de guerra sucia que durante sucesivos gobiernos han estado asociadas a las violaciones a los Derechos Humanos y al Derecho Internacional Humanitario provocadas por el paramilitarismo en Colombia y que son consideradas por el movimiento como crímenes de Estado. El Movimiento Nacional de Víctimas de Crímenes de Estado, (en adelante Movice), inscrito como la Ruta en un movimiento por los derechos humanos más amplio en Colombia, estableció uno de los desafíos más radicales dentro de la política reciente del país: demostrar que en Colombia no solamente hay un conflicto político armado sino que existe una forma de violencia socio-política desplegada desde el Estado contra la población civil y un proceso sistemático de eliminación de la oposición política. Bajo esa comprensión, éste movimiento desarrolló numerosas acciones por la reivindicación de derechos y contra las prácticas criminales del Estado y se involucró en diferentes episodios de contienda para adelantar la exigibilidad de sus derechos. Uno de ellos fue el proceso político por el reconocimiento oficial de la existencia de los crímenes y de las víctimas del Estado, lo que conllevó a abrir el debate sobre la inclusión de las víctimas de crímenes de Estado en los instrumentos legales sobre la asistencia y la reparación a

\footnotetext{
${ }^{2}$ Los Autos de seguimiento son providencias expedidas por la Corte Constitucional mediante las cuales hace seguimiento al cumplimiento de las órdenes impartidas por la Sentencia T-025 de 2004 sobre Desplazamiento Forzado a causa del conflicto armado, amplía las solicitudes al Gobierno, solicita informes y define criterios, entre otros, con el objetivo de superar el Estado de Cosas Inconstitucional establecido allí.
} 
las víctimas del conflicto, debate que llegaría a influir en la redacción final del artículo 3 de la Ley 1448 de $2011^{3}$.

Se trata entonces de dos movimientos que no solamente lograron calar en el escenario público del nivel nacional, sino que participaron de la generación de importantes resultados en política pública que bien vale la pena estudiar. Con esta perspectiva, en esta investigación se hará: (a) una descripción densa de la Ruta y el Movice a partir de los elementos de la agenda clásica de los movimientos sociales, como son, procesos enmarcadores, estructuras de movilización y repertorios de acción; luego, de acuerdo con la propuesta de análisis dinámico de la contienda política, (b) se identificarán los episodios de contienda en los que participaron estos movimientos y que determinaron la generación de impactos en forma de políticas públicas y (c) se indagarán y analizarán las oportunidades políticas y los mecanismos que intervinieron en la producción del resultado; finalmente (d) se realizará un análisis comparativo tratando de identificar aspectos comunes y diferentes entre estos dos episodios de contienda.

Sin embargo, antes de ello, en esta introducción haremos una revisión de las principales teorías que nutrido el estudio de los movimientos sociales, con el fin de brindarle al lector mayor información sobre el marco de comprensión teórico y conceptual sobre el cual reposa esta investigación, se presentará el diseño metodológico que da cimiento al trabajo de campo y al análisis de la información y se planteará la estructura general del documento.

\subsection{Las teorías para el estudio de los Movimientos Sociales}

El sistema democrático como mecanismo dinámico de los procesos políticos decisorios de las sociedades contemporáneas se caracteriza, entre otros factores, por la competencia que establecen diferentes actores políticos, económicos y sociales que coexisten en su seno y que elaboran de manera fluctuante sus formas y

\footnotetext{
${ }^{3}$ Ley de Víctimas y Restitución de tierras por medio de la cual se dictan medidas de atención, asistencia y reparación integral a las víctimas del conflicto armado interno y se dictan otras disposiciones.
} 
contenidos. Entre los actores de estas disputas están los Movimientos Sociales, muchos de los cuales han incluido en su quehacer la defensa de los derechos humanos $\mathrm{y}$, con las singularidades propias de sus enfoques, han construido discursos que amplían los alcances y sentidos de la democracia.

Considerando que la Acción Colectiva es un fenómeno de principal importancia para la comprensión de estas sociedades ya que juega un papel protagonista en los procesos de conformación del orden social y de las transformaciones del mismo, el estudio de los movimientos sociales cobra importancia en la investigación sociológica y en la ciencia política a partir de la preponderancia creciente que han adquirido estas formas de acción colectiva en las dinámicas de los procesos políticos decisorios en los Estados modernos.

De esta forma, las preguntas que los investigadores se han hecho alrededor del tema del surgimiento y el desarrollo de los Movimientos Sociales pueden enmarcarse en dos grandes problemas de los estudios sobre las sociedades humanas: la Acción Social y el Orden Social. En este apartado vamos a hacer un recorrido por los enfoques desde los cuales se han abordado los estudios sobre movimientos sociales.

\subsubsection{Las teorías sobre el Comportamiento Colectivo}

Las teorías del comportamiento colectivo surgen en Estados Unidos en el periodo posterior a la segunda guerra mundial a partir del interés por la proliferación de movimientos disruptivos respecto al sistema de valores de las democracias occidentales. Estas miradas abarcan un espectro amplio de fenómenos de comportamiento colectivo tales como: "los movimientos religiosos, las sectas, las modas y el pánico" (García Villegas, 2005, p. 12). Desde este enfoque se considera a los movimientos sociales como "acciones colectivas en respuesta a la sensación de inseguridad producida por procesos de cambio y por la incapacidad de las instituciones para reproducir la cohesión social" (Godàs i Pérez, 2007, p. 49). Desde esta perspectiva se asume la irrupción de los movimientos sociales como una reacción frente a una frustración o una carencia, y a esa frustración "se le confiere 
un poder detonador de la movilización" (González Gil, 2006, p. 14). En este orden de ideas, las teorías del comportamiento colectivo se agrupan en dos corrientes: el Estructural Funcionalismo y el Interaccionismo Simbólico.

El Estructural Funcionalismo parte del análisis del tipo de acción social que resulta de la interacción de dos o más actores sociales colectivos en un marco institucional determinado sin tomar en cuenta las motivaciones individuales de las personas que conforman tales grupos. Define que existen dos posibles tipos de acción resultante: el Comportamiento Convencional y el Comportamiento Colectivo (Godàs i Pérez, 2007, p. 51). Asimismo considera que el comportamiento colectivo se puede presentar en dos formas: como estallidos colectivos o como movilizaciones sostenidas y organizadas. Estas últimas dan lugar a la aparición de los movimientos sociales.

Desde esta perspectiva los movimientos sociales cumplen la función de "señalar la necesidad de restituir el orden social modificando las bases normativas convencionales de la acción social o creando otras nuevas" (Godàs i Pérez, 2007, p. 50).

Esta función de los movimientos sociales repercute en el enfoque funcionalista en una noción de los movimientos sociales como detonantes de procesos de cambio social, es decir, como un tipo de acción con "una cierta racionalidad" la cual se fundamenta en lo que Neil Smelser denomina "creencia generalizada" (González Gil, 2006, p. 16).

Smelser considera que el tipo de creencias generalizadas que predominan en un proceso de movilización da origen a dos tipos de movimientos: los movimientos orientados a normas y los movimientos orientados a valores (Smelser, 1989). Sin embargo, el mismo autor considera que esta diferenciación está íntimamente relacionada con la conductividad estructural en la que se produce la movilización, es decir, que cuando las condiciones estructurales tienden a facilitar la acción colectiva es más posible que la creencia generalizada oriente los movimientos hacia 
las reformas normativas, mientras que cuando las condiciones estructurales limitan la acción colectiva los movimientos tenderán hacia la redefinición del sistema de valores sociales.

El Interaccionismo Simbólico, a diferencia del estructural funcionalismo, no centra su atención en el tipo de acción o en la función de los movimientos sociales sino que hace énfasis en "los procesos de interacción entre individuos para la definición colectiva de los problemas sociales donde se fundamenta la motivación individual para la participación en la movilización” (Godàs i Pérez, 2007, p. 56).

En este sentido, los movimientos sociales constituyen espacios para la reflexión y para la acción colectiva donde se controvierten o redefinen el sistema de valores o la proyección normativa del orden social. Las dinámicas sociales son el motor de la producción de significados sociales.

De esta manera, la acción colectiva resulta sujeta a un proceso de renovación constante, pues la acción colectiva no es algo distinto de las acciones individuales sino que es el resultado de la adaptación de los individuos en su interacción e interpretación recíproca.

\subsubsection{La Agenda Clásica sobre los Movimientos Sociales}

Pronto se abrió paso a una agenda clásica en el estudio de los movimientos sociales compuesta por tres paradigmas: Paradigma Estratégico, del Proceso Político, y de los Procesos Enmarcadores (Delgado, 2007).

El Paradigma Estratégico concibe la acción social desde un enfoque de la racionalidad individual. De esta manera se concentra en identificar los mecanismos que determinan el surgimiento de los movimientos sociales en las motivaciones individuales para la participación en la movilización, estableciendo que estas se refieren a un esquema de identificación de los costos y los beneficios que se derivan de tal participación. Se le critica el radical racionalismo que se le otorga a la acción 
dejando por fuera de consideración los elementos simbólicos o no racionales que la afectan. Asimismo ese individualismo de tipo economicista que se le atribuye a la valoración de los costos y beneficios como si no influyera el contexto en el que se produce la acción. Sin embargo, para autores como Doug McAdam, esto permitió reconocer que los movimientos sociales tienen la necesidad de racionalizar su organización y sus recursos para su supervivencia (García Villegas, 2005, p. 17).

De otro lado, las aportaciones teóricas sobre la "movilización de recursos" de autores como John McCarthy y Mayer Zald (McCarthy \& Zald, 1977), incorporan al análisis la noción de "adherente", a partir de la cual se pueden evidenciar influencias sobre la relación de costos y beneficios que motivan la participación en la movilización cuando ésta cuenta con el respaldo de miembros de las élites políticas. Estos aportes empiezan a incorporar categorías políticas que permitieron pasar de la pregunta sobre el surgimiento de los movimientos sociales a preguntas sobre cómo se movilizan y sobre el porqué de su éxito o fracaso. Finalmente, la identificación de la búsqueda de "la inserción en el sistema político como un objetivo estratégico" de los movimientos, llevó a posicionar la noción de los movimientos sociales como fenómenos políticos, con lo cual se dio un nuevo giro en su estudio (Archila, 2003).

Ahora bien, el paradigma del Proceso Político busca ofrecer una alternativa al silencio que guardaron las teorías de la movilización de recursos sobre el contexto en el cual surgen los movimientos sociales. Aborda un enfoque racional y colectivista en cuanto a su concepción de la acción y del orden sociales, planteando que el surgimiento de las movilizaciones está relacionado con la mayor o menor apertura a las oportunidades de participación que ofrece la dinámica de la política institucional.

En este sentido autores como Charles Tilly, Doug McAdam y Sidney Tarrow, plantean que un movimiento social es siempre una "relación política", una "relación contenciosa" entre un grupo que persigue un cambio y quienes se oponen, en el marco de unas estructuras políticas e institucionales (Ibarra Güell, 2005, p. 108), y 
que tales estructuras determinan el surgimiento, el desarrollo y los resultados de los movimientos (Delgado, 2007).

Las principales críticas a este paradigma se refieren a la ambigüedad con que se ha manejado el concepto de Oportunidad Política y a la dificultad que se presenta al tratar de establecer sobre qué opera exactamente dicha oportunidad, es decir, cuáles serían las variables dependientes de la oportunidad política. Sin embargo, a este respecto se han realizado diversas propuestas tipológicas para delimitar y concretar los factores relevantes. Una síntesis de tales propuestas la elaboran McCarthy, McAdam y Zald, quienes para el análisis de esas estructuras se concentran en cuatro conjuntos de factores: i. la apertura o estrechez de sistema político; ii. las alineaciones de las élites políticas; iii. las alianzas de los movimientos con élites políticas; iv. y la capacidad de represión del Estado (McAdam, McCarthy, \& Zald, 1999).

Por último, el Paradigma de los Procesos Enmarcadores o de los marcos de la acción colectiva retoma las propuestas iniciales del interaccionismo y del constructivismo. Reacciona a las concepciones racionalistas de los paradigmas anteriores y reintroduce el énfasis en la importancia que tiene para la movilización la Interpretación del mundo social que hacen los individuos y la consiguiente producción de ideas y significados sobre las problemáticas sociales (Delgado, 2007).

Autores como Erving Goffman y David Snow introducen la noción de "marco" para referirse a los "esquemas de interpretación" que permiten a los individuos relacionar una problemática determinada con la necesidad de la movilización. Estos autores destacan que la presencia de unas estructuras políticas determinadas es insuficiente para explicar el surgimiento de la movilización si no se produce el reconocimiento de una situación social como problemática y si no se identifica la movilización como una forma de adecuada de reacción ante ésta; esto es el marco de la acción colectiva (Godàs i Pérez, 2007, p. 113). Así, los movimientos sociales se constituyen como agentes de construcción de significados en medio de "la lucha 
por la definición legítima de la realidad" y de las problemáticas sociales (Delgado, 2007).

El concepto concreto que Snow planteó como "marco de la acción colectiva", derivó hacia una noción mediante la cual se utilizó el término para referir casi cualquier aspecto de la dimensión cultural en el entorno de los movimientos sociales (McAdam et al., 1999, p. 27). De ahí que la principal crítica que se le hace a este paradigma, es el limitado alcance que tendría frente a la definición de las categorías que formarían parte de la dimensión simbólica y cultural de la acción colectiva desde un enfoque colectivista (Delgado, 2007).

\subsubsection{Los Nuevos Movimientos Sociales}

Paralelamente a la agenda clásica desarrollada por la sociología norteamericana (Archila, 2003, p. 38), en Europa se fue configurando una corriente de investigación fundamentada en superar las limitaciones que exhibía el marco interpretativo de la lucha de clases que había dominado hasta entonces, ante la irrupción de movimientos sociales como el estudiantil, el feminista, el ambientalista o el de consumidores, conformados principalmente por clases medias con buenos niveles educativos (García Villegas, 2005, p. 25). Autores como Alain Touraine y Alberto Melucci destacan como factores centrales del análisis de los nuevos movimientos sociales, los procesos de construcción de identidades y de objetivos comunes entre los actores en el marco de unas nuevas condiciones materiales de la sociedad postindustrial europea, donde el conflicto se desplaza de la producción y distribución de los bienes hacia la producción de los significados y los símbolos culturales ((Ibarra Güell, 2005, p. 109).

El Constructivismo propuesto por Alberto Melucci procura avanzar hacia otros aspectos más allá del debate desatado, que él considera irrelevante, sobre lo novedoso de los nuevos movimientos sociales. El énfasis de este autor se concentra en "los procesos de reconocimiento y configuración de la identidad de los actores" ya que considera que los conflictos sociales tienen un sustrato fundamentalmente 
cultural, de donde plantea que los movimientos sociales son "generadores de códigos culturales alternativos" y que su característica fundamental es la confrontación con las autoridades (González Gil, 2006, p. 27).

Este énfasis, sin embargo, conlleva un reduccionismo cultural que pasa por alto las condiciones objetivas que enmarcan los conflictos sociales. Aquí radica la principal crítica que se ha planteado a las corrientes de tipo identitario o culturalista (Archila, 2003).

\subsubsection{Las Agendas Contemporáneas}

A partir de la década de los noventas se iniciaron intercambios académicos entre investigadores americanos y europeos, de donde han surgido nuevos horizontes para los estudios sobre movimientos sociales. Los principales retos que se plantean consisten en avanzar en la construcción de perspectivas de trabajo Relacionales y Comparadas que pueden dar cuenta de manera más integral de las múltiples dimensiones de los movimientos y de la diversidad de contextos en los cuales actúan (Delgado, 2007).

En este sentido se destacan las obras de McAdam, McCarthy y Zald, donde los autores proponen la incorporación de una perspectiva integradora de las herramientas teóricas existentes en los estudios de movimientos sociales, al tiempo que proponen avanzar en la realización de estudios de caso con perspectiva comparada con el fin de enriquecer esas herramientas en su capacidad de comprensión y explicación (McAdam et al., 1999).

Más allá llegan McAdam, Tarrow y Tilly, al proponer un desplazamiento relacional de las categorías tradicionales en la construcción de un "modelo dinámico de la movilización”. Estos autores proponen avanzar de la Estructura de Oportunidades Política hacia la Atribución de Amenazas y Oportunidades, de las Estructuras de Movilización hacia la Apropiación Social de esas estructuras, del Enmarcamiento estratégico hacia la Construcción Social de los marcos de interpretación (McAdam, 
Tarrow, \& Tilly, 2005). En Dynamics of Contention (DOC) $)^{4}$ los autores consignan una nueva propuesta teórica y metodológica que aborda el estudio de algunos procesos políticos, como los movimientos sociales, a partir de la noción de “contienda política", que expresa la "interacción episódica, pública y colectiva entre los reivindicadores y sus objetos".

Los autores plantean el abordaje de tales procesos como "episodios", es decir, delimitaciones abstractas de eventos complejos, contingentes e interactivos, para lo cual recuperan las categorías elaboradas por la agenda clásica de los movimientos sociales y las enfocan con un lente que se concentra en las múltiples interrelaciones que se producen entre ellas resaltando el hecho de que algunas de esas interrelaciones, a las cuales denominan "mecanismos", se presentan de manera recurrente en las diferentes formas de contienda, aunque en diversas combinaciones, a las cuales denominan "procesos". Estos procesos a su vez, producen cadenas causales que en diferentes contextos generan resultados diferentes, los cuales podemos estudiar mejor mediante la comparación de sus respectivas dinámicas (McAdam et al., 2005, p. 5).

Tras el amplio debate generado a partir de la publicación de DOC, en 2007 Tarrow y Tilly publicaron Contentious Politics, obra en la cual hacen una exposición más detallada y consolidada de la ruta metodológica para el estudio y la explicación de diversos eventos políticos mediante el enfoque de la contienda política y de mecanismos y procesos (Tilly \& Tarrow, 2007).

Los autores de este enfoque advierten que no tienen como objetivo el trazar leyes generales que gobiernen todos los fenómenos políticos sino que buscan principalmente encontrar similitudes en los tipos de relaciones que producen determinadas cadenas causales en una amplia variedad de eventos políticos. Este interesante conjunto de herramientas teóricas y metodológicas resulta especialmente propicio para motivar un nuevo esfuerzo en el estudio y la

\footnotetext{
${ }^{4}$ Para las referencias a este texto en el presente estudio utilizaremos la edición española: Dinámica de la Contienda Política, Editorial Hacer, 2005. Para el original remitirse a: Dynamics of Contention, Cambridge University Press, 2001.
} 
explicación de los impactos que producen los movimientos sociales que, como veremos, han sido temas de difícil acceso para los investigadores sociales.

\subsubsection{Impactos de los Movimientos Sociales}

En lo que concierne de manera específica con los impactos que producen los movimientos sociales, los estudios dedicados de manera principal a este tema, aunque muy pocos hasta finales de los años 90 s, se han incrementado de manera importante en la última década. Desde la obra de William Gamson The strategy of social protest de 1975 hasta el libro editado por Giugni, McAdam y Tilly en 1999 How Social Movements Matter, se desarrollaron muy pocos trabajos de acercamiento al estudio y la explicación de las consecuencias de las acciones de los movimientos sociales y esos pocos apenas alcanzaban a hacer notar esa misma situación:

"Sabemos muy poco sobre el impacto de los movimientos sociales en el cambio social. En parte porque es muy difícil demostrar la cantidad y calidad del cambio social que produce un movimiento social" (Ajangiz, 2002, p. 25).

No obstante lo anterior, es de resaltar la revisión elaborada por Rafael Aganjiz en su tesis doctoral (Ajangiz, 2002), en la cual no solamente recoge la bibliografía producida sobre este tema hasta entonces, sino que, a partir de ella, elabora una taxonomía bastante completa de los tipos de resultados que se pueden desprender de las acciones de los movimientos sociales, recordando la importancia de abordar el estudio de las consecuencias de los movimientos sociales, pues, en palabras de McAdam, McCarthy y Zald, "muchos de los que estudian los movimientos sociales lo hacen porque creen que los movimientos constituyen una fuerza importante del cambio social" (Ajangiz, 2002, p. 24).

La clasificación elaborada por el autor repasa el legado de algunos movimientos sociales ampliamente estudiados y sistematiza los resultados propuestos por los 
especialistas a la luz de los diferentes paradigmas teóricos, desde la simple división de Gamson entre éxito o fracaso, pasando por los impactos en los procesos de las políticas públicas, los efectos en las dimensiones sociales simbólicas, los aprendizajes para los propios y los futuros movimientos, hasta los efectos negativos y/o no deseados por los movimientos (Ajangiz, 2002, p. 40).

Para finales de la década de los 2000, los trabajos sobre este tema han sido cada vez más cuantiosos e interesantes. De esto dan cuenta artículos como Political, Biographical, and Cultural Consequences of Social Movements, publicado por Marco Giugni en 2008 y en el cual realiza un esfuerzo de sistematización similar al de Ajangiz (Giugni, 2008). También se destaca el artículo de Lorenzo Bosi y Katrin Uba para la introducción del número especial que Mobilization dedicó a los impactos de los movimientos sociales en diciembre de 2009, donde hacen un recuento de la evolución que ha tenido el estudio de este tema así como de las dificultades que enfrenta (Bosi \& Uba, 2009). En particular sobre los impactos políticos, el artículo de 2010 de Edwin Amenta The Political Consequences of Social Movements realiza una revisión de los estudios que sobre este tema se publicaron entre 2001 y 2009 (Amenta, Caren, Chiarello, \& Su, 2010).

Finalmente, encontramos un panorama muy completo sobre la situación actual del estudio de los impactos de los movimientos sociales en la revisión elaborada por Giugni y Bosi en 2012, The impact of protest movements on the Establishment (Giugni \& Bosi, 2012). En este artículo los autores refinan una matriz de consecuencias de los movimientos sociales que evoca la clasificación elaborada por Ajangiz aunque complejizada a partir de dos tipos de clasificación: por un lado unas consecuencias Internas o Externas y por otro unas consecuencias de carácter biográfico, cultural y/o político. Los autores reiteran aquí cómo, a pesar del incremento de los estudios en este tema y el amplio consenso sobre la producción de consecuencias deseadas o indeseadas por parte de los movimientos, persiste un enorme desafío teórico y metodológico para llegar a establecer las relaciones causales entre las actividades de los movimientos y los cambios políticos, sociales y culturales. 
En el artículo se describen las principales dificultades metodológicas que han enfrentado los investigadores y se plantean algunos de los avances alcanzados entre los cuales se destaca el impulso que ha significado para este tipo de investigación el cambio de enfoque de las condiciones que favorecen la producción de impactos a la identificación de mecanismos y procesos que constituyen cadenas causales en cada caso.

\subsection{El Marco Teórico de esta investigación}

La diferentes teorías elaboradas a partir de los estudios sobre las condiciones del surgimiento y el desarrollo de la movilización social como fenómeno socio-político, desde mediados del siglo XX hasta ahora, han avanzado permanentemente en la profundidad y complejidad de las herramientas teóricas que nos permiten acercarnos, comprender y explicar por qué surgen los movimientos sociales, cómo surgen, cómo se constituyen, qué persiguen y cómo lo logran. Estas teorías, que entran en debate en los estudios sobre los movimientos sociales, reflejan diversos enfoques que subyacen y atraviesan concepciones, intereses y metodologías de las ciencias sociales en general. En lo corrido del siglo XXI los investigadores han transitado hacia modelos más relacionales y más integrales en el diseño de sus estudios en busca de respuestas más ajustadas a las realidades concretas de los movimientos sociales, siempre tan diversas y complejas.

Para el desarrollo del presente trabajo avanzaremos en la dirección planteada por algunas de las apuestas teóricas que recientemente han promovido una perspectiva integradora y relacional del conocimiento acumulado por la agenda clásica de los movimientos sociales. En este sentido, nos acercaremos a la complejidad empírica de los movimientos estudiados a partir de la propuesta integradora de McAdam, McCarthy y Zald (1999), indagando por los factores de surgimiento y desarrollo de cada movimiento en su contexto. Elaboraremos una descripción de cada uno de los movimientos estudiados a partir de los tres grupos de factores considerados en la síntesis teórica propuesta por los autores, a saber: los procesos colectivos de 
interpretación y construcción de sentidos o Procesos Enmarcadores, las formas o estructuras de organización, de comunicación y de interacción o Estructuras de Movilización y los Repertorios de Acción, en medio de los cuales surgen y actúan estos movimientos.

Es preciso recordar aquí que partimos de la concepción de los movimientos sociales como agentes activos de los procesos democráticos y de cambio social y que esta noción está en la base del interés fundamental de este estudio. En esta perspectiva, nuestro trabajo procura indagar por los eventos históricos que permiten relacionar la existencia y las actividades de los movimientos estudiados con unos efectos políticos determinados.

De acuerdo con lo anterior resulta muy pertinente la propuesta teórica relacional de la dinámica de la contienda política de McAdam, Tarrow y Tilly (2005), con su enfoque en los mecanismos y los procesos que componen las cadenas causales que conllevan a un resultado específico en un episodio de contienda determinado. En ese sentido, la delimitación espacio temporal del análisis resulta determinante en la medida en que nos indica las fronteras de cada uno de nuestros estudios. Siguiendo el modelo propuesto en este marco teórico definiremos los "episodios" como: "lugares iterativos de interacción en los que se solapan diferentes oleadas de movilización y desmovilización, se forman y evolucionan las identidades y se inventan, se afilan y se rechazan nuevas formas de acción cuando los actores interactúan entre sí y con sus oponentes y terceras partes” (McAdam et al., 2005, p. 32). La delimitación de los episodios nos permite identificar la cadena principal de eventos que se suceden en su interior y con ellos los mecanismos que se activan durante la contienda y que eventualmente vehiculan los resultados obtenidos en la lucha. A partir del análisis de tales mecanismos buscaremos establecer la influencia que cumplen las actividades desplegadas por los movimientos para la introducción de una temática propia de sus reivindicaciones en los procesos decisorios de las políticas públicas nacionales. 
Nos referimos aquí específicamente a la introducción de una reivindicación de un movimiento social en el proceso de discusión y definición de una política pública, con el propósito de delimitar de una manera precisa el tipo de impactos que constituye el objeto de este estudio. De acuerdo con la más reciente clasificación, consolidada por Giugni y Bosi, de los diversos tipos de impactos que pueden producir los movimientos sociales, nos ocuparemos aquí de los "impactos políticos externos" referidos a la "alteración de los procesos de toma de decisiones políticas con respecto a derechos legales" que forman parte de las reivindicaciones propias de los movimientos estudiados (Giugni \& Bosi, 2012, pp. 18-19).

Finalmente, siguiendo la reflexión que han puesto de presente estos y otros autores con respecto a las necesidades que enfrenta la investigación sobre movimientos sociales, consideramos pertinente, como ejercicio, realizar una lectura comparativa de los casos estudiados que nos permita explorar la posibilidad de identificar regularidades, similitudes o diferencias, que enriquezcan nuestra comprensión de los procesos políticos concretos, de sus posibles abstracciones y de los alcances y limitaciones de las herramientas teóricas utilizadas.

A continuación expondremos brevemente cada uno de los componentes conceptuales que están en la base de los análisis de esta investigación, en este intento por abordar una perspectiva integradora y relacional de los movimientos sociales. En ese orden de ideas abordaremos: los procesos enmarcadores, las estructuras de movilización, los repertorios de las acciones colectivas, las estructuras de oportunidades políticas y el análisis de mecanismos en episodios de contienda política.

\subsubsection{Los Procesos Enmarcadores}

Considerando que los movimientos sociales contienen formas particulares de percibir los hechos e interpretarlos, es menester adentrarse en los procesos cognitivos que permiten la percepción y la interpretación de los agravios que motivan su acción. Este tipo de análisis, referido a los "marcos cognitivos" que dan 
sustento al movimiento social, resulta ser también un elemento primordial para comprender la lógica que los guía.

Para Snow y Benford el marco cognitivo es "un esquema interpretativo que simplifica y condensa el mundo de afuera, puntuando y codificando selectivamente los objetivos, situaciones, acontecimientos, experiencias y secuencias de acciones dentro del entorno presente o pasado de cada uno" (Ibarra, Martí, \& Gomà, 2002, p. 45). Desde este esquema interpretativo es posible entonces leer el tipo de valores compartidos que le dan sentido e identidad colectiva al movimiento y que pueden explicar los juicios de valor que hacen sobre los hechos que les rodean y los agentes que los llevan a cabo.

También recordando a Snow y Benford, señalan Mac Adam, Tarrow y Tilly: "El enmarcamiento, (es) un proceso colectivo de interpretación, atribución y construcción social, (que) media entre la oportunidad y la acción. Por lo menos, la gente debe sentirse agraviada en algún aspecto de sus vidas y optimista respecto al hecho de que actuar colectivamente puede reconducir el problema" (McAdam et al., 2005, p. 45).

Identificar y analizar estos agravios compartidos nos permite entender mejor las acciones y los mecanismos que los movimientos ponen en funcionamiento durante el tiempo en que duran sus reclamos. Esto además nos facilita la caracterización del tipo de discurso en el cual fundamentan sus acciones y nos acerca a la lógica que domina sus planteamientos. Como nos lo explica Zald, los movimientos sociales recurren al stock cultural de que se dispone para decidir lo que consideran justo o injusto y así dan sentido a los agravios infligidos: "La estructuración real de la injusticia y los objetivos políticos descansan, casi siempre, sobre definiciones sociales de las relaciones, los derechos, y las responsabilidades, que son las que permiten señalar los defectos de la ordenación social actual y sugerir la dirección que debe aportar el cambio" (McAdam et al., 1999, p. 377). 
Este proceso de enmarcamiento, al final de cuentas, posibilita a los movimientos sociales reconocer una determinada problemática, identificar oponentes y movilizar a sus miembros. De esta forma, su análisis permite reconocer lo que persiguen, la lógica que les subyace y los comportamientos que asumen a la hora de accionarse colectivamente.

Es necesario también considerar que este enmarcamiento no se produce exclusivamente al interior del grupo de ciudadanos comprometidos, se construye interactivamente en la relación de éstos con los demás actores, los sucesos externos, los oponentes, el Estado, los medios de comunicación y las terceras partes. Por tanto, esta construcción también es dinámica, constituyéndose y modificándose con base en las interpretaciones que se vayan dando de diferentes elementos externos los cuales pueden ser percibidos, a su vez, como oportunidades o amenazas. De allí que es importante revisar el proceso de enmarcamiento no solo en el momento de la definición de los objetivos del movimiento social sino también en momentos posteriores que pueden acotar o modificar el cauce interpretativo.

De otro lado es también útil desentrañar el contenido y perfil de las identidades políticas que se fueron constituyendo con el paso del tiempo en la interacción con los oponentes, el Estado y las influencias llegadas desde el exterior y que se convirtieron en los pilares de trabajo de estos movimientos. El análisis de las identidades que se pusieron en juego durante los episodio nos va a facilitar además, la explicación de los contenidos que nutrieron el desencadenamiento de los resultados estudiados (McAdam et al., 2005, pp. 48-61).

En suma, la construcción de objetivos y su transformación en el tiempo como respuesta a la identificación de los agravios y la conformación de identidades políticas en medio de todo el proceso, serán de gran importancia para el análisis del papel cumplido por los movimientos en los episodios de contienda.

\subsubsection{Estructuras de Movilización}


Otro elemento indispensable para abordar el estudio de los movimientos sociales son las estructuras de movilización que usan para organizarse y desarrollar sus actividades. Se trata de "las formas consensuadas de llevar a cabo acciones colectivas, los repertorios tácticos, las formas organizativas de movimientos sociales concretos y repertorios modulares de los movimientos sociales" (McAdam et al., 1999, p. 206), a través de las cuales es posible reconocer los mecanismos que han adecuado para aglutinar a sus miembros, conseguir recursos y establecer relaciones con otras organizaciones e instituciones. Se sabe que los tipos de organización que construyen los movimientos sociales se caracterizan por ser más porosos y más horizontales que los de otros actores colectivos y que en realidad se parecen mucho más a "una maraña entrelazada de pequeños grupos, redes sociales y conexiones entre todos ellos" (Ibarra et al., 2002, p. 40).

En el estudio de estas formas organizativas, el enfoque neoinsitucionalista señala que es posible identificar, por un lado, un "núcleo duro" donde se hallan los líderes comprometidos, los cuales organizan las propuestas, dotan de un marco cognitivo los agravios y trabajan en pro de su expansión, y por otro lado, un "entorno social" que se identifica con las demandas, apoya las estrategias de denuncia y se activa colectivamente para su puesta en práctica. La simbiosis entre el núcleo duro y el entorno social es producto, no de un cálculo racional como expusiera Olson, sino más bien de la identificación, cercanía y confianza de sus integrantes, generada por la experiencia previa en procesos colectivos. Estos núcleos, denominados de micromovilización, son donde en últimas se establecen las redes personales necesarias de las que se nutre el grueso del movimiento social.

McCarthy nos señala por su parte la importancia de acometer procesos de clasificación que permitan ordenar el mundo de posibilidades organizativas de los movimientos sociales y sus relaciones con las oportunidades políticas, con el proceso de enmarcamiento y construcción de objetivos, así como con la producción de resultados. Para este autor existe una línea de continuidad entre varios modelos, clasificados por su nivel de organización de menor a mayor grado de formalidad (McAdam et al., 1999, pp. 208-209). 
Tomando la propuesta de Steven Buechler sobre comunidades de movimientos sociales, McCarthy engloba en el concepto de "Industrias de Movimientos Sociales" IMS, a grupos que tienen como propósito desarrollar los objetivos de un determinado movimientos social, a todas las Comunidades de Movimientos Sociales CMS y a los Movimientos Sociales Organizados MSO, con la diferencia de que los primeros lo hacen usando redes informales, con formatos de trabajo más flexibles y amparándose en liderazgos políticos con límites difusos, mientras los segundos lo hacen recurriendo a estructuras organizativas altamente formales y complejas.

Nos explica también que entre uno y otro hay otra suerte de posibilidades organizativas que ha denominado híbridos. Se trata de estructuras tan formales como los MSO que se inscriben en procesos de movilización más amplios lo cual les permite interactuar con otros grupos independientes y actuar en red. También hay comités de campaña que tienen como función aglutinar diversos grupos en pro de una acción más concreta y que terminan tejiendo redes más estables en el tiempo que conforman eventualmente familias de movimientos.

Dentro de los MSO a su vez también existen numerosas variantes. Hay movimientos que se aglutinan desde las bases y se interconectan con otros similares para lograr una acción nacional o grupos que actúan como extensión de espacios nacionales organizativos muy fuertes y centralizados. Por supuesto hay muchas más posibilidades que aumentan o disminuyen la complejidad en relación al alcance de sus objetivos y el nivel geográfico al que aspire el movimiento social.

Los estudios de las estructuras de movilización han sido usualmente realizados con el propósito, no solo de conocer con detalle monográfico uno u otro movimiento social en específico, sino también de crear categorías que permitan la comparación, la identificación de patrones, el análisis de sus relaciones con las estructuras de oportunidades políticas o con los marcos interpretativos, e incluso, con la intención 
de proyectar comportamientos organizativos a partir del tipo de sistema político y tipo de Estado en el que se encuentran inmersos.

Sin embargo, en un enfoque dinámico del análisis de las estructuras de movilización, tal vez el interés principal es conocer el grado de "apropiación" que puede tener un movimiento social en un determinado momento de los antecedentes organizativos, de los recursos disponibles y de las nuevas organizaciones creadas para canalizarlos. Sobre este punto señalan McAdam, Tarrow y Tilly que "es la capacidad del desafiador para apropiarse de una organización y de suficientes personas que le presten una base social organizativa, y no la organización en sí misma, lo que hace posible la movilización” (McAdam et al., 2005, p. 51).

En este sentido puede suceder en ocasiones que el medio social en el que se desarrolla el episodio no cuenta con organizaciones que sirvan de base previa a la movilización, ello implica desarrollar un esfuerzo de aglutinamiento importante para enlazar formas sociales no pensadas políticamente y organizarlas durante la contienda. También puede ocurrir que en el contexto social sí se cuente con organizaciones importantes previamente constituidas y lo suficientemente fuertes como para impulsar una acción colectiva, caso en el cual, el punto clave es la capacidad que tengan los líderes de las protestas para "apropiarse" de estas estructuras, moldearlas y modificar parte de sus acciones en pro de sus objetivos.

En cualquier caso veremos en este estudio, cómo estos elementos finamente se combinan para generar movimientos altamente capaces de generar desafíos sostenidos en el tiempo mientras van acomodando y modificando sus estructuras.

\subsubsection{Los Repertorios de Acciones Colectivas}

Como parte del estudio de las estructuras de movilización es importante adentrarse en los mecanismos y dinámicas que adoptan los movimientos sociales para llevar a cabo acciones colectivas. La necesidad de buscar empatías, apoyos, solidaridad y sobre todo, el deseo de acercarse al cumplimiento de sus propósitos, es atendida por 
los movimientos a partir del despliegue de distintas actividades públicas. Estas acciones son vistas por los movimientos como las herramientas más poderosas y cercanas con la que cuentan sus miembros para hacerse conocer y cumplir sus objetivos. Estos listados de actividades o "performances", denominados "repertorios de acciones colectivas", que son aprehendidos por los miembros a partir de experiencias pasadas de otros colectivos y de sus mismos miembros y continuamente reinventadas mediante fórmulas de innovación en combinación con las vivencias anteriores, pueden a su vez tomar diferentes modalidades.

Ya sea que se trate de actividades de confrontación directa y violenta, de acciones más convencionales admitidas socialmente por su continua práctica como ciertas alteraciones al orden, o aún con más frecuencia, de los mecanismos suministrados por los mismos Estados mediante instrumentos de participación y control social, los movimientos van recogiendo y adaptando los que consideran más idóneos para el logro de sus objetivos. Estos repertorios a su vez están mediados por lo que los movimientos interpretan del contexto y se van desarrollando y transformando a partir de las oportunidades políticas que se vayan presentando. Las necesidades de "comunicar y transmitir exigencias", "generar solidaridad e identidad", “convencer", "desafiar" y "generar incertidumbre", se ven plasmadas en la combinación de los distintos mecanismos que van adoptando en el tiempo.

Varios autores también le han atribuido al tipo de repertorios usados por los movimientos su capacidad de éxito o de impacto. Si bien ha sido frecuente señalar que los movimientos que actúan dentro de canales ajustados a lo permisible por los Estados suelen tener mejores resultados, William Gamson encontró en uno de sus estudios que los grupos que usaban la fuerza y la violencia solían tener más éxito que aquellos que no lo hacían. La explicación de esta hipótesis es que los movimientos sociales suelen carecer de los recursos políticos necesarios para activar canales más pacíficos o rutinarios, como la influencia o el dinero, situación que los aboca a buscar alternativas de acción más llamativas y disruptivas. Sobre este mismo punto Tarrow señala que son precisamente estas tácticas transgresivas, o la amenaza de ellas, las que pueden dotar en un momento determinado al 
movimiento social de la capacidad, remota en otras circunstancias, de realizar cambios sociales. (McAdam et al., 1999, pp. 37-38).

McAdam por su parte nos señala que las decisiones tácticas que los movimientos sociales adoptan pueden enseñarnos mucho sobre los significados y mensajes que quieren transmitir, pero además, que dependiendo del grado de amenaza que estos desplieguen en sus acciones encontrarán una u otra respuesta del exterior. En sus palabras: "El grado de amenaza latente que se percibe a través de las tácticas y acciones de un movimiento, determina, decisivamente, las respuestas de otros grupos". Esto, sumado a los objetivos que mantenga el movimiento, según el autor, es definitivo para reconocer la reacción de los demás actores en el conflicto en sistemas democráticos. Así, un objetivo más extremo o revolucionario, combinado con tácticas no institucionales más violentas, seguramente encontrará en el contexto que le rodea mayores posibilidades de represión. Al otro extremo, un objetivo moderado de corte reformista impulsado por tácticas institucionales rutinarias, seguramente se encontrará con la indiferencia o hasta podría eventualmente ser apoyado (McAdam et al., 1999, p. 479).

Sin embargo, una visión más dinámica de los repertorios de acción colectiva nos invita a estudiar este factor, más que como rutinas establecidas que se producen en la interacción entre actores, objetivos y oponentes, como performance que se van innovando en el tiempo a partir de los repertorios que han heredado de otros y que evolucionan en la relación que se establece con terceros en medio de la contienda y la lucha por unos objetivos determinados. Este carácter innovador de los performance, además, no es exclusivo de los desafiadores, también los oponentes y el Estado puede producir modificaciones a sus acciones a partir de la interpretación que vayan realizando de los sucesos.

Este conjunto de performance reunidos en repertorios también establece un marco de interacción que limita las formas en que se relacionan las partes en contienda. De allí que no presenciemos altos grados de innovación entre contienda y contienda, sino que más bien encontremos algunos cambios creativos o pequeñas 
modificaciones a las acciones colectivas ya conocidas (McAdam et al., 2005, pp. 53-54).

En todo caso, lo importante aquí es ampliar nuestra comprensión de la forma en que se desarrollan y evolucionan estos repertorios de acción colectiva, bajo el descubrimiento de la interacción entre los distintos actores que entran en escena en un episodio de contienda, como centro de conocimiento de las variaciones que se presentan. Esta apertura conceptual nos podrá permitir identificar en los movimientos estudiados las diferentes adaptaciones de los repertorios al contexto y la forma en que éstos entran a jugar dentro de la producción de resultados concretos en la producción de políticas públicas.

\subsubsection{Estructuras de Oportunidades Políticas}

De acuerdo con Tarrow y Tilly, para explicar las intrincadas interacciones que componen un episodio de contienda deben ser analizadas las condiciones del contexto que potencian o inhiben determinadas características de los elementos descriptivos de los actores sociales. De manera reiterada la literatura sobre la Acción Colectiva nos ha invitado a identificar los cambios en algún aspecto del sistema político como una posible ventana de oportunidades para la movilización. Este enfoque de análisis se ha denominado estudio de la Estructura de Oportunidades Políticas EOP. Si bien las oportunidades políticas comenzaron siendo un elemento para analizar estudios de caso, pronto se configuró en un punto central para el análisis comparado tratando de hallar en las similitudes y diferencias entre elementos del contexto de diversos movimientos sociales, las explicaciones de la conformación, desarrollo y resultados de la acción colectiva.

En pocos años la Estructura de Oportunidades Políticas se convirtió en el concepto clave explicativo del modelo del "proceso político". Se entendía entonces que "el surgimiento y éxito de los movimientos sociales dependía, en gran medida, de las oportunidades al alcance de los contestatarios generadas por cambios en la 
estructura institucional y de la disposición ideológica de los grupos en el poder" (McAdam et al., 1999, pp. 42-50).

Esta concepción que se hizo tan popular en su momento también ha tenido sus propios detractores, particularmente por la ambigüedad de las definiciones de las distintas dimensiones que la componen, y aún, por la falta de consenso sobre los aspectos a considerar entre elementos de análisis. De allí que cada autor asignara unos contenidos y unas definiciones, más o menos similares o diferentes como variables de análisis. No obstante, haciendo un importante esfuerzo de síntesis, McAdam organiza los elementos considerados relevantes por 4 de lo más prestigiosos autores de la materia: Charles Brockett (1991), Kriesi y otros (1992), Dieter Rutch (1999) y Tarrow (1994), quienes diferencian entre un estructura más formal e institucional del sistema político y otra dominada por las relaciones de poder intrínsecas del sistema desde una lógica más informal.

De esta síntesis se derivan 4 dimensiones: “a. El grado de apertura relativa del sistema político institucionalizado; b. La estabilidad o inestabilidad de las alineaciones entre elites, alineaciones que ejercen una gran influencia en el ámbito de lo político; c. La presencia o ausencia de aliados entre las elites: y d. La capacidad del Estado y su propensión a la represión" (McAdam et al., 1999, pp. 5455). Al tiempo y retomando el trabajo de Azza Salama Layton (1995), este autor recuerda la importancia que tienen los hechos y las tendencias internacionales como un factor de gran trascendencia a la hora de constituir instituciones o generar alineamientos internos. En este caso, la presión internacional se convierte en un elemento movilizador de aliados entre las élites y generador de aperturas legal/institucionales que marcan la diferencia en la forma y resolución de una contienda política. De esta forma, el componente internacional se convierte en un elemento más a tener en cuenta a la hora de analizar la Estructura de Oportunidades Políticas.

Por su parte Tarrow, uno de los teóricos que han hecho más aportaciones sobre esta temática, formula cuatro dimensiones de las oportunidades políticas: a. acceso 
político pleno, b. alineaciones inestables, c. aliados influyentes, y d. elites divididas. Este autor ha sostenido con insistencia que la acción colectiva "surge cuando se dan las oportunidades políticas para la intervención de agentes que normalmente carecen de ellas" (Tarrow, 2004, p. 22). Por tanto, no basta con la conciencia de un agravio colectivo ni con el deseo genuino de movilizarse, además, es necesario que existan las condiciones adecuadas para que esto se pueda llevar a la práctica. Nos explica que es necesario a la hora de analizar los movimientos sociales revisar el contexto en el cual se mueven y la disposición de los demás actores en el escenario público, ya que de esto depende en gran medida las posibilidades del surgimiento, mantenimiento y desarrollo del movimiento en un espacio originalmente adverso.

De esta forma, "cuando se abre el acceso institucional, cuando emergen conflictos entre las élites, cuando pueden conseguir alianzas y disminuye la capacidad represora del estado, cuando todo esto se combina con una percepción elevada de los costes que supondría la inacción", se entenderá que existen unas condiciones apropiadas para la acción política colectiva (Tarrow, 2004, p. 110). Estos elementos deben a su vez ser estudiados a la luz de situaciones más estructurales como la fuerza o la debilidad el Estado y el nivel de represión de que se vale. Es necesario recalcar que este enfoque considera que así como la estructura de oportunidades puede moldear la acción colectiva, la movilización puede a su vez impactar esa estructura, bajo la comprensión de que el conflicto "rehace al Estado mismo una y otra vez". De allí que este concepto pueda ser usado como variable tanto dependiente como independiente dentro de las investigaciones de los movimientos sociales ampliando el panorama de posibles enfoques de trabajo.

De otro lado, Tarrow ha señalado que existen dos maneras de estudiar la relación entre estructuras políticas y acción colectiva; la primera, que denomina transseccional, se enfoca en un análisis estático de las estructuras de oportunidad, y la segunda, dinámica, que toma en cuenta los cambios en el conflicto y en las alineaciones. El autor, remembrando los trabajos de Tilly, se decanta más por la segunda al reconocer que "es el sistema político entero el que se ve sometido a cambios que modifican el medio en el que se mueven los actores sociales, al menos 
lo suficiente como para ejercer cierta influencia sobre el inicio, las formas y los resultados de la acción colectiva" (McAdam et al., 1999, p. 76).

Posteriores desarrollos teóricos de estos autores han dado pie para una comprensión más consolidada del análisis dinámico de este tema. En Dinámica de la Contienda Política, McAdam, Tarrow y Tilly, se unen para señalar que más que el análisis de las estructuras de oportunidades políticas como categorías objetivas, las oportunidades y las amenazas para la movilización se constituyen a partir de la atribución que los actores hacen de las situaciones en su contexto. No solo se requiere de una variación en el sistema que haga posible la movilización, se hace necesario que estas modificaciones sean interpretadas, bien como oportunidad, bien como amenaza, por los diferentes actores comprometidos en la contienda. La interpretación permanente de la realidad por parte de los protagonistas de la acción colectiva, en la cual comprenden los cambios en el sistema, las acciones de otros y las interacciones entre todos, es la que les permite explicar su posición y su acción en el entramado de la contienda.

Charles Tilly y Sidney Tarrow continúan con el refinamiento de estas dimensiones y, en Contentious Politics, presentan una nueva propuesta, ahora enmarcada en el análisis dinámico del tipo de sistema político que se esté revisando. Mediante la medición y el cruce de dos aspectos principales: por un lado, las capacidades de los Estados para afectar el carácter y la distribución de la población y las actividades y los recursos en su territorio a partir del control de los impuestos, la distribución de beneficios, la regulación del tráfico, y el control del uso de los recursos naturales, por ejemplo; y, por otro lado, el grado de democracia que ostenta el Estado, medible en la igualdad de derechos políticos de sus ciudadanos, la frecuencia con la que son consultados mediante elecciones o referendos y la protección que se les garantiza frente a la arbitrariedad de agentes del gobierno, es posible identificar las condiciones que constituyen las oportunidades y las amenazas para los desafiadores en un determinado régimen político (Tilly \& Tarrow, 2007, pp. 54-55). 
En tal sentido y en la perspectiva de un enfoque dinámico de explicación de la contienda política, los autores finalmente identifican seis elementos de la Estructura de Oportunidades Políticas que nos pueden permitir avanzar, de la descripción estática de estas estructuras, a una explicación dinámica de las causas que conectan las características que conforman un episodio de contienda con las condiciones del contexto en que ocurre. "a. La multiplicidad de centros independientes de poder, b. La apertura a nuevos actores, c. La inestabilidad de los alineamientos políticos, d. La disponibilidad de aliados influyentes o de partidarios de los desafiadores, e. Los grados de represión o facilidades para la acción colectiva, y f. Los cambios decisivos en cualquiera de los anteriores" (Tilly \& Tarrow, 2007, p. 57).

\subsubsection{Los Mecanismos de la contienda política}

En este enfoque dinámico de la contienda política, los autores proponen además el fundamento de la explicación de los procesos sociales y políticos a partir de la identificación de Mecanismos. Entendidos éstos como "una clase delimitada de acontecimientos que alternan las relaciones entre conjuntos especificados de elementos de maneras idénticas o muy similares en toda una variedad de situaciones" (McAdam et al., 2005, p. 26) estos mecanismos pueden proveer una explicación de "qué sigue a qué" en un episodio de contienda (McAdam, Tarrow, \& Tilly, 2008, p. 308).

Desde esta lógica, es más importante fijar la atención en los mecanismos que enlazan las variables entre sí, que en la potencia de las posibles correlaciones que se puedan identificar en un estudio de carácter basado en el cruce de variables. Para estos autores es posible distinguir tres tipos de mecanismos. a. Mecanismos ambientales: aquellas influencias externas sobre las condiciones que alteran la vida social; b. Mecanismos cognitivos: aquellos que operan mediante alteraciones de la percepción individual y colectiva y c. Mecanismos relacionales que influyen en las conexiones entre personas, grupos y redes interpersonales (McAdam et al., 2005, p. 27). 
Estos mecanismos pueden también concatenarse con otros mecanismos en procesos aún más amplios. Estos procesos condensan cadenas causales, secuencias y combinaciones de mecanismos que son frecuentemente recurrentes. De allí que los autores traten de identificar aquellos que operan de forma idéntica o por lo menos de forma muy parecida en una variedad amplia de episodios y situaciones. Es importante señalar que las diferencias entre mecanismos y procesos está más asociado al nivel en el que se desarrolle la observación. Así, es posible observar que al interior de un mecanismo es posible identificar mecanismos a menor escala, o aún, incluir procesos más amplios y verlos en contextos históricos mayores en los que podrían ser identificados también, aunque bajo la comprensión de estarlos observando a una escala mucho mayor.

De esta forma, los autores han podido identificar numerosos mecanismos y procesos en episodios prolongados sin que exista una lista agotada de ellos. Algunos ejemplos de estos son: Correduría, certificación, cooptación, defección, difusión, emulación, atribución de similitudes, activación y desactivación de fronteras, formación de coaliciones, constitución de actores, acción colectiva, cambio de identidad, y nueva coordinación entre muchos otros. Sin embargo, lo importante aquí es identificar aquellos mecanismos que aportan en la generación de cambios importantes en el lugar, el carácter o las consecuencias de la contienda para luego enlazarlos y comprender las secuencias que se conforman para la producción de un determinado resultado (Tilly \& Tarrow, 2007, pp. 214-217).

\subsection{Diseño Metodológico}

Como hemos señalado previamente, esta investigación siguió un modelo síntesis de dos columnas vertebrales del estudio de los movimientos sociales: la perspectiva integradora y comparada de los movimientos sociales (McAdam et al., 1999) y el estudio dinámico de la contienda política (McAdam et al., 2005).

Al mismo tiempo, este estudio reconoce la importancia del análisis histórico para la construcción de un esquema de explicación condicional. Tal importancia radica 
en su contribución a dilucidar si es válido o no imputar una relación de causalidad entre el hito analizado y la movilización social, a partir de una selección o delimitación, en medio del amplio y complejo campo de los hechos y las relaciones que interactúan en la producción de un hecho social determinado (Weber, 2001). El análisis histórico retrospectivo implica la deconstrucción de las posibles relaciones causales que ligan el Hito respectivo, con los factores de oportunidades políticas en que ocurrió, así como con los factores organizativos, formas de acción y formas cognitivas del movimiento estudiado.

La importancia de este tipo de análisis histórico de tradición weberiana puede rastrearse hoy en día en los desarrollos teóricos y metodológicos más recientes que procuran contribuir al análisis de los impactos de los movimientos sociales. En efecto Giugni y Bosi reconocen que, dada la complejidad y la ambigüedad de las relaciones entre las actividades de los movimientos y sus impactos, la tarea principal frente a este tema no se orienta tanto a buscar formas de medir los impactos generales de los movimientos como a buscar formas de mostrar las relaciones entre las acciones de un movimiento y unos efectos particulares (Giugni \& Bosi, 2012, p. 23). Estos mismos autores recogen también los planteamientos de Tilly en el sentido de que la explicación de los impactos de los movimientos sociales comienza con una profusa descripción de sus procesos históricos, sus elementos, sus dinámicas e interacciones con otros actores: "Multiple causal chains lead to a plethora of possible effects in a situation where influences other than social movement activity necessarily contribute to the effects" (Giugni, McAdam, \& Tilly, 1999, pp. 253-270).

Así las cosas y a partir de un análisis principalmente cualitativo y desde una perspectiva histórica y dinámica, se hizo una descripción detallada de cada uno de los movimientos sociales intentando identificar los elementos principales de sus procesos enmarcadores, estructuras organizativas y repertorios de acción.

Con esta información descriptiva de los principales actores políticos, se siguió la propuesta metodológica de análisis dinámico (Tilly \& Tarrow, 2007, p. 207). Los 
autores de Contentious Politics plantean que la forma de explicar los procesos y los resultados de la contienda política involucra por lo menos tres pasos: a. la descripción del proceso, b. la descomposición del proceso en sus causas básicas y c. la reconexión de estas causas en un relato más general de cómo el proceso se desarrolló.

De acuerdo con ello, para desarrollar una línea de explicación es necesario delimitar y especificar adecuadamente el evento, el cambio y el resultado que se va someter a estudio; es decir, crear unos límites espaciales y temporales, denominados por estos autores como Episodio, sobre el cual se quiere determinar una secuencia de eventos y de mecanismos que conformen una cadena causal que lo conecte con los elementos descriptivos. Las secuencias de eventos denominadas por Tarrow y Tilly como "streams of contention", contienen un conjunto de momentos conectados de las acciones colectivas, determinados y expuestos por el investigador para la elaboración de la cadena causal de explicación del impacto (Tilly \& Tarrow, 2007, p. 204).

Para nuestro caso específico, el propósito de identificar estos episodios y secuencias es el de constatar la influencia efectiva de las acciones y las reivindicaciones de los movimientos en la producción del resultado. Esta consecuencia, denominada por nosotros como "hito" se delimitó aquí de acuerdo a la definición de Giugni y Bosi como un "impacto político externo referido a la alteración de los procesos de toma de decisiones políticas con respecto a derechos legales que forman parte de las reivindicaciones propias" del movimiento correspondiente (Giugni \& Bosi, 2012, p. 18). Este impacto específico para nuestro caso, está constituido por una decisión de política pública que durante la investigación los movimientos han destacado como un evento importante en el proceso de sus reivindicaciones.

Con base a esta estructura se identificaron las fronteras de los episodios, se describieron las condiciones iniciales, el flujo y la secuencia de los eventos, se especificaron y narraron los resultados de la contienda y se buscaron los mecanismos que produjeron cambios significativos asociados al hito para volver a 
recomponer en todas sus partes a los episodios estudiados y generar una explicación más integral. A modo de conclusión, se hizo una comparación entre los dos episodios intentando hallar similitudes y diferencias con el objetivo de ganar en comprensión sobre los procesos políticos estudiados.

Considerando que nuestro objetivo central es la identificación, descripción, análisis y comparación de los elementos que intervinieron en la generación de impactos de dos movimientos sociales que han logrado introducir temáticas propias de sus reivindicaciones en la definición de políticas públicas, dividimos su abordaje en 9 partes secuenciales:

a. Descripción de los Procesos Enmarcadores de cada uno de los movimientos seleccionados.

b. Descripción de algunos elementos de las Estructuras de Movilización de los movimientos constituidos durante la contienda.

c. Descripción de los principales Repertorios de Acción Colectiva desplegados por los Movimientos Sociales durante su existencia y en el episodio contencioso

d. Identificación de dos hitos (impactos percibidos por los movimientos como positivos y relevantes) presuntamente producidos por la actividad desplegada por cada uno de los movimientos seleccionados.

e. Constitución y delimitación de cada uno de los episodios en función de los hitos y la secuencia histórica de constitución de los Movimientos Sociales.

f. Aislamiento de la cadena de eventos interrelacionados en la producción de los hito, involucrando todos los elementos vistos previamente desde una perspectiva dinámica y relacional.

g. Identificación y análisis de las Oportunidades y Amenazas Políticas involucradas en la cadena de producción del Hito de cada movimiento social estudiado

h. Identificación y análisis de los Mecanismos que intervienen en la cadena de producción del Hito de cada movimiento social estudiado. 
i. Comparación de los elementos principales de investigación surgidos del estudio de dos movimientos sociales.

Con el propósito de abordar estas tareas se construyó una estrategia de investigación en cuatro momentos separados pero complementarios: a. de indagación: en esta fase se hizo un recorrido por la literatura sobre movimientos sociales y acción colectiva y se recaudó una gran cantidad de información secundaria de los movimientos sociales seleccionados. Con esta información se avanzó en la construcción del Estado de Arte y el Marco Teórico para la investigación y se ajustaron las metodologías e hipótesis de trabajo. En esta misma fase se comenzaron a hacer las visitas de campo a las sedes de los movimientos y a algunas de las regiones donde hacen presencia. Se comenzó la realización de las entrevistas semiestructuradas y se identificaron los hitos. b. de descripción: Con la información recolectada se identificaron los episodios, se documentaron las condiciones iniciales, el proceso histórico de cada movimiento social hasta llegar al hito y se identificaron los elementos constantes de los movimientos para una descripción estática de cada uno de ellos. Particularmente se narró lo concerniente a procesos enmarcadores, estructuras de movilización y repertorios de acción; c. de análisis: identificados los hitos a estudiar y definidos los límites de los episodios, se estableció una cadena causal de los eventos inmediatos al resultado trabajado en cada movimiento. Asimismo se realizó un análisis sobre las oportunidades y amenazas políticas y los mecanismos que operaron en el episodio de contienda. Este momento implicó la descomposición de las cadenas de acontecimientos descritos anteriormente para identificar los mecanismos y oportunidades que articularon las acciones de los actores en los flujos de eventos con un resultado específico considerado como un "Hito", es decir, como un impacto positivo de cada movimiento; y d. de comparación a manera de conclusión se cotejaron los principales resultados de cada caso en estudio mostrando similitudes y diferencias entre movimiento en su versión estática, pero sobre todo se buscaron contrastes entre las oportunidades políticas y los mecanismos que rodearon la constitución del hito. 
El siguiente gráfico nos ofrece un esquema del diseño metodológico adoptado para la investigación.

llustración 1. Diseño Metodológico.

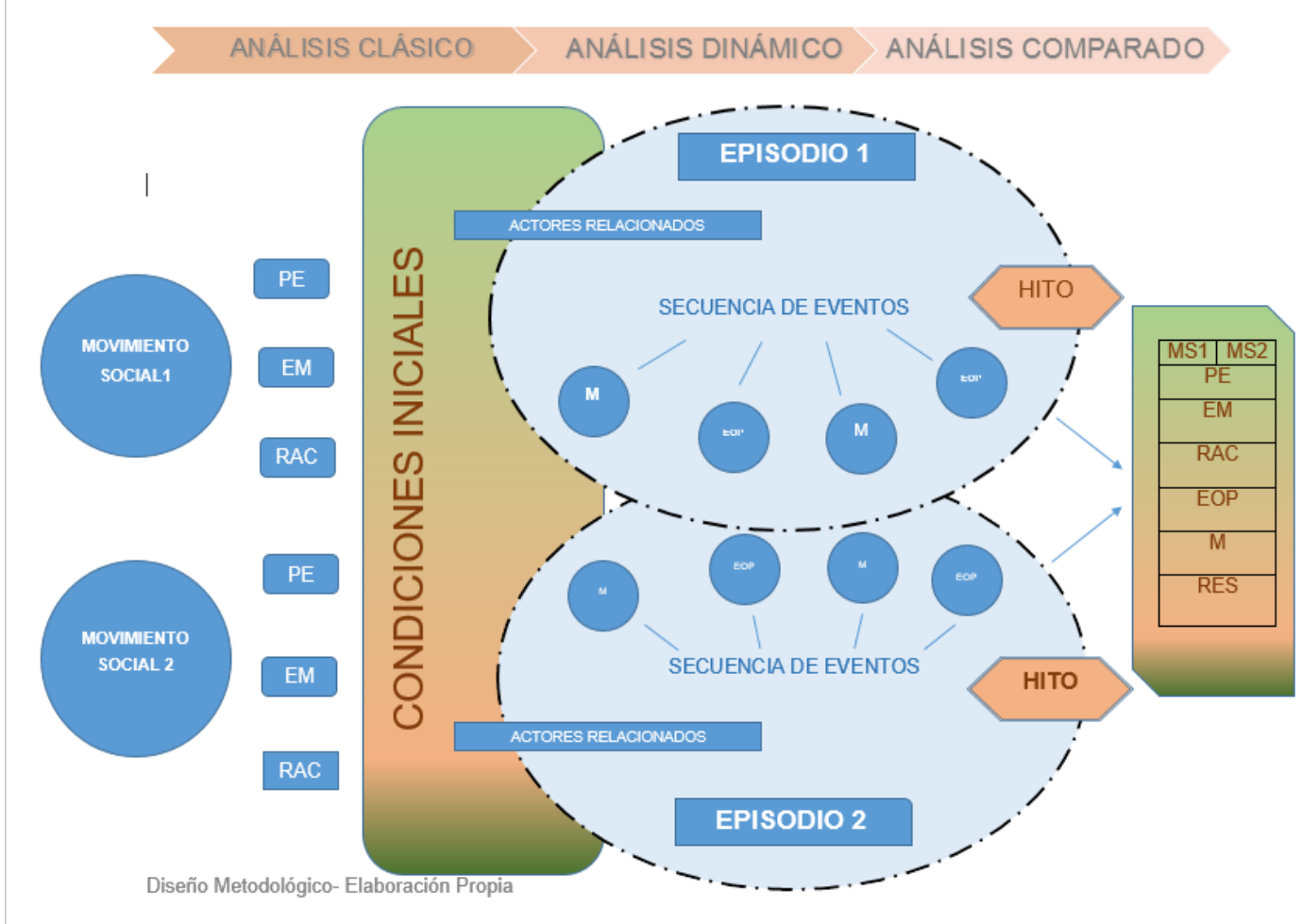

1.4.1. Desarrollo del Diseño Metodológico

Habiendo definido el diseño metodológico y el plan de investigación, en diciembre de 2012 se dio inicio al proceso de indagación. El primer paso consistió en la revisión de las páginas web de los movimientos donde pudimos encontrar un importante archivo de documentos que dan cuenta de su trasegar histórico así como de su conformación cognitiva y organizativa. Mediante la herramienta informática de manejo bibliográfico "Zotero" se organizó la bibliografía y se crearon bibliotecas para cada componente temático e histórico de la investigación. De acuerdo con el marco teórico y el diseño metodológico, se recopiló, sistematizó y organizó la información relativa a los procesos enmarcadores, las estructuras de

${ }^{5}$ Ver: https://www.zotero.org/ 
movilización y los repertorios de acción colectiva que caracterizan a los movimientos sociales seleccionados, así como las condiciones generales del contexto político en el cual surgieron.

Al mismo tiempo se inició el proceso de acercamiento a los movimientos con el fin de realizar entrevistas con algunos de sus líderes o integrantes de larga trayectoria. Para este proceso se utilizó un formato de entrevista semiestructurada ${ }^{6}$. En total se realizaron 10 entrevistas con integrantes de la Ruta, 12 entrevistas con miembros del Movice y 7 entrevistas con personas externas y expertas en los temas tratados ${ }^{7}$. En el proceso de realización de las entrevistas también fue posible acceder a algunos eventos masivos desarrollados por los movimientos. Asimismo, en este tiempo fue posible acceder a nueva documentación interna de los movimientos que no estaba disponible en las páginas web.

Para apoyar el proceso del análisis y el procesamiento de la información recopilada se utilizó el programa de análisis cualitativo Atlas Ti 7. Para tal efecto se crearon dos unidades hermenéuticas separadas, una para cada movimiento, y se utilizaron como documentos primarios las entrevistas y los documentos que estaban en formato electrónico. Para el análisis de la información se creó previamente un índice de códigos que permitiera la recuperación de información de acuerdo con las categorías de análisis establecidas; este índice también se fue nutriendo con nuevos códigos durante el desarrollo del proceso $^{8}$. Con la información codificada fue posible crear diversos niveles de vinculación y cruce de elementos que apoyaron el análisis y la posterior elaboración del texto final.

Por último y como apoyo a la documentación de los casos, se incorporó la utilización de la "Base de Datos de Luchas Sociales" del Centro de Investigación y Educación Popular CINEP. Como filtros de recuperación de campos en la base de datos se utilizaron los criterios “mujeres" y "víctimas y familiares". La información

\footnotetext{
${ }^{6}$ Ver Anexo 1. Formato de Entrevista.

${ }^{7}$ Ver Anexo 2. Entrevistas Realizadas.

${ }^{8}$ Ver: Anexo 3 Esquema de Codificación para análisis en Atlas Ti.
} 
recuperada de la base de datos permitió complementar la información recopilada sobre cantidad de movilizaciones por fecha y por lugar, con lo cual se obtuvo una mejor caracterización de los repertorios de acción y de sus posibles relaciones con los contextos específicos.

\subsection{Relevancia del Estudio}

El estudio de los movimientos sociales en Colombia ha sido centro de atención de varios académicos desde hace algunas décadas en el país. Diversos actores se han dado a la tarea de desentrañar los procesos de constitución de muchos actores colectivos clásicos como el movimiento obrero, los movimientos populares, el movimiento afrodescendiente, movimientos cívicos y la movilización estudiantil. Se trata de investigaciones que marcaron un derrotero importante para el abordaje y comprensión de los actores colectivos en Colombia y sus múltiples reivindicaciones. Investigadores como Mauricio Archila Neira (2002; 2005; 2006); Mauricio García Villegas, 2005: Leopoldo Múnera Ruiz (1998); Mauricio García Durán, 2005: ; Medina, 1984; Ramírez, 2001; Restrepo M., 1989; 1995; 1996; Torres Carrillo, 2007; Torres Carrillo, et al., 2003, son algunos de los exponentes más importantes de finales del siglo XX y principios del siglo XXI.

En este marco, el estudio de las luchas sociales ha sido un tema frecuentemente abordado. Libros como: "Pacífico ¿desarrollo o diversidad? Estado, capital y movimientos sociales en el Pacífico colombiano" (Escobar y Pedrosa, 1996), "Rupturas y continuidades. Poder y movimiento popular en Colombia 1968-1988" (Múnera Ruiz, 1998), “Las luchas sociales en Colombia 1975-2000” (Archila, 2002), "Idas y venidas vueltas y revueltas. Protestas sociales en Colombia" (Archila, 2003), "Resistencia civil artesana de paz: experiencias indígenas, afrodescendientes y campesinas" (Hernández, 2004), "Formas de acción colectiva contra la guerra en el movimiento indígena del suroccidente colombiano. Acción política no-violenta una opción para Colombia.” (Hernández Lara, 2005), o, La rebelión de los límites (Quimeras y por-venir de derechos ante la opresión (Ruíz, 2008), entre otros, han sido el resultado de los desarrollos académicos nacionales 
sobre movimientos sociales que han dado un marco teórico y de comprensión a los estudios posteriores sobre la Acción Colectiva en Colombia.

Al tiempo, han surgido interesantes análisis sobre las relaciones entre Movimientos sociales, democracia y partidos políticos. Un ejemplo de ello son los artículos: "Los movimientos sociales y las paradojas de la democracia en Colombia" (Archila, 2006) y "Movimientos sociales y democracia: una reflexión a propósito del caso colombiano" (Cruz, 2012) que nos muestran esa controversial relación en un país que además de mantener una democracia ininterrumpida padece una violencia endémica.

Sin embargo, no son muchos los avances en descripciones densas y explicativas de los movimientos sociales actuales y sus resultados, caracterizados por su pluralidad y diversidad. Movimientos LGBTI, feministas, ambientalistas, animalistas, étnicos y de víctimas, entre otros, han emergido en pocos años en el país, remplazando los movimientos clásicos de campesinos y sindicalistas que, si bien se resisten a su extinción, empiezan a ceder terreno ante las nuevas expresiones de inconformidad. Estos se encuentran concentrados en varios trabajos de grado sobre estudios de casos que brindan una aproximación importante a algunos de estos actores políticos. Tesis como: "Memoria colectiva y procesos de identidad social en el movimiento de víctimas de crímenes de Estado" (Herrera, 2008), "Memorias, pluralidad y movimiento social: la experiencia del Movice" (Mora, 2010), "La construcción de identidades de resistencia contra la guerra en Colombia. Caso de estudio: Ruta" (Forero, 2009) y “La Ruta pacifica de las mujeres y su aporte en la construcción de paz en Colombia. (Estudio de caso)" (De Ávila, 2011), son una muestra de ello.

Esta situación del estado de arte nos anima a pensar que la investigación que acá se presenta puede comenzar a llenar los vacíos que existen en la actualidad sobre los movimientos sociales actuales por los menos en dos sentidos. De un lado mediante la entrega de descripciones densas de dos de ellos y sus relaciones con el mundo político desde una perspectiva histórica. Explicar el telón de fondo histórico que alimenta y alienta la iniciativa de la acción colectiva nos puede ayudar a 
comprender la forma en que estos movimientos surgen y se desarrollan, así como a explicarnos la forma que van tomando a partir del ambiente que los rodea y los sujetos que la impulsan.

De otro lado, indagar por la participación de estos dos movimientos en cambios importantes de la política pública colombiana nos permite adentrarnos no solamente en la forma en que finalmente los movimientos intervienen en las distintas arenas de decisión, sino además, a entender los aportes casi silenciosos que hacen los movimientos sociales a la democracia en Colombia y de los cuales se sabe muy poco, y que en ocasiones, hasta pasan desapercibidos.

Se trata en últimas de dejar construidos dos estudios de caso lo suficientemente documentados en relación a uno de sus resultados, que permita a nuevos investigadores retomar desde allí para hacer comparaciones y relaciones más complejas que permitan inferencias más abarcadores. Al tiempo, se busca contribuir a la difícil tarea que tienen los movimientos de recoger sus pasos, aportando en la sistematización de sus luchas.

\subsection{Estructura del documento}

El presente estudio está dividido en dos partes, dando cuenta del trasegar histórico de cada uno de los episodios de contienda delimitados para los movimientos sociales seleccionados en esta investigación. En la primera parte se estudia a la Ruta y en la segunda parte al Movice. Cada uno de ellos relata el contexto histórico del surgimiento y desarrollo del movimiento para identificar y analizar los procesos enmarcadores, la estructura de movilización y los repertorios de acción, generando una descripción densa de estos elementos. Posteriormente se abordan los efectos de la movilización haciendo una narración de la principal cadena causal de los eventos inmediatos al hito, una explicación del contenido de este hito y luego un análisis dinámico de la estructura de oportunidades políticas y mecanismos que intervienen en la producción del resultado estudiado. Por último, en las conclusiones se hace un cotejo entre los movimientos tratando de identificar elementos similares y 
diferentes en relación con los elementos que intervienen en la generación de los resultados.

Ahora bien, considerando que los dos movimientos sociales comparten el mismo país y tiempo histórico, antes de abordar los episodios específicos que estudiaremos quisiéramos presentar un brevísimo marco histórico general en torno al conflicto político, social y armado que ha vivido Colombia en las últimas décadas y que ha determinado el surgimiento y la existencia de estos movimientos y la actual estructura del sistema político que sustenta los procesos políticos en el país. Con este marco pretendemos presentar el telón de fondo que acompaña las contiendas estudiadas en esta investigación y que puede ser muy útil para la comprensión de los eventos que se abordarán posteriormente dentro de la investigación. 


\section{El Contexto del Conflicto Político, Social y Armado en Colombia}

Para abordar el ámbito de los movimientos sociales de finales del siglo XX en Colombia, en particular el de los movimientos cuyas reivindicaciones gravitan en torno a un enfoque fundamentado en los principios y los estándares promovidos por el derecho internacional de los derechos humanos, es necesario reconocer y comprender el proceso histórico de formación y transformación del sistema político colombiano, el cual ha estado atravesado de manera determinante por la presencia casi permanente de las acciones violentas y del conflicto armado como mecanismo consuetudinario en el trámite de la contraposición entre las distintas facciones políticas a lo largo de los 200 años de historia republicana colombiana. La paradoja de la coexistencia entre "la democracia más estable de América Latina" y "el conflicto armado más antiguo del mundo" (Grupo de Memoria Histórica, 2013, p. 111), ha permeado gran parte de la historia nacional determinando en buena medida el devenir político del país y el cúmulo de contradicciones políticas y sociales surgidas de vivir en una democracia en guerra.

\subsection{El Estado Colombiano}

Es importante señalar que el surgimiento y establecimiento del Estado Nación aún es motivo de debate, aunque se suele afirmar que comienza con el proceso de independencia de la monarquía española en los años 20 del siglo XIX y tienen su punto culmen en la época de la "Regeneración", momento en el cual tuvo lugar la expedición Constitución de 1886, Carta que resulta ser vital para la configuración de las instituciones y del sistema político actual y que se erigió por más de un siglo en el estandarte y guía del desarrollo de esta nación. Si bien esta estabilidad sufrió dos altibajos importantes con las dictaduras de los Generales Rafael Reyes Prieto (1904-1909) y Gustavo Rojas Pinilla (1953-1957) en las que se suspendieron algunas de las garantías democráticas, en general el Estado Colombiano mantuvo durante más de un siglo la vigencia de sus instituciones bajo un sistema bipartidista (liberales vs conservadores) con un marcado acento al consociacionalismo como 
mecanismo para frenar la violencia partidista suscitada durante la segunda parte del siglo XX.

Esta distribución del poder comienza a ser modificada a partir de la expedición de la Nueva Constitución colombiana en 1991 que da paso al multipartidismo y crea algunas nuevas instituciones, brindando un nuevo escenario a las disputas sociales y la canalización de las protestas y reivindicaciones. Se dispuso en aquella Carta que el Estado colombiano permanecería centralista y unitario, y que se compondría de las ramas del poder público y los organismos del Estado.

En un marco de división de poderes se establecen las tres Ramas del poder público: la Ejecutiva, la Legislativa y la Judicial, acompañadas de los entes de control: Procuraduría General de la Nación, Defensoría del pueblo y Contraloría General de la República y los organismos de la Organización electoral: Consejo Nacional Electoral y la Registraduría Nacional del Estado Civil. En este orden, el poder ejecutivo tiene en su cabeza al Presidente de la República como Jefe de Estado, Jefe de Gobierno y Suprema Autoridad administrativa, acompañado por el Vicepresidente y los Ministros de despacho y elegido por voto popular por periodos de 4 años no reelegibles. Este último criterio fue modificado por el gobierno de Uribe quién propugnó por varias reformas constitucionales logrando instaurar la reelección; sin embargo esta reforma solo estuvo vigente de 2004 a 2015, ya que fue abolida posteriormente a instancias del Presidente Santos. El Gobierno a su vez quedó conformado por las gobernaciones, las alcaldías, las superintendencias, los establecimientos públicos y las empresas industriales o comerciales del Estado.

El poder Legislativo quedo constituido por un Congreso bicameral -Cámara de representantes, conformada por 166 representantes de Departamentos y el Distrito Capital y Senado conformado por 102 miembros de circunscripción nacional, en los dos casos elegidos por voto popular- el cual tiene bajo su responsabilidad la discusión y producción de las leyes de la República; y por último, el Poder Judicial, órgano encargado de administrar justicia conformado por las altas cortes: la Corte Suprema de Justicia, órgano de cierre de las jurisdicciones civil, penal y laboral; el 
Consejo de Estado, órgano de cierre de la jurisdicción administrativa y órgano de consulta de la rama ejecutiva; la Corte Constitucional, garante de la interpretación constitucional; el Consejo Superior de la Judicatura, órgano encargado de la administración de la rama judicial; la Fiscalía General de la Nación y las Jurisdicciones Especiales como la de justicia y paz o la de menores.

Este ordenamiento como señalábamos previamente, se encuentra acompañado desde los años 90 de un proceso de multiplicación de partidos políticos que se van desprendiendo del conservadurismo y de liberalismo sin que pueda considerarse que cobije un espectro ideológico de izquierda- derecha de forma marcada, exceptuando el Polo Democrático Alternativo quién se auto identifica como el partido de izquierda colombiano y quién ha detentado varios periodos la Alcaldía de Bogotá, considerado el segundo cargo de mayor importancia en el país, seguido de la Presidencia de la República.

Se abrió entonces la gama de posibilidades creándose y extinguiéndose agrupaciones políticas con vocación electoral, sobresaliendo entre estos por su mantenimiento en el tiempo: el Centro Democrático (bajo la actual jefatura del ex Presidente y Senador Álvaro Uribe Vélez), el Partido de Unidad Nacional o Partido 'De la U' (partido del actual presidente de la República Juan Manuel Santos), el Partido Conservador Colombiano, el Partido de Integración Nacional (PIN), el Partido Cambio Radical (Actual partido del Vicepresidente de la República German Vargas Lleras), Partido Verde, Movimiento Independiente de Renovación Absoluta (MIRA) (Partido de orientación confesional cristiano), el Partido Liberal Colombiano, y La Unión Patriótica (Partido surgido de las negociaciones con las FARC-EP en los años 80, que sufrió el genocidio de sus miembros y afrontó de una ardua lucha por conservar su Personería Jurídica la cual fue cancelada al no alcanzar el umbral de votación y luego fue reconocida como mecanismo de reparación mediante sentencia de Consejo de Estado en la cual se reconoció la responsabilidad del Estado en el genocidio). Además están los partidos de las minorías étnicas: Autoridades Indígenas de Colombia, Movimiento Alternativo Indígena y Social y Movimiento Afrovides. Todos estos, partidos entran en las disputas por el poder 
local, regional y nacional y aspiran a cubrir los cargos públicos disponibles, tal como ha sido la usanza desde los tiempos del bipartidismo9.

Esta forma de distribución partidista viene acompañada de otra serie de expresiones populares, movimientos sociales y expresiones gremiales: campesinas, obreras, indígenas y sindicales, entre otras, que amplían constantemente los debates y encienden las principales contiendas políticas, sociales y económicas en el país.

\subsection{Historia del Conflicto Armado}

Ahora bien, como marco y fondo de la evolución del sistema político, económico y social en el país, y como contexto del surgimiento de los movimientos de derechos humanos, se encuentra el conflicto político y armado vigente desde el comienzo de la década de 1960 y sin solución de continuidad hasta la actualidad.

Este conflicto armado contemporáneo en Colombia echa sus raíces, además de las condiciones sociales, económicas y políticas determinadas, en dos situaciones históricas especiales. Por un lado, en las atroces herencias de las guerras auspiciadas por los partidos políticos, liberal y conservador, que alcanzaron su paroxismo en la barbarie bipartidista de las décadas de 1940 y 1950, conocida coloquialmente en nuestra historia como la época de La Violencia, con mayúscula. Y por otro lado, en el consiguiente acuerdo consociacional entre los dos partidos tradicionales conocido como el Frente Nacional, vigente entre 1958 y 1974. La violencia política y la exclusión política configuran así el caldo de cultivo para un nuevo periodo de guerra interna, caracterizado por el surgimiento y la persistencia de la lucha política armada de organizaciones guerrilleras de izquierda que hoy alcanzan cinco décadas alzadas en armas, por el auspicio, la promoción, la implementación y/o la tolerancia desde sectores del establecimiento de prácticas sistemáticas de guerra sucia y conformación de grupos paramilitares como mecanismos de represión social, y por

\footnotetext{
9 Para una narración extensa sobre la historia política, económica y social colombiana puede consultarse la obra de referencia "Nueva Historia de Colombia" en 9 volúmenes, dirigida por Álvaro Tirado Mejía y editada por la Editorial Planeta en 1989.
} 
la explosión de la violencia social desatada y sostenida por el incontenible poder corruptor de la economía ilegal del narcotráfico.

El Informe General del Grupo de Memoria Histórica $\mathrm{GMH}^{10}$ da cuenta de 220.000 muertes relacionadas con el conflicto armado en Colombia entre 1958 y 2012, de las cuales el $81 \%$ han sido víctimas civiles. Al tiempo, el informe advierte que según estimaciones hechas por organizaciones de derechos humanos, unas tres cuartas partes de los homicidios han quedado por fuera de las estadísticas, lo cual se debe, por un lado, a las limitaciones en los registros de las entidades estatales y, por otro, a la eficacia de las estrategias de impunidad de los perpetradores. Entre otros datos del mismo informe se destacan las más de 45.000 desapariciones forzadas relacionadas con el conflicto y las más de 6 millones de víctimas de desplazamiento forzado ya reconocidas por el Registro Único de Víctimas RUV ${ }^{11}$. No obstante la escalofriante magnitud de estas cifras, ese es solo uno de los aspectos en los cuales el conflicto ha impactado a la sociedad colombiana. La profesora Martha Nubia Bello advierte en la presentación del informe: “Además de la magnitud de muertos, los testimonios ilustran una guerra profundamente degradada, caracterizada por un aterrador despliegue de sevicia por parte de los actores armados sobre la inerme población civil" (Grupo de Memoria Histórica, 2013, p. 20).

El Grupo de Memoria Histórica ha clasificado esta fase del conflicto armado interno en Colombia en cuatro periodos. El primero de 1958 a 1982, caracterizado por una transición de un tipo de violencia bipartidista a una subversiva, por la formación y proliferación de guerrillas de izquierda y por una presencia importante de manifestaciones de movilización social. El segundo entre 1982 y 1996, con el trasfondo del final de la guerra fría, se caracteriza por el fortalecimiento y expansión de las principales guerrillas y paralelamente el surgimiento del paramilitarismo junto con la irrupción y propagación del narcotráfico. En el tercer periodo entre

\footnotetext{
${ }^{10}$ El Grupo de Memoria Histórica fue creado como un grupo de investigación dependiente de la Comisión Nacional de Reparación y Reconciliación creada por la Ley 975 de 2005 y fue transformado en el Centro Nacional de Memoria Histórica por la Ley 1448 de 2011.

${ }^{11}$ Sistema de Registro de la Unidad para la Atención y Reparación Integral a las Víctimas creado por la Ley 1448 de 2011.
} 
1996 y 2005, se produce la mayor intensificación y degradación del conflicto armado, con la expansión simultánea de las guerrillas y los paramilitares y con el colapso parcial del Estado entre la guerra y la corrupción. Y el cuarto periodo entre 2005 y 2012 muestra un fortalecimiento militar del Estado, un debilitamiento de las guerrillas $\mathrm{y}$, tras un fallido intento de reintegración, una transformación de los grupos paramilitares, en un violento proceso de fragmentación en grupos mucho más volátiles y desafiantes (Grupo de Memoria Histórica, 2013, p. 111).

La persistencia de la violencia política conllevó el surgimiento de organizaciones cívicas de defensa y promoción de los derechos humanos hacia finales de los años 70 s que abrieron caminos a manifestaciones de acción colectiva como las que abordaremos en este estudio. No obstante, esos caminos serían sinuosos, pues, como lo describe Fernán González, este periodo del conflicto colombiano, desde los primeros años 80 s, está dotado de unas condiciones particularmente paradójicas.

Por un lado, se realizaron negociaciones de paz por parte del gobierno con las guerrillas de izquierda, negociaciones que condujeron a la reintegración de algunos grupos como el M-19, el EPL y el Quintín Lame pero que fracasaron y conllevaron al fortalecimiento y la expansión de las FARC-EP y el ELN. Por otro lado, se dio inicio a un proceso de ampliación de la participación democrática y descentralización administrativa mediante las elecciones populares de alcaldes y gobernadores, lo cual, sin embargo, llevó al fortalecimiento de grupos de poder locales y regionales reactivos a los intentos de modernización del Estado y proclives a la defensa de sus intereses y de su poder territorial mediante el paramilitarismo (González, 2014, p. 379).

La aparición del paramilitarismo estuvo también auspiciada por la estrecha relación entre las fuerzas militares y las élites locales quienes habían colaborado previamente con los militares en la lucha contrainsurgente. Esto determinó la relación de las fuerzas militares con la población civil a quienes veían como marginados y como una amenaza, a diferencia de las élites que eran consideradas sus aliados. De la misma manera, la irrupción de la desbordante economía del 
narcotráfico y sus necesidades de expansión y protección terminó por configurar una red alianzas que el Grupo de Memoria histórica explica a partir de tres elementos en juego: las élites económicas buscando defender su patrimonio, los narcotraficantes intentando extender su negocio y evitar las extorsiones de la guerrilla, los militares que querían acabar a la guerrilla y al enemigo civil interno (Grupo de Memoria Histórica, 2013, p. 143).

Estas situaciones llevaron a una enorme polarización política y social y a una degradación de la violencia y de la represión que encontraron respuesta en la intensificación del activismo de derechos humanos ante la crisis humanitaria, política y social. Es en medio de esa crisis y violencia exacerbada que los dos movimientos acá estudiados surgen y se desarrollan como alternativas populares de movilización social.

En los mapas que veremos continuación podemos apreciar gráficamente la evolución de la victimización que ha arrojado el conflicto en los últimos años y su incidencia en las diferentes regiones del país. 

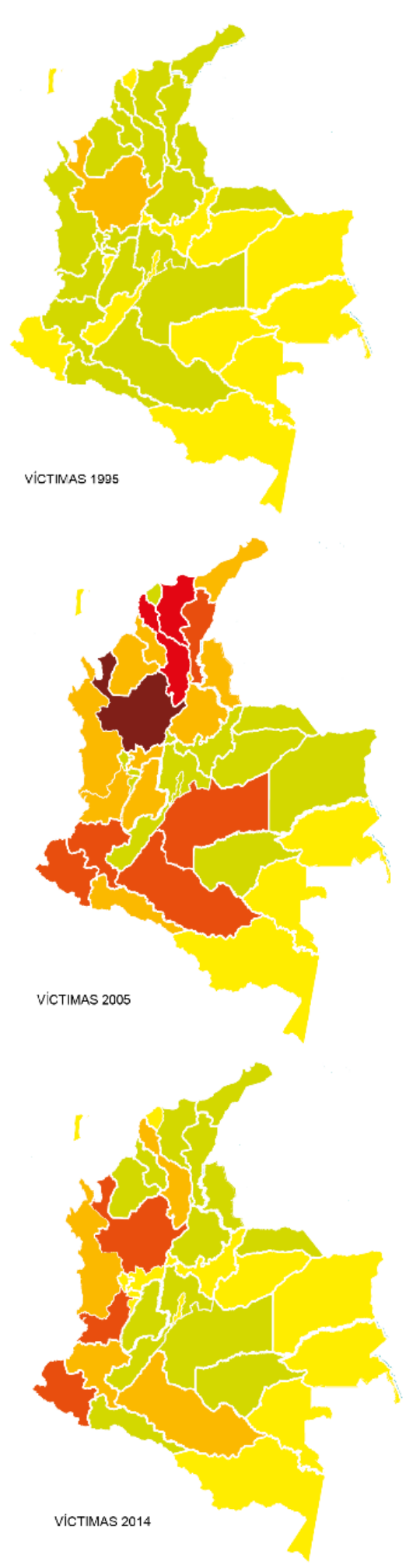
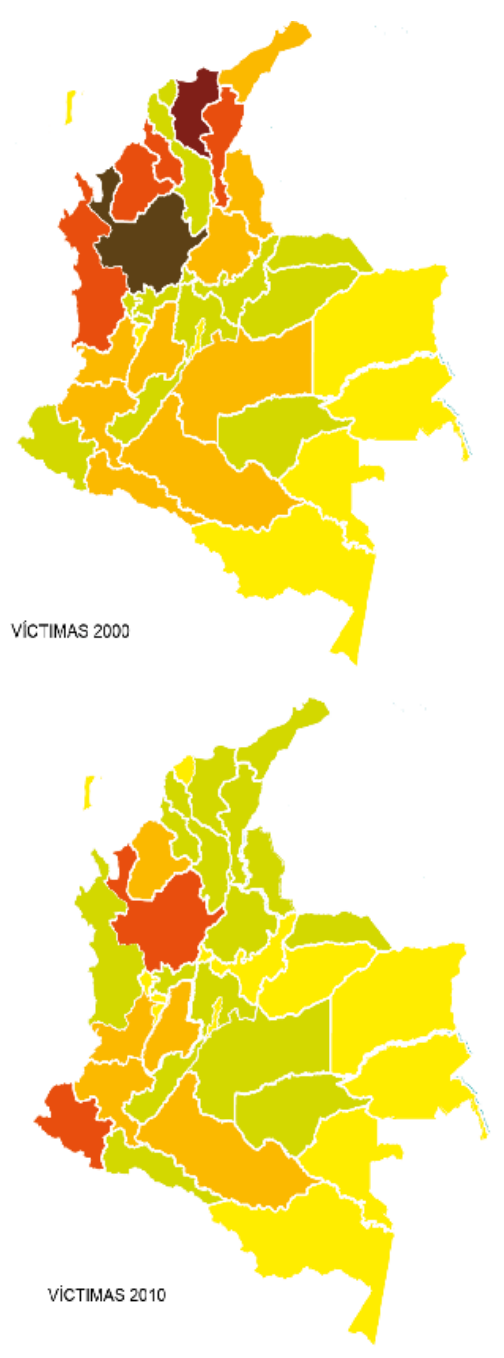

CONVENCIONES

Número de personas Victimas

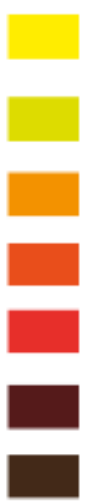

$0-1.000$

1.000-10.000

$10.000-20.000$

20.000-35.000

$35.000-50.000$

$50.000-75.000$

$75.000-100.000$

100.000- 150.000
Fuente: Elaboración propia a partir de los datos obtenidos de la Red Nacional de Información de la Unidad de Atención y Reparación Integral para las Víctimas, con corte en octubre de 2015. (Ver cifras de victimización por año en el Anexo 4). 


\section{Primera Parte. La Ruta Pacífica de las Mujeres}

En esta primera parte del documento nos interesa presentar al lector una lectura exhaustiva del surgimiento y desarrollo de este movimiento. Mediante un recorrido histórico pretendemos explorar particularmente las condiciones iniciales sobre las cuales se cimentaron las luchas de las mujeres en Colombia, la situación fáctica de las vulneraciones de sus derechos y los diferentes mecanismos que comenzaron a desarrollase para la defensa y agencia de sus reclamos.

El propósito es mostrar el marco histórico y geográfico del surgimiento y consolidación del movimiento hasta momentos previos a la secuencia de eventos que condujeron al hito, los elementos descriptivos propuestos por McAdam, McCarthy y Zald (1999) a saber: Procesos Enmarcadores, Estructuras de Movilización y Repertorios de Acción desde una perspectiva integradora, así como la identificación de aquellos aspectos en los que intervendría la Ruta durante el episodio de contienda y que produjeron transformaciones influenciadas por su acción movilizadora.

Para ello dedicaremos los tres primeros capítulos a la narración de los hechos del conflicto y a la movilización de las mujeres que desde mediados de los años 90 generó el nacimiento de este movimiento social y el trasegar histórico que emprendieron durante cerca de una década, para luego adentrarnos en una descripción densa de cada uno de los elementos enunciados. El cuarto capítulo se concentrará en la narración de la cadena causal de eventos durante el episodio demarcado como límite de estudio, y por último se hará, desde la perspectiva de la Contienda política propuesta por Tarrow y Tilly (2005), un análisis de las oportunidades políticas y los mecanismos que intervinieron en la producción del resultado analizado.

\subsection{Capítulo 1. EI Surgimiento de la Ruta Pacífica de las Mujeres}


En este apartado nos ocuparemos de las condiciones sociales, políticas y jurídicas que sirvieron de base al nacimiento de este movimiento social, haciendo énfasis particularmente en el desarrollo del conflicto armado a mitad de la década de los años 90. Se busca presentar en detalle toda la suerte de situaciones que facilitaron la explosión social feminista y las bases ideológicas y conceptuales que ayudaron a su constitución.

\subsubsection{La guerra en el Urabá ${ }^{12}$}

Luego de la época de la violencia en los años 40s y 50s y tras la conformación de varias organizaciones guerrilleras como las FARC-EP y ELN, Colombia comenzó un nuevo ciclo de contención violenta contra el Estado. Desde los años 70 los grupos guerrilleros habían tomado posiciones en la costa Caribe colombiana, al tiempo que el narcotráfico continuaba su crecimiento implantando el caldo de cultivo necesario para el surgimiento del paramilitarismo. Este fenómeno finalmente vio la luz de forma nítida en los años 90, en la región del Magdalena Medio en el centro del país, donde las autodefensas alcanzaron un desarrollo en armas y condiciones para la guerra y su consecuente expansión. Así lo narra el GMH:

“En 1994, los Castaño, una familia antioqueña asentada en Córdoba cuyo padre había sido asesinado por las FARC-EP, decidieron replicar la experiencia de las Autodefensas del Magdalena Medio que ellos conocían a fondo por haber participado en ella, y auspiciaron la creación de las Autodefensas Campesinas de Córdoba y Urabá (ACCU). La estrategia importada por los Castaño desde el Magdalena Medio consistía en auspiciar la alianza entre finqueros, narcotraficantes, agentes de la Fuerza Pública y dirigencias políticas, para garantizar las condiciones de financiación e impunidad requeridas para el avance de conquista y dominio de su proyecto. Militarmente, las ACCU operaban iniciando con la identificación de los

\footnotetext{
${ }^{12}$ Región geográfica de Colombia ubicada en la confluencia de los departamentos de Antioquia, Córdoba, Chocó y el Tapón del Darién en la frontera con Panamá.
} 
supuestos integrantes de las redes clandestinas de las guerrillas que se encontraban inmersos dentro de la población civil. Además de esta persecución selectiva, también adoptaron técnicas de terror -el uso de masacres sobre todo - para desplazar y desarticular a comunidades enteras acusadas de ser simpatizantes de la guerrilla” (Grupo de Memoria Histórica, 2011, p. 31).

Entre 1992 y 1996 los paramilitares empezaron a atacar las bases de la Unión Patriótica, del Partido Comunista y de todos aquellos que consideraban apoyos de las guerrillas. En el año 1995 se dio un repunte de sus acciones, la mayoría de las cuales fueron dirigidas contra las organizaciones sociales por medio de homicidios y masacres. Para ese entonces las milicias de la guerrilla hacían presencia en el casco urbano de Apartadó y las FARC-EP tenían una fuerte presencia en todo Urabá. En enero de 1995, el jefe de las autodefensas Carlos Castaño, que venía avanzando por el norte de Urabá en la frontera con Córdoba, anunció en un comunicado su entrada al eje bananero, la cual cumplió con una masacre el 12 de agosto de este año en la discoteca de Aracatazo, un barrio de la Unión Patriótica, en Chigorodó. Las FARC-EP contestaron al ataque con una masacre en la finca de los Cunas, el 29 del mismo mes. En este periodo, el Eje Bananero experimentaba una de las arremetidas más violentas, tras lo cual las FARC-EP retiraron sus núcleos armados de las ciudades y una parte se replegó hacia la serranía de Abibe, mientras que el contingente más grueso lo hizo hacia Mutatá, Dabeiba y Ríosucio. En 1995, también se registró en el municipio de Necoclí, la muerte de 130 personas, otras 122 desaparecidas y 2.500 desplazados (OPPDH, 2006, p. 11).

"En este contexto se gestó el modelo paramilitar de alianza ilegal, captura del poder político local y control del territorio que luego se exportó a todo el país. El exterminio recíproco en Urabá alcanzó su máxima expresión a mediados de la década del noventa. Durante cinco años se presentaron en esta zona los más altos índices de violencia del país con perpetración de masacres, desplazamientos forzados y asesinatos selectivos. Del total de 52 masacres registradas en la región de Urabá, 32 se produjeron 
en el eje bananero y 11 al sur de Urabá.” (Grupo de Memoria Histórica, 2013, p. 163).

La oficina en Colombia del Alto Comisionado de las Naciones Unidas para los Refugiados describió el tipo de violencia que estaba soportando la región del Urabá durante la década de los 90. En un Informe de 2004 señaló que en 1993 se registraron 14 masacres con 79 víctimas, en 1994 disminuyeron los casos a 3 con 46 víctimas. En 1995 se dispararon los registros con 15 masacres y 116 víctimas. En 1996 disminuyeron a 11 los casos y las víctimas a 71; durante 1997 se presentan 7 masacres con 36 víctimas y en 19982 casos con 15 víctimas. En 1999 y 2000 se registran 5 masacres, con 27 víctimas en el primer año y 30 víctimas en el siguiente (ACNUR, 2004).

También los homicidios se incrementaron por aquellos años. Según datos de esta misma agencia, entre 1990 y 2004 la tasa de homicidios por cien mil habitantes del Urabá antioqueño fue más alta que la tasa nacional, excepto en 1990, 2003 y 2004. Por otra parte, la tasa de homicidio fue superior al promedio departamental los años 1993, 1995, 1996 y 1997. Las afectaciones se vivieron particularmente en Chigorodó, Mutatá, Turbo y Carepa (ACNUR, 2004).

En 1995 también llegó Álvaro Uribe Vélez a la gobernación del departamento de Antioquia, periodo en el que los grupos paramilitares se beneficiaron y ampararon en las denominadas Cooperativas de Vigilancia y Seguridad Privada CONVIVIR. Estas estructuras de seguridad privada se constituyeron mediante el Decreto 356 de 1994, el cual permitía a los particulares asociarse para prestar servicios de vigilancia privada, constituir esquemas de vigilancia especiales referida a un grupo de personas específico en zonas de alto riesgo o interés público y aún prestar servicios comunitarios de vigilancia y seguridad privada (art 23, 39 y 42) mediante el uso de armas y medios de comunicación. El gobierno nacional las describiría como fuerzas defensivas contrainsurgentes dotadas por el ejército de armas financiadas con recursos públicos y privados. 
Estas estructuras optaron por realizar acciones bélicas en el marco de la lucha contrainsurgente, especialmente por el repliegue del Ejército durante estos años y su connivencia con amplios sectores del paramilitarismo. Vale decir que muchos de los más reconocidos jefes paramilitares como Salvatore Mancuso, Rodrigo Tovar Pupo alias Jorge 40, Diego Vecino y Rodrigo Mercado Peluffo alias Cadena, en aquella época fueron representantes legales o pertenecieron a las CONVIVIR. Con estas estructuras se llevaron a cabo varias masacres, algunas de ellas con el acompañamiento y apoyo del ejército o bajo la "omisión reiterativa" de éste. Según datos proporcionados por el Grupo de Memoria Histórica, a diciembre de 2012 la Unidad de Justicia Y paz compulsó a la Justicia ordinara incriminaciones contra 1023 miembros de la Fuerza Pública por hechos delictivos confesados por paramilitares (Grupo de Memoria Histórica, 2013, p. 158).

En estos años la situación de crisis humanitaria había desbordado completamente la capacidad de acción estatal, comenzaban a hacerse evidente los estragos de la guerra y se empezaban a recibir noticias diarias de masacres y asesinatos en diferentes regiones del país. Hasta ese momento las normas existentes para ayudar a las víctimas eran casi inexistentes y el Estado no tenía registros oficiales del número de víctimas ni de las zonas más afectadas.

"En un informe de la Consultaría para los Derechos Humanos y el Desplazamiento (CODHES) y del Fondo de las Naciones Unidas para la Infancia (Unicef), se revela que durante 1996, cerca de 36.202 hogares, aproximadamente 181.000 personas, fueron desplazadas por la violencia, fenómeno que afecta más a las mujeres y a los niños, que generalmente huyen tras haber perdido el esposo o al padre. El informe concluye que la cifra de las familias enteras desplazadas puede equipararse con la siguiente afirmación: "Cada hora, dentro del territorio nacional, se desplazan por causas de la violencia cuatro hogares", lo que indica que hoy, uno de cada 40 colombianos se encuentra en situación de desplazamiento. Las instituciones que elaboran el informe, sacaron un promedio que les permitió establecer que durante 1996, los departamentos que más reportaron 
expulsión fueron: Antioquia (45\%), Cesar (10\%), Córdoba (8\%) y Caquetá (5\%). Las amenazas, los asesinatos, las desapariciones, los atentados y las torturas son, en su orden, las razones que finalmente llevan a tomar esa decisión. Las acciones desatadas por los paramilitares han generado un éxodo sin precedentes: fueron ellos, en 1996, los responsables del 33\% del fenómeno del desplazamiento, seguido por los grupos guerrilleros en un 29\%” (Jaramillo Londoño, 1997, p. 127).

Era tal la desprevención del Ejecutivo sobre la materia que a esas alturas no existían políticas claras para el desplazamiento, el Plan Nacional de Desarrollo de Ernesto Samper denominado "E1 Salto Social" ni siquiera tenía dentro de sus ejes de trabajo esta problemática.

Por otro lado, la movilización social y popular, pese a esta tragedia, aún mantenía algún nivel de acción para 1995 y 1996. Fue llamativa particularmente la iniciativa de miles de campesinos vinculados a algún nivel de la siembra, producción y comercialización de la mata de coca, quienes marcharon por sus derechos en el suroriente del país, mostrando la imbricación entre el narcotráfico y los problemas sociales de los pobladores rurales del país.

\subsubsection{Violencia contra las Mujeres}

La guerra se encargó de cercenar la vida de miles hombres pero de embestir particularmente la vida y el cuerpo de mujeres y niñas que vivían en estos territorios en disputa. Esta situación sin embargo no se evidenció en el acto; fue necesario que varias organizaciones de la sociedad civil y el empeño político de muchas mujeres víctimas se dieran a la tarea de denunciar y registrar las múltiples violencias que se ejercían en el cuerpo de las mujeres para que lentamente el país empezara a conocer lo que sucedía en estos territorios alejados de los principales centros urbanos y la capital de la República. En el Urabá, aunque no solamente allí, el despliegue militar de guerrilla y paramilitares se trenzó en asesinatos, masacres, violencia sexual, desaparición forzada y tortura entre otros vejámenes. Esta violencia, es necesario 
señalarlo, se inscribe en un contexto cultural que facilita otras formas de violencia contra las mujeres al punto de su naturalización. Tal vez fue por ello, que durante un largo tiempo, no fueran ostensibles las afectaciones que tenían las mujeres y los informes estuvieran más enfocados en registrar el número de muertos en masacres o asesinatos colectivos. El Informe Mujeres y Guerra, lo sintetiza así:

"la violencia sexual contra las mujeres, además del acceso carnal violento, se ejerció, entre otras formas, mediante la desnudez forzada, la tortura sexual, el establecimiento y exigencia de pautas de relación entre hombres y mujeres en el ámbito afectivo y sexual, y la esclavitud sexual y doméstica. Es posible afirmar que hay en este tipo de manifestaciones una direccionalidad de género, es decir, la violencia infligida contra las mujeres en gran medida estuvo asociada a la transgresión de los arreglos de género o definiciones de hombre y mujer, que tuvieron gran centralidad en el proyecto de orden paramilitar” (Grupo de Memoria Histórica, 2011, p. 19).

Las formas de la violencia contra la mujer también se desarrollaron a partir de un patrón de motivaciones definido. En muchas ocasiones la violencia, particularmente la sexual, se circunscribía a un método de guerra para humillar a los enemigos e intimidar a las poblaciones, es decir, se colocaba a la mujer como un intermediario capaz de crear sensaciones de frustración y temor en terceros. En otros casos era la mujer en sí misma quién representaba el adversario, las mujeres líderes fueron objeto de amenazas, persecución y muerte por su acción política y social. También la mujer fue usada de manera funcional a las necesidades de la guerra, ellas en muchas ocasiones eran quienes "servían" a los combatientes en tareas domésticas o como esclavas sexuales. Por último, también fueron vulneradas de manera oportunista, sin que el ataque tuviera un fin específico para la guerra, pero sí aprovechándose del contexto de violencia.

Sobre los grados de terror infringidos por los paramilitares en 1996 en el Urabá existen algunos relatos, unos más conocidos que otros, unos con mayores descripciones que otros. Sin embargo las cifras de víctimas y el grado de 
afectaciones sigue siendo una tarea pendiente. Lentamente se ha comenzado a conocer parte de la realidad a partir de las confesiones en el marco de los procesos de Justicia y Paz, en las que se empiezan a develar los grados de crudeza y sevicia con que fueron ejecutados la mayoría de estos crímenes. Empero estos adelantos, los delitos cometidos contra las mujeres, particularmente la violencia sexual, son de los que menos datos se tienen, sobre todo porque han sido los menos confesados por los paramilitares. Así lo señala uno de los informes de la Ruta publicado en 2011, haciendo un balance de la aplicación de la ley de Justicia y paz. Explican que de 138.000 víctimas reconocidas hasta ese momento solo 96 habían sido reconocidas como víctimas de violencia sexual (Montealegre, Bautista, Castaño, Betancur Marín, \& Jaramillo Burgos, 2011, p. 21).

Tampoco las bases de datos oficiales contienen variables que permitan identificar si los crímenes se han cometido en el marco del conflicto armado, si responden a feminicidios y tampoco registran los autores responsables. Si bien la calidad de este tipo de información, ha venido mejorando con el tiempo, un registro juicioso del tema solo comienza a llevarse desde el año 2000.

"No existe una correspondencia entre las cifras oficiales y las de las diversas organizaciones de derechos humanos, como tampoco con las que proporcionan los testimonios de las mujeres víctimas y familiares. No existe uniformidad en las cifras proporcionadas por las instancias estatales, variables e indicadores estandarizados. Lo cual no posibilita realizar análisis de períodos históricos, cruzar información sobre el número de hechos de violencia contra las mujeres, las investigaciones iniciadas y terminadas y los resultados de las mismas. Adicionalmente, la sistematización de los datos de las instancias estatales no se realiza desde una perspectiva de derechos humanos de las mujeres y diferencias por sexo/género, etnia y orientación sexual; con la finalidad de conocer las características y especificidades de las violencias contra las mujeres, sus causas, los perfiles de las víctimas y de los agresores. Las instituciones responsables de administrar justicia no 
disponen de información sobre las causas penales de los asesinatos y los feminicidios" (Sánchez, 2008, p. 92).

Las cifras más antiguas de delitos contra mujeres en el marco del conflicto armado son las relacionadas por la Comisión Colombiana de Juristas que señala que entre enero de 1997 y diciembre de 2007 se registraron 103 víctimas de violencia sexual, 100 víctimas de estos casos correspondieron a mujeres, 2 a hombres y en uno de los casos se desconocía el sexo (Mesa de Trabajo «Mujer y conflicto armado», 2008). Entre otros datos aún más generales PROFAMILIA reveló un estudio estadístico sobre violencia contra la mujer según el cual en 1990 el porcentaje de mujeres víctimas de violencia sexual en el país era del 8,8 \% (Gómez López, Murad, \& Calderón, 2013, p. 14), no obstante, esta cifra no tiene la posibilidad de ser contrastada con más información ni se puede inferir cuales de estas victimizaciones ocurren en el marco del conflicto armado.

Sin embargo, algunos estudios cualitativos provenientes de las organizaciones sociales y feministas sí permiten entrever la dimensión de la violencia contra la mujer en la guerra. Los tres testimonios que se transcriben a continuación recogidos en el año 1999 y que hacen parte del libro Las violencias contra las mujeres en una sociedad en guerra pueden acercarnos a lo que intentamos referir.

"Era de noche. Llegaron dos varones armados vestían prendas militares, camuflado, armas y se identificaron como paramilitares. Se llevaron a mi esposo fuera de la casa y todo el tiempo le apuntaron con el arma. La niña lloraba. Yo cerré la puerta. Uno de los varones se devolvió y gritó que abriera la puerta o la tumbaba (...) Yo logré calmar a la niña y la arrullé hasta que se durmió. Entonces el hombre me sacó de la habitación y me llevó al corredor para interrogarme. Allí, en un banco que hay en el corredor, me amenazó con matarme si no me dejaba. Me quitó la ropa, me tapó la boca y me forzó. Me violó. Luego me dijo que me vistiera y también dijo: “Aquí no pasó nada. Las mujeres, al fin y al cabo son para esto". 
“En 1997, en zona rural del Departamento de Santander, en la que confluyen dos actores armados (paramilitares y guerrilla), fueron violadas dos niñas de 6 y 8 años y su madre obligada varias veces a sostener relaciones sexuales con el violador de su hija mayor, para evitar que volviera a abusar de la niña. A la niña mayor la violó un guerrillero y como castigo, lo mataron los mismos miembros de su grupo. La niña de 6 años fue violada por un vecino con la complicidad de otro hombre y los paramilitares mataron a los agresores delante de la niña, "para que eso no volviera a pasar". La niña dejó de hablar por mucho tiempo porque pensaba que a ella le podía pasar lo mismo y se sentía culpable de la muerte de los dos varones. Este caso se mantuvo en silencio durante cinco años".

“El 3 de agosto de 1997, en Medellín Antioquia en el sector de Brisas de Oriente, Barrio Santo Domingo, cuatro amigas estaban conversando frente a la casa de una de ellas, como a la una de la madrugada, se fue una de ellas y llegaron unos siete u ocho muchachos milicianos, a quienes las muchachas reconocían. Estaban muy violentos, las trataron mal, las insultaron y les pegaron puños y patadas. A una líder juvenil, de 22 años, la amenazaron, le dijeron que le iban a dar golpes en la cara y a matar si no hacía lo que ellos pedían. Luego, cuatro de ellos la llevaron a un callejón, la pusieron contra una pared, le bajaron los pantalones y subieron su blusa. Ella no gritó porque no pudo, tenía mucho miedo. Trataron de penetrarla por delante y por detrás, no lo lograron. La obligaron a que tuviera sexo oral con todos. La mantuvieron como hora y media allí. Luego le dijeron que se fuera, pero uno de ellos que estaba muy disgustado porque no pudo penetrarla, dijo que "eso no se quedaba así”. La condujo junto con otros dos hasta un lugar más apartado donde había un carro y en la parte de atrás del carro, la violaron los tres. Aproximadamente a las tres de la mañana la dejaron ir. Tuvo mucho miedo de volver a su casa y acudió a un integrante del grupo juvenil, a él contó lo sucedido y pidió ayuda" (Sánchez, 2008, p. 67). 
Todo esto sucedía en el ámbito de una sociedad que aún no tomaba seriamente en cuenta los parámetros jurídicos internacionales sobre la no violencia contra la mujer, ni tenía incorporados en su legislación interna mecanismos de prevención y protección para las mujeres en contextos de conflicto armado.

Cabe recordar que en aquel momento ya Colombia había adquirido compromisos en las Conferencias Internacionales de las Naciones Unidas sobre Derechos Humanos (Viena 1993), Población y Desarrollo (Cairo 1994) y de la Mujer (Beijing 1995), así como la Declaración para la Eliminación de la Violencia contra la Mujer emitida por la ONU en 1993, y había aprobado en 1995 la Convención Interamericana para Prevenir, Sancionar y Erradicar la Violencia contra la Mujer Convención de Belém do Pará (OEA, 1994). Sin embargo, la normatividad interna aún no se planteaba la posibilidad de la violencia fuera del ámbito familiar. Esto es evidente en la legislación existente en aquel momento -ley 294 de 1996-, en la que sólo se estipulaba como tipo penal la violencia intrafamiliar. Esto solo cambiaría en 2008 cuando se expidió la ley 1257 en la que se legisló sobre múltiples entornos de violencia contra las mujeres, incluida la guerra (Gómez López et al., 2013, p. 15).

Es importante señalar que después de la Cuarta conferencia de la ONU celebrada en Beiging en 1995, el Gobierno Nacional creó la Dirección de Equidad de Género con el objetivo de cerrar la brecha de género existente hasta ese momento en Colombia. Aunque no tenía estatus ministerial, esta oficina intervenía en las reuniones de gabinete y adelantaba programas en diferentes carteras. Se trataba de una importante oportunidad para la agenda de las mujeres.

\subsubsection{Neutralidad Activa}

Mientras tanto la guerra también se ensañaba contra otros sectores de la población históricamente discriminados. La población afrocolombiana y los pueblos indígenas eran permanentemente atacados y violentados en sus territorios. Así fue en Antioquia, donde la disputa de los actores armados por el territorio los ponía en una situación de particular vulnerabilidad. Sin embargo el pueblo indígena 
enseñaría una nueva alternativa de defensa y supervivencia frente a la guerra: la neutralidad activa. Pocos años después de que la Constitución de 1991 se convirtiera en un hito para el reconocimiento de los derechos de los pueblos étnicos y ante el incremento de la violencia en el Urabá propiciado por la guerra entre las FARC-EP, la disidencia del EPL y el paramilitarismo, entre 1994 y 1996, la Organización Indígena de Antioquia (OIA) declaró la neutralidad activa de sus pueblos en relación con los actores armados y el Estado. Ya en aquel momento el Consejo Regional Indígena del Cauca CRIC también había comenzado a hacer público su adhesión a iniciativas de paz en el país y se planteaban claramente las diferencias entre las comunidades indígenas y los grupos de guerreros.

"Como elementos fundamentales de lo que la OIA llamó "neutralidad activa", los pueblos indígenas de Antioquia demandaban el respeto a sus autoridades por parte de los actores armados, y el fortalecimiento de los cabildos por parte de las comunidades. Demandaban la presencia de organizaciones internacionales e instituciones estatales de acompañamiento humanitario. Proponían que, con la presencia de organizaciones de carácter humanitario tanto estatales como no gubernamentales, las autoridades indígenas emprendieran diálogos con los actores armados, en ejercicio de la autoridad que les otorga el artículo 246 y en el marco del derecho internacional humanitario. Se proponía también la divulgación de la neutralidad de las comunidades indígenas y la denuncia de los infractores de ésta, la creación de espacios comunitarios y no violentos de resolución de conflictos como instrumentos y la no participación, en ninguna forma posible, en la confrontación armada. Finalmente, se proponía el refuerzo de la jurisdicción indígena" (Caviedes \& Caldón, 2007, p. 89).

Esta expresión hacia la no violencia fue varias veces tergiversada por el gobierno departamental de Álvaro Uribe Vélez, quien pretendió que la neutralidad activa fuera una forma de apoyo al Estado. Esta situación deslegitimó la propuesta ante las guerrillas que sintieron que se trataba de un mecanismo de apoyo al gobierno. 
Así las cosas, las organizaciones indígenas optaron por ampliar su propuesta, ya no solo a un neutralidad activa que les permitiera estar por fuera de la barbarie de la guerra, sino también a asociarse con el movimiento de paz en Colombia en una muestra clara del deseo de hacerse partícipes de acciones propositivas para la consecución de la paz. En cualquier caso, la OIA marcó una nueva forma de pensar y entender el problema de la guerra y dejó plantada la semilla de la no violencia. Simiente que fuera recogido poco tiempo después por la Ruta e incorporado a su forma de entender y hacer su lucha.

\subsubsection{La década de los 90 para el feminismo en Colombia}

El marco normativo internacional para la protección de los derechos de las mujeres fue creciendo al tiempo con el surgimiento y el afianzamiento de los feminismos en el mundo. Cada nuevo instrumento se sucedía tras la acción de los sectores feministas y servía de motor para nuevos planteamientos y acciones de las mujeres. Marcó una pauta importante de impulso el Pacto Internacional de Derechos Civiles y Políticos y su Protocolo Facultativo de 1966, a partir del cual las mujeres adelantaron un proceso de acción transnacional y lograron que las Naciones Unidas designen 1975 - 1985 como el decenio de las mujeres. En 1975 durante la Conferencia Mundial del Año internacional de la Mujer se creó el Instituto Internacional de Investigaciones y Capacitación para la Promoción para la Mujer INSTRAW y el Fondo de Desarrollo de las Naciones Unidas para la Mujer UNIFEM. En esta conferencia se planteaba la igualdad de género plena, la eliminación contra la discriminación sexual y la participación de la Mujer en el fortalecimiento de la Paz. En 1979 nace la Convención para la eliminación de todas las formas de discriminación contra la mujer CEDAW, en la que se hace hincapié en la violencia basada en género obligando a los Estados a tomar medidas. En 1980 se realiza la Conferencia Mundial del Decenio de las Naciones Unidas para la Mujer: Igualdad, Desarrollo y Paz. En 1985 se realizó la Conferencia mundial para el examen y evaluación de los logros de las Naciones Unidas para la Mujer: Igualdad, Desarrollo y paz en Nairobi, y en 1999 se realiza la Conferencia del Llamamiento de la Haya por la Paz (Ibarra Melo, 2011, p. 249). 
En Colombia se vivió una situación similar. Tras las acciones de las mujeres en los años 50s exigiendo el voto femenino comenzaron a desplegarse grupos $\mathrm{y}$ organizaciones que dieron cuenta de la historia del Feminismo en el país. En 1970 se crearon los primeros grupos de autoconciencia intentando romper esos muros que aún separaban lo privado de lo político con el objeto de insertar en lo público temas como la sexualidad, el aborto, el derecho a decidir sobre el propio cuerpo, las relaciones de poder y la doble militancia.

La Conferencia Internacional de la Mujer de 1975 fue un nuevo aire para el movimiento de mujeres. La Unión de Ciudadanas por Colombia, enmarcada en el bipartidismo y sufragismo desde los 50, en estos años se vuelca a la comprensión de los problemas económicos de las mujeres. La Unión de Mujeres Demócratas, asociada al Partido Comunista, se comienza a plantear el sentido de la doble militancia creando algunas rupturas con el partido, creando en 1977 el Frente Amplio de Mujeres bajo la bandera de la autonomía de género (Archila \& Gómez, 2005). Esta ruptura con los movimientos políticos se afianzó en el I Encuentro Latinoamericano y del Caribe llevado a cabo en Bogotá en 1981, en el que se continuaron las discusiones alrededor de la autonomía, doble militancia, sexualidad y opción sexual. Allí también se consolidaron propuestas organizativas como la conformación de la Casa de la Mujer (1982) y de la Corporación Centro de Acciones Integrales en Cali. También se consagró el 25 de noviembre como el día de la no violencia contra las mujeres (Forero Acosta, 2009, p. 19).

Así relata este primer encuentro Olga Amparo Sánchez:

"Nos otorgamos la oportunidad de encontrarnos en el Primer Encuentro Feminista Latinoamericano, julio de 1981, doscientas sesenta mujeres caribeñas, latinoamericanas, norteamericanas y europeas, estuvimos en la gran odisea de aunar esfuerzos, ganas, dolores, frustraciones, sueños y esperanzas y nos comprometemos a conmemorar desde ese año, todos los 25 de noviembre, como el Día Internacional de No 
a la Violencia contra las Mujeres. Fue y es una acción de la política de crédito-deuda con nosotras y con las otras, con todas las mujeres que en sus cuerpos, almas, sueños y esperanzas les han quedado marcadas las violencias perpetradas contra nosotras" (Sánchez, 2008, p. 23).

Los años 80s para el feminismo en Colombia transcurrieron en medio de los debates sobre la vida cotidiana de las mujeres y lo político. La identidad, la sexualidad, la maternidad, los derechos reproductivos y sexuales, los derechos humanos y la paz fueron algunos de los temas centrales del debate feminista. También comenzó a aparecer la discusión sobre el rol del movimiento de mujeres, su relación con el Estado y con otros sectores de la sociedad civil. Estos debates y discusiones abrieron paso a una movilización social el 29 de noviembre de 1985 en la que se demandaron el derecho a la vida y a la no violencia contra la mujer. Esta movilización, que pretendía sacar del marasmo que dejó al país la toma del Palacio de Justicia y el fin de los diálogos de paz con la guerrilla, también facilitó la creación del Colectivo de Mujeres de Bogotá, una iniciativa que pretendía generar espacios para el análisis de la estructura del poder y la construcción de una nueva ética de los derechos humanos y que se irradió por todo el país, surgiendo numerosos colectivos de mujeres que intentaban actuar como grupo de presión (Arango \& Rey, 1997, p. 401). También en esa década, se celebraron importantes encuentros sectoriales como el de mujeres afiliadas a la Acción Comunal en 1985, el Primer Congreso de la Mujer Trabajadora en 1987 y el Primer Encuentro de Mujeres Indígenas en 1990 (Archila \& Gómez, 2005).

Para esa época el conflicto armado había dejado miles de violaciones a los Derechos Humanos y las organizaciones sociales y de mujeres comenzaban a manifestar su indignación por la violencia a la que eran sometidas. El 8 de marzo de 1986 y de 1987 en Cali, Medellín y Bogotá se organizaron "marchas por la vida” en rechazo a las acciones violentas. Se trató de movilizaciones con gran contenido simbólico en las que, sin descuidar los asuntos de género propios de sus planteamientos, se volcaron en la exigencia del respeto de los derechos humanos. Para ese momento 
la paz ya no era un tema exclusivo de los gobiernos, era también un asunto de la sociedad civil (Arango \& Rey, 1997, p. 403).

A nivel Internacional esta década también enmarcó el surgimiento de uno de los movimientos de mujeres que tendrían en los años posteriores una gran influencia en varias de las organizaciones nacionales de mujeres: las Mujeres de Negro. Esta expresión organizativa tuvo su primera expresión en 1988 en Jerusalén, cuando grupos de mujeres vestidas de negro se manifestaron en contra de la ocupación de Israel en territorios Palestinos. Se trataba de grupos conformados por mujeres tanto israelitas como palestinas. Para 1990 fueron apareciendo en diferentes lugares del mundo expresiones similares con reivindicaciones propias de sus contextos. En Italia protestaron por la posición de su gobierno frente a la Guerra del Golfo, en Alemania por la venta de químicos al régimen Iraquí, en la India por el fundamentalismo Hindú, en Estados Unidos por los sin techo y para poner fin a la violencia en los barrios, en Australia contra la violencia doméstica (Corporación Vamos Mujer, 2008).

Los años 90 comenzaron para las mujeres colombianas como para el resto de la ciudadanía, con el sueño de una nueva Constitución. En los meses de antesala los diferentes gremios y sectores sociales se preparaban para la conformación de la Asamblea Nacional Constituyente y las mujeres y grupos feministas también participaron de ello. La demanda por una salida negociada al conflicto ya era explícita desde el movimiento social de mujeres y se prepararon para una "Marcha del Silencio", partiendo del Cementerio Central hasta llegar a la Plaza de Bolívar en Bogotá. En ella se reunieron especialmente familiares de líderes políticos asesinados junto con otras víctimas de la violencia, quienes hicieron un llamado a todas las personas afectadas por el conflicto, a pensar en la paz como una opción para detener el desangre del país y al reconocimiento del profundo dolor de las personas por las pérdidas y por el sufrimiento causado por la guerra, para superar los sentimientos de odio y de venganza que solo podrían atizar más el conflicto (Arango \& Rey, 1997, p. 405). 
En 1996 el movimiento social de mujeres había implementado mecanismos de movilización lo suficientemente desarrollados que, si bien no tenían un interlocutor directo, les permitía tener visibilización política nacional y plantear sus reclamos contra los estragos de la guerra. Este año se realizaron tres marchas centradas en la visibilización de las víctimas y de las consecuencias de la guerra: protestaron en Bogotá las madres que enviaban a sus hijos bachilleres a la guerra, se movilizaron en Putumayo las madres de los soldados detenidos en la toma a la base Las Delicias, y marcharon desde todas las regiones del país hasta el municipio de Mutatá, en el Urabá Antioqueño, “las mujeres en la Ruta por la resolución de los conflictos”. Desde ese momento se consolidaron las organizaciones feministas a nivel nacional y se desarrollaron numerosas acciones y movilizaciones en torno al fin del conflicto mediante la salida política negociada. Las mujeres de la Ruta hicieron nuevas apuestas, para enfrentar la guerra dialogaron con los indígenas y los campesinos, se identificaron con la neutralidad activa y se propusieron la posibilidad de actuar políticamente desde la No Violencia, en medio de un país en guerra desde siempre.

Encontramos así el punto de interés central para nuestro estudio de este episodio de contienda política enfocado en la movilización de la Ruta: Ellas comenzaron a identificar cómo el conflicto armado, visto con otros lentes, afectaba de manera particular y diferenciada a las mujeres en las zonas de guerra. Notaron que aunque el asesinado era el padre, el esposo o el hijo, eran ellas las que debían huir con los niños y los ancianos, ponerlos a salvo de los guerreros, proporcionarles los mínimos básico para la supervivencia en lugares desconocidos y además rehacer los proyectos de vida de ellas y de sus familias. Vieron también que aunque los desaparecidos solían ser ellos, a ellas les marcaban su cuerpo, las violaban y torturaban, las utilizaban para tareas domésticas y las esclavizaban sexualmente. Se dieron cuenta también que le servían a los guerreros como mecanismo para humillar al hombre, desconsolar a la población y evitar sublevaciones. En suma, que eran botín de guerra y que de eso nadie hablaba.

\subsubsection{El nacimiento de la Ruta Pacífica de las Mujeres}


Son varios los factores que incidieron y las versiones que se recuerdan sobre el nacimiento de la Ruta. La existencia previa de organizaciones de mujeres y colectivos feministas, la presencia en el espectro nacional de algunas líderes feministas, la experiencia adquirida en estos años por el movimiento de derechos humanos para la movilización social y popular, una Constitución Política nueva y unas herramientas jurídicas internacionales que ambientaban la defensa de los derechos de las mujeres, fueron elementos que facilitaron la construcción de este nuevo movimiento social. Sin embargo fue motor de impulso el análisis y el conocimiento que las mujeres organizadas comenzaron a tener sobre la vida de otras mujeres que padecían los estragos de la guerra. Así lo recuerda una de sus integrantes:

“En ese entonces ya veníamos preguntándonos de manera esporádica, de manera individual: bueno, y las mujeres frente a la guerra qué, y frente a la construcción de paz qué hacemos, qué decimos, cómo vamos ahí, y entonces estaba Gloria Cuartas de alcaldesa en Apartadó, con ella nos encontrábamos y nos había contado que estaba muy preocupada. Ella iba a las regiones y tenía una capacidad de oratoria y de conversación muy buena, hizo todo un proceso muy político no solo en Apartadó sino a nivel nacional, nosotros la invitábamos y ella iba, y nos había contado que en Mutatá las mujeres eran violadas sistemáticamente por los diferentes actores armados, entonces como que nos fuimos sintonizando con la pregunta de: y las mujeres en la guerra y en la paz qué, en aquel momento estaba la Escuela Nacional Sindical, estaba Mujeres que Crean, estaba SUIPPCOL, yo trabajaba en SUIPPCOL, Marina (Gallego) trabajaba en Mujeres que Crean, estaba María Teresa (Arizabaleta) en el Valle con Mujeres Ciudadanas. Éramos básicamente las mismas que estamos en este momento en términos de regiones y dijimos: armemos aquí un cuento, un colectivo un proceso donde comencemos a preguntarnos por el impacto de toda esta guerra, del narcotráfico, de los cultivos ilícitos, de la corrupción, de cómo todos los actores están vulnerando el cuerpo y la vida de las mujeres y cómo eso afecta la vida familiar, personal. Nos fuimos juntando y 
comenzamos a preparar la primera movilización que fue a Mutatá. Eso fue una cosa súper emocionante. Fue como el acto fundacional de la Ruta y desde eso no hemos parado de tejer, de destejer" (Entrevista 7$)^{13}$.

Desde esta óptica, la Ruta surgió por el análisis y la toma de conciencia sobre los daños infringidos en el cuerpo y la vida de las mujeres en el marco del conflicto armado colombiano. A los debates sobre los derechos económicos, sociales, civiles y políticos propios de otros años, las mujeres agregaron la necesidad específica de reconocer los daños causados por la guerra a las mujeres y la manera desproporcionada en que estas eran afectadas en medio del horror general. Afectaciones que, además, la sociedad colombiana y los sucesivos gobiernos involucrados en esa guerra decidían no ver. Sin embargo, y como señalamos antes, también influyeron situaciones del contexto, varias conquistas políticas feministas previas y la presencia de lideresas influyentes en el país. Estos elementos habilitaron un ambiente político y púbico que permitió la emergencia de este movimiento.

Como se dijo previamente, en 1995 el gobierno de Ernesto Samper creó la Dirección Nacional para la Equidad de la Mujer DINEM bajo la dirección de Olga Amparo Sánchez. Esta nueva dependencia enfocó sus acciones hacia tres objetivos: en primer lugar, se propuso formar a congresistas y funcionarios públicos para que estos a su vez promovieran desde sus cargos cambios legislativos que beneficiaran a las mujeres, por otro lado, se concentró en introducir la perspectiva de género en los planes de desarrollo y, por último, la entidad se dedicó a apoyar política y financieramente a las organizaciones sociales de mujeres (Forero Acosta, 2009, p. 21). Paralelamente Piedad Córdoba surgió como figura pública ganando espacio en el panorama político del país. Como militante del Partido liberal y con las banderas del progresismo fue elegida Senadora de la República para el periodo comprendido entre 1994 y 1998 con un alto caudal de votación en Antioquia y Chocó. La amistad entre la nueva Directora de la oficina para la equidad de la mujer, quien esgrimía

\footnotetext{
${ }^{13}$ Para las referencias de las entrevistas realizadas por la autora ver el Anexo 2 Listado de Entrevistas.
} 
un interés fuerte en apoyar económicamente iniciativas de mujeres y una Senadora Liberal conocedora del territorio e interesada en la paz favoreció el escenario para la emergencia de un nuevo movimiento social de corte feminista y pacifista. Así lo recuerda Martha Elena Giraldo:

"Entonces ellas toman la decisión, Piedad Córdoba y Olga Amparo Sánchez, que está en ese momento en la Dirección Nacional para la Equidad en el periodo de Samper, ella y Piedad que eran tan amigas deciden empezar a trabajar por la paz porque había una presión muy fuerte, desde el Chocó y Urabá sobre todo, el Urabá antioqueño. Era una situación muy fuerte la que se estaba viviendo por la presión del conflicto armado, y entonces ellas decían, bueno y porqué nosotras no vamos allá a mirar qué es lo que pasa. Por primera vez las mujeres empiezan a moverse y a querer conocer de primera voz y de viva voz, y en el cuerpo -como decimos las mujeres-, y entonces organizan la primera salida a Mutatá y ese es el origen de la Ruta, y en Mutatá estaba pasando de todo, las mujeres estaban sufriendo las cosas más horribles, y entonces por primera vez las mujeres de todas las organizaciones, que eran muy famosas, muy conocidas y muy estables, deciden unirse y así comienzan los puntos focales" (Entrevista 6).

Desde otro lugar de la memoria Olga Amparo Sánchez, una de las fundadoras de la Ruta, sitúa su surgimiento en el año 94 en un escenario distinto. Así lo recuerda ella:

"Las historias tiene muchas caras, entonces te voy a hablar desde la cara que yo conozco. La Ruta tiene su origen en una primera discusión que hubo en la Casa de la Mujer como a finales del 94, que estábamos la Escuela Nacional Sindical en cabeza de Rocío Pineda, la Unidad de Mujeres de la CUT con Patricia Buriticá, y estábamos tres de la Casa de la Mujer, en una reunión de concertación porque estábamos hablando sobre qué hacemos frente a la situación del país y la situación tan dificultosa en relación de la violencia contra las mujeres. En ese momento dijimos, pues hagamos una 
movilización de 50 mil mujeres, Norma Enríquez, que en ese momento estaba en la Casa nos dice, ustedes están locas, una movilización de 50 mil mujeres, como se les ocurre. Entones en esa reunión nosotros dijimos, entonces porque no le planteamos a las mujeres de Medellín que tienen la Mesa de Mujer y Trabajo, que era una mesa de concertación con los grupos de mujeres y la institucionalidad en ese momento del departamento, que si se medían a esa idea de la movilización. Rocío Pineda quedó encargada de hablar con las mujeres de Medellín y ver quién estaba a favor de eso, y llamó la atención. Y ahora, cómo conseguimos plata, esto coincidió con que a mí me ofrecieron la Dirección Nacional de la Equidad para las Mujeres, la oficina de la mujer en el gobierno de Samper y desde allí movilizamos recursos para que se pudiera realizar la primera movilización que fue la de Mutatá y que coincidió con unos elementos que estaban ahí, todo el trabajo que estaban haciendo las comunidades indígenas en ese momento de la "neutralidad activa", y la situación de violencia contra algunas de las mujeres o contra mujeres indígenas, más la situación de Medellín. Se dijo bueno, vámonos a una movilización a Mutatá, entonces se hizo la primera movilización que fue en el 96" (Entrevista 11).

Como puede leerse, el año de reunión también está en cuestión, pues mientras para Olga Amparo ésta se realizó a finales del año 94, los documentos de la Ruta la ubican en el 95 (Ruta Pacífica de las Mujeres, 2003, p. 13), las asistentes siguen siendo las mismas, se reunieron: el Programa de Mujeres de la Escuela Nacional Sindical, el Departamento de Mujer de la CUT y la Casa de la Mujer de Bogotá, con el fin de programar un viaje hasta Urabá para extender su solidaridad a las mujeres que vivían allí y de las que se sabía estaban sufriendo las barbaries de la guerra producida por el enfrentamiento entre las FARC-EP y los paramilitares. Sin embargo, debe decirse que fueron numerosas las mujeres que participaron en la construcción de la propuesta y que muchas de estas mujeres aún hacen parte de la Ruta en los territorios. También debe destacarse que estuvieron organizaciones como vamos Mujer y Mujeres que Crean, que son organizaciones que al encontrar 
elementos comunes en sus preocupaciones les fue fácil comenzar a trazar un camino conjunto (Entrevista 3).

Empero, fue necesario esperar hasta 1996 cuando las cosas parecían que llegaban a su límite. Ante un consejo de seguridad en Antioquia el grupo Renacer de Apartadó aseguró que el 95\% de las mujeres de esta población habían sido violadas. Este fue el detonante, el agravio que finalmente decidió a las organizaciones de mujeres, que habían estado pensando en movilizarse desde un año atrás, a que lo hicieran. De esta forma lo recuerdan las mujeres de la Ruta:

"La historia de la Ruta es como la de cualquier mujer colombiana. Fue concebida en 1995 en una región donde la guerra había dejado su huella sangrienta por doquier: Urabá. Allí, la región donde el banano brota de la tierra fértil sin que la mano humana se lo exija, donde la mezcla de negros, indígenas, paisas y chilapos, es un jolgorio de músicas, rituales y vida. Allí, en esa esquina casi perfecta de la patria, las mujeres callaban en los cementerios, mascullaban a solas el dolor de enterrar hijos, pares, hermanos, maridos y amigos. Y gemían también por verlos como verdugos de otros. Y se desgarraban de rabia y vergüenza porque el paso de las hordas guerreras les había significado a muchas de ellas la violación. Y ese llanto colectivo, mustio y lejano, empezó a ser un crujido que llegaba a los oídos de las mujeres del resto del país” (Ruta Pacífica de las Mujeres, 2003, p. 13).

La Ruta fue el producto del acumulado que venían construyendo las mujeres y sus organizaciones desde hacía varias décadas. Desde la lucha por el voto en los años 50, la constitución de pequeños grupos de discusión sobre la vida cotidiana de la mujer o la conformación de organizaciones no gubernamentales de corte feminista, hasta el ingreso en la vida pública de mujeres que defendían ideales similares. Sin embargo, tal vez lo más notable, fue la intención consiente de comprender lo que les pasaba a las mujeres en la guerra, de visibilizar estas afectaciones y evidenciar que no eran las mismas que afectaban a los hombres. Encontramos entonces, un interés explícito, aunque hasta ese momento inexplorado, por mostrar que las 
mujeres sufren unos impactos particulares y desproporcionados como consecuencia del conflicto armado.

\subsubsection{La Marcha a Mutatá}

La Ruta, como movimiento social, nació con la movilización. Una vez tomada la decisión, las organizaciones de mujeres que venían planificando la movilización a Urabá decidieron que ésta comenzara el 25 de Noviembre en consideración al Día de la No Violencia Contra la Mujer. El municipio de Mutatá fue el escenario escogido para esta primera gran movilización. La convocatoria, empero, no era asunto fácil. Tratar de reunir miles de mujeres, de todos los puntos cardinales del país, en un lugar del país reconocido por los altísimos grados de violencia, desde donde se tenían noticias de homicidios, torturas, masacres y violaciones y que en aquel momento era el centro de disputa entre los grupos armados más peligrosos del país, resultaba poco atractivo para las mujeres y sus familias, que veían en este recorrido un riesgo innecesario.

Las instituciones oficiales regionales también esgrimieron sus propios puntos de vista. Planteaban que intentar atravesar las carreteras de esa región podría llevar a la marcha a encontrarse directamente con los grupos de guerrillas y paramilitares, particularmente en ciertos lugares del camino donde eran tradicionales los combates entre todas las facciones, por lo que sugirieron incluir una escolta militar para acompañar los buses que llevarían a las mujeres. Ellas la rechazaron, pues, se trataba de presentar una visión diferente, alternativa y no violenta de las movilizaciones sociales, contraria de las visiones militaristas del conflicto social y político (Ruta Pacífica de las Mujeres, 2003, p. 15).

Había, también, argumentos a favor para pensar que Mutatá podía albergar a la Ruta. De un lado Gloria Cuartas, en aquel momento alcaldesa de Apartadó, había logrado crear un consenso con diferentes movimientos políticos en la región, su lucha por la paz hacía suponer que sectores sociales de esta región estarían interesados en desarrollar acciones de paz y eventualmente albergarían la propuesta 
de movilización de la Ruta. De otro lado, la Organización Indígena de Antioquia OIA había declarado este municipio en Neutralidad Activa. Significaba esto que los pueblos indígenas deseaban que sus territorios no fueran afectados por ninguno de los bandos y que animaban acciones que condujeran al cese de las hostilidades y de la intromisión de guerreros en sus pueblos. Eulalia Yagarí miembro de la "Nación Embera" y diputada ante la Asamblea de Antioquia desde 1992, resultó ser una persona clave para la concertación con la alcaldía de Mutatá y para llevar a cabo la movilización. Con estas condiciones, las mujeres de las organizaciones pioneras sintieron el respaldo suficiente para emprender la marcha. Ahora comenzaba la tarea de convocar:

"Entonces empezaron a llamar a organizaciones fuertes que estuvieran interesadas y que siguieran algunas líneas similares entre ellas. Que fueran organizaciones feministas, que pudiesen jalonar procesos en sus territorios, que fueran antimilitaristas. En ese momento no existía Ruta sino organizaciones con querencias similares. Ahí se juntaron varias organizaciones, por ejemplo: FUNSAREP en Bolívar, en el Cauca con COMUNITAR, desde el Valle con la Asociación de Mujeres de Cali, con la Fundación Mujer y Futuro en Santander, con la Casa de la Mujer Stella Brand en Pereira, y así, entonces se empezaron a juntar varias iniciativas" (Entrevista 3).

Junto con esta tarea de convocar, era necesario también explicar la iniciativa y preparar a las mujeres que participarían para el recorrido y las acciones que se desarrollarían en Mutatá. Se realizaron entonces acciones de formación política y de análisis del contexto, para la construcción de una identidad colectiva que les permitiera a las mujeres enfrentar juntas el miedo, comprender los objetivos y los alcances de la marcha, y así, tomar decisiones libres sobre su participación. Se realizaron decenas de talleres por todo el territorio nacional y se comenzaron a forjar algunos de los pilares identitarios que caracterizan hasta hoy al movimiento, tales como, el feminismo, la neutralidad activa y el pacifismo. Las mujeres fueron a Mutatá habiendo debatido ampliamente sobre la situación de la guerra en el Urabá, 
sobre la importancia de trabajar por una salida negociada al conflicto armado, sobre las múltiples aproximaciones a los planteamientos feministas y sobre el pacifismo como modelo de acción política.

Durante este proceso, decidieron como punto de encuentro la ciudad de Medellín. Allí se dieron cita cerca de 1500 mujeres que venían desde la Costa Atlántica, Popayán, Pasto, Putumayo, Pereira, Ibagué, Apartadó, Chigorodó, Turbo, Chocó y Urabá (Arango \& Rey, 1997, p. 408). Más de 40 buses se dirigieron desde Medellín, transitando en caravana durante 12 horas la ruta hasta Mutatá. El evento, en muy corto tiempo, se volvió noticia y fue cuestión de pocas horas para que en todo el país y en el exterior se conociera tal osadía.

Pero en los talleres preparativos, las mujeres de la Ruta, no solamente habían aprendido de política y de guerra. También habían invertido parte importante del tiempo en imaginar y construir símbolos, elementos artísticos, acciones simbólicas que hicieran el viaje y del encuentro con las mujeres de Mutatá un momento inundado de afecto, intuición y solidaridad. Ya en Mutatá, se realizaron varios rituales mezclando la política con la mística y la denuncia con la solidaridad. La imaginación y la creatividad hicieron juego para poner color al miedo, se idearon los primeros lemas que determinarían la forma y el tipo de feminismo que plantearían en lo sucesivo. El lema "No parimos hijos ni hijas para la guerra" se instauró además como propósito. Esta frase seguiría a la Ruta durante el resto de sus movilizaciones.

En aquella jornada se redactó la declaración fundante de las Mujeres de Colombia en Ruta para la Resolución de los Conflictos:

"Recogimos en el camino toda la sal de las lágrimas, nos nutrimos de las alegrías producidas por la fuerza de nuestras vacilaciones. Descubrimos las atrocidades que se ocultan detrás de los silencios: mujeres desplazadas, viudas, huérfanas, solas, mal acompañadas. Nos sentimos enlazadas por las cintas solidarias y amorosas de nosotras, mujeres 
solidarias. Con peguntas al cielo, compartiendo la suerte del plantea, haciendo sonar la campana de cristal del corazón. Manifestamos:

No permitir que de nuestras manos y vientres, brote ni un solo alimento para la guerra y la violencia.

Enseñaremos a nuestros hijos e hijas a cambiar los gritos de horros y estupefacción ante la muerte, por la esperanza solidaria.

No callar ante el dolor o el sufrimiento producido por la guerra, o por la violencia que se comete contra las mujeres de cualquier parte del planeta, así no aparezca en las estadísticas.

No olvidar nuestro compromiso político de proteger a nuestro planeta, la madre tierra.

Siempre recordar que se invierten en la guerra, los recursos que deberían invertirse en el desarrollo. Sin desarrollo sostenible y sustentable, no habrá paz.

Levantar nuestra voz, porque hoy se pretende pacificar al país, con proyectos totalitarios de muerte. Crecen los grupos que a nombre de la defensa ciudadana, bajo el amparo legal, riegan más sangre y resentimientos

¿Cómo pacificar entonces a los pacificadores?

Desactivar todos los artefactos de la guerra, los de hierro, los de la palabra que la incita, los del olvido.

Acompañamos a las mujeres del Suroeste, a las del resto del país y del mundo en sus acciones fundantes, de una nueva convivencia y de acciones organizativas que nos permitan soñar el presente.

Nos pronunciamos contra el desastre ecológico que se avecina a las entrañas de nuestra tierra.

Nos declaramos veedoras de todos los procesos de diálogo, pues en ellos también se juega la vida, la esperanza de las mujeres, las (os) jóvenes y niñas (os).

Propugnamos porque se abran como alternativa los diálogos regionales, porque la paz se construye más fácilmente si se teje desde cada parte, se gesta desde las particularidades, si se impulsa e invierte en desarrollo local." (Ruta Pacífica de las Mujeres, 2003, p. 17). 
Este manifiesto permite identificar varios de los elementos que constituyen la identidad de la Ruta y determinan sus acciones políticas.

En primer lugar, las mujeres de la Ruta encuentran en su ser, como mujeres y como madres, un escenario de acción, lucha y resistencia. Sabiéndose madres y esposas que hasta el momento han participado pasiva o activamente en la guerra, se comprometen a no facilitar ni permitir actos de violencia en su presencia y a educar a sus hijos en la paz y la solidaridad, o incluso, a no tener más hijos si continuara la ruindad de la guerra.

En la lógica de hacer visible lo invisible, la Ruta se compromete a no callar frente la violencia contra las mujeres en medio del conflicto, planteando además una visión supranacionalista, ya que hablan del sufrimiento de la mujer no solo en Colombia sino en el mundo.

Se declaran en contra de la visión militarista del gobierno nacional, haciendo una fuerte crítica a su modelo de defensa ciudadana, implementado en aquel momento en el país y fuertemente desarrollado en el Urabá, propugnando por una salida política y negociada al conflicto armado mediante diálogos regionales que observen las situaciones locales y que cuenten con una veeduría internacional.

Plantean una visión ecológica y una gran preocupación por el medio ambiente y hacen una fuerte crítica al modelo económico que se sustenta en la guerra y que debe ser reemplazado por un modelo sostenible capaz de reconocer e invertir en el desarrollo local.

Con este manifiesto empieza a tomar forma el pensamiento y la acción de la Ruta. A partir de allí comienzan los debates, las reuniones, los talleres y otras iniciativas que empezarían a darle sustento a sus afirmaciones y a conformar un cuerpo identitario más definido. 


\subsection{Capítulo 2: EI Desarrollo de la Ruta Pacífica de las Mujeres}

Para la época comentada ya existían unas organizaciones sociales consolidadas, una estructura de oportunidades que facilitó la constitución de nuevos actores sociales y políticos y la persistencia de una situación agraviante que demandaba ser atendida con prontitud. En este contexto la Ruta emergía como una nueva forma de contienda que entraba en diálogo y choque con otras expresiones más o menos cercanas, abriéndose paso para abanderar un sector específico del feminismo en el país. Un feminismo diverso, complejo y aún en construcción.

Pero para que este movimiento tuviera un desarrollo más allá de las primeras expresiones de inconformismo, fue necesario otra serie de sucesos que las alimentaría y fortalecería. Un cambio presidencial con unas políticas reprochables desde su visión, una serie de encuentros y reconocimientos con otros sectores y luchas similares, el develamiento del desplazamiento forzado como una forma de victimización particular para la mujer y una serie de acciones colectivas que iban dándole una identidad e imagen pública. Por ello, estos serán los caminos que recorreremos en este capítulo, aquí abordaremos precisamente el relato de los años que siguieron y que terminaron de dar forma a las características específicas de este movimiento.

\subsubsection{Primeras movilizaciones y nuevos repertorios}

La Ruta había adquirido la experiencia, el conocimiento y la fortaleza para continuar su camino y, antes de acabar el cuatrienio del gobierno Samper (19941998), había realizado tres movilizaciones más. En 1997, con el ánimo de ir sedimentando el nuevo pensamiento que nacía con la marcha a Mutatá y que acercaba el pacifismo al feminismo, se convocó al Cabildo Internacional de Mujeres por la Paz el 25 de Noviembre. Esta reunión, a la que invitaron a mujeres de distintos países, tenía como propósito comenzar a pensar la guerra en función de la negociación política y el papel de las mujeres en este proceso. En la declaración final las mujeres de la Ruta llaman al cese de la guerra y se pronuncian en contra 
del armamentismo y el militarismo, denuncian la violencia sexual contra las mujeres y se ubican en el centro de posibles negociaciones entre los actores armados, como veedoras del proceso.

Este mismo año dos delegaciones de la Ruta deciden marchar hacia lugares apartados con el propósito de visibilizar los efectos del conflicto, denunciar las arbitrariedades cometidas por los señores de la guerra y llevar su sororidad a las mujeres que allí habitan. De un lado el punto focal de Antioquia se moviliza al municipio Los Andes en el suroeste de este departamento. Allí el conflicto entre guerrilla y paramilitares había llevado al desplazamiento forzado masivo de la comunidad indígena Embera Chamí, un pueblo que se había declarado en neutralidad activa. Nuevamente la diputada Eulalia Yagarí jugó un papel protagónico en esta movilización sirviendo de anfitriona. Las mujeres de la Ruta encontraron nuevamente allí los estragos de la guerra y el maltrato a las mujeres. En la declaración hecha al final de esta marcha la Ruta muestra con más ahínco su repudio a la guerra y a los guerreros. Rechaza tajantemente el uso de las armas y condena el desalojo de las poblaciones indígenas de sus territorios. Reitera su llamado al cese de las hostilidades, a los diálogos regionales, emplaza a los empresarios y dueños de la tierra para que redistribuyan sus riquezas y por último invoca la paz y la sitúan como un proceso que debe ser construido entre todos (Ruta Pacífica de las Mujeres, 2003, p. 24).

Pero como también la guerra seguía azotando al Urabá, el otro grupo de mujeres de la Ruta decide emprender viaje a Pavarandó vereda de Mutatá, esta vez en compañía del Centro de Investigación y Educación Popular CINEP. Allí se dieron cita con cientos de mujeres, hombres y niños que venían huyendo de sus territorios en la zona chocoana que limita con Panamá como consecuencia de la encarnizada disputa entre guerrilla, paramilitares y ejército. Era entonces un triste punto de encuentro en el que se refugiaban estas comunidades y al que acudieron las mujeres de la Ruta para acompañarlas en Navidad. 
Después de realizar 9 talleres con cerca de 100 mujeres, ellas decidieron visibilizar la situación mediante una nueva declaración. La Declaración de las Mujeres Desplazadas en Pavarandó relata paso a paso los vejámenes de la guerra, muestra cómo las mujeres recuerdan su territorio en el medio y bajo Atrato chocoano y antioqueño y su vida en la pobreza pero en la tranquilidad. Luego la llegada de los bombardeos de los helicópteros, las violaciones sexuales, torturas y asesinatos con sevicia y el comienzo de la huida. Caminos a pie que duraron más de dos semanas con niños pequeños y acianos en medio de la desesperación pero también de la solidaridad, la trágica llegada a Pavarandó, el asedio del Ejército, el hambre y la desatención estatal, el recuento y búsqueda infructuosa de cera de 15 personas que habían desaparecido en medio de las hostilidades y la incertidumbre del futuro cercano. En semejante escenario las mujeres declararon la importancia de mantener la esperanza, fortalecer la relación entre las organizaciones de hombres y mujeres, reivindicar su papel en la comunidad como mujeres organizadas, afirmar el deseo de retornar en condiciones de seguridad y, sobre todo, el deseo de ver sus hijos vivos (Ruta Pacífica de las Mujeres, 2003, p. 32). Esta declaración además denota, no solamente la lucha contra la guerra y los actores armados, sino también el proceso de fortalecimiento organizativo de las mujeres y la correlación de fuerzas con los hombres de sus mismas comunidades.

Estos dos años de caminar algunas regiones del país le permitieron a la Ruta reconocer las diferentes formas de violencia, el grado de barbarie de los actos cometidos contra las mujeres en medio del conflicto armado, pero sobre todo, el altísimo índice de impunidad imperante en el país, especialmente cuando de violencias contra la mujer se trata. Por ello decidieron en noviembre de 2008 en la ciudad de Cartagena convocar un "Tribunal de la Verdad Contra los Delitos de Lesa Humanidad Hacia las Mujeres". Esta acción para juzgar a los responsables de los crímenes cometidos contra las mujeres en el marco del conflicto armado y por violencia intrafamiliar, permitiría el encuentro de los diferentes procesos de mujeres en el país, constituiría un símbolo de reconocimiento hacia las víctimas, de visibilización pública de la gravedad de los crímenes sufridos, del derrotero ético que las mujeres y sus organizaciones le exigían a las instituciones de la justicia y 
del gobierno y ayudaría a elaborar procesos de duelo y reconstrucción de sus proyectos de vida. Para ello las mujeres de la Ruta realizaron talleres preparatorios en las regiones y recopilaron testimonios. Durante los dos días que sesionó el Tribunal se escucharon los relatos sobre las masacres, la desaparición forzada, los desplazamientos, la violencia sexual contra las mujeres al tiempo que se evidenciaba la capacidad de las mujeres para resistir, organizarse y luchar por sus derechos. Tras escuchar los testimonios, las juradas, provenientes de distintos departamentos del país declararon culpables a la cultura patriarcal, al Estado colombiano, a los grupos paramilitares y a las guerrillas. A cada uno, según los crímenes expuestos por los testimonios. También le solicitaron a la jueza exponer este veredicto ante el Tribunal Permanente de los Pueblos y ante la Corte Penal Internacional (Ruta Pacífica de las Mujeres, 2003, p. 38).

El Tribunal también sirvió para hacer célebre una forma de acción contenciosa denominada por Fabiola Lalinde, su promotora, como "Operación Cirirí". Ella, tras la desaparición de su hijo, miembro del partido comunista, comienza un trasegar lento y permanente ante diferentes instancias que no prestan atención, pero con su empeño y paciencia logra que lenta y paulatinamente se atiendan las exigencias de sus derechos. Este modelo de acción es retomado por el Tribunal como propio, pues plantea que las mujeres también pueden con constancia y decisión enfrentar la impunidad, así como el Cirirí, un pájaro que con empeño logra ahuyentar a las águilas y aves rapaces por el gran escándalo que hace y la intensidad con la que llega a molestar.

A esas alturas la ruta era un movimiento social reconocido y con experiencia en la movilización social. Era capaz de movilizar miles de mujeres en diferentes lugares del país y sus planteamientos y sus intereses en relación la violencia de género y con la paz negociada comenzaban a tener una estructura sólida. La Ruta se constituyó como una alternativa de movilización social cuando, excepto por los campesinos cocaleros en el sur del país, eran muy pocas las organizaciones sociales que se decidían a protestar y a exigir al Estado la garantía de sus derechos, y cuando la guerra se encontraba en un momento crítico con un número creciente de 
violaciones a los derechos humanos e infracciones al Derecho Internacional Humanitario. El movimiento de las mujeres planteó como herramienta principal de la acción colectiva, su presencia física para desplegar afecto y sororidad en la geografía del dolor y la barbarie.

\subsubsection{El contexto de la guerra y de la paz}

Durante la contienda electoral de 1998, Andrés Pastrana Arango planteó su intención de realizar a acercamientos de paz con las FARC-EP. Esta posibilidad selló su victoria y al comenzar su mandato dio inicio a nuevo proceso de paz desmilitarizando un territorio en el municipio de San Vicente del Caguán en Caquetá. Aunque el proceso no llegó a buen puerto, sí reconfiguró las posiciones de los actores armados y de la ciudadanía mayoritaria.

Durante las negociaciones, tanto las guerrillas de las FARC-EP y el ELN como los grupos paramilitares, crecieron y se extendieron ampliamente por el territorio nacional. Esto hizo que muchos de los ciudadanos que antes veían la guerra como algo lejano y rural, sintieran que era posible que la confrontación armada llegara a sus barrios en pleno corazón de las principales ciudades del país. De esta forma la población citadina comenzó a sentir la presión de la guerra y a optar por planteamientos de seguridad más ofensivos.

El proceso de paz comenzó formalmente en enero de 1999 en torno a los temas principales de: canje de militares retenidos por guerrilleros presos, lucha contra el paramilitarismo y mantenimiento de la zona de despeje. Sin embargo, generó respuestas diversas en los sectores sociales, mientras algunos sectores los consideraron necesario y valioso, otros lo vieron con sospecha y desconfianza. Y es que la realidad cotidiana del país estaba cargada de hechos ambiguos y contradictorios. Por un lado, las FARC-EP insistían en ganar militarmente corredores estratégicos, hacían despliegues de fortaleza y radicalidad en su retórica y mantenían el control de la zona desmilitarizada donde se denunciaban continuos abusos de su parte. Por otro, el gobierno de Pastrana comenzaba un complejo 
proceso de reingeniería y fortalecimiento de las Fuerzas Militares en desarrollo del denominado "Plan Colombia" financiado por el gobierno estadounidense, el cual, aunque se proyectaba como estrategia de guerra contra el narcotráfico, se vislumbraba como continuidad de la guerra contrainsurgente, mediante las reiteradas acusaciones que se le hacían a este grupo guerrillero de ser el principal cartel narcotraficante de Colombia (González, 2014, p. 432).

Algunos hechos específicos enturbiaron el ambiente de manera especial. El 4 de abril de 2000 las FARC-EP promulgaron su Ley 002, mediante la cual establecían un "impuesto para personas que tuvieran en su patrimonio más de un millón de dólares”. El 11 de septiembre de 2001 el gobierno de los Estado Unidos declaró la "guerra total contra el terrorismo" y extendió su alcance a nuestro país con la profundización del Plan Colombia y su abierta aplicación a la lucha contrainsurgente (González, 2014, p. 432).

En medio de toda esta situación, una serie de acciones de las FARC-EP, como los asesinatos del congresista Diego Turbay Cote y la exministra Consuelo Araujo Noguera, los secuestros de tres indigenistas norteamericanos, de la candidata presidencial Ingrid Betancur y del senador Jorge Gechem Turbay, quien presidía la Comisión de Paz del Senado de la República, hizo insostenible para el gobierno Pastrana el mantenimiento de la zona de despeje y las presiones políticas llevaron a declarar oficialmente rotos los diálogos de paz el 20 de febrero de 2002 (Grupo de Memoria Histórica, 2013, p. 170).

Para aquel momento la expansión de los grupos paramilitares también reclamaba la atención del gobierno mediante varios secuestros de personajes de la vida pública intentaron presionar al ejecutivo a entablar un proceso de negociación con ellos. El ELN por su parte también buscó cercamientos con el Gobierno Nacional para realizar una Convención Nacional. Desde 1998 esta organización formuló propuestas de negociación, sin embargo, al mismo tiempo, los continuos ataques a la infraestructura eléctrica y petrolera, los secuestros masivos en diferentes lugares 
del país, enturbiaron las posibilidades de diálogo (Grupo de Memoria Histórica, 2013, p. 174).

El balance de este periodo es de un grave recrudecimiento de la guerra entre todos los grupos armados, especialmente por parte de las AUC que realizaban despliegues por diferentes lugares de la geografía nacional intentando copar las regiones de tradicional presencia guerrillera. Se expandían de la Costa Caribe al sur buscando el apoyo de los poderes locales y regionales que se sentían amenazados por un eventual acuerdo de paz entre la guerrilla y el gobierno nacional (González, 2014, p. 436). Pretendían continuar el desarrollo de la lucha antiguerrillera, instaurar el modelo agrario latifundista y agroindustrial que sostenía su apuesta económica y excluir cualquier tipo de oposición política y social mediante la violencia (Grupo de Memoria Histórica, 2013, p. 170). El Meta, el Magdalena Medio, la región del Catatumbo, Bolívar, Sucre y Antioquia, entre otras, fueron testigos de masacres, homicidios selectivos, desplazamiento y desapariciones forzadas. El Grupo de Memoria Histórica caracteriza esta época del paramilitarismo como reactivo, preventivo y oportunista. Reactivo porque se presenta como alternativa para repeler las acciones de las FARC-EP contra las élites regionales, las cuales buscan la protección de sus intereses mediante el paramilitarismo. Preventivo porque estas élites sentían que los acuerdos que se planteaban en los diálogos de paz en el Caguán podrían afectar directamente su posición como élites regionales. Y oportunista porque el control territorial permitía el ascenso social, político y económico de los mandos altos y medios del paramilitarismo (Grupo de Memoria Histórica, 2013, p. 161).

La expansión paramilitar contó con un importante apoyo por parte de sectores sociales afines en su ideología y en sus intereses. El desgaste ante la opinión pública de las luchas guerrilleras y la creciente polarización política de la ciudadanía sirvieron de base para lo que vendría a continuación. Esta reacomodación de fuerzas alcanzó su mayor auge en el año 2002 cuando los actores armados coparon 561 municipios de los 1096 con los que cuenta actualmente el país. Es decir, la mitad 
del territorio nacional tenía presencia de alguno de los actores ilegales y se encontraba en medio de la disputa armada (González, 2014, p. 440).

Tras el fracaso de los diálogos del Caguán, la gente observaba el conflicto como algo mucho más cercano a su cotidianidad, se percibía la posibilidad de ser afectado directamente, situación que allanó el camino al discurso de la "Seguridad Democrática". Con el apoyo de importantes actores económicos y políticos, regionales y locales, el paramilitarismo anunció que habría obtenido el 35\% de las curules del Congreso las elecciones legislativas realizadas en marzo de 2002. Este parte de victoria resultó ser bastante coherente con los resultados de los posteriores procesos judiciales conocidos como "la parapolítica" donde fueron condenados más de 60 parlamentarios.

Una concepción militarista de la seguridad y la identificación de la insurgencia con el terrorismo fueron los elementos enmarcadores primordiales de un discurso político que capto un amplio respaldo en importantes sectores de la opinión pública nacional. El más hábil vocero de este sector era reconocido por el manejo que había dado a estos temas en su paso por la Gobernación de Antioquia, desde donde participó en la configuración del conflicto armado en el Urabá en la época que analizamos anteriormente. Álvaro Uribe Vélez fue elegido presidente en el año 2002 con la bandera de la "política de seguridad democrática", que consistía, según estaba definida en su plan de desarrollo, "en involucrar a la ciudadanía en la consecución de los fines sociales", siendo el principal objetivo "la seguridad democrática" entendida como "control del territorio y defensa de la soberanía" (Departamento Nacional de Planeación, 2003, p. 18). En este sentido, la mayor parte de los esfuerzos del primer periodo de gobierno de Uribe se concentraron en el fortalecimiento de las fuerzas militares, dando continuidad y profundizando la cooperación en la guerra antiterrorista del gobierno de los Estados Unidos y su identificación con la guerra contrainsurgente a través del Plan Colombia. En función de esta estrategia de guerra las fuerzas militares pasaron de 215.000 hombres en 1998 a 445.000 en 2010 (Grupo de Memoria Histórica, 2013, p. 179). 
Si bien algunos sectores sociales y académicos entraron en contradicción con esta concepción militarista del conflicto colombiano, el estilo de comunicación de Uribe en el que se mostraba lejos de la politiquería tradicional, clientelista y corrupta, con una visión técnica del mercado que llamaba la atención de los industriales y otros gremios, y un estilo caudillista y populista en sus continuas alocuciones presidenciales, facilitaron que amplios sectores sociales apoyaran sus políticas con entusiasmo e incluso con fanatismo.

La guerra emprendida por Uribe contra las guerrillas provocó su debilitamiento y la modificación de su presencia en el territorio. Se volvieron más fuertes en los zonas de frontera y en las áreas de nueva colonización cafetera oriental, en Vaupés, Guainía y Vichada, y en el pacífico nariñense y caucano (Grupo de Memoria Histórica, 2013, p. 181). En lugar de derrotarlas, lo que se presentó fue un proceso de readaptación en los territorios y en las formas de hacer la guerra. De una guerra de posiciones lograda los años anteriores, las FARC-EP decidieron volver a su tradicional estilo de "guerra de guerrillas" que les permitía salir, asaltar y desvanecerse en la selva hasta lograr el agotamiento del enemigo. Se estructuraron en grupos pequeños y livianos, lo cual les permitía moverse con mayor rapidez y tener menores posibilidades de ser hallados por la tecnología militar. La guerrilla perdió su posición en el centro del país pero se mantuvo en el sur, el occidente y en las fronteras (González, 2014, p. 451).

Por otro lado, el gobierno inició un proceso de negociación con los paramilitares agrupados en las Autodefensas Unidas de Colombia AUC, que desde diciembre de 2002 dejaron ver su cercanía con el gobierno, la cual se haría aún más evidente con la agenda pactada en junio de 2003 y el Proyecto de Alternatividad Penal propuesto por el Gobierno para otorgar beneficios jurídicos a los jefes paramilitares.

La expectativa de impunidad frente a los crímenes atroces cometidos por los paramilitares situó el debate alrededor de la expedición de la ley 975 de 2005 llamada ley de "Justicia y Paz". La Ley aprobada en el Congreso tras largos e intensos debates fue objetada de inmediato por múltiples y diversos sectores 
nacionales e internacionales y hasta por los mismos paramilitares. Esta norma fue acusada, entre otras cosas, de establecer límites inadecuados de tiempo para realizar las investigaciones debidas, de no exigir confesiones completas por parte de los paramilitares en detrimento del establecimiento de la veracidad de los hechos delictivos, de otorgar beneficios jurídicos excesivos, de hacer rebajas exageradas de las penas, etc. Todo esto llevó a la corte Constitucional a examinar las diversas demandas formuladas y expedir una sentencia trascendental para el reconocimiento de los derechos de las víctimas a la verdad, la justicia y la reparación. Las intervenciones de la Corte Constitucional y de la Corte Suprema de Justicia para proteger mínimamente los derechos de las víctimas, las continuas violaciones a la tregua, los escándalos por los crímenes organizados desde el lugar de concentración de los paramilitares en Santafé de Ralito, el encarcelamiento de varios de ellos por cuenta de sus nuevas acciones criminales y la orden de extradición que dio el gobierno de Uribe para 14 de los principales jefes, agotaron las posibilidades del proceso y revelaron las justas dimensiones de la pretendida desmovilización paramilitar. Los jefes paramilitares dieron por terminado el proceso el 7 de diciembre de 2006, sin embargo, de acuerdo con los procedimientos establecidos por la ley de "Justicia y Paz", quienes se mantuvieron, fueron condenados y cumplieron con las condenas que fueron de un máximo de 8 años de prisión, hoy comienzan quedar libres.

El epílogo de este proceso fue el rearme y la reorganización de nuevas formas de la violencia paramilitar. Desde 2007 en adelante, diferentes grupos paramilitares inconformes con el desarrollo y culminación del proceso optaron por reorganizar sus tropas vinculando a los recientes desmovilizados, cambiando el nombre de las estructuras y reclutando nuevos miembros entre niños, niñas y adolescentes en sus territorios históricos. Visto de lejos lo que sucedió en aquel momento fue la convergencia de tres fenómenos distintos: un proceso rearme de las mismas tropas desmovilizadas que se reagruparon y reorganizaron, la reacción de grupos disidentes que no quisieron entrar a participar de los diálogos de Ralito y se mantuvieron activos todo el tiempo, y la aparición de nuevos grupos claramente vinculados a los intereses del negocio del narcotráfico (González, 2014, p. 456). 
Ante la evidencia de las acciones criminales de estos grupos, desde el gobierno se les catalogó como bandas emergentes o bandas criminales para eludir el debate sobre los logros y los fracasos del proceso de desmovilización. Informes de aquella época pudieron constatar que este rearme, si bien se identificó en todo el país, coincidía especialmente con regiones con alta aglomeración de cultivos ilícitos y que con el tiempo también se fueron trasladando a los corredores de las distintas fases del narcotráfico y de las exploraciones mineras. A final de cuentas, el proceso de desmovilización no condujo en los territorios a una disminución sensible de la violencia sino que tuvieron que soportar incursiones guerrilleras y acciones bélicas de los desmovilizados y de los grupos reorganizados (González, 2014, p. 457).

Por otro lado, el gobierno Uribe decidió a generar en la opinión pública la idea de la necesidad de ser reelegido para permanecer por más tiempo en la presidencia y poder cumplir sus objetivos y sus promesas. Pero para eso era necesario modificar la Constitución Política. En medio de un álgido debate, de intrigas políticas y hasta investigaciones por delitos cometidos por funcionarios del gobierno para sacar adelante la reforma, esta fue aprobada en mayo de 2005. En las elecciones presidenciales de 2006 Uribe fue reelegido sin mayores dificultades.

En este nuevo periodo, la Política de Seguridad Democrática se convirtió en la Doctrina de Acción Integral y definió sus principios y objetivos sobre la necesidad de afianzar los lazos entre la población civil y las fuerzas militares, para lo cual les otorgó a estas últimas atribuciones propias de autoridades civiles. De acuerdo con esta nueva política, en los territorios en los que se habían desarrollado las operaciones militares, en los que ya se había "conquistado" el terreno, eran las fuerzas militares quienes realizaban las tareas propias de las demás agencias del Estado con el fin de legitimar su presencia. Por eso no era extraño por aquellos años encontrar municipios en los que los soldados asistían como médicos, dentistas o peluqueros, repartían mercados o materias primas para cultivos o ganadería, y hasta hacían de recreadores infantiles. Se trataba de una ya conocida estrategia en el ámbito nacional: las acciones cívico militares. 
Este enfoque, por supuesto, levantó airadas críticas, pues, violaba el principio de distinción al mezclar y confundir las competencias de las entidades civiles y las fuerzas militares y por esa vía las funciones y las relaciones con la población, la cual se veía obligada a acudir a un actor militar para tramitar cualquier situación de competencia del Estado. Esta práctica hacía desvanecer los límites entre los diferentes poderes y autoridades permitiendo que las fuerzas militares asumieran el control total en las regiones. Sobre este tema y la forma como se desarrollaba en las regiones explica Hernando Gómez Serrano:

“Así, por ejemplo, y entre muchos casos similares, en los Montes de María (departamentos de Sucre y Bolívar) el coronel Rafael Colón coordina la acción de las entidades estatales (SENA, ICBF, otras), las cuales atienden con celeridad sus demandas y difícilmente les responden a los alcaldes y aún a los gobernadores de la zona" (Gómez Serrano, 2008).

Las denuncias que se venían haciendo contra el gobierno nacional desde el periodo anterior derivadas de los "falsos positivos", las detenciones masivas e ilegales, las desapariciones, los homicidios selectivos y el desplazamiento forzado, no cesaron durante el segundo periodo de Uribe en la Presidencia.

A ello se sumó la persecución directa a miembros y organizaciones defensoras de derechos humanos nacionales e internacionales los cuales fueron permanentemente estigmatizados por el presidente como aliados de los grupos subversivos, fueron tildados frente a los medios de comunicación como "politiqueros al servicio del terrorismo" o "profetas del desastre” (Borda Guzmán, 2012).

La problemática del desplazamiento forzado continuó agravándose, para el año 2007 se calculaba un promedio diario de 743 personas desplazadas por la violencia durante los 6 primeros meses del año para un total estimado de 191.313 personas desplazadas forzosamente. Esta cifra, ya considerada elevada para ese momento, fue superada durante el mismo periodo del siguiente año cuando se elevó un $41 \%$, es decir, 270.675 personas debieron huir durante el primer semestre de 2008 de sus 
hogares. Finalmente, para todo final de año se reportó el desplazamiento de 380.863 personas (76.172 núcleos familiares) produciéndose un aumento total del $24.47 \%$ con relación al año inmediatamente anterior. El fenómeno para ese momento ya era devastador teniendo en cuenta que solo en el periodo de 2006 a 2008 más de un millón de personas habían sido desplazadas y esta cifra, además, iba en aumento recordando los años 2000 a 2002 cuando se desplazaron forzadamente cerca de 804,897 personas. Los factores seguían siendo los mismos, aunque para ese momento el desplazamiento y el despojo de las tierras, las fumigaciones, la violencia contra la población indígena, las masacres y la violencia sexual contra las mujeres, eran mucho más evidentes. Al tiempo, en estos años también empezaron los desplazamientos masivos e intraurbanos. Un fenómeno que el gobierno se negaba aceptar porque demostraba que la guerra ya estaba incrustada en las ciudades de mediano y gran tamaño.

\subsubsection{El Desarrollo de la Ruta Pacífica de las Mujeres}

Mientras tanto, la Ruta vivió lo que ellas han denominado "un lapso difícil”. Luego de 4 movilizaciones de gran reconocimiento nacional e internacional y un despliegue mediático causado en buena parte por la osadía con que se realizaron, ellas describen el comienzo del gobierno de Pastrana como un momento de reflujo, de ensimismamiento, y de transición. Paradójicamente no fue un año de crisis sino de una "calma chicha", causada porque el proyecto de la Ruta cada vez crecía más y las instituciones comprometidas también tenían sus propias agendas que no podían descuidar. Hasta ese momento la Ruta seguía siendo una alianza, una iniciativa común, pero carecía de infraestructura propia y si no hubiese sido por las inmensas ganas que las mujeres depositaron en ella, tal vez la Ruta no hubiese llegado a ser lo que es (Ruta Pacífica de las Mujeres, 2003, p. 38).

Este estado de ánimo, que coincidió con el inicio de los diálogos de paz, lleva a la Ruta al análisis de la participación de sus miembros en los procesos. Se plantearon entonces varias visitas a los voceros del ELN, quienes se encontraban en la cárcel, para plantear sus inquietudes y propuestas. Pese que los diálogos no prosperaron, 
la Ruta siguió moviéndose. Ahora, junto con la Organización Femenina Popular OFP y el movimiento de Mujeres de Negro.

En los últimos años de la década de los 90 el conflicto golpeó crudamente la región del Magdalena Medio, sede de la refinería de petróleo más grande de Colombia. No era la primera vez que la violencia se ensañaba contra esta región, desde 1970 Barrancabermeja, corazón del Magdalena Medio, había tenido presencia del ELN, EPL y las FARC-EP, pero fue en 1998 cuando los paramilitares la tomaron como objetivo militar. El 16 de mayo de ese año, alias "Camilo Morantes" y alias "el Panadero" llegaron al barrio el Campín, desapareciendo y asesinando a 32 personas, de las cuales solo 12 han sido encontradas hasta el momento. A esa masacre, que por su magnitud conmocionó la ciudad, le siguieron otros tres asesinatos múltiples que dejaron 20 muertos y 6 heridos (Verdad Abierta, 2011). El miedo finalmente se había apoderado de la región. Se conocían noticias diariamente sobre desaparecidos, asesinados y múltiples amenazas a las organizaciones sociales incluyendo a las de mujeres.

En ese escenario se encontraba la Organización Femenina Popular, organización nacida en el sector nororiental de Barrancabermeja en el año 1972. La OFP ya era reconocida nacionalmente, en particular por su capacidad de resistencia y su origen popular y feminista. Se había adherido hacía poco tiempo al movimiento de Mujeres de Negro, una organización internacional de mujeres que con el tiempo, influiría mucho en los objetivos y formas de ser y de hacer de la Ruta. Y fue precisamente ese el marco de acción que halló la Ruta para hacer alianzas, para proseguir su lucha por la reivindicación de los derechos de las mujeres.

Ya la Ruta y la OFP se habían encontrado en otras ocasiones, pero fue esta dura situación del Magdalena Medio la que las estimuló más los acercamientos. En el año 2000 se realizó la primera reunión de concertación y luego de varios encuentros sucesivos se llegó a dos acuerdos principales. De un lado, se enlazó a la Ruta a la Cadena de Mujeres Contra la Guerra con Mujeres de Negro y, de otro lado, se 
decidió hacer una gran movilización de la Ruta a Barrancabermeja (Ruta Pacífica de las Mujeres, 2003, p. 40).

\subsubsection{El Movimiento de Mujeres contra la Guerra}

En noviembre de 2000 y coincidiendo con la celebración del IV Bazarte, un espacio para la cultura creado por la OFP hacía algunos años, aproximadamente 2.500 mujeres salieron de distintos lugares del país para manifestar su apoyo a las mujeres Barranqueñas. Allí nuevamente hablaron de política, denunciaron y condenaron a los verdugos, mientras que con rituales hacían limpiezas del cuerpo y del alma, bailaban, cantaban y soñaban con el fin de la violencia. Cerrando esta visita también firmaron un Manifiesto de mujeres contra todas las violencias, por la vida, la dignidad, la libertad, la justicia social y la paz. En este Manifiesto cuentan al mundo que han decidido aliarse para exigir salidas negociadas al conflicto social, político y armado. Insisten en la necesidad imperiosa de construir la paz y critican la forma en que el Gobierno de Pastrana ha decidido llevar los diálogos en los que ni las mujeres ni sus agendas están incluidas. Señalan que los actores armados no respetan los Derechos Humanos ni el Derecho Internacional Humanitario y que el 70\% de la población afectada por el desplazamiento forzado son mujeres con sus niños y niñas y afirman la necesidad de Verdad, Justicia y Reparación. Estas razones las llevan a solicitar al gobierno nacional la creación de una mesa de diálogo social en la que encuentren asiento las diversas organizaciones y comunidades que han contribuido en los distintos procesos sociales, para ponerle freno inmediato al paramilitarismo, para que se concreten los diálogos con las guerrillas y para hacer un llamado al respeto de los derechos humanos. Por último convocan a las mujeres, a las organizaciones sociales y a las diferentes iniciativas de paz a que mantengan su fuerza activa en la búsqueda de una salida negociada al conflicto y a los aliados internacionales a que mantengan su solidaridad y compromiso por esta causa.

Esta acción generó mayores hostigamientos y persecución contra la OFP. Quemaron su propaganda y amenazaron las casas de las mujeres donde la OFP albergaba a víctimas de desplazamiento forzado en la región. Fue un momento para 
activar los recientes lazos de sororidad que se habían conformado. Se hicieron denuncias públicas, se internacionalizaron las demandas y se puso en marcha la campaña Movimiento de Mujeres Contra la Guerra.

A esas alturas era imperioso ganar apoyo internacional. Con la idea de crear un "protectorado para las mujeres colombianas" se convocó del 14 al 17 de agosto de 2001 al Primer Encuentro Internacional de Mujeres contra la guerra. A éste acudieron las mujeres de Negro de Belgrado, las Locas de Brasil y las Dignas del Salvador. Querían volver a Barrancabermeja pero la movilización por carretera era en ese momento aún más peligrosa. Solicitaron entonces la creación de un "corredor humanitario". Mediante la expedición de un documento público donde planteaban su deseo de caminar hacia Barranca, la Ruta pidió a todos los actores armados que permitieran la llegada de las mujeres de todos los rincones del país y del mundo hasta Barrancabermeja. Se ampararon en el convenio de Ginebra relativo a la protección de personas civiles en tiempos de guerra, sus protocolos adicionales de 1977 que establecen que las mujeres deben ser amparadas contra todo atentado a su integridad y su dignidad, reafirmaron su descontento con los procesos de paz desarrollados por Pastrana en los que aún no encontraban espacios para la participación de las mujeres y llamaron a la creación de otros espacios para la negociación política del conflicto (Ruta Pacífica de las Mujeres, 2003, p. 46)

Finalmente, la movilización se realizó y se destacó, no solo por el número de mujeres que asistieron, entre 2.000 y 2.500 , sino por la alegría y algarabía que produjeron con su llegada. Nuevamente y como empezaba a ser costumbre para la Ruta, el simbolismo se volvió protagonista, los cantos, los bailes, las poesías, las muñecas y las ollas de barro se mezclaron para conjurar la paz. También allí firmaron una declaración, en esta ocasión para fundar el Movimiento de Mujeres contra la Guerra. La Ruta y la OFP se juntaron para declararse en resistencia civil no violenta. Las mujeres señalaron su intención de entrar en desobediencia civil contra la violencia, y afirmaron su derecho a no pertenecer a ningún grupo armado, incluyendo la fuerza pública. Su propósito principal era neutralizar los efectos de la guerra en la vida de las mujeres y apoyar el movimiento por la paz. Apelaron por el 
cese al fuego para facilitar las conversaciones de paz y nuevamente mostraron su descontento con los diálogos de Pastrana. Elevaron nuevamente su lema de "No queremos parir hijos e hijas para la guerra" y señalaron específicamente su desacuerdo con el servicio militar obligatorio. En este caso, además de los temas de la guerra y la paz, incluyeron un apartado para hablar de la igualdad del hombre y la mujer en las labores del hogar y en la economía.

Tras esta nueva acción, la Ruta pasó de reivindicar la neutralidad activa aprendida de los pueblos indígenas que buscaban que sus vidas y territorios fueran respetados por los grupos en contienda, a un modelo de resistencia civil no violenta. Además, había construido una suerte de puentes de comunicación con la OFP que les permitían aprender nuevas formas de acción colectiva y de entender los problemas nacionales. Esta sinergia sin embargo no fue en todos los campos. Estar juntas les permitió identificar sus diferencias internas y comprender sus posturas particulares. Las dos organizaciones tenían formas distintas de concebirse, de relacionarse con el Estado y de definir los actores armados: la OFP se caracterizaba por ser una organización popular mientras la Ruta se había definido como una organización pluriclasista; también tenían matices en las comprensiones del pacifismo y la no violencia. Eso sin embargo no las desanimó para mantener un trabajo articulado. Por eso tal vez, como ellas mismas lo reconocen, una de las mayores ganancias de este acercamiento fue el encuentro de la Ruta con el movimiento Internacional Mujeres de Negro (Ruta Pacífica de las Mujeres, 2003, p. 50).

Mediante este enlace la Ruta logró integrarse a un movimiento internacional. Ello les permitió, no solamente conocer otras guerras y realidades de la resistencia de las mujeres, sino también poder contar con un apoyo internacional sólido y reconocido. A su vez, aprendieron el sentido del silencio y del luto como una expresión de duelo y una manera contundente y precisa de plantear sus pensamientos y emociones. En el mismo manifiesto de Mujeres de Negro Contra la Guerra se halla la explicación de sus acciones y simbolismos. En primer lugar, se unen a los plantones todos los martes de la última semana del mes, lo que las identifica y les permite mantener una identidad propia como mujeres de negro 
trascendiendo las fronteras de Colombia. Además, adoptan el silencio como un llamado de atención al ruido de la guerra que imposibilita la reflexión sobre sus causas y sus estragos. Se visten de negro, no solo por la muerte de sus seres queridos, sino por la muerte de todos y todas las víctimas de la guerra.

\subsubsection{La persistencia de la violencia contra las mujeres}

Como vimos antes, el cambio de siglo en Colombia vino acompañado de la exacerbación del militarismo, el involucramiento de la población civil en la guerra y trajo consecuencias directas sobre la vida de las mujeres, particularmente en las regiones donde se presentaban los más fuertes combates.

Si bien en aquel momento aún no se contaba con información sistematizada y con variables específicas para monitorear la violencia contra las mujeres ni el Estado incluía en sus estadísticas oficiales mecanismos para medir la relación entre el conflicto y la violencia contra la mujer, ya existían algunas iniciativas desde las organizaciones sociales que comenzaban a contar y medir las expresiones de la violencia contra las mujeres en los contextos de la guerra.

Las organizaciones comenzaron a identificar los efectos diferenciales que sufrían las mujeres en las situaciones de desplazamiento forzado y de violencia sexual. También que buena parte de las agresiones se desprendían de las lógicas del sistema patriarcal que imperaba en el país y que se profundizaban con los discursos exaltados y las políticas guerreristas del gobierno Uribe. Además comenzaron a identificar y a caracterizar otras múltiples violencias que se ejercían contra las mujeres. Identificaron como la cultura patriarcal finalmente se expresaba en el cuerpo de las mujeres mediante la violación, el feminicidio, el hostigamiento, el acoso sexual, la esclavitud sexual, la servidumbre doméstica, la dependencia afectiva y económica. Constataron que los actores armados usaban sus cuerpos como campos de guerra, violándolas, humillándolas, torturándolas, maltratándolas, raptándolas, para complacerse a sí mismos pero también con la convicción de que así golpeaban a su enemigo. Detectaron que esas situaciones se normalizaban en el 
proceso de formación de los soldados en el que se les inculcaba el dominio sobe la mujer como forma básica de la virilidad necesaria para el combate (Sánchez, 2008, p. 65).

Estos esfuerzos de sistematización y caracterización han permitido hoy en día contar con algunos datos sobre las violencias contra las mujeres. Por ejemplo, en relación a los homicidios se ha podido estimar:

"En el período 2002 y primer semestre de 2006, aún con la implementación de la política de seguridad democrática, los grupos armados continuaron cometiendo delitos, crímenes de guerra y de lesa humanidad contra las mujeres y las niñas en Colombia. Para el año 2002, según las fuentes consultadas, 89 mujeres y niñas -por fuera de combate- fueron asesinadas por los actores armados ilegales y la fuerza pública. En el año 2003, la cifra de mujeres y niñas ejecutadas o asesinadas por los actores armados fue de 80. Para el año 2004, de acuerdo con las fuentes consultadas se registraron 43 asesinatos de mujeres por parte de los actores armados. En el año 2005, según información del Instituto Nacional de Medicina Legal y Ciencias Forenses se registraron un total de 233 asesinatos de mujeres. En 89 asesinatos de mujeres los presuntos responsables fueron las fuerzas militares; en 5 la Policía; en 1 los servicios de inteligencia, en 15 las FARCEP; en 17 paramilitares-autodefensas; en 1 el ELN; en 1 otras guerrillas, lo cual significa que en el 55,36\% de los asesinatos de mujeres en el país los presuntos responsables son los actores armados ilegales y la fuerza pública. Y para el mismo período 44 mujeres y niñas perdieron la vida a manos de desconocidos, hombres sin identificar, grupos armados sin identificar o simplemente, sin registrar el responsable de los crímenes" (Sánchez, 2008, p. 77).

Estas cifras nos muestran la terrible situación de la violencia contra la mujer en el marco del conflicto armado y la enorme responsabilidad que en ella cabe a la Fuerza Pública. Durante el primer periodo del gobierno Uribe los asesinatos contra mujeres 
en el marco del conflicto armado se elevaron y llegaron a ser más de la mitad de los homicidios de mujeres para todo el año y casi en el 70\% de los casos las Fuerzas Militares son identificadas como perpetradoras. El militarismo desplegado en la política y en la sociedad estaba afectando gravemente a las mujeres. Es necesario señalar que esta cultura militarista en contextos patriarcales no solo se expresa en la acción de la Fuerza Pública. Los demás actores armados colocaron su cuota de homicidios contra mujeres en aquel momento y esto se demuestra en las cifras expuestas adjudicadas a las guerrillas y el paramilitarismo.

Se debe resaltar que las investigadoras y defensoras de derechos humanos encontraron que la violencia sexual era una de las mayores expresiones de agresión contra las mujeres en contextos de guerra. La Primera Encuesta de Prevalencia sobre la Violencia Sexual en el contexto del conflicto armado, una investigación realizada en el contexto de la campaña "Violaciones y otras violencias: Saquen mi cuerpo de la guerra" entre 2001 y 2009, tal vez uno de los primeros ejercicios serios para medir y entender esta problemática, señaló en su introducción que:

"La prevalencia de violencia sexual — para el periodo 2001-2009_ con base en 407 municipios con presencia de Fuerza Pública, guerrilla, paramilitares u otros actores armados en Colombia se estimó en $17.58 \%$, lo cual significa que durante estos nueve años 489.687 mujeres fueron víctimas directas de violencia sexual. Es decir que, desde 2001 hasta 2009, un promedio de 6 mujeres, cada hora, han sido víctimas directas de este tipio de violencia en municipios con presencia de fuerza pública, guerrilla, paramilitares u otros actores armados” (Campaña «Violaciones y otras violencias: saquen mi cuerpo de la guerra», 2010).

Por otro lado, aunque no existen cifras oficiales, los relatos de las mujeres que han sido víctimas o testigos de estos hechos permiten afirmar que casi siempre estos agravios se acompañan de detención arbitraria, desaparición forzada, embarazo forzado o eliminación de fetos y hasta del asesinato (feminicidio) de las víctimas, 
haciendo aún más deplorable la acción de los actores armados (Sánchez, 2008, p. $67)$.

Como señalamos antes, en este marco de violencia política armada las mujeres debieron sufrir las más graves violaciones a los Derechos humanos y al Derecho Internacional Humanitario. En el X Informe sobre violencia sociopolítica contra mujeres, jóvenes y niñas en Colombia 2000-2010 de la mesa de Trabajo Mujer y Conflicto Armado pueden encontrarse algunas cifras que, aunque mantienen un alto subregistro, permiten dimensionar el problema. En relación a la violencia sexual se estima que entre 2004 y 2009 se presentaron 665 hechos de violencia sexual en el marco del conflicto armado. De estos casos, el 73,7\% se atribuyen a la Fuerza Pública, el 18,5\% a los grupos guerrilleros y el 7,7 a los grupos paramilitares. Estas cifras dejan ver también el aumento sensible de la participación de la Fuerza pública que pasa del 25\% en 2002 a 66,67\% en 2008 (Mesa de Trabajo «Mujer y conflicto armado», 2010, p. 82).

Para este mismo periodo se registra el asesinato de 1.235 mujeres a manos de grupos armados legales e ilegales, lo cual corresponde al 18, 9\% del total de mujeres asesinadas en el país. Estos homicidios tienen nuevamente el agravante que se trata de acciones cometidas mayoritariamente por agentes del estado. Así, para el año 2005 se registraron 233 asesinatos contra mujeres (16,4\% del total nacional) en el marco del conflicto armado. De ellas, 52 fueron asesinadas en enfrentamiento armado, 22 por acción guerrillera, 33 por acción militar, 8 por acción paramilitar y 4 por terrorismo. En el año 2006, se conocieron 212 homicidios contra mujeres $(17,2 \%$ del total nacional) a manos de actores armados legales e ilegales. Por enfrentamiento armado murieron 34; por acción de la guerrilla 17; por acción militar 48; por acción paramilitar 3 y por acción terrorista, 1 mujer.

En 2007 se cometieron 186 homicidios contra mujeres (15,4\% del total nacional) que tuvieron como presuntos responsables a actores armados legales e ilegales. Por acción de la guerrilla murieron 25; por acción militar 75; por acción paramilitar 8; por enfrentamiento armado 30; por intervención legal 3; por secuestro 2, y por 
terrorismo, 3. Para 2008, se registraron 1.139 homicidios en contra de las mujeres. De estos 115 (10\% del total nacional) cayeron a manos de actores armados ilegales. Por acción militar murieron 43 mujeres; por enfrentamiento armado, 29; por acción guerrillera, 10; por acción paramilitar, 2; por terrorismo, 4 y por secuestro, 3. Para el 2009 se registraron 1.523 homicidios de mujeres, evidenciándose un aumento sensible respecto a 2008. De estos, el 32\% (489 del Total Nacional) tuvo como presunto responsable a actores del conflicto armado. El 3,8\% (58 mujeres) murió por acción militar; 1,6\% (25 mujeres), por acción guerrillera, y el 2\% (31 mujeres), por enfrentamiento armado (Mesa de Trabajo «Mujer y conflicto armado», 2010, p. 36).

Se sabe también que entre 2002 y 2008 cayeron asesinadas 373 mujeres en 69 masacres. De los casos en los que se conoce al autor (45 casos) el 66,66\% se atribuye la responsabilidad al Estado: por acción directa de alguno de sus agentes el 13,33\% (6 masacres), y por tolerancia o apoyo grupos paramilitares el 53,33\% (24 masacres). Las guerrillas fueron responsables de 33,33\% de casos (15 masacres).

En este mismo periodo se registraron torturas en 173 mujeres. En 89 casos las mujeres fueron posteriormente asesinadas, 38 quedaron con vida y 46 fueron víctimas de tortura psicológica. De estos, en el 94,60\% (111) el Estado tiene responsabilidad: por acción directa en el 47,75\% (53 torturas), y por omisión, aquiescencia o apoyo a los grupos paramilitares, el 46,85\% (52 torturas). A las guerrillas se les atribuyó el 5,40\% de los casos (6 torturas).

También las mujeres fueron víctimas de detenciones arbitrarias y secuestros en estos años. Por lo menos 572 mujeres fueron detenidas arbitrariamente por parte de agentes del Estado, aumentándose casi el doble en relación al periodo anterior, 1997-2002, en el que se registraron 224 mujeres detenidas arbitrariamente. Por otro lado 701 mujeres fueron secuestradas o retenidas en el marco del conflicto armado. La guerrilla fue autora del 83,87\% (588 víctimas) y los paramilitares y "bandas 
criminales" cometieron el 12,41\% (87 víctimas) (Mesa de Trabajo «Mujer y conflicto armado», 2010, p. 80).

Se trataba de una violencia que pretendía determinar la vida y el comportamiento de las mujeres en zonas con alta presencia de actores armados y que se efectuó con sistematicidad en su acontecer sin que puedan señalarse como hechos aislados. En la guerra las mujeres seguían siendo sometidas a violencia sexual, esclavitud, trabajos domésticos forzados, eran usadas para servir de correo, para obtener información, son perseguidas por sus relaciones de parentesco o afectivas y sus las líderes sociales son estigmatizadas, hostigadas y asesinadas. En general, el panorama no distaba mucho del de los años 90s, cuando surgió la Ruta.

\subsubsection{Las acciones de la Ruta}

La situación de violencia contra las mujeres ya la conocían las mujeres de la Ruta que venían, desde 1996, movilizándose para visibilizar los crímenes contra las mujeres en el marco del conflicto armado, apostando por el feminismo, por el pacifismo, por el antimilitarismo, exigiendo participación en el proceso de paz entre el gobierno y las FARC-EP. Sin embargo, cuando el proceso se rompió, el país dio un giro a la derecha eligiendo a Álvaro Uribe Vélez con la promesa de la derrota militar al terrorismo. La Ruta entonces se aferró a sus planteamientos de partida y en colaboración con otros sectores feministas organizaron una de las movilizaciones más importantes que se desarrollaron en aquella época en contra de la guerra.

Iniciativas de mujeres por la Paz, la Red Nacional de Mujeres, la Mesa de Concertación Nacional de Mujeres, la Organización Femenina Popular y la Ruta conformaron un equipo de coordinación para el desarrollo de esas acciones. El 25 de Julio de 2002 se dieron cita en el centro de la capital colombiana cerca de 40 mil personas, la gran mayoría mujeres, alrededor de la consigna: "Las mujeres paz...harán”. En la declaración que acompañaría esta manifestación las mujeres volvieron a oponerse al tratamiento militar de conflicto político y social, rechazaron 
las acciones criminales contra mujeres y hombres y las continuas violaciones a los derechos humanos y al derecho internacional humanitario, hicieron un llamado a la resistencia civil ante cualquier tipo de involucramiento en la guerra $y$, particularmente, rechazaron la idea de Álvaro Uribe de constituir una red con un millón de civiles cooperantes de las fuerzas militares, le exigieron al presidente electo que buscara el camino del diálogo y que incluyera la agenda de las mujeres, aprovecharon el momento para solicitarle nuevamente al gobierno la realización de acuerdos humanitarios y se comprometieron contrarrestar la reproducción de los imaginarios belicistas en los niños, niñas, adolescentes y jóvenes en cambio acompañarlos en su resistencia al militarismo (Ramírez Parra, 2009).

Como se había hecho habitual en la conmemoración del 25 de Noviembre como Día de la No Violencia Contra las Mujeres, en 2003, la Ruta se movilizó, esta vez al municipio de Puerto Caicedo en el departamento del Putumayo. El aumento de aspersiones con glifosato sobre los cultivos de coca, como medida privilegiada por el gobierno para atacar la producción de cocaína, había sido denunciado por los campesinos e indígenas mostrando a la opinión pública los desastres ambientales y las afectaciones a la salud humana que provocaban. Las mujeres se unieron a los campesinos e indígenas para evitar más fumigaciones. Allí se reunieron cerca de 3500 mujeres llegadas de muy distintos lugares del país, la mayoría conocerían por primera vez esta región tan olvidada. Desde allá denunciaron la política militarista, el tratamiento criminal que el Estado les estaba dando a los campesinos e indígenas habitantes de la región, los daños causado por las fumigaciones y nuevamente exigieron la firma de acuerdos humanitarios que mitigaran los daños causados por la guerra, especialmente el infringido contra las mujeres. Levantaron la voz por la manera en que se estaba desarrollando la guerra contra las drogas, que convertía a los más débiles de la cadena en chivo expiatorio de las acciones militares.

En el 2004 la Ruta conmemoró el 25 de noviembre con una movilización al departamento del Chocó, otra región abandonada por el Estado donde se mezclaban el desplazamiento forzado y el confinamiento de las comunidades por parte de los grupos armados legales e ilegales trenzados en una guerra sin cuartel cebada en la 
pobreza, el analfabetismo y la segregación. Las mujeres decidieron marchar entre las regionales de Antioquia y Chocó y así visibilizar la crisis humanitaria y los efectos producidos por el desplazamiento y confinamiento en la vida de las mujeres. Según los datos sobre desplazamiento forzado aportados por la Ruta, Chocó hacía parte de los cinco primeros departamentos expulsores de población. Hasta el 2003 habían salido expulsadas del departamento 2.232 familias y 180 mil personas vivían allí en situación de confinamiento en las riberas del río Atrato. Si se cruzaba esa información con la de CODHES, que señalaba que entre la población desplazada en el 47\% de los casos las mujeres eran jefes del hogar y de ellas el 65\% eran separadas, viudas o solteras, entonces, era posible señalar la enorme vulnerabilidad que asolaba a las mujeres desplazadas y sus familias. El día de la No Violencia Contra las Mujeres, cerca de 500 mujeres se movilizaron por el río Atrato entre el municipio de Quibdó y el municipio de Tanguí, para llamar a la solidaridad del resto del país frente a lo que le estaba sucediendo a esas comunidades y específicamente a sus mujeres (Ruta Pacífica de las Mujeres, 2004).

El año 2005 llevó a las mujeres de la Ruta por otro lugar de la geografía nacional. Durante los días 22 y 23 de Julio, junto al Programa Mujer del Consejo Regional Indígena del Cauca CRIC, 1.600 mujeres de la Ruta visitaron las comunidades de indígenas Nasa para visibilizar la situación de violación de sus territorios por la presencia de grupos armados. Esta movilización "promovió la desmilitarización de los territorios indígenas, la exigencia del respeto hacia la población civil en medio del conflicto armado y una negociación política al conflicto que vive el país (Sala de Situación Humanitaria, 2005).

Hay que recordar que la política de Seguridad Democrática del gobierno Uribe había determinado el aumento de pie de fuerza en aquella zona, asignando mayor número de policías al municipio de Toribío y reubicando una base del ejército en el municipio de Jambaló, de donde se había retirado poco antes. Esta presencia militar generó una serie de violaciones a los derechos humanos de las mujeres especialmente. La situación fue reconocida por el Relator Especial de ONU Rodolfo Stavenhagen durante su visita a Colombia en marzo de 2004 y por la 
Relatora Especial de los Derechos de la Mujer de la CIDH quien verificó en 2005 que la situación de las mujeres indígenas era especialmente crítica en aquel momento (Mesa de Trabajo «Mujer y conflicto armado», 2005, p. 30).

E1 25 de Noviembre de ese mismo año, las mujeres de la Ruta insistieron en regresar al Chocó. La violencia sexual contra centenares de mujeres, el asesinato y las agresiones físicas y psicológicas contra muchas otras, se sumaron a los continuos desplazamientos forzados y confinamientos, llevando a 3000 mujeres a reunirse en Quibdó. En esta ocasión, reclamaron al Congreso de la República realizar un control político al gobierno de Uribe para que diera cumplimiento a la Sentencia T025 de 2004 de la Corte Constitucional, en la cual se le ordenaba la protección y la restitución de los derechos de las mujeres y hombres en situación de desplazamiento forzado. De esta manera la Ruta, como otras organizaciones por todo el país, comenzaron a hacer uso de esta herramienta jurídica, expedida por el más alto tribunal constitucional, que establecía nuevos mecanismos para la defensa de los derechos de la población víctima de desplazamiento forzado.

Al mismo tiempo, el movimiento realizó numerosos procesos de formación en todas sus regionales y publicó documentos, libros e investigaciones. También para este momento la propuesta de Mujeres de Negro se había instalado en el corazón de la Ruta y el último martes de cada mes realizaban plantones en todos los municipios donde trabajaban. Las mujeres planteaban las profundas preocupaciones que les causaba el aumento de la violencia y los daños y secuelas que afectaban de manera diferencial las vidas de ellas.

En 2007 las mujeres acudieron al llamado que hiciera el Encuentro Nacional de Víctimas de Organizaciones Sociales, al que asistieron cerca de 300 organizaciones de distintos sectores y regiones. Allí pudieron manifestar su preocupación por la ausencia de información que impedía registrar lo que acontecido a las mujeres en el conflicto armado y plantearon sus propuestas para garantizar sus derechos a la verdad, la justicia y la reparación integral. En este encuentro ellas recalcaron que "uno de los primeros pasos para reparar a las mujeres víctimas, es que la sociedad 
y quienes están comprometidos en la defensa de los derechos humanos, se puedan detener, percibir y se percaten de la realidad cotidiana, sistemática de las violencias que se ejercen contra las mujeres, en lo privado y lo público" (Ruta Pacífica de las Mujeres, s. f.-c, p. 5).

A finales de mayo y principios de junio de ese año las mujeres decidieron movilizase hasta el puerto más importante del Pacífico colombiano: Buenaventura. Esta ciudad, caracterizada por ser uno de los lugares con mayor flujo económico en el país pero además con una de las mayores tasas de pobreza, ha sido escenario de una cruenta disputa territorial por parte de los grupos armados. Para aquel año los asesinatos, las masacres, las desapariciones, las torturas, el confinamiento y la violencia sexual contra las mujeres eran signos característicos de las consecuencias de estos enfrentamientos. La visibilización y denuncia de estas situaciones convoco a cerca de 2000 mujeres que acompañadas de los consejos comunitarios de la región, pueblos indígenas y víctimas de crímenes de Estado, entre otros, caminaron por las calles del puerto "por la vida, la libertad y la dignidad en nuestro territorio".

Nuevamente en noviembre de 2007 decidieron aglutinarse para dirigirse a la frontera Colombo Ecuatoriana al puente Internacional de Rumichaca. A esta acción llegaron cerca de 5000 mujeres colombianas y ecuatorianas. En esta ocasión, los maltratos cometidos contra las mujeres que habían sido expulsadas de Colombia por el conflicto armado y que llegaban a este país vecino, la mayoría de manera irregular, fueron el acicate que las motivó a desarrollar esta movilización. Es importante señalar que por aquella época comenzaba a ser notorio el continuo desplazamiento forzado de colombianos al exterior saliendo por las fronteras terrestres y particularmente el caso de las mujeres quienes eran sometidas a tratos xenófobos, violencias sexuales y trabajos forzosos en el vecino país. Por eso optaron por movilizarse al Puente fronterizo como un símbolo de rechazo y llamado de atención a los dos países sobre esta situación.

El siguiente año, en octubre de 2008 las mujeres decidieron acudir también a la Comisión Interamericana de Derechos Humanos. En esta ocasión la Ruta, de 
manera coordinada con otras organizaciones, como Casa de la Mujer, Mujeres que Crean y Vamos Mujer, presentaron la crítica situación de los derechos humanos de las mujeres en Colombia. Allí señalaron a la Comisión la manera en que las mujeres viven el conflicto armado:

"Para las mujeres en las zonas de conflicto armado la situación no sólo tiene que ver con la confrontación armada entre los diferentes actores: guerrilla, militares y paramilitares, sino también con el abuso sexual, el maltrato físico, el chantaje y la presión a que son sometidas por estos generadores del conflicto. Ellas deben enfrentar consecuencias visibles e invisibles. En las primeras, se pueden ubicar la viudez, la pobreza, el deterioro físico, los cambios en las dinámicas familiares y del entorno, la destrucción de bienes y el desarraigo de su territorio y de su cultura. En las segundas, el miedo, el sufrimiento, el chantaje, el abuso sexual, la redefinición de roles, el no disponer de tiempo para elaborar el duelo por las pérdidas afectivas y materiales, porque el reto que deben asumir es la sobrevivencia inmediata, y la pérdida de identidad y autoestima." (Ruta Pacífica de las Mujeres, Vamos Mujer, Casa de la Mujer, \& Mujeres que Crean, 2008).

Ese mismo año la Ruta publicó el libro "Las violencias contra las mujeres en una sociedad en guerra", de Olga Amparo Sánchez, una de las feministas más importantes del país y quién fuese una de las fundadoras de la Ruta y una de sus integrantes desde su trabajo en la corporación Casa de la Mujer. En este libro la autora plantea los cimientos del socio sexo patriarcalismo, las estructuras de discriminación y opresión de la mujer y su relación con la guerra y la forma en que esta se desarrolla entre los años 2000 y 2005, dándole a la Ruta un marco teórico y analítico para su acción y haciendo un aporte invaluable al proceso enmarcador de este movimiento social.

También, en septiembre de 2008, las mujeres quisieron sincronizarse con los acontecimientos que estaban ocurriendo a nivel nacional. Como se narró 
previamente, los años de mandato del Presidente Uribe estuvieron signados por varios escándalos relacionados con la violación a los Derechos Humanos y al Derecho Internacional Humanitario. Uno de ellos fue el destape de las relaciones entre políticos y paramilitares, de allí los procesos por "parapolítica" que comenzaron en la Corte Suprema de Justicia y que produjeron un sismo en las relaciones entre la Corte y la Presidencia de la República. En este contexto la Ruta participó en el acto simbólico mediante el cual las mujeres abrazaron a la Corte Suprema de Justicia mediante una gran cadena humana. Con ello querían significar su apoyo y respaldo a las acciones que venía adelantando la Corte en contra de los “parapolíticos".

Y cuando más que nunca el país y el poder ejecutivo daban la espalda a la salida negociada, nuevamente la Ruta se empecinaba en promover la paz. El 25 de noviembre en conmemoración al día Internacional de la no violencia contra las mujeres se convocó a la movilización denominada "Todas y todos a la mesa. Negociación política YA", a la cual asistieron cerca de 10000 personas quienes marcharon por las calles bogotanas con esa consigna. Con esta convocatoria, a la que acudieron numerosos sectores sociales, y movimientos populares, las mujeres pretendían mantener vivo el reclamo por una paz negociada que diera fin a seis décadas de conflicto y que a su juicio avergonzaba al país (Bautista Revelo, 2010, p. 6).

Por otro lado, cada regional contaba con su propia agenda, realizando movilizaciones subregionales, Foros, encuentros, plantones de mujeres de negro, talleres e informes que se sumaban al trabajo del movimiento social en este periodo.

\subsubsection{La Ruta Pacífica de las Mujeres contra la impunidad}

El proceso de negociación de los grupos paramilitares con el gobierno Uribe, también concentró buena parte importante de las energías de las mujeres de la Ruta, quienes venían denunciando el carácter diferenciado de la violencia contra las mujeres y la necesidad de formas diferenciadas para la reparación de los daños 
sufridos. Empero, la reacción suscitada por el proceso entre las diversas organizaciones de mujeres no fue la misma. Mientras que Iniciativas de Mujeres por la Paz, una organización que venía gestándose desde el proceso de negociación de las FARC-EP con el gobierno Pastrana, encontraba en el proceso con los paramilitares una oportunidad de participación política, la Ruta lo rechazaba porque consideraba que las AUC no solamente no tenían estatus político, sino que además no reconocían a las víctimas, evadían una adecuada desmovilización de los armados y protegían las estructuras del narcotráfico. Además, porque para la Ruta las negociaciones también debían incluir a las organizaciones guerrilleras (Ibarra Melo, 2011, p. 251).

Estas visiones diferentes hicieron transitar a las dos redes de mujeres más grandes de Colombia por caminos diferentes. Recordemos que estas dos organizaciones antes se habían unido junto a la Red Nacional de Mujeres, la Mesa Nacional de Concertación y la Organización Femenina Popular OFP, para rechazar el belicismo impuesto por el gobierno Uribe y habían organizado una de las manifestaciones más grandes de mujeres que se hubiesen conocido hasta ese momento: "Las mujeres paz... harán”. Sin embargo estas posiciones antagónicas las alejarían por un buen tiempo y determinaría la creación de dos corrientes. Por un lado la Ruta, la Mesa de Concertación de Mujeres y la OFP oponiéndose al proceso y, de otro lado, Iniciativas de Mujeres por la Paz IMP como veedora de la Mesa de Diálogos y constituyendo la Mesa de Incidencia.

Una vez expedida la Ley 975 de 2005, conocida como Ley de Justicia y Paz, marco legal expedido para la desmovilización de los jefes paramilitares, las distintas organizaciones de las mujeres denunciaron las dificultades para participar en los procesos judiciales contra los paramilitares y por la escasa posibilidad de investigar crímenes sexuales en el contexto de esa justicia transicional. IMP interpuso una demanda contra la ley y mantuvo su lucha por la participación de las mujeres en los procesos contra los paramilitares. La Ruta comenzó a estudiar el impacto que tenía para las mujeres el proceso de desmovilización de grupos paramilitares. En su informe "Efectos de la (Des) movilización paramilitar en la vida y en el cuerpo de 
las mujeres en Colombia", Una mirada a la situación en Santander, Chocó, Cartagena y Medellín, la Ruta reseñó la poca credibilidad que había tenido el proceso en los territorios, los incumplimientos del cese de hostilidades, el aumento de los ataques contra las mujeres y la falta de visibilización de los delitos sexuales en el contexto de la guerra (Ramírez Parra, 2010).

En este Informe, la Ruta planteó su preocupación por el rearme y reorganización de los paramilitares supuestamente desmovilizados y por su vinculación con empresas de seguridad privada en las ciudades. También explicó cómo, desde su punto de vista, la Ley 975 y el proceso de impunidad a favor de los paramilitares, en el marco de la Política de Seguridad Democrática, constituía una arremetida contra la organización de las mujeres, niñas y jóvenes en Colombia.

Este análisis se vendría a reafirmar posteriormente mediante la publicación del libro: "Verdad, Justicia y Reparación, una deuda pendiente con las mujeres víctimas de las violencias", en el que se sintetizaron las numerosas críticas que desde las mujeres se le hicieron a la forma en que se desarrolló la desmovilización paramilitar, los diversos obstáculos y la estigmatización que enfrentaron las mujeres para avanzar en la exigibilidad de derechos en el marco de un proceso diseñado para la impunidad. Un buen resumen de este planteamiento se puede leer a continuación

“...La ausencia de las mujeres desde las primeras etapas del proceso, el desconocimiento de la violencia contra las mujeres como estrategia de guerra por parte de los actores armados; la indiferencia frente a la forma de interacción de los actores armados con las mujeres especialmente en contextos de extrema militarización y sus repercusiones frente a las violencias contra las mujeres; la reproducción de roles tradicionales de género en programas de formación que pretenden preparar a hombres y mujeres para el "posconflicto" entre otros factores, ilustran muy bien las dinámicas socio-sexuales patriarcales que presidieron o resultaron concomitantes al desarrollo del marco normativo; y las formas cómo estas 
han determinado actores, roles y estrategias en el proceso de desmovilización paramilitar incluso con posterioridad a la aprobación de la ley" (Montealegre et al., 2011, p. 17).

\subsubsection{La lucha contra el desplazamiento forzado y sus consecuencias}

Durante todo su proceso de organización y lucha por sus derechos, las mujeres habían identificado el desplazamiento forzado como una de las situaciones que generaba los efectos más desproporcionados para la vida de las mujeres.

La abrumadora y terrible realidad del desplazamiento forzado, cuyas víctimas ya se contaban por millones, apenas empezaba a ser reconocida en el país. Tan sólo hasta el año 1997 el Congreso de la República asumió el tema y expidió la Ley 387, mediante la cual estableció medidas para la prevención, la atención, protección, la consolidación y estabilización socioeconómica de las víctimas de desplazamiento forzado interno. Esta norma resultó trascendental porque, además de conceptualizar la situación de desplazamiento, definió la responsabilidad del Estado, creó el sistema Nacional de Atención Integral a la Población Desplazada por la violencia SNAIPD y dictó medidas para la prevención, la atención humanitaria de emergencia, la estabilización socioeconómica y el retorno de esta población.

Ante el permanente incumplimiento de la ley 387 de 1997, numerosas familias en situación de desplazamiento, en su mayoría mujeres madres cabeza de familia, recurrieron a la Acción de Tutela, como mecanismo judicial expedito para reclamar la protección de sus derechos fundamentales, por considerar que no se estaban atendiendo adecuadamente las necesidades de las víctimas de desplazamiento. Para el año 2004, ante la gravedad del problema y la negligencia del gobierno se habían acumulado miles de tutelas exigiendo respuesta de los jueces, lo cual obligó a la Corte Constitucional a estudiar el tema y a proferir la sentencia T-025 el 22 de enero de 2004. 
Bajo el expediente T-653010 y mediante la ponencia del Magistrado Manuel José Cepeda Espinosa, este Alto Tribunal decidió acumular 108 acciones de tutela interpuestas por 1150 familias en situación de desplazamiento compuestas en su mayoría por mujeres cabeza de familia, para declarar la existencia de un "Estado de Cosas Inconstitucional”. Mediante la figura del Estado de Cosas Inconstitucional la Corte constataba una situación de prolongada y sistemática vulneración de los derechos fundamentales de un número importante de ciudadanos por lo que la solución implicaba la acción inmediata y coordinada de múltiples entidades estatales. De esta forma la Corte estableció las insuficiencias de la Política Pública vigente hasta el momento y además su rotundo incumplimiento:

"Varios elementos confirman la existencia de un estado de cosas inconstitucional respecto de la situación de la población internamente desplazada. En primer lugar, la gravedad de la situación de vulneración de derechos que enfrenta la población desplazada fue expresamente reconocida por el mismo legislador al definir la condición de desplazado, y resaltar la violación masiva de múltiples derechos. En segundo lugar, otro elemento que confirma la existencia de un estado de cosas inconstitucional en materia de desplazamiento forzado, es el elevado volumen de acciones de tutela presentadas por los desplazados para obtener las distintas ayudas y el incremento de las mismas. En tercer lugar, los procesos acumulados en la presente acción de tutela, confirma ese estado de cosas inconstitucional y señalan que la vulneración de los derechos afecta a buena parte de la población desplazada, en múltiples lugares del territorio nacional y que las autoridades han omitido adoptar los correctivos requeridos. En cuarto lugar, la continuación de la vulneración de tales derechos no es imputable a una única entidad. En quinto lugar, la vulneración de los derechos de los desplazados reposa en factores estructurales enunciados en el apartado 6 de esta providencia dentro de los cuales se destaca la falta de correspondencia entre lo que dicen las normas y los medios para cumplirlas, aspecto que adquiere una especial dimensión cuando se mira la insuficiencia de recursos dada la evolución del problema de desplazamiento y se aprecia la magnitud 
del problema frente a la capacidad institucional para responder oportuna y eficazmente a él. En conclusión, la Corte declarará formalmente la existencia de un estado de cosas inconstitucional relativo a las condiciones de vida de la población internamente desplazada. Por ello, tanto las autoridades nacionales como las territoriales, dentro de la órbita de sus competencias, habrán de adoptar los correctivos que permitan superar tal estado de cosas" (Corte Constitucional de Colombia, 2004).

En un extenso documento la Corte constató la multiplicidad de derechos constitucionales amenazados o vulnerados por el desplazamiento forzado y la falta de una respuesta adecuada por parte del estado. Entre ellos: El derecho a la vida en condiciones de dignidad, los derechos de los niños, de las mujeres cabeza de familia, los discapacitados y las personas de tercera edad, y de otros grupos especialmente protegidos, el derecho a escoger el lugar de domicilio, el derecho al libre desarrollo de la personalidad, los derechos de acceso a educación, salud y trabajo, el derecho a la unidad familiar y a la protección integral de la familia, el derecho a la salud en conexión con el derecho a la vida, el derecho a la integridad personal, el derecho a la libre circulación por el territorio nacional, el derecho a una alimentación mínima, el derecho a una vivienda digna, el derecho a la paz, el derecho a la personalidad jurídica, el derecho a la igualdad entre otros.

En respuesta a ello la providencia emitió dos tipos de órdenes: De un lado, aquellas referidas específicamente a los demandantes y que respondían a solicitudes específicas de los accionantes sobre sus casos particulares y, de otro lado, una serie de medidas más complejas referidas a todo el universo de víctimas de desplazamiento en el país, independientemente de si recurrieron a la acción de tutela o no, para que el Estado y las diferentes entidades responsables asignaran recursos económicos en sus planes y programas y mejoraran su capacidad institucional, para dar respuestas a las necesidades de las víctimas de desplazamiento forzado.

La Corte además estableció un mecanismo para hacerle seguimiento al cumplimiento de las órdenes impartidas, en el que participarían, el gobierno 
nacional, organizaciones de derechos humanos, agencias humanitarias de la comunidad internacional, organismos de control y organizaciones de población desplazada, constituyendo así la Comisión de Seguimiento a la Política Pública sobre Desplazamiento Forzado en el mes de agosto de 2005. De manera particular, la Corte resaltó la importancia de atender, de manera especial, los derechos fundamentales de las personas desplazadas más vulnerables, tales como, mujeres cabeza de familia, menores de edad, minorías étnicas y personas de la tercera edad, con lo cual esta sentencia se convirtió en una herramienta fundamental para la exigibilidad de los derechos de los sectores de la población más vulnerables.

Muy pronto el contenido de la Sentencia se propagó por todo el país y las organizaciones sociales comenzaron a hacerle seguimiento a su cumplimiento. La Comisión de Seguimiento a la Política Pública sobre desplazamiento forzado muy pronto comenzó sus labores y junto con otras organizaciones y movimientos se fueron dando alianzas para estudiar la situación del desplazamiento forzado, las situaciones diferenciadas para sectores de la población y el funcionamiento de las políticas públicas correspondientes.

La Ruta no fue ajena a este nuevo ciclo de acciones de exigibilidad, en especial, evidenciando la particular situación de vulnerabilidad de las mujeres desplazadas y el impacto diferenciado y desproporcionado de las consecuencias que ellas debían afrontar. La visibilización y el reconocimiento de esa situación desencadenarían, poco tiempo después, la expedición del Auto 092 de 2008 en el que la Corte analizó esta problemática a profundidad.

\subsection{Capítulo 3: Análisis de los Elementos Descriptivos de la Ruta}

Hasta ahora hemos hecho un relato histórico denso del surgimiento de la Ruta, la forma en que lentamente fueron construyendo sus discursos $\mathrm{y}$ probando $\mathrm{y}$ reinventando sus repertorios, y la manera en que se fueron relacionando con otros actores políticos y sociales. También hemos hablado de los cambios políticos y las visiones de la guerra que modificarían en lo sucesivo las luchas políticas y sociales 
en este país, así como las innovaciones jurídicas que servían de oxígeno a los sectores sociales más vulnerables. Es imperativo ahora hacer una pausa para identificar en esa narración aquellos elementos conceptuales que nos ofrece la perspectiva sintética de los autores enunciados previamente. Nos referimos al análisis de los procesos enmarcadores, las estructuras de movilización y los repertorios de acción.

Siguiendo la línea teórica y conceptual marcada por Snow, Benford y Zald (Ibarra et al., 2002; McAdam et al., 1999) expuesta en la introducción, en la que se señala la importancia de estudiar los procesos de enmarcamiento como uno de los elementos principales para comprender cómo los movimientos sociales identifican las problemáticas, reconocen a sus contradictores y consiguen seguidores para desarrollar sus contiendas, en este apartado nos introduciremos en el estudio y caracterización de los agravios, objetivos, principios, simbolismos e identidades. Al tiempo, mostraremos la manera en que la construcción de estos elementos se han producido en relación permanente con el Estado, los actores armados, otros feminismos y movimientos sociales (McAdam et al., 2005), así como con otros actores políticos.

A su vez, y bajo la guía conceptual de MaCarthy (McAdam et al., 1999), nos adentraremos por la fisonomía de la Ruta intentando develar la forma organizativa que ha adquirido, sus transformaciones en el tiempo así como los mecanismos de supervivencia y reproducción que han implementado. Nos interesa particularmente ver el grado de apropiación que ha hecho el movimiento de otras organizaciones sociales (McAdam et al., 2005) y la forma en que se ha relacionado con otros actores políticos y sociales. Para ello comenzaremos haciendo una breve descripción de las redes organizativas feministas en Colombia para dar paso a la forma organizativa de la Ruta, su funcionamiento interno, los recursos económicos con los que cuenta y las redes y alianzas que ha establecido o a las que se ha unido.

Finalmente en este capítulo le daremos paso al estudio de los performance que han adaptado las mujeres de la Ruta para la generación de acciones movilizadoras 
durante las contiendas que han emprendido. Desde la identificación y análisis de las movilizaciones masivas, los rituales, los plantones, los informes e investigaciones, los Foros, encuentros y talleres, las acciones de cabildeo e incidencia y la formación política, desentrañaremos la ambivalencia entre el carácter simbólico y pacífico de sus repertorios y la generación de incertidumbre y provocación hacia sus oponentes (Gamson, 1990; Tarrow, 2004). En este punto, y como un mecanismo para ilustrar el grado de incidencia de sus performance, haremos un rastreo cuantitativo sobre la historia reciente de las movilizaciones de los movimientos sociales feministas de tal suerte que nos sea posible darle un lugar a la Ruta en el concierto diverso de la acción colectiva de mujeres en el país.

\subsubsection{Los Marcos Cognitivos de la Ruta}

Varias cosas sucedieron entre las luchas feministas de las mujeres colombianas de los años 70 y las luchas del siglo XXI: el surgimiento de normativas internacionales para las mujeres y su participación en procesos de paz, las convergencias de liderazgos femeninos para realizar acciones conjuntas, la llegada de mujeres feministas a cargos de poder, la conformación de un ideario social contra la guerra, la expansión de organizaciones defensoras de derechos humanos y la expedición de la Sentencia T-025 de 2004.

Sucedió también que, en ese contexto y gracias a estas oportunidades políticas y la realización de las primeras acciones concertadas de mujeres de distintos lugares del país bajo liderazgos concretos, surgió la Ruta como una propuesta feminista, pacifista, antimilitarista y de resistencia no violenta.

¿Qué fue necesario para que un estado de cosas "normalizado", es decir: que la violencia machista en general contra las mujeres en Colombia y, en particular, en el contexto de la guerra, fuera considerada por algunas como una afrenta a la dignidad, un agravio suficiente para rebelarse?, ¿Cuáles fueron sus principales reivindicaciones, consignas y símbolos?, ¿Cuáles líneas de pensamiento fueron recogidas, qué tanto fueron transformadas y cuáles han sido construidas?, ¿Qué 
elementos constituyen su identidad, sus identidades? Intentaremos en las próximas páginas acercarnos a algunas de las respuestas a estas preguntas.

\subsubsection{Los Agravios}

Cuando varias mujeres se reunieron en 1996 para pensar en el conflicto armado y su repercusión en la vida y el cuerpo de las mujeres, tenían en mente algo que hasta ese momento no era considerado relevante ni por los actores armados ni por las políticas públicas en el país: que la violencia contra la mujer, elemento característico sempiterno de la cultura colombiana, se exacerbaba en la guerra produciendo impactos diferentes a los que se producen en los hombres en esa guerra ni entre las mujeres que no se encuentran en contextos de conflicto armado.

Por supuesto que no se trataba de mujeres indeterminadas, era un grupo de mujeres que habían caminado largamente por los múltiples senderos del feminismo, habían participado en organizaciones sociales y sindicales durante varios lustros y algunas de ellas ya se encontraban en cargos de poder. Esta experticia les permitía tener acceso a mejor información, hacer análisis con enfoque de género, comparar situaciones entre regiones y poner en perspectiva la situación. Ellas lograron ver algo que en aquel momento era velado para la mayoría. Pocos años después lo sintetizaría de esta forma Diana Rodríguez, abogada de la Corporación para la Vida Mujeres que Crean, organización miembro de la Ruta:

"Las mujeres ya no sólo son víctimas indirectas de la guerra a través del asesinato de sus esposos, hijos y parientes, además de quedar con la responsabilidad económica de sus familias, también son asesinadas, violadas, desplazadas y/o amenazadas, acusadas de ser informantes, amantes, novias, hermanas, hijas, auxiliares, compañeras, del enemigo" (Ruta Pacífica de las Mujeres, 2003, p. 118).

Se comenzaba a reconocer que las mujeres eran aquejadas por el conflicto más allá de la viudez y la orfandad y que ellas eran en sí mismas sujetos directos de la acción 
violenta. Que por el hecho de ser mujer, el tipo de ofensas eran moldeadas para afectarlas particularmente y que por los roles tradicionales que habían desempeñado históricamente las consecuencias de las afectaciones también eran exclusivas de su género. De esta forma comienza a entenderse que la violencia sexual era ya de tiempo atrás un método de guerra común en todo el país mediante el cual se subyugaba a poblaciones enteras y que el impacto del desplazamiento forzado no era el mismo en hombres que en mujeres. Este relato de otra de sus integrantes nos acerca a estas realidades:

“Aquí estás oyendo como las mataron, casi literalmente, les mataron su hombre, les mataron sus familias y verlas como se tenían que quedar en los pueblos para que sus hijos terminaran la escuela, como son ellas las que han sido restauradoras de sus sueños, como son ellas las nuevas habitantes de esos pueblos fantasmas, como son ellas las que en los refugios se levantan al otro día a alistar el agua de panela para los niños mientras los maridos quedan maltratados y deprimidos. Los hombres se mueren, se mueren de pena moral, no, nosotras nos tenemos que levantar al otro día a ver el agua de panela de los niños, no hay ninguna posibilidad de no hacerlo y eso la hace conocer primero el territorio a donde llega nueva, también recibir primero la maldad de nuestro pueblo, la estigmatización, es ella la que recibe primero todo ese golpe" (Entrevista 6).

La sociedad que hasta el momento desconocía esta realidad, ponía el acento y la atención en los hombres asesinados, desaparecidos y encarcelados, pese a que ya por estos años comenzaba a ser un hecho evidente el fenómeno del desplazamiento forzado y muchas ciudades veían apostarse en sus esquinas a centenares de familias afirmando haber sido desplazadas por la violencia, la mayoría de estas compuestas por mujeres, niños, niñas y ancianos. De allí que la identificación de los agravios que hace la Ruta al poner de presente el sufrimiento particular de las mujeres en la guerra, aún por encima de la violencia desatada entre hombres, resulta un llamado de atención a una sociedad acostumbrada a ver el belicismo entre guerreros. 
Este enmarcamiento además, no se hacía desligado de la cultura nacional. Este grupo de mujeres encuentra una relación directa entre estas violencias con aquellas experimentadas por las mujeres cuando no se encontraban en contextos de guerra. Nos los explica Marina Gallego:

"Nosotras no separamos las violencias, no creemos que en tiempos de paz la violencia contra las mujeres cese, por el contrario, en tiempos de guerra la violencia contra las mujeres se exacerba, se recrudece y se sale de los marcos cotidianos para volverse pública y normalizada. Son las mismas violencias, una extensión de las violencias que sufren en sus casas: el acoso, las prohibiciones, las violencia sexual, la invisibilización de sus situaciones como madres, toda esa invisibilización que la cultura hace de las demandas y de lo que hacemos" (Entrevista 1).

De esta forma, la violencia contra la mujer no tenía su origen exclusivamente en las diferencias políticas e ideológicas, no se trataba del dualismo clásico entre amigo y enemigo, o aún, no partía meramente de los intereses económicos que mueven las economías ilegales; era por el contrario aumento y degradación de algo que se encontraba enclavado en las diferentes culturas colombianas: el patriarcalismo. La violencia contra la mujer en el conflicto armado representaba una forma de ser y de hacer de la sociedad masculinizada del país, que encontraba en la escenificación y profundización de las formas rutinarias de esta violencia, mecanismos eficientes para hacer daño al oponente, para afectar su "virilidad", su imagen de protector y proveedor.

Estas mujeres comenzaron a identificar que ciertas prácticas como la violencia sexual o el desplazamiento forzado de mujeres se reproducían en diferentes rincones del país y no eran exclusividad de ningún actor armado en particular, eran la forma en la que se planeaba y ejecutaba la guerra en Colombia.

\subsubsection{Los Objetivos}


Con estos convencimientos se fue erigiendo la Ruta, movimiento que fue construyendo paulatinamente sus planteamientos pero que desde el principio fijó un horizonte de acción concreto. Así lo recuerda Olga Amparo Sánchez, una de sus fundadoras:

"la Ruta nace con una postura, inicialmente, de la importancia de poner en la agenda pública la situación de las mujeres víctimas de los diferentes actores armados con la negociación política como el elemento central. Nació también feminista. Ya todo el discurso antimilitarista y de la no violencia se fue enriqueciendo con el trabajo, con la realidad. Por supuesto se vislumbraba que la Ruta podía estar dirigida a un discurso de la no violencia cuando sale a apoyar en el 96 la neutralidad activa de las comunidades indígenas de Mutatá. Nos resistimos al conflicto activamente pero no vamos a tomar partido por ninguno, era lo que decíamos" (Entrevista 11).

Esta aproximación nos permite evidenciar dos elementos importantes sobre la construcción de sus objetivos: por un lado, sintetiza lo que a lo largo de 18 años han sostenido las mujeres que hacen parte de la Ruta, es decir, la necesidad de una salida negociada al conflicto colombiano junto con la importancia de visibilizar los impactos diferenciados que han sufrido las mujeres en la guerra; por otro lado, que sus principios o ejes políticos de acción se han ido nutriendo y evolucionando con las dinámicas del contexto en el tiempo.

Desde este punto de vista, la superación de esos agravios sólo podría lograrse si se llegaba al fin del conflicto. Pero este fin debía tener un solo modo: la negociación política. El sufrimiento de las mujeres, víctimas de todos los bandos, madres, hermanas e hijas de los hombres de cualquiera de los bandos, solo podía mitigarse por la vía negociada. Se proyectaba así la Ruta como un movimiento en búsqueda de la salida negociada al conflicto armado como respuesta a la barbarie que se estaba cometiendo contra las mujeres en el país por cuenta de la confrontación. De allí que sus solicitudes aunque se dirigían a todos los actores armados, siempre 
tuvieron como destinatario el Estado como el responsable de encontrar salidas al conflicto armado.

Con estas claridades en mente la Ruta comenzó su peregrinar por el país lo cual estrechó su relacionamiento con las regiones y comunidades que iban visitando. Cada año y con cada acción colectiva sus fundamentos políticos y el enmarcamiento de sus planteamientos se iba nutriendo de nuevos y variados derroteros descubiertos en la experiencia:

"Es la primera vez que veo en vivo y en directo cuatro camiones incinerados. Me había acostumbrado a verlos en la televisión o en los diarios. Confieso que sentí una profunda tristeza que no pude contener, al punto que se me aguaron los ojos. ¿Cómo es posible que para poder conocer mi país tenga que andar con un grupo de mujeres pacifistas y con pañuelos blancos?... ¿Dónde está el gobierno?... ¿Qué pasará con esta gente del Chocó y su comida si ya hace más de un año que volaron el único puente que los comunicaba por la parte baja, con el pretexto de incomunicar a la guerrilla? Es claro que esta guerra nos jode a todos y a todas, pero definitivamente a los que más afecta es a los campesinos y campesinas que habitan estás zonas tan vulnerables porque igual, nosotras ahora nos regresamos." (Ruta Pacífica de las Mujeres, s. f.-a).

Esta cercanía con los problemas que acarreaba para las comunidades la guerra, le permitió a la Ruta sensibilizarse frente algunos aspectos específicos de la confrontación. El pedido a las partes del conflicto de llevar a acabo acuerdos humanitarios para aliviar el sufrimiento de las familias de retenidos por las guerrillas y presos políticos, las protestas por los efectos al medio ambiente y a las comunidades por las fumigaciones con glifosato, las diferentes formas de violencia sexual contra las mujeres, el feminicidio, el desplazamiento forzado y sus efectos particulares en las mujeres, los impactos ecológicos de la carrera armamentista y los derechos a la verdad, la justicia y la reparación integral que tienen las víctimas del conflicto, se constituyeron como algunas de sus más importantes banderas. 
Estas apuestas se fueron desarrollando y profundizando con cada marcha que hacían, al tiempo que sus integrantes se iban encontrando con más duras y crueles realidades en estos viajes, lo cual hacía que perfilaran y detallaran más sus planteamientos y solicitudes al gobierno nacional.

Sin embargo, como anotábamos previamente, estas temáticas devienen de un análisis cuidadoso de las realidades del conflicto visto por mujeres con unas perspectivas particulares. Las reivindicaciones que realizan se posan sobre tres pilares o principios fundamentales basados en el marco de interpretación que han construido como resultado de su interacción con el conflicto y sus valores de partida: el feminismo, el pacifismo y el antimilitarismo. Veamos cada uno de ellos.

\subsubsection{Los Feminismos de la Ruta}

Para la Ruta el socio-sexo patriarcalismo que domina la cultura actual, genera una relación de subordinación de los hombres sobre las mujeres que se ve reflejado en una de sus máximas expresiones: la guerra. Mediante ella, la opresión y subordinación a la que es sometida la mujer si bien se recrudece, no se devela con facilidad al estar incrustada precisamente en el dominio del patriarcalismo. A su vez, este patriarcalismo, que se nutre de otros sistemas, incluido el capitalismo, hace que la división del trabajo no solo sea social sino también sexual, apropiándose no solo del trabajo de las mujeres sino también de su sexualidad y de sus emociones.

Esta situación se evidencia de manera prominente en el contexto de la guerra, pero también está presente y permea todas las relaciones sociales, políticas y afectivas, inunda los subtextos de las instituciones formales e informales de la sociedad, haciendo más abrumadora y oprobiosa la subordinación. Por ello, por ejemplo, las mujeres son las más pobres entre los pobres, están menos calificadas, ejercen profesiones peor remuneradas y, junto a los niños, son las más victimizadas en la violencia intrafamiliar. Esta lectura del mundo, hace que las mujeres de la Ruta construyan estrategias para superar a sus enemigos: el patriarcalismo y el 
capitalismo, esos "hermanos siameses" que impiden a las mujeres salir de ese estado de sometimiento:

"La Ruta como nuevo movimiento social, subvierte los códigos culturales dominantes. Pero lo peculiar de sus prácticas reside en lo que ya señalara Kate Millett: desafía el orden social y el código cultural más ancestral, universal y arraigado de los existentes, el patriarcado. La Ruta, heredera de la teoría y la práctica feminista plantea la necesidad de establecer mecanismos sociales y políticos capaces de romper la dinámica excluyente del sistema patriarcal de hacer y entender la política.” (Sánchez, 2006, p. 69).

Esta ruptura se plasma desde el comienzo, cuando las mujeres que van en Ruta asumen como uno de sus lemas principales: "El cuerpo de la mujer no es botín de guerra". Esta verificación de la intromisión del patriarcado en la forma de hacer la guerra, permite a las mujeres evidenciar que han sido víctimas, además de las armas, de un sistema de pensamiento machista que en tiempos de guerra escarba en su surtido de violencias rutinarias contra las mujeres, las incrementa, las exacerba, pretendiendo por este medio castigar a al enemigo varón.

Al tiempo, gracias a esta revelación, "subversión", las mujeres encuentran un modo de liberar sus cadenas poniendo en público las diferentes formas de la violencia contra ellas y manifestando su intención de impedir que se repitan.

"No permitiremos que de nuestras manos y vientres, broten ni un solo alimento para la guerra y la violencia"... "Desactivaremos todos los artefactos de la guerra, los de hierro, los de la palabra que incita, los del olvido"... "Que la palabra dialogante y comprometida sea la única arma que aquí se esgrima. Y si no es la palabra y la fuerza material que de ella deviene, ¡Ay de nuestras hijas e hijos! futuro incierto el de nuestro país, el de este planeta. Depararemos entonces una tierra estéril, y las mujeres no tendremos hijas-os que vean este oprobio"... “Que los intolerantes y los guerreros de 
todos los colores, de todas las clases, que habitan hoy nuestra tierra, sientan que hoy están sembrando, lo que mañana recogerán las hijas-os de sus hijasos" (Sánchez, 2006, p. 69).

Por supuesto el feminismo no es visto desde una única visión teórica, este se va conociendo, aprendiendo y modificando con cada una de las participantes de la Ruta. Así, el feminismo no solo es asumido como una postura teórica sino como una práctica social cotidiana. De allí que se aprecie la existencia de varios enfoques feministas que pueden ir, desde aquellos fundados en la mujer como dadora de vida: "no pariremos hijos e hijas para la guerra", justificando su acción contra la guerra en su amor sin límites y politizando el vínculo de la maternidad, hasta aquellas que sabiéndose dueñas únicas de su cuerpo y de sus vidas encuentran en la interrupción voluntaria una alternativa legítima para evitar embarazos no deseados. De esta forma, dentro de la Ruta tienen cabida variados matices que pueden ir desde los más radicales hasta algunos más moderados. Allí se encuentran organizaciones que trabajan por la diversidad sexual o el ecofeminismo, hacen parte también mujeres cristianas y lideresas indígenas con su especial cosmovisión ancestral.

A su vez, no todas las mujeres llegan a la Ruta luego de haber alcanzado un convencimiento de los contenidos feministas. Estos muchas veces se van adquiriendo en la práctica mediante la ritualidad de la movilización social y los discursos que circulan entre ellas y que se instalan en sus manifestaciones. También el feminismo, como los otros dos pilares, es asignatura de estudio de las múltiples escuelas que se realizan en las regionales y que buscan la formación y cualificación ideológica de sus integrantes. Esto hace que las mujeres ostenten, cada una, una forma particular de entender y practicar el feminismo y de proyectarlo hacia el exterior, siempre en disputa con un discurso dominante que desprecia y estigmatiza a quien se autodefine como feminista.

\subsubsection{El Pacifismo de la Ruta}


Si bien el feminismo fue un punto de partida para la Ruta, el pacifismo se fue edificando poco a poco. Como bien lo recuerda Marina Gallego, no es de extrañar que este terminara siendo uno de los senderos de la Ruta, si se observa que la primera movilización a Mutatá programada por estas mujeres fue para acompañar y respaldar la propuesta de neutralidad activa propuesta por la Organización Indígena de Antioquia. Como lo señalamos previamente, la neutralidad activa surge como una apuesta de las comunidades para evitar el involucramiento de sus miembros y de sus territorios en la guerra. Era la manera en que los indígenas reclamaban su autonomía y el derecho a mantener sus tierras y comunidades libres de una violencia ajena.

Este aprendizaje lo toma la Ruta y lo desarrolla en razón a algunos planteamientos foráneos como el de la No Violencia y el pacifismo de Martin Luther King y Gandhi (Ruta Pacífica de las Mujeres, s. f.-b). Para ellas además, el rechazo a la guerra tiene un fundamento feminista. Si la guerra es la máxima expresión del patriarcado, por ende, ésta debe ser contestada. No obstante, las mujeres de la Ruta son conscientes de la participación de la mujer en la guerra. Se admite que ellas no solamente son las esposas y novias de los guerreros, sino también que en muchas ocasiones participan de las hostilidades y se hacen miembros de los actores armados, por tanto, el pacifísmo no deviene como atributo de ser mujer, es más bien producto de un análisis de las consecuencias nefastas que causa la guerra y de la lucha contra la dominación y opresión en que se encuentra sumergida la mujer en una sociedad patriarcal.

"Desde las posturas pacifistas en la Ruta rechazamos la guerra, realizamos actos de desobediencia civil contra las guerras y las violencias, reivindicamos el derecho a no involucrarnos en el conflicto armado, no somos parte de ninguno de los actores armados, no le delegamos a ninguno de los actores armados muestras apuestas ni nuestras agendas, no creemos que haya guerras santas, ni justas, ni sucias, ni limpias, no apoyamos a ninguno de los actores armados y esto incluye a las fuerzas armadas del Estado, que tienen gran responsabilidad en la agudización del conflicto 
armado y de la crisis humanitaria cuando estimulan y encubren grupos paraestatales que imponen terror y pretenden someter a la población civil a sus propios parámetros de justicia” (Ruta Pacífica de las Mujeres, 2003, p. 118).

Así las cosas, la contestación a la guerra se hace contra todos los actores que participan en ella indistintamente del bando que ocupan y si pertenecen o no al Estado. Para la Ruta resulta una cuestión de honor deslindarse de las pretensiones de representación que suelen tener los grupos armados en sus discursos y plantean la desobediencia civil como un mecanismo para lograrlo.

Recordemos que durante varios años, luego de las fallidas conversaciones de paz en el Caguán, la participación de la sociedad civil en la guerra era casi que un mandato gubernamental. De allí que para la Ruta, "desobedecer" este mandato se convirtió en una cuestión de principios. Ante ello oponen una visión integral del ser humano como actor civilista dentro de la sociedad basado en una ética de la no violencia en la que prima el principio de la dignidad humana. Para la Ruta, una salida negociada políticamente es la única forma de conservar tal dignidad.

Es importante anotar que no es del conflicto del que se huye, sino de su forma de tramitarlo. Tampoco existe una inclinación ideológica específica por alguno de los bandos, si bien muchas de las mujeres y organizaciones que hacen parte de la Ruta hicieron parte o hacen parte de procesos organizativos de izquierda. Se trata de encontrar salidas distintas a las de la fuerza para encontrar el equilibrio entre los planteamientos políticos y los intereses que permean el conflicto. Por tanto, el uso de la palabra, el dialogo y la resolución por vía del derecho deben primar a la hora de finalizar el conflicto armado. Este planteamiento sella su alianza con un movimiento de paz que se venía gestando de tiempo atrás en Colombia y que encontraba en el anhelo de la paz concertada un punto común que alimentaba y facilitaba su acción colectiva.

\subsubsection{El Antimilitarismo de la Ruta}


Derivado también del feminismo surge el antimilitarismo como una oposición directa contra un orden militar que concibe a los hombres para combatir y a las mujeres para procrear. Pero además, porque finca su accionar en la industria armamentista en donde se establece una relación entre el Estado, el mercado y los financistas interesados en la producción y compraventa de armas, estableciendo un sistema económico de guerra para la dominación y la subordinación.

"La cultura militar valora la agresividad y refuerza los estereotipos machistas, al tiempo que subvalora las cualidades que se atribuyen tradicionalmente a las mujeres. En el proceso de formación de los soldados, las fuerzas armadas estimulan la vinculación emocional entre varones y las expresiones de virilidad, a fin de que los soldados tengan confianza mutua y se muestren reacios a hacer cualquier despliegue de debilidad en presencia de sus pares, lo cual se ridiculiza como una actitud femenina” (Sánchez, 2008, p. 65).

Las mujeres de la Ruta explican que el militarismo al fundarse en la cultura patriarcal, produce toda una suerte de agresiones contra la mujer: violaciones, feminicidios, hostigamiento, acoso sexual, esclavitud sexual y, en contextos de guerra, convierte a la mujer y a su cuerpo en "arma y botín de guerra". Este hecho es denunciado permanentemente por la Ruta mostrando que los actores del conflicto armado escogen mecanismos de violencia específicos para la mujer en el que el dominio del varón y su despliegue de virilidad, sumerge en la humillación y en el maltrato a la mujer y todo aquello que represente lo femenino.

Sin embargo, señalan las integrantes de la Ruta, el militarismo no es exclusivo de las fuerzas armadas de los grupos en disputa. Este también se filtra por las hendiduras sociales y se apodera de todos los demás espacios de la vida. Así, la familia, la escuela o el trabajo adquieren visos jerárquicos y despóticos y se actúa en función de la lógica de amigo contra enemigo, apoderándose de la forma de ser y de actuar de una sociedad, incluso de niños y niñas que encuentran en el juego de 
la guerra una manera más de entretención. Desde esta visión, detener el conflicto bélico implica el desarme no solo físico sino también mental y simbólico.

La Ruta también relaciona el poderío económico de ciertas empresas y países y hace una crítica aguda a la acumulación económica y de poder gracias al mercado de las armas y de la guerra. Este planteamiento viene a equipararse a otros tantos que ellas realizan en sus marchas y que rechazan un modelo económico de desarrollo a espaldas de las comunidades mediante la implementación de megaproyectos inconsultos. En este caso, el mercado de las armas beneficia precisamente a quienes detentan el poder económico y político encarnados en empresarios, congresistas, gobernadores y alcaldes en detrimento de las bases y la sociedad civil que sólo reciben los descalabros de la guerra.

Por todas estas razones, la Ruta plantea en sus discursos la necesidad perentoria de disminuir el armamentismo como mecanismo trascendental para desactivar ese orden militar que subyuga y denigra a la mujer, oponiendo su contestación, ya no solo a los actores armados locales o al gobierno nacional, sino instando a otros gobiernos y a las empresas armamentísticas transnacionales a detener la producción de armas adjudicándoles también la responsabilidad de lo que esto produce a las comunidades y a las mujeres particularmente.

\subsubsection{Los Simbolismos en la Ruta}

"Un día las mujeres descubrimos que al igual que la palabra, lo simbólico tenía poder. En este trasegar de lo femenino por los distintos lenguajes (el gesto, el cuerpo, la palabra y los símbolos), como posibilidad de comunicación de nuestros deseos, propuestas, sueños e ideas, hemos dado toda la apertura a que nuestra capacidad creativa renazca, se exprese, se de a entender y tenga la fuerza necesaria para hacerse oír." (Ruta Pacífica de las Mujeres, 2003, p. 132). 
Un elemento característico de las acciones de la Ruta durante sus movilizaciones y manifestaciones públicas es la parafernalia artística que usualmente les acompaña. Con bastante frecuencia sus actividades están seguidas de rituales, poesía, música y danza en la que se despliegan colores y olores diversos y en las que se involucran todas sus participantes. Otras veces, en sus plantones de Mujeres de Negro, el color negro y el silencio las acompañan. Con ello la ruta trasciende el uso de la palabra como único medio de comunicación y penetra el mundo de lo mágico, de la metáfora y del ritual.

Si bien cada nueva acción compromete la creatividad de sus integrantes y se construyen nuevos artefactos simbólicos dando respuesta a la coyuntura a la que asisten, la Ruta en el tiempo ha plasmado parte importante de sus pensamientos y planteamientos políticos en los elementos simbólicos que exponen. Ejemplo de ello es el uso de los colores o la enunciación reiterativa de ciertos mensajes. El amarillo para la verdad: que nada quede oculto en el horror de la guerra y que los hechos sean conocidos y sea visible la responsabilidad de los culpables, que todas puedan contar sus versiones pero que también los nuevos proyectos de vida de las mujeres vean la luz. El blanco para la justicia: que se sancione sin retaliación, se equilibre la balanza y el poder no esté en cabeza de unos sino en la democracia. El verde es la esperanza: un mundo más digno y justo en el que se conozca la verdad y se repare a las mujeres, un país incluyente y digno para los excluidos. El azul para la reparación: que cura las heridas, restablece la dignidad, reconoce los daños y los resarce.

En otros casos, son los mensajes los que calan en el imaginario de sus integrantes y se vuelven elementos distintivos de su acción política. Con consignas como, "las mujeres no parimos más hijos ni hijas para la guerra", "ni un peso más, ni un alimento más para la guerra, todo para la vida y la paz" o "ninguna guerra en mi nombre", entre muchas otras, las mujeres de la Ruta condensan la manera en que leen el conflicto armado, plantean sus reclamos y reivindicaciones y fijan posiciones sobre el devenir de la guerra y la sociedad haciendo una síntesis de su interpretación política y de las transformaciones que deben suceder. De esta forma, 
con mensajes, ritmos, bailes, poesía, máscaras, esencias florales y cuerpos pintados, las mujeres de la Ruta comienzan sus rituales de acción política.

"Nos acompañan todos los elementos: Agua, tierra, fuego, madera y viento. Las diosas míticas latinoamericanas, las abuelas de todos los tiempos; los silencios de todas las enmudecidas; el grito de las amazonas y heroínas; las anónimas y las locas que empezaron y continúan el barullo; todas se disponen a acompañarnos. El viaje se emprenderá en el crepúsculo del día 24, iluminado por la luz tenue del sol y la incandescencia presentida de la luna llena. Lavaremos la sangre, la limpiaremos de lamentos, exorcizaremos las iras y lanzaremos nuestros resueltos 'No a la Guerra' en el momento en que nos disponemos al viaje que nos conduce por nuestro propio pie hacia la Mutación en seres neutros frente a los actores de la guerra, en mujeres que se sienten y se piensan en medio de los sonidos ensordecedores, en medio del terror y la incertidumbre de una confrontación ajena a la esencia humana. Al llegar a Mutatá estaremos dispuestas para el acto fundante de identidad, de actos creadores. Fundaremos, a ritmo de campanas, sinfonía musical, estruendo vocal, danza, juego de niñas y niños, mecidas por los vientos y movidas por la alegría y el amor, nuevos signos y símbolos para la acción política de las mujeres por la Vida y la Paz en Colombia y en el mundo" (Sánchez, 2006, p. 78).

Mediante el uso de la simbología, las integrantes de la Ruta encuentran un vehículo para alcanzar varios de sus objetivos. Por un lado, los símbolos les permiten transmitir sus reclamos de forma novedosa y creativa, haciendo que sus adversarios y el público en general, deban entrar en otra dinámica mental para comprender los mensajes que les están siendo enviados. Se intenta con ello desarmar el criterio racional con el que se suele asumir los hechos y las situaciones políticas al debatir sobre los asuntos de la guerra y de la paz. Se trata de una manera distinta de hacer incidencia política pública, de tal suerte que sea posible romper la indiferencia y el descuido de los colombianos sobre las consecuencias del conflicto armado, crecer en visibilidad y notoriedad ante el auditorio que las ve y las escucha. En últimas, la 
Ruta pretende mediante el uso de ciertos símbolos encontrar otras formas de hacer y decir la política.

De otro lado, el uso de la simbología también busca generar escenarios de contención y sanación personal y colectiva. La música, la danza, el teatro, la construcción de artesanías y sus usos rituales pretenden llevarles a las mujeres que han sido víctimas una voz de aliento y de 'sororidad' de parte de las integrantes de la Ruta. Una manera de acompañar en un abrazo metafórico y real el duelo de las mujeres, pero también de enfrentar el miedo y la frustración que dejan las acciones armadas en sus poblaciones. Imaginar otros colores para la vida, con ritmos y canciones que espanten los fantasmas de la guerra y las sombras de la muerte.

En este proceso, el cuerpo y la sexualidad también se vuelven un lugar para la expresión de la denuncia. En el cuerpo, lugar de abuso de los guerreros, también se encuentra la posibilidad creativa y amorosa capaz de resistir y transmitir la indignación. La puesta en escena del cuerpo invita a la reflexión sobre los estragos que la guerra ha dejado sobre las mujeres y la invitación al diálogo que desarme a los violentos. También subvierte el lugar adjudicado por el socio-sexo patriarcalismo a las mujeres en el mundo de lo privado para sacar a lo público su expresión más íntima en donde lo personal también es público y las violencias sexuales se exclaman para que los demás las conozcan y las rechacen.

Pero también las acciones simbólicas son manifestaciones de poder. Mediante este tipo de despliegues, las mujeres de la Ruta buscan la recuperación de los territorios desalojados por los paramilitares, las guerrillas y la fuerza pública en su acción criminal. Al coparlos con música, danza y artilugios teatrales, las mujeres de la Ruta pretenden transmitir un mensaje claro de resistencia a los actores armados; es una manera de tomarse pacíficamente las tierras que se encuentran en disputa.

Con la simbología las mujeres además buscan transformaciones culturales más profundas. Para ellas la ruptura de las lógicas patriarcales implica una revolución de los esquemas rígidos racionales que cran dominación y subordinación de los 
hombres hacia las mujeres. Los colores, el movimiento, las imágenes y los sonidos crean fisuras en este mundo y abren rendijas para interpretar la realidad y a los sujetos que en ella habitan de un modo distinto, fracturan los poderes tradicionales, rompen el miedo y la tristeza que causan la guerra y la muerte, invitan a imaginar otros mundos posibles mediante la fuerza renovadora de lo femenino.

\subsubsection{Las Identidades de la Ruta}

Estas lecturas de la realidad y mezclas de lo que se dice, no pasa ligero por las vidas de las mujeres que integran la Ruta. La identificación de agravios, construcción de objetivos, elaboración de principios y el uso de la simbología, integran de formas particulares a las mujeres y las identifican entre y para sí. El movimiento se vuelve escenario para compartir identidades previas y construir nuevas, para interactuar.

"En la Ruta nos reconocemos tejedoras, desde la diversidad cultural y los diferentes saberes de las mujeres colombianas, donde cada una es portadora de un hilo, en el que se anuda lo público con lo privado, el corazón y la intuición con la razón, lo individual con lo colectivo, lo sagrado con lo pagano. La urdimbre, los hilos, los colores, nuestras manos, nuestros vientres trascienden el propio cuerpo y el tejido. Tejer y destejer, para volver a tejer, es un ritual que alberga propósitos de las mujeres que hemos construido otras propuestas para instituirnos en procesos personales, sociales, culturales y políticos” (Ruta Pacífica de las Mujeres, 2003, p. 127).

Como señalábamos anteriormente, en la Ruta participan mujeres de distintas procedencias. Hay mujeres de izquierda, campesinas, obreras, políticas, congresistas, docentes, estudiantes, jóvenes, adultas mayores, profesionales, indígenas, mujeres lesbianas y bisexuales, mujeres cristianas, ente muchas otras, de allí, que esta conjunción de identidades previas produzcan que los principios éticos y políticos, como el feminismo, el pacifismo y el antimilitarismo, se expresen en una multiplicidad de interpretaciones. A su vez, estos marcos de referencia permean 
la vida cotidiana de estas mujeres y las rehace como sujetos políticos empoderadas en sus espacios sociales habituales.

Sin embargo, mientras ello sucede, también sus vidas personales se modifican. Con su acción movilizadora no solo ellas le aportan en conocimientos y experiencia al movimiento sino que el colectivo en sí mismo genera cambios en las percepciones y en la forma de vida de sus integrantes.

"A mí la Ruta también me ha permitido disfrutar lo que es ser mujer, el hecho del afecto, del cariño, de la sensibilidad, de la creatividad, de los colores, de disfrutar de las cosas sencillas. La ruta no solo es una apuesta política sino también es resaltar el hecho de ser mujer, de que hay que ser creativas, tú ves mujeres maravillosas, la Ruta te permite conocer mujeres de todos los colores, de todos los sabores, de todos los pensamientos y pues para mí ha sido maravilloso estar ahí” (Entrevista 8).

Existe un proceso de "enamoramiento", de seducción que facilita el ingreso y la permanencia de las mujeres en este Movimiento. La Ruta se convierte en el lugar donde se "permite", se permite a las mujeres soñar, construir, luchar, salirse de las convenciones subyugantes, romper el cerco de los planteamientos socio-sexo patriarcales y subvertir el orden machista. Se permite diseñar propuestas de paz, de convivencia, de igualdad y equidad y se busca en el arte y en la creatividad mil estrategias para comunicar estas ideas más allá de sus propios límites. El movimiento busca acercar a las mujeres y dotarlas de capacidades para buscar transformaciones en todo nivel. Desde lo que les sucede en la casa cuando deben buscar las formas de soltarse de las amarras que les dificultan su participación en las reuniones del movimiento, hasta las estrategias para la incidencia política en la cual ordenan planteamientos, identifican objetivos, construyen parlamentos y se preparan para alocuciones públicas. En muchos casos, a nivel familiar, las mujeres encuentran caminos para modificar su relación con la pareja y con los hijos, de tal suerte que es la misma familia la que recibe directamente las influencias del 
movimiento. Asimismo, en el espacio público y en su relación con las otras, las mujeres desarrollan dotes que les permiten acercarse y ser parte de la solución.

"El hacer parte del grupo de hadas que simbolizan la Ruta me ha servido para reconocer mi parte artística. Mis compañeras y yo hemos tenido asesoría en lo estético y en lo artístico y eso nos ha despertado las cualidades y el reconocimiento de saberes que nos han dado mucha riqueza y mucha lúdica... Al ser las hadas sanadoras nos hemos interesado en otros procesos educativos en el sentido de la sanación, de lo simbólico, y uno quisiera sanar a todas las mujeres, sanarlas en el momento, tener esa capacidad, pero esto tiene que ser un proceso lento, poco a poco... En la Ruta nos sentimos respaldadas, protegidas porque ya sabemos que en un momento coyuntural vamos a tener apoyo y no de una mujer sino de un movimiento completo" (Ruta Pacífica de las Mujeres, s. f.-a).

Todos estos procesos, revolucionarios y libertarios para las mismas mujeres, terminan convergiendo en los principios orientadores del movimiento y en las estrategias de comunicación de los idearios para cada movilización política. Esta posibilidad surge del permanentemente esfuerzo que hace la Ruta por aglutinar a sus integrantes en aspectos básicos de su pensamiento mediante procesos de formación política y durante las mismas acciones colectivas, discutiendo una y otra vez aquello que les es común y por lo que se mantienen unidas.

Esta tarea constante modela los planteamientos ético-políticos y las lecturas de sus participantes de lo que las rodea, finalmente las anima a concentrarse en algunos aspectos específicos de la vida política y del acontecer del conflicto armado. Ello les permite construir un horizonte compartido con una identidad única y propia que las reúne como sujeto colectivo y las diferencia de los demás movimientos y organizaciones de mujeres.

"Podemos afirmar que estamos comprometidas en construir formas inéditas de relación entre las mujeres, para autorizarnos entre nosotras, para 
situar algunas coordenadas de lectura que sean colectivas, para pensar juntas, para hacer habitable la propia posición feminista. Nuestro camino teórico y práctico, ha sido y es, asumir el feminismo no sólo como un movimiento intelectual y político a favor de las mujeres, sino también y principalmente como movimiento subjetivo de politización de la vida cotidiana, que hace de lo personal, de lo cotidiano, de lo más ínfimo, una constante problematización, capaz de subvertir los modos de vida y ampliar nuestra capacidad de decisión y autonomía sobre nuestras vidas" (Sánchez, 2008, p. 8).

Se constituye un forma particular de ver el mundo a partir de una visión feminista del conflicto y las consecuencias que este le acarrea especialmente a la mujer, mostrándole al país que la guerra va más allá de los intereses expuestos por las partes y que sus resultados afectan al conjunto de la sociedad más allá de los muertos de cada bando. También explican que la guerra es una expresión más del patriarcalismo y que una buena forma de desarticularla es buscar una salida política negociada que dé al traste con el camino militarista que ha predominado en el proceso.

Es necesario también resaltar que además del feminismo, el pacifismo y el antimilitarismo, postulados generales la Ruta, se van construyendo en la coyuntura otra suerte de planteamientos que entran a dar cuerpo y sentido a sus planteamientos generales. Por ejemplo, una lucha por la verdad, la justicia y la reparación de las víctimas, en la que sea posible subvertir la concepción masculina de Justicia y se busque en la justicia transicional un medio para verificar la realización de los derechos de las víctimas; o el postulado de que el desplazamiento forzado ha sido uno de las mayores y más inclementes perjuicios que ha dejado el conflicto sobre las mujeres; que se reconozca que el narcotráfico y las economías ilegales han sido un factor poderoso en la guerra pero que la solución no es la fumigación de los cultivos de los campesinos ni su persecución; que las empresas multinacionales y los megaproyectos inconsultos tienen un papel protagónico en la continuación de la guerra; todas estos planteamientos nutren de contenido a esa nueva identidad. 
Todos estos elementos convergen para hacer de la Ruta un movimiento social en el que anidan interpretaciones singulares del mundo con la capacidad de identificar esos agravios producidos por la guerra que están más allá de los convencionales, y así, convencerse de la necesidad y la pertinencia de acción colectiva como un recurso suficientemente poderoso para desarticular la violencia y ofrecer alternativas de solución. En este trámite, sus integrantes, pese a la diversidad social y cultural, se encuentran en los pilares fundamentales del movimiento para recrear un nuevo espacio que les "permite" ser mujeres y recrear una vida lejos de los marcos socio sexo patriarcales que les limita su existencia y los cuales deben ser eliminados paulatinamente con cada acción emprendida.

\subsubsection{Organización y Repertorios de la Ruta Pacífica de las Mujeres}

\subsubsection{Las organizaciones de mujeres en Colombia}

El recuento de la historia de la conformación del movimiento feminista en Colombia, por la dinámica tan compleja y el volumen de organizaciones que lo integran, aún es una deuda académica y política. No existen trabajos detallados que den cuenta de las múltiples formas y mecanismos usados por las mujeres para organizarse y reivindicar sus derechos en todo el territorio nacional. Sin embargo, si hay varios estudios que nos permiten acercarnos a una mejor comprensión del tipo de organizaciones sociales de mujeres y las estructuras de las que se han valido para la movilización.

Acogiendo los planteamientos de Manuel Castells, Alain Tourine y Alberto Melucci, encontramos que este movimiento ha estado conformado por varias redes de organizaciones de muy distinto calado que se han activado a partir de la defensa de sus derechos y han entendiendo el problema de la subordinación de la mujer como un asunto político (Sánchez, 2006, p. 48). Esta referencia nos permite vislumbrar que el movimiento feminista en este país, más que un grupo de organizaciones aliadas por un propósito, ha sido la suma de múltiples propuestas de 
acción colectiva que se han juntado y se han separado en determinados momentos, motivadas por los acontecimientos y por la forma en que han interpretado el irrumpir de los agravios. Además, son numerosos los grupos de mujeres organizados a lo largo y ancho del país y, por lo tanto, pueden encontrarse pequeñas organizaciones de mujeres rurales o locales asociadas por intereses concretos de su contexto, organizaciones de corte regional o de segundo nivel que aglutinan asociaciones más pequeñas, redes nacionales que conectan estos múltiples focos organizativos $\mathrm{y}$, a su vez, en algunos casos, en alianza también con redes internacionales.

Las redes de nivel nacional si bien suelen tener comunicación entre sí y compartir algunos escenarios de incidencia política, no necesariamente mantienen los mismos principios y postulados ni van tras los mismos objetivos políticos, de allí que no actúen como un único actor sino como múltiples actores que se encuentran y se separan dependiendo el contexto político que les rodee y las apuestas organizativas que estén desarrollando. Es frecuente sin embargo que en algunos casos, luego de realizar concertaciones políticas e ideológicas, se comprometan a trabajar solidariamente por algún propósito común. En general, las organizaciones van construyendo su propia historia y ganando simpatizantes a partir del prestigio que van conquistando con el acontecer político nacional.

El Informe del Grupo de Memoria Histórica de la Comisión Nacional de Reparación y Reconciliación, "Mujeres y Guerra, Víctimas y Resistentes en el Caribe Colombiano", nos muestra también que existe un mecanismo extendido de difusión del pensamiento feminista en Colombia que sirve de transmisor de ideas para la emergencia de organizaciones feministas. Mediante "dinámicas de polinización" el discurso de feministas reconocidas o de organizaciones consolidadas es difundido por todo el espacio geográfico sirviendo de semilla para nuevas iniciativas organizativas que se refieren a los derechos de las mujeres y a su rol en la sociedad colombiana. A su vez, las mujeres con acción local recogen sus propias demandas, leen los contextos inmediatos y producen reclamos específicos 
que aterrizan y cuestionan los discursos más generales y abstractos alimentando el debate estructural (Grupo de Memoria Histórica, 2011, p. 329).

Hay que reconocer también que muchos de estos procesos, si bien se ocupan de la exigibilidad de los derechos de las mujeres en diversos ámbitos, durante los últimos 30 años la mayoría han estado ligados a contextos de guerra, lo cual ha determinado parte importante de sus procesos enmarcadores. Esta situación ha determinado en algunos casos límites y barreras imposibles de sortear e incluso procesos de revictimización. Sin embargo es notable cómo, aún en contextos tan complejos, las mujeres han logrado sacar adelante sus organizaciones valiéndose de redes de apoyo que trascienden los límites geográficos.

\subsubsection{La Ruta se organiza}

Muchos de esos elementos los apreciamos en el proceso organizativo de la Ruta Pacifica de las Mujeres. Como pudimos ver en capítulos anteriores, la Ruta surgió por la iniciativa de varias feministas que encontraron las acciones de guerra contra las mujeres repudiables, suficientemente indignantes como para confrontar al Estado y a los grupos armados. Si bien en un primer momento, durante la organización de la primera marcha a Mutatá, se trataba de la acción concertada de varias organizaciones de mujeres en un territorio particularmente afectado junto a las de otras regiones del país, fue en la movilización y en la lectura de sus resultados que surgió el deseo de construir un andamiaje de nivel nacional que pudiera hacer seguimiento a estos hechos y mantener la contienda con los responsables de los agravios. Así se construyó entonces la propuesta y comenzó a estructurarse alrededor de las organizaciones participantes de la movilización de aquel momento. 


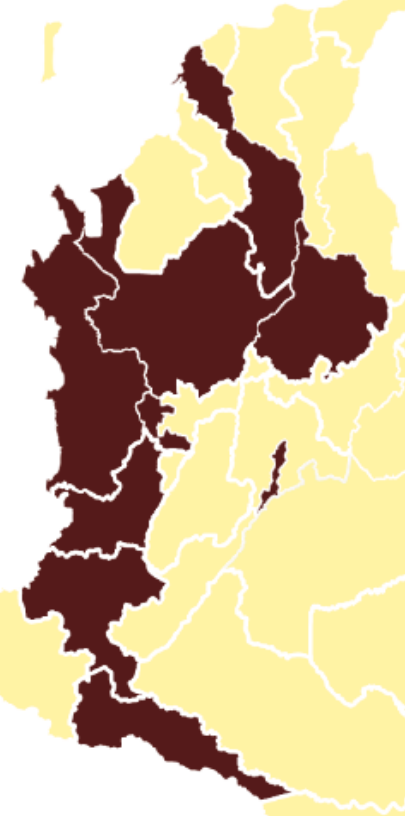

Fuente: Ruta Pacífica de las Mujeres. Elaboración Propia.

Actualmente la Ruta cuenta con una coordinación nacional y nueve regionales en Antioquia, Chocó, Santander, Bolívar, Cauca, Risaralda, Valle, Putumayo y Bogotá. A la Ruta pertenecen cerca de 288 organizaciones de las que hacen parte mujeres de todos los niveles sociales y académicos, muchas son profesionales, otras campesinas y obreras, provienen de diferentes culturas locales, religiones e idiosincrasias, tienen diferentes edades aunque la mayoría son mujeres adultas y adultas mayores exceptuando algunos departamentos donde se ha logrado vincular a mujeres más jóvenes. Al movimiento se pueden adherir personas naturales como lideresas y feministas, pero por lo general lo hacen organizaciones ya constituidas. La Ruta se autodefine como una organización pluriclasista y admite organizaciones mixtas aunque la mayoría de sus integrantes son mujeres. 
La conformación de la Ruta se distingue no tanto por fundar nuevas organizaciones locales y regionales, sino más bien por hacer uso de organizaciones regionales consolidadas, en su gran mayoría instituidas como organizaciones no gubernamentales feministas, que cuentan con gran reconocimiento de su trabajo. De esta manera, mantienen un diseño horizontal que se condensa en una coordinación nacional en la que toman parte representaciones de cada uno de los departamentos, más una coordinadora general. Así, esta coordinación nacional está integrada por nueve miembros elegidas desde las regionales y una coordinación ejecutiva que activa y facilita la ejecución de las acciones.

Por su parte cada regional tiene un punto focal que es la organización encargada de dinamizar la acción colectiva en su departamento y que aglutina a las demás organizaciones locales que conforman la Ruta en el departamento respectivo. En algunos casos existen espacios subregionales que asocian municipios y que con otras subregionales conforman la regional del departamento. Estos puntos focales suelen ser organizaciones feministas reconocidas y con capacidad de movilizar organizaciones locales que fueron conectando durante los primeros años de existencia de la Ruta y que han incluido su pertenencia a este movimiento social como parte de su ideario político.

Es importante recalcar aquí la capacidad que ha tenido la Ruta para "apropiarse" de organizaciones existentes con una notada trayectoria feminista y con capacidad de acción y ejecución en las regiones, lo cual ha facilitado enormemente estas articulaciones. Este proceso se da mediante invitaciones a jornadas de trabajo, movilizaciones o procesos de formación y se da de manera paulatina buscando interesar a las mujeres y generarles un sentido hondo de pertenencia. Así lo describe una de sus actuales miembros:

"Yo conocí la Ruta por allá en el año 2002, yo participo en una asociación que se llama Fundación Santa Rita para la Educación y la Promoción FUNSAREP. En esta fundación trabajamos el tema del feminismo y en un evento, para un noviembre, se invitó a la coordinadora 
en aquella época de la Ruta en Medellín, y ella nos fue a hablar de las distintas iniciativas de mujeres que estaban jalonando todos los procesos contra la guerra, y la verdad fue que quedamos encantadas, quedamos enamoradas. En esa época además iba a estar la movilización hacia el Putumayo y nosotras solicitamos la posibilidad de participar en esa movilización. Aún no éramos parte de la Ruta pero nos dieron unos cupos, fuimos 20 mujeres y nos fuimos enamorando más, y entonces hicimos la solicitud de querer participar en la Ruta como organización. Allí fuimos conociendo y nos fuimos enamorando hasta ahora que todavía estamos así todas tragaditas de la Ruta. Ya luego desde FUNSAREP empezamos a invitar a las organizaciones amigas y fue así como varias organizaciones, primero de la ciudad y luego más adentro en el departamento, fueron aceptando la propuesta de la Ruta y están participando activamente" (Entrevista 2).

De esta forma, las mujeres van adquiriendo el compromiso político, el cual es nutrido permanentemente por las actividades y movilizaciones que se desarrollan en el tiempo y que las implica en su desarrollo y resultados. Esta estructura es relativamente estable, aunque las organizaciones locales y regionales suelen entrar y salir con alguna frecuencia por lo que el número total de organizaciones involucradas es variable. Estos ingresos y salidas se deben, más que a asuntos estructurales o diferencias políticas, a las posibilidades y capacidades que se tengan localmente para activarse en determinados momentos, de allí que no se cuenta con instrumentos específicos para formalizar estos cambios.

Es necesario señalar que esta forma de vincular a otras organizaciones no está exenta de problemas. En ocasiones algunas, organizaciones pares han reprochado posibles procesos de "absorción" por parte de la Ruta lo cual ha implicado divisiones o fracciones entre los grupos locales y otras redes de nivel nacional. Este hecho no es tampoco extraño a los diferentes procesos colectivos que se tejen en el país y que suelen producir algunos choques entre las diferentes vertientes políticas y organizativas. 


\subsubsection{Funcionamiento Interno de la Ruta}

La Ruta no cuenta con una personería jurídica legalmente constituida en el país, aunque está compuesta en su mayoría por asociaciones reconocidas legalmente como organizaciones no gubernamentales sin ánimo de lucro. Sus formulaciones políticas y análisis de la realidad les han llevado a la conclusión de que su estructura de funcionamiento se establece a partir de la simple voluntad de sus miembros y buscar su formalización legal implicaría ir en detrimento de su identidad como movimiento social.

Empero, sí existe un mecanismo administrativo formal para la búsqueda de financiación y el manejo de los recursos económicos. Mediante un consorcio de tres organizaciones miembros, La Casa de la Mujer, Vamos Mujer y Mujeres que Crean, la Ruta administra y gestiona recursos. Este diseño ha promovido una rutina de trabajo relativamente compleja. En el nivel nacional, las coordinadoras regionales y la coordinación ejecutiva se reúnen en Bogotá donde tienen su sede nacional cada dos meses, aunque esta periodicidad se puede ver afectada por contingencias lo que no hace extraño que se encuentren con mucha mayor frecuencia. En estas reuniones se discuten las cosas fundamentales del que hacer de la Ruta, se hacen los balances y se toman las decisiones. Cada una de las mujeres delegadas asume la representación de su regional y son las encargadas de "subir y bajar" la información a las organizaciones departamentales y locales. Usualmente la toma de decisiones se surte mediante un mecanismo de consulta que implica la participación de las regionales mediante discusiones en cada uno de los departamentos, sin embargo se reconoce que aunque se pretende mantener un esquema democrático, algunas decisiones de tipo operativo o que requieren algo de urgencia suelen ser tomadas desde la coordinación nacional.

A nivel regional no existe un único patrón organizativo ni de funcionamiento. Cada departamento ha construido su esquema de trabajo a partir de las posibilidades y necesidades del territorio. Así cada regional, con la dinamización del punto focal 
constituye un espacio colegiado con las mujeres delegadas de todas las organizaciones pertenecientes a la Ruta y allí se coordina el trabajo regional, se establece la agenda política y se coordinan las acciones colectivas. En este espacio también se escoge la persona que representará a la regional en el espacio nacional.

Cada departamento tiene su propio ritmo de trabajo. En algunos casos este espacio colegiado se reúne semanal o quincenalmente, sin embargo, dependiendo de las distancias y los recursos con los que se cuente, estas reuniones pueden desarrollarse cada mes o dos meses. Las mujeres de la Ruta explican que la periodicidad de las reuniones en Bogotá pueden ser muy diferentes a las que se dan en Putumayo por ejemplo. Mientras en la capital las distancias y los costos económicos para recorrerlas son asequibles para muchas de las mujeres, en departamentos como Putumayo en el que las distancias por su particular geografía selvática pueden ser de horas o de días, hace que los costos de traslado sean elevadísimos. De allí que no se guarde sincronía entre regiones y cada una de ellas adapte sus propios mecanismos de reunión y consulta.

A la vez, cada cierto tiempo, se organizan plenarias o asambleas en las regionales a las que asiste todas las mujeres que son miembros de organizaciones de la Ruta. Nuevamente en este caso, dependiendo de las posibilidades de traslados y recursos y de la pertinencia o necesidad de estas convocatorias.

En estos procesos se van erigiendo liderazgos y se van desarrollando habilidades comunicativas y de gestión. Las integrantes encuentran un espacio para intercambiar apreciaciones y conocimientos sobre su situación en la guerra y en muchos casos, adquieren destrezas para desempeñar labores organizativas y de gestión. Es importante señalar que si bien la Ruta puede ser una escuela para muchas, su operación interna requiere de ciertas capacidades profesionales que no todas las mujeres poseen. Ello hace que se presenten interrogantes sobre cuál es el mejor modelo de funcionamiento interno teniendo en cuenta que quieren ser una organización democrática pero que su permanencia y crecimiento depende de la capacidad política, administrativa y de gestión de quienes tienen la responsabilidad 
de la dirección del movimiento. El resultado ha sido que no se presente una rotación continua entre las lideresas y muchas de ellas hayan asumido estas responsabilidades durante varios años por falta de un remplazo adecuado.

A ello se suma el tiempo y la constancia que se requieren para sacar adelante un proceso de esta envergadura. A pesar de que en la mayoría de ocasiones la Ruta destina algunos recursos para corresponder el trabajo de las coordinadoras regionales, usualmente estos no son suficientes para cubrir sus necesidades económicas lo que las obliga a financiarse mediante su vinculación laboral en otros ámbitos no relacionados con el movimiento social. Este hecho también limita en algunas ocasiones los alcances de los procesos o las posibilidades de liderazgos con amplias capacidades políticas, administrativas y de gestión. Así lo expresa una de sus integrantes:

"El movimiento tiene cosas muy buenas, pero pues también quienes participamos es porque queremos, no hay un reconocimiento, nuestras coordinadoras, por ejemplo, durante muchos años tenían era un apoyo, no era un salario completo para ser coordinadora, entonces eso también hace que sea cuando tú tienes tiempo de dedicarle al movimiento, pues se lo dedicas, pero si tú no tienes tiempo, no se lo puedes dedicar, entonces eso es complejo. Por ejemplo hoy en día a mí, mi trabajo no me permite participar, pero a uno le duele, entonces trata uno de mirar cómo puede participar, entonces eso a veces disminuye que todas las mujeres realmente estén en todos los momentos en que deben estar, que participemos en todas las acciones, entonces es un poco complicado" (Entrevista 8)

\subsubsection{Los recursos de la Ruta}

Señalábamos previamente que la forma de organización interna de la Ruta nos recuerda el clásico funcionamiento de una organización no gubernamental (ONG). Mediante la construcción de agendas, líneas estratégicas, planes operativos anuales y planes trienales, la Ruta se traza objetivos tácticos y estratégicos para sacar 
adelante sus reivindicaciones. Este hecho se relaciona, además del interés de ser sistemáticas y organizadas, con la necesidad de buscar apoyos económicos externos para poder avanzar hacia sus metas. La necesidad de buscar cooperación hace que sus objetivos sean traducidos a proyectos formales, con tiempos específicos, lo suficientemente atractivos para posibles agencias interesadas en apoyar este tipo de procesos. Sobre este punto, en relación con la toma de decisiones no comenta una de sus miembros:

"Son democráticas, en general son democráticas, yo creo que una que otra decisión a veces es compleja, por qué? porque depende de los financiadores, entonces ahí también entran las agencias de cooperación internacional, que es de donde vienen los fondos de la Ruta, y es que se necesitan muchos fondos, yo no sé ahorita con cuanto están funcionando, pero la operación de la Ruta cuesta, más o menos para que funcione se necesitan entre unos 700 a mil millones, para que cada año pueda funcionar la Ruta. Ahorita creo que está funcionando con menos recursos, porque no tienen toda la plata, pero para que un movimiento como la Ruta funcione también se necesita plata, y se necesita de las agencias de cooperación internacional, y eso no se ha estudiado teóricamente, yo no conozco, pero yo sé que también acá hay unas agendas, unas agendas de la cooperación internacional y unas agendas que tiene también la Ruta, lo que pasa es que eso no se devela y todavía no se ha estudiado, no hemos estudiado el efecto de las agencias de cooperación internacional, tanto en el movimiento de víctimas en general como en la Ruta, porque efectivamente si uno mira a los financiadores casi siempre son los mismos" (Entrevista 10)

Encontramos en este punto una doble situación. De un lado, la importancia de construir estos proyectos y planes sin torpedear las agendas y proyectos regionales independientes de las organizaciones que sirven de punto focal, y de otro lado, adaptar sus planteamientos a marcos lógicos coherentes para los posibles financiadores. Estamos acá ante una lucha, casi siempre velada de imposición de 
agendas, entre las organizaciones que hacen parte de la estructura que normalmente se conjura con la habilidad de quienes presentan y conciertan los proyectos.

En relación con el cruce de agendas con las organizaciones locales y regionales, sabemos que ha logrado sortearse separando conscientemente las actividades que se derivan de la Ruta y las acciones que se desarrollan en función de los proyectos que ejecutan las organizaciones de manera independiente. Esto permite llevar cierto orden sin que se trastoquen unos y otros objetivos. También ha sido posible por la comprensión interna que existe de las diferencias, de enfoque y temáticas de acción, entre las organizaciones que componen la Ruta y la acción de la Ruta en sí misma. En otras palabras, sin que haya contradicción en los elementos fundamentales, en muchas ocasiones las organizaciones ejecutan propuestas feministas que no se encuentran en la agenda política de la Ruta y hay claridad en que lo hacen en función de su misión organizativa y con recursos propios o de financiadores externos que apoyan a la organización en específico y no a la Ruta.

Es corriente también que las organizaciones que sirven como puntos focales coadyuven a la Ruta de múltiples maneras. Es el caso de la Casa de la Mujer en Bogotá, quién no solamente facilita dentro de sus instalaciones la presencia de la sede de las oficinas de la Ruta del nivel nacional, sino que con frecuencia entra a apoyar como ONG acciones de la Ruta actuando en alianza y coordinación.

En cuanto a las tensiones que se puedan presentar con los financiadores de la Ruta, es menos lo que sabemos, sin embargo, dada la estabilidad de su apoyo, particularmente con ciertas agencias de cooperación internacional, podríamos inferir que ya se ha establecido un mecanismo de mediación que facilita la prolongación de la ayuda económica en el tiempo. Sin embargo, sí parece cierto que la forma de acceso a la financiación, enmarcada en unos criterios establecidos por las agencias de cooperación internacional, bajo la cual opera la inmensa mayoría de organizaciones no gubernamentales de derechos humanos en el país, genera unas dinámicas internas de trabajo que las acerca a los ritmos y rutinas de cualquier ONG. Queda en cualquier caso este campo abierto para futuras 
indagaciones en procura del reconocimiento de los grados de influencia que tienen las agencias de cooperación y en general los financiadores en las agendas políticas de la Ruta.

Es importante en todo caso mencionar que la Ruta ha logrado mantener una cooperación estable en el tiempo con varias agencias internacionales. Entre ellas están: el Programa Suizo para la Promoción de la Paz en Colombia SUIPPCOL, Agència Catalana de Cooperació, Intermón Oxfam, Agencia Española de Cooperación Internacional para el Desarrollo AECID y ONU Mujeres, entre otras.

\subsubsection{Redes y Alianzas}

Más allá de las organizaciones que han ido adhiriendo a la propuesta de la Ruta y que actúan como un solo movimiento y bajo unos mismos postulados y principios ideológicos y políticos, como es usual en la mayoría de las organizaciones que trabajan en la defensa de los derechos humanos en Colombia, este movimiento social suele crear alianzas y realizar ejercicios de cooperación y coordinación con otras organizaciones.

Tanto para los ejercicios de incidencia política como para acciones de movilización callejera, la Ruta desde muy temprano encontró en la cooperación una estrategia positiva para demostrar sororidad, elevar la eficiencia en los resultados de la acción colectiva y generar espacios de protección y autoprotección en territorios donde la guerra se exacerba por momentos. Estas redes y alianzas pueden ser regionales, nacionales e internacionales y pueden ser permanentes o activarse para situaciones específicas u objetivos concretos.

Es usual que la Ruta convoque o sea convocada a participar en asocio con otros sectores en procesos regionales y nacionales. Ejemplos de ello pueden hallarse permanentemente en las regionales en donde las organizaciones de mujeres de diferentes redes nacionales y locales, se organizan para hacer plantones, encuentros, capacitaciones y acciones de incidencia política ante los alcaldes y gobernadores. 
Estas redes y alianzas se ven en acción en múltiples procesos. Es el caso de las acciones de incidencia para la promulgación de la Ley 1257 de 2008, por la cual se dictan normas de sensibilización, prevención y sanción de formas de violencia y discriminación contra las mujeres, proceso en el cual trabajaron diversas organizaciones de mujeres que entraron a cooperar solidariamente por una causa compartida.

A nivel nacional esta práctica también es frecuente, sin embargo hay algunas alianzas que han calado de manera más honda por los actores y la situación histórica que les rodea. Nos referimos a la alianza creada en el año 2000 con la Organización Femenina Popular OFP. Esta tal vez fue una de las primeras alianzas que tejió la Ruta y significó un ejemplo de sororidad y agenciamiento conjunto para las integrantes de la Ruta. Así lo recuerdan desde la Ruta

“Barrancabermeja vivió las horas más oscuras de su historia reciente a finales de los noventa. La muerte no daba tregua, ni las desapariciones. Las amenazas se cernían sobre todas las organizaciones sociales y a ellas no escaparon las organizaciones de mujeres. El miedo se apoderó del puerto sobre el Magdalena donde el olor de la violencia brotaba del agua y del asfalto. Pocas veces se atrevían a oponerse a la guerra y en medio de esa estela de silencio que deja a su paso el terror, se escuchaba, sonora y audible, la voz de la Organización Femenina Popular, una organización con profundas raíces en los barrios de Barranca. Las mujeres de la OFP y las de la Ruta ya se habían encontrado en muchos escenarios y, sorprendidas, habían descubierto que sus consignas eran prácticamente las mismas (...) Las organizaciones empezaron un proceso de mutuo acercamiento, convencidas de que las identidades entre ambos movimientos representaría una alianza importante para el país (...) Allí se expresaron los puntos de identidad: ambas organizaciones están contra la guerra, contra todos los actores armados y por la defensa de las mujeres como actoras de paz. Pero también se hicieron explícitas las diferencias en cuanto a caracterización de 
los actores del conflicto, la defensa de la neutralidad y el feminismo. Este fue el comienzo de una relación duradera y fructífera" (Ruta Pacífica de las Mujeres, 2003, p. 39).

Esta alianza le valió a la Ruta la posibilidad no solo de acompañar a las mujeres de la OFP que en aquel momento vivían una situación de persecución muy violenta, sino que además le permitió fortalecer su propia identidad en la comparación, negociación e identificación de límites en su relación, que sirvieron de base para las acciones de colaboración y trabajo conjunto. Además, les mostró el camino para la realización de alianzas internacionales y el trabajo en red.

Como señalamos anteriormente, dentro de los acuerdos de trabajo conjunto, la Organización Femenina Popular invitó a la Ruta a unirse a Mujeres de Negro. Esta nueva relación marcaría un punto importante en la construcción identitaria de la Ruta, en el que se dio un salto cualitativo importante para la comprensión de las violencias contra la mujer, ya no solo en Colombia sino en el mundo. Con esta alianza, las mujeres de la Ruta comenzaron a conocer nuevas realidades que les permitieron mejorar e internacionalizar sus argumentos. A su vez, les abrió el camino para presentar sus planteamientos a nivel mundial y expresar la indignación que les causaba lo que las mujeres colombianas víctimas del conflicto tenían que enfrentar.

Adicional a esto, la Ruta ha consolidado estrechos lazos con organizaciones en Europa y en especial en Cataluña mediante los cuales ha sido posible visibilizar la tragedia colombiana y ganar apoyos para su causa. Entre estos espacios está: la Taula Catalana por la Paz y los Derechos Humanos en Colombia, la realización en Colombia del XV Encuentro Internacional de Mujeres de Negro en 2009 y la conformación de la Plataforma Catalana de Apoyo a la Ruta. Estos escenarios han ampliado su conocimiento de la situación en otros contextos, les ha permitido mostrar el trabajo de la Ruta internacionalmente y les ha facilitado la ampliación de su red de apoyos. 
En suma, la Ruta aprende a trabajar en red y crea coaliciones que le favorecen nacional e internacionalmente, al tiempo que va fortaleciendo su estrategia interna de consolidación como movimiento y cooperación con otras organizaciones.

\subsubsection{Los "Performance" de la Ruta}

En 18 años de existencia la Ruta ha construido alrededor de sí un número importante de mecanismos para comunicar sus objetivos y plantear sus reproches a la guerra. Algunos han ido surgiendo en la contienda con el Estado y los actores armados y otros han sido tomados del stock de repertorios de los movimientos sociales y organizaciones de derechos humanos colombianos.

Uno de los performance más emblemáticos y que le da el nombre a este movimiento: "Ruta", es precisamente las movilizaciones masivas que desde el comienzo comenzaron a realizar las mujeres a distintos puntos de la geografía colombiana. Si bien la idea de caminar gritando consignas y portando carteles por lugares populosos de las ciudades es algo habitual en los movimientos urbanos y la toma de carreteras y bloqueo de vías es también muy común en los sectores rurales, la Ruta hace una diestra combinación de estos dos mecanismos y decide realizar caravanas que pueden recorrer cientos de kilómetros desde distintos lugares del país para aglutinarse finalmente en un lugar específico donde desarrollan toda una programación preparada para el momento.

Tal como explicábamos en capítulos anteriores, la Ruta organiza cada tanto este tipo de movilizaciones mediante las cuales espera expresar su sororidad con las mujeres de las regiones que han padecido el conflicto. Estas movilizaciones combinan el discurso político de no a la guerra con los tres pilares fundamentales del movimiento, pacifismo, antimilitarismo y feminismo y su repudio a las formas de violencia que padecen las mujeres en contextos de conflicto armado. Mediante una suerte de artilugios asociados al cuerpo, la música, el teatro, la danza y la poesía, estas movilizaciones tienen como característica principal una fuerte carga simbólica con la que esperan transmitir sus ideas. 
Estas movilizaciones se hacen a nivel nacional, vinculando mujeres procedentes de todas las regionales, cuando se considera que la magnitud del problema requiere una presencia masiva o pueden ser más locales, a las que asisten organizaciones de una o dos regionales, cuando se trata de un contexto más departamental y local y vasta con la solidaridad de las mujeres de la región. Estas caravanas suelen tener una importante cobertura mediática, particularmente por el volumen de mujeres que logran convocar, que pueden ser dos mil o tres mil mujeres, o muchas más, como por ejemplo la movilización que se realizó en el año 2002 en la ciudad de Bogotá que logró convocar a cerca de 20 mil personas. Este performance tiene algunos elementos distintivos que vale la pena mencionar.

En primer lugar existe toda una suerte de preparación de las mujeres que asisten. Mediante talleres, charlas y conversatorios las integrantes que van a participar estudian el contexto, la dinámica del conflicto, la forma en que la guerra ha afectado a las mujeres de ese territorio y las condiciones generales del lugar que visitarán. Al tiempo, se prepara la agenda que se va a desarrollar paso a paso sin dejar nada al azar, de tal suerte que las mujeres saben lo que irá sucediendo a cada paso del camino y el programa que se va a desarrollar una vez estén en el punto elegido. Usualmente esto se hace en colaboración con las organizaciones locales anfitrionas con las que previamente se ha hecho un trabajo de concertación política. Así nos lo explica Angélica Badillo, Integrante de la Ruta:

"Cada movilización colectiva tiene un proceso, y esos procesos demandan mucho tiempo, demandan organización y demandan también ideologizar a las mujeres. Hay que hacer un taller de cómo se hace una movilización, cómo responder ante los actores armados, preparar el cuerpo porque son muchas horas de camino, hay que conseguir recursos, planear los talleres, quiénes van a ir, que organizaciones, es todo un proceso" (Entrevista 10). 
Este tiempo de preparación de las mujeres sirve también de formación política y les ayuda al proceso de motivación, sensibilización y generación de sentimientos de pertenencia a la Ruta.

"que las mujeres vayan informadas, que no se van de paseo sino que van a una movilización, pero para muchas también es irse de paseo porque primero van con las amigas, así a uno le toquen 10 horas pues se va con las amigas, porque la gran fuerza del movimiento es que uno logra que sus amigas del movimiento son sus amigas de la vida" (Entrevista 10).

Las mujeres encuentran en la expectativa de cada viaje la posibilidad de estrechar sus lazos afectivos y políticos y de sentirse parte de algo importante y justo: la búsqueda de la paz.

"Se prepara todo, yo tengo algunos guiones simbólicos, tenemos una compañera que es historiadora y es como la bruja, entonces ella empieza que las goticas de no sé qué, que las goticas para la tranquilidad, y es agua de rosas, pero no importa, para nosotras son las goticas de la tranquilidad, y es que todo se prepara, qué música se va a poner en los buses, qué películas colocamos, porque no se va a poner cualquier película, tiene que ser una películas sobre el pacifismo o cosas así. Ahí hay unos productos de ideología y claro, cómo no te vas a enamorar de un movimiento como la Ruta si estás yendo allá y te sientes rico, las mujeres lo dicen: es que yo me sentí enamorada y cuando uno se siente enamorado pues tiene unos inputs y tiene unas ganas de hacer y por eso les gusta ir al plantón, les gusta ir a la movilización y a todas las actividades que programe la Ruta.” (Entrevista $10)$.

De esta forma las mujeres encuentran motivaciones suficientes para emprender caminos largos que seguramente las llevarán por realidades complejas. En la preparación, las lideresas imprimen un esfuerzo importante para desarrollar este tipo de movilización en un contexto de guerra en el que los actores armados estarán 
también en permanente observación. Y es que, cabe decirlo, si bien la algarabía del encuentro y el compartir ilusionan profundamente a las mujeres, de otro lado está la realidad de la guerra y lo que esta conlleva en estas movilizaciones.

"Luego vino la del Chocó y nosotras la recordamos por todas las dificultades que hubo por el camino, y saber que las mujeres todo eso lo están enfrentando, primero porque las carreteras no servían, nos tocaba bajarnos de los buses, echarle piedra, empujar y eso es lo cotidiano de las mujeres, de tener que cruzar por esas carreteras. En el camino no había comida, había actores armados por todos lados, había del uno del otro, es la cotidianidad de las mujeres del Chocó, eso fue en el 2005, y luego al llegar nos recibieron las mujeres como con esa alegría, pero la gente estaba asustada, se asomaba a las puertas y yo no sé, pero yo sentía como el miedo en la gente. Llegamos a Quibdó, y se hizo toda una simbología en el agua pero yo vi mucho miedo en la gente, muchísimo miedo" (Entrevista 2).

En segundo lugar, una vez se ha realizado el desplazamiento y las mujeres llegan a su lugar de destino, se ejecuta toda una estrategia de intervención sobre el territorio visitado. Este factor tal vez es uno de los más llamativos de las acciones de la Ruta y tiene que ver con el carácter ritual que tienen la mayoría de sus performance. El cuerpo se vuelve referente central y las mujeres comienzan a desplegar desde sí elementos simbólicos con los mensajes que se han construido en el tiempo de preparación.

"El ritual se propone como una acción creadora que explicite la fuerza renovadora de lo femenino en nosotras como alternativa que busca caminos de acercamiento, de relación amorosa en el ejercicio de la política entre las mujeres y de nosotras con el resto de actores que se mueven en el escenario de la guerra (...) Nos acompañan todos los elementos: Agua, tierra, fuego, madera y viento. Las diosas míticas latinoamericanas, las abuelas de todos los tiempos; los silencios de todas las enmudecidas; el grito de las amazonas y heroínas; las anónimas y las locas que empezaron y 
continúan el barullo; todas se disponen a acompañarnos. (...) Con los símbolos, llegamos las mujeres de la Ruta a los lugares de este país herido, para recuperar los territorios robados por el conflicto armado, para la toma simbólica de nuestros proyectos de vida construidos por años (...) Los símbolos son una propuesta para construir otras maneras de interrelación, para quebrar esquemas y lógicas preestablecidas” (Sánchez, 2006, p. 77).

Los usos simbólicos se vuelven centro de la acción colectiva. Esto les permite explorar en la creatividad de las participantes posibilidades diversas de comunicación y de comprensión del problema. Además, facilita que la intuición, tan preciada por sus integrantes, aflore y conduzca la acción política. A su vez, esta simbología, pacifista por naturaleza, cubre con un manto de protección a las asistentes de posibles retaliaciones de los actores armados al cambiarles el tono de la contienda. Es necesario señalar que la Ruta no entra jamás en confrontación directa con los actores armados, ni establece discusiones o acciones de fuerza. Por el contrario, intenta hacer uso de los mecanismos normativos internacionales de tratamiento de la sociedad civil en conflictos armados internos y rehúsa la intervención de cualquiera de los grupos, legales e ilegales, para la realización de sus actividades.

Por último, estas movilizaciones que suelen durar varios días y combinan rituales, conversatorios, talleres, reuniones, y eventos masivos, concluyen siempre con la elaboración y publicación de una Declaración Política sobre la visita. Como lo hemos venido explicando en la narrativa cronológica, en cada viaje se identifica el tema, se construyen lemas, se construye una simbología y se realizan encuentros de análisis y reflexión con las comunidades que se visitan. De estos elementos se construye un documento que usualmente resume los agravios, plantea las denuncias que se consideren pertinentes y cierra con unas solicitudes o exigencias al Estado colombiano y a los actores armados de todos los bandos. Estos planteamientos en ocasiones también trascienden estos actores y se elevan a otros como empresas o multinacionales, o aún, a otros países que se consideren vinculados a los agravios. 
De esta forma, la movilización genera mensajes en tres niveles. De un lado, el que se cuece internamente y que les permite a las integrantes de la Ruta tener la capacidad de desplazarse durante días a lugares lejanos y desconocidos; de otro lado, el mensaje que llevan a las comunidades que visitan, incluyendo los planteamientos políticos concretos de cómo interpretan los hechos y la invitación a ver el mundo de esta manera; y por último, el mensaje a los oponentes, al Estado y a todos los actores armados, legales e ilegales, mediante el cual expresan sus repudios y plantean sus exigencias.

Otro performance importante para la Ruta, que aunque es menos visible mediáticamente se desarrolla de forma permanente, son los plantones de mujeres de negro en las diferentes regionales donde existen puntos focales. Como lo recordábamos previamente, durante los primeros años de existencia de la Ruta este movimiento generó una alianza con esta red internacional adoptando una de sus prácticas habituales por lo que en adelante, todas las regionales el último martes de cada mes se reúnen en lugares específicos de la ciudad para hacer un plantón. También se realizan para cuestiones coyunturales: la muerte o desaparición de alguien o una acción bélica en algún municipio. Sobre este performance nos explican:

“Por qué se dicen plantones de mujeres de Negro? porque es vivir el luto en el cuerpo, el luto por todas las víctimas del conflicto armado que vive el país y es también estar recordando con el cuerpo que estamos viviendo una situación de conflicto. Y es que es muy particular ver a las mujeres que interrumpen la cotidianidad en lugares emblemáticos y se paran allí vestidas de negro con carteles y en silencio a decir no a la guerra, o a develar o interrumpir ese discurso hegemónico que dice que en Colombia no pasa nada. (...) Y en silencio, porque pues nos duele y porque decir el dolor que se siente a través de la lengua también es difícil” (Entrevista 10).

Además de estas acciones colectivas callejeras, la Ruta también ha desarrollado una suerte de repertorio menos llamativo pero también efectivo. Mediante elaboración 
de documentos, investigaciones, informes, publicaciones y libros la Ruta está en permanente discusión con el Estado y los Actores Armados. Mediante estas acciones se pretende comunicar a la ciudadanía, a los medios de comunicación, al Estado, a los organismos de control y a los entes internacionales los sucesos de la guerra en Colombia y la manera en que esta afecta a las mujeres en Colombia. También se elaboran documentos que contienen los planteamientos políticos de la Ruta y que sirven para la visibilización del movimiento, para buscar solidaridad.

Las temáticas de los materiales escritos varían y no existe una periodicidad específica para su publicación. Hay boletines que se publican anualmente pero también informes que tienen como vocación servir de instrumentos de incidencia, de allí que solo salgan por una sola vez. También se realizan investigaciones sobre temas que afectan a las mujeres en la guerra y material didáctico y político. Con frecuencia las regionales también publican sus propios documentos dando cuenta de la situación de un departamento o ciudad, de allí que existe un volumen muy alto de material con este propósito.

Podríamos decir que constantemente la Ruta está transmitiendo sus posiciones por escrito y que se publican para ser leídos por múltiples públicos. Estas acciones se combinan con una fuerte tarea de comunicaciones en redes sociales mediante la página web que es alimentada permanentemente con estos materiales y varios blogs y páginas en facebook, particularmente de las regionales, en las que se "cuelga" información de interés para sus seguidores y que sirve de plataforma de socialización y divulgación de la información.

A esta práctica se suma la realización de encuentros nacionales e internacionales de mujeres, mingas, y presentación de galerías de la memoria, que tienen como objeto comunicar, sensibilizar y buscar apoyos para la consecución de sus objetivos. Es usual que estas actividades se realicen en coordinación con otras redes de mujeres y organizaciones de la sociedad civil y busquen respaldos en la sociedad. 
Un elemento más que nutre de forma relevante los repertorios de acción colectiva de la Ruta es la Incidencia Política que realizan sus integrantes a diferentes niveles. Si bien en un comienzo, parte importante de las energías eran usadas para la movilización y los plantones, con el tiempo las lideresas han encontrado en los ejercicios de lobby y cabildeo un mecanismo seguro de incidencia para la trasformación de las realidades que les afectan. Es frecuente entonces encontrar a miembros de la Ruta junto a otras organizaciones en reuniones con autoridades municipales, departamentales y nacionales, haciendo demandas expresas y buscando la construcción de políticas públicas que benefician a las mujeres.

Este ejercicio ha permitido conquistas importantes a la Ruta y al feminismo en general ya que mediante este se han erigido normas y procedimientos importantes como la ley 1257 de 2008 o las Secretarías de la Mujer en varias ciudades y departamentos del país. Esta práctica también facilitó la promulgación del Auto 092 de 2008 al que nos referiremos detalladamente más adelante.

Pero el cabildeo no solo se hace con las organizaciones del Estado, las mujeres han logrado a través de sus alianzas tejer relaciones con organismos internacionales que les ha permitido presentar informes situacionales y de contexto, no solo para buscar la solidaridad y el financiamiento, sino para ejercer presión internacional sobre el Estado colombiano y que este actúe en uno u otro sentido. Así, tampoco es extraño verlas presentando informes a los relatores de Naciones Unidas o a otras instancias de poder internacional para plantear sus preocupaciones y hacer recomendaciones.

Por último, la Ruta ha dedicado parte importante de sus esfuerzos a la formación política de sus integrantes y a realizar acompañamiento a mujeres afectadas por la violencia. Mediante talleres, Foros, paneles y escuelas itinerantes, las mujeres de la Ruta reproducen sus principios básicos y sensibilizan a sus integrantes sobre los objetivos fundamentales del movimiento político. Para ellas este punto es trascendental en la medida en la que buscan no solo el reconocimiento del efecto diferenciado de la violencia contra las mujeres en el conflicto armado y la salida negociada, sino también modificar las estructuras socio-sexo patriarcales que 
dominan actualmente los territorios nacionales. De allí que estos espacios de formación intentan cambiar en las mujeres visiones y prácticas patriarcales y machistas, al tiempo que invitan a la transformación cultural de la sociedad. El empoderamiento de nuevos liderazgos y el aumento de capacidades políticas y críticas de las mujeres son ejes fundamentales de estos procesos formativos.

Al tiempo y casi siempre en coordinación con otras organizaciones, las integrantes de la Ruta han adelantado procesos de acompañamiento a mujeres víctimas de la violencia, ya que aunque este movimiento no es de víctimas, también queda claro que muchas de sus integrantes lo son. De allí que en algunas regionales se han desarrollado procesos para la contención psicosocial de las víctimas, el restablecimiento de derechos, la recuperación de la memoria colectiva y la exigibilidad de la verdad, justicia y reparación integral.

En general podríamos decir que los performance que usa la Ruta conforman un repertorio más convencional y pacífico que transgresivo, lo cual parece ir en coherencia con los planteamientos axiológicos de este movimiento. Sin embargo, llega a ser disruptivo en la medida en que reta a sus oponentes mediante la presencia masiva de mujeres en territorios que han sido destinados por los actores armados para la confrontación bélica. Esta actitud "provocadora" es neutralizada por la carga simbólica de la que se suelen servir las mujeres, que deja a los guerreros con pocos argumentos para entrar en una confrontación directa. De allí que no se conozcan muchas acciones de retaliación contra las mujeres ni se presentan enfrentamientos físicos o armados cuando se encuentran en un mismo espacio. Pareciera que los actores armados ante esta forma de la presencia de las mujeres prefieren evitar la contienda.

Esto por supuesto no implica que no existan niveles importantes de represión contra las integrantes. Con frecuencia las lideresas del movimiento han sido amenazadas de muerte, han debido desplazarse o han sufrido alguna victimización a propósito de su participación en estos escenarios políticos. Sin embargo la postura de la Ruta ha sido firme al señalar que, aunque comprenden el miedo y lo que esto puede 
causar en sus militantes, este debe ser contenido y manejado de tal suerte que no implique la inmovilización de las integrantes y del movimiento en general. De allí que una de sus integrantes nos diga:

"El silencio es el camino de la impunidad, a medida que las víctimas vayamos hablando pues la impunidad se va combatiendo. Hemos aprendido que si hablamos, mal, y si no hablamos, también, entonces precisamente uno de los refranes o una de las frases bonitas de la Ruta que aprendimos es que es mejor ser con miedo que dejar de ser por miedo. Eso nos conlleva realmente a hablar, a denunciar. Sin embargo nos preguntamos, las víctimas queremos hablar, realmente ¿quién nos quiere escuchar?” (Entrevista 9).

A su vez, los repertorios también han ido teniendo algunas variaciones. Mientras los primeros años las movilizaciones a ciertas regiones fue fundamental para visibilizar ante los ojos de toda la sociedad colombiana lo que pasaba en lugares específicos, esto con el tiempo empezó a dar paso a acciones de incidencia más convencionales.

De esta forma, si bien durante los años de presidencia de Álvaro Uribe Vélez los plantones de negro fueron fundamentales para la Ruta en la medida en que desafiaban el desconocimiento que hacía este mandatario de la existencia de un conflicto armado y ponía en evidencia en escenarios públicos la existencia de una guerra, los últimos años, si bien las otras formas del repertorio se mantienen, la Ruta ha optado por jalonar una iniciativa sobre comisiones de la verdad mediante una investigación profunda de la violencia contra las mujeres. Esta nueva perspectiva coincide con la tendencia actual de contribuir al proceso de paz con las guerrillas y un eventual acuerdo final. En síntesis, los repertorios de la Ruta han respondido a la forma en que las mujeres han leído el contexto y han identificado oportunidades y amenazas, buscando las mejores formas de tener ventajas para continuar la contienda.

\subsubsection{Una mirada Cuantitativa}


Un repaso por la Base de Datos de Luchas Sociales del Centro de Investigación y Educación Popular CINEP nos permite realizar una mirada panorámica sobre el papel que ha jugado la Ruta en el marco de las movilizaciones de las mujeres en el país y de la introducción de las problemáticas de las mujeres víctimas en esas movilizaciones.

La búsqueda efectuada en la base de datos da cuenta de un total de 640 movilizaciones de mujeres registradas entre 1975 y 2013. Allí podemos apreciar que entre 1975 y 1996, desde el comienzo del registro de las acciones colectivas por parte de CINEP hasta el año de la conformación de la Ruta, las movilizaciones de las mujeres fueron esporádicas y se produjeron principalmente con motivo de reclamaciones asociadas con la prestación de los servicios públicos domiciliarios, es decir, que en ese periodo correspondían fundamentalmente al rol de amas de casa asignado a las mujeres en el sistema patriarcal. No obstante, aunque del total de 94 movilizaciones entre 1975 y 199668 obedecieron a este tipo de asuntos, ya se cuentan 22 movilizaciones que estuvieron asociadas a reivindicaciones de género o de rechazo a la violencia contra las mujeres.

Ilustración 4. Movilizaciones Ruta Pacífica entre 1996 y 2011

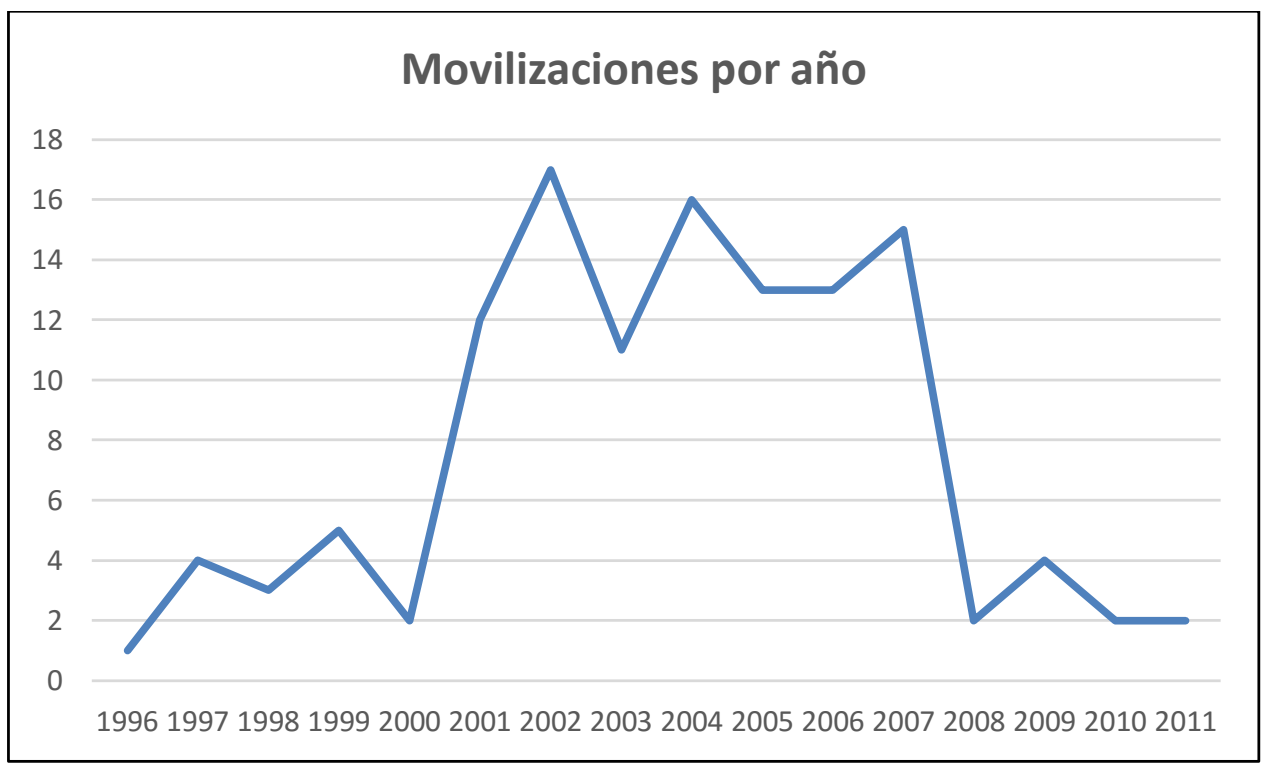

Fuente: Base de Datos de Luchas Sociales. Sistema de Información General del CINEP. Consultada el 12 de Febrero de 2014. 
A partir de 1996 podemos encontrar un gran incremento de las movilizaciones de las mujeres, así como una gran diversificación de las temáticas asociadas, aunque con una agenda tendiente a los asuntos políticos y de género. En efecto, en cuanto a las movilizaciones relacionadas con asuntos de género o violencia, las mujeres realizaron 128 movilizaciones entre 1996 y 2013, de las cuales podemos observar una importante concentración entre los años 2002 y 2008. Finalmente, podemos verificar claramente la importancia del papel jugado por la Ruta en este tipo de movilizaciones, pues, de 128 realizadas entre 1996 y 2013, este movimiento aparece como convocante en 104. Más aún, entre las 87 realizadas entre 2002 y 2008, periodo que concentra la lucha por la reivindicación de los efectos diferenciados del conflicto armado sobre las vidas y los cuerpos de las mujeres víctimas de desplazamiento forzado, en 78 es convocante la Ruta.

Tabla 1. Análisis de la incidencia de la Ruta en el número y el tipo de movilizaciones de mujeres entre 1975 y 2013

\begin{tabular}{|l|l|}
\hline \begin{tabular}{l} 
Base de Datos de Luchas Sociales. Sistema de Información General del \\
CINEP \\
\hline Filtro: Mujeres
\end{tabular} \\
\hline Rango: 1975 - 2013 & 640 \\
\hline Total Acciones Colectivas de Mujeres Registradas 1975-2013 & 94 \\
\hline Total Acciones Colectivas de Mujeres entre 1975-1996 & $\mathbf{2 2}$ \\
\hline Acciones Colectivas asociadas con Género y Violencia 1975-1996 & 3 \\
\hline Acciones Colectivas asociadas con Conflictos Laborales 1975-1996 & 1 \\
\hline Acciones Colectivas asociadas con Reclamo de tierras 1975-1996 & 68 \\
\hline Acciones Colectivas Asociadas con Servicios públicos 1975-1996 & $\mathbf{1 2 8}$ \\
\hline Total Acciones Colectivas sobre Género y Violencia 1996-2013 & $\mathbf{8 7}$ \\
\hline $\begin{array}{l}\text { Acciones Colectivas sobre Género y Violencia concentradas entre } \\
\mathbf{2 0 0 2} 2008\end{array}$ & 104 \\
\hline Acciones Colectivas convocadas por Ruta 1996-2013 & 78 \\
\hline Acciones Colectivas convocadas por Ruta 2002-2008 & \\
\hline
\end{tabular}

Fuente: Base de Datos de Luchas Sociales. Sistema de Información General del CINEP. Consultada el 12 de Febrero de 2014. 


\subsection{Capítulo 4: Los efectos de la movilización de la Ruta Pacífica de las Mujeres}

El rastreo por los eventos más importantes que rodearon el surgimiento y consolidación de la Ruta, así como la identificación de actores e instituciones que jugaron un papel predominante en sus luchas, permitieron entrar al corazón de este movimiento y conocer desde sus entrañas, los objetivos, las ideologías, los mecanismos y las acciones del movimiento. Hasta aquí hemos podido ampliar un poco más el conocimiento que teníamos sobre la Ruta mediante un análisis descriptivo de sus diversos componentes sin olvidar que se trata de elementos relacionales y por tanto dinámicos de la política. Sin embargo, por el momento no hemos podido decir nada concluyente acerca de los niveles de impacto, sus resultados y las consecuencias de sus luchas.

Como señalábamos en la introducción, adentrarnos en los marcos cognitivos, las estructuras de movilización y los repertorios de acción de los movimientos sociales nos permite conocer por qué la gente se moviliza y cómo lo hacen, pero desde ese ángulo, no mucho sobre lo que producen. Una forma potencial de hacerlo es pensarnos modelos que nos permitan, desde el reconocimiento del impacto específico, la identificación de factores intervinientes a modo de cadenas causales de eventos en los que participan nuestros actores de estudio, de tal suerte que podamos identificar oportunidades políticas y mecanismos intervinientes que nos ofrezcan una explicación plausible. En otras palabras, se trata de narrar secuencialmente la principal cadena de eventos que se desprenden del análisis histórico realizado durante la investigación, mediante el cual podamos identificar, en el amplio y complejo mundo de los hechos y las relaciones, elementos causales que atan la acción de los movimientos y la producción del resultado estudiado (Weber, 2001).

Sin embargo, para lograr esto es necesario hacer una delimitación sobre el principio y fin espacial y temporal de nuestro análisis, más, cuando se trata de movimientos 
que se extienden en el tiempo y sobre los cuales pesan múltiples escenarios de contienda. Aislar los elementos a estudiar, los actores y los eventos, nos facilita encontrar las relaciones cercanas que pueden estar eventualmente comprometidas con la producción del resultado.

Esta acción, según nuestro marco teórico, se denomina "Delimitación del Episodio" (McAdam et al., 2005), y nos permite cercar el número de eventos por analizar y con ellos las oportunidades y amenazas políticas así como los mecanismos que intervinieron en la producción del resultado que aquí hemos llamado hito. Se trata, como decíamos previamente, de una tarea necesaria si no queremos terminar vinculando largas cadenas causales interconectadas entre sí que, de ser analizadas al infinitum, nos llevarían por caminos improductivos.

Por eso para el análisis de este movimiento social, la promulgación del Auto 92 de 2008 como límite hacia adelante y la activación en el 2005 de procesos de formación a mujeres víctimas de desplazamiento forzado hacia atrás, son nuestros límites temporales. Esta delimitación, si bien se desprende de una decisión de quién investiga, no es tampoco arbitraria en sí misma. En realidad es el resultado de la indagación al mismo movimiento social sobre un impacto político externo relevante y notorio en relación a derechos legales (Giugni \& Bosi, 2012) y por tanto considerado "hito", y la secuencias de eventos reconocidos por diversas fuentes como próximos y relacionados, desde los cuales reconocen e interpretan este resultado. Esta demarcación temporal nos ayuda también a ampliar el foco y diversificar el número y características de los demás actores comprometidos.

Así las cosas, en este capítulo haremos la presentación de nuestro episodio, haciendo hincapié en la cadena causal de eventos tal y como fueron acopiados durante el trabajo de campo.

3.4.1. Y comienza a "cocinarse" el hito 
Como se ha narrado hasta ahora, las mujeres que conforman la Ruta se movilizaron con el propósito de promover una solución política que ponga fin al conflicto armado en Colombia y a sus nefastas consecuencias, fundamentándose en una comprensión política del efecto diferenciado y desproporcionado que tiene el conflicto armado en la vida y en el cuerpo de las mujeres. Durante cerca de 12 años, ellas habían abierto caminos, elaborando planteamientos y realizando acciones para promover el diálogo y las soluciones pacíficas a los conflictos sociales, pero al mismo tiempo, habían documentado y denunciado las consecuencias de la guerra en las mujeres y la necesidad de garantizarles unas medidas de protección, atención y de reparación, adecuadas a los daños sufridos y a su condición de mujeres. Cada etapa de su camino así lo demostraba.

Numerosas organizaciones de mujeres también enfocaban sus esfuerzos en este sentido. Sisma Mujer, la Mesa de Trabajo Mujer y Conflicto Armado, Humanas Colombia, Iniciativas de Mujeres por la Paz, la Red Nacional de Mujeres y muchas más, venían sumando esfuerzos a nivel local, nacional e internacional para mostrar las secuelas del conflicto armado en las mujeres y la necesidad de avanzar en la realización de sus derechos a la verdad, la justicia y la reparación integral. Todas ellas, en algunas ocasiones desde lugares distintos y en otras de manera coordinada, desarrollaban procesos de visibilización, cabildeo y denuncia que fueron habilitando las condiciones para que finalmente el país tuviera que reconocer que las mujeres eran afectadas de manera diferencial y que su condición de mujer las ponía en unos riesgos particulares en los contextos de guerra.

Ocurrieron también algunos hechos que facilitaron que esto se produjera. En el año 2005 la Corporación Casa de la Mujer, una de las muchas organizaciones que componen la Ruta, pero en esta ocasión actuando como organización independiente, inició un proceso de acompañamiento y formación a mujeres víctimas de desplazamiento forzado habitantes de 5 localidades de Bogotá. Mediante procesos de formación política y jurídica en los que se estudiaban los diversos mecanismos para el restablecimiento de derechos, la Casa de la Mujer facilitó el empoderamiento de mujeres líderes en Bogotá y habilitó el escenario para 
que ellas fortalecieran sus organizaciones, crearan otras nuevas y mejoraran su acción política. Así lo recuerda Esperanza Ramírez, una de las mujeres que participó en este proceso:

"Una víctima con odio, con rencor, con deseos de venganza no es y mucho menos puede hacer un trabajo social. De allí mi preocupación de aprender, de estudiar, ya nos dieron los talleres en la Casa de la Mujer y luego dijimos: ¿qué vamos a hacer con todo eso que aprendimos? que somos sujetas políticas de derechos pero también de deberes, que tan bonitas las herramientas jurídicas, que el derecho de petición, que la tutela, que el incidente de desacato, que la movilización, que las acciones políticas, legítimas, pacíficas, de hecho, ¿qué vamos a hacer con eso? (...) Con todo lo que aprendimos conformamos una red que se llamó Red de Mujeres en Acción Hacia el Futuro, eso fue para el año 2006. Nosotras llegamos a la Casa de la Mujer como para el año 2004, 2005 y 2006, o sea, la formación, los talleres, para ese tiempo también fuimos a la movilización del Putumayo a denunciar las fumigaciones en la vida y en el cuerpo de las mujeres, y en la de Chocó que convocaron desde la Ruta. (...) En el momento del empoderamiento y el fortalecimiento político de todas, cuando la Red de mujeres en acción hacia el futuro se conformó, éramos mujeres de varias organizaciones, entre esas estaba GERMINAR, estaba Yo Mujer, estaba ADESCOP, eran varias organizaciones, entonces ya nos invitaron a participar de la Ruta” (Entrevista 9).

Había comenzado un proceso de empoderamiento y visibilización de las mujeres víctimas de desplazamiento forzado que reñía con lo que ya era una tradición en Bogotá, que las organizaciones de población desplazada era lideradas por hombres y que las mujeres, si hacían parte de estas organizaciones, no desempeñaban cargos de responsabilidad. Se habilitaban entonces las condiciones para que las mujeres empezaran procesos de largo aliento para la reivindicación de sus derechos desde una perspectiva feminista, más allá de las clásicas solicitudes de las organizaciones de población desplazada lideradas por hombres. 
Por aquella misma época la Casa de la Mujer comenzó a detectar la repetición de un fenómeno de criminalidad contra mujeres líderes mediante actos de violencia sexual. Así lo recuerda Osana Medina, funcionaria en aquel momento de esta organización no gubernamental:

“A la Casa de la Mujer en 2006 empezaron a llegar muchas mujeres víctimas de violencia sexual aquí en Bogotá. Sobre todo las líderes empezaron a llegar buscando ayuda por ese tema y un poco eran las bacrim (bandas criminales), que en esa época no había salido la sentencia que las calificaba como actores armados, entonces no podíamos hacer muchas cosas porque no nos recibían la denuncia, y en esa época estaba el gobierno de Uribe y no estaban recibiendo denuncias tampoco de paramilitares, y nosotras quisimos también meter esas denuncias, pero como en esa época supuestamente el paramilitarismo no existía, solo estaban recibiendo denuncias si venían de guerrilla. Entonces en la Casa de la Mujer lo primero que hicimos fue un Foro para visibilizar esta situación, y ese Foro resultó un Foro muy grande" (Entrevista 27).

El Foro al que se refiere fue el Foro denominado: "Verdad, Justicia y Reparación para las Mujeres Víctimas de Desplazamiento Forzado", que se realizó el 8 de marzo de 2007, en el marco del día internacional de la Mujer, organizado por la Corporación Casa de la Mujer, la Ruta, CLADEM, la Red de Mujeres en Acción Hacia el Futuro, víctimas de desplazamiento forzado, el Tribunal de Mujeres y DESC y la Marcha Mundial de Mujeres (Ruta Pacífica de las Mujeres, s. f.-c).

Este Foro tuvo un efecto especial porque en él se logró la participación y la intervención de importantes personalidades, algunas para animar la convocatoria, otras como mediadoras, otras como referentes de las mujeres víctimas y otras como objeto de las reclamaciones. Por ejemplo, sobresale la participación de Piedad Córdoba, en aquel momento Senadora del Congreso de la República quien teniendo cercanía y familiaridad con la Casa de la Mujer, coadyuvó en la invitación al 
magistrado de la Corte Constitucional Manuel José Cepeda para participar. También se recuerda mucho la intervención de Pilar Rueda, en aquel momento funcionaria de alto nivel de la Defensoría del Pueblo quién ayudó facilitando alianzas. Participaron feministas reconocidas como María Eugenia Sánchez, Olga Amparo Sánchez y María Eugenia Ramírez, quienes sirvieron de referente para las mujeres víctimas que asistieron al Foro a plantear sus denuncias. También resultaron ser protagonistas el mismo magistrado de la Corte Constitucional Manuel José Cepeda y su magistrado auxiliar Federico Guzmán, quienes como representantes del Estado recibieron los reclamos por los agravios cometidos, y así, se convirtieron en el objetivo principal de esta acción pública y de la estrategia de incidencia que se desarrollaría posteriormente.

En el marco de este Foro se denunció la situación que afectaba particularmente a las mujeres víctimas de desplazamiento forzado en la ciudad de Bogotá. Especialmente llamó la atención una de las mujeres líderes, Esperanza Ramírez de la Asociación de Desplazados y Desplazadas por la Convivencia Pacífica ADESCOP, organización miembro de la Ruta en Bogotá y de la Red de Mujeres en Acción Hacia el Futuro. Así recuerda Esperanza aquel Foro:

“(...) entonces en esa reunión yo me preguntaba ¡Hay Dios mío yo qué le digo a ese hombre! (en referencia al magistrado Cepeda). Toda la biblioteca se llenó. Una de las propuestas era que las mujeres en Bogotá, por el contrario de que el gobierno nos estuviera dando una respuesta a nuestros derechos, nos estaba re victimizando. Entonces le pudimos llevar pruebas, documentos de la atención en salud, de la atención en educación para nuestros hijos, la atención en el tema de ayudas humanitarias, la atención en vivienda, la crisis humanitaria que estábamos viviendo las mujeres en Bogotá, que no se cumplían las tutelas, que ya había salido la T-025 y que mire la renuencia del Estado a cumplirnos, bueno, una cantidad de cosas y el hombre anotaba y anotaba y hubo un momento en que yo le dije: señor magistrado yo quiero que por favor me mire a los ojos porque las ventanas del alma son los ojos y nosotras no elegimos ser desplazadas, nosotras 
vivíamos en el campo. Entre paréntesis, vivíamos bien, teníamos agua limpia, aire puro y nosotras ninguna levantamos la manito para decir me quiero ir para la ciudad de Bogotá, porque están dando muchas cosas, entre ellas la vivienda, no, teníamos vivienda digna, no la pudimos traer entre el costalito, pero vivíamos dignamente en el campo, teníamos trabajo, bueno... Y el hombre hace un balance, ahí hay varias compañeras que también hablaron de sus historias, desde el público tomaron quien intervenía, entonces pasaron el micrófono, que a mí me asesinaron mi hijo, que a mí me violaron mi hija, que el gobierno no me ha cumplido, bueno, testimonios (...) Y el magistrado finalmente en ese Foro se compromete a hacer una audiencia con mujeres desplazadas de organizaciones de Bogotá pero también con mujeres de otras regionales.” (Entrevista 9).

Aquel compromiso se convirtió en una nueva y trascendental oportunidad para las mujeres víctimas de desplazamiento forzado en el proceso de reclamación de sus derechos, ya que, sin haberlo previsto, encontraron en la Corte Constitucional un receptor atento e interesado. Señala Osana Medina quién también se encontraba en el auditorio aquella vez:

"Yo creo que cuando (el magistrado) Cepeda abría los ojos, lo que no comprendía era eso, yo le decía a Olga Amparo que la tenía al lado: - yo creo que ese man está pensando: ¡yo en que ciudad vivo! Yo creo que también salió del Foro lleno de miedo, pues por todas las historias de terror que contaban las mujeres, y no precisamente en Ciudad Bolívar, en esa época Suba estaba peor, porque acuérdense que en esa época Suba era la localidad con mayor violencia sexual para las mujeres pero lo que la gente no sabía era que era contra las mujeres víctimas del conflicto. Entonces creo que eso fue una cosa motivadora para él (...) Entonces el magistrado Cepeda escuchó a las mujeres, y Esperanza Ramírez fue la que más tomó la palabra y fue la que más lo convenció (...) Ya era tarde, eran como las 6 y media, entonces el Magistrado nos dijo que hiciéramos una audiencia especial para 
mirar las demandas específicas de las mujeres, entonces nosotras le cogimos la palabra”. (Entrevista 27).

El Foro superó con creces todas las expectativas, incluidas las de las convocantes. Concluyó con la necesidad de hacer un informe sobre las problemáticas de las mujeres víctimas del desplazamiento forzado y con el compromiso de la realización de un Audiencia Pública en la Corte Constitucional. Se erigió así esta acción como el referente principal que comenzó a darle forma a la promulgación de un pronunciamiento de la Corte Constitucional, un de Auto de seguimiento especial a la Sentencia T-025 de 2004.

Es importante señalar que la participación de la Ruta en este Foro tiene dos versiones. Mientras las mujeres entrevistadas pertenecientes a la Ruta señalan haber participado como convocantes y haber estado durante todo el proceso, la Casa de la Mujer no lo recuerda de la misma forma. Para las funcionarias entrevistadas, la Ruta entró al proceso de construcción del Auto en un momento posterior. Esta falta de certeza puede deberse a múltiples causas, como por ejemplo, el hecho de que la Ruta y la Casa compartieran sede durante tantos años puede haber producido, para este caso, una fusión inconsciente de acciones que les impide trazar la frontera entre lo que ha hecho una y otra. También puede deberse a que las mujeres líderes representantes de las bases decidieran portar "múltiples camisetas" y actuar en función de todas ellas al mismo tiempo. Esto lo muestra claramente Esperanza Ramírez cuando afirma haber sido formada por Casa de la Mujer al tiempo que conformaba una organización local mixta de desplazados en pro de la vivienda digna, pertenecía a una más de mujeres víctimas en la red de mujeres de acción hacia el futuro, y además, pertenecía a la Ruta, todo ello, al momento del Foro. Por último, podría intervenir también en la interpretación de la historia, hechos posteriores que se produjeron durante la Audiencia y el seguimiento al Auto una vez promulgado, en los que algunos sectores tomaron mayor fuerza y protagonismo que otros. 
Sin embargo, independientemente de eso, las dos versiones si dan cuenta de la participación de otros sectores feministas y organizaciones no gubernamentales que coadyuvaron seriamente en la producción del efecto estudiado. Organizaciones de base y del nivel nacional, pronto se unieron a la oportunidad que se abría desde la Corte para hacer una Audiencia temática que permitiera la exposición de la problemática de las mujeres víctimas de desplazamiento forzado, haciendo que esta línea de incidencia involucrara a una diversidad de colectivos de mujeres feministas de la mayor parte del territorio nacional.

\subsubsection{La Ruta en la preparación de la Audiencia}

Una vez las mujeres interpretaron el llamado a la Audiencia como una oportunidad política importante, empezó un nuevo proceso de movilización, ya no en forma acción pública callejera, sino mediante la coordinación y agregación de capacidades regionales y nacionales. Nos cuenta Dunia León como fue esta experiencia vivida desde las regiones:

"Sobre el trabajo en las regiones, si, ¡de hecho eso fue algo tan lindo! cuando yo me acuerdo me encanta, eso se venía maquinando y en las regiones nosotras animamos mucho a las mujeres (...) Eso fue en el 2007, se planteó una reunión Casa de la Mujer y la Ruta, pues digamos que por la relación que hubo con el magistrado Cepeda. Entonces hubo un acercamiento con el auxiliar de Cepeda que era Federico, entonces concertaron una reunión donde pudieran participar mujeres víctimas y pudieran manifestar ellas mismas cuáles eran los problemas que tenían y entonces vinieron de las regiones. Yo recuerdo mucho que de la Ruta Bolívar invitamos a varias mujeres que vinieron incluso por tierra porque no había así como mucha financiación y la idea era que viniera la mayor cantidad de gente. Yo no estuve porque era para las mujeres víctimas, pero de hecho las 600 mujeres que aparecen en el auto fueron las 600 mujeres que vinieron, y allí hay como 200 y algo de Bolívar, no solo de la Ruta, 
también de la Liga de Mujeres Desplazadas y de algunas otras organizaciones de base, pero también Mujeres de la Ruta" (Entrevista 2).

Ese momento también es recordado por Esperanza Ramírez:

"Entonces qué empezamos a hacer, empezamos a trabajar con la Casa de la Mujer que convocó otras regiones donde estaba la Ruta, las nueve regionales que tiene, mujeres del Chocó, mujeres del Putumayo, mujeres de Antioquia, mujeres de Santander, de todas las regionales, y nos preparamos un buen informe para el día que él nos había dicho de la audiencia. En la Audiencia estuvo el magistrado Manuel José Cepeda, estuvo el magistrado Luis Ernesto Vargas Silva, y otros que ya no están ahí. La preparamos en la Casa de la Mujer, cómo íbamos a hacer el informe, quién iba a hablar, quién iba a hablar del tema de la educación, quién iba a hablar del tema de la salud, de la vivienda" (Entrevista 9).

Fue así como las organizaciones prepararon un documento para a la Corte Constitucional denominado: “Análisis Crítico de la Política Pública para las Mujeres en Situación de Desplazamiento Forzado". En este informe se hacía un balance sobre el incumplimiento del Estado de las órdenes proferidas en la Sentencia T-025 de la Corte y en general sobre la incapacidad del Estado para proteger y brindar garantías a las mujeres víctimas de desplazamiento forzado en todo el país. Fueron 6 particularmente sus reclamos e aquel momento: a. No existía un conocimiento real por parte del Estado sobre las afectaciones a las mujeres, b. El tipo de acciones desarrolladas por el gobierno estimulaban roles tradicionales y percepciones patriarcales sobre el papel de las mujeres en la sociedad; c. Las instituciones tenían serias limitaciones para desarrollar la política. d. La política pública desconocía que el desplazamiento forzado pone a las mujeres en situaciones de mayor vulnerabilidad; e. el efecto del desplazamiento era particularmente grave y desproporcionado en las mujeres y e. Las mujeres sufrían de mayor violencia antes, durante y después del desplazamiento. 
Pero junto a estos reclamos, las mujeres también hicieron propuestas. Allí consignaron su apuesta por la no discriminación, la inclusión social, el acceso equitativo a los servicios y recursos del Estado y la importancia de reconocer la situación de mayor vulnerabilidad de las mujeres. Llamaron también a promover su participación en la toma de decisiones, la organización, la realización de acciones para promover la autoestima y la autonomía, la eliminación estereotipos que impiden el desarrollo de los derechos y la inclusión de las mujeres. Todo ello con una perspectiva diferencial dándole prevalencia a los derechos de las niñas y las minorías étnicas (Ruta Pacífica de las Mujeres, s. f.-c).

Se trató de una condensación de lo que las mujeres venían diciendo desde finales de los 90 y que encontraba en este escenario una oportunidad única para plantearlo frente a un actor con poder de decisión que podría eventualmente inclinar la balanza a favor de ellas.

Con este nivel de organización y claridad, las mujeres asistieron a la audiencia que se realizó el 10 de mayo de 2007, turnándose el uso de la palabra y abordando cada uno de los temas preparados con anterioridad. Fue necesario extender el tiempo de la Audiencia para poder permitir más intervenciones y aunque al final muchas mujeres sentían que ser escuchadas no era suficiente y exigían respuestas de inmediato por parte de la institucionalidad, la mayoría consideraron valioso el escenario. Tal vez presentían que este no era el final del camino sino un momento previo necesario para la acción de la Corte.

Es importante señalar que a esta Audiencia, además de los magistrados de la Corte y las organizaciones de mujeres, acudieron funcionarios de la Consejera Presidencial para la Equidad de la Mujer, Acción Social, SENA, Procuraduría, Defensoría del Pueblo y el Alto Comisionado de las Naciones Unidas para los Refugiados ACNUR. Con ellos se analizaron los componentes de la política pública tal como fue planteada en la sentencia T-025: prevención y protección, atención humanitaria y estabilización socioeconómica, y, aunque fueron pocas las respuestas que las mujeres obtuvieron, quedó en el ambiente la percepción de su capacidad 
organizativa y de su conocimiento fundamentado sobre los impactos del desplazamiento forzado en la vida de las mujeres y sobre la incapacidad del gobierno de responder adecuadamente a las demandas (Ruta Pacífica de las Mujeres, s. f.-c). Esperanza Ramírez recuerda esta Audiencia así:

“(...) fue un jornada bastante larga, sin embargo el hombre (el magistrado Cepeda) nos dijo al final que con esa audiencia iba a haber una esperanza para el país, y bueno, todo bonito el hombre, fue muy sensible a nuestra problemática. De las regionales le impactó mucho la exigibilidad de los derechos de las mujeres en medio del conflicto, en medio de la guerra, porque tener los actores armados allá en las regiones e ir a exigir los derechos pues era más alta la vulnerabilidad. De ahí ya a los pocos días pues sale el Auto 092 y ahí empezamos hacer una trabajo muy importante". (Entrevista 9).

En efecto, la Audiencia era solo un paso en el camino. Una vez concluyó, se abrió un nuevo proceso, ahora venía la recolección y validación de la información y la redacción del texto final. También aquí cobró fuerza un actor decisivo en la elaboración del Auto que, aunque había estado en escena no había tenido tanta visibilidad. Se trataba del Magistrado Auxiliar Federico Guzmán, a quién las mujeres le otorgan un papel principal en la elaboración de los contenidos de este pronunciamiento de la Corte.

Para este momento, el poder de acción se encontraba en manos de los magistrados de la Corte. La forma de la incidencia se tornó más serena, analítica y privada. No se realizaron grandes manifestaciones de apoyo público o presión política al trabajo de la Corte, más bien, las mujeres se enfocaron en la documentación del tema. Nos lo explica Marina Gallego:

"No se hicieron acciones porque ellos no hicieron eso muy público, como protestas y eso, no. Ellos llamaron a las organizaciones, pidieron información sobre mujeres en situación de desplazamiento y estudiaron los 
casos. Entonces no, eso no fue un trabajo público. Digamos que surgió y ellos se pusieron en el estudio. La información que ellos querían era directamente de las mujeres, querían hacer como un estudio directamente, una muestra. (...). Ellos hicieron su estudio pidiéndole información a diversas organizaciones, ya no solamente con nosotras de la Ruta, ni la Casa de la Mujer, sino con diversas organizaciones y con esa muestra hicieron el Auto" (Entrevista 1).

Este proceso de recolección de información, que recayó en su mayoría en el Magistrado Auxiliar, se convirtió en otro momento de acción política de las mujeres. En estas sesiones las organizaciones lograron proveer información valiosa para la argumentación del fallo, pero además, lograron transmitir a un actor tan importante las claves de los contenidos y el sentido que desde su visión debía orientar al pronunciamiento de la Corte. Con ello se pretendía no solamente que el Auto recogiera las problemáticas de las mujeres víctimas de desplazamiento forzado sino que basara su planteamiento en el reconocimiento de los efectos diferenciales que sufrían las mujeres en el conflicto armado.

\subsubsection{La expedición del Auto 092 de 2008}

El 14 de abril de 2008 la Sala Segunda de Revisión de la Corte Constitucional, integrada por los Magistrados Manuel José Cepeda Espinosa, Jaime Córdoba Triviño y Rodrigo Escobar Gil, con ponencia elaborada por el primero, aprobó la expedición del Auto 092 para la "Protección de los Derechos Fundamentales de las Mujeres Víctimas del Desplazamiento Forzado por causa del conflicto armado, en el marco de la superación del Estado de Cosas Inconstitucional declarado en la sentencia T-025 de 2004”, después de realizada la sesión pública de información técnica el día 10 de mayo de 2007.

Mediante este Auto, paradigmático en el país, la Corte dictó una serie de medidas en diferentes niveles para la protección de los derechos de las mujeres víctimas de desplazamiento forzado y la prevención del impacto de género desproporcionado 
del conflicto armado y del desplazamiento forzado. En general, se dictaron 4 medidas:

“a. Se ordena la creación de trece (13) programas específicos para fortalecer la política pública existente de tal suerte que se minimicen los riesgos que viven las mujeres en el conflicto y las facetas de género que existen en el desplazamiento, b. Se establecen dos presunciones de constitucionalidad para proteger los derechos de las mujeres desplazadas, c. Se adoptan órdenes individuales de protección a seiscientas (600) mujeres desplazadas en el país, y d. Se comunican al Fiscal General de la Nación los casos conocidos por la Corte sobre crímenes sexuales cometidos en el marco del conflicto armado" (Corte Constitucional de Colombia, 2008).

Esta providencia cobró especial importancia como herramienta para la protección de los derechos de las mujeres, porque basó su decisión en el impacto desproporcionado, tanto cuantitativo como cualitativo, que sufren las mujeres a causa del conflicto armado, reconociendo así el planteamiento que habían hecho las organizaciones de mujeres durante más de una década. A su vez, emitió órdenes en el marco de la protección especial que deben tener las mujeres víctimas de desplazamiento forzado, como merecedoras de protección constitucional reforzada. Para ello los magistrados de la Corte realizaron sendos análisis de la situación de las mujeres desplazadas para lo cual diferenciaron entre dos categorías: (1) la prevención del impacto desproporcionado del desplazamiento forzado sobre las mujeres, y (2) la atención especial a las mujeres que son víctimas del desplazamiento forzado y el restablecimiento de sus derechos constitucionales fundamentales.

En lo relacionado con la Prevención, la Corte identificó diez clases de riesgos de género en el marco del conflicto armado. Se trata de factores de vulnerabilidad que enfrentan las mujeres en la guerra que no viven los hombres y que explican el impacto desproporcionado que las afecta. Estos son: 
“1. El riesgo de violencia sexual, explotación sexual o abuso sexual en el marco del conflicto armado; 2. El riesgo de explotación o esclavización para ejercer labores domésticas y roles considerados femeninos en una sociedad con rasgos patriarcales, por parte de los actores armados ilegales; 3. El riesgo de reclutamiento forzado de sus hijos e hijas por los actores armados al margen de la ley, o de otro tipo de amenazas contra ellos, que se hace más grave cuando la mujer es cabeza de familia; 4. Los riesgos derivados del contacto o de las relaciones familiares o personales voluntarias, accidentales o presuntas- con los integrantes de alguno de los grupos armados ilegales que operan en el país o con miembros de la Fuerza Pública, principalmente por señalamientos o retaliaciones efectuados a posteriori por los bandos ilegales enemigos; 5. Los riesgos derivados de su pertenencia a organizaciones sociales, comunitarias o políticas de mujeres, o de sus labores de liderazgo y promoción de los derechos humanos en zonas afectadas por el conflicto armado; 6. El riesgo de persecución y asesinato por las estrategias de control coercitivo del comportamiento público y privado de las personas que implementan los grupos armados ilegales en extensas áreas del territorio nacional; 7. El riesgo por el asesinato o desaparición de su proveedor económico o por la desintegración de sus grupos familiares y de sus redes de apoyo material y social; 8. El riesgo de ser despojadas de sus tierras y su patrimonio con mayor facilidad por los actores armados ilegales dada su posición histórica ante la propiedad, especialmente las propiedades inmuebles rurales; 9. Los riesgos derivados de la condición de discriminación y vulnerabilidad acentuada de las mujeres indígenas y afro descendientes; y 10. El riesgo por la pérdida o ausencia de su compañero o proveedor económico durante el proceso de desplazamiento." (Corte Constitucional de Colombia, 2008).

El análisis de cada uno de estos riesgos llevó a la Corte a ordenar un programa para la "prevención de los riesgos de género que causan un impacto desproporcionado del desplazamiento sobre las mujeres" el cual debía ser diseñado y comenzar a ser ejecutado tres meses después de expedida la providencia. Además hizo especial 
énfasis en el Riesgo de Violencia Sexual, surgido de los reiterativos relatos de las mujeres que participaron en el proceso de elaboración del Auto, a partir de los cuales organizó la siguiente tipología:

"A. Actos de violencia sexual perpetrados como parte integrante de operaciones violentas de mayor envergadura -tales como masacres, tomas, pillajes y destrucciones de poblados-, cometidos contra las mujeres, jóvenes, niñas y adultas de la localidad afectada, por parte de los integrantes de grupos armados al margen de la ley; B. Actos deliberados de violencia sexual cometidos ya no en el marco de acciones violentas de mayor alcance, sino individual y premeditadamente por los miembros de todos los grupos armados que toman parte en el conflicto, que en sí mismos forman parte: 1 . De estrategias bélicas enfocadas en el amedrentamiento de la población, 2. De retaliación contra los auxiliadores reales o presuntos del bando enemigo a través del ejercicio de la violencia contra las mujeres, sus familias o comunidades, 3. De retaliación contra las mujeres acusadas de ser colaboradoras o informantes de alguno de los grupos armados enfrentados, 4. De avance en el control territorial y de recursos, 5. De coacción para diversos propósitos en el marco de las estrategias de avance de los grupos armados, 6. De obtención de información mediante el secuestro y sometimiento sexual de las víctimas, o 7. De simple ferocidad; C. La violencia sexual contra mujeres señaladas de tener relaciones familiares o afectivas (reales o presuntas) con un miembro o colaborador de alguno de los actores armados legales e ilegales, por parte de sus bandos enemigos, en tanto forma de retaliación y de amedrentamiento de sus comunidades; D. La violencia sexual contra las mujeres, jóvenes y niñas que son reclutadas por los grupos armados al margen de la ley, que se ejecuta de forma reiterada y sistemática como: 1. La violación, 2. La planificación reproductiva forzada, 3. La esclavización y explotación sexuales, 4. La prostitución forzada, 5. El abuso sexual, 6. La esclavización sexual por parte de los jefes o comandantes, 7. El embarazo forzado, 8. El aborto forzado y 9. El contagio de infecciones de transmisión sexual; 10. El sometimiento de las mujeres, 
jóvenes y niñas civiles a violaciones, abusos y acosos sexuales individuales o colectivos por parte de los miembros de los grupos armados que operan en su región con el propósito de obtener éstos su propio placer sexual; 11. Actos de violencia sexual contra las mujeres civiles que quebrantan con su comportamiento público o privado los códigos sociales de conducta impuestos de facto por los grupos armados al margen de la ley en amplias extensiones del territorio nacional; 12. Actos de violencia sexual contra mujeres que forman parte de organizaciones sociales, comunitarias o políticas o que se desempeñan como líderes o promotoras de derechos humanos, o contra mujeres miembros de sus familias, en tanto forma de retaliación, represión y silenciamiento de sus actividades por parte de los actores armados; 13. Casos de prostitución forzada y esclavización sexual de mujeres civiles, perpetrados por miembros de los grupos armados al margen de la ley; o 14. Amenazas de cometer los actos anteriormente enlistados, o atrocidades semejantes." (Corte Constitucional de Colombia, 2008).

Se trató de un compendio de las conductas descritas en los testimonios de las mujeres a la Corte, que demostraba la barbarie que ellas sufrían a causa del conflicto armado. Sobre este punto la Corte, en lo relacionado con las competencias penales, trasladó a la Fiscalía y a la Procuraduría la información para que fuera desde este escenario que se realizaran las respectivas investigaciones.

Ahora bien, en lo relacionado con la Atención de las mujeres víctimas del desplazamiento forzado y el restablecimiento de sus derechos, la Corte identificó a su vez 18 facetas de género del desplazamiento forzado. Se trata de situaciones que se producen en el marco del desplazamiento y que afectan de forma específica y grave a las mujeres por el hecho de ser mujeres y, por lo tanto, requieren de una atención especial diferenciada. Estas son:

“(1) patrones de violencia y discriminación de género de índole estructural en la sociedad colombiana, preexistentes al desplazamiento pero 
que se ven potenciados y degenerados por el mismo, impactando en forma más aguda a las mujeres desplazadas, y (2) problemas específicos de las mujeres desplazadas, producto de la conjunción de los factores de vulnerabilidad que soportan, y que no afectan ni a las mujeres no desplazadas, ni a los hombres desplazados. En la categoría (1) se cuentan los riesgos acentuados de las mujeres desplazadas de ser víctimas de patrones estructurales de violencia y discriminación de género tales como: i. La violencia y el abuso sexuales, incluida la prostitución forzada, la esclavitud sexual o la trata de personas con fines de explotación sexual; ii. La violencia intrafamiliar y la violencia comunitaria por motivos de género; iii. El desconocimiento y vulneración de su derecho a la salud y especialmente de sus derechos sexuales y reproductivos a todo nivel, con particular gravedad en el caso de las niñas y adolescentes pero también de las mujeres gestantes y lactantes; iv. La asunción del rol de jefatura de hogar femenina sin las condiciones de subsistencia material mínimas requeridas por el principio de dignidad humana, con especiales complicaciones en casos de mujeres con niños pequeños, mujeres con problemas de salud, mujeres con discapacidad o adultas mayores; v. Obstáculos agravados en el acceso al sistema educativo; vi. Obstáculos agravados en la inserción al sistema económico y en el acceso a oportunidades laborales y productivas; vii. La explotación doméstica y laboral, incluida la trata de personas con fines de explotación económica; viii. Obstáculos agravados en el acceso a la propiedad de la tierra y en la protección de su patrimonio hacia el futuro, especialmente en los planes de retorno y reubicación; ix. Los cuadros de discriminación social aguda de las mujeres indígenas y afro descendientes desplazadas; x. La violencia contra las mujeres líderes o que adquieren visibilidad pública por sus labores de promoción social, cívica o de los derechos humanos; xi. La discriminación en su inserción a espacios públicos y políticos, con impacto especial sobre su derecho a la participación; y xii. El desconocimiento frontal de sus derechos como víctimas del conflicto armado a la justicia, la verdad, la reparación y la garantía de no repetición. La categoría (2) incluye xiii. Los especiales requerimientos de atención y 
acompañamiento psicosocial de las mujeres desplazadas, que se han visto gravemente insatisfechos; xiv. Problemas específicos de las mujeres ante el sistema oficial de registro de la población desplazada, así como ante el proceso de caracterización; xv. Problemas de accesibilidad de las mujeres al sistema de atención a la población desplazada; xvi. Una alta frecuencia de funcionarios no capacitados para atender a las mujeres desplazadas o abiertamente hostiles e insensibles a su situación; xvii. El enfoque a menudo "familista" del sistema de atención a la población desplazada, que descuida la atención de un altísimo número de mujeres desplazadas que no son cabezas de familia; y xviii. La reticencia estructural del sistema de atención a otorgar la prórroga de la Atención Humanitaria de Emergencia a las mujeres que llenan las condiciones para recibirla." (Corte Constitucional de Colombia, 2008).

Una vez la Corte hizo este análisis, llegó a la conclusión evidente de la necesidad de incorporar a la política pública 13 programas específicos capaces de dar cuenta de esta situación. Nuevamente, en este caso le impuso al Gobierno Nacional la obligación de diseñarlos y ponerlos en operación en un máximo de tiempo de tres meses. Esos programas fueron:

“a. El Programa de Prevención del Impacto de Género Desproporcionado del Desplazamiento, mediante la Prevención de los Riesgos Extraordinarios de Género en el marco del Conflicto Armado.

b. El Programa de Prevención de la Violencia Sexual contra la Mujer Desplazada y de Atención Integral a sus Víctimas.

c. El Programa de Prevención de la Violencia Intrafamiliar y Comunitaria contra la Mujer Desplazada y de Atención Integral a sus Víctimas.

d. El Programa de Promoción de la Salud de las Mujeres Desplazadas.

e. El Programa de Apoyo a las Mujeres Desplazadas que son Jefes de Hogar, de Facilitación del Acceso a Oportunidades Laborales y 
Productivas y de Prevención de la Explotación Doméstica y Laboral de la Mujer Desplazada.

f. El Programa de Apoyo Educativo para las Mujeres Desplazadas Mayores de 15 Años.

g. El Programa de Facilitación del Acceso a la Propiedad de la Tierra por las Mujeres Desplazadas.

h. El Programa de Protección de los Derechos de las Mujeres Indígenas Desplazadas.

i. El Programa de Protección de los Derechos de las Mujeres Afrodescendientes Desplazadas.

j. El Programa de Promoción de la Participación de la Mujer Desplazada y de Prevención de la Violencia contra las Mujeres Líderes o que adquieren Visibilidad Pública por sus Labores de Promoción Social, Cívica o de los Derechos Humanos.

k. El Programa de Garantía de los Derechos de las Mujeres Desplazadas como Víctimas del Conflicto Armado a la Justicia, la Verdad, la Reparación y la No Repetición.

1. El Programa de Acompañamiento Psicosocial para Mujeres Desplazadas.

m. El Programa de Eliminación de las Barreras de Acceso al Sistema de Protección por las Mujeres Desplazadas" (Corte Constitucional de Colombia, 2008).

Al mismo tiempo, la Corte definió como criterio de interpretación para las actuaciones administrativas dos Presunciones Constitucionales, que debían ser en adelante de obligatorio cumplimiento en procura de constituir la protección de los derechos de las mujeres desplazadas como sujetos de protección constitucional reforzada:

“a. La presunción constitucional de vulnerabilidad acentuada de las mujeres desplazadas, para efectos de su acceso a los distintos componentes del SNAIPD (Sistema Nacional de Atención a la Población Desplazada) y 
de la valoración integral de su situación por parte de los funcionarios competentes para atenderlas;

b. La presunción constitucional de prórroga automática de la ayuda humanitaria de emergencia a favor de las mujeres desplazadas, hasta que se compruebe la autosuficiencia integral y en condiciones de dignidad de cada mujer en particular" (Corte Constitucional de Colombia, 2008).

En relación a los casos de las 600 mujeres desplazadas que allegaron información a la Corte, impartió órdenes específicas de protección individual, su vinculación a los programas existentes en el momento, además de recibir la atención a la que tenían derecho.

Por último, como ya lo había hecho en anteriores sentencias, la Corte invitó a varias organizaciones sociales que acompañaban a mujeres víctimas de la violencia para participar en el proceso de diseño e implementación de los trece programas y en el seguimiento a la situación de las 600 mujeres beneficiarias de las órdenes directas de la Corte. Para ello incluyó un numeral en la parte resolutiva de la providencia ordenando la comunicación de esta decisión a las siguientes organizaciones:

“(1) CODHES; (2) Corporación Casa de la Mujer; (3) Corporación Sisma Mujer; (4) Liga de Mujeres Desplazadas; (5) AFRODES; (6) PROFAMILIA; (7) Comisión de Seguimiento a la Política Pública sobre el Desplazamiento Forzado; (8) Plan Internacional; (9) Comité Internacional de la Cruz Roja; (10) Amnistía Internacional; (11) Human Rights Watch; (12) Comisión Colombiana de Juristas; (13) Comisión Intereclesial Justicia y Paz; (14) Asociación Nacional de Mujeres Campesinas, Negras e Indígenas de Colombia (ANMUCIC); (15) Red Nacional de Mujeres Desplazadas; (16) Mesa de Trabajo Mujer y Conflicto Armado; (17) Consejo Noruego para Refugiados; (18) Corporación Opción Legal; (19) Pastoral Social de la Iglesia Católica; (20) la Mesa Nacional de Fortalecimiento a Organizaciones de Población Desplazada; (21) UNICEF; (22) ONIC; (23) Conferencia Nacional de Organizaciones 
Afrocolombianas; (24) Comisión Interamericana de Derechos Humanos; (25) Organización Femenina Popular; (26) Ruta Pacífica de las Mujeres; (27) Comité de América Latina y el Caribe para la Defensa de los Derechos de la Mujer (CLADEM)" (Subrayado fuera de texto) (Corte Constitucional de Colombia, 2008).

Este gesto de reconocimiento público de la Corte Constitucional a las organizaciones sociales no solo es una valoración simbólica que la Corte hace de su participación y de su trabajo, además, las reconoce como interlocutoras legítimas del Estado y certifica la autenticidad de la información y las denuncias que producen desde la máxima entidad del poder judicial. Se trata de una certificación concreta a su acción política, frente a la estigmatización generada por el poder ejecutivo, y la apertura de una nueva ventana de oportunidades que se aprovecharía con la lucha por el cumplimiento del Auto.

El Auto 092 de 2008 recogió gran parte de los planteamientos y las denuncias que las organizaciones sociales, de derechos humanos, de mujeres, y particularmente la Ruta habían venido elaborando y posicionando durante años con su movilización.

\subsection{Capítulo 5: La influencia de la Ruta Pacífica de las Mujeres en la expedición del Auto 092 de 2008 de la Corte Constitucional}

En el anterior capítulo nos ha sido posible relatar al lector la secuencia de eventos que precedieron a la promulgación del Auto. Se trata de una narración lineal que nos invita a plantearnos la hipótesis sobre la participación de la Ruta en la expedición del Auto y nos muestra cómo otros sectores intervinieron directa o indirectamente en la producción de este resultado. Sin embargo, es necesario ahora descomponer esta narración en sus elementos principales para tratar de construir una explicación razonable sobre las situaciones y eventos que fueron necesarios para que se produjera el hito y asumiera las características que finalmente tiene (Tilly \& Tarrow, 2007). 
Para ello vamos a hacer uso de dos conceptos más de la literatura estudiada. De un lado tomaremos la propuesta de Contentious Politics sobre Estructura de Oportunidades Políticas, pensando en ellas menos como variables independientes que explican el surgimiento y éxito de un movimiento social (McAdam et al., 1999), y más como elementos del contexto político a los cuáles los desafiadores, los oponentes y los demás actores políticos, al atribuirles significados de oportunidad o amenaza política, les otorgan capacidades para facilitar u obstaculizar el desarrollo de una determinada contienda política (Tilly \& Tarrow, 2007).

Tras este análisis y concibiendo los procesos políticos no sólo como resultados atribuibles a factores externos, institucionales y de contexto en lógica de oportunidades y amenazas políticas, sino también a las situaciones concretas en las que intervienen los distintos actores sociales y políticos relacionados en el episodio como protagonistas de la constitución del hito, nos adentraremos en la identificación de los Mecanismos relacionales que se conjugaron en la agencia de los movimientos durante la contienda. La intención de reconocer estos Mecanismos, considerados como una clase determinada de eventos que se repiten de maneras similares en diversas contiendas (McAdam et al., 2005), es mejorar nuestra capacidad explicativa de las formas en que se producen los resultados. La conjugación de estructura y agencia desde una perspectiva dinámica en la que se congregan atribuciones de oportunidades y amenazas políticas, así como mecanismos, puede contribuir de mejor manera a la comprensión de nuestro problema de investigación.

\subsubsection{La Estructura de Oportunidades Políticas}

El paisaje político que se observaba en 2007 y 2008 estaba compuesto por una serie de eventos acumulados en el tiempo que permitieron que en el país por fin se hablara de las consecuencias que la guerra descargaba sobre las mujeres. El trabajo de las organizaciones sociales había habilitado varios caminos para la incidencia política y pública y las mujeres habían aprendido a reconocer y aprovechar las oportunidades que se presentaban. Sin embargo, algunos elementos del contexto 
hicieron posible que estas iniciativas tuvieran mayores probabilidades de éxito. Situaciones en las que también influyeron las mismas mujeres desde tiempo atrás y que eventualmente ayudaron a moldear. Como ya lo hemos analizado anteriormente, el Auto 092 de 2008 de la Corte Constitucional marcó un hito en el tema de la protección de los derechos de las mujeres víctimas del conflicto armado, tanto por las órdenes expedidas constitutivas de políticas públicas para la prevención, la protección y la atención de las mujeres, como por la exhaustiva comprensión de la problemática que realiza la Corte en sus consideraciones.

Del análisis de la información acopiada para este estudio hemos logrado identificar tres elementos de la estructura de oportunidades que aceitaron la contienda política y le dieron un rumbo específico que determinó la forma y el contenido del resultado. Se trata de la multiplicidad de centros de poder independientes, la apertura a nuevos actores y la disponibilidad de aliados influyentes. Veamos cada uno de ellos.

3.5.1.1. La multiplicidad de centros de poder: los tres poderes del Estado

El primer elemento con el que contaron las organizaciones de mujeres y las feministas involucradas en la producción el Auto 092, fue la posibilidad de avanzar decididamente en su trabajo de incidencia con la Corte Constitucional, la cual se mostró como un tribunal independiente y autónomo del poder ejecutivo, toda vez que, ante la intransigencia y la intolerancia del gobierno frente a los reclamos y los planteamientos de las organizaciones populares y de derechos humanos, la posibilidad de diálogo y acercamiento estaba completamente cerrada.

Con la Constitución de 1991, surgida como resultado del último proceso de paz desarrollado en Colombia con algunas de las guerrillas de izquierda, entre ellas el M-19, Colombia había mejorado las herramientas para la defensa de los derechos humanos en el país. Existía una clara estructura de separación de los tres poderes del Estado, ejecutivo, legislativo y judicial, así una cierta independencia y autonomía entre estos poderes pensada como un sistema de pesos y contrapesos que 
limitara los abusos del poder, aun cuando la configuración de las relaciones entre el legislativo y el ejecutivo siempre han generado la posibilidad de buscar mayorías que permitan la gobernabilidad. Este diseño, que ya para ese momento llevaba 15 años en uso, comenzaba a ser permeado por las vicisitudes políticas del país en las que no eran pocas las situaciones de conflicto entre esos tres poderes.

Es importante recordar que, mientras el Congreso estaba cuestionado por las investigaciones judiciales que venían develando los vínculos de decenas de parlamentarios con el paramilitarismo, parlamentarios que conformaban las bancadas coaligadas con la agenda política del gobierno Uribe, éste a su vez había comenzado un fuerte enfrentamiento público con la Corte Suprema de Justicia precisamente por esas investigaciones. Al mismo tiempo, el gobierno había asumido una actitud abiertamente hostil y represiva contra los sectores de la sociedad civil que cuestionaran su proyecto político, su administración o ejercieran la defensa y promoción de los derechos humanos, especialmente estos últimos, a quienes en múltiples ocasiones acusó pública e insustancialmente de ser "aliados del terrorismo". La negación del ejecutivo a la existencia de un conflicto armado, la política de militarización de la sociedad civil, las capturas masivas y arbitrarias de civiles por parte de las fuerzas militares y muchas más violaciones a los derechos humanos y al derecho internacional humanitario, ambientaban un clima de sospecha y desconfianza mutua entre las organizaciones sociales y las instituciones.

Dado este contexto, las mujeres encontraron en el enfrentamiento entre el poder judicial y el ejecutivo una ventana de oportunidad importante para introducir sus reivindicaciones en la agenda. Por supuesto esta confianza en la Corte era animada también por varios precedentes que las hacía pensar que la Corte Constitucional podría ser un buen escenario para el debate. Es importante recordar que el Auto 092 se derivó directamente del incumplimiento a las órdenes impartidas en la Sentencia T-025 de 2004, en la cual la Corte evidenciaba las falencias de las políticas del gobierno frente a la crisis del desplazamiento forzado que generaba el mismo conflicto que el gobierno negaba. El Estado de Cosas Inconstitucional definido por la Corte, cuestionaba las acciones del gobierno y daba crédito a las denuncias de las 
organizaciones de víctimas y de derechos humanos. No se trataba entonces de una acción sobre el vacío. Existían serios indicios de que la Corte Constitucional se podría volver a pronunciar favorablemente, en este caso en defensa de los derechos de las mujeres.

Pero este no era el único antecedente. Ya para ese momento Colombia había adquirido una serie de obligaciones internacionales que debían ser consideradas como de rango constitucional por los jueces en sus pronunciamientos jurídicos, pues el artículo 93 de la Constitución de 1991 estableció el "Bloque de Constitucionalidad", un precepto que establece que todas las normas internas deben ser concordantes con los tratados internacionales sobre derechos humanos. Las obligaciones derivadas del derecho internacional humanitario y del derecho internacional de los derechos humanos, como la Declaración Universal de Derechos Humanos, el Pacto Internacional de Derechos Civiles y Políticos, la Convención Americana sobre Derechos Humanos, la Convención Sobre la Eliminación de Todas las Formas de Discriminación Contra la Mujer, la Convención Interamericana para Prevenir, Sancionar y Erradicar la Violencia Contra la Mujer y los Principios Rectores de los Desplazamientos Internos, fueron las guías que usó la Corte Constitucional para amparar los derechos que tienen las mujeres para vivir dignamente, libres de discriminación y libres de violencia. De acuerdo con eso, la Corte consideró las garantías que deben rodear a las víctimas de conflictos armados y las obligaciones del Estado colombiano, para establecer la especial atención a las mujeres víctimas y sus necesidades particulares. Esa especial atención ya había sido planteada en las recomendaciones que hizo en 2007 el Comité para la Eliminación de todas las Formas de Discriminación contra la Mujer CEDAW, en las que instó al Estado colombiano a atacar las causas subyacentes de la violencia contra la mujer y a mejorar el acceso de las víctimas a la justicia y a los programas de protección, las cuales fueron una respuesta al esfuerzo y trabajo previo desplegado por las organizaciones de mujeres para visibilizar esta problemática (Quintero, Rodríguez, \& Rodríguez, 2013, p. 6). Así lo señala Cecilia Barraza: 
"Hay otras cosas que ocurrieron. Es cierto que desde el año 2000 más o menos las organizaciones de mujeres concentran sus esfuerzos en el impacto que el conflicto ha tenido en la vida de las mujeres y comienzan los observatorios a ver qué está pasando con las mujeres desplazadas. Se hace la incidencia con el ACNUR para ver que los kits humanitarios incluyeran toallas sanitarias, lleven anticonceptivos, etc. Hay un trabajo permanente de decir que la mayoría de las víctimas son mujeres, hasta mostrar estos aspectos del impacto diferenciado. Aparecen los discursos de cómo el desplazamiento genera un cambio en la vida de las mujeres que les permite hasta empoderarse, que la afectación del desplazamiento es distinta para el hombre que para la mujer. Empieza a generarse mucho ese discurso, hasta que tomando la recomendación general 19 de la CEDAW se establece la teoría que el impacto del conflicto armado tiene un impacto diferencial en la vida de las mujeres.

“O sea, hay todo un recorrido previo, que no es solo de la Ruta. Hay otras organizaciones que estuvieron a cargo también de ese proceso, se empieza a hablar de ese efecto que ha tenido el conflicto y su vínculo con la violencia. Al estar cerrados los canales de diálogo con el gobierno, para avanzar en una política pública real para las mujeres es que se convierte en un escenario importante de incidencia la Corte. Recuerden que la composición en esa época de la corte es muy distinta a la que existe ahora y en segundo lugar, ya recordarán que dos años atrás ya se había utilizado lo que podía decir la Corte en materia de delitos sexuales y reproductivos. Fue la sentencia que despenalizó parcialmente el aborto, o sea el escenario de la Corte se convirtió en ese momento en un escenario en el que se podía incidir. (...) Demostrar el impacto del desplazamiento, y no solo con la Corte, también se hizo todo un trabajo para que viniera a Colombia la Relatora Especial de Violencia, que es una gestión que hace la "Mesa de Trabajo Mujer y Conflicto armado", y que tiene mucho que ver con la agencia que después moviliza lo del Auto, y para que haya un informe de la Corte Interamericana de Derechos Humanos que se refirió específicamente sobre 
la situación de las mujeres en Colombia en el marco del conflicto armado. Entonces todo eso lleva luego al Auto, pero es un proceso en el cual el trabajo previo demora 10 años, yo creo que desde el año 2000, y con más fuerza con la resolución 1325 sobre paz y seguridad ${ }^{14}$, la idea de mostrar las consecuencias del conflicto empieza a ser cada vez más fuerte" (Entrevista 28).

Como se observa, se trató de un agregado político y jurídico que en la Corte avanzó por un camino que se venía construyendo de forma contundente desde el año 2004 con la emisión de la Sentencia T-025. Fue una oportunidad que las mujeres supieron interpretar y que les permitió construir una estrategia para avanzar en el reconocimiento del impacto diferencial del conflicto armado en la vida y en el cuerpo de las mujeres.

El que la relación entre las organizaciones sociales y el Gobierno nacional pasara por su peor momento sin que existiera ninguna señal de que se cumplieran las garantías y las obligaciones desde el Gobierno para con las mujeres, condujo a que la incidencia política con la Corte se volviera central. Esto solo fue posible porque existía previamente un diseño institucional que se basaba en la independencia, el equilibrio y el control entre los poderes públicos, por el reclamo que venían haciendo las organizaciones sociales y porque las herramientas jurídicas nacionales e internacionales obligaban a la Corte a actuar en coherencia con el ordenamiento constitucional, aunque entrara en contradicción con el Gobierno central.

3.5.1.2. La apertura del sistema a nuevos actores: La sociedad civil comienza a ganar espacios

Los avances normativos y jurisprudenciales de los que hemos hablado también habían impactado en el fortalecimiento de las organizaciones sociales y populares, particularmente de población en situación de desplazamiento forzado, y habían

\footnotetext{
${ }^{14}$ Resolución 1325 sobre Mujeres, Paz y Seguridad, aprobada por el Consejo de Seguridad de la Organización de Naciones Unidas el 31 de octubre de 2000.
} 
abierto espacios de interlocución directa entre organizaciones de derechos humanos, expertos de la sociedad civil y diferentes entidades del Estado. Este fortalecimiento posibilitó que grupos de ciudadanos ganaran confianza y conocimiento para el cabildeo que con el tiempo se fue transfiriendo a otras organizaciones y asociaciones.

El antecedente más inmediato lo encontramos precisamente al comienzo de la historia que desembocó en la sentencia T-025. Las familias desplazadas, reclamando por el incumplimiento de la ley 387 de 1997 que establecía los derechos y la atención para las víctimas del desplazamiento forzado, comenzaron su peregrinar por los tribunales para solicitar el reconocimiento de sus derechos. La figura de la Acción de Tutela se convirtió en la clave de este proceso. Las organizaciones, los líderes y las familias comenzaron a adquirir el conocimiento necesario para redactar un Derecho de Petición, una Tutela o un Desacato. Estas acciones de protección de los derechos ciudadanos consagradas constitucionalmente, empezaron a ser reconocidas por los ciudadanos gracias a la experticia ganada por algunos sectores sociales organizados, fueron utilizadas de manera masiva aunque sin coordinación y, así, las víctimas comenzaron a abonar a la incidencia ante el poder judicial.

La posibilidad de reunirse alrededor de los agravios para exigir la acción del Estado confirió un poder importante a las víctimas de desplazamiento que sirvieron luego de germen a la acción posterior de las mujeres desplazadas. Si bien las asociaciones mixtas de población desplazada en los barrios y municipios periféricos de Bogotá fueron en muchas ocasiones barreras para el trabajo de las mujeres líderes, fue precisamente allí donde comenzaron a juntarse y perfilarse muchas de las mujeres que serían las gestoras del proceso de incidencia posterior.

Al tiempo, las organizaciones feministas y sus voceras, que hacían parte de la contienda desde los ochentas y noventas, eran ya bastante visibles y sostenían un discurso contundente sobre sus derechos. El país ya reconocía la existencia de estas organizaciones y asumía como posible que las mujeres y las víctimas participaran 
en el diseño e implementación de la política pública como mecanismo para restablecer sus derechos. Al mismo tiempo, organizaciones de profesionales que acompañaban y asesoraban a las víctimas eran consideradas como interlocutoras válidas del Estado, capaces de diseñar y evaluar políticas públicas y de proponer al Estado las acciones necesarias y eficaces para el reconocimiento y la realización de los derechos.

A finales de 2005, un grupo de expertos reunidos alrededor de la Consultoría para los Derechos Humanos y el Desplazamiento Forzado CODHES, comenzó a realizar esfuerzos importantes de interlocución con la Corte Constitucional, convirtiéndose en un actor importante del proceso de reivindicación de los derechos de la población víctima de desplazamiento forzado. Mediante instrumentos de alta calidad técnica, propuestas sólidas de indicadores y trabajo de campo riguroso, elaboraron documentos de seguimiento del "goce efectivo de derechos" que permitían realizar evaluaciones efectivas de las políticas públicas. La Comisión de Seguimiento a la Política Pública sobre Desplazamiento se convirtió en referencia para la Corte Constitucional en el seguimiento a este tema, ampliando la dimensión de la problemática y dándole un enfoque más participativo al proceso de judicial de restablecimiento de los derechos de la población desplazada. De esta manera las organizaciones sociales comenzaron a adquirir práctica en el trabajo con los magistrados de la Corte y se acercaron los protagonistas entre sí.

Estos elementos fueron fundamentales para que las organizaciones ganaran experiencia de interlocución con la Corte Constitucional y facilitó que se emprendiera un diálogo abierto y permanente con los magistrados. Pero también les permitió a estos mismos funcionarios reconocer, en el amplio mundo de la sociedad civil, a las organizaciones de mujeres que venían haciendo procesos de exigibilidad y que habían acopiado información cualificada sobre la situación de las mujeres desplazadas en el país.

3.5.1.3. Y las mujeres disponen de aliados influyentes 
Con varias décadas de trabajo encima y una multiplicidad de acciones y de enfoques de trabajo, las feministas habían conquistado seguidores activos e importantes dentro del sistema político. Llamaban fuertemente la atención dos mujeres que resultaron ser vitales para avanzar en la acción contenciosa. De un lado la senadora Piedad Córdoba del partido Liberal, de antaño reconocida y apreciada por las mujeres de las distintas organizaciones feministas y, de otro lado, Pilar Rueda funcionaria de la Defensoría del Pueblo quién en su papel como garante de derechos se volvió motivadora y sustentadora de algunas acciones. Osana Medina nos recuerda su participación en el Foro del 2007:

"Entonces en la Casa de la Mujer lo primero que hicimos fue un Foro grande para visibilizar, y ese Foro se llamó así: el camino para visibilizar las violencias de las mujeres en Colombia, y nos resultó un Foro muy grande. En esa época estaba la delegada de la Defensoría Pilar Rueda que nos ayudó tanto, con ella hicimos una alianza para ese Foro, hicimos también una alianza con Piedad Córdoba y ella invitó a los magistrados al Foro, y teníamos todo un plan y teníamos una metodología, pero al final las mujeres víctimas se tomaron la palabra y nosotras también soltamos" (Entrevista 27).

La formalidad y seriedad que le imprimía a las acciones la presencia de algunos sectores de la institucionalidad representada en Pilar Rueda de la Defensoría del Pueblo, y la capacidad política de Piedad Córdoba que permitió acercar al Magistrado Manuel José Cepeda y lograr su presencia en este Foro, lo cual sería fundamental para el posterior acontecimiento del hito.

$\mathrm{Y}$ es que fue precisamente en ese espacio de trabajo donde las organizaciones de mujeres conocieron a quienes se convertirían luego en importantes aliados para la defensa de sus derechos. Nos referimos a los mismos magistrados de la corte Constitucional, Manuel José Cepeda y Federico Guzmán su magistrado auxiliar. Fueron ellos quienes propusieron el desarrollo de la Audiencia Temática y fueron ellos quienes finalmente le dieron forma y contenido al Auto 092 de 2008. A 
diferencia del caso de Pilar Rueda y Piedad Córdoba, ambas feministas de largo trecho y conocedoras de las luchas de las mujeres desde décadas atrás y, por tanto, ideológicamente cercanas a las desafiadoras, estos magistrados contrastaban por no tener en su historia política una aparente inclinación feminista, más allá de la defensa juiciosa de los derechos humamos como constitucionalistas.

Sin embargo, su papel se volvió vital, pues, en el desarrollo de sus funciones como miembros del alto tribunal, dieron vida al documento que sería posteriormente una de las herramientas jurídicas feministas más importantes que tendría Colombia. La pregunta entonces, se vuelve necesaria. ¿Qué hizo que estos magistrados se comprometieran de manera tan ostensible en la comprensión de la situación de los derechos de las mujeres desplazadas y produjeran un documento con tales características? Marina Gallego nos plantea su versión:

"Yo creo que a él (el magistrado Cepeda) lo motivó el conocimiento que las mujeres tenían de la T-025, yo creo que también estaba un poco conmovido con la falta de respuesta hacia ellas y todos los obstáculos que ellas expresaron ahí que tenían para acceder a sus derechos y a lo mínimo que era la declaración como desplazadas, y él se comprometió públicamente que iba a estudiar esta situación. También manifestó que la mayoría de las tutelas de la T-025 habían sido interpuestas por mujeres. Yo creo entonces que él salió un poco inquieto con eso y comprometido a que iba a revisar las situación de las mujeres y efectivamente se da a la tarea de empezar a mirar con más detalle lo que le pasaba a las mujeres". (Entrevista 1).

Para Osana Medina el interés de Federico Guzmán fue de carácter más subjetivo: “¿Por qué a Federico le interesó tanto el tema? No sé, él es muy sensible, tiene una gran sensibilidad, pero es que él está recomprometido y retocado con el tema, pero además tiene una capacidad de escucha impresionante" (Entrevista 27).

Curiosamente para el Magistrado Federico Guzmán la respuesta a la misma pregunta deviene de un análisis más objetivo y jurídico. Poco tiempo después de 
expedido el Auto durante una alocución pública, a la pregunta del por qué la Corte decidió priorizar la situación de la mujer, él respondió:

"Bastante simple, en la Corte nosotros habíamos recibido muchísimos reportes, quejas, información, consultas acerca de muchos aspectos sobre este punto, así que la Corte no podía simplemente hacerlo de otra manera. Por esa misma razón la Corte también decidió realizar la audiencia técnica con el propósito de informarse de la mejor forma posible sobre la situación para tomar medidas urgentes, hecho que a final resultó ser una estrategia exitosa.” (Traducción propia) (Vergel Tovar, 2009, p. 14).

Así las cosas, aunque las mujeres otorgan una explicación más política y subjetiva a la intervención de la Corte y los magistrados conciben su participación desde una lógica más jurídica y técnica, esta alianza resultó ser la pieza clave en la consecución del resultado de la acción colectiva contenciosa.

Si bien es cierto, había situaciones objetivas en el sistema político que provenían de procesos de contienda política previos, para ser provechosos estos debieron ser leídos e interpretados de esta manera por las mujeres que acudían a la contienda. Los tres elementos referidos: multiplicidad de centros de poder, la apertura a nuevos actores y los aliados influyentes, nos permiten acercarnos a la comprensión de cómo estos actúan durante un proceso contencioso.

En primer lugar, nos muestra que las acciones de los desafiadores pueden modificar estructuras del poder que facilitan eventualmente la acción contenciosa futura. Así lo harían los gestores de la Constitución Política del 91 con la introducción en la Carta Política de la Acción de Tutela, o las organizaciones de mujeres y de población desplazada que abrirían los caminos para que la institucionalidad y la sociedad las asumiera como interlocutoras válidas para la construcción y monitoreo de las Políticas Públicas. 
En segundo lugar, este análisis nos permite comprender la importancia del tipo de atribución que los actores colectivos le otorgan a tales cambios y modificaciones. Solo si introducimos en la narración el hecho de que las mujeres se sentían amenazadas por el ejecutivo y que había unos antecedentes garantistas con la Corte, podemos comprender porqué el hito deviene en forma de providencia judicial y no de una clásica política pública emitida por el ejecutivo o el legislativo.

En tercer lugar este análisis nos permite ver el protagonismo que pueden llegar a tener los aliados estratégicos en un momento dado de la contienda y la forma en que estos deben ser activados para que se unan a las acciones. En este caso la invitación de Casa de la Mujer a Piedad Córdoba, y la de esta última al Magistrado Cepeda, si bien puede pasar por situaciones personales y de conocimiento y cercanía política e ideológica previa, solo en un marco de acción colectiva contundente se puede desplegar la reacción esperada.

En suma, la estructura de oportunidades se va construyendo con el tiempo sobre las interacciones sostenidas de múltiples actores y éstas se activan cuando los participantes de una contienda lo interpretan así y sacan provecho de ello.

\subsubsection{Mecanismos y Procesos}

Hemos compartido con los autores de Contentious Politics que el desarrollo y los resultados de las acciones colectivas de los movimientos sociales, pueden ser analizados desde el estudio de los mecanismos observables en lugar o en conjunto con los métodos basados en correlación de variables. Esto porque no solamente nos advierte de las posibles relaciones que existen entre los distintos eventos, sino que nos puede explicar cómo estos se producen y a entender cómo estos se articulan con la estructura y la agencia.

A continuación nos detendremos en cada uno de los eventos significativos de nuestra cadena causal para examinar los mecanismos que allí operaron y que le 
dieron dinamismo y cauce a la acción colectiva que finalmente desembocó en la producción del hito.

\subsubsection{Difusión y Cooptación}

Tilly y Tarrow definen la Difusión como la propagación de repertorios de contención, de problemáticas y/o de estructuras de interpretación de un lugar a otro, y la Cooptación como la incorporación de actores políticos previamente excluidos en algún centro de poder (Tilly \& Tarrow, 2007, p. 215). Si analizamos el primer momento de la secuencia de eventos que hemos delimitado podríamos concluir que estos dos mecanismos se activaron allí.

Recordemos que esta fase de la contención comenzó con un proceso formativo agenciado por la Casa de la Mujer en cinco localidades de Bogotá. Este hecho ha sido narrado tanto por antiguas funcionarias de esta organización como por una de las mujeres que participaron del proceso. En aquel momento la Casa tenía un interés particular, difundir en las mujeres víctimas de desplazamiento forzado de diversos rincones de la ciudad capital, los planteamientos feministas y de derechos humanos que ellas ostentaban y que consideraban legítimos en el proceso de reivindicación de sus derechos. En ese proceso se encontraron con numerosas mujeres que a su vez hacían parte de organizaciones de población desplazada, lo cual les permitió mejorar su conocimiento de las diferentes redes y estructuras organizativas que existían para aquel momento en la ciudad, además, conocieron el estado de los liderazgos y el perfil de las mujeres que usualmente participaban de esos espacios.

Esa estrategia de difusión que tardó varios meses finalmente rindió frutos importantes. De un lado, la Casa de la Mujer se hizo visible en muchos barrios en los que antes no era conocida y, de otro lado, se logró la cooptación de varias de sus líderes para la causa feminista. Vale decir sin embargo, que este último proceso no se hizo sin algunas dificultades (Entrevista 27). 
Penetrar en organizaciones mixtas, casi siempre lideradas por hombres que habían encontrado en los procesos políticos locales los mecanismos, no solo para buscar su supervivencia económica en la contención con el Estado, sino además para obtener una posición de poder en relación con los miembros de sus propias organizaciones, resultaba en algunos casos conflictivo. Se trataba de pasar de una lógica mediante la cual la contención con la institucionalidad estaba enfocada en conseguir los recursos materiales necesarios para subsistir en medio del desplazamiento forzado, por ejemplo: ayudas humanitarias, vivienda, salud, etc, a pensar desde una perspectiva de derechos sobre los riesgos y violencias que enfrentaban las mujeres en un contexto patriarcal cuando éstas eran desplazadas.

De allí que no resultara extraño cuando se encontraron en ocasiones con alguna resistencia para la participación de las mujeres, pues un trabajo formativo no solventaba las necesidades económicas que tenían estas familias y sí generaba conflictos en los roles tradicionales dentro del hogar. Sin embargo, la estrategia de difusión siguió su curso y mediante procesos mantenidos de formación en derechos y capacitación en habilidades para su exigibilidad, las mujeres que participaron poco a poco fueron adquiriendo las herramientas que las facultaban para pensar en la posibilidad de organizarse, más allá de sus estructuras participativas previas en espacios mixtos, como mujeres víctimas desde una identidad feminista. Así las cosas, al tiempo que la Casa adelantaba procesos de difusión lograba aumentar el número de mujeres interesadas en liderar procesos en sus barrios y localidades mediante la cooptación.

Pero también es importante señalar que allí se estaba desarrollando otro fenómeno. Se pasó de un ejercicio individual de entrega de ayuda y solidaridad hacia las mujeres, a la conformación de una organización surgida de las mismas participantes. Así las cosas, el trabajo de una ONG pasó a ser un proceso articulado y ordenado de denuncia y defensa de derechos de las mujeres.

Recordemos que por estos mismos años la Casa de la Mujer se había convertido en un referente central para las mujeres víctimas de violencia sexual, particularmente 
líderes sociales y comunitarias. La visita permanente de estas líderes denunciando tales hechos condujo a las profesionales de esta organización a intentar desentrañar lo que allí pasaba a la vista de todos, pero que no se reconocía como algo sistemático y generalizado; la agresión directa mediante la violencia sexual a las mujeres víctimas que ahora eran líderes en sus comunidades. Esto significó un trabajo paralelo que permitió, de un lado, fortalecer la capacidad de las mujeres en situación de desplazamiento $\mathrm{y}$, de otro lado, comprender mejor los agravios que venían padeciendo y que motivaban una acción más decidida.

Como consecuencia, la acción de la Casa facilitó, mediante el mecanismo de difusión, crear un contexto que permitía que las mujeres víctimas en Bogotá asumieran roles más protagónicos en lo que restaba de la contienda, comunicando y trasladando la idea de trabajar en una problemática específica a otros lugares de Bogotá y, mediante el mecanismo de cooptación, involucrando a más mujeres líderes que originalmente, aunque pertenecían a organizaciones de desplazados, no desempeñaban roles protagónicos en las estructuras de sus organizaciones.

En últimas, los mecanismos de difusión y de cooptación que operaron en ese momento permitieron ampliar la presencia y la capacidad del movimiento en la contienda emprendida contra la victimización y la re victimización que sufrían las mujeres desplazadas por querer exigir sus derechos. Este proceso junto con la radicalización de las violencias contra las mujeres líderes en la ciudad desembocó en el siguiente paso de contienda.

\subsubsection{Constitución de Nuevos Actores}

Como podremos observar a continuación, la combinación específica de ciertos mecanismos es capaz de producir efectos de mayor envergadura que pueden explicar también la forma en que se desarrollan algunos eventos durante la contienda. 
En este caso resaltamos el proceso mediante el cual se produjo la emergencia de nuevos actores políticos, o de la transformación de los ya existentes, que constituyeron con sus acciones la caracterización de la contienda política, haciendo reivindicaciones o siendo objeto de ellas. Como lo hicieron notar Tarrow y Tilly, los actores pueden ser muy variados, desde agentes del Estado hasta poblaciones organizadas (Tilly \& Tarrow, 2007, p. 74). En este caso estamos ante sectores de la comunidad que adquirieron una identidad y una posición política pública (McAdam et al., 2005, p. 351) a partir de la coincidencia de una serie de mecanismos como la apropiación social, la acción innovadora, la atribución de amenazas y oportunidades, el cambio de identidad, la formación de categorías y la certificación / descertificación.

En el caso acá estudiado, la difusión y la cooptación fueron los que habilitaron el camino para que surgiera un nuevo sector organizado. Nos referimos a la Red de Mujeres en Acción Hacia el Futuro. Esta red, surgida mediante la expansión del ideario de la Casa y la constitución de nuevos liderazgos, se convirtió en el centro circunstancial de la contienda en ese momento. Debemos recordar que una de las protagonistas del primer Foro que se convocó para tratar concretamente las problemáticas de las mujeres en situación de desplazamiento fue precisamente una líder de esta organización naciente. Así las cosas este nuevo actor, compuesto por mujeres que provenían de diversas organizaciones, algunas de ellas mixtas, constituyó un centro de atención alterno sobre el cual se empezó a desarrollar un nuevo momento dentro de la cadena de eventos.

Sin embargo, luego de su constitución, la Red no tardó mucho en ampliar su frontera identitaria. Si bien nació como producto del proceso realizado por la Casa de la Mujer y tenía entonces como objetivo central la visibilización del efecto diferenciado del desplazamiento forzado en la vida y cuerpo de las mujeres y la exigibilidad de los derechos a la verdad, justicia y reparación mediante el seguimiento a la sentencia T-025 de 2004, no pasó mucho tiempo para que sus objetivos, sus acciones y sus integrantes se sumaran al fortalecimiento de la Ruta. 
En este nuevo escenario ampliaron sus marcos cognitivos con nuevos conocimientos sobre feminismo y con los conocimientos directos de las problemáticas de las mujeres víctimas a partir de sus viajes a regiones apartadas del país. Esta incursión por la Ruta, no fue sin embargo, tan tranquila y natural. En realidad implicó un proceso de análisis y revisión interna, a tal punto que no todas las mujeres que conformaron la Red decidieron integrar la Ruta. Finalmente lo que había en el escenario eran varias organizaciones traslapadas unas sobre otras que hacían que existiera una red bastante tupida, con elementos identitarios diferentes pero armonizables, conformando tres niveles de acción: las organizaciones originales de las que hacían parte la mayoría de mujeres cuando comenzaron a recibir la formación de Casa de la Mujer, la Red de Mujeres en Acción Hacia el Futuro conformada por algunas de estas lideresas y la participación de la Red en la Ruta.

Este es el motivo tal vez más fuerte por el cual existe una gran dificultad para saber cuál de estas organizaciones y mujeres activaron de mejor manera el resultado acá estudiado. Sobre todo porque finalmente quienes plantearon las demandas en el Foro reconocen haber portado todas estas identidades al tiempo en ese momento, sin que en ello vieran incoherencia alguna (Entrevista 9). Al final de cuentas, el papel de la Red, como conjunción de organizaciones locales y como parte de un movimiento más grande, resultó ser decisivo para motivar un compromiso por parte de los magistrados de la Corte Constitucional que vieron en ellas reflejada la condensación empírica de las luchas feministas y de las víctimas en el país.

\subsubsection{Correduría}

Un tercer momento en la cadena de eventos es precisamente el Foro denominado "Verdad, Justicia y Reparación para las Mujeres Víctimas de Desplazamiento Forzado", llevado a cabo el 8 de marzo de 2007. Allí las mujeres tuvieron por vez primera la posibilidad de entablar un diálogo con la Corte Constitucional y plantear sus reivindicaciones. Y encontramos que otro de los mecanismos definidos por Tarrow y Tilly intervino para que esto fuera posible, la Correduría o Brokerage, que 
consiste en la creación de nuevas conexiones entre sectores previamente desconectados o con conexiones muy débiles (Tilly \& Tarrow, 2007, p. 215). Se trata de uno de los mecanismos más estudiados por los autores de Dinámica de la Contienda, particularmente por ser familiar a un amplio número de muy diversos tipos de contienda política.

Recordemos que la convocatoria al Foro fue clave para que se produjera el hito. La invitación que hicieron la Casa de la Mujer y Piedad Córdoba al Magistrado de la Corte Constitucional Manuel José Cepeda constituye la activación del mecanismo que conlleva el despliegue del resto de los sucesos que desembocaron en la expedición del Auto 092 de 2008 por la Corte Constitucional. En este punto la Casa y la Senadora aprovecharon su experiencia previa y el conocimiento que tenían de las dinámicas políticas nacionales del momento al vincular al magistrado de la Corte que hacía el seguimiento al cumplimiento de la Sentencia T-025 de 2004 sobre desplazamiento forzado, para que representara al Estado y fuera objeto de las reivindicaciones de las mujeres que participaban, entre ellas las lideresas de la Red de Mujeres en Acción Hacia el Futuro.

De esta manera se vinculan dos actores que previamente no habían tenido ninguna relación y de su interacción se desata una nueva situación en la contienda. Esto es posible a partir de dos situaciones previas, por un lado, la experiencia conjunta entre la Casa de la Mujer y Piedad Córdoba en la lucha por los derechos de la mujer y, por otro lado, la confianza creada a partir de trabajo conjunto entre la Corte y la sociedad civil en la Comisión de Seguimiento a la Sentencia T-025. Estos espacios habían demostrado, tanto la pertinencia de crear vínculos de confianza y trabajo conjunto entre los sectores populares y los institucionales, muchas veces considerados antagónicos, como la facilidad de mantener lazos estables en el tiempo mediante la construcción de objetivos comunes. De allí que este ejercicio de correduría se hiciera más efectivo por cuanto existía una pasado previo que invitaba a generar lazos de confianza que permitieran influir en los procesos de toma de decisiones políticas con buenas posibilidades de éxito. 
Es necesario señalar que si bien lo que allí se desata no es una contención transgresiva tampoco se trata de una típica contención por caminos regulares o institucionalizados. A lo que estamos remitiendo en ese momento es a una nueva manera de sostener la contienda entre el Estado y la sociedad civil, más allá del clásico enfrentamiento entre la población y el gobierno. Estamos ante actores ampliamente diferentes: mujeres de base, feministas, organizadas, de escasos recursos económicos, la mayoría de zonas rurales y bajos niveles educativos, frente a Magistrados de la más alta Corte del poder judicial, hombres, urbanos y con altos niveles académicos, vinculados por la reivindicación y el reconocimiento de los impactos diferenciados del conflicto armado en el cuerpo y la vida de las mujeres víctimas en el país. Y eso ocurrió, ya no en la plaza pública o en la marcha y el plantón, sino en un espacio semipúblico, donde las mujeres expresaron sus reclamos, exigencias y reivindicaciones de manera coordinada y sin violencia, pero con beligerancia y mucha vehemencia en sus palabras.

Podríamos decir que en ese momento la contención se realizó a medio camino entre uno y otro extremo, tomando escenarios formales y rutinarios, como un Foro, para exhibir su malestar y exigir de manera ordenada pero enérgica un reclamo que presionara respuestas inmediatas y concretas. Para ello se valieron del uso insistente de la palabra, la cual se fueron turnando durante toda la jornada.

Esta forma del reclamo finalmente rindió sus frutos y el magistrado Manuel José Cepeda, como representante del Estado a quién las mujeres dirigían sus reclamos, se comprometió con la promesa de llevar a la atención de la Corte Constitucional las problemáticas de las mujeres víctimas. De allí surgió la oportunidad de transformar las reivindicaciones en una providencia judicial de la Corte Constitucional en la forma de Auto de Seguimiento de obligatorio cumplimiento para el gobierno y el Estado en su conjunto.

\subsubsection{Formación de Coaliciones}


Este episodio de contención requirió a su vez altas dosis de acción concertada entre varias organizaciones y personas. Mediante el mecanismo de formación de coaliciones, comprendido como un proceso en el que se realiza una coordinación nueva, visible y directa para la realización de reclamaciones entre los diversos actores (Tilly \& Tarrow, 2007, p. 216), las mujeres encontraron la manera de sumar capacidad para la acción, la movilización y la reivindicación. Estas coaliciones fueron necesarias en varios momentos de la cadena causal de eventos inmediatos a la promulgación del Auto que acá estamos describiendo.

El primer momento fue precisamente la convocatoria al Foro. Allí fueron la Corporación Casa de la Mujer, la Red de Acción de Mujeres en Acción Hacia el Futuro, el Tribunal de Mujeres y DESC, la Marcha Mundial de Mujeres y la Ruta, quienes se aliaron con el fin de desarrollar el Foro en mención, que finalmente se constituiría como uno de los eventos más importantes de aquel entonces para las mujeres víctimas del país. Esto fue posible porque estas organizaciones previamente habían tenido la experiencia de juntarse en algunos momentos para tratar de sacar adelante procesos conjuntos, de allí que no fuera extraño ni difícil lograr acuerdos sobre la acción coordinada que adelantarían.

Esta acción coordinada tuvo nuevamente otro momento protagónico justo después del Foro. Recordemos que aquella jornada terminó con la promesa del Magistrado de realizar una audiencia técnica ante la Corte Constitucional para debatir los problemas de las mujeres desplazadas no solo de Bogotá sino de todo el país. El hecho que para el Magistrado Cepeda resultara muy útil y esclarecedor escuchar las voces de las mismas mujeres exigiendo sus derechos, las animó a desplegar todas sus redes de trabajo para lograr la preparación y coordinación necesaria para adelantar cabalmente la Audiencia. Fue así que muy pocos días después de realizarse el Foro, las organizaciones convocantes se pusieron manos a la obra y comenzaron no solo a invitar a otras mujeres del país a venir a Bogotá, sino a documentar los casos y levantar archivos con toda la información que se considerara útil para la denuncia. Habían comprendido que tenían una magnifica ventana de oportunidad y no pensaban desaprovecharla de ninguna manera. Se trató de un 
trabajo ordenado, pensado con atención y esmero, lleno de optimismo por lo que pudiera ocurrir. Allí la Ruta sacó el mejor provecho de su forma de trabajo en red $\mathrm{y}$, además de convocar a mujeres de todas las regionales del país a participar activamente de la Audiencia, presentaron un documento denominado "Análisis Crítico de la Política Pública para las Mujeres en Situación de Desplazamiento” en el que evidenciaron la incapacidad del Estado por incluir un enfoque de derechos humanos en las políticas para las mujeres.

Una vez se comenzó a desarrollar la sesión, las mujeres, en el orden y temática programada previamente, plantearon sus reclamos ante los magistrados de la Corte. Es importante mencionar que no se dejó ningún detalle al azar. Las intervenciones fueron asignadas previamente a las mujeres que harían uso de la palabra y se organizaron de acuerdo con los componentes de la sentencia T- 025 de 2004. Así, las intervenciones se dividieron temáticamente en: prevención y protección, atención humanitaria y estabilización socio-económica siguiendo los parámetros legales previos. Se trató de una jornada extensa en que las lideresas mostraron su capacidad organizativa, el respeto por lo acordado previamente entre ellas, y la claridad del mensaje que querían trasmitir. También allí evidenciaron una vez más las debilidades del gobierno nacional de dar respuestas acordes a las necesidades de las víctimas ya que durante la Audiencia los representantes del Ejecutivo no pudieron esgrimir respuestas contundentes a sus demandas.

En cualquier caso fue evidente la importancia de formar esas coaliciones para el desarrollo de la contienda, hecho que les resultó relativamente fácil, particularmente por la experiencia que habían desarrollado varios años antes en otros procesos de movilización, y sumamente provechoso.

\subsubsection{Cambio de Escala}

El último mecanismo sobresaliente en este proceso es el cambio de escala. Se trata del incremento o decrecimiento del número de actores y/o rangos geográficos en donde y con quienes se realizan acciones coordinadas (Tilly \& Tarrow, 2007, p. 
217). En este caso podemos decir que hubo un cambio de escala considerable entre el Foro y la Audiencia que hizo que, a un ejercicio reivindicativo realizado en la capital, se sumara un número considerable de organizaciones de otras regiones del país.

Es importante notar que el cambio de escala puede ser hacia arriba o hacia abajo en lógica de aumento o descenso de número de actores y áreas geográficas comprometidas. Desde esta perspectiva, es usual también que acciones locales se difuminen desde la periferia hacia el centro. Sin embargo, en este caso, si bien sigue siendo un cambio de escala hacia arriba, se presenta desde el centro hacia la periferia tanto en términos geográficos como en términos numéricos. Ello sucedió una vez terminado el Foro cuando se abrió la opción de participar en una Audiencia en la Corte.

Hasta el momento se trataba de una acción reivindicativa de los derechos de las mujeres desplazadas que habitaban Bogotá, sin embargo el llamado a una Audiencia técnica empujó la acción hacia las regiones para presentar lo que pasaba en el resto del país. Esto hizo que se activaran inmediatamente las relaciones previas que tenían las organizaciones de mujeres, en particular las de la Ruta, en distintos lugares, lo cual facilitó enormemente que en muy poco tiempo (cerca de dos meses) mujeres de todo el país estuvieran preparadas para presentar sus casos y sus planteamientos ante la Corte Constitucional.

Así las cosas, numerosas organizaciones de diferentes rincones el país tuvieron asiento en este espacio y la oportunidad de plantear la forma en que las mujeres deben vivir la guerra en regiones aparatadas. Este hecho fue reconocido ampliamente por los demás actores del proceso político, quienes corroboraron que se trataba de una situación que afectaba a un número enorme de mujeres de todas las geografías del país, lo cual fue determinante para la forma y los contenidos del hito, es decir el Auto 092, que posiblemente no hubiese tenido el impacto deseado de no haberse desarrollado de esa forma. 
Esta parte de la travesía finalmente concluyó con la redacción del Auto tras varias reuniones privadas entre organizaciones de mujeres y el Magistrado Auxiliar en las que se continuó con la presentación de casos, la exposición de agravios, el análisis de las causas y la definición de los propósitos. Estas sesiones terminaron de apuntalar parte importante del sentido de los contenidos del Auto, en las que los posicionamientos y los planteamientos influyeron de forma determinante en la lógica con la que se construyó la providencia.

\subsubsection{Algunas Conclusiones}

Los procesos de lucha feminista en Colombia se extienden varias décadas en el pasado y han tomado distintas facetas. Desde las luchas de las sufragistas de los años 50 hasta las mujeres que han venido exigiendo el derecho a decidir sobre su propio cuerpo y reivindicando la despenalización del aborto en la actualidad, las mujeres han identificado distintos agravios y se han organizado de diferentes maneras para confrontar al Estado en la exigencia de sus derechos. Podríamos decir, sin temor a caer en exageraciones, que el hito analizado, la expedición del Auto 092 de 2008, es una condensación de múltiples luchas y es producto de una suma de acciones históricas del movimiento de mujeres en Colombia.

Sin embargo, para lograr una mejor explicación del proceso de generación de este resultado identificaremos algunos conceptos preponderantes, de acuerdo con el enfoque de análisis dinámico de la contienda política (Tilly \& Tarrow, 2007, p. 201), a saber, los actores que consideramos intervinieron de manera directa y la secuencia de eventos que constituyeron la cadena de acontecimientos más inmediata a la decisión de la Corte y que activaron la producción del resultado, con el fin de construir una explicación plausible de cuáles fueron los elementos que condujeron a la generación de este impacto, que ha sido considerado como positivo en la política pública para las mujeres víctimas del conflicto armado en Colombia por parte de movimiento que hemos estudiado, la Ruta. 
Así las cosas, por supuesto, un actor principal del episodio de contienda es precisamente la Ruta. Por esta razón en la primera parte de este recorrido dimos cuenta de su surgimiento, planteamientos iniciales, construcción de identidades, formas organizativas y repertorios utilizados en la contienda, descubriendo las formas en que se relacionaron con otros grupos similares y cómo consiguieron apoyos externos durante el proceso.

De esa descripción extensa podemos destacar que la Ruta emergió a partir de una sumatoria de agravios contra las mujeres en distintos lugares del país en el marco del conflicto armado, acogiendo y desarrollando las concepciones del feminismo, del pacifismo y del antimilitarismo, y se proyectó como objetivo principal luchar por la salida negociada al conflicto armado colombiano y la por la visibilización de los efectos que la guerra descarga en las vidas y los cuerpos de las mujeres. Se trata de un movimiento que nació por la acción política de algunas feministas de la época, quienes aprovecharon las experiencias organizativas acumuladas, interpretaron los agravios y las oportunidades políticas del contexto y decidieron movilizarse públicamente para reivindicar ante el Estado y los actores armados sus derechos y los de todas las mujeres colombianas agraviadas por la violencia machista y el conflicto armado. Pero no solo lucharon por el reconocimiento del Estado o contra las infamias de los actores armados, fundamentalmente entraron en contienda contra un sistema de pensamiento, el socio-sexo-patriarcalismo, y lo hicieron mediante la movilización pública y pacífica en la que enarbolaron el simbolismo y el uso de artefactos lúdicos para desconcertar a los oponentes, tan racionalizados y estructurados en la guerra.

Hicimos antes una descripción densa de la forma en que se ha desarrollado el conflicto armado en Colombia desde finales de los ochenta y comienzo de los noventa. La configuración de los actores, algunos factores sobresalientes de sus luchas, los intereses que los guiaron y las formas en que sus violencias han afectado de manera específica y diferenciada a las mujeres generando un impacto desproporcionado en sus cuerpos y en sus vidas. En esa descripción fue posible observar la forma en que los actores armados legales e ilegales se fueron 
desplegando por los territorios, las interacciones entre ellos y con la población y el legado de atrocidades e ignominias que dejaron en sus víctimas. Allí pudimos observar no solamente la situación de violencia contra la población civil y en especial contra las mujeres, sino además la inexistencia de políticas públicas específicas para atender las necesidades y los derechos de esas mujeres afectadas por el conflicto armado. La realidad implacable marcada en el cuerpo de la mujer como botín de guerra y la indiferencia del Estado y la sociedad ante esta situación, eran las condiciones dominantes al inicio del episodio de contienda que hemos estudiado.

Desde el surgimiento de la Ruta en 1996 hasta la expedición del Auto 092 de 2008 pasaron muchas cosas. Las mujeres crearon redes nacionales e internacionales, se aliaron con algunos sectores y crearon divisiones con otros, se conformaron nuevas organizaciones feministas y se diversificaron los objetos de la contienda. Sin embargo, es menester fijar algunos momentos y eventos que se encuentran directamente encadenados a la producción el hito estudiado. Hemos delimitado esa cadena causal, la cual está estrechamente relacionada a otras luchas previas y paralelas, a partir de las acciones de formación en derechos humanos adelantadas por el movimiento en varias localidades de Bogotá en 2005.

Esta experiencia formativa condujo al empoderamiento de algunas lideresas que crearon la Red de Mujeres en Acción Hacia el Futuro al interior de la Ruta y promovieron la realización del Foro "Verdad, Justicia y Reparación para las Mujeres Víctimas de Desplazamiento Forzado" realizado el 8 de marzo de 2007. Este Foro fue el evento que vinculó al movimiento con los magistrados que abrieron la posibilidad de promover la expedición de una providencia de la Corte sobre la problemática de las mujeres.

Es necesario señalar la importancia de la correduría adelantada por Piedad Córdoba al vincular al magistrado de la Corte Manuel José Cepeda en el diálogo directo con las mujeres. Este encuentro y los eventos sucesivos, solo pudieron ser posibles por dos situaciones previas paralelas. De un lado, el proceso que se llevaba en la Corte 
Constitucional frente al tema de desplazamiento, que reunía una serie de disposiciones internacionales que conminaban al poder judicial a actuar de manera garantista a favor las víctimas de la guerra y particularmente de las mujeres y la sentencia T-025 que este mismo órgano había expedido algunos años atrás en el 2004 cuando declara la situación de los desplazados como un Estado de Cosas Inconstitucional lo cual les habilitaba para seguir actuando en el tema mediante el seguimiento a sus órdenes. De otro lado, todo el proceso de organización política y empoderamiento de las mujeres víctimas de desplazamiento forzado que les permitía conocer las normas nacionales e internacionales que las amparaban e interpretar los agravios a las que eran sometidas en diferentes lugares del país y la capacidad de estas mismas mujeres de atribuir amenazas y oportunidades al contexto, hecho que les indicó acertadamente que debían enfilar sus reclamaciones hacia la Corte Constitucional y no al ejecutivo con quien mantenía para esa época hondas diferencias.

Es esta suma de elementos los que hacen que el Magistrado Cepeda decida convocar una audiencia técnica en la Corte para atender los reclamos y emitir órdenes al ejecutivo definiendo la forma que va a tener el impacto. Sin embargo, pasaron algunas cosas más durante la preparación de las mujeres para la Audiencia que nutrieron el enfoque y el contenido del pronunciamiento, lo que a nuestro juicio es lo que hace que la providencia de la Corte se convierta en un impacto positivo en la política pública para las mujeres víctimas de desplazamiento forzado.

Por lo tanto, parte importante de nuestra cadena causal es el despliegue que hace la Ruta entre todas sus redes para alimentar, con la documentación necesaria, la comprensión y la exposición detallada de la problemática de las mujeres en sus diferentes niveles. Este cambio de nivel es el que genera en los magistrados responsables de la redacción del Auto la capacidad de comprender que en efecto la guerra produce un impacto diferenciado en las mujeres y que existen unos riesgos de género en el marco del conflicto armado que no viven los hombres, y unas facetas de genero durante el desplazamiento que hace que las mujeres requieran una atención diferenciada. Al final de esta cadena de eventos está el estudio juicioso 
que adelantó la Corte en conjunto con la Ruta y con muchas otras organizaciones que venían de tiempo atrás exigiendo tener en cuenta el impacto diferenciado del conflicto en las mujeres y que serían la base del Auto 092. Una vez hecho este recuento, es necesario ahora revisar de manera concreta el papel de los elementos de la Estructura de Oportunidades Políticas y de los mecanismos en el desarrollo de la contienda que nos explican la producción del Hito.

Si bien es cierto había situaciones objetivas en el sistema político que provenían de procesos contenciosos previos, para ser provechosos estos debieron ser leídos e interpretados de esta manera por las mujeres que acudían a la contienda. Los tres elementos contenidos: multiplicidad de centros de poder independientes, la apertura a nuevos actores y los aliados estratégicos, nos permiten acercarnos a la comprensión de cómo estos actúan durante un proceso contencioso.

En primer lugar, nos muestra que las acciones de los desafiadores pueden modificar estructuras del poder que facilitan eventualmente la acción contenciosa futura. Así lo harían los gestores de la Constitución Política del 91 con la introducción en la carta Política de la Acción de Tutela, o las organizaciones de mujeres y de población desplazada que abriría los caminos para que la institucionalidad y la sociedad las asumiera como interlocutores válidos para la construcción y monitoreo de las Políticas Públicas.

Por otro lado, este análisis nos permite comprender la importancia del tipo de atribución que los actores colectivos le otorgan a tales cambios y modificaciones. Solo si introducimos en la narración el hecho de que las mujeres se sentían amenazadas por el ejecutivo y que había unos antecedentes garantistas con la Corte, podemos comprender por qué el hito deviene en forma de fallo y no de una clásica política pública emitida por el ejecutivo.

En tercer lugar este enfoque nos muestra el protagonismo que puede llegar a tener los aliados estratégicos en un momento dado de la contienda y la forma en que estos deben ser activados para que se unan a las acciones. En este caso la invitación de 
Casa de la Mujer a Piedad Córdoba, y la de esta última al Magistrado Cepeda, si bien puede pasar por situaciones personales y de conocimiento y cercanía política e ideológica previa, se produce solo en un marco de acción colectiva contundente de tal suerte que se despliega la reacción esperada. De esta forma, la estructura de oportunidades se va construyendo con el tiempo sobre las acciones sostenidas de múltiples actores y éstas se activan cuando los participantes de una contienda lo interpretan así y sacan provecho de ello.

Pero la EOP no nos explica mucho de los contenidos ni de la forma en que se produjo el hito. A estos tres elementos de la Estructura de Oportunidades Políticas se van engranando seis mecanismos que amplían y mejoran la explicación de la producción del Auto cuando este es analizado en una cadena causal de acontecimientos. Difusión, cooptación, constitución de actores, correduría, formación de coaliciones y cambio de escala se van sucediendo en un proceso acumulativo que aprovecha los elementos de la EOP dándole agencia a la estructura que se va interpretando y a la cual se le va adjudicando un uso particular.

Estos mecanismos y procesos nos permiten comprender la forma en la que operan los dispositivos que enlazan los hechos y la estructura y ponen en funcionamiento el aparato político aparentemente estático que les rodea. Así las cosas era necesario que operara un proceso de difusión y cooptación que permitiera a las mujeres juntarse para hacer procesos de exigibilidad de derechos, que ellas conformaran una nueva plataforma de acción de donde emergieran líderes capaces de representar los reclamos en un momento dado, que las organizaciones feministas más maduras optaran por la acción coordinada y en coalición, que una de ellas sirviera además para conectar dos escenarios distintos pero capaces de corresponderse y que finalmente tuvieran la capacidad de irradiar el reclamo y la urgencia de la movilización por múltiples rincones del país.

Todo ello cuando se han conjugado tres elementos de la EOP, algunos de más largo aliento histórico que otros: una multiplicidad de centros de poder capaz de generar actores estatales diferentes para la contienda y unos avances legislativos y 
jurisprudenciales jalonados por otros procesos políticos que dieron luz a la Constitución Política del 91, a la ley 387 de 1997, a la acción de Tutela y a la sentencia T-025 de 2004; un proceso de movilización feminista en el país, el cual dotó de identidad, capacidad y destreza política a las organizaciones de mujeres para adelantar procesos políticos pertinentes y contundentes y unos aliados que se fueron haciendo al calor de la contienda más larga de la lucha de las mujeres por sus derechos en Colombia. Desde este enfoque nos es posible explicar entonces cómo una cadena de eventos bastante frecuente en la acción política de un movimiento social en Colombia: una acción formativa, la construcción de un nuevo actor, un Foro y un proceso de documentación, se trasforman en una Audiencia Técnica en la Corte y en un Auto de Seguimiento. En breve, seis mecanismos y procesos y tres elementos de la EOP es lo que lo hacen posible.

Ilustración 5. Modelo de explicación del Hito en el Episodio de Contienda

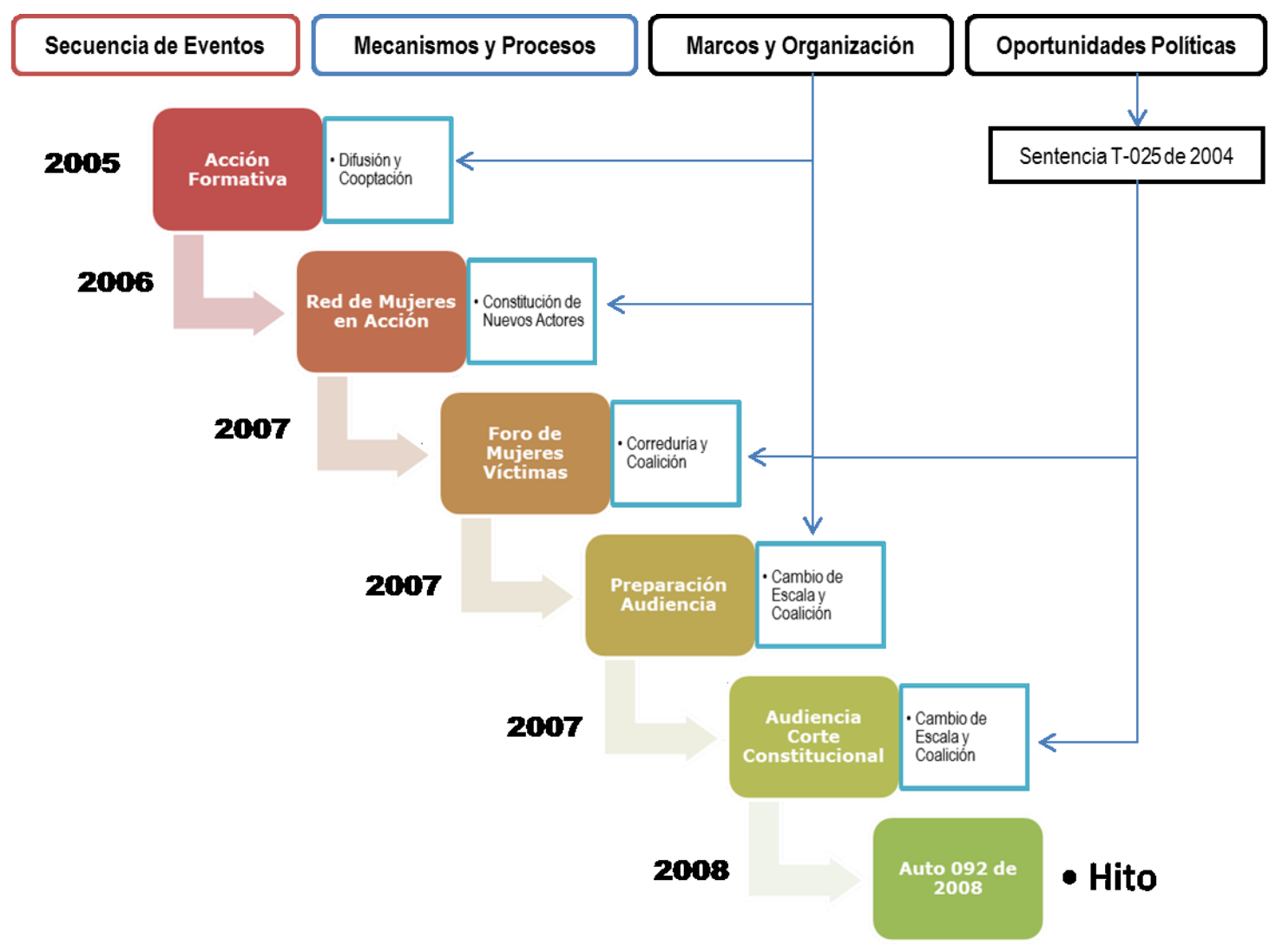

Fuente: Elaboración Propia. 


\section{Segunda Parte: El Movimiento Nacional de Víctimas de Crímenes de Estado en Colombia}

Otro movimiento social significativo en el marco de la lucha por la defensa de los derechos humanos y que ha logrado importantes resultados reivindicativos de sus objetivos ha sido el Movice. Este Movimiento, caracterizado por su combatividad, capacidad de resistencia y movilización, se ha convertido en uno de los actores más representativos de las luchas de las víctimas en este país por sus derechos. Para su estudio y análisis, y tal como lo hiciéramos con la Ruta, dedicaremos los tres primeros capítulos de este aparatado a narrar la historia de su surgimiento y desarrollo, para referirnos en los siguientes 2 capítulos a uno de sus impactos y los elementos analíticos que participaron en su producción.

Para ello nos adentraremos, en el capítulo 6, en la aparición y consolidación de diversas luchas por el respeto a los derechos humanos en el marco del conflicto armado, la acción del paramilitarismo en las diferentes épocas, y conoceremos las primeras reacciones de los movimientos en Colombia por la elección de Uribe Vélez como Presidente de la República, hasta el momento del surgimiento del Movice. En el capítulo 7 haremos una descripción sobre las principales acciones del movimiento, la batalla contra la ley de "Justicia y Paz" y todo el proceso de visibilización y empoderamiento de las víctimas de Estado en el país.

Más adelante en el capítulo 8 nos introduciremos, aprovechando el marco conceptual propuesto por la perspectiva integradora (McAdam et al., 1999), en los procesos enmarcadores cognitivos, la estructura de movilización y los repertorios de acción colectiva y en el capítulo 9 haremos una descripción del resultado analizado y la posible cadena de eventos que lo determinó. Finalmente, en el capítulo 10 haremos un análisis de las principales oportunidades y amenazas políticas, así como de los mecanismos que consideramos intervinieron decisivamente en la generación de este impacto desde un marco dinámico del estudio de los movimientos sociales, siguiendo las recomendaciones de (McAdam et al., 2005). 


\subsection{Capítulo 6: Surgimiento del Movice}

El segundo episodio de contienda política que vamos a analizar en este estudio lo delimita el proceso de caracterización de las víctimas del conflicto político, social y armado en Colombia, tal como lo vivieron las víctimas de la represión estatal, desde el surgimiento del Movice en el contexto de la pretendida legalización de las estructuras paramilitares mediante su aparente desmovilización al amparo de la Ley de Justicia y Paz del gobierno Uribe, hasta el avance oficial en el reconocimiento de la existencia de las víctimas de agentes estatales en el marco del debate sobre la definición de víctima en el artículo 3 de la Ley 1448 de 2011. Conoceremos las vicisitudes que rodearon su surgimiento y desarrollo y los elementos que dieron sentido y estructura a sus luchas.

\subsubsection{El paramilitarismo de Estado en el conflicto colombiano}

El Movice surgió en el año 2005 como reacción al proceso de negociación iniciado por el gobierno de Álvaro Uribe Vélez con las Autodefensas Unidas de Colombia AUC, grupos paramilitares responsables de miles de crímenes atroces en contra de la población civil colombiana, especialmente de sectores populares y de izquierda. Para este movimiento el proceso de negociación era una manera velada para que los sectores tradicionales detentadores del poder del Estado pudieran propiciarse un auto indulto, pues con ello el establecimiento pretendía cubrir con impunidad los crímenes cometidos por tales grupos, los cuales habían sido presentados por los sucesivos gobiernos como un tercer actor en el conflicto pero que, para el Movice, formaban parte de una estrategia de guerra sucia contra la oposición política creada desde el Estado y sostenida por las tácticas de sus fuerzas militares regulares durante décadas.

Como hemos anotado antes, el Informe General del Grupo de Memoria Histórica GMH ha realizado una aproximación a las cifras oficiales del conflicto armado en Colombia, entre las que resaltamos, 220.000 muertes entre 1958 y 2012, de las 
cuales el $81 \%$ han sido víctimas civiles, más de 25.000 desapariciones forzadas relacionadas con el conflicto reconocidas por el Registro Único de Víctimas y casi 6 millones de víctimas de desplazamiento forzado. No obstante la escalofriante magnitud de estas cifras, ese es solo uno de los aspectos en los cuales el conflicto ha impactado a la sociedad colombiana. La profesora Martha Nubia Bello advierte en la presentación del informe: “Además de la magnitud de muertos, los testimonios ilustran una guerra profundamente degradada, caracterizada por un aterrador despliegue de sevicia por parte de los actores armados sobre la inerme población civil’. Y destaca más adelante:

"Ahora bien, la probada participación de agentes estatales como perpetradores de crímenes, resulta particularmente inquietante para la sociedad, el Estado en su conjunto, y para ellos mismos, dado el grado particular de legalidad y responsabilidad que les compete. Además de su participación directa en la violación de Derechos Humanos, todos los casos documentados por el GMH registran con notable regularidad la connivencia y las omisiones de miembros de la Fuerza Pública, con acciones violatorias de los Derechos Humanos y alianzas con grupos poderosos que por métodos violentos defienden intereses económicos y políticos, o buscan con codicia el acceso a más tierra y/o recursos" (Grupo de Memoria Histórica, 2013, p. 20).

Y a pesar de todo lo anterior, la profesora Bello hace notar además que:

“... la guerra se ha librado mayoritariamente en el campo colombiano, en los caseríos, veredas y municipios, lejanos y apartados del país central o de las grandes ciudades. Es una guerra que muchos colombianos y colombianas no ven, no sienten, una guerra que no los amenaza. Una guerra de la que se tiene noticia a través del lente de los medios de comunicación, que sufren otros y que permite a miles de personas vivir en la ilusión de que el país goza de democracia plena y prosperidad, a la vez que les impide entender la suma importancia de cada decisión, 
afirmación o negociación política para quienes la sufren" (Grupo de Memoria Histórica, 2013, p. 22).

Como lo reconocen los datos del Grupo de Memoria Histórica y del Registro Único de Víctimas, entre los últimos años del siglo XX y los primeros del XXI la degradación del conflicto y la victimización de la población civil alcanzo su mayor exacerbación a manos de los grupos paramilitares y sus estrategias de horror. Las masacres, caracterizadas por ser asesinatos múltiples ejecutados en medio de ritos aterradores en los que se realizaban torturas, desmembramientos, violaciones sexuales y todo tipo de humillaciones a las comunidades para amedrentarlas o desplazarlas, se concentran especialmente en este periodo, más de mil masacres fueron cometidas entre 1996 y 2002 (Grupo de Memoria Histórica, 2013, p. 47)

Este contexto resulta determinante para el análisis y la comprensión del proceso del surgimiento y evolución del Movice como un proceso de lucha por los derechos a la verdad, la justicia y la reparación para las víctimas del conflicto y especialmente por el reconocimiento y la visibilización de los crímenes cometidos por las fuerzas estatales directamente o por medio de estrategias de guerra sucia como lo es, para ellos, el paramilitarismo.

4.1.2. La Legalidad y la Impunidad del paramilitarismo: la historia de los crímenes de Estado vista por el Movice

Como lo reconoce el Informe General del GMH, a partir de la documentación de los casos tratados en los diversos informes que ha elaborado, se puede observar en la reconstrucción histórica, por un lado, que la permisividad y la omisión por parte de la fuerza pública se constituyeron en una situación recurrente que facilitó la comisión de miles de crímenes de los paramilitares y, por otro, que quedó ampliamente demostrada su participación directa en la ejecución de otros tantos. La realidad de los crímenes de Estado en Colombia está rigurosamente documentada en numerosos expedientes judiciales a nivel nacional $y$ en instancias internacionales, así como en numerosos estudios académicos, incluso de origen 
oficial como el del $\mathrm{GMH}^{15}$. No obstante, a diferencia de otros planteamientos como el del informe del GMH, el Movice ha enfatizado reiteradamente que para el proceso de reconstrucción de la memoria histórica sobre el conflicto colombiano es importante reconocer que estos crímenes no han sido un comportamiento “ocasional" de agentes particulares, sino que hacen parte de "una lógica política estratégica" del comportamiento del Estado en el conflicto, planteamiento que ha sido ampliamente desarrollado en el informe Paz sin crímenes de Estado, memoria y propuestas de las víctimas, presentado por el Movice en noviembre de 2013.

El estudio del Movice examina y da cuenta de la criminalidad estatal en dos periodos. El primero periodo, entre 1946 y 1959, está caracterizado por la creación de una sección especial de la Policía, conocida popularmente como los "chulavitas", conformada para ejecutar los crímenes en contra de la militancia liberal y comunista ordenados por los gobiernos conservadores de Mariano Ospina y Laureano Gómez y mantenida durante la dictadura de Gustavo Rojas Pinilla y la Junta Militar. En este apartado el Movice recoge los datos de monseñor Germán Guzmán quien cuantificó las muertes violentas relacionadas con la violencia bipartidista en cerca de 180 mil (Moncaleano, Tenthoff, Samudio, \& Duarte, 2013, p. 18).

El segundo periodo estaría comprendido entre 1979 y 2012, comenzando con la instauración del Frente Nacional en el cual, según el Movice, se instituyó un pacto entre las élites dirigentes liberales y conservadoras para asegurar el control del Estado y se adoptó la estrategia paramilitar para exterminar cualquier oposición a esa hegemonía. Esta estrategia paramilitar se originó en la misión militar estadounidense encabezada por el General Yarborough en 1962, a partir de la cual se enmarcó la lucha contrainsurgente en Colombia dentro de la política anticomunista norteamericana y se exigió a los gobiernos colombianos combatir la

\footnotetext{
${ }^{15}$ Sobre este tema se puede consultar: GUZMÁN, UMAÑA y FALS BORDA. La Violencia en Colombia, estudio de un proceso social. Ed. Tercer Mundo. Bogotá. 1962; URIBE, María Victoria. Violencia y masacres en el Tolima: desde la muerte de Gaitán al Frente Nacional. En Credencial Historia No. 18. Bogotá, junio de 1991; Deuda con la humanidad. paramilitarismo de Estado en Colombia 1988 - 2003. CINEP. Bogotá. 2004; ROMERO, Mauricio. Editor. Parapolítica. La ruta de la expansión paramilitar y los acuerdos políticos. Corporación Nuevo Arco Iris. Bogotá. 2007; RONDEROS, María Teresa. Guerras Recicladas. Ed. Aguilar. Bogotá. 2014.
} 
simpatía por la ideología comunista mediante "actividades terroristas paramilitares". A partir de entonces esta doctrina orientó la formación militar contrainsurgente contenida en las normas sobre seguridad nacional y en los manuales de las fuerzas militares colombianas, resaltándose dos premisas principales: por un lado, la doctrina difumina la distinción entre lo civil y lo militar y apunta a involucrar a la población civil en el conflicto armado ya sea como amigos o como enemigos según sus opiniones frente a las políticas oficiales; por otro lado, mediante la estrategia paramilitar se da rienda suelta a la barbarie criminal como mecanismo de disuasión mediante el terror para evitar la colaboración de la población con el enemigo interno pero de manera encubierta pretendiendo no afectar la legitimidad del Estado (Moncaleano et al., 2013, p. 21). Para el Movice entonces, está claramente demostrado que los crímenes de lesa humanidad cometidos por las fuerzas militares y los grupos paramilitares en contra de la población civil que expresa posiciones políticas distintas a las oficiales han constituido una política de Estado contenida en documentos con carácter jurídico administrativo vinculante y que se han mantenido vigentes a través de los sucesivos gobiernos.

Para analizar esta política el informe del Movice divide este periodo en cuatro fases. En la primera entre 1962 y 1981, se da cuenta de la creación del marco legal del paramilitarismo a partir del Decreto 3398 de 1965 que fue el antecedente directo de la ley 48 de 1968 y del Reglamento de Combate Contraguerrillas de 1969, donde se contemplaba la creación de grupos de "autodefensas" constituidos por civiles armados. Bajo la vigencia de la Ley 48 de 1968, una sucesión de manuales de contrainsurgencia de las fuerzas militares mantuvieron la inclusión de modalidades de guerra sucia como el paramilitarismo y el hostigamiento a la población civil. Para el Movice, en este periodo, la mayor parte de los crímenes recaían aun directamente sobre las fuerzas militares a quienes se otorgaron poderes extraordinarios que alcanzaron su paroxismo en el Decreto 1923 de 1978 mediante el cual se les permitió detener, incomunicar y juzgar secretamente a personas “sospechosas" de delitos políticos. El Informe da cuenta de más de 60 mil detenciones arbitrarias, más de 20 mil casos de tortura y más de mil asesinatos 
atribuibles a la fuerza pública. Desde entonces, la desaparición forzada de personas es una de las tragedias humanitarias que ha azotado terriblemente a la sociedad colombiana.

La segunda fase tiene lugar entre 1981 y 1989 y abre paso a la aparición pública y expansión del paramilitarismo a partir de su articulación con el narcotráfico. En 1981 se creó el grupo MAS (Muerte a Secuestradores) con la participación de los principales capos del narcotráfico, políticos y miembros activos de la fuerza pública. En 1982 se creó el grupo MORENA (Movimiento de Renovación Nacional) que alrededor de las actividades del Batallón Bárbula en Puerto Boyacá organizó el accionar de políticos regionales, narcotraficantes y mercenarios internacionales. De la misma manera, alrededor de los batallones de la fuerza pública, en diferentes regiones surgieron alianzas entre narcotraficantes, terratenientes, políticos y militares para garantizar el control territorial. En esta perspectiva, entre 1985 y 1989, ocurrió el exterminio contra la Unión Patriótica, movimiento político de izquierda surgido a partir de las negociaciones de paz entre el gobierno y las FARC-EP, que tuvo una exitosa participación en las elecciones regionales de 1986 y del cual fueron asesinados en este periodo más de 500 dirigentes, en medio de una guerra sucia que se constituiría en todo un genocidio con más de 5 mil víctimas, perpetrado conjuntamente por paramilitares y agentes estatales, tal como lo reconoce la condena al Estado colombiano proferida por la CIDH en 2010 (Corte Interamericana de Derechos Humanos, 2010). El Informe calcula en total más de 20 mil víctimas mortales en esta fase, hasta 1989 cuando fueron derogados los apartes de la Ley 48 que sustentaban legalmente a los grupos paramilitares.

La tercera fase de evolución de la estrategia paramilitar para la represión política se ubica entre 1990 y 2002. Este periodo está enmarcado por la promulgación de la nueva Constitución Política de Colombia en 1991 y la caracterizan dos hechos fundamentales: por un lado, la aparición de un nuevo fundamento legal para las actividades paramilitares mediante el Decreto 356 de 1994 que dio origen a las tristemente célebres cooperativas de vigilancia privada CONVIVIR y, por otro 
lado, la progresiva consolidación del pie de fuerza paramilitar hasta la conformación de las Autodefensas Unidas de Colombia AUC. Con todo esto el proyecto paramilitar se convirtió en un fenómeno mucho más ambicioso y peligroso de lo que el establecimiento mismo había pretendido, hasta que finalmente entró en una franca disputa por el poder político y el control del Estado. Este proceso de evolución del paramilitarismo marcó el periodo más sangriento y degradado del conflicto armado en Colombia. El Informe del Movice da cuenta de más de 50 mil asesinatos asociados a masacres y torturas.

Pero aún más aterradora resulta la utilización de la desaparición forzada como mecanismo de encubrimiento. La Fiscalía General de la Nación ha dado cuenta de más de 25 mil desapariciones y ha constatado la utilización de fosas comunes, hornos crematorios, descuartizamientos y hasta de animales carnívoros como caimanes para la desaparición de los cuerpos; al tiempo, datos de la Unidad de Atención a Víctimas señalan que el conflicto armado ha dejado cerca de 45 mil personas desaparecidas. En cualquier caso, para el Movice es claro que los paramilitares requerían "el apoyo y protección institucional para perpetrar baños de sangre de tal magnitud en completa impunidad, situación que seguramente alentó sus proyectos de comprar y controlar el Estado en su totalidad, como se revelará en la fase siguiente" (Movimiento Nacional de Víctimas de Crímenes de Estado, Fundación Comité de Solidaridad con los Presos Políticos, \& Corporación Colectivo de Abogados José Alvear Restrepo, 2009, p. 29).

La cuarta fase la establece el Informe entre los años 2002 y 2010 que corresponde a los dos periodos del gobierno de Álvaro Uribe, periodo durante el cual se da cuenta de más de 8 mil asesinatos entre los cuales se destacan más de 3 mil cometidos bajo la modalidad de los conocidos popularmente como "falsos positivos", que consiste en el asesinato inerme de personas con el fin de presentarlas como delincuentes dados de baja en combate por parte de la fuerza pública, con el objeto de presentar cifras exitosas en materia de seguridad. 
El contexto de la violencia política expresada en los crímenes cometidos, ya directamente desde las fuerzas regulares del Estado o por medio de su estrategia paramilitar, así como en la negación tozuda de esos crímenes y en la implementación de mecanismos de impunidad para sus autores, constituirá el marco que definirá el sentido de los agravios sufridos por las víctimas y de la necesidad de la movilización colectiva para la visibilización y la exigibilidad de sus derechos.

\subsubsection{El monólogo entre el gobierno y los paramilitares}

En el año 2002 llegó a la presidencia de Colombia Álvaro Uribe Vélez apalancado en un discurso de lucha contra el terrorismo, el cual gozaba de una amplia popularidad tras el reciente fracaso de los diálogos de Andrés Pastrana con la guerrilla de las FARC-EP ${ }^{16}$ y tras los atentados en Estados Unidos en septiembre de 2001. Para entonces los grupos paramilitares habían excedido su propósito de control militar territorial y disputaban el control político local y regional incursionado de manera directa en todos los niveles de la política electoral en el país mediante alianzas o imposiciones de candidatos, desde las alcaldías o concejos municipales hasta en el Congreso de la República, y habían iniciado la cooptación de diversas entidades públicas como universidades y entidades de salud (M. Romero, 2007).

Para muchas organizaciones sociales y de defensa de los derechos humanos, el gobierno de Uribe, aún más que sus antecesores, desplegaba su discurso de la “seguridad democrática" en contra de cualquier sector de oposición política por un lado, mientras por otro evidenciaba su simpatía con el proyecto paramilitar de cooptación o "refundación"17 del Estado y su compromiso con el proceso de

\footnotetext{
${ }^{16}$ El Fallido proceso de conversaciones de paz adelantado entre el gobierno de Andrés Pastrana y las FARC-EP tuvo lugar entre enero de 1999 y febrero de 2002.

17 La "refundación de la patria" fue un término extraído del Pacto de Ralito que se acuño como etiqueta para referirse al proyecto político, económico y militar que se hizo público en 2006 cuando se conocieron documentos que demostraban los pactos ilegales y criminales realizados entre paramilitares, políticos, empresarios y funcionarios públicos en diferentes regiones del país, con el objeto de constreñir las jornadas electorales de 2002 y de cooptar entidades y recursos del Estado. El descubrimiento de estos pactos dio lugar a los procesos judiciales conocidos como "parapolítica".
} 
impunidad para el desmonte de sus estructuras criminales más repudiadas y la legalización de sus más sofisticadas estructuras logísticas, económicas y políticas (Moncaleano et al., 2013, p. 30).

Desde el comienzo de su mandato, el gobierno Uribe inició gestiones para proveerse con las herramientas jurídicas y el respaldo político que le permitieran sacar avante un proceso de desmovilización de los grupos paramilitares que para ese entonces se habían agrupado en las autodenominadas Autodefensas Unidas de Colombia AUC. Como primera medida, el gobierno solicitó al Congreso la prórroga de la Ley 418 de 1997 que establecía las condiciones para las negociaciones con grupos armados al margen de la ley y cuya vigencia expiraba en diciembre de 2002. En segundo lugar, mediante la Ley 782 de 2002, que prorrogó la vigencia de la Ley 418, el gobierno logró que el Congreso derogara la exigencia que la ley hacia sobre el reconocimiento de estatus político a los grupos con los que se entablaran negociaciones.

Al tiempo con la expedición de la Ley 782, en diciembre de 2002, las AUC expidieron un comunicado en el que anunciaban un cese unilateral de hostilidades, su disposición para las conversaciones y, además, solicitaban el reconocimiento como actor político del conflicto, la excarcelación de los paramilitares presos y que el gobierno garantizara el sostenimiento de sus tropas (Semana, 2002). Finalmente el gobierno y los paramilitares firmaron el Acuerdo de Santa Fe de Ralito el 15 de julio de 2003 mediante el cual daban inicio formal a la negociación. En agosto de este mismo año, el gobierno presentó al congreso el "Proyecto de Alternatividad Penal", mediante el cual buscaba otorgar a los paramilitares el estatus de "sediciosos", es decir delincuentes políticos, incluyendo así la posibilidad del indulto o "suspensión de la pena" incluso para los responsables de crímenes atroces, de guerra y de lesa humanidad, pues estos habían quedado excluidos en la Ley 782 de 2002 y eso generaba incertidumbre sobre la situación jurídica de los jefes paramilitares. 
De esta manera, el proyecto dejaba ver la intención de legalizar el poder político acumulado por las estructuras paramilitares y por sus figuras más visibles, mientras sus crímenes quedaban en la impunidad (Gómez Sánchez, 2011, p. 148). En palabras del entonces Senador Juan Fernando Cristo:

"La ausencia de verdad, justicia y reparación en el proyecto era tan evidente y el propósito de impunidad tan descarado, que hasta los propios amigos del gobierno en la Comisión Primera del Senado -con pocas excepciones- se negaron a apoyar la iniciativa y expresaron su disposición a respaldar el proceso con un instrumento legal distinto, 'más presentable', según sus palabras" (Cristo, 2012, p. 29).

De esta manera, el anuncio de un proceso de negociación entre el gobierno y los paramilitares fue considerado por las ONGs de derechos humanos, por las organizaciones sociales y por las víctimas de los crímenes de lesa humanidad como una treta, urdida por los sectores del establecimiento que habían auspiciado a estos grupos criminales, para legalizar el despojo de tierras, la cooptación de las entidades públicas y en general el control político, económico y militar, obtenidos a sangre y fuego en amplias zonas del territorio nacional (Carreño, 2003; Cepeda, 2004). Este hecho, en los términos planteados, constituía un agravio intolerable para las organizaciones sociales y de derechos humanos, pues, al mismo tiempo, dejaba en la impunidad crímenes atroces, legalizaba los beneficios y los beneficiarios de esos crímenes y desconocía cínicamente los derechos de las víctimas.

\subsubsection{Resistencia civil y lucha contra la impunidad}

Lar organizaciones de derechos humanos habían aparecido en Colombia a finales de la década de 1970, especialmente como grupos de profesionales que apoyaban y acompañaban a los movimientos sociales y políticos que luchaban contra la exclusión política impuesta por los gobiernos del Frente Nacional. Paradójicamente, la labor de estas organizaciones se incrementó sustancialmente luego de finalizado el periodo de vigencia del Frente Nacional cuando en 1978 el 
gobierno de Julio Cesar Turbay Ayala profundizó la represión y la persecución a las manifestaciones sociales de protesta con la implantación del tristemente célebre Estatuto de Seguridad ${ }^{18}$. Bajo el auspicio del estatuto de seguridad de Turbay, las fuerzas de seguridad del Estado efectuaron detenciones arbitrarias, torturas, juicios militares contra civiles y en general todo tipo de atropellos con la consigna de la lucha contra el "enemigo interno" derivada de la Doctrina de Seguridad Nacional impuesta por los Estados Unidos en toda Latinoamérica en el marco de la guerra fría. Esta situación creó preocupación tanto a nivel nacional como internacional y propició la realización del Primer Foro Nacional de Derechos humanos en 1978 y las visitas de verificación de Amnistía Internacional y la Comisión Interamericana de Derechos Humanos en 1980 (Archila \& Pardo, 2001, p. 447).

Para mediados de la década de 1990 un grupo de organizaciones de derechos humanos que ya contaban con una amplia trayectoria, tras una ardua labor de reconocimiento de las violaciones a los derechos humanos en todo el país y ante la evidencia de la profunda responsabilidad de las fuerzas de seguridad del Estado en muchas de esas violaciones y en la rampante impunidad que las fomentaba, decidió emprender una campaña de denuncia a nivel nacional e internacional denominada Colombia Derechos Humanos Ya. La realización de esta gran campaña de denuncia les permitió a las organizaciones conocer y compartir con distintas experiencias de lucha contra la impunidad a nivel internacional, pero también, constatar la renuencia sistemática del Estado colombiano a reconocer, prevenir y castigar las violaciones de derechos humanos que se estaban presentando.

Esta fue la razón que motivó a las organizaciones para comenzar a dar forma a lo que sería el Proyecto Colombia Nunca Más para la lucha contra los crímenes de lesa humanidad en el país. Así fue que en 1996, 17 organizaciones de derechos humanos y organizaciones sociales se reunieron y se impusieron la tarea de registrar, documentar y sistematizar los casos de crímenes de lesa humanidad en las diferentes regiones donde trabajaban, con el objetivo de visibilizar la existencia de tales crímenes, luchar contra la impunidad que los cobijaba, así como recuperar y

${ }^{18}$ Decreto Extraordinario 1923 del 6 de septiembre de 1978. 
dignificar la memoria histórica de sus víctimas («Proyecto Colombia Nunca Más», s. f.)

Para el año 2002 el movimiento de derechos humanos colombiano ya contaba con una amplia red de organizaciones a nivel nacional y con un amplio reconocimiento entre entidades y organizaciones internacionales. Algunas de las más importantes ONGs nacionales habían sido reconocidas con estatus consultivo por la ONU y mantenían dentro de sus actividades rutinarias la documentación de casos y la elaboración periódica de informes sobre las violaciones a los derechos humanos en el país. El Proyecto Colombia Nunca Más, entre otras iniciativas, había avanzado más allá de la denuncia, documentación y judicialización de los casos individuales, había emprendido la tarea de elaborar documentos de contextualización y análisis global sobre las características de los crímenes de lesa humanidad cometidos en el país y sobre las estrategias de impunidad que los rodeaban y fomentaban. Para entonces, diversas organizaciones que habían realizado este tipo de análisis, ya definían y ubicaban el origen del paramilitarismo en Colombia en la estrategia de la guerra contrainsurgente del Estado, consignada en los manuales de entrenamiento militar desde 1962, a veces amparada legalmente, a veces tolerada de manera irregular, a veces auspiciada de manera clandestina (Centro de Investigación y Educación Popular, 2004, p. 17; Proyecto Colombia Nunca Más, 2000, p. 28).

Después de años de una intensa represión y de la rutinización de las acciones de documentación y denuncia de los crímenes, la movilización social volvió a ser planteada como forma principal de oposición política frente a los agravios y las amenazas del poder. Los nuevos intentos de amparo legal al paramilitarismo, la estigmatización y criminalización de la oposición política mediante los discursos y las normas antiterroristas, la cooptación de los aparatos estatales a nivel local y regional, el desconocimiento de los crímenes y de los derechos de las víctimas, fueron algunos de los argumentos presentados por un grupo de organizaciones sociales que en mayo de 2004 convocaron al primer "Encuentro Nacional de Víctimas de Crímenes de Lesa Humanidad”, planteándolo así: 
"En Colombia las violaciones a los derechos humanos y crímenes de lesa humanidad son sistemáticas y persistentes desde el estamento oficial, con el fin de eliminar los opositores políticos y movimientos sociales organizados que durante décadas han ejercido oposición, exigiendo reivindicación y aplicación de los derechos humanos.

Desde la década de los sesenta, los grupos de autodefensa o paramilitares fueron creados por decretos y normas de Estado de Sitio. Hoy se pretende desconocer el largo historial de los horrores cometidos contra amplios sectores populares, gestando desde el Estado políticas que buscan leyes de perdón y de olvido y mayor impunidad, premiando con amnistías e indultos a los responsables de masacres, asesinatos de líderes políticos y sociales, desapariciones forzadas, torturas, desplazamiento forzado, bombardeos, estigmatizaciones, señalamientos, detenciones masivas y arbitrarias, campañas sicológicas de terror, control de poblaciones y de territorio y empadronamientos entre otros, cometidas contra los Colombianos.

Ante la negación y tergiversación de los postulados de la verdad y de la justicia frente a las violaciones de derechos humanos, con estatutos antiterroristas y leyes de alternatividad penal.

Ante la dinámica militar de fragmentación de familias, grupos, comunidades y organizaciones, a través de judicializaciones, señalamientos, amenazas, controles territoriales y reinstitucionalización del paramilitarismo que niega los derechos de las víctimas.

Ante la decadencia del aparato de investigación judicial a través de nuevos mecanismos de impunidad y el cuestionamiento a la independencia judicial.

Ante la desinformación y ocultamiento por parte de los grandes medios de comunicación de las propuestas y exigencias de las víctimas de Crímenes de Lesa Humanidad. 
Convocamos al Encuentro Nacional de Víctimas de Crímenes de Lesa Humanidad"19.

Esta convocatoria fue realizada por 39 organizaciones sociales, de víctimas y de derechos humanos, y al encuentro asistieron alrededor de 400 personas, entre víctimas, familiares y representantes de organizaciones, provenientes de todas las regiones del país (Movice, s. f.-b). Durante el encuentro se estudiaron temas como: las estrategias de represión del Estado, los orígenes y la financiación del paramilitarismo, los componentes de la Política de Seguridad Democrática del gobierno Uribe, el Estatuto Antiterrorista, el Proyecto de Ley de Alternatividad Penal y las propuestas desde las víctimas para la verdad, la justicia y la reparación integral. Al final del evento, los participantes suscribieron el "Manifiesto por la verdad, la justicia y la reparación integral", documento en el cual constatan la existencia de las "víctimas de la actuación abierta o encubierta del Estado colombiano a través de las fuerzas armadas legales y los grupos paramilitares", afirman que la política de seguridad democrática y la negociación del gobierno con los paramilitares "pretende la legitimación y consolidación de esta estrategia", reclaman los derechos a la Verdad, la Justicia y la Reparación Integral como derechos innegociables de las víctimas de crímenes contra la humanidad", y especialmente anuncian:

Hacer pública nuestra voluntad de avanzar firmemente hacia la conformación de un movimiento nacional en el que, coordinada y mancomunadamente, converjan las personas, comunidades y organizaciones víctimas de los crímenes contra la humanidad cometidos en Colombia (Movice, 2004).

Es de resaltar que, a pesar de las contundentes afirmaciones planteadas tanto en la convocatoria inicial como en el manifiesto final, antes, durante y después del evento se presentó un interesante debate alrededor de la identidad del naciente movimiento,

\footnotetext{
${ }^{19}$ Facsímil de la convocatoria al "Encuentro Nacional de Víctimas de Crímenes de Lesa Humanidad. Propuestas por la Verdad, la Justicia y la Reparación Integral”, realizado en Bogotá, durante el 27, 28 Y 29 de mayo de 2004.
} 
pues, aun cuando se señalaba claramente al Estado como el principal agente responsable de los crímenes de lesa humanidad cometidos por sus fuerzas legales o ilegales, entre los miembros de muchas organizaciones regionales persistía un profundo temor a identificarse como víctimas de Estado, por lo cual los participantes decidieron constituirse como "Movimiento Nacional de Víctimas de Crímenes de Lesa Humanidad".

En este sentido, se debe recordar que una de las estrategias de la política de seguridad democrática del gobierno Uribe fue la implementación de las llamadas “zonas de rehabilitación y consolidación”, que consistían en delimitar algunas zonas del territorio nacional, principalmente zonas rurales, definidas en función de intereses militares, donde la fuerza pública contaba con atribuciones especiales que desconocían los derechos constitucionales de los ciudadanos, lo cual derivó en procesos de estigmatización y persecución en contra de la población civil, algunos tan absurdos y abyectos como el caso de la detención de 2 mil personas por parte del ejército el 12 de noviembre de 2002 en el Municipio de Saravena ${ }^{20}$ en una sola de las redadas que por entonces fueron conocidas como "detenciones masivas", dirigidas fundamentalmente a desvertebrar las organizaciones sociales y de derechos humanos (Amnistía Internacional, 2004, p. 16).

En el mismo sentido, se debe considerar también, que en el marco de la política pública para la atención de la crisis humanitaria generada por las graves violaciones a los derechos humanos, a partir del anuncio del proceso de negociación con los grupos paramilitares, la posición oficial del gobierno consistió en la negación de la existencia de las víctimas de estos grupos bajo el argumento de que habían desaparecido a partir de su concentración, con lo cual, a quienes manifestaban haber sido víctimas de crímenes de los paramilitares se le negaba el derecho a ser registrados en las bases de datos de víctimas lo mismo que a quienes se referían a acciones del Estado (Corte Constitucional de Colombia, 2009). Esta práctica tuvo consecuencias especialmente sensibles entre la población víctima de

\footnotetext{
${ }^{20}$ Pequeño municipio situado en el departamento de Arauca en el oriente colombiano que contaba para la época con aproximadamente 30 mil habitantes.
} 
desplazamiento forzado, la cual, en medio de la angustia y de la inopia, entendió que para acceder a alguna ayuda humanitaria debía declararse víctima de la guerrilla.

En el mes de agosto de 2004, con el respaldo de entidades como la Facultad de Derecho de la Universidad Nacional de Colombia y de la Comisión de Derechos Humanos del Senado de la República, el cual provino gracias al apoyo de personas como la profesora Lilia Solano y la Senadora Piedad Córdoba, se llevó a cabo un nuevo evento dedicado a la resistencia de las víctimas y la lucha contra la impunidad. El "Encuentro de Voces del Mundo por la Vida en Colombia" reunió de nuevo a las víctimas, a sus familiares y a sus organizaciones y contó con el acompañamiento de personalidades de la academia y la política de Latinoamérica, Europa y Estados Unidos. Este evento hoy cuenta con gran recordación debido al incidente que se conoció años después, en el 2010, cuando estalló el gran escándalo y se conoció que el Departamento Administrativo de Seguridad DAS realizó toda clase de actividades ilegales, tales como seguimientos, interceptaciones y saboteos, tanto en Colombia como en sus países de origen, en contra de las personalidades y las instituciones extranjeras que participaron en el encuentro (El Espectador, 2010; Justicia por Colombia, 2010).

\subsubsection{Las víctimas del Estado perseveran en su lucha}

El 7 de abril de 2005 el Movimiento Nacional de Víctimas de Crímenes de Lesa Humanidad se movilizó y organizó un mitin en la Plaza de Bolívar de Bogotá, frente al Congreso de la República, para manifestar su rechazo frente al trámite del Proyecto de Ley de Alternatividad Penal, que para entonces había sufrido una serie de modificaciones y era conocido como Proyecto de Ley de Justicia y Paz. Durante la manifestación, el movimiento dejó ver algunos rasgos que más adelante se convertirán en aspectos representativos de su identidad y su repertorio de acciones. La manifestación tuvo un carácter profundamente simbólico, los participantes se vistieron de negro, llevaron flores y dispusieron un ataúd y una galería con las imágenes y los nombres de cientos de víctimas en representación y homenaje a los 
miles de asesinados, desaparecidos, torturados, desplazados y perseguidos por las fuerzas militares y paramilitares, exigieron la realización de sus derechos a la verdad, a la justicia y a la reparación integral y la erradicación total de los crímenes de Estado y de la guerra sucia. El acto duró todo el día y allí mismo los manifestantes presentaron la convocatoria para la realización del Segundo Encuentro Nacional de Víctimas de Crímenes de Lesa Humanidad, que habría de llevarse a cabo en el mes de junio de ese año.

De esta manera, desde las víctimas se iba resaltando el proceso de polarización política que producía en la sociedad colombiana el tratamiento que el gobierno quería imponer frente a los temas centrales que involucraba el proceso negociación con los grupos paramilitares, pues la impunidad con la cual se buscaba cobijar a los crímenes y los criminales contrastaba con el desconocimiento de los derechos de las víctimas y la represión a sus protestas. En un análisis sobre la asimetría de la situación de los derechos de las víctimas en relación con los intereses de los sectores del poder político durante el trámite de la Ley de Justicia y Paz, el profesor Gabriel Ignacio Gómez la relata así:

"La emergencia de un discurso hegemónico en materia de seguridad, liderada especialmente por el gobierno de Álvaro Uribe, trajo consigo la redefinición de los términos del conflicto, en la medida que para el gobierno, no había conflicto político sino 'amenaza terrorista'. Así mismo promovió una nueva construcción política de enemigos y amigos, en virtud de la cual los enemigos, dejaban de ser percibidos como contendores con los cuales se podía promover una negociación política, para adquirir la categoría de “terroristas" con quienes era inadmisible adelantar un proceso de paz. Por su parte, las representaciones de los grupos paramilitares, que décadas atrás habían sido considerados los mayores desestabilizadores del país y los responsables de múltiples violaciones de derechos humanos, se transformaban de tal manera que para comienzos de la década anterior comenzaban a ser considerados como adversarios con los cuales se podía intentar una negociación política. En este contexto, el conflicto político, 
lejos de estar resuelto, y a pesar de ser negado por el gobierno de Álvaro Uribe, persistía en el lenguaje político, en las representaciones sobre "amigos" y "enemigos", en las medidas institucionales adoptadas, en los debates (y silencios) públicos, en las prácticas sociales de la vida cotidiana y en el escenario micro político de los procesos judiciales. En este contexto, el alto nivel de apoyo por parte de la opinión pública y los medios de comunicación al gobierno de Uribe, así como cierto nivel de aceptación en algunos sectores sociales de los grupos paramilitares como un 'mal necesario', contrastaban con el débil respaldo político de las organizaciones de derechos humanos en el contexto nacional y, aún más, con la invisibilidad y marginalidad de las víctimas de violaciones de derechos humanos" (Gómez Sánchez, 2012, p. 99).

Esta asimetría se expresó de manera irrefutable en los hechos ocurridos el 28 de julio de 2004. En medio de las críticas que ya levantaban el proceso de negociación y el proyecto de ley que se estaba tramitando, el Gobierno y algunos congresistas decidieron promover la asistencia de tres jefes paramilitares a una audiencia en el capitolio nacional. Sin vergüenza propia o ajena, frente a la gran mayoría del parlamento, los cabecillas se presentaron como héroes "sacrificados por la patria", le increparon exigencias al país y se negaron rotundamente a recibir como "recompensa" a su sacrificio el encarcelamiento. Semejante espectáculo fue una exhibición de la arrogancia de los criminales, que dejó en vergonzosa evidencia a un grupo de parlamentarios que los aplaudieron impúdicos, ante la mirada desconcertada de la mayor parte de la opinión pública nacional e internacional que siguió los acontecimientos en directo por la transmisión de la televisión pública. Y mientras los asesinos eran aplaudidos, el defensor de derechos humanos, Iván Cepeda, quien sostenía en silenció un retrato de su padre, el Senador Manuel Cepeda asesinado por esos paramilitares, fue obligado a salir del recinto junto con la profesora Lilia Solano quien desde la tribuna del salón exigía verdad, justicia y reparación para las víctimas (Faciolince, 2004). 
Pero la situación más representativa de ese contraste se vivió paralelamente en la Plaza de Bolívar, afuera del Congreso, donde se manifestaba un grupo de víctimas y miembros de organizaciones de derechos humanos, marchando alrededor de la plaza, vestidos de negro, con sombrillas negras y cargando dos ataúdes abiertos que contenían miles de papeletas marcadas con los nombres de miles de víctimas. Hasta allí llegó una romería de personas en caravanas preparadas desde diversas regiones de influencia paramilitar, con camisetas y carteles de respaldo a los grupos paramilitares, quienes se enfrentaron y agredieron a los manifestantes. Ante la tensa situación, la reacción de la Policía consistió en impedir que las víctimas continuaran con su manifestación, entregando el uso exclusivo del espacio público a los simpatizantes de los paramilitares (El Tiempo, 2004; Gómez Sánchez, 2011, p. 157).

Este acontecimiento, sin embargo, fue contraproducente para los intereses promovidos por el Gobierno pues profundizó las críticas y las polémicas frente al manejo del proceso, especialmente en la comunidad internacional, pero también en sectores políticos nacionales que, aunque hasta entonces habían apoyado al Gobierno, en esta ocasión rechazaron abiertamente el espectáculo y comenzaron a abrir fisuras en la coalición gobernante, las cuales se notarían más adelante (KienyKe, 2011).

Un día después de la aprobación de la Ley 975 de 2005 por parte del Congreso, conocida como Ley de Justicia y Paz, se inició el Segundo Encuentro Nacional de Víctimas de Crímenes de Lesa Humanidad el cual se llevó a cabo en Bogotá entre el 23 y el 25 de junio de 2005. A este encuentro asistieron más de 800 delegados de organizaciones sociales, de víctimas y de derechos humanos de todo el país y contó con el respaldo y la asistencia de personalidades y representantes de diversas entidades nacionales e internacionales, entre ellas, la Senadora de la República Piedad Córdoba y el Representante en Colombia de la Oficina del Alto Comisionado de las Naciones Unidas para los Derechos Humanos Michael Frühling. 
Uno de los aspectos más importantes en el desarrollo del evento sería la discusión que venía planteada desde el encuentro anterior alrededor de la identidad del movimiento. En esta ocasión, la discusión la lideró el entonces conocido activista de derechos humanos Iván Cepeda, director de la Fundación Manuel Cepeda Vargas, ONG de derechos humanos creada en homenaje a su padre quien fue Senador de la República por el partido político Unión Patriótica y quien fue asesinado por los paramilitares en connivencia con agentes del Estado, junto con miles de copartidarios (Corte Interamericana de Derechos Humanos, 2010).

El señor Cepeda, durante su intervención en el Encuentro hizo un vehemente llamado al movimiento para definirse claramente como el movimiento de las víctimas del Estado, con una propuesta de lucha contra la impunidad, argumentando que el proceso que se venía adelantando entre el gobierno y los paramilitares, no solamente cubría de impunidad los crímenes atroces cometidos por los paramilitares como autores materiales, sino que además sumía en el silencio y el olvido la responsabilidad que correspondía a sectores políticos, económicos y militares que desde el poder del Estado habían promovido y se habían beneficiado de esos crímenes.

Otro argumento que ayudó a definir la discusión durante el encuentro, fue la necesidad de asumir una reacción frente a la estrategia de creación de organizaciones formales de víctimas por parte de sectores cercanos a los paramilitares y al gobierno, con el objetivo de generar confusión pública con respecto a los conceptos de los derechos de las víctimas, en torno a la verdad sobre los crímenes cometidos, a las formas de justicia aplicables y a los elementos mínimos de reparación y garantía de no repetición de esos crímenes (Entrevista 23). Bajo estas circunstancias nació formalmente el Movice, cuya acta de constitución fue suscrita por los asistentes al encuentro en su declaración final (Movice, 2005).

De esta manera el movimiento definió claramente su identidad acogiendo a las víctimas directas, a los familiares de víctimas y a las organizaciones acompañantes de víctimas de los crímenes de lesa humanidad, de los crímenes de guerra y del 
genocidio político, cometidos por el Estado colombiano, directamente o mediante estrategias paramilitares y de guerra sucia, al tiempo que señaló claramente su derrotero:

"Actuar por una transformación social e histórica planteando y construyendo alternativas contra la impunidad de los Crímenes contra la Humanidad, el Genocidio y las Violaciones a los Derechos Humanos perpetrados por el Estado a través de sus estructuras militares y paramilitares, de sus modelos represivos, de sus leyes arbitrarias y, en general de todas las expresiones del terrorismo estatal.

Buscar que las víctimas y sobrevivientes del terrorismo de Estado sean reconocidas como sujetos de derecho, testigos históricos, y sectores participantes en la vida política del país, preservando y reconstruyendo desde la memoria histórica iniciativas que posibiliten que en Colombia Nunca Más se repitan crímenes contra la humanidad” (Movice, 2005).

Las tensiones políticas y la polarización social constituían así el contexto en el cual germinaba el movimiento de víctimas. Entre la realización del primer encuentro nacional en 2004 y el segundo en 2005, a pesar de la movilización y la denuncia a nivel nacional e internacional y a pesar del rechazo expresado por los organismos internacionales de derechos humanos, el Congreso y el Gobierno habían promovido la visita de los jefes paramilitares al capitolio y habían expedido la Ley 975 de 2005, configurando claramente el panorama de impunidad que perseguía el proceso de legalización de las consecuencias del paramilitarismo.

\subsection{Capítulo 7: EI Desarrollo del Movice}

La indignación producida por la promulgación e implementación de la ley de “Justicia y Paz", la profunda polarización que se generó en el país tras algunos años de ejecución de la política de" Seguridad Democrática" y los largos años de una práctica paramilitar extendida en el país, fueron el acicate para la emergencia de un nuevo movimiento social con las características del Movice. Pero no fueron los 
únicos elementos que asistieron a su nacimiento, fue necesario también un proceso de largo aliento en el que los defensores de derechos humanos reconstruyeron la historia de los crímenes de Estado y se interesaron en conflagrar una lucha decidida contra la impunidad; realizaron un análisis complejo de las realidades colombianas y particularmente de la forma en que se venía desarrollando el conflicto armado y concluyeron que era necesario emprender una contienda política y pública para desafiar al Estado.

En este capítulo abordaremos el desarrollo de sus luchas en medio de un acontecer político complejo. El debate jurídico de la Ley de Justicia y paz, el proceso de reelección presidencial, el estallido de los escándalos por para política y el descubrimiento de los falsos positivos, estuvieron marcando la pauta de las principales acciones del Movimiento. Nos adentraremos en los repertorios que fueron implementando y la manera en que se edificaron la mayoría de sus tácticas y estrategias, el avance en algunos de sus objetivos y el virtual reconocimiento de los derechos a la verdad, la justicia y la reparación integral de las víctimas en Colombia.

\subsubsection{La Ley 975 en el centro de la contienda}

A pesar del enorme poder alcanzado por el proyecto paramilitar en Colombia, que incluso le había permitido allanar el ambiente político y el contexto jurídico necesarios para promover la legitimación y la institucionalización de su "refundación” a sangre y fuego, la movilización de las víctimas y las denuncias de las organizaciones de derechos humanos habían logrado llamar la atención de importantes aliados en algunos sectores políticos, académicos, de la rama judicial y de la comunidad internacional, para generar presión sobre el proceso.

El debate suscitado en torno al marco jurídico para la reintegración de los máximos jefes del paramilitarismo, que había comenzado con el Proyecto de Ley de Alternatividad Penal, presentado por el Gobierno ante el Congreso y que pretendía reconocerles estatus de delincuentes políticos y otorgarles el indulto, enfrentaba 
serios cuestionamientos, especialmente por parte de agencias internacionales de derechos humanos, por cuenta de las gabelas a la impunidad y el desconocimiento de los derechos de las víctimas. Para evitar las presiones internacionales, el Gobierno y otros promotores del proceso habían modificado y presentado nuevas versiones "más presentables" del proyecto, mientras que otros sectores políticos y sociales habían elaborado y presentado otros proyectos en los cuales apelaban a la aplicación de los estándares internacionales para la creación de mecanismos de justicia transicional. De esta manera, para comienzos del año 2005, en el Congreso reposaban nueve proyectos diferentes (Gómez Sánchez, 2011, p. 162; Palau van Hissenhoven, 2006, p. 103). Finalmente, el 22 de junio de 2005, el Congreso aprobó la Ley 975 de 2005 denominada Ley de Justicia y Paz, la cual fue sancionada por el presidente Uribe el 25 de julio y reglamentada mediante el Decreto 4760 el 30 de diciembre.

La ley de Justicia y Paz buscaba definir un marco jurídico que permitiera la reintegración de los máximos jefes paramilitares a sus actividades políticas y económicas dentro de la legalidad, toda vez que sobre estas personas existían investigaciones e incluso condenas por crímenes de lesa humanidad, los cuales no estaban cobijados por las normas existentes que regulaban la desmovilización de los miembros de grupos armados ilegales hasta entonces. Vale la pena recordar aquí que al comenzar el proceso, el Gobierno había expresado que los grupos paramilitares contaban con unos 12 mil combatientes y que como fruto del proceso de negociación se desmovilizarían alrededor de $8 \mathrm{mil}$, por lo cual, afirmaba, era necesario tramitar una ley de justicia transicional. No obstante, para el año 2005 ya se habían desmovilizado más de 30 mil paramilitares bajo la normativa existente anterior a la ley de justicia y paz. Hasta entrado el 2006 el Gobierno presentó a la Fiscalía una lista con tan sólo 3600 paramilitares que debían ser procesados bajo la ley de justicia y paz, de los cuales apenas comparecieron menos de mil. Es decir que, al final, menos del 3 por ciento de las desmovilizaciones de los paramilitares se tramitaron realmente bajo esta ley (Gallón, 2014; Gutierrez Arguello, 2010). 
A pesar de todo lo anterior, el debate que se abrió en torno a la implementación de un mecanismo legal de carácter transicional también abrió la puerta para la discusión pública sobre la integración de los conceptos propios del derecho internacional de los derechos humanos, tales como los derechos de las víctimas a la verdad, a la justicia y a la reparación integral ${ }^{21}$. Sin entrar a hacer énfasis en las inquietudes que generaron las inconsistencias en las cifras del Gobierno (de 12 mil paramilitares que supuestamente había a finales de 2002, para finales de 2005 se habían desmovilizado 30 mil y aun así estos grupos continuaban delinquiendo), se debe hacer notar aquí, que alrededor del 90 por ciento del proceso de desmovilización se realizó al amparo de la normativa existente, especialmente de la Ley 782 de 2002 y el Decreto 128 de 2003, con lo cual la política de desmovilización se constituyó en la práctica en una amnistía que cubrió de impunidad e impidió el esclarecimiento de la verdad sobre los crímenes cometidos, pues, no se permitió ninguna participación de las víctimas ni se exigió a los desmovilizados colaborar con la justicia ni reparar a las víctimas para acceder a los beneficios judiciales ${ }^{22}$ (Movice et al., 2009, p. 24).

\footnotetext{
${ }^{21}$ Entre los instrumentos internacionales más relevantes que reconocen los derechos de las víctimas a la reparación, a la verdad y a la justicia, se encuentran la Declaración Universal de Derechos Humanos -art.8-, la Declaración Americana de Derechos del Hombre -art. 3-, la Declaración sobre los principios fundamentales de justicia para las víctimas de delitos y del abuso del poder -arts.8 y 11-, el Informe Final sobre la impunidad de los autores de violaciones de los derechos humanos, el Protocolo II adicional a los Convenios de Ginebra -art. 17-, el Conjunto de Principios para la protección y la promoción de los derechos humanos mediante la lucha contra la impunidad o "principios Joinet" -arts. 2, 3, 4 y 37-, la Convención Americana de Derechos Humanos, la Declaración de Cartagena sobre Refugiados, adoptada en el seno de la Organización de Estados Americanos (OEA), que extendió las normas de los refugiados a las situaciones de violencia generalizada y a los desplazados internos - parte III, párrafo 5- la Declaración de San José sobre Refugiados y Personas Desplazadas, y la Convención Sobre el Estatuto de los Refugiados de Naciones Unidas y su Protocolo Adicional. Sentencia C 715 de 2012 Corte Constitucional.

22 Según cifras oficiales, que varían de una entidad a otra, para el año 2010 más de 31 mil paramilitares se habían acogido al programa de "reincorporación a la vida civil" definido en el decreto 128 de 2003 mediante el cual, sin necesidad de confesar o ayudar a esclarecer los crímenes cometidos, tenían acceso a beneficios como "ayuda humanitaria, incentivos económicos, jurídicos y sociales" y, además, "aplazamiento o suspensión de la ejecución de la pena o indulto".
} 
Todas las normas anteriores a la ley de justicia y paz eran normas diseñadas bajo los criterios del manejo del orden público, que involucraban la desmovilización como un mecanismo de lucha contra los grupos armados ilegales y se enfocaban en la situación legal de los victimarios de acuerdo con sus delitos pero sin tomar en cuenta la existencia de las víctimas ni sus derechos. Con el debate propuesto por las víctimas en torno a la ley de justicia y paz y su desbordada pretensión de impunidad, pero en especial, con la introducción en el discurso de los elementos del derecho internacional de los derechos humanos y el derecho internacional humanitario para discutir sobre los fundamentos de la justicia transicional, el tema del reconocimiento de las víctimas y de sus derechos adquirió una nueva dimensión jurídica y política. La lucha contra la impunidad y por el respeto de los derechos que durante décadas habían sostenido las organizaciones sociales y de derechos humanos se hizo visible. Gabriel Gómez resalta este aspecto:

"En la segunda mitad de 2004, en el Congreso Nacional no se había debatido formalmente ninguno de los proyectos de ley relacionados con el proceso de paz o los derechos víctimas. Durante este tiempo, las tensiones entre los diferentes actores se intensificaron en la arena política. Las organizaciones de derechos humanos continuaron mostrando su descontento con el Proyecto de Alternatividad Penal y crearon conciencia sobre las limitaciones éticas y legales en las negociaciones de paz. Diferentes ONGs y académicos contribuyeron, no sólo para introducir el lenguaje de la verdad, la justicia y la reparación, sino también para mejorar el debate público sobre el proceso adelantado con los grupos paramilitares. Esos activistas y académicos promovieron debates públicos, organizaron conferencias académicas y empezaron a publicar libros sobre experiencias internacionales de justicia transicional y sobre los estándares internacionales de derechos humanos” (Traducción propia) (Gómez Sánchez, 2011, p. 155).

A pesar del contexto político adverso y de las medidas de estigmatización y de represión, la visibilización del movimiento de víctimas y la lucha por sus derechos seguía creciendo, más aún cuando las organizaciones de víctimas y de derechos 
humanos se decidieron a acudir a la Corte Constitucional y reclamaron la declaración de la inconstitucionalidad de la Ley 975 por desconocer los estándares internacionales sobre los derechos de las víctimas y encontraron su respaldo en importantes aspectos. La demanda por inconstitucionalidad en contra de la ley de justicia y paz fue precisamente una de las primeras acciones del recién creado Movice y significó un primer logro en el largo camino de resistencia y lucha contra impunidad que habría de recorrer este movimiento.

La Corte Constitucional, en un fallo que abordó diversas demandas en contra de la Ley de Justicia y Paz, impuso modificaciones o condicionamientos que redujeron el margen de impunidad que allí había quedado consignado, especialmente, al anular la posibilidad de cobijar como delitos políticos a los graves crímenes de los paramilitares y, por lo tanto, anular la posibilidad de que los jefes paramilitares fueran indultados o amnistiados, así como al reconocer el derecho de las víctimas a participar en los procedimientos judiciales para la defensa de sus derechos (Corte Constitucional de Colombia, 2006). Para el profesor Gómez, esta reacción de la Corte cobra gran importancia si se tiene en cuenta que en el ámbito judicial en Colombia se reproducían las tensiones que se vivían en el ámbito político y se reflejaban las estrategias de impunidad que cobijaban los crímenes:

“... Durante mucho tiempo las respuestas sociales e institucionales frente a las violaciones de los derechos humanos en el país han pasado de la negación a la normalización. Durante mucho tiempo las diferentes instituciones del Estado y los sectores sociales privilegiados negaron la existencia de prácticas como las desapariciones forzadas, la tortura o los vínculos entre los grupos paramilitares y agentes del Estado...

... En muchos casos las víctimas sobrevivientes tuvieron que permanecer en silencio como reacción a una mentalidad de 'culpa de las víctimas' que surgió en Colombia. De acuerdo con esa mentalidad, las víctimas de la violencia política han sido etiquetadas como relacionadas con los ‘militantes de izquierda'...” (Gómez Sánchez, 2011, p. 176). 
4.2.2. Las víctimas del Estado se reúnen y se visibilizan

Los encuentros nacionales pronto se convirtieron en los escenarios más importantes para la proyección del movimiento de víctimas del Estado. En ellos las víctimas y sus familiares se encontraron, compartieron sus historias y sus esperanzas, sintieron la fuerza que se generaba en el reconocimiento y la solidaridad. Al mismo tiempo, los encuentros les permitieron hacerse visibles, contarle al mundo los horrores de las tragedias que el gobierno pretendía ocultar, pues ellos y ellas eran sobrevivientes de la sevicia militar y paramilitar. Y también, en estos encuentros, lograron alcanzar acuerdos para actuar como movimiento en todos los rincones del país, enarbolando unos argumentos y unas exigencias compartidas.

Entre el primer y el segundo encuentro las víctimas encauzaron el sentido de los agravios sufridos en función de los crímenes padecidos, de la impunidad que los cobijaba y del silenciamiento al que habían sido sometidos. Allí definieron claramente su voluntad de visibilizarse y de romper los mecanismos de ocultamiento y de impunidad que cobijaban el lado tenebroso de la historia del Estado colombiano. En ese proceso de encontrarse recordaron lo que los movimientos populares colombianos habían legado muchos años antes, que la acción colectiva era el mecanismo para romper con las cadenas del miedo y de la exclusión y que su movilización era necesaria para recuperar la dignidad propia y de la nación. De esta manera, tras el segundo encuentro, el movimiento había definido una identidad clara que orientaba sus reivindicaciones y sus acciones, lo cual por supuesto, le permitió visibilizarse claramente ante otros actores.

Así, un aspecto importante en el desarrollo del segundo encuentro resultó ser la participación y el respaldo ofrecido por parte del Representante en Colombia de la Oficina del Alto Comisionado de las Naciones Unidas para los Derechos Humanos Michael Frühling, quien en su intervención resaltó el incumplimiento de la obligación convencional del Estado de respetar y garantizar los derechos de las víctimas, pues estaba implementando normas con cuya aplicación se abría paso a la impunidad. Asimismo, el señor Frühling insistió en varios aspectos de la recién 
aprobada Ley de Justicia y Paz sobre los que, según dijo, su oficina había manifestado reiteradamente su preocupación por cuanto "no se ajustan a los principios y normas internacionales sobre los derechos de las víctimas de delitos graves conforme al derecho internacional” (Frühling, 2005). Esta capacidad de convocatoria y de interlocución del naciente movimiento con una de las entidades más importantes en materia de defensa de los derechos humanos a nivel mundial, por un lado, reflejaba su capacidad de aprovechar y apropiar relaciones y estructuras ya constituidas a lo largo del proceso histórico precedente, pero también, significaba la presencia de un aliado importante para certificar la legitimidad de la acción colectiva cuyo contexto interno ya era bastante hostil.

Este tipo de movilización orientada a buscar que las organizaciones y las instituciones de la comunidad internacional generaran presión al Estado colombiano hizo evidente su eficacia también cuando el Movice demandó la inconstitucionalidad de la Ley 975 y logró que 150 organizaciones internacionales, en su mayoría europeas, en septiembre de 2005, suscribieran una carta en la cual respaldaban los argumentos presentados en la demanda ante la Corte y otra en la cual las organizaciones europeas junto con un grupo de eurodiputados solicitaban al Consejo Europeo no respaldar al Gobierno colombiano en el proceso con los paramilitares si no se garantizaba el respeto a los derechos de las víctimas. Incluso representantes del movimiento de víctimas y de las organizaciones de derechos humanos pudieron presentar directamente sus argumentos y sus críticas ante el parlamento europeo y en diferentes Foros realizados por organizaciones sociales europeas. Finalmente, aunque el Consejo Europeo se pronunció al respecto y decidió respaldar el proceso, también recogió fuertes críticas y preocupaciones como las manifestadas por instituciones internacionales como la OACNUDH y la OMCT (Morsolin, 2005).

Por aquel entonces el repertorio de acciones del movimiento se concentró, por un lado, en una ardua labor de denuncia en el exterior en busca de respaldo de la comunidad internacional para promover el lenguaje de los derechos de las víctimas en la política nacional y para ejercer presión frente al Estado colombiano; por otro 
lado, en lo que el profesor Gabriel Gómez resaltó como resistencia legal y litigio estratégico en busca de que, a través de la jurisprudencia de las altas cortes, especialmente la Corte Constitucional, se introdujeran al ordenamiento colombiano los principales conceptos del derecho internacional de los derechos humanos; y finalmente, en una paciente y constante labor de acompañamiento y fortalecimiento de los procesos organizativos de las víctimas en los niveles local y regional, donde las condiciones sociales, la guerra y la represión generaban un contexto sumamente hostil para las expresiones de promoción de los derechos humanos y de oposición política. La combinación de estas acciones se puede ver claramente en el relato del profesor Gómez sobre la demanda contra la ley de justicia y paz:

"Una vez que la Ley de Justicia y Paz fue promulgada, las ONGs de derechos humanos, como el CAJAR, el MOVICE, y la CCJ, interpusieron recursos ante el Tribunal Constitucional. [...] Para los abogados, el objetivo era hundir la Ley o, al menos, limitar los privilegios e incentivos a los paramilitares desmovilizados y ampliar el alcance de los derechos de las víctimas, hacerlo significaba responder a diferentes retos. [...] En primer lugar, la demanda de inconstitucionalidad era especialmente difícil debido a que los defectos constitucionales de la ley no eran explícitos o evidentes. [...] Este hecho exigía un cuidadoso proceso de argumentación y requería de los abogados asumir un papel pedagógico con el fin de demostrar cómo la aplicación de la ley afectaba los derechos de las víctimas. En segundo lugar, con el fin de garantizar los derechos de las víctimas a la verdad, la justicia y la reparación, el debate no se limitaba a una contradicción entre la Ley y la Constitución, tenían que demostrar que, según la Constitución, era necesario aplicar las normas del derecho internacional de los derechos humanos. [...] Finalmente, los abogados aprovecharon la amplia documentación generada durante los debates. Esta documentación rigurosa permitió aclarar la irregularidad de las disposiciones que reconocían la categoría de delincuentes políticos a los paramilitares. [...] Además de los argumentos esgrimidos por los abogados que interpusieron la acción, diferentes ONGs transnacionales de derechos humanos presentaron escritos 
de Amicus Curiae. Algunas organizaciones como el Centro Internacional para la Justicia Transicional (ICTJ), la Comisión Internacional de Juristas (CIJ) y la Confederación Internacional de Organizaciones Sindicales Libres (CIOSL), proporcionaron sólidos argumentos basados en el derecho internacional y en experiencias comparadas de justicia transicional" (Gómez Sánchez, 2011, p. 165).

\subsubsection{Las estrategias para la movilización}

Mientras la Corte Constitucional tramitaba la demanda contra la Ley de Justicia y Paz, el Movice preparaba su tercer encuentro nacional convocado entre el 6 y el 9 de julio de 2006. Si bien para entonces los reclamos por el reconocimiento de las víctimas y de sus derechos concitaban la solidaridad de nuevos sectores sociales, sus perspectivas de oportunidades políticas se veían abrumadas por un contexto que se cerraba aún más por cuenta de la reforma constitucional que aprobó el Congreso para posibilitar la reelección del presidente Uribe, la cual se confirmó en las elecciones del mes de mayo y con la cual se reforzaba el talante autoritario de su gobierno.

La declaración final de ese tercer encuentro del movimiento de víctimas contiene algunos recuerdos curiosos sobre el ambiente político de la época, como por ejemplo, la mención al llamado Plan 2019 que hace referencia al documento Visión Colombia II Centenario con el que el gobierno Uribe pretendía determinar la orientación de los planes de desarrollo del país para todos los gobiernos desde el 2006 hasta el 2019 y que, como se hizo evidente pocos años después, incluía la pretensión de que el presidente de esos gobiernos fuese él mismo, pretensión en la que fracasó a pesar de su esfuerzo por reformar nuevamente la Constitución para permitir su reelección indefinida.

Sin embargo, más allá de esas curiosidades históricas, hoy poco recordadas, el Encuentro rindió resultados muy importantes para el desarrollo y la consolidación de la identidad y la estructura organizativa del movimiento pues allí se definió un 
catálogo de ocho estrategias que enmarcarían y orientarían sus actividades en adelante: Ocho propuestas para la verdad, la justicia, la reparación integral, la memoria y la no repetición de los crímenes contra la humanidad (Movice, 2006).

El crecimiento y el posicionamiento del Movice como referente de lucha por los derechos de las víctimas y en contra de la impunidad de los crímenes del paramilitarismo y del Estado, habían alcanzado un nivel importante y abrían cada vez más el camino a la exigibilidad de los derechos a la verdad, la justicia y la reparación en medio de la arena política nacional, marcadamente hostil frente a estos planteamientos, apoyándose en la legitimidad y el respaldo que congregaba en sectores de la comunidad internacional y del poder judicial al invocar insoslayables principios del derecho internacional de los derechos humanos y al promover un debate sólidamente fundamentado y ampliamente democrático en todo tipo de escenarios sociales, políticos y académicos.

La experiencia acumulada durante décadas por las organizaciones de derechos humanos pertenecientes al movimiento le permitió la apropiación de una importante experticia de litigio estratégico; asimismo, la larga trayectoria del espíritu organizativo popular en las diferentes regiones aún vigente a pesar del largo y degradado conflicto armado, expresado en cientos de organizaciones campesinas, étnicas, cívicas, etc, junto con las experiencias aprehendidas de los éxitos y fracasos de múltiples intentos de unidad organizativa y política, permitieron mantener cierta claridad acerca de las posibilidades y las limitaciones frente a los objetivos y las acciones del movimiento; todo lo anterior, soportado con cierto margen de apoyo de la comunidad internacional y con la apropiación de las capacidades desarrolladas por las organizaciones para la gestión de recursos, confluyó para que en poco tiempo el movimiento lograra, hacia adentro, definir una identidad, concertar unos objetivos y bosquejar una trayectoria de acción, y hacia afuera, legitimar sus reclamos y posicionar su papel como interlocutor válido para un tema que cobraba cada vez más importancia en la agenda política del país. 
Esta confluencia de factores se expresa en toda su dimensión en la claridad de las ocho estrategias definidas como carta de navegación para el movimiento y consignadas en la declaración final de tercer encuentro, las cuales resumimos para evidenciar la claridad y concreción de los planteamientos del Movice:

1. Una estrategia jurídica que persiga a los máximos autores de los crímenes y la responsabilidad de los agentes estatales

Luego del análisis de las diferentes legislaciones que en concepto del Movice han alimentado, legitimado y legalizado la impunidad del paramilitarismo en el país, el Movimiento se impone como tarea develar estos mecanismos de impunidad mediante el uso de instancias jurídicas nacionales e internacionales. Con ello, develar la verdad de lo ocurrido, establecer los vínculos entre los paramilitares y las autoridades militares y civiles, los políticos corruptos, los empresarios, ganaderos, terratenientes y multinacionales y buscar sanción para los máximos responsables se convierten en centro de sus demandas y su accionar.

\section{Una estrategia para la verdad y la memoria histórica}

Para el Movice la verdad es un elemento indispensable para la superación de la impunidad y un paso fundamental para la plena realización de los derechos a la justicia y reparación integral. Evidenciar esa verdad a la vista del Movimiento, permite también refutar la legitimidad que los grupos de poder han logrado mediante el uso sistemático de la mentira y la justificación de los crímenes, de allí que, continuar con el trabajo realizado en el Proyecto Nunca Más es una estrategia fundamental para el cumplimiento de sus objetivos.

Fortalecer la recolección de testimonios, pruebas forenses y todo tipo de documentos con valor probatorio se convierte entonces en una tarea insoslayable. Pero además, no solamente es importante descubrir la verdad, es necesario conservarla y difundirla. Por esto el Movice mediante esta estrategia propone la creación de un Centro de memoria y documentación que sirva de archivo de 
seguridad y de espacio para dialogar con el público sobre esta verdad y sus significados.

3. Una estrategia para el acompañamiento solidario con las víctimas: la Comisión Ética

Para el Movimiento la constitución de la Comisión Nacional de Reparación mediante la ley 975 de 2005 no solo desconoció los derechos de las víctimas sino que banalizó los contenidos de la verdad, la justicia y la reparación. Por ello mediante esta estrategia plantea necesaria la creación de una Comisión que salvaguarde la memoria y custodie y comparta la verdad histórica de las víctimas. Esta comisión es propuesta para sesionar durante 10 años con 25 miembros internacionales y 5 nacionales y tiene como objetivo central trabajar en la construcción de propuestas de verdad, justicia y reparación con los familiares, las comunidades y las organizaciones de víctimas incluyendo indígenas, afrocolombianos, mestizos, mujeres, niños y jóvenes. Para el Movice esta Comisión debe además recopilar los insumos fundantes para la conformación de una genuina Comisión de Esclarecimiento Histórico que se espera surja cuando existan garantías reales para ello.

4. Una estrategia para la no repetición: la prohibición legal del paramilitarismo

Para el Movimiento la garantía más importante para la no repetición es la proscripción de cualquier tipo de estrategia paramilitar en el país. Por ello enfoca esta estrategia al diseño de un proyecto de ley con carácter de reforma constitucional en el que se prohíba por lo menos tres modalidades de paramilitarismo: a. La eliminación de cualquier política que pretenda armar a los civiles u otorgarle funciones propias de las Fuerzas Militares o de seguridad. b. La tipificación del delito de alianzas entre los agentes del Estado y los grupos paramilitares y el aumento de sanciones para quienes fomenten la infiltración paramilitar o se valgan de la contratación pública para beneficiar a articulares 
pertenecientes a grupos paraestatales y c. la prohibición de operaciones encubiertas de tipo paramilitar por pate de miembros de la Fuerza Pública y la conformación de escuadrones de la muerte.

\section{Una estrategia para la reparación: el catastro alternativo}

Para el Movimiento la reparación no es un acto de caridad, es un proceso de justicia con las víctimas y la sociedad que debe ser pagado por los causantes del daño y los detentadores de la riqueza usurpada a las comunidades. Estos daños, producidos en su mayoría por una estrategia de contra reforma agraria mediante la cual se produjo el desplazamiento forzado de millones de víctimas y el despojo de otros tantos millones de hectáreas, debe ser revertido mediante un Mandato Agrario que, entre otras cosas, elabore un Catastro Alternativo como mecanismo para compilar información sobre bienes, tierras y territorios que les fueron usurpadas a las víctimas. Con esta estrategia se espera que los campesinos, comunidades afrocolombianas, indígenas y colonos puedan demandar este despojo y reclamar la responsabilidad de Estado por haber permitido o facilitado estos crímenes.

6. Una estrategia de lucha contra la desaparición forzada: la exhumación de las fosas comunes y el derecho a enterrar

La desaparición forzada ha sido uno de los mecanismos de exterminio comunes en los crímenes de Estado. Para el Movice, el derecho a encontrar a los desaparecidos, a saber dónde están y a recuperar sus restos es decisivo. También lo es el poder exhumar los cuerpos de las víctimas que han sido ocultados por los perpetradores en fosas comunes o en las fincas donde fueron asesinados, pero que, aun siendo conocido el paradero por sus familiares, no pueden dar dignamente sepultura por tratarse de lugares que siguen siendo controladas por las mismas estructuras militares que produjeron los crímenes. Por ello, ratifican el derecho a la resistencia, a la resiliencia a exhumar la vida y la memoria. 
7. Una estrategia de lucha contra el genocidio político: verdad, justicia y reparación para las víctimas y los sobrevivientes de la Unión Patriótica

Mediante esta estrategia el Movimiento presenta su apoyo incondicional a las víctimas del Partido Comunista y la Unión Patriótica y reafirma su rechazo al genocidio de que fueron objeto estas organizaciones de oposición política. Respalda el proceso que está desarrollando este Partido ante la Comisión Interamericana de derechos Humanos contra el Estado colombiano y denuncia la persecución anticomunista realizada por el Presidente Uribe Vélez y su incentivo a continuar con la aniquilación de los grupos de oposición.

8. Una estrategia de organización: el fortalecimiento del Movimiento de Victimas

Por último, el Movimiento recuerda la importancia de buscar mecanismos que posibiliten a las diferentes expresiones de víctimas, reunirse alrededor de un mismo propósito mediante la consolidación de un espacio organizativo unificador que les permita avanzar en el cumplimiento de sus objetivos. De allí que esta estrategia invite a generar dinámicas de educación y capacitación en temas relacionados con el conflicto y la paz y las vías de exigibilidad de los derechos de tal suerte que se vea fortalecido su accionar.

Posteriormente, durante el quinto encuentro nacional del Movice realizado en 2011, se planteó la necesidad de definir una estrategia de lucha en contra del exilio político, acogiendo el llamado de los capítulos internacionales que han surgido a partir de la presencia de víctimas de crímenes del Estado colombiano en diferentes países de Europa y América Latina.

4.2.4. El contexto de la "Seguridad Democrática": estigmatización y re victimización 
Como hemos mencionado anteriormente, apenas por mitad del mandato de Álvaro Uribe, el 27 de diciembre de 2004, la bancada de gobierno en el Congreso logró la aprobación del Acto Legislativo 02 de 2004, por medio del cual se modificó la Constitución para permitir la reelección inmediata del Presidente de la República, incluyendo al presidente en curso. La turbiedad que rodeó este proceso de reforma constitucional para extender el mandato de Uribe ha llegado a instancias de la Corte Suprema de Justicia que, hasta ahora, ha condenado a tres congresistas, 2 ministros y el secretario general del presidente de ese entonces, por el delito de cohecho, es decir por recibir y por ofrecer sobornos con el fin de aprobar de la reforma.

La situación del uso y el abuso del poder y la popularidad del presidente para la imposición arbitraria de políticas de gobierno tales como los acuerdos de libre comercio, la hostilidad en las relaciones con países vecinos o la priorización de la dinámica de la guerra en materia de seguridad, conllevó un enrarecimiento de las dinámicas de los procesos y los actores políticos que se reflejaban en un alto grado de polarización y en una lectura del conflicto político y social a partir de la cual, a quienes expresaran oposición o cuestionamiento de las posiciones oficiales, se les trataba como enemigos y eran estigmatizados, hostigados y perseguidos.

Por supuesto, quienes no solamente se atrevían a oponerse a esas políticas gubernamentales sino que además denunciaban la existencia de crímenes de Estado eran sometidos a un intenso y constante proceso de estigmatización, amedrentamiento y revictimización. En efecto, en diversas ocasiones, el propio presidente Álvaro Uribe se refirió sobre las organizaciones de derechos humanos como "politiqueros al servicio del terrorismo" o "traficantes de derechos humanos" (Comisión Colombiana de Juristas, 2004, p. 133). Estas expresiones, por supuesto, en el contexto mundial posterior a los ataques del 11 de septiembre de 2001 en Estados Unidos, no se quedaban en mera retórica populista, por el contrario, esa retórica se constituyó en marco teórico y exposición de motivos de toda una agenda política y legislativa que pretendía la supresión de derechos civiles y políticos de los ciudadanos y la expansión de los poderes del presidente caudillo que 
representaba los anhelos autoritarios de un amplio sector de la sociedad colombiana.

La ley de justicia y paz para reincorporar estructuras ilegales de la estrategia paramilitar y la reelección presidencial para consolidar procesos de control político y territorial, tan sólo eran una parte de esa agenda. Otras limitaciones a libertades ciudadanas y mecanismos democráticos que pretendía el gobierno se vieron frustradas, como fue el caso de la reforma constitucional conocida como Estatuto Antiterrorista (Semana, 2004) que le otorgaba facultades extraordinarias a las fuerzas militares y que fue declarada inexequible por la Corte Constitucional, o el caso del Referendo mediante el cual el presidente pretendió recortar la representación y las competencias del Congreso y que a pesar de la enorme popularidad de Uribe no obtuvo una votación suficiente.

No obstante los tropiezos en el desarrollo de su agenda política y legislativa, el gobierno logró generar un ambiente político profundamente hostil contra los procesos sociales que proponían agendas progresistas y democráticas. El contexto en el cual se desarrollaba el movimiento de víctimas lo describe el profesor Gómez así:

"La emergencia de un discurso hegemónico en materia de seguridad, liderada especialmente por el gobierno de Alvaro Uribe, trajo consigo la redefinición de los términos del conflicto, en la medida que para el gobierno, no había conflicto político sino "amenaza terrorista" (...) En este contexto, el alto nivel de apoyo por parte de la opinión pública y los medios de comunicación al gobierno de Uribe, así como cierto nivel de aceptación en algunos sectores sociales de los grupos paramilitares como un "mal necesario", contrastaban con el débil respaldo político de las organizaciones de derechos humanos en el contexto nacional y, aún más, con la invisibilidad y marginalidad de las víctimas de violaciones de derechos humanos" (Gómez Sánchez, 2012, p. 98). 
4.2.5. La movilización de las víctimas del Estado por sus derechos

Las ocho estrategias concertadas en el tercer encuentro nacional del Movice recogían las más apremiantes problemáticas y los principales intereses del amplio y diverso abanico de organizaciones, de sectores y de regiones que confluían en el movimiento. De esta manera las estrategias proveían cohesión y coherencia para que las organizaciones de base, en el marco de una identidad compartida, proyectaran sus acciones particulares, de acuerdo con sus propias posibilidades, comprendiéndolas en concordancia con unas estrategias y un movimiento de alcance nacional.

Tras la reelección del presidente Uribe, el Movice comprendió que se avecinaba un periodo de profunda confrontación con el gobierno, que encontró en la expresión del respaldo popular en las urnas el aval a su noción de "Estado de opinión". Con el presidente reelecto, la Ley de Justicia y Paz en firme y la función de la supuesta desmovilización paramilitar en marcha, el Movice optó por una intensa movilización para la visibilización de las víctimas en el país. En el aspecto organizativo, el Movice comprendió la necesidad de fortalecer las organizaciones populares locales y regionales, por lo cual promovió la creación de Capítulos Regionales que contaran con un Comité de Impulso, de la misma manera como se había conformado el Comité de Impulso Nacional, para impulsar y coordinar el desarrollo de las 8 estrategias.

Un ejemplo de las posibilidades que se potenciaron con la flexibilidad de las 8 estrategias puede reconocerse en un tipo de acción específica que se difundió rápidamente y se convirtió en símbolo de identificación del Movice. Las Galerías de la Memoria constituyeron una forma de reivindicación particularmente bien acogida, tanto por las víctimas y sus familiares como por la comunidad, pues este tipo de instalaciones públicas itinerantes y temporales constituyen un mecanismo versátil y al alcance de los familiares para "actualizar la presencia de las víctimas" de crímenes que han quedado en la impunidad al tiempo que le permite a esas familias un espacio de encuentro en esta ceremonia por la memoria de sus seres 
queridos más allá de mitin político y la represión oficial. Las Galerías de la Memoria son exposiciones construidas con fotografías, retratos y otros objetos que den cuenta de la cotidianidad y el proyecto de vida de las víctimas junto con las cuales se reseñan los datos de la victimización que conozcan sus familiares, siendo así al mismo tiempo un acto de conmemoración y de lucha contra la impunidad. Las Galerías fueron acogidas rápidamente por las organizaciones regionales y se convirtieron en una contundente herramienta de visibilización de las víctimas del Estado y de articulación simbólica de las regiones (Documento Borrador obtenido en Entrevista 12). A lo largo del año 2007 las Galerías de la Memoria se consolidaron, implementándose semanal o mensualmente de acuerdo con las posibilidades de las organizaciones locales, confrontando así el contexto de estigmatización y represión promovido por el gobierno y dando cuenta de la existencia de los crímenes y de las víctimas del Estado y de su estrategia paramilitar.

Así mismo, una acción aún más contundente para develar y confrontar la barbarie de la estrategia paramilitar que quería encubrir con impunidad el gobierno Uribe, fue la realización de las Audiencias Ciudadanas por la Verdad. Estas Audiencias se constituyeron en el marco de la estrategia para la verdad y la memoria, como eventos públicos para la denuncia y la visibilización de los crímenes cometidos y de la grave situación de derechos humanos que afrontaban algunas regiones. La primera Audiencia Ciudadana se llevó a cabo a finales del año 2006 en San Onofre Sucre y en 2007 se realizaron en Buenaventura y Arauca. Este tipo de acción significaba una apuesta audaz teniendo en cuenta los contextos regionales de control paramilitar y de represión oficial que se vivían en el marco del proceso entre el gobierno y los paramilitares.

La Audiencia convocada el 27 de noviembre de 2006 en San Onofre Sucre se realizó en medio del horror persistente del control paramilitar regional de Rodrigo Mercado Pelufo alias "Cadena”. Aun así, el Movice logró establecer una importante alianza que sería condición de posibilidad para la realización de todas las audiencias realizadas en 2007 y 2008, la participación como convocante de la Comisión de Derechos Humanos del Senado de la República presidida por el Senador Alexander 
López y el acompañamiento de otros congresistas como la Senadora Piedad Córdoba impulsó la participación de funcionarios del gobierno nacional, departamental y municipal así como de los entes de control y de la comunidad internacional. En estas condiciones fue posible rodear y acompañar a las víctimas que expusieron públicamente sus relatos demostrando ante el mundo la existencia de los crímenes, la resistencia de las víctimas y la connivencia del Estado y los paramilitares (Corporación Colectivo de Abogados José Alvear Restrepo, 2006). Las denuncias y los testimonios sobre la connivencia del gobierno local y el grupo paramilitar de alias Cadena presentados en la audiencia terminaron por llevar a la cárcel al entonces alcalde de San Onofre Jorge Blanco y sentaron un importante precedente en la lucha del Movice contra la impunidad y la estrategia paramilitar (Cepeda, 2007).

Finalmente, a pesar de todos los obstáculos, las Audiencia Ciudadanas por la Verdad fueron una experiencia de visibilización y reivindicación sin antecedentes para las víctimas en las regiones más afectadas por la violencia política y los crímenes de Estado. En 2006 se realizó la audiencia en San Onofre, en 2007 en Buenaventura y Arauca, en 2008 en Barrancabermeja, en el Catatumbo, en Montería, una audiencia especial sobre desaparición forzada en Medellín y una audiencia especial sobre exilio en París, en 2009 en Florencia y en 2011 en Puerto Asís (Documento Borrador obtenido en Entrevista 12).

Es de destacar que con la audiencia especial sobre desaparición forzada realizada en Medellín se buscó impulsar la estrategia definida en tercer encuentro contra la desaparición forzada, por el derecho a exhumar las fosas comunes y por el derecho a enterrar dignamente. En este sentido el Movice ha realizado una paciente e incesante labor de seguimiento y contacto de experiencias internacionales en antropología forense y trabajo psicosocial, participó en la organización del Segundo Congreso Mundial de Trabajo Psicosocial en Desaparición Forzada en 2010 y promovió la creación en 2012 de la Comisión Internacional de Esclarecimiento de las graves violaciones de derechos humanos cometidas en el marco de la Operación Orión del Ejército en la Comuna 13 de Medellín a partir de la cual se ha llegado al 
actual proceso de exhumación de las fosas comunes ubicadas en la escombrera en esa ciudad.

Gracias a esta intensa labor de visibilización y movilización de las víctimas de crímenes de Estado en 2007 el Movice logró un gran reconocimiento y fue convocado a participar junto con las plataformas de derechos humanos en el proceso promovido por la Oficina de Naciones Unidas en Colombia para la concertación de un Plan Nacional de Acción en Derechos Humanos y Derecho Internacional Humanitario, en el marco del compromiso del Estado colombiano con la Declaración y Programa de Acción de Viena de 1993, no obstante, dada la intensa persecución y estigmatización en contra del Movice por parte del gobierno Uribe, el movimiento decidió interrumpir su interlocución con el gobierno hasta tanto no se ofrecieran las garantías de respeto por los derechos de las víctimas de los crímenes de Estado y finalmente decidió publicar en 2008 su propuesta para una Política Integral de Acción en Derechos Humanos (Movice, 2009), como aporte a ese proceso de concertación que aún no ha logrado resultados.

El 2008 ha sido quizás el año de más intensa movilización y visibilización del Movice. Para entonces más de 30 congresistas de la coalición de gobierno se encontraban en la cárcel por sus vínculos con los paramilitares, también fue detenida la congresista Yidis Medina tras confesar que había aceptado sobornos por votar a favor de proyecto que permitió la reelección de Uribe en 2006. Aun así, el presidente estaba decidido a llevar al límite su estrategia de polarización social con el fin de proveerse una base política que le permitiera perpetuarse en el poder. Para comienzos de ese año el gobierno promovió una marcha multitudinaria para que la ciudadanía expresara su rechazo en contra del secuestro y de la organización guerrillera FARC-EP-EP, la cual se realizó el 4 de Febrero y empezó a ambientar el respaldo popular necesario para lanzar el proyecto de realización de una nueva reforma constitucional que permitiera su segunda reelección.

En medio del enorme respaldo social que obtuvo la marcha del 4 de febrero se pudo apreciar que la percepción en torno a las víctimas del conflicto en el país ya estaba 
cambiando. Frente a la instrumentalización política hecha por el gobierno del sentimiento popular de rechazo a la persistencia de la violencia de la izquierda armada, el Movice entendió que era necesario y era el momento para que las víctimas del terrorismo del Estado y su estrategia paramilitar se expresaran también de forma masiva y contundente para visibilizar el otro lado de la violencia política. Desde noviembre de 2007 había sido convocado el Cuarto Encuentro Nacional del Movice a realizarse entre el 6 y el 8 de marzo de 2008 en Bogotá, así, se decidió iniciar el encuentro con una gran movilización el 6 de marzo, "como homenaje a las víctimas del paramilitarismo, de la parapolítica y de los crímenes de Estado, por los desaparecidos, por los desplazados, por los masacrados y por los ejecutados" (Semana, 2008b).

La marcha del 6 de marzo del 2008 movilizó a cientos de miles de personas en más de 60 ciudades en Colombia y en el mundo, inclusive, en el acto central en la Plaza de Bolívar en Bogotá se presentó un comunicado conjunto de organizaciones de víctimas de crímenes del Estado y de la guerrilla en contra de los crímenes de lesa humanidad y por la terminación del conflicto armado en Colombia. No obstante el amplio respaldo social que logró concitar la movilización, el gobierno Uribe se empeñó en obstaculizar su realización. Días antes, el consejero presidencial José Obdulio Gaviria anunció en medios de comunicación que la marcha era organizada por las FARC-EP y que invitaba a no participar. Así mismo, años después se comprobó que existió toda una operación llamad "Estímulo" mediante la cual el DAS elaboró un gran montaje para hacer creer que en efecto se trataba de una acción de las FARC-EP y “diseñó panfletos, pasacalles, afiches y comunicados de prensa que fueron distribuidos en 18 ciudades (...) para contaminar la marcha del movimiento de víctimas" (Noticias UNO, 2015).

A pesar de sus limitaciones organizativas y económicas, el 6 de marzo el Movice demostró que en Colombia no se podía continuar negando y ocultando la realidad de las víctimas de los crímenes del Estado y su estrategia paramilitar. En medio del unanimismo promovido por concepción gubernamental del "Estado de opinión", a pesar de la estigmatización y de la represión oficial o encubierta, el país y el mundo 
pudieron reconocer que las víctimas eran muchas y que estaban dispuestas a reclamar y a ejercer sus derechos.

Esta realidad animó la realización del Cuarto Encuentro Nacional, que en su declaración final la resaltó y, así mismo, llamó a continuar fortaleciendo la implementación de las ocho estrategias y el movimiento de víctimas en todas las regiones y sectores sociales y denunció una vez más el proceso de impunidad para los victimarios en la Ley de Justicia y Paz y la desprotección de las víctimas (Movice, 2008a).

\subsubsection{Se cierra un círculo criminal en torno al gobierno}

Poco después, el 22 de abril de 2008, un nuevo escándalo sacudió al círculo político más cercano al presidente, cuya trayectoria evidenciaba cada vez más claramente la tendencia corrupta y criminal de su comportamiento político tradicional. Ese martes, en horas de la mañana, se conoció la noticia de la orden de captura emitida por la Fiscalía en contra del Senador Mario Uribe, primo del presidente Álvaro Uribe, en el marco de la investigación penal a la cual estaba sometido por sus vínculos con los grupos paramilitares. Al enterarse de la noticia Mario Uribe intento escapar de la justicia ingresando en la embajada de Costa Rica en Bogotá y solicitando asilo ante ese país. Esta situación motivó a que el Movice convocara a las organizaciones sociales, de derechos humanos y a todas las personas que pudieran hacerse presentes esa tarde para realizar un plantón frente al edificio de la embajada y solicitar al gobierno de Costa Rica que negara el asilo (Movice, 2008b; Semana, 2008a). La manifestación del Movice se mantuvo allí hasta el día siguiente cuando el gobierno costarricense anunció su decisión de negar la solicitud de Mario Uribe por improcedente, por lo cual, el primo del presidente fue capturado y luego condenado a siete años de prisión por el delito de concierto para delinquir por sus nexos con paramilitares (Semana, 2011).

Las investigaciones penales en contra de Mario Uribe y otras cuantas decenas de congresistas se ampliaban cada vez más por cuenta de las declaraciones que los 
paramilitares que se acogían a la Ley de Justicia Paz rendían ante la Fiscalía. Esta situación se había hecho tan notoria que el propio presidente había llegado a expresarse públicamente en ese sentido, tal vez inconscientemente, y en una reunión con el gremio cafetero llamó "a todos los congresistas que nos han apoyado, a que, mientras no estén en la cárcel, a votar" los proyectos de la agenda legislativa del gobierno (Colombia Herald, 2006; Semana, 2006).

Por esta situación y a pesar de lo expresado por los medios de comunicación, no sorprendió al movimiento de víctimas la intempestiva decisión gubernamental de extraditar el 13 de mayo de 2008 a 14 de los más altos mandos de los grupos paramilitares a los Estados Unidos donde eran requeridos por narcotráfico. Este hecho puso al Movice en una situación paradójica, pues, aunque no respaldaba los procesos de la Ley de Justicia y Paz, comprendía que las declaraciones de los jefes paramilitares sobre los actores y los contextos del surgimiento y desarrollo del paramilitarismo en Colombia eran importantes para la reconstrucción de la verdad histórica que el establecimiento procuraba silenciar. Por esto, el Movice ha acudido desde entonces a las instancias judiciales y diplomáticas nacionales, estadounidenses e internacionales para procurar que a los extraditados se les garanticen los medios para continuar rindiendo declaración ante la justicia colombiana.

Como si esto fuera poco, en septiembre de 2008, las denuncias que el movimiento de víctimas venía realizando sobre ejecuciones extrajudiciales por parte de la fuerza pública alcanzaron el grado de escándalo por cuenta del develamiento de lo que los medios de comunicación llamaron los "falsos positivos". Los falsos positivos consisten en una estrategia de asesinatos premeditados por parte la fuerza pública en contra de jóvenes desempleados, personas marginadas, pequeños delincuentes o indigentes, quienes con la esperanza de un empleo o en busca de ganar dinero fácil han sido engañados o llevados contra su voluntad hacia otras regiones donde han sido asesinados y presentados públicamente como guerrilleros muertos en combate con el fin de que esas unidades militares obtengan beneficios, de acuerdo con la política de seguridad democrática. De acuerdo con el informe de la visita realizada 
en junio de 2009 por el Relator Especial de las Naciones Unidas para las Ejecuciones Extrajudiciales Philip Alston, en lo corrido del gobierno Uribe entre 2002 y 2008 se habían conocido aproximadamente dos mil ejecuciones atribuibles a la fuerza pública (Alston, 2010; Semana, 2008c).

En medio de todos estos escándalos, durante 2008 y 2009, el gobierno y sus aliados políticos concentraron grandes esfuerzos en promover otro referendo, un "acto legislativo reformatorio de la Constitución por vía popular" para permitir una segunda reelección de Álvaro Uribe. Esta iniciativa, tan turbia como la que permitió la primera reelección, estuvo rodeada de irregularidades en la financiación, la recolección de firmas y el trámite legislativo, fue aprobada en agosto de 2009 por el Congreso pero fue declarada inexequible por la Corte Constitucional en febrero de 2010 (Semana, 2010), quedando así cerrado finalmente el capítulo de Álvaro Uribe Vélez en la Presidencia de la República de Colombia.

La arbitrariedad, la corrupción y los vínculos con la criminalidad paramilitar que rodearon las agendas de la "seguridad democrática" y del "Estado comunitario" de Uribe se aprecian claramente en el consolidado actual que muestra que, de los 30 más altos funcionarios del gobierno Uribe, 9 han sido condenados penalmente y 10 más están siendo investigados (Lewin \& Morelo, 2015), al tiempo que de la coalición política que lo apoyó en el Congreso, han sido condenados 60 congresistas, entre ellos un primo del propio presidente (M. Romero, 2011).

No obstante, como veremos más adelante, en estas condiciones del contexto político nacional se habían abierto las puertas de manera definitiva para que los actores de los procesos y de las decisiones políticas tuvieran que incluir en su agenda el tema de las víctimas de la violencia política y reconocer la existencia de las víctimas y los crímenes del Estado.

\subsection{Capítulo 8: Análisis de los Elementos Descriptivos del Movice}


Tal como lo hiciéramos para el caso de la Ruta, hemos hecho un relato por los diferentes sucesos que rodearon el surgimiento y desarrollo del Movice. Tuvimos la oportunidad de conocer las condiciones políticas, sociales y jurídicas que antecedieron el trabajo de este movimiento y que de alguna manera motivaron su accionar y pudimos establecer la presencia en el debate político de otros actores, particularmente de la posición del Gobierno Nacional durante estos años. Este recorrido nos permitió a su vez conocer algunos pormenores sobre la constitución del movimiento, identificar el tipo de agravios y objetivos que enmarcaron su lucha estos primeros años y los repertorios que decidieron usar para enfrentar al Estado.

Es necesario aquí también hacer una pausa para sacer en limpio de estas narraciones los pilares analíticos de la perspectiva integradora de los elementos clásicos del estudio de los movimientos sociales, de tal suerte que sea posible identificar sus características particulares y comprender mejor las contiendas que emprende y los resultados que obtiene. Nuevamente acá nos respaldaremos en algunas de las líneas teóricas que sustentan la literatura de los procesos en marcadores, las estructuras de movilización y los repertorios de acción.

Recurriremos en un primer momento a la identificación y análisis de la interpretación de agravios, objetivos, uso de símbolos y de la memoria, formación de discursos, e identidades, para conocer más sobre los marcos cognitivos y los procesos enmarcadores que desarrollan, abordaremos también la forma organizativa que constituyeron, los mecanismos de comunicación y toma de decisiones, los recursos y las redes y alianzas con las que cuenta para conocer más acerca de sus estructuras de movilización y nos introduciremos en sus acciones de memoria y jurídicas, en los procesos de formación política, en los mecanismos de incidencia que utiliza, en el tipo y número de movilizaciones que realiza y en las comunicaciones y campañas que emprende para conocer algo más de sus repertorios de acción colectiva (Ibarra et al., 2002; McAdam et al., 1999, 2005). Todo ello bajo una mirada más dinámica de la contienda política de tal suerte que nos permita entender al movimiento, más que un actor aislado en el escenario de lo político, como un personaje colectivo y complejo internamente, en permanente 
relacionamiento con otros, a quién también cambia y en medio del cual se producen transformaciones sociales y políticas que les afectan y potencializan (McAdam et al., 2005; Tilly \& Tarrow, 2007).

\subsubsection{Los marcos cognitivos del Movice}

La primera década del siglo XXI comenzó con una sólida experiencia en la defensa de los derechos humanos en el país. A esta altura, no era poco el conocimiento que decenas de organizaciones de derechos humanos habían adquirido en el proceso de la lucha por la garantía y la defensa de los derechos de las víctimas y de las comunidades que ya comprendían y utilizaban con destreza las normas nacionales e internacionales que les amparaban. Estaban, sin saberlo, casi listas para enfrentar la arremetida a la que iban a ser expuestas en los siguientes años. Podría decirse que el surgimiento del Movice, más que el resultado de la coincidencia de eventos coyunturales, resultó ser la consecuencia inevitable del proceso de victimización que sufrió el movimiento de derechos humanos que había comenzado a desarrollarse a mitad de la segunda parte de siglo anterior teniendo a estas alturas afincada una fuerte tradición en el país. Señala Marcela Duarte:

"Yo diría que el Movice es una red, una red de organizaciones y de personas que luchan contra la impunidad. Yo no sé si es un movimiento social, yo diría que el movimiento de derechos humanos sí es un movimiento social por la cantidad de tiempo que llevan en esa lucha, porque el movimiento de derechos humanos uno sí claramente lo puede ubicar desde los años 70 con las mismas reivindicaciones, con unas estrategias muy similares en los años 70, 80, 90. El Movice surge como una de esas estrategias del movimiento de derechos humanos en Colombia para posicionar un tema y es decir, existe un grupo de personas que tienen unas características y que han sufrido ciertos crímenes y esas personas tienen derecho a ser reconocidas, tienen derecho a la verdad, la justicia y a la reparación. Entonces yo lo vería así, como una estrategia del movimiento de derechos humanos y no en sí como un movimiento social" (Entrevista 14). 
Los que posteriormente serían integrantes protagónicos del Movice, de tiempo atrás habían realizado ingentes esfuerzos por la compilación y denuncia internacional de miles de crímenes mediante el Proyecto Colombia Nunca Más. Habían acumulado lustros de paciente trabajo de documentación en todo el territorio nacional, conocían como nadie más en el país las violencias de la guerra y particularmente, la forma en que el Estado y sus agentes se habían hecho parte del conflicto mediante artimañas legales e ilegales produciendo cientos de miles de víctimas de los más diversos hechos. Se trató de años de acopio de agravios ostensibles que daban solidez y argumentación a sus reclamos y que encausaron con rapidez la indignación de sectores importantes del país.

Pero también fueron décadas de aprendizaje profundo de los caminos para la superación de la impunidad. Se forjaron organizaciones como la Comisión Intercongregacional de Justicia y Paz, la Asociación de Familiares de Detenidos Desaparecidos de Colombia ASFADDES, el Colectivo de Abogados “José Alvear Restrepo", la Fundación Comité de Solidaridad con los Presos Políticos CSPP, el Comité Permanente por la Defensa de los Derechos Humanos CPDH, entre muchas otras organizaciones sociales, sindicales, campesinas, comunitarias, eclesiales, locales y nacionales, que aprendieron a desafiar al Estado en su conjunto y a los sucesivos gobiernos nacionales y locales que encarnaban las violencias del país. Para los primeros años del 2000, ya las organizaciones se encontraban listas para dar un paso adelante en las estrategias y mecanismos de contención contra su oponente principal.

\subsubsection{Los Agravios}

Sin embargo, sí debió ocurrir un hecho dramático que colmó la paciencia de estas organizaciones y que determinó en ellas la necesidad de modificar el escenario de las luchas sociales en el país. El proceso de negociación de Uribe con los paramilitares y la forma en que éste se desarrolló fue, a todas luces, el elemento disparador de la acción colectiva. Las siguientes frases, retomadas de los 
documentos internos del Movice, pueden recoger de alguna forma la indignación producida por este acontecimiento.

"Se realizó el Encuentro Voces del Mundo por Colombia, justo cuando el ejecutivo tramaba la realización de un proyecto que amnistiara grupos paramilitares, tras lo que se conoció como las negociaciones de Santafé de Ralito. Se hablaba por doquier de la desmovilización de las Autodefensas Unidas de Colombia, AUC, en cabeza de Carlos Castaño Gil. Sueño idílico para los victimarios. Pesadilla penumbrosa para las víctimas. Beneficio para quienes han hecho un daño irreversible a la humanidad. Golpe bajo para la dignidad de las personas que sufrieron el daño. Antilógica en resumen" (Movice, s. f.-b).

La creciente sensación de impunidad que se vivía en Colombia, sumado a la certeza incuestionable de la participación directa e indirecta del Estado en los más graves crímenes de lesa humanidad, se apoderó de las diversas expresiones del movimiento de derechos humanos del país. Esta situación se amplificó aún más por el carácter reaccionario del Presidente Uribe, cuestionado por promover las CONVIVIR mientras fue gobernador del Departamento de Antioquia, además de ser permanentemente señalado por las víctimas como auspiciador de la violencia paramilitar en el país.

Con esta conjunción de eventos se hacía realidad uno de los temores más abrumadores para los defensores de derechos humanos en Colombia. La existencia y consolidación de un marco de impunidad construido con esmero por el gobierno central para los más horrendos crímenes de Estado. Así lo expresa el abogado Eduardo Carreño, integrante del Colectivo José Alvear Restrepo:

"El Movice surge fundamentalmente a raíz de una política en la cual el gobierno del presidente Uribe inicia los diálogos con el paramilitarismo y comienza a plantear las tesis que venía anunciando el movimiento de derechos humanos sobre verdad, justicia y reparación integral. El gobierno 
presenta una ley con estos elementos quitándole así el nombre a las reivindicaciones del movimiento de derechos humanos. A raíz de eso comenzó a hacerse el planteamiento fundamental del lugar de las víctimas dentro del proceso de negociación y cómo se hablaba de las víctimas pero las víctimas no aparecían por ninguna parte” (Entrevista 23).

Desde la perspectiva de las organizaciones y las víctimas, mediante esta política el gobierno de Uribe pretendía zanjar las dudas que existían sobre las relaciones entre grupos paramilitares y el Estado intentando evadir la responsabilidad que le cabía en los más horrendos crímenes de lesa humanidad. Ofensa demasiado alta para las organizaciones que desde hacía años trabajaban fuertemente para evitar precisamente que esto sucediera.

Esta lectura del mundo les permitió a su vez identificar su oponente principal. A estas alturas no se trataba de una lucha contra la impunidad en abstracto, no era solamente una demanda para el mejoramiento y superación de la crisis de la justicia. Se trataba de una contención con nombres y apellidos:

"El Movice desde su surgimiento tuvo un principal enemigo: el presidente Álvaro Uribe Vélez. Desde el surgimiento de Movice no gratuitamente el presidente lo catalogó como un importante oponente, como un importante enemigo y lanzó una campaña de estigmatización y de seguimiento a través del DAS, del discurso oficial que se señalaba al Movice como una organización que estaba del lado de las banderas de la insurgencia" (Entrevista 18).

No era entonces raro escuchar por aquellos meses en los medios de comunicación la batalla que había comenzado entre estos dos actores quienes se trenzaban con vehemencia en discusiones sobre la criminalidad del otro. Para las organizaciones y sus víctimas, Uribe era un exponente del paramilitarismo. Para este presidente a su vez, el Movimiento era la condensación política de la guerrilla. En definitiva, las organizaciones vieron en la construcción y fortalecimiento del Movimiento el 
camino idóneo para combatir las posturas del gobierno Uribe que se estaban convirtiendo ya en Política Pública.

Este encuentro de eventos superaba entonces una mera indignación individual. Considerando que las organizaciones de derechos humanos habían crecido en el abanderamiento de los derechos de las víctimas de crímenes de lesa humanidad, conocían a profundidad el Derecho Internacional de los Derechos Humanos y el Derecho Internacional Humanitario, estaban entrenados en la exigibilidad de los derechos de las víctimas en tribunales internacionales y encabezaban la lucha por la verdad, la justicia y la reparación integral de las víctimas en el país, no resultó extraño que su primer planteamiento como colectivo, si bien fue profundamente humanista, tuviera una forma jurídica: la crítica técnica a los proyectos legislativos que se estaban construyendo para la desmovilización paramilitar.

Desde la visión del naciente Movice, la normatividad propuesta por el gobierno excluía completamente un actor clave en los procesos de justicia transicional: las víctimas, y en este caso particular, las víctimas de crímenes de Estado. Desde este enfoque, este desconocimiento cimentaba las bases del ocultamiento pleno de las responsabilidades del Estado en la guerra colombiana haciendo incontenible desatar una contención pública y sonora con el gobierno nacional. Sobre este punto nos explica Eduardo Carreño:

${ }^{66}$ Esta ley fue demandada por los grupos de derechos humanos y por el Movice también. Es decir, es una ley que no se comparte por cuanto integralmente no recoge los derechos de las víctimas y lo que hay ahí inmerso es un proceso que nosotros denominamos de legalización y de legitimización del paramilitarismo" (Entrevista 23).

Sin embargo esta perspectiva, aparentemente técnico jurídica, se basó en una interpretación aún más elaborada de aproximación al mundo. Para las organizaciones comprometidas, este tipo de políticas eran simplemente la 
representación de un estado de cosas intrínsecas a un Estado neoliberal e injusto, que debía ser expuesto y confrontado. De fondo lo que allí se estaba planteando era un profundo rechazo al sistema político, económico y social de un Estado capitalista y victimizante. Así lo expresa el mismo Movice en su descripción:

"El Movice, ha adoptado una postura política clara, surgida de la concepción de que buena parte de los crímenes cometidos contra el movimiento social y popular en Colombia obedecen a una intensión social, política, económica e ideológica promovida por el Estado colombiano y sus agentes o permitida por este e implementada por grupos paramilitares en favor de intereses particulares ligados a las clases dominantes y empresas transnacionales, crímenes todos que son de clara responsabilidad estatal. Por tanto, es este quien tiene la obligación de responder ante las víctimas, sus familiares, las organizaciones a las que pertenecen y al conjunto de la sociedad colombiana, garantizando el derecho a la verdad, la justicia, la red de reparación integral, la garantía de no repetición.” (Movice, s. f.-c).

Vale decir que no se partió de una sola premisa ideológica o política. En su seno estaban representadas diversas expresiones sociales y políticas que encontraban como común denominador su rechazo a los mecanismos de impunidad propuestos por el gobierno de Uribe. Sin embargo el que muchas de las organizaciones allí aglutinadas bebieran de los fundamentos ideológicos de la izquierda facilitó que un agravio sostenido en el tiempo y un ideario político se concretaran en la lucha directa contra el Estado mediante la contención política y social.

\subsubsection{Los Objetivos}

Esta suma de elementos le permitió rápidamente al Movice concretar un guion político y una ruta de trabajo lo suficientemente sugestiva para motivar todo un despliegue de acciones en diferentes regiones del país durante un tiempo sostenido. Pero además lo habilitó para la construcción relativamente pronta de una serie de objetivos estratégicos sobre los cuales trazarían su movilización política y social en 
el que se mezclarían el sentimiento de agravio producido por las acciones de Uribe y la experticia adquirida por sus miembros décadas atrás. Sobre este punto, el actual Secretario Técnico del Movice, Camilo Villa nos señala:

"Yo creo que el objetivo principal del movimiento en el momento que nace, que ha cambiado porque se ha tenido que ajustar a todas las cosas que han pasado en el país, pero que es el objetivo general del Movice, es unir todas las fuerzas de la sociedad civil para evidenciar el estado de impunidad en que están la mayoría de casos de crímenes de estado y de crímenes de paramilitares, que para nosotros hacen parte de un solo campo. Hacer una lucha por la justicia y con esto acompañar a las víctimas desde todas las organizaciones que hacen parte del Movice en estrategias de justicia y de recuperar la memoria histórica de las luchas y de los conflictos sociales en el país. Yo creo que ese podría ser un buen resumen de los objetivos generales del movimiento. Ahora, los otros serían objetivos más específicos, la forma en que en cada momento se ha pensado que se pueden dar pasos hacia adelante" (Entrevista 19).

Es evidente en este caso que los primeros momentos del Movice estuvieron concentrados en la lucha contra la impunidad. Existía un derrotero muy claro sobre la justicia como epicentro de toda la acción y fin último de la contención. Los culpables, es decir, el Estado en asocio con los grupos paramilitares, debían ser expuestos, censurados y sancionados, al tiempo que las víctimas debían ser reconocidas, sus luchas reivindicadas y sus familiares reparados integralmente.

Al tiempo, la afirmación de los derechos a la verdad, la justicia y la reparación se erigía como protagonista de la lucha. Para este momento estaban bien inmersos estos planteamientos en los líderes más prominentes y la lucha jurídica estaba encausada. Eran los años 2000 y ya existían ejemplos internacionales suficientemente consolidados para que en Colombia no se pensara en la justicia internacional como escenario necesario para desarrollar su contienda. 
Además de ello era necesario buscar aliados y aumentar la presión mediante la acción coordinada de diversos actores previamente aislados, de tal suerte que se pudiese conformar un bloque mayor por la defensa de las víctimas más allá del trabajo jurídico de algunos abogados. Se pretendía alcanzar la suficiente visibilidad que les permitiera ganar en capacidad de confrontación e incidencia. Por tanto, los primeros encuentros estuvieron también perfilados en ese sentido. Era necesario aglutinar las diferentes expresiones que por décadas se había consolidado en los territorios y a nivel nacional y encontrar un punto en común que les permitiera la articulación coherente y sostenible.

Pero sus propósitos no paraban allí. La lista de objetivos era un poco más larga al principio de la contienda. Actuar por una transformación social, buscar el reconocimiento de las víctimas como sujetos de derecho, testigos históricos y participantes de la vida política del país, conquistar plenas garantías para la oposición, exigir el desmonte de las estructuras de la guerra, animar la unidad de las organizaciones de víctimas, exigir a los medios de comunicación detener la manipulación que legitima el terror estatal, demandar justicia integral, crear una comisión para el esclarecimiento de los crímenes, abogar por el reconocimiento de la verdad histórica, dignificar las víctimas mediante la reparación integral, realizar acciones jurídicas nacionales e internacionales, desobedecer la ley de "Justicia y paz" y desarrollar prácticas de memoria, entre otras, son las principales apuestas del Movice al momento de sus surgimiento.

Se constituye así una propuesta más amplia en la búsqueda de derechos en la que se hace una lectura, no sólo de los crímenes de Estado y sus principales perpetradores, sino de aquellos elementos del contexto que los alimentan y amparan. Sin embargo estos objetivos de partida con el tiempo han tomado nuevas formas a partir de las realidades a las que se han visto expuestos, si bien no modificándolos o derogándolos, si ampliándolos y adoptándolos a las necesidades, al contexto y a las expectativas de sus líderes.

Esta ampliación y reelaboración de los objetivos nos la sugiere Iván Cepeda: 
"Yo creo que es muy importante el reconocimiento legal de algunas luchas y el establecimiento de políticas públicas, pero para mí el trasfondo esencial es hasta dónde avanzamos en construir un factor de poder. Lo otro es como la manifestación externa de eso que es fundamental. Para mí lo fundamental es que el movimiento de víctimas tenga hoy la posibilidad de ejercer un cierto grado de influencia en la opinión, que tenga que ser tomado en cuenta para discutir ciertos asuntos, que tenga la oportunidad de elegir gente, que tenga la posibilidad de movilizar gente, de echar para atrás cierto tipo de medidas, eso para mí es lo fundamental” (Entrevista 25).

Así las cosas, no se trata solamente de disminuir las estadísticas de impunidad, de juzgar y encarcelar a militares involucrados en crímenes de Estado o de sacudir a la opinión pública para que puedan observar la realidad de los acontecimientos de la guerra, es necesario además interpretar los mecanismos de dominación del Estado, las relaciones de poder establecidas, el mundo de lo político y las transformaciones necesarias para modificar las estructuras de opresión. Es intervenir protagónicamente en los destinos del país y poder influir certeramente en los derroteros como sociedad.

Estos objetivos orientados al poder, por supuesto, no resultan extraños si se tiene en cuenta que muchos de las víctimas lo fueron precisamente por su beligerancia y rebeldía contra el Estado constituido y que las organizaciones que concibieron el movimiento mantenían a su vez rasgos ideológicos que los caracterizaban y los dotaban de una identidad política particular.

Estos objetivos macro también se han venido ajustando a las agendas políticas locales y nacionales. El trascurso del tiempo, el ingreso de un nuevo gobierno y el cambio de perspectiva de algunas políticas ha obligado al Movimiento a adaptar sus planteamientos a estos nuevos desafíos. Así, mientras para muchos era poco lógico que el Movice rechazara vehementemente la extradición a Estados Unidos de los paramilitares involucrados en el proceso de "Justicia y Paz" y realizaba visitas en 
las cárceles para dialogar con los principales responsables de crímenes de lesa humanidad, para ellos era apenas natural que se pretendiera evitar que se extraditara la verdad.

Al tiempo, mientras la mayoría de víctimas históricas de crímenes de Estado habían sido producidas en su mayoría por su carácter político y beligerante, el Movice debió aprender con el tiempo que cualquiera, aún sin la más mínima formación política, podía convertirse en víctima de un crimen de Estado, por lo que el trabajo en formación y transmisión de conocimientos se volvió centro de acción.

A su vez, el debate de los distintos proyectos que determinaron la ley de víctimas, y aún, el proceso de paz actual en la Habana, les ha estimulado a revisar sus orígenes, interpretar las realidades y tomar decisiones que les permitan avanzar de manera coherente y compacta ante la adversidad. Aprendizajes que fueron modelando día a día sus derroteros y sus planteamientos.

De esta forma, la lucha contra la impunidad, el reclamo por los derechos de las víctimas a la verdad, la justicia y la reparación integral, la necesidad de ganar en extensión y profundidad mediante la agrupación de organizaciones previamente aisladas, la importancia con el tiempo de convertirse en factor de poder e incidencia política y de ir atendiendo las coyunturas del país, han sido los móviles principales de la movilización social por las víctimas de crímenes de Estado.

\subsubsection{Los Símbolos y la Memoria}

Esta contienda implicaba además un reconocimiento por los muertos, los desaparecidos, aquellos que fueron martirizados por los gobiernos y sus Fuerzas Militares y que sufrieron las consecuencias genocidas de la acción paramilitar. Era necesario recordar a los mártires, reconocer sus luchas, develar por qué habían sido victimizados y quién o quienes se habían beneficiado con las acciones criminales, de allí que fuese imperioso avanzar en procesos de reconstrucción de memoria histórica que permitiera mantener vivo el recuerdo de los seres queridos, las 
realidades del conflicto, sus razones y consecuencias y la lucha por la reivindicación de sus derechos.

Para ese entonces la reconstrucción de la memoria histórica ya era un ejercicio bien conocido por las organizaciones de Derechos Humanos motivadas por el proyecto “Colombia Nunca Más”, pero el Movice la convertiría en símbolo y tributo, acción pública y reclamo colectivo. Lo hacía donde era imposible mirar hacia otro lado. Así lo refiere Jairo Ramírez:

"Yo creo que el Movice le dio un vuelco al trabajo de derechos humanos en el país a partir del 2002 para acá, porque ya es un movimiento de derechos humanos en la calle, ya dejó de ser un movimiento de recinto. Es un movimiento que ya ha desplegado toda una cantidad de iniciativas para desenmascarar la responsabilidad del estado en crímenes de lesa humanidad cometidos en el país" (Entrevista 21).

Se trataba de la exposición "en voz alta" de los dolores causados por el Estado y el reconocimiento de la verdad de las víctimas y de sus familiares tantas veces acallada por el poder del oponente. Una de estas experiencias de memoria es relatada por Prensa Rural, un medio de comunicación alternativo muy cercano a los movimientos sociales en el país, al referirse a la presentación oficial del Movimiento el jueves 7 de abril de 2005.

"Cientos de personas, vestidas de negro, con mantos violetas, flores en las manos, fotografías de sus seres queridos y desaparecidos, desfilaron ayer jueves 7 de abril por la galería de la memoria, instalada en la Plaza de Bolívar de Bogotá, a propósito de la presentación oficial del Movimiento Nacional de Víctimas de Crímenes de Lesa Humanidad y violaciones a los Derechos Humanos. En efecto, la jornada que se extendió desde las 9 de la mañana hasta las 7 de la noche, contó con la presencia de más de 800 personas, quienes, a pesar del intenso frío capitalino, la llovizna a veces persistente, a partir de las 4 de la tarde, escucharon atentas, la lectura de los 
nombres de cada una de las víctimas del paramilitarismo de Estado, realizadas por miembros de organizaciones defensoras de derechos humanos que las agrupan. (...) El punto máximo de este mágico ritual de la memoria, tomó forma cuando en medio de la multitud, integrantes de la Comisión Intereclesial de Justicia y Paz desfilaron por la plaza, cargando un ataúd, y con palabras entrecortadas por el llanto, solicitaron a los asistentes un aplauso, que se prolongó por más de cinco minutos, en memoria de todos los desaparecidos, asesinados, desplazados y amenazados por la violencia paramilitar" (Prensa Rural, 2005).

Así, la memoria de los crímenes que reposaban en el seno familiar y en uno que otro expediente judicial, rompe el silencio y se expone ante una ciudadanía inerte, apática, sin conocimiento ni comprensión histórica, haciendo que el paisaje cotidiano se vea interrumpido por las imágenes y las voces de las víctimas clamando justicia. El uso del luto, las flores, los cantos y las consignas se hicieron rutina en las acciones del Movice. Ya no se trataba de librar la batalla entre los expedientes solamente, o de "contar los muertos" e irlos registrando en bases de datos, implicaba la exposición pública, el encuentro con el otro que no conocía o prefería desconocer la realidad de la guerra, pero además lo hacía en el centro de la capital del país, en los ejes de desarrollo urbano más importantes.

Con el tiempo, los ejercicios de memoria histórica han comenzado a convertirse en una herramienta poderosa para la lucha contra la impunidad y en muchas regiones el Movice la ha adoptado como bandera de su acción política, de allí que no es extraño encontrar actividades permanentes que invitan al análisis de los crímenes, sus autores, los contextos y a la apreciación en perspectiva de los hechos. Líneas del tiempo, reconstrucción de sucesos, conversatorios políticos de momentos históricos y encuentros de acompañamiento a víctimas son algunos de los mecanismos dispuestos para hacer memoria histórica y colectiva de los crímenes y sus víctimas. 
De manera particular, aunque acompañadas siempre de otros rituales y performance, las galerías de la memoria se erigieron como marca diferencial de las apuestas públicas del Movimiento. Con las fotos de las víctimas en sus manos, los familiares y sobrevivientes muestran en público el rostro de su dolor buscando en los ciudadanos de a pie reacciones que los motiven a la solidaridad. Pero también es una forma de confrontación al Estado "opresor" para demostrar su entereza y necedad contra el olvido. Se trata de darle una identidad a la víctima expresando a la institucionalidad que no será olvidada y que la lucha por la justicia y la verdad permanecerán en el seno del Movimiento.

\subsubsection{Y se tejen los Discursos}

La identificación de unos agravios y la construcción de unos objetivos comunes reflejaban a su vez una interpretación compartida del mundo. Interpretación compleja pero con la ventaja de derivarse de una relación cercana con la realidad y un compromiso serio con lo que ocurría en el país en aquel momento y que los hacía identificarse con el otro pese a tener una historia personal y organizativa diferente. Se entroncaron así varios planteamientos políticos y prácticos que si bien eran distintos, no necesariamente eran contradictorios. Se trataba más bien de planteamientos que en diversos sentidos resultaban complementarios y con cierto grado de coherencia y unidad interna.

Para entender esto es necesario recordar que el surgimiento del Movimiento es trazado por la acción política consiente de varias organizaciones que de tiempo atrás luchaban en el movimiento amplio de derechos humanos que se había gestado desde los años 70. Así nos lo recuerda Camilo Villa:

"Es necesario conocer la historia para entender por qué funciona, cómo funciona el Movice. El antecedente es la lucha general por los derechos humanos. Eso habla de las historias que hacen parte del Movice: del Comité Permanente por los Derechos Humanos, el Comité de Solidaridad con los presos políticos, el Colectivo José Alvear Restrepo, 
todos vinculados hace 40 años a la lucha por los derechos humanos. Unas organizaciones más orientadas al trabajo con presos políticos, otros más orientados al trabajo de defender víctimas y llevar casos ante instancias internacionales. Es un antecedente también directo la historia de las organizaciones de víctimas propiamente dichas, por ejemplo la historia de ASFADES, la historia de Nomadesc, la historia de todos estos colectivos de víctimas y de abogados nacionales y regionales, que también son muy importantes: Luis Carlos Pérez, la Corporación libertad en Antioquia. En cada región ese acumulado fue trabajando individualmente con redes de contacto y apoyo entre ellos" (Entrevista 19).

Existía entonces un conocimiento previo, un contacto básico que les permitía actuar con altos niveles de confianza alimentada por unos agravios compartidos. Pertenecían ya a un movimiento más amplio por la defensa de los derechos humanos que los implicaba en la demanda de verdad y justicia. Sin embargo, había algo en su planteamiento que los hacía aún más cercanos, su similitud en relación al planteamiento sobre la existencia de crímenes de Estado, el papel desempeñado por las Fuerzas militares en la guerra y las formas que asumían las violencias en un tipo de Estado capitalista y opresor.

"Lo primero es que la historia de unidad del discurso del movimiento tiene que ver con la inspiración de la fundación del movimiento. Era muy clara la lucha contra la impunidad, la lucha por la justicia, la lucha por la verdad, la lucha por la realización de los derechos de las víctimas y la idea de una narrativa sobre la violencia. Una narrativa en la que el Estado aparece como promotor de la violencia. Esto hacía que la gente estuviera de acuerdo con las cosas más generales y más importantes. Como que la coherencia ideológica alrededor del movimiento finalmente se dio en el momento fundacional y eso ayudó mucho a que los debates y a que la posiciones del Movice representaran un grado de unidad muy alta" (Entrevista 19). 
Así las cosas, diversas izquierdas se encontraron en el mismo escenario construyendo un discurso único del Estado Colombiano y su relación con la guerra. Veían en éste un elemento generador de violencia interesado en desarrollar una visión única de sociedad de mercado, dividida en clases y de talante tirano mediante un poder estatuido y legalizado por una democracia de urnas y sostenido a su vez por un cuerpo militar interesado en mantener las cosas inamovibles. De esta manera, se ubicaba el Movimiento al lado de una serie de actores declarados en rebeldía contra el statu quo mantenido históricamente por una clase dominante que se resistía a abandonar el poder y que tomaba cada cuatro años un rostro diferente pero igual de ilegítimo. Sin embargo, no lo hacía en forma de partido o grupo político sino en forma de movimiento social, aglutinando actores originalmente dedicados a las luchas jurídicas por las víctimas y no a las contiendas políticas electorales.

Esta experiencia, basada en el estudio permanente de expedientes judiciales y de trabajo directo con las víctimas y testigos, les implicó una mayor comprensión del rol de las fuerzas militares y sus responsabilidades en las acciones criminales. Pero además, les permitió identificar las variaciones en el tiempo de su papel en el Estado y las connotaciones que ciertas modificaciones podría traer a la situación de conflicto en Colombia. Así los expresa uno de sus miembros en relación a la llegada de Uribe al poder y los cambios que esto trajo en los militares del momento:

"Nosotros habíamos dicho que el ejército y la fuerza pública estaba tomando gran fuerza en el Estado y en la clase política porque precisamente en ellos se fincó la campaña por mejorar la imagen del Estado y por mejorar la imagen de la clase política. En el momento en el que se le dice a la fuerza Pública que la legitimidad del Estado la da la fuerza, la da el despliegue militar, la dan los resultados militares, entramos en una dinámica donde hay una captura por parte de los militares de la función estatal. Yo creo que eso es lo que estamos viendo hoy." (Entrevista 19). 
Se constituye así un nuevo elemento de cohesión. Su lucha por el desenmascaramiento de los militares y sus actuaciones en relación con el poder establecido por el gobierno de turno. Se trata de una modificación sobresaliente entre el periodo de Pastrana, en el que, si bien iba en aumento la potencia militar del Estado, este aún no era el centro de acción del gobierno, y el periodo de Uribe en el que las Fuerzas Militares disfrutaron de una posición privilegiada como epicentro de la acción gubernamental, permitiéndoles mayor maniobrabilidad y una posición moral única frente a los ciudadanos. Se trata de la visión militarista y violenta de estos primeros años del presente siglo en los que las violencias se exacerbaron trayendo consigo el incremento de los "falsos positivos", una modalidad de ejecuciones extrajudiciales poco conocida hasta el momento por la ciudadanía en general.

\subsubsection{Y se consolida su Identidad}

Estos elementos trajeron consigo las partes constitutivas de una identidad fuerte, capaz de conquistar nuevos miembros y aliados y de diferenciarse de uno de los movimientos más importante que ha tenido el país: el movimiento de derechos humanos. Ahora bien, esta identidad, si bien tuvo un núcleo determinante al inicio de la contienda, como en muchos otros casos también ha sufrido modificaciones con el tiempo las cuales permiten hacer un rastreo por los diferentes momentos que ha vivido el movimiento.

Tal como lo referenciábamos anteriormente, durante el momento previo al comienzo de la contienda protagonizada por el Movice, las organizaciones defensoras de los derechos humanos habían logrado articularse y sacar adelante proyectos conjuntos y varias organizaciones de víctimas estaban constituidas y habían comenzado su proceso movilizador. Cabe suponer entonces que lo que les diera su punto distintivo era agruparse precisamente como víctimas de Estado. Esta toma de decisión no fue sencilla ya que debía debatirse la legitimidad de constituirse como un movimiento sobre la base del victimario y no sobre el hecho victimizante 
o la idea de la paz o el pacifismo como ya muchos otros lo habían hecho. Así los expresa Franklin Castañeda:

"Creo que el Movice al abrir el debate y que otros digan, ¡Ay, es que son guerrilleros!, ¡desconocen a las otras víctimas! y el Movice poder decir, no, no es que las desconozcamos, es que quienes nos desconocen son la sociedad y las autoridades en Colombia y por eso nos ponemos este apellido y eso comienza a marcar un hito concreto en Colombia." (Entrevista 15).

Se trataba en efecto de plantear un desafío directo al Estado y a los sucesivos gobiernos al anunciar desde de su mismo nombre el agravio cometido, navegando contracorriente con los discursos pro militaristas de aquel momento. Esto les valió no solamente problemas con la institucionalidad que desde el principio los descalificó, sino diferencias y divisiones con otros movimientos y organizaciones de víctimas que fundaban su accionar en la condición de víctima independientemente del perpetrador. Este es el caso de una de las plataformas de mayor reconocimiento finalizando los años 2000, la Mesa de Víctimas de organizaciones sociales, que pretendía reunir las diversas manifestaciones organizativas al nivel nacional para trabajar conjuntamente la exigibilidad de sus derechos. Este debate permanente sobre la legitimidad de agruparse teniendo como punto de referencia el perpetrador facilitó delinear con claridad los sustentos de su planteamiento político.

Insistimos por supuesto, en que esta postura no era gratuita. Obedecía principalmente a las historias de vida personal y política de sus miembros fundadores:

"Hay muchas víctimas, pero es que las víctimas de estado son víctimas políticas, que no estaban en el lugar equivocado simplemente. Son los sindicalistas que luchaban contra las trasnacionales, los campesinos que lucharon por la reforma agraria, la Unión Patriótica, el Partido Comunista, A Luchar. No es un sector que exija meramente la verdad, la justicia y la 
reparación como un problema humanitario, cosa que a mi modo de ver no está mal, sino como un problema político, y eso que significa, significa que la verdad, la justicia y la reparación son para cambiar la sociedad, no para cambiar la situación de una víctima individualmente considerada, que eso también está bien puesto que una persona puede tener una reparación por el caso individual, está muy bien, pero el problema es que eso no tiene efectos transformador en términos colectivos y sociales.” (Entrevista 25).

En sus inicios, queda claro entonces, existía un elemento revolucionario no solo en lógica de exigibilidad de derechos sino en procesos de más alto calado que implicaran cambios profundos al sistema político y económico. Diversas izquierdas que, si bien se hallan hacia un lado del espectro de la política colombiana, no son homogéneas ni conservan las mismas posturas ideológicas. Por el contrario y como ha sido tradicional en las izquierdas de este país, el debate y la confrontación han sido parte del proceso movilizador del Movice.

En este caso particular, la presencia de "comunistas" y "camilistas" conforman el principal clivaje en el escenario y es epicentro de disputas en el seno de la organización. La forma en que se vive este hecho sin embargo, es distinta en los territorios y en el centro del país. Mientras en los departamentos y municipios esta diferencia se experimenta con mayor apasionamiento, el cual se incrementa en época electoral, en el Comité de Impulso se han venido construyendo mecanismos que equilibran la balanza entre unos y otros, permitiendo la generación de consensos y el desarrollo de las acciones en un marco de respeto y armonía.

Este hecho sin embargo, no significa que perviva el debate entre las dos corrientes de manera consistente sobre todo en los capítulos. Las formas de realizar el trabajo, el enfoque de acción o los acentos puestos sobre determinados temas, son motivos comunes de debate, hecho que devela la existencia de identidades previas afincadas en posturas ideológicas y de acción política. Estamos entonces ante el encuentro de dos identidades de izquierda que se reúnen en el movimiento y que comienzan a generar una nueva identidad a partir de aquello que les es común, sin necesidad de 
despojarse de sus identidades políticas anteriores. Podría decirse que el Movice es un espacio aglutinador de procesos identitarios fuertes y previos que unen algunos de sus elementos para movilizarse en torno a un interés común.

Es importante señalar también que allí están representados otros sectores más neutrales, que, sin compartir completamente los planteamientos políticos de "comunistas" y "camilistas", o de otras corrientes, entran en la discusión con mayor serenidad y sin modificar los equilibrios definidos. Sin embargo, esta conformación, que ha sido estable desde el comienzo y que de alguna forma subsiste actualmente, ha sufrido sismos importantes que han planteado desafíos serios a la identidad del movimiento. Tal vez el más representativo fue la incursión de víctimas de crímenes de Estado individuales y no politizadas al Movimiento.

Para entender este tema es necesario recordar que el Movice fue construido por iniciativa de organizaciones no gubernamentales en las que participaban estos sujetos políticos con el objeto de visibilizar la impunidad estatal que venía en ascenso desde la llegada de Uribe a la presidencia y aunque, su nombre sea movimiento de víctimas, en realidad allí no se encontraban aglutinadas víctimas como tal.

"Cuando entraron víctimas no organizadas al Movice fue cuando comenzaron las tensiones, porque finalmente había un nombre: era movimiento de víctimas, ese nombre es muy complicado porque significa eso, que supuestamente hay un movimiento social de personas víctimas de crímenes de Estado y cuando tu ibas a mirar no era de víctimas, era de organizaciones que acompañan víctimas. Entonces las víctimas no organizadas empezaron esa pelea por ingresar al Movice. Qué implicaba eso, que eran personas que no tenían formación política, hecho que para el Movice al principio era muy grave, que era gente de la Unión Patriótica o que era del Partido (comunista), gente que venía de los Camilistas pero todo el mundo era parte de un movimiento político, entonces era muy fuerte la reivindicación política, pero cuando sale esto, aparece todo lo de los "falsos 
positivos", todo lo de la brutalidad policiaca y un pocotón de víctimas que no tenían claramente una alineación con partidos y con nada de esto, pero que sí eran víctimas de crímenes de Estado y empiezan a pedir esa entrada, eso sí que generó tensiones, porque es muy diferente que usted establezca un diálogo con una persona que toda la vida ha estado militando a establecer un diálogo con una madre de Soacha, eso genera una tensión bravísima. La madre de Soacha es Uribista, o sea, sus hijos todos están en el ejército, entonces esta entrada fue brutal y ahora tenemos muchos capítulos conformados así, ¿y qué pasó?, la gente militante se fue” (Entrevista 14).

El ingreso al Movimiento de personas sin identidad política previa o con tendencias contrarias, trajo consigo uno de los debates internos en términos de identidad más fuertes en la historia del Movimiento. Se trataba del ingreso de nuevas y variadas formas de interpretar la realidad en las que no existía una lectura crítica a la configuración del Estado y del poder pero si un común denominador: ser víctima de crimen de Estado. Sin embargo, la carencia de un móvil estrictamente político en los delitos cometidos en estos casos generaba planteamientos ambiguos sobre el concepto clásico de crimen de estado, ampliando el debate y las molestias. La idea de crímenes de Estado sistemáticos, generalizados y con un móvil político casi siempre asociado a la actividad de liderazgo de la víctima y su alto perfil político debió dar paso a la sistematicidad y generalidad pero no necesariamente recayendo sobre el sujeto "líder o "político". Era necesario admitir que cualquier joven, campesino o trabajador de base podía ser víctima del abuso policial o caer como "falso positivo". No requería ser reconocido, ni visible, ni ostentar un papel particular en su comunidad, de allí que por ello tampoco le precedían necesariamente preguntas existenciales sobre la acción del Estado o del sistema político y por tanto su acción política estaba alejada de la de aquellas organizaciones defensoras de víctimas que les precedieron en la conformación del movimiento.

Sin embargo era en el modo de hacer y de interpretar la realidad política donde estaba tal vez el centro de la incomodidad. Realizar debates políticos desde marcos conceptuales, históricos e ideológicos distintos se volvía extenuante y difuso, pero 
además generó una división en bandos dentro del movimiento. De un lado estaban las víctimas no organizadas previamente y de otro lado se encontraban las organizaciones defensoras de los derechos de las víctimas. Durante mucho tiempo el movimiento se trenzó en una lucha interna sobre quién tenía la mayor legitimidad de abanderar los designios del proceso político y de liderar el movimiento, al punto que en algunas regiones los capítulos modificaron su composición o en crearon dos capítulos como reflejo de las dificultades para actuar conjuntamente. Por supuesto, este no fue el fin de la historia. El tener el elemento común de ser víctima de crimen de Estado fue aún más potente que la inexistencia de ideologías o del encuentro de posturas políticas antagónicas. Las formas para superar estas dificultades las encontraron mediante la implementación de mecanismos internos para la tramitación de conflictos y la estructuración de procesos de formación política a sus miembros.

"Lo que se ha logrado es que dejen de tener esa discusión, que entiendan que este era un movimiento de organizaciones y no de víctimas y que las víctimas llegaron después y que ambos tienen cabida. Que no pueden decir, que salgan todos los oenegeros y nos quedamos solo las víctimas y que además reconozcan todo ese trabajo que han hecho los oenegeros. Pero que los oenegeros también reconozcan el trabajo que han hecho las víctimas últimamente, porque también se la pasan diciendo que las víctimas no hacen nada, pero es que ustedes con sueldito y todo, es fácil decir que hacen cosas, pero ellos no tienen un sueldo y tienen que salir a buscar que comer y lo poquito que hacen es más valioso que lo que ustedes hacen que tienen sueldo, tiene un carro blindado y todo eso. Entonces hay que ver todo en su justa medida, usted tiene un pocotón de plata en su organización para hacer un pendón, pero ellos no, entonces lo hacen ellos mismos y los pintan y entonces es más bacano, pero es el reconocimiento mutuo el que se ha ganado como fortalecimiento organizativo últimamente". (Entrevista 14).

Es el tiempo y la relación permanente en medio de la confrontación lo que ha permitido que los diferentes actores del Movice hayan logrado crear acuerdos y 
comprensiones del otro dentro de su mismo movimiento, habilitándolos para seguir adelante en la contienda. Pero es tal vez su percepción mantenida de injusticia lo que los hace mantenerse juntos en la contienda.

"Lo más curioso es saber por qué se sigue insistiendo, a Yury la familia le dice que está loco, le dicen: ¡ya supérelo! no los van a meter a la cárcel, deje así, y a todas las víctimas, todo el tiempo les están diciendo ¡deje así!, y a uno como defensor de derechos humanos le están diciendo ya, pero para que se pone a toda hora con este tema. Y no es por plata, porque mucha gente lo hace hasta gratis, entonces explicarse porqué la persistencia, de donde acá le sale tanto convencimiento. Porque a las víctimas obviamente lo hacen por la memoria de sus familiares, otra cosa son los defensores de derechos humanos. Tal vez es por reconocimiento pero ni eso porque uno ni puede contar en la casa qué es lo que hace porque piensan que está de guerrillero. Entonces que motiva a alguien a meterse en esto, que es peligroso, que es desalentador, esa me parece una pregunta interesante" (Entrevista 14).

Se constituyen así los diferentes componentes de su identidad. Unos agravios compartidos expresados en el repudio a una política pública de saneamiento de las atrocidades de las acciones paramilitares, la construcción de unos objetivos con una línea común: la lucha contra la impunidad, pero además una interpretación compleja del mundo desde diversas ideologías de izquierda que comprenden el proceso político no solo en clave de denuncia sino también de transformación, un proceso de adaptación constante al contexto que les fue permitiendo, sin variar sus objetivos centrales, conversar con las realidades del país que se fueron sucediendo y una forma propia de expresar las indignaciones y sacarlas a la calle. Todo ello se consolida y crea unas líneas de pensamiento compartidas desde las cuales son capaces de explicar el mundo desde la lógica de lo que es y no es justo, reconociendo en su condición, plasmada en su nombre, el motor principal de su acción colectiva. Pero además, en un proceso permanente de reconocimiento de realidades que les sugiere el acercamiento a debates novedosos de los cuales surgen 
marcos conceptuales nuevos y cada vez más complejos. El Movice se constituye y se recrea en cada escenario político, aprendiendo del ambiente, de los otros movimientos sociales y de la lucha política, pero resistente en sus posturas originales.

\subsubsection{Organización y Repertorios del Movice}

Para los años 2000 en Colombia ya existía toda una gama amplia de organizaciones y procesos sociales que constituían un ambiente propicio para el surgimiento de nuevos movimientos sociales. Como lo señala Romero (F. A. Romero, 2003), el movimiento de derechos Humanos ya había atravesado por varias etapas desde los 70 s y había recorrido caminos sinuosos en un contexto de guerra que les imprimía unas características específicas y les definía unas formas particulares de organización y relacionamiento. Para esta autora, este movimiento fue construyendo en el tiempo relaciones de articulación, de oposición y de exclusión que les dio una definición concreta en su acción:

"De articulación, en la medida en que en el transcurso de su historia ha creado formas progresivas de coordinación, interlocución y adhesión a otros movimientos, atrayendo especialmente a las organizaciones sindicales, a los grupos eclesiásticos o al movimiento popular. De oposición, porque define una postura indeclinable de rechazo a cualquier forma de abuso contra la vida humana, tanto frente al Estado como ante los particulares y los grupos armados de izquierda o de derecha. De exclusión, en cuanto a la actitud diferenciada de admisión de sus miembros, de aceptación de alianzas y de evitar provocaciones provenientes de sectores que pretenden silenciarlo" (F. A. Romero, 2003).

Mecanismos de comunicación y organización que les permitió mantenerse a flote en momentos de tempestad mientras iban incorporando nuevas demandas y ampliando sus bases. Sin embargo, aún no había una tendencia masiva de las organizaciones, tal como existe ahora en el país, de aglutinarse alrededor de la 
condición de víctimas generadas por el conflicto armado, ni tampoco un nivel de organización nacional que aglutinara las diferentes iniciativas regionales que ya existían. Excepto algunos procesos surgidos desde los años 80s como el de la Asociación de Familiares de Detenidos- Desaparecidos ASFADDES o las mesas y organizaciones de población desplazada animadas por la ley 387 de 1997, en el país no era tan común esta forma de organización pese a que el movimiento de derechos humanos ya se encontraba consolidado y realizaban actos frecuentes para denunciar la barbarie que representaba la guerra contra la población civil.

En este contexto, el nacimiento del Movice en junio de 2005 fue apenas el resultado del desarrollo de una serie de acciones y situaciones propiciadas por varias organizaciones del movimiento de derechos humanos para llenar este vacío organizativo, con el ingrediente esencial de tener la pretensión de liderar la discusión desde la condición de las víctimas y de generar debates de fondo frente a la exigibilidad de los derechos a la verdad, la justicia y la reparación integral en el marco de la lucha contra la impunidad que habrían emprendido varios lustros antes las organizaciones no gubernamentales defensoras de derechos humanos

\subsubsection{El Movimiento de Víctimas de Crímenes de Estado se organiza}

Una de las primeras discusiones que emprendieron las personas y organizaciones que dieron nacimiento al Movice es quienes lo conformarían, teniendo en cuenta la importancia de la identificación del victimario en su nombre. Así, decidieron desde su acta de constitución generar un listado cerrado y claro de sus integrantes. En adelante, el naciente Movimiento recogería en su seno a víctimas de crímenes de lesa humanidad, víctimas de crímenes de guerra cometidos por el Estado, víctimas de genocidio de orden político y étnico, organizaciones de sobrevivientes de estos crímenes y organizaciones acompañantes de víctimas de violaciones de derechos políticos, sociales, económicos, culturales y ambientales. Actualmente, el Movimiento es descrito así por Iván Cepeda: 
"El Movimiento de Víctimas de Crímenes de Estado es un movimiento social. No es una ong, ni es simplemente una asociación de familiares de víctimas. Reúne más de 200 organizaciones en las cuales hay distintos sectores y grupos, partidos políticos, organizaciones sindicales, movimientos agrarios y desde esa perspectiva tiene una visión de los conceptos de verdad, de justicia y de reparación que no se limitan estrictamente a un reclamo neoliberal de esos derechos. El movimiento ha definido unas estrategias de carácter jurídico, y unas estrategias de carácter político y también unas estrategias de movilización. Y lo esencial es que todas estas estrategias tienen una concepción de que son las víctimas, de cuál es el lugar de sus derechos en la sociedad colombiana y en el proceso de transformación de esa sociedad e igualmente del reconocimiento público de las víctimas, en este caso, de Estado" (Entrevista 25).

Ilustración 6. Presencia regional del Movice

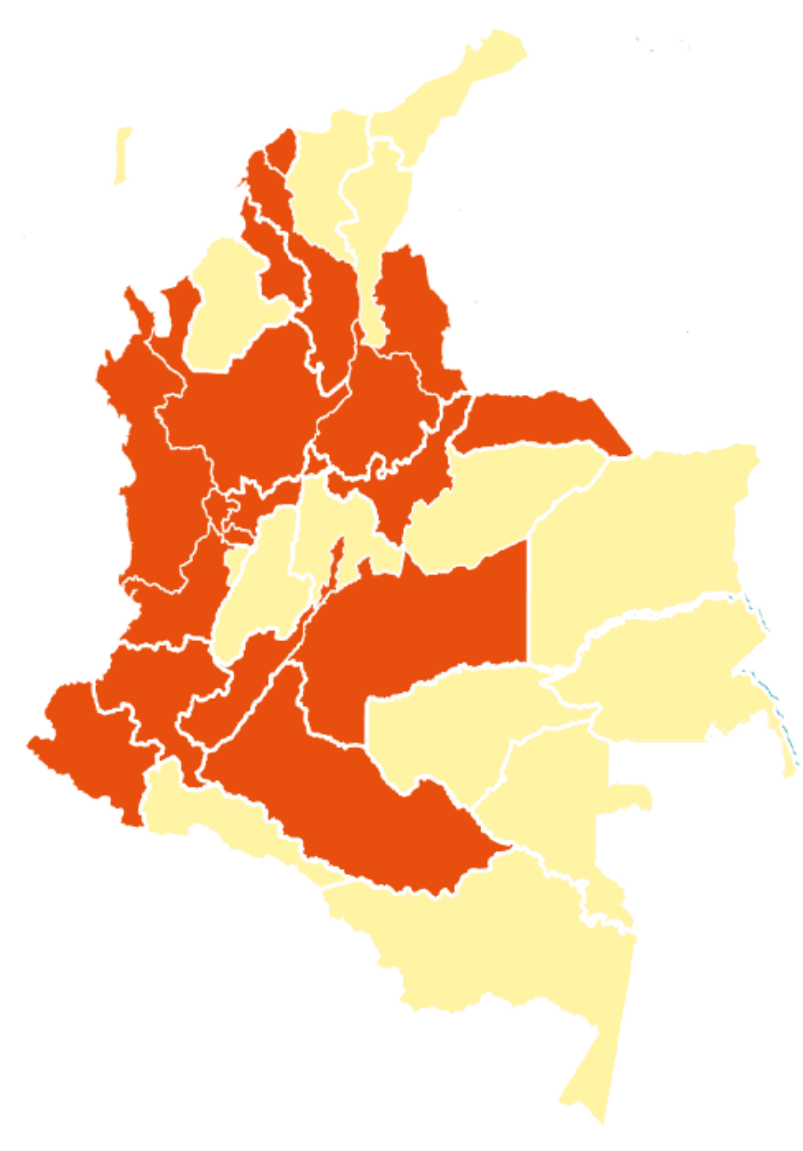

Fuente Movice. Elaboración Propia. 
Con estas premisas, las organizaciones que hacen parte del movimiento, además han construido una estructura para la acción colectiva que les permite tener cierto grado de organización y maniobrabilidad. Habría que decir que, como en otros casos, esta organización tiene un nodo principal en la capital del país y varios nodos regionales, denominados capítulos, distribuidos en los departamentos y principales regiones, así como unos más en el exterior, que les permite tener una presencia nacional y unos referentes internacionales. Actualmente el Movice tiene capítulos en 18 departamentos y en 1 región: Antioquia, Arauca, Atlántico, Bogotá, Bolívar, Boyacá, Caldas, Caquetá, Cauca, Chocó, Huila, Meta, Nariño, Norte de Santander, Risaralda, Santander, Sucre, Valle del Cauca y Barrancabermeja. Además, tiene capítulos internacionales: Argentina, España, México y Bélgica conformados por organizaciones y víctimas que se encuentran exiliadas a causa de su trabajo como defensores de derechos humanos.

Estos espacios nacen a partir de reuniones regionales de víctimas donde se dispone la necesidad de conformar un capítulo del Movice, se crea una ruta de acción y luego se informa al Comité de impulso de manera formal su creación mediante un acta de fundación (Movice, s. f.-a). Cada uno de estos capítulos tiene su propia estructura organizativa la cual puede variar en función del número de miembros y de los objetivos trazados, siendo más o menos activos dependiendo las condiciones para la movilización. Cada uno cuenta con una secretaría técnica y un plan de trabajo propio para viabilizar el trabajo y actúan bajo sus propios criterios de funcionamiento. Por tanto, se trata de escenarios que no son homogéneos en sus tiempos de trabajo y los énfasis puedan ser distintos pese a que conserven los objetivos primarios del movimiento. Esto dependerá de los recursos con los que se cuenten, el contexto político, social y de conflicto armado del departamento o la región y los intereses de las organizaciones y las víctimas que hacen parte de este. Sobre estas diferencias comenta Alfonso Castillo:

"Hay unos capítulos regionales, pero en estos en realidad lo que hay es algunas organizaciones regionales y muchas víctimas y poner a funcionar 
eso ha sido complicado, porque te digo: existe una estructura pero no existe porque haya surgido de la discusión, sino que los capítulos son realidades distintos en cada uno de los 18 capítulos. Funciona distinto, pero además no existen criterios claros para la conformación de un capítulo, lo que al final hace que en algunas regiones por ejemplo el capítulo sea una organización, y como no existen normas claras, el capítulo en cada región o departamento puede tomar cualquier forma. En eso no hay mucha coordinación. La mayor coordinación se da en el comité de impulso" (Entrevista 18).

A nivel nacional se cuenta además con varios espacios de discusión y de decisión que representan el acumulado de los capítulos regionales. En primer lugar, cada dos años se realiza un Encuentro Nacional donde tienen asientos delegados de cada capítulo en el que el Movimiento toma las principales disposiciones orientadoras de su acción política y ética, decidiendo los objetivos que los guiarán en este periodo. Estas decisiones y orientaciones son afinadas en otro espacio nacional permanente denominado Comité de Impulso, con sede en Bogotá, en donde hacen presencia delegados de 24 organizaciones.

Estas son: Comité permanente por la defensa de derechos humanos - CPDH-, Corporación Yira Castro, ASONAL Judicial, AVRE, Corporación Sembrar, ANDAS, Comité de Solidaridad con los presos políticos, Comisión intereclesial de Justicia y paz, la Unión Patriótica, Partido Comunista de Colombia, la Fundación Manuel Cepeda, el Partido Socialista de los trabajadores, el Colectivo de Abogados José Alvear Restrepo, Fedeagromisbol, Coordinación Nacional de Desplazados, la Asociación colombiana de estudiantes -ACEU, Fensuagro, el Sindicato de trabajadores de la Universidad Nacional de Colombia -Sintraunicol-, Sindicato de trabajadores independientes -Sintragrim-, Acción humanitaria por la convivencia Cahucopana-, Central Unitaria de trabajadores -CUT- Asociación de profesores universitarios -ASPU-, la Corporación Jurídica Libertad y el Equipo colombiano de investigaciones antropológico forenses. 
Este Comité se reúne cada 15 días y tiene como cometido hacer seguimiento a las acciones que se van desarrollando en función de los objetivos trazados. Paralelamente, hay otro comité llamado Comité de Impulso Ampliado que se reúne dos veces al año y congrega dos delegados de cada capítulo y el comité de impulso en pleno para hacer los balances generales y construir los planes operativos anuales.

Estas tres estructuras, son a su vez soportadas por un Comité Operativo encargado de administrar los recursos económicos del Movice y hacer seguimiento a la ejecución presupuestal de los proyectos. Esta labor ha sido ejercida los últimos años por: La Fundación Comité de Solidaridad con los Presos Políticos, el Colectivo de Abogados José Alvear Restrepo CAJAR, el Comité Permanente por la Defensa de los Derechos Humanos, la Comisión Intereclesial de Justicia y Paz y la Asociación Nacional de Ayudas Solidaria - ANDAS-. Este Comité se reúne una vez al mes o con la periodicidad que se lo exijan los proyectos para elaborar informes y tomar decisiones operativas.

Por último, existe un Equipo Técnico Nacional liderado por la Secretaría Técnica conformado por profesionales y voluntarios que tienen como misión garantizar que se desarrollen los planes y proyectos y en general, todas las acciones que el movimiento haya decidido realizar. Dependiendo los perfiles de estos profesionales y de la capacidad institucional y económica que exista en cada momento, este Equipo cuanta con las siguientes área de trabajo: Secretaria técnica Nacional, Proyectos, Jurídica, Protección, Prensa e Investigación (Movice, s. f.-a).

Si bien esta estructura nos recuerda desde el enfoque neo institucionalista la existencia de un núcleo duro y un entorno social que acompaña la acción, lo cierto es que tenemos más bien la apariencia de un movimiento social organizado que cubre un conjunto de actores bien articulados en el centro y con focos regionales importantes pero desiguales en los niveles de coordinación entre sí y con el centro. De allí que los capítulos pueden tener una forma organizativa definida en la que se aglutinan organizaciones defensoras de derechos humanos, partidos de izquierda, líderes y víctimas, ser tan solo una o dos organizaciones regionales o locales con 
visiones compartidas e idearios comunes al Movice, o aún, capítulos con múltiples conflictos internos y problemas de coordinación y cooperación con el centro.

Es importante señalar que estas formas de organización son dinámicas y se van adecuando a las exigencias del contexto. Por tanto, es posible encontrar a un Movice más articulado y coordinado en ciertos momentos específicos de su lucha como durante la preparación y el desarrollo de la marcha del 6 de marzo de 2008, o bastante menos en épocas más recientes caracterizadas por menos recursos y desconcierto ante la política de un gobierno como el del presidente Santos.

Esta situación, que es captada por algunos de sus miembros como una debilidad organizativa, en parte por falta de formación política en muchos de sus miembros o por divisiones políticas internas, podría estar dibujando una alto grado de heterogeneidad en las relaciones entre el centro y las regiones, y aún más, al interior de cada capítulo que se traducen al Movimiento en general. En este orden de ideas podríamos estar ante un híbrido en el que ciertos espacios y relaciones son más formales y organizados, mientras que en otros la estructura de movilización es menos densa y más porosa.

En todo caso se trata de una red de organizaciones y víctimas que se teje en lo local y regional pero que tiene un epicentro importante en las lógicas centrales determinadas por el comité de impulso y nutridas por los delegados de los capítulos en los comités de impulso ampliados. Así, mientras en unas regiones lo que hace el MOVICE es ejercer una acción de apropiación de ciertas organizaciones reconocidas y con una alta reputación local y regional, en otros casos los capítulos resultan ser un esfuerzo de constitución de actores menos fuertes y más antagónicos entre sí que se adhieren a una estructura más amplia que les proporciona una sombrilla identitaria.

\subsubsection{Las Comunicaciones y la toma de Decisiones}


Pese a esta heterogeneidad entre el Comité de impulso y los capítulos y de los capítulos entre sí, con el tiempo el Movice ha construido un esquema orientativo para la toma de las decisiones fundamentales. Podríamos decir en términos generales que actualmente el Movimiento tiene tres escenarios importantes de decisión que se relacionan con los espacios de trabajo existentes y el tipo de decisiones a considerar. Nos cuenta Camilo Villa,

"En el primero momento solo se tomaban decisiones grandes en los Encuentros nacionales; el Encuentro era el escenario donde se orientaba el trabajo, no se podía crear una estrategia por fuera del Encuentro, es más, todavía es así, el espacio más importante de toma de decisiones son esos Encuentros. Pero eso está relacionado con consultas y discusiones a nivel nacional que te daban por cada departamento, después se llevaban al comité de impulso ampliado y después se les presentaba a todas las víctimas con propuestas y distintas alternativas de construir estas estrategias. Esa era la forma de tomar decisiones. Ahora, cada Departamento, cada capítulo, tiene cierta autonomía, digamos que se adscribe al movimiento en sus estrategias pero el movimiento no les ordena que hacer, el movimiento no les da órdenes a los capítulos sino que trata de hacer una red de apoyo entre todos los capítulos y una plataforma identitaria” (Entrevista 19).

Esta primera aproximación nos muestra que el lugar con mayor legitimidad para los miembros del Movice es la suma de sus partes representadas en los delegados de todos los capítulos en los Encuentros Nacionales. Allí se han construido las estrategias y se ha desarrollado parte importante de su ideario. Este sería entonces el primer escenario de toma de decisiones en el que a partir de la interpretación de los agravio y la suma de demandas territoriales, se van construyendo los objetivos principales y definiendo el sentido de la acción.

A su vez, este testimonio nos muestra un tercer nivel de toma de decisiones más locales y autónomas. Se trata de las agendas políticas locales de los capítulos. En este caso, si bien existe un nexo cercano entre las estrategias construidas por el 
Movice en sus Encuentros Nacionales y los planes de los capítulos, estos se desarrollan en relación a la capacidad organizativa, los recursos disponibles, el contexto político que les rodea y las iniciativas que más tengan sentido local. De allí que no todos los capítulos ni todas las organizaciones tengan responsabilidades en las estrategias nacionales y es frecuente que cada región concentre esfuerzos en cosas diferentes.

Al tiempo, existe otro nivel intermedio de debate y decisión de coyuntura que guía la posición política de todo el Movimiento y que finalmente determina la orientación táctica y estratégica del resto del movimiento. Se trata del Comité de Impulso, donde las organizaciones de nivel nacional y de mayor raigambre en el movimiento disciernen sobre la forma en que hay que leer las oportunidades políticas y las decisiones frente a estas. Sobre este nivel nos habla Franklin Castañeda, miembro del Comité de Solidaridad con los presos políticos

“El Movice comenzó a crecer muy espontáneamente pero se han ido dando acuerdos. Se han ido dejando acuerdos que están en actas que luego nadie muchas veces mira, pero luego cuando se necesitan ahí están y están en la memoria de todos nosotros, una de ellas es que nosotros actuamos en consenso, no aplicamos mayorías y muy rara vez entramos a votar en temas políticos. Por ejemplo cuando las organizaciones del Movice en el 2005 discutieron si litigaban o no en Justicia y Paz, 8 meses duramos discutiendo, y en últimas al Movice le tocó dejar en libertad a las organizaciones de derechos humanos. Y unas dijimos que no, y otras dijeron que si y luego las que dijimos que no empezamos a hacerlo y algunas de las que dijeron que si retrocedieron, de todo se dio, pero lo cierto es que el Movice se demoró 8 meses discutiendo una misma vaina. Yo no sé cómo se dieron ese lujo pero así es. Otro ejemplo, Ley de víctimas, similar. La discusión en torno a ley de víctimas fue dura, fue fuerte, ahí el tema era si la saludamos, no la saludamos, nos vamos en contra, qué orientamos a las víctimas en esto, todo para llegar a un consenso. Las discusiones fuertes de lo estructural, el Movice lo discute y lo discute hasta llegar a una postura, así la postura sea: 
ok, no podemos llegar a un acuerdo, entonces que cada quien mire, pero se discute. Hay cosas que sí se van a votación, por ejemplo, la contratación de personal, pero en esos debates estructurales el Movice se va al consenso y eso permite que quienes son minorías tengan la oportunidad de tener una voz y un disenso claro, que si está bien argumentado mucha veces puede terminar siendo un consenso" (Entrevista 15).

En este caso vemos este escenario como el espacio generador de las decisiones centrales del Movimiento en cada momento histórico donde se desarrolla el ideario más amplio plasmado originalmente en las estrategias. Es el encargado de interpretar las oportunidades políticas en cada momento, contrastar con los objetivos principales y dirigir las posturas del resto del movimiento.

Otro elemento que nos permite identificar este testimonio es el uso del consenso como un mecanismo interno de toma de decisiones. Y resulta trascendental si consideramos que se trata de una red de organizaciones que provienen de distintas corrientes de la izquierda, así como de otros sectores más neutrales, que de no encontrar caminos para el disenso harían difícil la supervivencia del movimiento. Esta relativa laxitud en la toma de las decisiones en los capítulos, y este esfuerzo por generar consensos en los debates más complejos, pueden ser el acicate que mantiene unido a grupos diversos y profundamente ideologizados, en una contienda política de largo alcance.

Estas características sin embargo, no cubren otro tipo de elementos que entran a jugar a la hora de tomar decisiones y que tienen que ver con las asimetrías que se han ido constituyendo con el tiempo y que se relacionan con la composición del mismo movimiento. Recordemos que el Movice reúne organizaciones jurídicas y de defensa de los derechos humanos, la mayoría de ellas compuestas por profesionales altamente calificados y con décadas de experiencia en el ejercicio profesional y de otro lado, personas naturales que antes de ser victimizadas no tenían relación con la política o la defensa de derechos. Este hecho genera desigualdades a la hora de presentar y sostener argumentos y suele inclinar la 
balanza por los más experimentados. Si a esto se suma que precisamente son las organizaciones nacionales las que componen en su mayoría el comité de impulso, estas desigualdades se posicionan más en los temas complejos. Nos explica Franklin Castañeda:

"Las regiones tienen muchas posibilidades de tomar decisiones sobre lo que quieren hacer en su región y tienen posibilidad de proponer hacia lo nacional, pero ahí todavía se está imponiendo un tema y es el peso de la formación política de quienes están en Bogotá en comparación con los demás. Porque todavía hay una diferencia. No quiero decir que el Movice sea antidemocrático, porque creo no lo es, pero claramente hay unos desniveles más complejos.” (Entrevista 15).

Estos desniveles se complejizan además por la inestabilidad en materia de comunicaciones hacia el interior del movimiento. Las dificultades que suelen presentarse en este campo, particularmente en la relación entre la Secretaría técnica y el Comité de impulso y los Capítulos, hacen difícil que muchas de las decisiones sean consultadas o tomadas en consenso. Sobre esta frustración nos habla Alfonso Castillo director de ANDAS:

"En la práctica lo que ha sucedido es que existen iniciativas en el comité de impulso y se hacen unas consultas vía correo electrónico, que generalmente no tienen respuesta. La comunicación no es de doble vía y eso tiene que ver con los problemas organizativos de los capítulos, porque si no hay discusión no hay respuesta. Al final terminamos haciendo las cosas por la oportunidad política. Eso tiene que ver con una costumbre, ya no del Movice sino de la gente en general, que nos mandamos correos electrónicos y no contestamos; esa es la forma de comunicarnos. Eventualmente hacemos una cosa que se llama el comité de impulso ampliado que es el comité de impulso, más los delegados de las regiones; este es un escenario de discusión muy importante, donde se definen cosas gruesas, importantes, pero no hemos logrado tener la suficiente continuidad con esas discusiones. 
Discutimos en el comité de impulso pero esto no logra trascender a los capítulos.” (Entrevista 18).

Situación que nos permite confirmar que si bien su estructura aparece bien definida y delimitada, la realidad de los hechos permite ver un movimiento menos denso e interconectado que lo que quisieran sus miembros. Esto por supuesto trae consecuencias de muy diverso orden, como que en las regiones no haya suficiente claridad sobre los debates y los sentidos de las orientaciones generadas desde Bogotá, o que en las reuniones en la Capital no se conozcan con suficiencia las necesidades de todos los capítulos, sin embargo, esta misma flexibilidad permite que los capítulos desarrollen con relativa espontaneidad sus repertorios y mantengan amplios márgenes de autonomía y libertad.

De otro lado, y en lógica de comunicación externa, el Movice ha reconocido la importancia de abrir un diálogo vía medios de comunicación con la ciudadanía para expresar sus ideales y deseos de justicia. Para ello, nombra con relativa frecuencia vocerías que tienen como objetivo establecer los diálogos con la prensa y otros sectores sobre los temas, posiciones y planteamientos que se van esgrimiendo durante la contienda. Estas vocerías, si bien se van rotando entre las organizaciones y las víctimas, y durante los últimos tiempos ha recaído particularmente en las segundas, sigue siendo desarrollada de manera informal por Iván Cepeda, a quién la prensa interpela con relativa frecuencia. Se trata de un líder natural que aunque no tiene actualmente a su cargo este rol, especialmente desde el momento en que llegó al Congreso de la República, sigue siendo el referente principal que tiene el país de lo que son y piensan las víctimas de crímenes de Estado.

En todo caso, estas vocerías muestran la intención del Movice de mantenerse activos en el escenario mediático, particularmente cuando se está desarrollando alguna acción colectiva de importancia. Al tiempo, esta comunicación permite que los colombianos conozcan las visiones y posiciones del Movimiento y las puedan contrastar con las posiciones del Estado, las Fuerzas Militares y el uribismo, que 
son en últimas contra quienes se establecen las acciones contenciosas, incluidas las que se desarrollan ante los medios de comunicación.

\subsubsection{Los Recursos}

El Movice, pese a reunir a un número importante de organizaciones sociales, sindicales, eclesiales y jurídicas, cada una de ellas establecidas según los requerimientos del Estado colombiano para su funcionamiento y administración, no cuenta con una personería jurídica o una junta directiva, ni se encuentra legalmente constituida. Estas labores, como señalábamos en el acápite anterior, son asumidas por algunas organizaciones parte y es desde allí donde se hace la administración que se requiere para jalonar las acciones colectivas.

Podría decirse que, aunque posee una serie de órganos internos que le permite mantener un grado importante de cohesión y organización, como sucede con otros movimientos sociales en el país, el Movice depende de los recursos económicos proporcionados por actores externos al movimiento casi siempre del nivel internacional. Sus fuentes de financiación han sido variadas y los volúmenes de esta también. Algunas de las agencias e instituciones financiadoras han sido: Consejería en Proyectos, Unión Europea, el Ayuntamiento de Barcelona, Ayuntamiento de San Sebastián, Ayuntamiento de Lleida, ICCO Cooperación, Oxfam, Diakonia, Ayuntamiento de Tarragona y Federación Internacional de Solidaridad compañía de María FISC. Además de ello, cada organización vinculada posee sus propios recursos, muchos de ellos también internacionales, permitiendo que las estrategias tengan un adecuado desarrollo por esta vía.

En cualquier caso, el papel protagónico de las agencias internacionales y la cooperación de otros Estados es reconocido ampliamente por sus miembros. Sobre ello nos habla Eduardo Carreño, abogado del Colectivo José Alvear Restrepo:

"En eso creo que juega un papel importante lo de las agencias de cooperación que nos han apoyado en lo que han podido para tener una 
mínima infraestructura, un equipo de apoyo; estas agencias han sido fundamentales en el trabajo. Eso no tiene para mí la menor duda." (Entrevista 23).

Y es así porque el Movice no cuenta con mecanismos propios que les permita producir los recursos económicos que necesitan para sus acciones, excepto por la voluntariedad de sus miembros y los aportes que estos mismos hacen cuando realizan acciones para el movimiento. De allí que el volumen de actividades y la fuerza del movimiento sean heterogéneas en el tiempo y entre los capítulos presentándose un robustecimiento cuando hay proyectos importantes para ejecutar y un languidecimiento cuando no existe la financiación suficiente para mantener un aparato más fuerte, situación que redunda directamente en la capacidad de acción y movilización que se tiene en ciertos momentos. Así nos lo explica Marcela, coordinadora de proyectos del Equipo técnico hasta 2013:

"Nosotros hemos hecho actividades de 1500 personas, por ejemplo el evento de falsos positivos tuvo como 500, luego hicimos el de tierras en el que hubo marchas en Córdoba, Meta, Nariño y Bogotá y cada una de esas marchas tenía unas mil o dos mil personas. Entonces, depende de la coyuntura y depende el tema se logra la gente sentir representada y reivindicada con lo que está haciendo el Movice. En ese sentido, nosotros si tuviéramos plata podríamos traer tranquilamente a dos mil víctimas de un día para otro. Yo tengo la posibilidad de mover una red de esas, pero con plata. Yo llamo a todos mis capítulos y les digo, les pongo un bus, tráigame 200 personas de Magdalena Medio y le pongo todo y así con otros capítulos, la gente tiene esa capacidad de movilización, pero como nunca tengo toda esa plata porque un evento de esa magnitud me costaría como unos 500 millones de pesos y no tengo 500 millones de pesos, pues entonces tengo que decir tráigame a tres delegados, tráigame a dos delegados porque no hay plata para nada más, entonces ese es un poco el tema.” (Entrevista 14). 
Esta situación tiene a su vez su correlato a nivel local. Así se relata desde el Movice Nariño su situación económica y la relación de esto con el trabajo político:

"Cuando el Movice surgió en Nariño, lo hizo con la voluntad de todo el mundo y había un proyecto de Humanidad Vigente, pero era un proyecto puntual. Después de eso pasaron muchos años y el trabajo funcionó netamente con las uñas, con la gestión que se pudiera hacer con la Gobernación, con los aportes puntuales que hacía el comité de impulso nacional pero para actividades concretas: un 6 de marzo, para la semana de la verdad, entonces nosotros nos apoyábamos mucho en la parte de cooperación internacional. Por la intensidad del conflicto en Nariño llegó un punto en el que había más de 32 organizaciones de cooperación internacional en el departamento, entonces también tuvimos alguna cercanía con ellos de interlocución, hacíamos propuestas conjuntas, obviamente sin perder los objetivos y la apuesta como tal. Actualmente hay un proyecto de Intermon-Oxfam, entonces con ellos se viene desarrollando una estrategia y nos ha facilitado bastantes cosas. Ha permitido mayor acompañamiento en terreno, se han abierto incluso algunos capítulos subregionales como el del norte." (Entrevista 22).

Esa fluctuación en la cooperación hace que el movimiento genere la sensación de fortalecimiento o debilitamiento organizativo, sin embargo, parece ser más bien una situación cíclica que los miembros van leyendo, por lo que cuando hay mayores recursos, el movimiento suele expandirse para aprovecharlos al máximo y al contrario, cuando hay problemas financieros, éste se contrae para seguir existiendo con lo mínimo.

Vale la pena resaltar que la mayoría de miembros del Movice trabaja en el Movimiento de manera voluntaria y no reciben ninguna contraprestación por las labores realizadas. Esto es diferente para los miembros del equipo técnico quienes suelen tener algún tipo de remuneración derivada de los recursos de proyectos en ejecución o ser voluntarios auspiciados por alguna organización internacional. 
Esta situación es relativamente similar para los capítulos, quienes también gestionan sus propios recursos con organizaciones aliadas aunque suele suceder que sea necesario desde el sector central, incluir en sus presupuestos nacionales acciones locales y regionales que les permitan a los capítulos realizar algunas de sus labores. Cabe decir sin embargo que mucho de este trabajo también es voluntario y sus miembros, excepto la Secretaría técnica, no cuentan con salarios o vinculaciones laborales. En realidad lo que reciben son aportes para cubrir ciertos gastos como transportes, arriendos, material de oficina o actividades. De allí que constantemente las organizaciones y miembros del Movice estén pensando formas diversas de financiación y buscando salidas recursivas para subsistir en medio de la carencia económica. Así lo plantea Rocío Campos, Secretaria Técnica del capítulo Magdalena Medio:

"Cuando se va a hacer un evento del Movice por ejemplo, para que aparezcan las tres organizaciones en la convocatoria, las tres organizaciones se reparten el costo para lograr hacerlo. Porque aquí todos estamos en crisis (risas), el año pasado la Secretaría técnica tuvo hasta noviembre un aporte de 410 mil pesos, y pues el proyecto llegó hasta ahí, no alcanzó para más y eso era para el sostenimiento de la oficina, pero como yo no devengo sueldo de ningún lado pues a mí me tocaba usar eso para transportes y también yo no sirvo para que la gente que está trabajando conmigo este por ahí a pie, entonces también transporte para las personas que están ayudando a hacer el trabajo. Este año, dentro de los proyectos lograron también otra vez colocarle 400 mil pesos a la secretaría técnica, pero si uno llegara a usar eso para un arriendo o para servicios eso no va a alcanzar para nada. Entonces qué es lo que hace uno, nosotros en CREDHOS al principio estuvimos dándole un aporte cuando tuvimos la oficina ahí, pero ya después como no hubo más recursos solo quedaron las cosas ahí guardadas, luego estuvimos en las oficinas de Andas, pero hubo muchas amenazas y Andas es muy vulnerable y no tiene protección entonces a mí eso me generó miedo y en 
esos momentos el OPI nos dio un espacio para trabajar y ahí tenemos el espacio para trabajar ahora." (Entrevista 20).

De esta forma, el Movice ha logrado subsistir de las contribuciones que hacen las organizaciones internacionales, los aportes que realizan las organizaciones no gubernamentales que le pertenecen al incluir en sus presupuestos la realización de acciones concretas en el marco de las estrategias del Movimiento, y el trabajo voluntario de sus miembros en las bases. Así las cosas, si bien este hecho pone en tensión al movimiento, estos recursos les permite avanzar en el cumplimiento de sus objetivos aunque de manera desigual en las temáticas y en el tiempo.

\subsubsection{Redes y Alianzas}

Como otros movimientos sociales, el Movice está compuesto en buena parte por un conjunto de organizaciones sociales, sindicales, jurídicas, eclesiales y de defensa de derechos humanos que trabajan en red para sacar adelante un propósito, por lo tanto, el trabajo en coordinación con pares es algo connatural al movimiento y también un elemento central de sus antecedentes. Cabe recordar que las primeras acciones políticas pensadas en lógica de víctimas de Estado mientras se discutía el proyecto de "Alternatividad Penal" que se aplicaría a los paramilitares, fueron precisamente planteadas en lógica de Alianzas y redes para salir en defensa de las víctimas y en contra del marco legal dispuesto para el proceso de desmovilización (Gómez Sánchez, 2011, p. 189), de allí que el Movice aprendió desde muy temprano los beneficios que trae consigo la actuación conjunta.

Sin embargo, al día de hoy este movimiento no ha desarrollado una estrategia comprehensiva para la participación estratégica en plataformas nacionales o internacionales. Este hecho resulta por lo menos curioso precisamente por tratarse de un Movimiento que se vale especialmente del trabajo en red de las organizaciones que lo conforman. Así lo explica uno de sus miembros: 
"Nos intentamos articular con otros, especialmente con la Coordinación Colombia Europa Estados Unidos CCEEU, actuamos relativamente cercanos en la idea de que muchas de las organizaciones del Movice hacen parte de la CCEEU, algunas son parte de su staff directivo y eso nos permite actuar muy juntas. Como Movice también participamos, pero con una participación bastante tímida, en la Mesa Nacional de víctimas pertenecientes a organizaciones sociales y ya. Lo que si hemos hecho en el pasado es participar en múltiples iniciativas que ha planteado la comunidad internacional pero realmente ahí no tenemos la suficiente contundencia. Ahora, si hay aliados del Movice, especialmente en Europa y USA pero no se trabaja en red." (Entrevista 18).

Esta no participación formal en otras redes nacionales e internacionales no implica que muchos de sus esfuerzos no se realicen de manera conjunta con otras organizaciones. Así por ejemplo, gran parte de la estrategia de litigio se realiza de la mano de otras organizaciones y en no pocas ocasiones se construyen demandas judiciales o se realizan acciones colectivas con otras organizaciones del movimiento de derechos humanos. Estas alianzas también son alentadas a nivel local, donde con más frecuencias el Movice requiere apoyos externos para su sostenimiento y la realización de actividades. Como lo veíamos en la sección anterior, no pocas veces el Movice participa en plataformas más amplias donde consideran que pueden tener algún nivel de incidencia, visibilidad y donde sienten que pueden desarrollar parte de sus objetivos. Tampoco es extraño ver a muchos de sus miembros participando en otras iniciativas de la sociedad civil como la Ruta social por la Paz, la Marcha Patriótica, el Congreso de los pueblos o las Constituyentes por la paz, entre otras.

Estas alianzas a su vez tienen su correlato en espacios internacionales en donde se busca generar acuerdos de respaldo y certificación de actores internacionales relevantes para el tema de derechos humanos hacia el Movice y buscar el apoyo y cobijo de la comunidad internacional. Esta búsqueda le permite al Movice conocer y participar de algunos escenarios internacionales como la Semana Internacional 
del Detenido Desaparecido o conformar plataformas de colombianos en el exterior, pero además, extender en otros territorios sus esfuerzos de lucha contra la impunidad. Este intento ha sido particularmente expuesto durante los últimos años en los que el Movimiento ha hecho un llamado a las víctimas de crímenes de Estado de países como España, Italia y América Latina a unirse en el propósito de exigir el restablecimiento pleno de sus derechos.

Así las cosas, si bien el Movice no ha optado por un trabajo en red de manera sostenida y suele generar procesos de manera independiente, si trabaja intensamente en la consolidación de lazos de apoyo y solidaridad con otras organizaciones locales, nacionales e internacionales que le permiten sumar aliados a su causa y conquistar mayores respaldos políticos.

\subsubsection{Los "Performance" del Movice}

Sin lugar a dudas, el Movice imprimió una nueva dinámica en la contienda que las organizaciones sociales y el movimiento de derechos humanos habían estado haciendo por décadas el Estado colombiano. Implicó juntar muchas voces en diferentes lugares del país para hacer de la molestia por las continuas violaciones a los derechos humanos un solo coro público arrojado a la calle a mostrar su indignación. Ya no era suficiente el litigio de los abogados defensores de derechos humanos, ni la paciente labor de recoger los datos de las muertes y desaparecidos que hacían algunos sectores de iglesia. Era necesario que los agravios fueran expresados por las mismas víctimas en vivo y en directo en los lugares de mayor tránsito y amplificado por los medios masivos de comunicación.

Salir a la calle, mostrar las imágenes de los muertos o discutir con el opositor ante las cámaras de televisión, fueron algunas de las estrategias de antaño conocidas por la acción de otros sectores sociales, pero nunca utilizadas por las víctimas de crímenes de estado hasta el momento. Este nuevo repertorio fue además combinado con los aprendizajes y experticias de sus antecesores inmediatos del movimiento de derechos humanos, conocedores de la estrategia jurídica y de visibilización 
internacional, hecho que permitió construir un marco integral de performance para casa lugar y situación.

Este performance además se fue construyendo bajo la sombra de las estrategias formuladas durante los primeros años del movimiento. Por ello, las acciones colectivas giran alrededor de estos planteamientos e intentan ser su desarrollo.

De esta forma, las 8 estrategias formuladas: 1. Estrategia jurídica que persiga a los máximos autores de los crímenes y la responsabilidad de los agentes estatales; 2. Estrategia para la verdad y la memoria histórica; 3. Estrategia para el acompañamiento solidario con las víctimas: la Comisión de Ética; 4.Estrategia para la no repetición: la prohibición legal del paramilitarismo; 5.Estrategia para la reparación: el catastro alternativo; 6.Estrategia de lucha contra la desaparición forzada: la exhumación de las fosas comunes y el derecho a enterrar; 7.Estrategia de lucha contra el genocidio político: verdad, justicia y reparación para las víctimas y los sobrevivientes de la Unión Patriótica y 8.Estrategia de organización: el fortalecimiento del Movimiento de Víctimas, encuentran espacios para su desarrollo si bien este no es homogéneo en el tiempo ni en el espacio. Recordemos que estas estrategias van siendo abordadas en la medida de las posibilidades del movimiento, y en cada capítulo pueden tener una evolución distinta, dependiendo de las necesidades y recursos existentes.

En cualquier caso, podría decirse que el Movice ha consolidado en el tiempo un performance agrupado en 6 tipos comunes de actividades en todo el país: a. Acciones de memoria, b. Acciones jurídicas, c. Formación política y en Derechos, d. Incidencia política y pública, e. acciones de movilización, y e. Comunicaciones y campañas. Estas actividades, como las estrategias, se van desarrollando en las regiones y en la capital de acuerdo a las circunstancias y capacidades, encontrando algunos picos en ciertos momentos y unos valles en otros. Veamos en que consiste cada una de ellas:

\subsection{Acciones de Memoria}


Un elemento fundacional para el Movice es su profundo deseo por contar los relatos sobre la violencia desde la voz de las víctimas de Estado. Hacer memoria significa para este movimiento tener la oportunidad de narrar las formas en que se han producido las victimizaciones, señalar a quienes las han cometido y exponer los motivos de fondo que condujeron a la arbitrariedad y la barbarie. Es una manera de encontrarse con la otra verdad. La verdad que la historia oficial se niega reconocer y que dicha en voz alta podría significar la oportunidad de encontrar justicia y la reparación integral.

“Otra estrategia es la de memoria histórica. En esta estrategia lo que se ha tratado es de documentar todo tipo de casos en los que ha estado involucrada la responsabilidad del Estado tratando de reconstruir una narrativa de la violencia en donde el Estado no es mostrado como han querido los últimos gobiernos, como una víctima, sino más bien como un instigador de la violencia y cómo un actor más de la violencia sociopolítica. Y el actor más importante desde nuestra posición, porque de alguna forma el Estado avanza en todos los sentidos, en el ámbito económico, en el ámbito social, pero se ha aprovechado de ciertas estrategias, se ha aprovechado de crímenes, se ha aprovechado de la disminución de la fuerza de la oposición y de la estigmatización de los grupos sociales y alternativos. Eso es lo que le preocupa al Movice en materia de memoria histórica. Cuál es el relato que le han contado a Colombia y cuál es el relato que nosotros quisiéramos contarle al país." (Entrevista 19).

Este deseo por contar esta verdad, toscamente acallada por el Estado, hace que estas acciones se conviertan en escenarios dirigidos a la reconstrucción de la memoria histórica mediante la compilación de testimonios que dan cuenta de la experiencia vivida por las víctimas. En ese caso no se trata solamente de recordar, se trata de hacer de este recuerdo un hecho político dinámico y con consecuencias concretas en la vida de los sobrevivientes y los perpetradores. De esta forma, con las acciones de memoria se rememora a las víctimas mientras se narra esta verdad frente a 
aquellos que pueden inclinar la balanza a su favor y detener la ignominia; donde el que quiera pueda escucharla sin matices ni vaguedades. Estas acciones tienen así, como último cometido, el uso político de la memoria como herramienta para emprender la búsqueda de la justicia y lucha contra la impunidad.

"La acción política más vigorosa del Movice son las Audiencias Ciudadanas por la verdad. Hemos realizado 10 que nos permitieron llegar con el acompañamiento de la Comisión de derechos humanos del Congreso y con parte de la comunidad internacional a muchas regiones del país a escuchar a las víctimas. Estuvimos en San Onofre que fue la primera, fuimos a Buenaventura, hemos ido a Barranca, y hemos realizado algunas Audiencias temáticas como la de la Universidad de Córdoba (...). Hemos realizado una audiencia ciudadana en Putumayo, alguna en el Meta, son diez y hay unas memorias. Ahí hay un insumo importante alrededor del tema de la verdad, pero sobre todo el tema de la visibilización de las víctimas. Estas Audiencias eran parte de la estrategia de la verdad del Movice." (Entrevista 18).

Pero no siempre las acciones de memoria han sido públicas. La zozobra y el miedo que rondaron durante varios años a los miembros del Movice y que se extendía al movimiento en general de derechos humanos, hicieron que estas acciones no solo se realizaran a puerta cerrada sino que se establecieran mecanismos de salvaguarda para protegerla en medio de las hostilidades y la persecución de la Fuerza Pública y del Estado. Se trata de otra memoria que se expuso, pero para su conservación y resguardo, y que espera tener utilidad plena en el futuro. Cuando no haya que temer y las víctimas sean finalmente escuchadas por la justicia.

"Se hizo una Comisión permanente que iba a terreno a hacer labores de verificación y recepción de documentación para hacer un archivo de la memoria cuyo depósito se hizo en el exterior. Era la recepción de pruebas que había sobre la responsabilidad del estado de crímenes de lesa humanidad, de pruebas muy importantes. Pero como el Estado comenzó a hacer allanamientos en las sedes de las organizaciones de derechos humanos 
y a violar los expedientes y los documentos y todas las cosas, entonces se constituyó una comisión de alto nivel de juristas, personalidades internacionales a quienes se les hizo depósito de esos documentos. Es una documentación que va a servir posteriormente cuando estén las condiciones realmente para hacerlo un juicio a los responsables de todos estos crímenes en el país. Responsables que van desde Presidentes de la República, Ministros de defensa, comandantes de brigadas, gobernadores y demás, pero eso es una archivo que se ha venido haciendo y que es muy importante." (Entrevista 21).

Pero las acciones de memoria también tienen para el Movice un matiz simbólico que nos habla de la ausencia, la tristeza y la orfandad que deja la guerra. Es también el camino para la dignificación del ausente y el reclamo por el derecho a no olvidar. Por ello la reivindicación de los muertos, desaparecidos y encarcelados es uno de los ejes centrales de la acción colectiva del Movice. Mediante las galerías de la memoria rescatan a las víctimas de la indiferencia de los demás ciudadanos, la mayoría ignorantes de la existencia de la violencia socio política, convirtiéndolas en una de las insignias más poderosas del movimiento y una luz para continuar la lucha en cada capítulo.

La consecución de las fotos, de los recursos para el montaje y su puesta en escena, se convierte en un reto concreto y en una de las acciones que más orgullo y tradición tiene en el movimiento. Es también, en muchas ciudades, la confirmación de su presencia en ciertos actos o movilizaciones y el sello que suelen colocar cuando desean enviar un mensaje en cualquier acción pública.

"El logro más importante que cohesiona a todas las víctimas es el tema de las galerías de la memoria. Yo creo que el Movice ha acostumbrado a las víctimas a que sus víctimas tienen derecho a estar en la calle, a salir a la calle, y creo que nosotros, sin que no hayamos inventado nada, hemos institucionalizado las galerías de la memoria de tal suerte que en todos los capítulos, con todas las debilidades que quieras, casi que el único elemento 
cohesionador son las galerías de la memoria. En muchos capítulos regionales esa galería es una cosa institucional. Un día de cada mes hay galería de la memoria del Movice y se va a una plaza pública, a un sitio público y se lleva la galería de la memoria, ahí pelando, unos mirando bien y otros mirando mal, pero el Movice hace su galería y eso se ha hecho ya sistemático en varios capítulos regionales, yo diría que en todos y eso es importante, que la gente pierda el miedo a salir con sus víctimas a la calle y que eso en algunas partes sea una cosa sistemática, organizada, todos con unos pendones de la misma manera, eso da una fortaleza para que las víctimas se empoderen.” (Entrevista 18).

Por supuesto "sacar a la calle a los Muertos" no siempre ha sido de buen recibo. Si bien todas estas acciones se realizan de manera pacífica, y en muchas ocasiones en medio de otras expresiones sociales, no siempre ha sido bien leído por los demás.

"Toda esa acción mediática, todo ese discurso oficial especialmente del gobierno Uribe, logró impactar en la fuerza pública, en la policía. Pensar que eso de colocar una galería señalando que unas personas fueron asesinadas por la fuerza pública, pues que eso era terrorismo. En muchas oportunidades hubo represión, señalamiento. Ahora no recuerdo detenciones, pero si hubo mucha estigmatización, mucha persecución. Particularmente con el capítulo de Bogotá y la galería de la memoria ha habido presión muy fuerte, mayor presencia policial donde está el Movice, mayor señalamiento, fotografías, videos que hace la fuerza pública." (Entrevista 18).

Existen también otras prácticas de memoria que se van hilando a las acciones más cotidianas e íntimas en el movimiento, particularmente en los territorios. Con relativa frecuencia muchas de las actividades que se realizan se acompañan con momentos de reflexión y recordación de los familiares asesinados, así como en la elaboración de objetos que recuerdan y pretenden dignificar a las víctimas. Las canciones, las velas, los abrazos, los objetos, las pinturas y otras maneras de 
recordación se juntan por momentos y les permite a las organizaciones y las víctimas hacer memoria de los hechos y las injusticias y mostrar a la sociedad y a su oponente, el Estado, que se encuentran en una acción contenciosa mantenida en el tiempo.

\subsection{Acciones Jurídicas}

El litigio estratégico es una de las herramientas más conocidas en las acciones nacionales del Movimiento. Heredada del movimiento de derechos humanos y de las organizaciones de abogados, la vía jurídica fue uno de los primeros repertorios implementados por el Movice. Recordemos la acción constitucional contra la denominada ley de "Justicia y Paz" cuando recién nacía el movimiento y que, junto al trabajo jurídico de otras organizaciones como la CCJ, determinó la expedición de la Sentencia C- 370 que disminuyó las facilidades a los paramilitares y reconoció los derechos de las víctimas.

Pero no solo han realizado acciones de inconstitucionalidad. Derechos de petición, demandas contra el Estado a nivel nacional e internacional y defensas jurídicas a militantes encarcelados, entre otras cosas, muestran el uso estratégico de la ley en lo que podría denominarse una "politización de los derechos humanos" y una “judicialización de la política” (Gómez Sánchez, 2011, p. 35). De esta forma, el movimiento logra combinar lo político con lo legal, en esa intención última de avanzar en pro de la lucha contra la impunidad.

Este componente jurídico además tiene un fin político, formativo y de movilización, adaptándose a las circunstancias, necesidades y contextos donde se encuentre el Movimiento. Este hecho hace que pocas veces se haga una acción judicial de manera aislada o en la que no se pretenda involucrar a otros actores del movimiento. Se usa también para animar la discusión y obtener posturas políticas que deberán ser jalonadas en los demás performance que se realicen mientras va formando en derechos y mecanismos de exigibilidad. Estas múltiples funciones de las acciones jurídicas permiten que muchos de los miembros se encuentren al día en los debates 
jurídicos nacionales y tengan la oportunidad de generar posiciones sobre los mismos. Así nos lo explica uno de sus miembros en relación a la construcción de las demandas que se hicieron a la ley 1448 una vez fue expedida.

"Estas se elaboraron colectivamente (documentos de las demandas). El Movice tiene una comisión jurídica, ésta elaboró inicialmente un borrador que luego fue discutido en las plenarias del Movice. Se sometieron a consulta a las regiones y luego se hicieron comités de impulso ampliados y finalmente ya se logró hacer unos documentos finales que fueron los que se pusieron en circulación, se publicaron en folletos y se presentaron ante distintas instancias". (Entrevista 21).

Pero el derecho visto por este Movimiento además trae consigo la movilización, y cuando se trata de víctimas de crímenes de Estado, los procedimientos judiciales, usualmente paquidérmicos y complicados, se convierten en verdaderos campos de batalla por la verdad y la justicia. Por eso en ocasiones las victorias jurídicas no se obtiene solamente a partir de la labor de los abogados, también se hacen posibles mediante la combinación del uso de los Códigos y las arengas, sobre todo cuando se encuentran fisuras en los procedimientos y hay lugar todavía a las interpretaciones diversas. Un caso particular sobre este uso recursivo de la combinación de dos performances nos lo relata Soraya Gutiérrez, una de las abogadas más antiguas y conocedoras del Movice:

"Yo me acuerdo que en el movimiento de víctimas creamos toda una estrategia en términos de la presencia de las víctimas cuando se empezaron a realizar las versiones libres en el marco de la 975 por parte de los paramilitares. Recuerdo que en un primer momento la participación de las víctimas en las versiones libres no existía. Entonces el movimiento decidió que era fundamental que en las Unidades de Justicia y Paz fuera necesario hacer acto de presencia. Entonces las víctimas hacían acto de presencia, hacían presión, entraban a las salas, en donde en ese momento no se permitía hacer absolutamente nada, solo que las víctimas permanecieran 
absolutamente quietas y sin poder decir nada, y generamos toda una campaña para que las víctimas pudieran preguntar. En ese momento las Unidades de Justicia y Paz no tenían claro como era que iban a desarrollar el procedimiento de las versiones libres y yo creo que en parte la presión de nosotros, que empezamos a enviar cuestionarios, de las víctimas a ir, de decir que ellas no iban a ir de simples testigos, ceo que eso generó que la Fiscalía tuviera que revaluar como se iban a hacer las audiencias." (Entrevista 17).

Estas "micro aberturas" del derecho se convierten en el camino de la esperanza para las víctimas que deben luchar contra una impunidad casi implacable. El derecho, los juicios y los Tribunales terminan por convertirse en escenarios para el Movimiento en donde desarrollar parte de la lucha. Por eso hay que advertir que estos esfuerzos no solo se realizan en la ciudad o en los recintos cerrados, ni son impulsados exclusivamente por los abogados. Muchas veces la sensación de injusticia hace que los miembros legados del Movimiento comiencen la acción con una visión más política y busquen luego el respaldo de los juristas. El siguiente, es uno de estos casos:

"Nosotros fuimos una vez que iban a desalojar esa comunidad, yo fui como Movice, fuimos varias organizaciones y nos presentamos y logramos parar ese día el desalojo, pero sobre todo logramos encontrar el fondo del porqué querían desalojar esa comunidad. Nos dimos cuenta que por ahí iba a pasar una sísmica, una petrolera, porque por ahí había petróleo, entonces por eso era el interés de sacar la gente y había complicidad con la estación de policía. Entonces logramos que viniera un abogado muy piloso de Bucaramanga y de aquí de Barranca se llevaron 3 abogados también y eso cuando llegaron los de la Inspección de Policía a hacer el desalojo, ellos no contaban con que esa comunidad iba a estar tan preparada, entonces cuando llegaron ahí se pagan tremendo estrellón y cuando les decían miren es que este desalojo no es legal por esto por esto y por esto, porque era que de verdad en esa comunidad si no se ponen las pilas los sacaban, porque eso 
no había nada legal ahí, incluso el líder que nos llevó allá lo desaparecieron en octubre del año pasado por todo el trabajo que estaba haciendo denunciando." (Entrevista 20).

De esta forma el mundo jurídico deja de ser lejano y distante para las víctimas y es comprendido y asimilado como una herramienta más de trabajo. Haciendo demandas y construyendo argumentos técnicos los abogados, acompañando las diligencias y ejerciendo presión durante las mismas las víctimas, unos y otros han incorporado en sus repertorios rutinas jurídicas que les permite continuar sus batallas políticas en los estrados o, al contrario, sacar estas batallas de los juzgados a las calles.

\subsection{Formación Política y en Derechos}

Si bien en sus inicios los integrantes del Movice eran veteranos defensores de derechos humanos, muchos de ellos con densas militancias políticas de izquierda y con gran experiencia en el campo jurídico, el ingreso más reciente de víctimas no organizadas ni politizadas ha implicado una acción fuerte de formación. Mediante encuentros, escuelas, talleres y diplomados, algunos líderes del movimiento buscan traspasar el conocimiento en derechos hacia los miembros menos expertos. Se trata de una acción más silenciosa y menos vistosa, que además ocupa mucho del tiempo de sus miembros, pero que en últimas es vital para la supervivencia del movimiento.

"Dentro de los procesos de organización de los equipos regionales hay todo un enfoque que a su vez lleva a que la gente en las regiones se asuma, porque eso va unido con procesos de capacitación. En eso se ha insistido muchísimo y es tal vez en lo que más se ha trabajado, para que la gente conozca cuáles son sus derechos y los reclame. Entonces eso ha llevado a que las regiones asuman protagonismos completos" (Entrevista 23). 
Esta acción ha permitido por momentos que surjan liderazgos nuevos y las víctimas logren un mayor espacio dentro del movimiento, pero a su vez también es una fuente de conflictos importantes en la medida en que el crecimiento político de las víctimas de base, les permite entrar en confrontación con los más veteranos generando desavenencias y en algunos casos deserciones. Pese a ello, esta acción sigue siendo fundamental en la tradición del Movimiento, por lo que cada vez que se comienza un trabajo, se llega a un territorio, o se explora un tema nuevo, se recurre a la formación con el fin de mejorar las comprensiones y la lectura del asunto.

Esta formación no solamente es en derechos, jurídicamente hablando, se trata también de enmarcar la lucha en unos principios en los que se ubica el rol del Estado, de las Fuerzas militares y del paramilitarismo en relación con la violencia y la guerra. Para ello los talleristas y facilitadores intentan ordenar el mundo político, cultural, social y económico que circunda la guerra y que puede brindar una explicación lógica a los hechos violentos. La lectura constante de la acción y los movimientos de los victimarios, el análisis de los intereses, más la experiencia de las víctimas, les permite en estos espacios de socialización y aprendizaje hacer análisis de contexto no solamente para revisar lo que pasó, sino también para prever lo que puede venir en un futuro cercano. De allí que en los espacios de formación se hable de derechos y del pasado y del futuro de las comunidades, convirtiéndose en escenarios de preparación de lo que puede venir.

\subsection{Incidencia Política y Pública}

El Movimiento también ha aprendido que mediante el cabildeo y el lobby es posible conseguir aliados y lograr ciertas modificaciones en las políticas públicas; de allí que es bastante frecuente que sus miembros tengan reuniones con misiones diplomáticas, miembros del Congreso, organizaciones pares y aún, con funcionarios del gobierno. Esto también es posible porque los entes del Estado cada vez con más frecuencia han optado por abrir canales de diálogo con actores de la sociedad civil lo cual hace posible que líderes sociales puedan establecer 
comunicación con funcionarios, que en otros momentos eran completamente inaccesibles. Es importante señalar que estos espacios de cabildeo se nutren diestramente con la elaboración de documentos sobre políticas públicas, leyes alternativas, comunicados o informes sobre la situación de derechos humanos en ciertas regiones, convirtiéndose en el epicentro de discusión para generar acuerdos entre el movimiento y terceros.

Vale la pena señalar que el lobby no es el centro de la acción del movimiento, en realidad es una práctica que ha comenzado a desarrollar junto a otras organizaciones sociales y defensoras de derechos humanos que sí lo tienen como epicentro de trabajo. Y es así porque el Movice espera mucho más que un cambio en las políticas públicas, sus miembros están apostando a una modificación estructural del sistema que entienden, no es posible realizar en reuniones, sin embargo, también han aprendido que en el diálogo con funcionarios también es posible ganar posiciones o por lo menos hacer claridad sobre sus demandas y solicitudes. Así las cosas, la interlocución termina siendo un buen escenario de disputa para los desafiadores, al tiempo que es el uso de una herramienta que posiblemente pueda tener buenos resultados.

Un ejemplo de este ejercicio es la presentación en 2009 de una política integral de acción en derechos humanos denominada: "Una propuesta desde las víctimas de crímenes de Estado" donde se recogen las principales propuestas para la realización de los derechos de estas víctimas en el marco de un modelo de Estado alternativo, en un contexto de seguridad democrática. Si bien estas medidas no fueron adoptadas por el gobierno nacional, si permitieron dotar de claridad el posicionamiento del Movimiento frente al tema, guiando las discusiones sobre el mismo. En otras ocasiones la construcción de políticas alternativas tiene resultados más concretos:

"Una acción, que no es exclusiva del Movice sino una es una suma de acciones, es el catastro alternativo. El catastro es la construcción de una herramienta para que las victimas cuenten con un instrumento para la participación en mejores condiciones en procesos de restitución y en la lucha 
contra la política de despojo de tierras. Es una herramienta a mi juicio bien importante, tan importante que el gobierno ha reconocido que la política de restitución se soporte en un catastro. Ellos lo llaman catastro social, pero cuando tu miras el diseño que ha hecho el gobierno no es más ni menos que el catastro alternativo tal cual." (Entrevista 18).

De esta forma, el Movice no solo genera espacios de interlocución con los gobiernos, sino que sus propuestas comienzan a tener eco y a convertirse, tímidamente, en políticas públicas. De otro lado es importante señalar que esta forma de relacionamiento con el Estado no se ha dado de manera similar en todos los momentos. Las formas y las intenciones de este cabildeo varían también dependiendo el contexto en el que se esté trabajando y las oportunidades políticas que existan. Si bien Colombia es una nación tradicionalmente centralista y la mayoría de las decisiones se toman en el Palacio de Nariño, ha habido desde los años 90 varias reformas para la descentralización que le ha dado un margen importante de maniobra a los departamentos, de allí que pueda suceder que las estructuras de oportunidades a nivel nacional y a nivel regional sean distintas. Estas diferencias determinan que el uso de cabildeo pueda tener temas y alcances desiguales y por tanto, que aunque la lucha sea la misma, entre el Comité de Impulso y los Capítulos puedan existir variaciones en las demandas y los acentos que se ponen a los temas.

De esta forma, mientras el equipo central se esmera en buscar espacios de interlocución con altos funcionarios, embajadores o altos jefes de las oficinas de Naciones Unidas intentando mejorar su posición en las políticas nacionales, en los capítulos regionales los militantes hacen lo mismo con las autoridades regionales y locales en donde intentan convencerlos de la necesidad de acoger sus planteamientos. Nuevamente es este nivel las experiencias ente las regiones son distintas dependiendo quienes estén comandando el departamento y el grado de apertura que estén dispuestos a tener con un movimiento que suele desafiar al gobierno nacional. 


\subsection{Acciones de Movilización}

El Movice puso en la calle la discusión de los derechos de las víctimas de crímenes de Estado, y de alguna forma encontró allí un excelente escenario para llamar la atención y generar inquietud en el oponente. Si bien desde la multitudinaria marcha del 6 de marzo de 2008 en la que estuvieron cientos de miles de personas apoyando al Movice, no se ve una acción callejera similar, durante todo el tiempo de existencia el movimiento ha convocado y asistido a múltiples acciones colectivas disruptivas.

Ya sea mediante plantones, marchas, jornadas de movilización o concentraciones menos formales a la que acuden decenas o centenares de personas en solidaridad, hasta la presencia de sus miembros arengando en el Congreso Nacional, los miembros del Movice van generando condiciones para la movilización y visibilización.

Es importante señalar que, aunque se trata de repertorios no violentos, durante las manifestaciones sí se mantiene un ánimo combativo, que aunque no suelen generar confrontaciones físicas con la Policía o el ESMAD (Escuadrón Móvil Antidisturbios) si trae consecuencias represivas para las víctimas y acompañantes luego de pasadas las marchas. Por lo tanto, no es extraño conocer casos en los que miembros del Movice han sido vinculados a investigaciones penales por terrorismo y rebelión y en algunos casos hayan sido condenados a varios años de prisión. Esta táctica, denominada por los sectores de derechos humanos como "falsos positivos judiciales", ha resultado ser una de las principales respuestas del Estado a las acciones del Movimiento en su lucha contra la impunidad. Sin embargo y pese a esto, el Movice mantiene vivo el interés por manifestarse públicamente y lo hace de muy diversas maneras. Así nos lo explica uno de sus miembros:

"Creo que hay que entrar a mirar algunas cosas que tienen que ver con activar mecanismos de exigibilidad de justicia y la respuesta del Movice a determinados contextos. Después del 6 de marzo de 2008, en 2009 estalla 
en septiembre los escándalos de los falsos positivos de Soacha y se comienza a escuchar en barranquilla y en otros lados y el Movice le responde al tema el siguiente 6 de marzo. Hace un encuentro de 300 madres de 300 casos diferentes de falsos positivos. Y se hace una movilización a la Plaza de Bolívar y se entra a denunciar la sistematicidad del tema y sale en los medios de comunicación a hacerle cubrimiento al asunto y comienzan a organizarse los colectivos de víctimas de falsos positivos y se empiezan a dar cosas cheverísimas como que las víctimas comienzan a generar solidaridad entre ellas, a acompañar las audiencias de otras víctimas y a armar el plantón afuera y eso ha permitido que mínimamente el tema de falsos positivos vaya avanzando, de poquito en poquito" (Entrevista 15).

De esta forma el Movice mantiene su interés por estar en las calles y hacer irrupciones en la cotidianidad, si bien son acciones colectivas casi siempre ligadas a propósitos jurídicos o políticos que se van desarrollando paralelamente en otros escenarios. Esta diestra combinación también se puede encontrar en las acciones realizadas en el marco del poder legislativo.

"El Movice empezó a hacer presión y se hacían cosas chéveres, y era que tratábamos de venir varios al Congreso y como no podíamos decir nada en barras, entonces lo que hacíamos era letreros, entonces cuando decían: se está votando la proposición numero tal. ¿Aprueban la proposición señores congresistas? y nosotros teníamos No y $\mathrm{Si}$ en unos letreros. Entonces nosotros decíamos Si o No, o lo que sea, e Iván venía con la foto de su papá y se la ponía de frente a la Senadora de la Comisión Primera, entonces una vez casi nos sacan del recinto porque él no se aguantó y gritó alguna cosa y nos iban a sacar, pero digamos que empezó a haber mucha más presencia en el debate, aunque era un acto simbólico" (Entrevista 24).

Estas formas más audaces de movilización penetraron recintos que en otros momentos no habían sido objetivo para los movimientos sociales, y lo empezaron a ser, precisamente porque estos espacios se convirtieron en los lugares de toma de 
decisión de los temas que les afectaban directamente. De allí que comienza a hacer uso de la creatividad y a adaptar los clásicos plantones y marchas callejeras a las necesidades de expresión del movimiento. Pero además de las distintas formas que toma la movilización dependiendo los contextos de sus reclamaciones, el Movice comienza a acompañar otros procesos de acción colectiva compartiendo su experiencia y conocimiento en acciones callejeras con otros actores sociales que comienzan más recientemente sus luchas. Un caso como estos lo podemos encontrar en Nariño:

"Nosotros hacemos un acompañamiento permanente de denuncia, de verificación. Por ejemplo, ahora con lo del paro nacional agrario se presentaron muchos desmanes por parte de la fuerza pública y obviamente muchas víctimas de crímenes de estado. Las más graves son las del municipio de Leyva con el desalojo de Mojarras en el sur del Cauca y el norte de Nariño. Allí la fuerza pública abre fuego contra los manifestantes a tal punto que se presenta una asonada y hasta ahora no ha podido volver la fuerza pública al municipio. En toda esa situación el Movice tiene un papel importante porque se le reconoce por su trabajo. Entonces lo que hace la gente es llamarnos y avisar lo que está pasando y el Movice hace uso de las buenas relaciones que tiene con la institucionalidad. Se participa de los comités de justicia transicional, de las comisiones de verificación que se hacen en las zonas y obviamente se orienta a la gente ya en los temas de denuncia penal, los casos netamente administrativos, lo que se pueda realmente hacer y obviamente las denuncias públicas, todo ese tipo de estrategias de visibilización se hacen.” (Entrevista 22).

De esta forma el Movice va adaptando sus movilizaciones a los contextos y va ganando en madurez organizativa permitiéndoles identificar con mayor claridad su papel en la acción, los momentos y los escenarios para realizarla.

\subsection{Comunicaciones y Campañas}


Como la mayoría de organizaciones y movimientos actuales, el Movice dedica parte importante de sus esfuerzos y recursos a mantener una página web activa, así como a generar contenidos virtuales y físicos sobre aspectos importantes de su trabajo, sus logros y sus principales derroteros. Con relativa frecuencia el movimiento publica documentos, informes e investigaciones que son presentados en eventos públicos y que después son alojados en la página web para su libre distribución. Además mantiene una revista llamada "En Movida" y esta enlazada a otros portales amigos y aliados. Este aspecto nos lo explica Julián Carreño el responsable de comunicaciones del movimiento:

"En el proceso fundacional, además de las estrategias de lucha contra la impunidad, también se crearon otras estrategias más transversales, entre ellas una estrategia de dinamización compuesto por un equipo técnico. Lo que he venido yo agenciando en este espacio es una apuesta comunicativa para la visibilización de posicionamientos ante la opinión pública nacional e internacional respecto a lo que son los planteamientos que tiene el movimiento de víctimas en torno a los derechos a la verdad, la justica, la reparación integral y a las garantías de no repetición. (,..) El rol que yo he venido cumpliendo es desde los espacios también de convergencia con otros escenarios o plataformas que tiene Colombia a partir de las apuestas que se generan desde las estrategias de lucha contra la impunidad con estas plataformas. (...) Y por supuesto ya lo que tiene que ver con medios convencionales o medios de comunicación no convencionales. En el auge de las redes sociales nosotros estamos tratando de incursionar en muchas de las redes como twitter, como facebook que son las más populares, hasta la página web del movimiento de víctimas que es una ventana bastante importante no solo en Colombia sino en el mundo. Esa página es un referente para mucha gente para saber qué es lo que pasa en Colombia con respecto a la victimización, a la continuidad de crímenes del paramilitarisno y demás, y ya lo que tiene que ver con otros formatos, entonces están las cuñas radiales donde visibilizamos a los defensores y defensoras, el tema del video, campañas comunicativas, la más visible que se hizo con el equipo 
técnico nacional que se llamó "En movida con los pies por la tierra" que consistía en recoger, en el marco de la ley de víctimas el tema de la tierra, y ahí planteamos la recolecta mundial de unos pies con fotos, entonces tu encuentras esto en click que es un lugar para alojar fotos y se hizo una campaña muy interesante." (Entrevista 12).

Mediante el uso de diferentes medios de comunicación, casi siempre alternativos y en línea, esta área de trabajo tiene como propósito mantener activo el movimiento compartiendo información de sus acciones y del contexto, motivando a sus miembros y buscando aliados en sus espectadores. Las comunicaciones, como suele suceder en muchos movimientos sociales en esta generación, se convierten en un instrumento principal porque finalmente es el que permite al movimiento informar al resto de actores, ya sean de su entorno inmediato o más lejano, de sus objetivos, sus estrategias, las opresiones que viven y la necesidad de mantener viva la movilización.

Pero las comunicaciones sirven, además de divulgar el agravio y los desarrollos del movimiento, como herramienta para comenzar la contienda con el oponente y plantear sus desafíos. Desde esta óptica y durante toda su existencia, el movimiento ha diseñado y desarrollado campañas mediante las cuales intenta poner acento sobre ciertos temas o situaciones que consideran de altísima relevancia. Varias de ellas son dedicadas a mostrar las injusticias cometidas contra sus miembros como es el caso de las campañas por Carmelo Agámez y David Ravelo, ambos miembros del Movimiento acusados y sentenciados por el Estado Colombiano en apariencia por su labor política.

En otras ocasiones las campañas se dirigen a develar violaciones sistemáticas a los Derechos Humanos como es el caso de las "madres de Soacha" a quienes las fuerzas militares les asesinaron sus hijos como un mecanismo para ascender o ganar dádivas, o aún, para impulsar temas específicos que hacen parte de sus estrategias como el caso de "con los pies por la tierra" mediante el cual se reivindica el derecho al territorio de la población desplazada y victimizada. 
De esta forma las comunicaciones cumplen un papel integral de informar, sensibilizar, amplificar los objetivos, promover la adhesión al movimiento, enviar mensajes al oponente, mantener viva la lucha entre sus miembros y solidarizarse con aquellos que consideran víctimas de la opresión estatal como resultado de su mismo activismo dentro del movimiento. Se trata de una estrategia cuidadosamente diseñada y puesta en marcha casi desde la gestación del movimiento la cual se ha convertido en uno de los medios más importantes con los que cuenta el Movice para comunicarse con el mundo y mediante la cual terceros pueden conocer y acercarse al Movimiento.

Podríamos decir, en general, que en efecto los performance han ido cambiando adaptándose a las oportunidades políticas que se van presentando y tras la lectura e interpretación que sus miembros hacen del contexto y las arenas que se escogen para plantear sus exigencias. De esta forma van combinando los diferentes recursos con los que cuentan intentando generar una acción ordenada y con sentido práctico. Allí donde consideran que es necesario abrir nuevos espacios de lucha se hace formación; cuando notan que las acciones jurídicas requieren la presión pública hacen plantones y marchas; cuando de leyes se trata, van al Congreso y cuando creen que es necesario hacer jornadas de movilización salen a las calles a irrumpir la cotidianidad de los ciudadanos. También dedican parte importante de su tiempo a recordar sus muertos y desaparecidos, a exigir justicia y a crear nuevas formas para la reconstrucción de la memoria.

Las formas de interlocución con el Estado a su vez, han variado a partir de los reacomodamientos de éste y particularmente a partir del cambo de administración presidencial. De esta forma, si bien la movilización y la denuncia siempre han sido los motores de las acciones colectivas del movimiento, mientras en el mandato de Uribe los ejercicios eran exclusivamente de presión, con el gobierno Santos comienzan a probarse acciones de cabildeo regional y nacional que, aunque de forma muy tímida, demuestra que los repertorios se ajustan dependiendo la acción y reacción del oponente, así como el lugar donde se desarrolla la contienda. 
Con el tiempo, el Movice ha aprendido a adaptar sus performance a la interpretación que hacen del tipo de relación que tengan establecida en ese momento con la institucionalidad. De allí que esta puede ser variable en el tiempo y en la geografía. Con esta lógica, este movimiento se ajusta a los cambios del Estado sin perder el ánimo contestatario, sin dejar de ubicarse en la oposición del espectro político e ideológico y sin dejar de plantear un modelo de Estado alternativo a partir de un cambio sustancial en su sistema económico, político y social.

Esta forma de entender el mundo le imprime además un carácter singular a su repertorio. Un performance que plantea un mensaje contestatario, fuerte y radical expresado en forma pacífica, o por lo menos sin pasar de las agresiones verbales o simbólicas, que es recibido a su vez por el Estado con muy poco ánimo pero que en todo caso le implica y le significa una respuesta, en algunos casos evasiva y en otros más directa.

\subsubsection{La mirada Cuantitativa}

Haciendo el repaso por la Base de Datos de Luchas Sociales del Centro de Investigación y Educación Popular CINEP en busca de la una mirada panorámica sobre el papel que ha jugado el Movice en el marco de las movilizaciones de las víctimas en el país, encontramos al menos dos factores que nos muestran las dificultades que enmarcan el seguimiento a este tipo de acciones. Por un lado, teniendo en cuenta que no encontramos registradas acciones locales y regionales realizadas por el Movice como las galerías de la memoria y otras movilizaciones públicas coyunturales de las cuales el movimiento da cuenta en su página web, consideramos que existe un importante sub registro de las acciones realizadas que posiblemente radica en la falencia propia de movimiento que no cuenta con un mecanismo adecuado de seguimiento, registro y difusión de sus propias acciones. Por otro lado, en el reporte de la base de datos para la categoría de "Víctimas y Familiares" encontramos un caso particular como es el de los plantones semanales que las Madres de la Candelaria de Medellín han realizado con extraordinaria 
regularidad desde 1999 y que por lo tanto tienen un gran impacto en los registros de esta categoría.

En efecto la base de datos da cuenta de un total de 951 movilizaciones de víctimas registradas entre 1986 y 2013, de las cuales 479 corresponden a las Madres de la Candelaria, quienes han realizado plantones desde 1999 para denunciar los secuestros y las desapariciones forzadas en su región. En este sentido podemos apreciar que el registro de las acciones colectivas de enfocadas en el tema de víctimas aumenta sensiblemente con la incursión de las madres de la Candelaria en 1999, pues entre 1986 y 1998 tan sólo se registran 27 movilizaciones mientras que en 1999 llegan a 85. Después de 1999 y hasta 2003 los registros se mantienen estables entre 60 y 70 movilizaciones mientras que en 2004 tienen un nuevo aumento significativo superando las 100. Según los datos del Cinep el 2007 es el año más agitado en cuanto a la movilización de las víctimas alcanzando 118 movilizaciones registradas y a partir de 2008 nuevamente se aprecia un descenso brusco en este número.

Ilustración 7. Movilizaciones de Víctimas por año entre 1986 y 2013

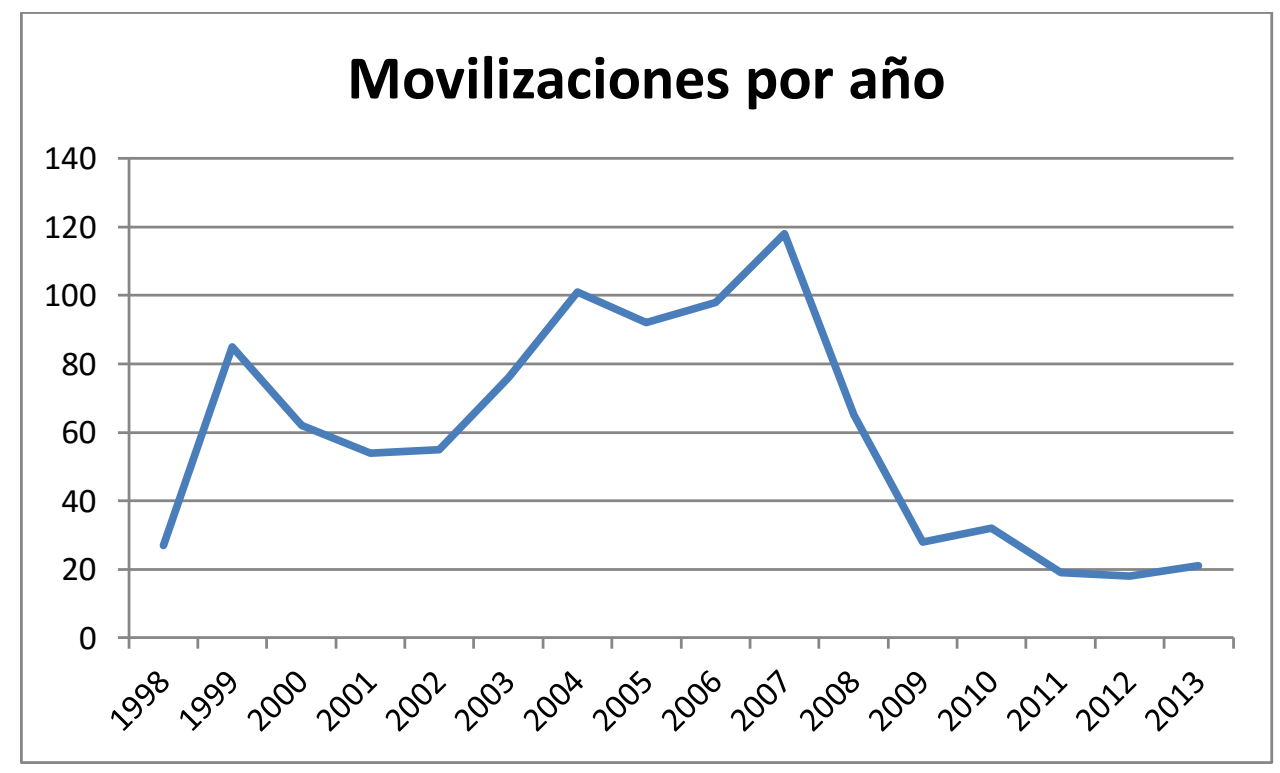

Fuente: Base de Datos de Luchas Sociales. Sistema de Información General del CINEP. Consultada el 12 de Febrero de 2014. 
Los datos del Cinep también nos permiten apreciar la posible influencia de la aparición del Movice en la tendencia de las movilizaciones de las víctimas en Colombia. Si tomamos los datos separados de los registros de las Madres de la Candelaria encontramos, entre 1986 y 2004, 178 movilizaciones de las cuales el $64 \%$ corresponden a víctimas de las guerrillas, apenas el 12\% a víctimas del Estado y el $24 \%$ son en contra de la violencia política de los diversos actores armados. Luego, entre 2004 y 2013, el número de movilizaciones aumenta considerablemente y la proporción también cambia, pues, de 297 movilizaciones registradas el 52\% son de víctimas de las guerrillas, el 25\% de víctimas del Estado y el $23 \%$ corresponden a manifestaciones en contra de la violencia y del conflicto armado, en muchas de las cuales participa y convoca el Movice.

Tabla 2. Análisis de la incidencia de MOVICE en el número y el tipo de movilizaciones de Víctimas entre 1986 y 2013

\begin{tabular}{|l|l|}
\hline \multicolumn{2}{|l|}{ Fase de Datos de Luchas Sociales. Sistema de Información del CINEP } \\
\hline Rango: 1986 - 2013 & $\mathbf{9 5 1}$ \\
\hline Total Acciones Colectivas Víctimas y Familiares 1975-2013 & $\mathbf{4 6 0}$ \\
\hline Total Acciones Colectivas Víctimas y Familiares entre 1986-2004 & 42 \\
\hline Acciones Colectivas de Víctimas de Violencia Política 1986-2004 & 114 \\
\hline Acciones Colectivas de Víctimas de las Guerrillas 1986-2004 & 22 \\
\hline Acciones Colectivas de Víctimas de Estado y Paramilitares 1986-2004 & 282 \\
\hline Acciones Colectivas Madres de la Candelaria 1986-2004 & $\mathbf{4 9 1}$ \\
\hline Total Acciones Colectivas Víctimas y Familiares entre 1986-2004 & 64 \\
\hline Acciones Colectivas de Víctimas de Violencia Política 1986-2004 & 155 \\
\hline Acciones Colectivas de Víctimas de las Guerrillas 1986-2004 & 75 \\
\hline Acciones Colectivas de Víctimas de Estado y Paramilitares 1986-2004 & 197 \\
\hline Acciones Colectivas Madres de la Candelaria 1986-2004 & \\
\hline Fuente: Base de Datos de Luchas Sociales. Sistema de Información General del CINEP. Consultada el 12 de \\
Febrero de 2014.
\end{tabular}

\subsection{Capítulo 9: Los Efectos de la Movilización del Movice}


Luego de adentrarnos por la historia del nacimiento y consolidación del Movice, y de conocer algunas de sus características más relevantes, bien vale la pena continuar nuestro camino hacia una mayor comprensión de la manera en que se relaciona y participa en la producción de resultados. Para ello, y como ya lo hiciéramos con la Ruta, creemos que una buena vía es identificar un impacto considerado como valioso por el movimiento y tratar de identificar la cadena causal de eventos más cercana en su producción. En este caso también trabajaremos sobre un resultado político externo en relación a derechos legales (Giugni \& Bosi, 2012), con el objeto de mantener elementos comunes con el primer estudio de tal forma que nos sea posible avanzar en un ejercicio de comparación posterior.

En este caso resulta ser el reconocimiento de la existencia de Víctimas de Crímenes de Estado a partir de la expedición de la ley 1448 de 2011 (art.3) uno de los hitos más importantes para el Movice; de allí que, siguiendo la propuesta metodológica que hemos usado hasta ahora y que nos indica que es necesario establecer un campo histórico y espacial pero también un acotado número de acontecimientos y actores relacionados (McAdam et al., 2005) para enmarcarlo en un Episodio de contienda, hemos realizado un paréntesis en la cadena de eventos definido entre la expedición de la ley en 2011 y la llegada de las víctimas al Congreso con el propósito de plantear demandas derivadas de su situación en el año 2007.

Esta delimitación nos permite realizar un proceso de indagación histórica en la que vamos definiendo e identificando los diferentes personajes y situaciones que participaron en su producción a partir de las memorias de los entrevistados y las huellas que van dejando los procesos de construcción normativa en un ejercicio retrospectivo de los acontecimientos. Ahora, si bien este ejercicio se realiza a partir del punto de llegada y hacia atrás en el tiempo y los eventos, la narración se presentará en orden cronológico (de atrás hacia adelante) de tal suerte que se facilite su lectura y comprensión.

4.4.1. Las voces de las Víctimas llegan al Congreso 
Los primeros meses de 2007 comenzaron con noticias diferentes para las víctimas. La Fundación Víctimas Visibles, organización dedicada a la visibilización de las víctimas, particularmente de la insurgencia, y acunada en la Universidad Sergio Arboleda, promovió junto al Senador Juan Fernando Cristo la realización de una jornada especial en el Congreso de la República para escuchar diversos testimonios de víctimas. Con este propósito se presentó la proposición No. 346 enmarcada en la idea de que las víctimas son más importantes que los victimarios, que ser oídas es su derecho y que los procesos de sanación y de memoria pasan porque la sociedad en su conjunto asuma que los muertos de la guerra son los muertos de todos (Cristo, 2012, p. 34). Esta iniciativa, acogida ampliamente por la bancada liberal, en un principio pasó inadvertida para la mayoría de los sectores políticos, sin embargo muy pronto despertó una gigantesca gresca en el Congreso motivada en su mayoría por los Uribistas quienes la consideraron una afrenta contra la Seguridad Democrática.

La Jornada se realizó el 23 de julio de 2007 en el marco de lo que se denominó: Día Nacional de Solidaridad con las Víctimas en el que, no sin algunos resquemores, se escucharon cerca de 40 testimonios de víctimas de diferentes hechos y de distintos actores armados. Comenzaba allí a gestarse la idea de un estatuto para las víctimas y el trabajo de incidencia de las organizaciones de víctimas en el Congreso de la República.

Así lo recuerda Fátima Esparza, miembro en aquel momento de la Comisión Colombiana de Juristas y quien realizaba seguimiento a los proyectos de ley tramitados en el Congreso de la República:

"La propuesta (de hacer una ley) surge de unos "considerando" de una audiencia que se realiza a mediados del 2007 en el Congreso promovida por una organización que se llama Víctimas Visibles. Esta organización, que aglutina muchas víctimas de las FARC-EP particularmente, pero en general, donde confluyen muchas víctimas de actos cometidos por los grupos guerrilleros, había hecho un trabajo de lobby ante congresistas para que se 
evidenciara que en la medida en que el proceso de la 975 (Ley de Justicia y paz) estaba cubriendo a paramilitares, las víctimas de los grupos guerrilleros no iban a tener acceso a medidas de reparación." (Entrevista 26).

\subsubsection{Primer Proyecto de Ley}

Esta propuesta se cristaliza en octubre de 2007 cuando el Partido liberal presentó ante el Congreso un proyecto para la conformación de un Estatuto de Víctimas. La iniciativa resultaba novedosa por cuanto pretendía recoger la normatividad dispersa sobre la materia y armonizarla con el derecho internacional, señalaba la integralidad de la reparación, hablaba de restitución de tierras y de memoria histórica, planteaba la necesidad de agrupar y organizar la legislación existente en materia de ayuda y asistencia humanitaria y creaba una institucionalidad para atender a las víctimas.

Aprobado en la Comisión primera como "Proyecto del ley 157 de 2007 Senado por el cual se crea el estatuto de víctimas de crímenes y actos violentos en el marco del conflicto colombiano", esta iniciativa pronto despertó el interés de algunas organizaciones como la Comisión Colombiana de Justicia, ICTJ y Dejusticia quienes decidieron participar de las primeras Audiencias promovidas en el Senado para debatir los contenidos de la ley.

Si bien durante el primer debate eran contados los que veían que este proyecto podría tener algún futuro y su trámite durante las primeras semanas pasó inadvertido para la mayoría de colombianos, en poco tiempo y al notar las implicaciones sobre las víctimas que una ley de esta naturaleza podría tener, varios sectores de la sociedad civil decidieron comenzar a movilizarse alrededor de este. Uno de los mecanismos que se implementaron para hacerle seguimiento al debate fue la creación de espacios plurales para su discusión.

Uno de ellos, tal vez el más visible y frecuentado por los congresistas interesados, fue la constitución de una mesa de trabajo de más de 30 organizaciones promovida por Fundación Social en la que se discutieron e hicieron recomendaciones de cada 
uno de los artículos del proyecto. Entre las organizaciones que participaron de este espacio estuvieron: Dejusticia, Corporación Nuevo Arco Iris, Iniciativa de Mujeres por la Paz, Consejería en Proyectos, Corporación Avre, Corporación Viva la Ciudadanía, la Mesa del encuentro de víctimas pertenecientes a organizaciones sociales, Reiniciar, Comisión de Seguimiento a la Política Pública sobre Desplazamiento, Comisión Colombiana de Juristas, ICTJ, PNUD, OACNUDH, UNIFEM, UNICEF, Procuraduría General de la Nación, Defensoría del Pueblo, entre otras.

Este trabajo se amplió mediante el respaldo del Sistema de Naciones Unidas quienes desde el PNUD promovieron y financiaron 9 audiencias públicas reglamentarias en las que se aglutinaron cerca de 3.000 víctimas (Gaviria Betancur \& Gil Savastiano, 2010, p. 52). Estas audiencias se realizaron en Medellín, Villavicencio, Pitalito, Sincelejo, Valledupar, Pasto, Quibdó, Barrancabermeja y Cúcuta (Cristo, 2012, p. 79). A juicio de Fundación social se trató de un proceso de deliberación que rompió los esquemas de participación en el legislativo, donde suelen discutirse los proyectos en completa ausencia de la ciudadanía. En palabras de esta organización:

"El proceso de incidencia legislativa fue también uno de construcción de la democracia. Dar la voz a los sin voz: ¿cómo no sería ello avanzar hacia una sociedad más incluyente? Decenas de congresistas viajaron a las regiones para escuchar a las víctimas que contaron su verdad; organizaciones no-gubernamentales de las regiones accedieron a legisladores; especialistas y congresistas confrontaron puntos de vista; y medios de comunicación relataron historias olvidadas. Mientras que varios procesos legislativos tienen lugar en el silencio de los corredores del C0ongreso, para el Estatuto de Víctimas, desde cientos de rincones del país, resonaron las palabras de las víctimas. No siempre existieron consensos, pero se construyó diálogo: en el seno de las organizaciones nogubernamentales que trabajan con las víctimas y por los derechos humanos, 
el Gobierno y el Congreso; entre actores locales e internacionales y entre la capital y las regiones" (Gaviria Betancur \& Gil Savastiano, 2010, p. 52).

Una versión algo diferente la brinda Ana Jimena Bautista quién tuvo a su cargo el seguimiento del proyecto de ley para el Movice y quien fue contratada por PCS:

"Había dos espacios fuertes. Uno era el de Fundación social que era el espacio de expertos y expertas, entonces ahí a quién encontrabas, encontrabas al ICTJ, encontrabas a Codhes, a la Comisión de seguimiento de la política pública de desplazamiento forzado, encontrabas a Pastoral Social, a Dejusticia, a la CCJ. Encontrabas también a las instituciones: a Acción social y al ICBF. Pero allá víctimas no había, el Movice no estaba ahí. Y estaba el otro espacio que nació con la Mesa de víctimas pertenecientes a organizaciones sociales, ahí si estaba el Movice, y ahí es cuando se empieza a hablar de cómo presionar a Cristo y a Rivera. Y comienzan las audiencias públicas y la participación del Movice. Incluso a mí me contrata PCS porque la impresión que tenían era que aunque el Movice estaba, no había nadie pendiente del seguimiento. Ahí la Mesa se monta y el Movice entra como Mesa al espacio de Fundación Social, lo que pasa es que el Movice también se ha debatido en el tema de no legitimar esos espacios porque puede ser contraproducente para las víctimas, además una cosa impulsada por los liberales, yo creo que al interior había una discusión de cómo se paraban allí y decidieron hacerlo a través de la mesa de organizaciones sociales.” (Entrevista 24).

Mientras esto sucedía en el seno de la sociedad civil, al interior del congreso las discusiones que se desarrollaron durante su trámite tampoco fueron muy pacíficas. El proyecto debió soportar múltiples arremetidas tanto de sectores progresistas y de representantes de víctimas como de los partidos de derecha, aunque por motivos muy distintos. Mientras las organizaciones de la sociedad civil notaron que se trataba de una ley que no contemplaba inicialmente a las víctimas del Estado y que tenía otra serie de debilidades, la derecha la consideraba una afrenta a los militares 
y a la política de seguridad democrática. De lado de la sociedad civil, algunas organizaciones pronto hicieron reclamos sobre los contenidos de este proyecto:

"Que fue lo que nosotros propusimos en nuestro texto (durante la primera Audiencia pública en Senado). El texto tenía 5 apartados que fueron las observaciones que hicimos al proyecto. La primera y la fundamental era que no se reconocía a las víctimas de actos cometidos por el Estado. Había otra observaciones como el hecho de que era una ley que se iba a dar en el marco del conflicto y eso tenía limitaciones para la reparación, que no se entendía realmente la naturaleza de la reparación porque este contemplaba medidas puramente asistenciales, incluso hubo un apartado sobre cómo la atención sicosocial estaba vista de una manera bastante precaria porque se pretendía que los estudiantes de último semestre de sicología fueran los que ofrecieran a título de servicio social esta atención, también la confusión de medidas de derechos sociales con reparación y que faltaba el tema de medidas de no repetición. El capítulo de tierras nos pareció bastante interesante, era un muy buen texto, sin embargo yo creo que hubo error en cuanto que quisimos exigirle más al texto. Y fue un error estratégico y no político porque yo comprendo que debíamos ir por el máximo de lo que se podía lograr en restitución". (Entrevista 26).

Pero estas, si bien eran críticas a los contenidos principales de la ley y buscaban su modificación profunda, no eran las más agresivas o amenazantes, en realidad la embestida principal contra el proyecto provenía de los sectores de derecha. Los primeros debates en el Senado estuvieron acompañados de las andanadas de los parlamentarios uribistas y hasta del propio presidente de la República quien en no pocas ocasiones manifestó la inconveniencia de un estatuto de estas características. Durante varios meses la discusión estuvo centrada en la existencia o no de un conflicto armado interno, el reconocimiento de la responsabilidad del Estado en las violencias y el costo fiscal que implicaría avanzar en un mecanismo de indemnización, pero fue en el posible reconocimiento de las víctimas de crímenes de Estado donde se encendió más la polémica. 
Fue durante el segundo debate en el Senado a comienzos de 2008 que el proyecto incluyó a todas las víctimas mediante una nueva definición en la que se estipulaba que la ley se refería a quiénes hubiesen "sufrido daños como consecuencia de acciones $\mathrm{u}$ omisiones que constituyen una violación manifiesta de las normas internacionales de derechos humanos o una violación grave del derecho internacional humanitario". El hecho de introducir "violaciones de derechos humanos" como causa de los daños avaló la universalidad de la ley (Gaviria Betancur \& Gil Savastiano, 2010, p. 66).

Este cambio surge de un paciente proceso de incidencia previa que se hiciera desde las organizaciones de la sociedad civil, quienes ya habían incorporado la demanda del Movice sobre la exigencia del reconocimiento de los crímenes de Estado en sus repertorios de trabajo para interlocución con los actores del Estado y que determinó en gran parte el curso de los acontecimientos en lo sucesivo. Así lo recuerda Fátima Esparza funcionaria en aquel momento de la CCJ.

"Desde mi apreciación personal cuando nosotros intervinimos en la Audiencia había mucho desinterés, yo me acuerdo tanto que los senadores se levantaban, lo típico en este tipo de dinámicas en el Congreso, es decir, había unos senadores que estaban como pendientes, pero decir que en la audiencia se pusieron los temas, los planteamientos y que ahí se dio un debate, pues realmente eso no ocurrió de esa forma. Pero lo que si nos permitió fue posicionarnos como actores con la Unidad de Trabajo Legislativo de Cristo que era la que estaba trabajando el tema y en esa Audiencia lo que dijimos fue, vamos a buscar una cita con estas personas para ver si es posible que esto tenga algún eco, y entonces buscamos una entrevista.

"Yo destaco muchísimo el papel que tuvo en ese momento Blanca Capacho que era la asesora principal en este tema, no era la asesora principal de despacho pero tenía a cargo este proyecto y nosotros buscamos una entrevista con ella. En ese momento no sé qué hicieron el ICTJ, ni Dejusticia 
que eran los otros actores. Nosotros buscamos una reunión con ella (recuerdo que en ese momento en Comisión primera de Senado estaba Cristo, estaba Gerlein, estaba Petro, estaba Vélez también, se me escapan muchísimos porque eran como 18) pero el hecho es que cuando nosotros llegamos, muy francamente te voy a contar lo que ocurrió.

"La asesora lo que nos dijo fue: bueno, ustedes tienen una posición crítica frente al proyecto y creo que pueden tener una posición más cercana como a la lógica que maneja el Polo, nosotros queremos que el Polo se una a este proyecto de ley, entonces, ¿con qué creen que en el articulado el Polo, Cristo podría hablar con Petro para que esto pase? Pues obviamente yo le dije: mira, lo que yo creo que haría que efectivamente el Senador Petro apoyara este proyecto es que no se discriminara a las víctimas de Estado, porque no solamente las víctimas de la guerrilla están por fuera, sino también las víctimas de Estado. Entonces, si vamos a hablar de las víctimas que faltan, pues faltan otros, y ella lo que dijo fue: no, lo que pasa es que si ponemos víctimas de Estado, los conservadores no van a apoyarnos porque eso es una reivindicación de hablar de criminalidad de estado y pues en esa línea nosotros no estamos ni el senador está.

"Entonces yo le dije: no, mira, quizás nosotros no nos hemos explicado bien, pues es una manera de decirlo, pero eso está ligado al derecho administrativo, tú sabes que efectivamente hay una lógica jurídica que habla de la responsabilidad de los agentes y eso está desarrollado por el Consejo de Estado. Nosotros en esa lógica lo que creemos es que podríamos buscar un consenso si se habla de agentes del Estado. A ella le sonó el tema y dijo: si, en ese sentido me parece razonable, ¿cómo lo redactaríamos? y con el otro abogado de la $\mathrm{CCJ}$ que estaba redactamos un texto donde pudiera ser incluida la palabra agentes. El otro abogado no estaba muy de acuerdo con lo que yo estaba planteando, porque de alguna manera estábamos hiriendo un puntazo, pero era de incidir, era al menos la posibilidad. Lo que nunca me imaginé era que efectivamente Cristo iba a decir que si y que efectivamente pasó lo que pasó porque Petro dijo que si, y que se formó un consenso. Entonces en ese momento sale el texto y tuvo votación unánime, 
que en mi criterio solamente se puede explicar por esa circunstancia. Esta es toda la historia de cómo ocurrió" (Entrevista 26).

Así las cosas, aunque con concesiones importantes en la redacción del texto, parecía que el pulso lo iban ganando las organizaciones defensoras de los derechos humanos y de las víctimas. Podría decirse que desde ese momento los esfuerzos de visibilización de las víctimas de crímenes de Estado del Movice ya habían empezado a hacerse eco en numerosos sectores, al punto que se comenzaba a perfilar en algunos círculos, fuera de la izquierda, la idea de una tratamiento igual a las víctimas de grupos ilegales y a las víctimas de crímenes de Estado. Se trataba apenas del comienzo de la mayor fuente de disputas entre la bancada liberal y el gobierno de Uribe en el Congreso durante ese periodo legislativo.

Y fue precisamente este tema el que se convirtió en el punto de honor de ambas partes durante toda la discusión de la ley. El centro de la diferencia, en síntesis, era que el Gobierno Nacional solo admitiría la aprobación de la ley única y exclusivamente si esta cobijaba a las "víctimas del terrorismo", bajo el argumento que la reparación a las víctimas del Estado solo podía derivarse de un fallo judicial condenatorio al responsable, mientras la bancada liberal señalaba que la norma debía cubrir a todas las víctimas independientemente de la individualización o juzgamiento del actor causante del hecho. No era un debate menor si consideramos que desde hacía unos años atrás el Movice había comenzado todo un trabajo político y de movilización social para evidenciar en el ámbito nacional e internacional la discriminación que sufrían las "Víctimas del Estado", hecho, que como lo hemos relatado previamente, desató una gran persecución por parte del Ejecutivo a este movimiento social.

Sin embargo, fue en el paso por la Cámara de Representantes donde las fisuras se hicieron grietas mediante la modificación sustancial del proyecto discutido en Senado. Se trataba de una estrategia uribista mediante la cual intentaban, o lograr una ley acomodada a sus planteamientos políticos o, preferiblemente, obligar a que los propios autores de la iniciativa decidieran hundirla por ser contraproducente. 
Así lo leyó el Movice quien en ese momento y mediante un extenso comunicado explicó punto por punto sus críticas al proyecto en debate. Para este movimiento social, el proyecto se había convertido en un "insulto" más y lo consideró como "una afrenta y una burla más a las víctimas y a sus exigencias legítimas frente a la garantía de sus derechos a la verdad, la justicia y la reparación integral.

Entre las críticas más profundas estuvieron la eliminación del principio pro hommine, el no reconocimiento de la responsabilidad del Estado como fundamento para otorgar la reparación basándose en el principio de solidaridad, la restricción temporal de las víctimas para ser beneficiarias y la no inclusión de víctimas futuras, la exclusión de las víctimas de "bandas emergentes", la discriminación a las víctimas de agentes estatales mediante la restricción de su condición y haciendo más onerosa su situación, la exclusión de la reparación administrativa a las víctimas de la fuerza pública y la posible usurpación ilegal de las tierras derivada de una aplicación regresiva de la restitución de tierras (Movice, 2008c).

Además de ello existían otros debates importantes que distanciaban a las organizaciones sociales, a los Congresistas y al Gobierno Nacional: la distinción entre ayuda, asistencia y reparación, el tema de tierras, la perspectiva diferencial, el diseño institucional y la forma en que debería ser incorporada la sentencia T-025 de 2004 sobre desplazamiento forzado y sus autos de seguimiento, entro otras, haciendo más evidente y sonoro el conflicto entre las múltiples fuerzas en el Congreso y en las calles, que permitieron en algunas ocasiones la paradoja de poner del mismo lado a uribistas y al Movimiento de Crímenes de Estado en su deseo por derrotar el proyecto buscando su archivo definitivo.

Se trataba en últimas de discusiones que lentamente los congresistas y la ciudadanía comenzaban tímidamente a comprender y por el que se empezaban a movilizar. Llegó a ser tan sensible la aprobación de la ley que se llegó a especular que el Ministro del Interior y de Justicia, Carlos Holguín, debió renunciar tras la 
aprobación del proyecto por el Congreso en sus primeros momentos (Gaviria Betancur \& Gil Savastiano, 2010, p. 54).

En todo caso fueron discusiones que animaron la acción: de los Congresistas ponentes quienes todo el tiempo estuvieron buscando mecanismos de conciliación y acuerdo con los representantes del Gobierno; de las organizaciones de la sociedad civil quienes en no pocas ocasiones presentaron redacciones alternativas a los artículos o propuestas completas de normatividad; y del Sistema de Naciones Unidas y del Sistema Interamericano de Derechos humanos que estuvieron siempre atentos enviando conceptos y comunicaciones así como mediante en algunos casos entre los actores dispares de la contienda.

Pero mientras el debate se avivaba en el Congreso y las diferencias se intentaban resolver a puerta cerrada entre los actores con poder en esta historia, el gobierno de Uribe adelantaba una agenda paralela que pretendía derrotar el objetivo de las víctimas de conquistar una reparación integral. Mediante la expedición del Decreto 1290, derivado de la ley 975 de 2005, se estipulaba la indemnización por vía administrativa para las víctimas de grupos armados ilegales. Con este instrumento el Gobierno estableció unas tablas de montos económicos por hecho victimizante y prometía entregar esta suma de dinero a las víctimas de grupos ilegales, es decir: guerrillas y paramilitares.

Si bien parecía un desarrollo importante en lógica del reconocimiento de las víctimas al incluir uno de los elementos de la reparación integral reconocidos internacionalmente, dejaba clara la posición del Gobierno Nacional de no ceder ante las voces que requerían el reconocimiento de la responsabilidad del Estado y la inclusión de las víctimas de sus crímenes. Todo esto además sucedía al tiempo que el Presidente de la República desarrollaba toda una campaña para adelantar un referendo reeleccionista que le permitiera quedarse un tercer mandato en el poder y estallaba el escándalo de los "falsos positivos", por lo que el ambiente nacional y particularmente en el Congreso, estaba bastante enrarecido. 


\subsubsection{Y "tumban" la Ley}

En este contexto y después de los respectivos debates en Cámara y Senado en el que el proyecto sufrió numerosas modificaciones, el texto debió entrar a Conciliación para ser votado en plenaria. Si bien aún los autores no descartaban la posibilidad de naufragar en el intento, el que hubiese llegado hasta este punto permitía mantener la esperanza en muchos de los sectores que se fueron uniendo a la iniciativa. Sin embargo esta esperanza fue prontamente cegada. Así lo recuerda Cristo, uno de los autores de la ley:

"La estocada final a la conciliación provino desde el mismo despacho presidencial. Todavía inseguro sobre la capacidad de persuasión de sus ministros y para que no quedara duda sobre la posición del gobierno, el propio Jefe de Estado, en un acto inusual, envió una comunicación a la Secretaría del Senado para que fuera leída en plenaria y escuchada por los Senadores de la coalición oficial. Allí directamente Alvaro Uribe solicitaba no aprobar el acta de conciliación porque "equipara a terroristas con agentes del Estado" (Cristo, 2012, p. 90).

Con esta posición se cerraba el primer capítulo de la ley en el Congreso en el que quedaban derrotados los sueños de las víctimas que por algunos meses vieron en la iniciativa liberal la oportunidad de sacar adelante procesos reivindicativos, pero además dejaba claras las posturas de las partes y el destino que tendía un nuevo proyecto de ser presentado en ese periodo legislativo.

Sin embargo, como prueba del interés que había suscitado en el gobierno y el empeño que tenía la bancada liberal poco tiempo después, el 20 de julio, estos dos sectores presentaron nuevamente proyectos sin que finalmente fueran discutidos en el seno del Congreso. Esta radicación pareció más una forma de coletazo a las discusiones previas, que un genuino interés de adelantar nuevamente la discusión en el legislativo. 


\subsubsection{El Gobierno Santos y la bancada de Unidad Nacional}

Tendría que haber una modificación sustancial en el contexto político del país para que una iniciativa de esta envergadura volviera a tomar aire. Luego de ser derrotada la iniciativa de Uribe de mantenerse un periodo más en el poder, llega a la presidencia de la República quien fuera el Ministro de Defensa de Uribe, Juan Manuel Santos. Su elección aparecía más como la continuación del Gobierno de Uribe quien durante la campaña optó por darle su bendición al notar que sus propios candidatos no tendrían muchas posibilidades de ganar, por lo que en las agendas de los movimientos sociales no se vislumbraban mayores oportunidades de incidencia.

Sin embargo los líderes del partido liberal, bastante bien versados en el arte de la política electoral y en la construcción de agendas presidenciales, aceptaron la invitación que el recién electo Presidente le hiciera a sus huestes a participar de una agenda de Unidad Nacional. Aceptación que traía bajo su manto un pacto de agendas. Así lo narra Cristo:

"La misma noche de su elección, Santos invitó nuevamente al liberalismo a hacer parte de una agenda de unidad nacional, con el propósito de impulsar iniciativas trascendentales para el país. Se reunieron nuevamente el Presidente electo y el Jefe liberal para discutir los términos de un eventual ingreso al partido a la denominada Unidad Nacional. Ya en ese momento la mayoría de la bancada se mostraba de acuerdo en cooperar con el gobierno y Pardo planteó un acuerdo programático en el que Santos acogerá como parte de la agenda legislativa de su gobierno la ley de víctimas, la ley de primer empleo y la creación de un sistema para garantizar pensión de vejez a los trabajadores informales e independientes del país. Santos aceptó de inmediato la propuesta y ese día resucitó la Ley de Víctimas bajo el liderazgo compartido del liberalismo y el nuevo jefe de Estado.” (Cristo, 2012, p. 102). 
Sucedía con esto una paradoja de interesantes consecuencias. El presidente electo, quien aparentemente era la continuación del gobierno de Uribe, acogía como propia una de las propuestas de la oposición de su antecesor. Sería este apenas el comienzo de las pugnas y divisiones que marcarían en adelante la relación de Uribe y de Santos y que finalmente terminarían en el rompimiento total de sus vínculos y el paso del uribismo a la oposición.

Pero no se trataba de algo sorpresivo. En realidad la posibilidad de conformar una Unidad Nacional al parecer fue anterior a las elecciones desde el momento del hundimiento de la ley de víctimas. Esto se deduce de las afirmaciones públicas que hiciera el Senador Cristo en aquel momento y que nos relatara Fátima Esparza:

"Cuando el proyecto se hunde el Senador Cristo dijo: este proyecto lo vamos a revisar porque nos comprometimos con las víctimas, pero yo creo que para que esto resulte, tendrá que ser con un nuevo gobierno y tendrá que ser con un gobierno de Unidad Nacional.” (Entrevista 26)

En cualquier caso, independientemente de las jugadas políticas que seguramente antecedieron a la elección del presidente Santos, con ello se lograba el espaldarazo a la iniciativa por parte del nuevo gobierno nacional. Era necesario ahora entrar en el detalle de los contenidos donde seguramente los acuerdos serían más difíciles, de allí que tanto el Senador Cristo como el Representante Rivera, acérrimos defensores de la ley, se apresuraron a conocer la posición de Santos para determinar el grado de compromiso que éste tendría con la iniciativa. El Presidente, tal vez en uno de los virajes más vertiginosos frente al anterior gobierno, adhiere también a la postura de reconocer a las víctimas de crímenes de Estado como parte fundamental de la ley de víctimas.

Esta modificación se dio en medio de algunas controversias con los sectores uribistas aún en el gobierno y conservadores que estaban negociando también su ingreso a la Unidad Nacional, quienes intentaron introducir la postura del anterior 
gobierno, pero fueron prontamente derrotados por la posición categórica del gobierno. Así describe el Senador Cristo este episodio:

"Se provocó en seguida un largo debate de los liberales con Pizarro (Presidente de la Comisión Nacional de Reparación y Reintegración, cercano a las posturas uribistas) y los conservadores sobre el tema, en el que se repitieron una vez más, los argumentos conocidos. Finalmente, el Ministro del Interior y Justicia zanjó la discusión al pararse de su asiento y con su característico estilo, señala a Pizarro que el gobierno había cambiado y que la posición del nuevo gobierno era clara en cuanto a que las víctimas eran iguales: no se podían discriminar. "Yo que he sido un permanente defensor de las fuerzas militares sí que tengo autoridad moral para fijar esta posición. No podemos discriminar a las víctimas", concluyó de forma contundente Vargas ante el silencio de los demás asistentes y el desconcierto de Pizarro que insistía en sus razones. Pocas semanas después se oficializaría su salida de la CNRR.” (Cristo, 2012, p. 106).

Se abría entonces el camino para presentar un proyecto de ley que recogiera los mejores apartes de las discusiones en el Congreso en la anterior legislatura y se continuara con el proceso de conformación de la ley. Podría decirse que el Gobierno Santos asumió completamente la defensa del proyecto hasta el punto que el mismo Presidente Santos se dirigió personalmente al capitolio Nacional a radicar la iniciativa. Fue en ese momento en que en medio del discurso que diera a las organizaciones, funcionarios y medios que le acompañaron el presidente Santos expresó: "Si sólo logramos aprobar esta ley y aplicarla exitosamente, habrá valido la pena para mí ser Presidente de los colombianos" (Cristo, 2012, p. 111).

Este viraje, repudiado por el recién salido presidente Uribe, tampoco fue de buen recibo para las organizaciones y las víctimas que habían trabajado fuertemente en el primer intento de incidir en la redacción del articulado un par de años antes. 
"Cuando se conforma la Unidad Nacional aparece el partido liberal en la coalición de gobierno. En ese momento se reactivaron todas las alarmas porque se dijo: bueno, Santos es el ex ministro de defensa del gobierno de Uribe, Uribe está en contra, qué va a pasar, cómo va a hacer esto. Ahí hubo una tensión implícita porque lo que hizo Cristo fue tomar el texto de la conciliación, el que había quedado por allá guardado, el mismo, el de siempre y decirle al gobierno: éste es el texto. Y si me presenta este texto, y si nos vamos con este texto y si usted le da respaldo a este texto y a esta discusión y lo pone en la agenda, más otras cosas porque no solamente era eso, pues vamos en la unidad Nacional. Lo que hace el gobierno es decir: listo yo lo presento como gobierno. Entonces era una cuestión supremamente complicada, porque primero era un trabajo de las organizaciones donde se había metido mucho elemento político y además porque se había trabajado con los liberales en buena medida porque había cierta "confianza" porque eran oposición al gobierno uribista. Pero ahora con esta movida pues obviamente las víctimas empezaron a hacer reclamos.

Hubo una reunión en el Museo del Oro y fue una reunión fuertísima, fuertísima, fuertísima, porque más o menos, guardadas las formas, lo que se les dijo a los liberales fue que le habían regalado el proyecto de las víctimas al gobierno de Uribe, que el proyecto no era liberal, era una concertación con las organizaciones. Y es que en ese momento Santos aparecía como el gran abanderado de las víctimas y en la historia quedará así, que el proyecto fue de iniciativa gubernamental.

Y no había nada más que hacer sino dejar constancias de la indignación que nos producía el hecho de que ahí se habían ignorado un montón de actores y un trabajo social. Solo quedaba por hacer un llamado de atención muy fuerte a los liberales que políticamente lo manejaron así." (Entrevista 26).

Independientemente de los destinos que corriera el proyecto de ley, para muchas víctimas y algunas organizaciones, este cambio de actitud fue la forma en que el nuevo gobierno nacional se apoderó de las banderas que enarbolaron durante 
muchos años y que les había costado la vida y los esfuerzos de decenas de militantes y activistas que habían participado durante años en la lucha por el reconocimiento de los derechos de las víctimas. Malestar que se mantuvo durante el resto del proceso y que determinaría en gran parte la posición de amplios sectores de víctimas en lo sucesivo.

\subsubsection{Segundo Proyecto de Ley}

Una vez radicado el proyecto en Septiembre de 2010 comienzan los debates del segundo intento de aprobación del proyecto en un Congreso en apariencias menos dividido, pero en su intimidad, profundamente guiado por las líneas ideológicas que los separaron en la legislatura anterior. Por un lado estaban los liberales, el Partido Verde, Cambio Radical y el Polo Alternativo Democrático con una visión amplia y garantista de los derechos de las víctimas y por el otro lado, aunque en una voz más baja que el año anterior, estaban los conservadores, el Pin y la U, con una visión restrictiva y minimalista de lo que debería contener la ley.

Nuevamente en este caso se suscitaron diversos conflictos en relación a algunos de los contenidos de la ley. La fecha desde la cual se debía comenzar a reconocer las víctimas, las zonas geográficas disponibles para adelantar proceso de restitución de tierras, la inclusión de insurgentes y sus familiares como posibles víctimas, y la ya clásica discusión sobre el costo fiscal que esta ley podría representar, fueron algunas de las principales discusiones que se realizaron durante este primer debate que comenzó en esta ocasión por la Cámara.

Ya en la fase de la plenaria se plantearon dudas respecto a la pertinencia de adelantar procesos de reparación en medio del conflicto, la conveniencia de cerrar la vía judicial luego de una reparación vía indemnización administrativa y se decidió incluir fuertes salvaguardas para evitar que los miembros de las fuerzas militares fuesen perjudicados por el reconocimiento de las víctimas de agentes del estado mediante fórmulas normativas como que este reconocimiento no implicaba la responsabilidad de los agentes la cual debía ser establecida judicialmente. Se 
pretendía por este medio zanjar las dudas que tenían las Fuerzas Militares de tal suerte que dejaran de ser un obstáculo para la aprobación de la ley.

También se discutió la institucionalidad que debía operar la nueva normatividad y la inconveniencia de mantener al frente de esta tarea a Acción social, un ente que para ese momento ya estaba bastante desprestigiado. Otro de los puntos que despertaron bastante polémica fue la inclusión de un contrato de transacción para que quien recibiera la indemnización firmase, a cambio de recibir una mayor cantidad de dinero, un documento que expresaba su intención de renunciar a la vía judicial para resarcir el daño.

Todos estos aspectos iban suscitando dudas y controversias en la sociedad civil y las organizaciones defensoras de derechos humanos que no descansaba en presentar propuestas alternativas y acompañar o rechazar las iniciativas que se discutían, pero que cada vez sentían más que la mayoría de estos aspectos, se decidían por fuera del debate público.

"El compromiso de Santos con los liberales para que los liberales se subieran en la Unidad Nacional era que los partidos del gobierno iban a apoyar el proyecto y lo iban a votar, es que ese fue el pacto. Esa decisión (la aprobación de la ley y las distintas modificaciones) no se tomó como cuando uno estudia los cursos de derecho legislativo donde nos enseñan que las leyes se aprueban en cuatro debates donde los legisladores plantean sus argumentos y votan dependiendo de cómo los convenzan. Fue un pacto que se hizo para las elecciones presidenciales y todos los de la bancada del gobierno sabían que era directriz de la bancada votar el proyecto de acuerdo a los lineamientos que iban dando los liberales. No hubo realmente una pugna; por supuesto se presentaron propuestas, hubo intervenciones, pero la correlación de fuerzas varió porque ya el gobierno tenía a la aplanadora que eran los liberales." (Entrevista 26). 
Hay que recordar además que para este nuevo intento se realizaron 5 audiencias públicas que no lograron la magnitud de las que se realizaron en el primer proyecto lo cual generó malestar entre algunas víctimas que sintieron cerrados los espacios para la participación.

A esta altura el Movice ya identificaba serias inconsistencias en el articulado que lo hacían alejar de la oportunidad de acompañar más tiempo la ley y, aunque algunos aspectos fueron subsanados, finalmente el Representante Iván Cepeda, miembro del Polo democrático y fundador del Movice tomó la decisión de no votarla positivamente. Se trató de un fracaso importante para el debate considerando que el mayor tema de división había sido precisamente el reconocimiento de las víctimas de Estado. Este hecho generó malestar en las toldas liberales que sentían que sus esfuerzos en el Congreso merecían el acompañamiento de este sector de las víctimas. Con estas palabras catalogaba la situación el Senador Cristo:

"Parecía increíble entonces que esta gente de izquierda, inmersa en sus propias divagaciones ideológicas y dogmatismo, no comprendiera que la ley desde hacía un tiempo se había convertido en el eje central de las diferencias políticas e ideológicas del gobierno Santos con el ex presidente Uribe" (Cristo, 2012, p. 172).

Lo que no podía ver Cristo en ese momento era que precisamente las salvaguardas, los matices y las exclusiones que se hicieran en medio de las votaciones a la ley para lograr las mayorías en el Congreso, implicaba para las víctimas de crímenes de Estado derrotas sucesivas sobre sus derechos y la renuncia a la posibilidad de obtener mayores garantías para las víctimas en su conjunto. De esta forma lo recuerda Iván Cepeda:

"Había que sopesar varias cosas. Primero, el costo beneficio que tenía la ley para las víctimas; segundo, si nuestro voto iba a influir o no para que la ley no pudiera salir adelante; y tercero, ver en una dinámica general 
de lo que queremos nosotros, hasta donde el habilitar a través de un voto la ley, era de alguna manera hacer una concesión. Entonces nosotros que hicimos, nosotros presentamos más de 100 proposiciones y muchas de ellas quedaron incluidas. Hay cosas que están en la ley que son obra o iniciativas del movimiento de víctimas, que fueron concertadas y negociadas. Pero en los puntos esenciales, cuando no llegamos a un acuerdo, ya era muy difícil para nosotros dar ese apoyo. Por ejemplo: el tema de la restitución de tierras donde veíamos la creación de un mecanismo jurídico en condiciones significativamente negativas para las víctimas que iba a significar que la restitución se convirtiera en un proceso formal, y en algunos contextos, que pudiera legitimar el despojo, cosa que efectivamente ya la realidad nos ha dado la razón. El tema de la UP y su reparación, el tema de los terceros de buena fe exentos de culpa, el tema del derecho del suelo, todo esos temas eran para nosotros temas de principio. Entonces si la ley no se iba a caer porque nosotros no votáramos, entonces optamos por tener una posición distinta. Vista esa decisión a la luz de unos años, creo que fue una decisión correcta," (Entrevista 25).

Así las cosas, mientras para los liberales la falta de apoyo del Movice era incoherente en relación a los logros obtenidos por esta colectividad, para este movimiento social resultaba más beneficioso aislar su voto y no conceder mayores espacios al gobierno nacional, que no podemos olvidar, ha sido su oponente político principal. Por supuesto se trató de un cálculo político mediante el cual, sin tener que perder la ganancia primordial del reconocimiento de las víctimas del Estado, pudieron apartarse del articulado que consideraban lesivo para las víctimas y mantener vivo el desafío a su oponente.

\subsubsection{Se aprueba la Ley}

Después de dos intentos en el Congreso, el cambio de un Presidente, un representante del Movice en la Cámara de Representantes, decenas de reuniones privadas y centenares de artículos redactados y corregidos uno y otra vez, el 10 de 
Junio de 2011 se aprueba la ley de Víctimas y restitución de tierras como una de las banderas principales del nuevo gobierno. Se trata de un documento de más de 200 artículos sobre un número amplio de temas relacionados con las formas de atender, asistir y reparar a las víctimas del conflicto, que sobretodo, ejemplifican el pulso entre Santos y Uribe en aquel momento y refleja las diferentes fuerzas que existían en el Congreso.

Pulso que en apariencia se inclinó a favor de Santos cuando optó por incluir el reconocimiento de la existencia de un conflicto armado interno en el artículo sobre Víctima y que daba una bofetada certera al planteamiento que esgrimiera durante 8 años el presidente Uribe sobre la existencia de una amenaza terrorista pero jamás de un conflicto armado. Finalmente, la primera parte del artículo que fue epicentro de la mayor parte del debate quedó con la siguiente redacción:

“Artículo 3. Se consideran víctimas, para los efectos de esta ley, aquellas personas que individual o colectivamente hayan sufrido un daño por hechos ocurridos a partir del $1^{\circ}$ de enero de 1985 , como consecuencia de infracciones al Derecho Internacional Humanitario o de violaciones graves y manifiestas a las normas internacionales de Derechos Humanos, ocurridas con ocasión del conflicto armado interno.

También son víctimas el cónyuge, compañero o compañera permanente, parejas del mismo sexo y familiar en primer grado de consanguinidad, primero civil de la víctima directa, cuando a esta se le hubiere dado muerte o estuviere desaparecida. A falta de estas, lo serán los que se encuentren en el segundo grado de consanguinidad ascendente. De la misma forma, se consideran víctimas las personas que hayan sufrido un daño al intervenir para asistir a la víctima en peligro o para prevenir la victimización.

La condición de víctima se adquiere con independencia de que se individualice, aprehenda, procese o condene al autor de la conducta punible y de la relación familiar que pueda existir entre el autor y la víctima”. (Congreso de la República de Colombia, 2011). 
De esta forma se zanjó definitivamente la discusión sobre si se debería reconocer a las víctimas de crímenes de Estado mediante la generalización del daño causado por consecuencia de infracciones al Derecho Internacional Humanitario o de violaciones graves y manifiestas a las normas internacionales de Derechos Humanos y la exclusión de la necesidad de independizar, aprehender, procesar o condenar al autor del crimen.

Se trató de un gran triunfo para las víctimas de crímenes de Estado que llevaban años buscando su reconocimiento, al tiempo que fue una estocada fuerte a su ideario que siempre ha considerado tener derecho a mayores y mejores garantías. Podríamos afirmar que fue un resultado agridulce, en el que se mezcló la satisfacción de haber conseguido lo que con tanto esmero se había luchado durante varios años de contienda política y la sensación de fracaso por un contenido legislativo tímido y lleno de salvaguardas para el Estado y sus agentes. La ausencia de la aceptación de la responsabilidad del Estado frente a las violencias ejercidas durante décadas en el conflicto seguirá siendo una deuda pendiente con las víctimas del Estado.

Lo que sí es indudable fue la victoria del presidente Santos que cumplía con ello una de sus mayores promesas al iniciar su mandato y que le permitía mostrar su fortaleza en el Congreso y su distanciamiento cada vez mayor con el ex presidente Uribe. Victoria que pudo celebrar en presencia del Secretario General de las Naciones Unidas, el Sr. Ban ki Moon, quién acompañó la ceremonia de sanción de la ley. Con ello el Presidente Santos demostraba además la complacencia y respaldo de la comunidad internacional a esta iniciativa legislativa, que, pese a que siempre había acompañado el proceso había tenido distanciamientos sobre algunos temas durante el trámite legislativo.

\subsection{Capítulo 10: La Influencia del Movice en la Ley 1448 de 2011}


Queda expuesta entonces la cadena de eventos que se puso en movimiento durante los pasos previos al reconocimiento de las víctimas de crímenes de Estado y su posibilidad de engancharse a procesos de atención y reparación integral; sin embargo, vale la pena ir más allá del relato simple de los acontecimientos para tratar de identificar cuáles fueron las razones para que los hechos se produjeran de esta manera y finalmente el hito adoptara la forma que hoy tiene.

Para ello, y guardando consonancia con el ejercicio desarrollado con la Ruta, identificaremos las oportunidades y amenazas políticas de la manera en que fueron interpretadas por los actores en disputa e intentaremos desentrañar los Mecanismos que entraron en juego durante este episodio a la manera de (Tilly \& Tarrow, 2007), esperando con ello poder reconocer los factores que intervinieron en la producción del hito y la forma en que el movimiento aportó en su producción.

\subsubsection{Estructura de Oportunidades Políticas}

Para entender lo que sucedió entre el primer proyecto de ley fracasado y el segundo proyecto que permitió finalmente el reconocimiento de las víctimas de Estado mediante la expedición de la ley 1448 de 2011, es necesario hacer un análisis de varios elementos del contexto político e institucional que afectaron las relaciones entre los poderes públicos y al interior del Congreso de la República. ¿Qué debió suceder para que la línea dura del presidente Uribe aparentemente respaldada por el conjunto nacional y las mayorías en el Congreso, fuera doblegada apenas algunos meses después de su salida de la presidencia?

Responder esta pregunta es una tarea indispensable para comprender los diferentes asuntos que se vieron involucrados en la constitución del hito estudiado. Para ello es menester valernos del marco teórico construido por la corriente de la Estructura de las Oportunidades políticas en una lógica dinámica. Y es así porque este logro no se obtiene en un único momento específico del tiempo sino que se deriva de la acción política en momentos políticos distintos en una suerte de acumulación de ganancias que finalmente se concretaron en la expedición de la ley. Por supuesto la 
agencia desarrollada por el Movice y otros organizaciones de derechos humanos fueron fundamentales en la generación del impacto y de ello hablaremos más adelante, sin embargo vale la pena ahora detenernos en algunos elementos externos a la acción del movimiento social.

De las pesquisas realizadas durante la investigación puede concluirse que el reconocimiento de las víctimas de Estado fue la acumulación de una serie de oportunidades políticas que se fueron cruzando y alimentando entre si y que eventualmente fueron leídas de esa forma por los actores en contienda que mediante su agencia las fueron ajustando a sus necesidades concretas. Es necesario entonces estudiar la variación de la Estructura de Oportunidades entre dos periodos presidenciales diferentes y sucesivos, -segundo periodo de Uribe y primer periodo de Santos-, que afectaron la toma de las decisiones en uno u otro momento y que finalmente sirvieron de escenario a la contienda y a sus consecuencias. Para ello es necesario separar la Estructura de oportunidades que rodearon estos dos periodos presidenciales, dado que es en los cambios que se presentan en estos dos momentos donde encontramos las fisuras por donde fue posible obtener logros para el movimiento social.

Si bien durante el segundo periodo de Uribe, como fue narrado previamente, se rechazaron categóricamente desde el ejecutivo las posibilidades de reconocimiento de los Crímenes de Estado y sus víctimas, en el legislativo, particularmente en el equipo de trabajo de Cristo, esta idea fue permeando el discurso hasta el punto que se convertiría en una de las banderas del primer proyecto de ley. La modificación de la redacción del artículo 3 en la que se decidió incluir los crímenes cometidos por agentes del Estado daría el puntal decisivo para la inclusión definitiva de las víctimas de Estado en la ley. ¿Cómo fue esto posible? En nuestro criterio tres elementos de la Estructura de Oportunidades Políticas nos pueden ayudar a explicarlo.

4.5.1.1. Inestabilidad de las Alineaciones Políticas 
Luego de la reelección, el segundo periodo de Uribe se mostraba como la consolidación de una forma de hacer y entender la política determinada por un pensamiento de derecha capaz de absorber las inmensas mayorías guerreristas del país, que veían en la confrontación armada la única salida posible a la guerra propuesta por las FARC-EP-EP. Sin embargo, lo que en apariencia se mostraba como una mayoría inquebrantable con un sólido respaldo popular, era visto con suspicacia por algunos sectores pertenecientes al mismo seno de las élites políticas del momento. Y no se trataba de aquellos que ejercían una oposición natural desde la izquierda en el Polo Democrático Alternativo, sino de un sector que en apariencia podría haber estado más alineado con el poder constituido.

Nos referimos a algunos líderes partidistas liberales clásicos que veían con desconfianza y poco agrado la permanencia en la Casa de Nariño del presidente Uribe y quienes preferían otro modelo de gobierno en la Presidencia de la República. Tal vez uno de los más representativos fue el mismo Senador Cristo, quién lentamente fue ganando consistencia en esta división, encontrando en el proyecto de ley de víctimas un magnífico argumento para desafiar al uribismo.

Allí confluyen dos aspectos importantes: El deseo de hacer oposición desde el Congreso al Ejecutivo y el interés de obtener logros concretos con el respaldo de una mayoría de congresistas, muchos de los cuales habían optado, tiempo atrás, por seguir órdenes irrestrictas de la Presidencia. Este ambiente le exigía al Senador Cristo buscar consensos entre los parlamentarios de tal forma que tuviera opciones de ganar batallas en su ejercicio de oposición política dentro del Congreso. Y fue en esa lucha que acudió a las distintas tendencias buscando introducir temáticas que sedujeran a unos y a otros mediante la adecuación del uso del lenguaje y la redacción de textos que permitieran los equilibrios necesarios para acunar los votos suficientes para que avanzara el proyecto de ley. Así recuerda Fátima Esparza el capítulo en el que la Unidad Técnica Legislativa opta por introducir el concepto de víctimas de agentes del Estado en el artículo 3. 
"A Cristo hay que reconocerle esto. Él siempre quiso que fuera de consenso, siempre quiso mantener eso. Para él hubiera sido quizás "fácil" volver a negociar para que el proyecto pasara moderando el artículo 3, pero él se compró en ese momento esa pelea de las víctimas de agentes del Estado en la búsqueda de que el proyecto fuera de consenso". (Entrevista 26).

Un consenso que se lo exigía el equilibrio de poderes en el legislativo donde la pelea era compleja y todos los votos contaban. Pero al tiempo que buscaba consensos y se esforzaba en crear alianzas con unos y otros, le era necesario generar diferencias políticas fundamentales con el Ministro Holguín, el Partido Conservador y en general el Uribismo, de tal manera que sus antiguos copartidarios, aliados ahora con el Presidente, comenzaran a identificar diferencias de fondo que los llevase a pensar en modificar sus recientes afectos políticos y volver al seno de su partido.

En últimas, lo que parece haber sucedido es que algunos líderes del partido liberal comenzaron a mostrar cansancio e incomodidad frente a una derecha uribista apoltronada en el poder y sin dar pistas de querer permitir el relevo al cual los partidos colombianos ya se encontraban acostumbrados. De esta forma, la oposición parecía ser el camino indicado para modificar las alineaciones que se habían creado desde 2002 y que dejaba por fuera del poder otras corrientes que se sentían con la legitimidad de suceder al Presidente. Incomodidades que finalmente se subsanaron en las siguientes elecciones cuando vino Juan Manuel Santos a relevar del cargo a Uribe, luego de sendas negociaciones con otros partidos, incluido el liberal.

Por supuesto este estado de cosas no era ignorado ni por la izquierda ni por las víctimas. Que Juan Fernando Cristo, un hombre liberal, víctima de la guerrilla y miembro de la élite colombiana durante varios lustros, fuese quien recogiera los postulados de las víctimas de crímenes de estado, no solo era una paradoja sino también un fuerte llamado de atención a las implicaciones de respaldar su oferta. 
Eduardo Carreño, abogado y miembro del Movice analiza las relaciones de su movimiento con el Congreso de la República en aquel momento:

"Con el partido liberal, específicamente con Piedad Córdoba, la relación fue muy fuerte y ella asumió un protagonismo muy importante en la defensa de los derechos de las víctimas. Con Wilson Borja, igual, pero en una escala menor. Con Alexander López, lo mismo, en una escala menor. En esas condiciones históricas quienes recogieron las aspiraciones de las víctimas y se apropiaron y las utilizaron para su beneficio personal fue Cristo y Rivera del partido liberal. Cuando estaban en el trámite de la ley de víctimas ellos fueron a hacer no sé cuántas reuniones en las regiones con el movimiento de víctimas ampliado a todas las víctimas. Nosotros en eso hemos sido claros, para nosotros el problema no es el movimiento nuestro, el problema es todas las víctimas, entonces pues inviten a todas las víctimas y que las víctimas opinen y que digan a ver cómo se recogen sus derechos, sus aspiraciones. Todo eso se hizo y el gran protagonista de la ley de víctimas es el Senador Cristo del partido liberal y el representante Rivera del partido liberal, no los compañeros de la oposición en el Congreso, ¡lamentablemente!” (Entrevista 23).

Se encontraban así las víctimas de estado en la encrucijada de apoyar los espacios creados para el debate de esta ley o generar estados de oposición calculada y directa. Finalmente ante esta división de las élites, las víctimas no optaron por ninguno de los dos extremos. Prefirieron navegar en la discusión apelando por momentos a sus principios más acérrimos quitándole respaldo a algunas propuestas mientras que en otros momentos se sentaban con la misma disciplina de los demás sectores de víctimas a construir iniciativas y participar juiciosamente de los escenarios planteados por los liberales para tal fin. Una estrategia más espontánea que planeada que a final de cuentas les rindió más frutos que costos políticos.

4.5.1.2. Multiplicidad de Centros de Poder independientes al interior 
La discusión por el reconocimiento de las víctimas de agentes de Estado en plena vigencia del segundo mandato de Uribe obedeció no solamente a las disputas entre las élites, fue también el resultado del trabajo realizado por las víctimas y las Cortes en el marco de un estado de derecho, que pese a la guerra, mantenía vigentes sus instituciones. La Sentencia T-025 de 2004 mediante la cual se declara el Estado de Cosas Inconstitucional había abierto la puerta para la reivindicación de los derechos de las víctimas de desplazamiento forzado y se comenzaba a entender integralmente los daños que la guerra había infringido a las mujeres, las comunidades étnicas y los niños y niñas, entre otros grupos poblacionales vulnerables. Las víctimas conocían sus derechos, buscaban los medios constitucionales para exigirlos y de forma menos tímida salían a las calles a reclamarlos y a demandar respuestas concretas del Estado.

También había sido expedida la ley 975 de 2005 -ley de Justicia y Paz-, mediante la cual se otorgaban prebendas a los grupos paramilitares que decidieran entrar en un proceso de desmovilización. Recordemos que fue precisamente la sanción de esta ley, el agravio que le dio paso al surgimiento del Movimiento de Víctimas de Crímenes de Estado, haciendo que las víctimas se aglutinaran alrededor de una sola voz contra el Estado para denunciar sus crímenes y reivindicar sus derechos.

Y fue precisamente en esta lucha que el Movimiento puso nuevamente a operar la multiplicidad de centros de poder mediante el debate constitucional que le hiciera a la norma frente a la Corte Constitucional y que diera como resultado la expedición de la sentencia C-370 de 2006. En esta sentencia, la Corte por primera vez introduce de forma clara y precisa, no solamente frenos a las licencias otorgadas a los paramilitares por el gobierno de Uribe, sino los argumentos técnicos y jurídicos para el reconocimiento de los derechos a la verdad, la justicia y la reparación integral. Se trató de un repertorio contencioso en lógica de pesos y contrapesos que limitó la intención política del ejecutivo de otorgar privilegios al paramilitarismo en el país. 
Pero la Corte Constitucional no fue la única que se activó en este sentido. La Corte Suprema de Justicia, reconocida en aquel momento por las diferencias con el Presidente Uribe y que determinó parte importante de las relaciones entre los poderes públicos, hizo su aporte decisivo a la hora de hacer la revisión de numerosos expedientes que se desprendieron de la aplicación de esta norma. Así lo recuerda Soraya Gutiérrez, abogada del Colectivo de abogados José Alvear Restrepo, miembro del Movice y quién hizo seguimiento cercano a varios de estos procesos:

"Yo creo que la Corte Constitucional a lo largo de la historia siempre se ha caracterizado por ser una Corte que ha tratado de ajustar todas las normas y las leyes de acuerdo a la Constitución y a los Tratados Internacionales de Derechos Humanos. La Corte Constitucional históricamente ha tenido una posición jurisprudencial de reconocimiento de derechos de las víctimas. Aunque siento que en este último tiempo se ha venido limitando (...). Ahora, la Corte Suprema de Justicia es distinta, es una Corte que le tocó asumir en segunda instancia procesos de justicia y paz y ahí entendió el tema de Crímenes de Estado, de graves violaciones a los Derechos Humanos, de todo lo que le implicó ese terrorismo de Estado a través del paramilitarismo. También estábamos en un contexto de todos los seguimientos que hubo hacia la Corte por parte del DAS; llegan una cantidad de casos de todo lo que ha implicado la criminalidad de estado en Colombia, la grave violación a los derechos humanos, y eso aunado a las investigaciones sobre el tema de la parapolítica, de cómo no fueron simplemente actores que cometieron crímenes sino que fueron estructuras apoyadas y financiadas por políticos y por actores económicos, pues llevó a que la Corte Supremas tuviera que asumir un papel protagónico al entender que eso era parte de un mismo engranaje de estructuras que cometieron crímenes. Entonces la Corte tuvo que tomar decisiones importantes en materia de derechos de las víctimas y en materia de verdad. En este momento la Corte Suprema de Justicia también es otra y las últimas decisiones en justicia y paz han sido muy limitadas" (Entrevista 17). 
Se convierte el poder judicial en la piedra en el zapato del uribismo, enfrentándose no solo directamente a éste mediante fallos judiciales, sino de paso, dando argumentos a la oposición en el Congreso para sostener su posición de incluir a las víctimas de agentes del estado en el proyecto de ley. Cada sentencia y cada afirmación de las máximas instancias del Poder judicial se convertían en una herramienta de trabajo invaluable a los propósitos de las víctimas y de los liberales en cabeza de Cristo y Rivera. Se hace entonces evidente que, pese a la aparente unanimidad que exteriorizaba el gobierno de Uribe, no solo algunos parlamentarios en el Congreso sino también el poder judicial tenían serias diferencias con un gobierno que parecía imbatible en las encuestas de opinión.

Por supuesto esta multiplicidad no se sostenía en la nada. Particularmente las Cortes hacían eco a lo que miles de víctimas venían denunciando ante ellas durante varios años, que originalmente resultó de un ejercicio espontáneo de la población desplazada y unos años después de un trabajo jurídico más coordinado entre las organizaciones defensoras de derechos humanos y del mismo Movice que ya había aprendido las ventajas del litigio estratégico y que disponía de la experticia de varias organizaciones legales comprometidas con su causa. Ana Jimena Bautista, encargada de hacer el seguimiento en el Congreso por el Movice para la discusión del primer proyecto de ley nos hace esta reflexión:

"Yo le doy mucho palo a la 1448, a mí la 1448 no me gusta, pero con todo y eso y tratando de precisar, yo sí creo que cuando uno estudia lo que es hoy la 1448, tiene uno que decir que es el resultado de muchas cosas. Ahora, yo diría: ¿del Movice directamente? no, definitivamente no. Por un lado tiene todos los antecedentes judiciales de la Corte constitucional que jugaron mucho en el debate, congresistas como Rivera lo sacaban cada dos minutos para poderse defender cuando estaba en la oposición. Ahora, la Corte tampoco empezó a hablar de la nada. ¿Cuándo la Corte empieza hablar de esto? cuando le empezaron a llenar de tutelas la Corte (...) Yo creo que uno tiene que hacer un reconocimiento de la labor de las víctimas en el país 
presentando tutelas para reclamar sus derechos. Muchas, en distintas partes y también haciendo tomas. Tomándose Acción Social, hubo muchas tomas que en realidad presionaron mucho a que hubiese pronunciamientos de la Corte más amplios y reconociendo diferentes derechos. El pronunciamiento más claro que tiene que ver con los derechos de las víctimas fue la C 370 de 2006, donde ya dicen los derechos de las víctimas son: verdad, justicia y reparación y explican cuál es el contenido de estos derechos, etc. Pero uno tiene que reconocer esa historia de que a la Corte no se le ocurrió de la nada, sino que hubo ahí un trabajo importante." (Entrevista 24).

Como lo evidencia la anterior narración, esta multiplicidad de centros de poder no comenzó a operar de forma automática o espontánea. Requirió que los contendores la reconocieran, aprendieran a estimularla y decidieran usarla dentro de la acción movilizadora para que esta rindiera frutos alrededor del objetivo en disputa.

A esta altura no era extraño que al Movice pertenecieran organizaciones jurídicas capaces de presentar demandas de gran complejidad, ni era descabellado que el Senador Cristo incorporara algunos de estos argumentos dentro de los debates en el Congreso para sumar apoyos de las diferentes corrientes; en cualquier caso, ambas partes, aunque con intereses independientes, estaban interesadas en que se reconociera la existencia de las víctimas del Estado.

4.5.1.3. Aliados Influyentes: las organizaciones defensoras de derechos humanos se comprometen

Un reconocimiento que no llegaría de forma espontánea por el parecer de un congresista, ni se derivaría del análisis jurídico que se hiciera en el Congreso para el reconocimiento de los derechos de las víctimas. Para ello fue necesaria la intervención de terceros que fungieron como aliados influyentes en una suerte de cadena causal que unieron las aspiraciones de las víctimas de Crímenes de Estado y la propuesta del Senador Cristo. 
En este caso, la inestabilidad de las alineaciones y la disponibilidad de aliados no eran dos caras de la misma moneda. Lejos de convertirse el mismo Cristo en el aliado influyente dentro de los alineamientos inestables que facilitaron la introducción del resultado, éste terminó siendo en un momento determinado el objetivo sobre el cual había que hacer un esfuerzo amplio de incidencia para modificar sus planteamientos y premisas. Fue entonces necesario recurrir a un eslabón más para convertir la acción de un Congresista poco beligerante, en un resultado positivo para un movimiento social con una marcada tendencia a la izquierda política.

Este trabajo recayó en las manos de algunas organizaciones no gubernamentales con amplia experiencia y reconocimiento en el país, quienes estuvieron atentas desde el primer momento al desarrollo de los debates en el Congreso convirtiéndose ellas mismos en los aliados influyentes para modificar las cargas a su favor en el Congreso. Ese estar atentos les permitió intervenir activamente y estar presentes en momentos importantes del proceso. Los resultados de este trabajo de incidencia se pueden ejemplificar en la participación de la Comisión Colombiana de Juristas en la inclusión en el artículo 3 de las víctimas de agentes del Estado. Se edificó de esta manera un puente entre las víctimas y los congresistas que posteriormente sería utilizado ampliamente para el reconocimiento de su existencia y la reivindicación de los derechos. Así lo plantea Fátima Esparza:

“Cuando nos llegó el texto del primer proyecto de ley vimos que el punto era víctimas. En ese momento dijimos: ¡listo! la tenemos clara, ¿dónde están las víctimas de estado?, pero no fue que al leer el articulado en ese momento dijéramos: oh si, según los principios de Naciones Unidas: la universalidad. No, era porque la voz de las víctimas se había hecho sentir durante todo el trámite de la ley 975, y iqué voz la que tuvieron ahí los del Movice! Entonces yo lo que siento es que fue una continuidad, nosotros en la CCJ vivimos la ley de víctimas como una continuidad del proceso de la 975 y en esa medida no era un argumento nuevo, no, el argumento ya se había planteado con ocasión de la demanda a la 975 ante la Corte 
Constitucional. Esta había sido una reivindicación fuertísima del movimiento, entonces nosotros como tenemos dentro del proyecto misional el hecho de que no hubiese discriminación, el hecho de que cualquier víctima de violaciones a derechos humanos debe ser respetada en sus derechos, todo ese entendimiento de quienes integramos la Comisión se traduce allí, se traduce en decir hay que hacer un llamado de atención de que lo que está pasando aquí, y era que estaban dejando por fuera a las víctimas más afectadas.

Pero eso no es una medallita que nosotros nos vamos a colgar porque a nosotros se nos ocurrió, sino porque el movimiento lo impuso. El hecho de que el Movice exista, plantee sus documentos, participe en los espacios de encuentro del movimiento de derechos humanos, sostenga reuniones con nosotros, que hayan organizaciones del Movice que hagan parte del movimiento de derechos humanos, que presenten casos, que nosotros representemos casos de Crímenes de Estado que hacen parte de la agenda de ellos, eso nos pone en un punto de encuentro y de diálogo, y hace que mantengamos un intercambio sobre la agenda. Eso quizás no es explícito y quizás no se recuerda pero está ahí, permea.” (Entrevista 26).

Se trataba de una relación de intercambio permanente entre las víctimas y las organizaciones no gubernamentales que facilitaban el traspaso de inquietudes y preocupaciones que permitió la creación de confianzas y la lectura compartida de ciertos eventos que hicieron posible que los unos hablasen por los otros en un momento determinado. Esta acción directa de estos aliados termina siendo determinante para que los hechos se desarrollaran de cierta manera, aunque, cabe decir, no exactamente de la forma en que el Movice lo hubiese querido.

Así las cosas, la inestabilidad de los alineamientos políticos, la multiplicidad de centros de poder y la presencia de unos aliados influyentes permitieron que durante el debate del primer proyecto de ley se incluyera en la redacción del artículo 3 a las 
víctimas de agentes del Estado y éste quedara apuntalado como una de las banderas principales del partido liberal en el resto del proceso de emergencia de la ley 1448.

Recordemos sin embargo que este logro quedó en el congelador cuando el presidente Uribe decidió echar abajo la ley durante el proceso de conciliación de cámara y Senado. Fue hasta el primer periodo del presidente Santos que revive como resultado de las negociaciones con los liberales. Y esto es así, por un cambio fundamental en la Estructura de Oportunidades Políticas que determinó la observación de otros elementos que influyeron en la toma de decisión del ejecutivo, ahora en otras manos.

\subsubsection{De la inestabilidad de Alineaciones Políticas al Cambio Político}

En un malabar político como pocos recuerdan en el país, quien tendría a su cargo la sucesión de las políticas uribistas optó por la creación de una agenda nueva que lo diferenciara de su antecesor y le permitiera generar un estilo de gobierno de otro tinte en lógica de Unidad Nacional. Este cambio de los alineamientos modificó el escenario al punto que lo que un par de años atrás era imposible en el panorama político nacional, se volviera ahora una causa defendible para la Presidencia de la República: el reconocimiento de la existencia de víctimas de Estado.

Estos realineamientos llegaron, como se describió previamente, por cuenta del desafío que el Senador Cristo y el Representante Rivera hicieran desde la bancada Liberal al Presidente Uribe y posteriormente mediante la negociación del partido liberal con el presidente Santos para integrar las mayorías que necesitaba para ganar gobernabilidad en el Congreso. Se trató de un logro escalonado protagonizado por las élites en el poder en el cual las víctimas parecieron tener poco margen de acción. Más aún, cambios en las alineaciones que el Movice considera poco reales y en donde los logros, a su juicio, se obtienen por otras vías de la Estructura de Oportunidades Políticas. Así lo plantea Alfonso Castillo, presidente de ANDAS, organización perteneciente al Movice: 
"Es que el cambio del discurso fue radical, este es un movimiento que no podemos perder de perspectiva, es que estamos hablando de un gobierno arrogante, prepotente, pendenciero y cambiamos radicalmente a un discurso conciliador, de buenos amigos, de arreglar los problemas, de facilitar cosas, de reconocer situaciones en el tema de derechos humanos. Todo esto, claro está, “discursivamente” (...) Cambió el estilo de gobernar, no cambió el trasfondo, no cambió nada, cambió el estilo.” (Entrevista 18).

Si bien como Ministro de Defensa del Presidente Uribe, Juan Manuel Santos al parecer nunca emitió una posición sobre el proyecto de ley que se hundió (Cristo, 2012, p. 103) no dejaría de ser paradójico que fuera el mismo fundador del partido de la $U$, partido que pretendía aglutinar las distintas fuerzas uribistas, quién decidiera años después ondear las banderas de las víctimas una vez llegó a la Presidencia. La explicación para ello, sin embargo, no hay que buscarla muy lejos. Desde muy temprano en la presidencia, Santos mostró un interés marcado por cambiar ciertos aspectos relevantes de la política colombiana, particularmente en lo que se refiere a la política económica internacional. Es así, que muchos de sus discursos y acciones fueron dirigidas a modificar la situación de Colombia en la región, que por causa de las continuas violaciones a los derechos humanos y su trato a los países vecinos estaba por aquella época, particularmente con Venezuela y con Ecuador, bastante deteriorada. Y es en ese contexto que el Movice encuentra una razón plausible para el viraje del ejecutivo en relación a este tema: la Presión Internacional

\subsubsection{Presión Internacional}

Dentro de la literatura sobre Oportunidades Políticas y la forma en que el contexto obstaculiza o facilita que los movimientos sociales se desarrollen plenamente al punto de lograr objetivos concretos en el escenario político, se ha planteado que la presión internacional puede en determinados casos llegar a jugar un papel crucial (McAdam et al., 1999, p. 63). Si bien no es el elemento más estudiado por los 
investigadores, siendo más común que se analicen los aspectos políticos internos de los países, el efecto que causa la situación internacional o el lugar en el que se encuentre el Estado en relación con el mundo, puede llegar a ser clave en la comprensión de la producción de resultados efectivos de los movimientos sociales.

De esta forma las relaciones internacionales que tejen el gobierno y/o los movimientos sociales ya sean de carácter económico, político, jurídico o social, y la visión y capacidad de influencia que ciertos países estratégicos u organismos multilaterales tengan sobre una nación, pueden determinar el curso de los acontecimientos al interior de una contienda política de alcance nacional. Este podría ser el caso para Colombia en el que, debido a la profundización de sus relaciones con actores internacionales, particularmente durante las últimas décadas del siglo XX, ha comenzado a ser frecuente buscar explicaciones de su acontecer más allá de las fronteras nacionales.

El caso acá estudiado es uno de los ejemplos más notables. En esa búsqueda por la comprensión del cambio de postura entre dos gobiernos que auguraban ser complementarios, se puede pasar por los análisis sobre: la modificación del estilo de gobierno, la diferencia de los temas sobre los cuales se pone énfasis y, de alguna forma, el ingreso de una nueva visión sobre cómo debía actuar el país para lograr mejores posiciones internacionales.

Desde muy temprano en el gobierno nacional, Santos inclinó la balanza hacia una postura de buena vecindad en la que se privilegió el mejoramiento de las relaciones económicas y comerciales con los países de la región, así como un cambio de imagen frente a una comunidad internacional interesada en la plena vigencia de los derechos humanos como premisa para un adecuado entendimiento internacional. Esta nueva forma de ver el tema puede ser una explicación plausible para comprender este viraje político en relación al reconocimiento de las víctimas de estado. Por lo menos así lo plantea el mismo Movice: 
"Yo creo que el Estado colombiano planifica las cosas mucho mejor de lo que nosotros podríamos pensar. Yo creo que Juan Manuel Santos es bastante inteligente y sagaz y se dio cuenta muy rápido que necesitaba mayor legitimidad internacional y que necesitaba recomponer lo que Uribe había hecho y lo necesitaba por su modelo económico. A mi juicio el modelo económico de Santos claramente está determinado por un nivel de apertura económica que permita inversiones principalmente en lo que él ha denominado locomotoras en su gobierno. Yo creo que Santos necesitaba una mayor confianza internacional para concretar un TLC con Estados Unidos, TLC con Europa, los TLC con México, Perú, Chile, la alianza del pacífico. Este tipo claramente quiere abrirse a un tema de TLCs y lo ha venido haciendo particularmente permitiendo que haya muchísima inversión en lo que Colombia puede hacer: minería, prestar el territorio para temas de agro combustibles y el tema de petróleo. A mi juicio Juan Manuel Santos tenía claro que tenía que recomponer cosas y que la mano dura de Uribe no le había servido mucho y que tenía los TLC represados con EEUU y Europa. ¿Y Como las reponía? Tenía que enviar mensajes contundentes en materia de derechos humanos. Yo creo que la ley de víctimas es eso, es una respuesta contundente de Juan Manuel Santos a esa exigencia que de inmediato comenzó a desbloquear todo. Comenzó a abrir puertas, eso y luego el proceso de paz (...) Yo creo que la ley fue una tremenda jugada política que nos ha dejado sin muchos aliados" (Entrevista 15).

Si bien la presión internacional en esta explicación toma exclusivamente la forma de interés económico como epicentro, también es cierto que las organizaciones sociales, de derechos humanos y el mismo Movimiento de Víctimas de Crímenes de Estado venían desde tiempo atrás desarrollando un trabajo de denuncia internacional frente a distintos organismos, especialmente de derechos humanos, que hacía que Colombia fuera permanentemente objeto de llamados de atención por parte de la comunidad internacional en relación a la necesidad de atender las miles de denuncias que circulaban en embajadas, parlamentos, movimientos internacionales y hasta en empresas transnacionales. De allí que el impulso dado 
por la sociedad civil podría haber sido también la fuente del cambio de postura que hacía que Colombia debiera modificar su comportamiento hacia las víctimas, comenzando por su reconocimiento.

En cualquier caso, y más allá de las intenciones personales, comerciales, políticas o éticas del gobierno del presidente Santos, la expedición de la ley de víctimas sí tuvo consecuencias en estos dos sentidos, hecho que nos permite afirmar que hubo una relación cercana entre la presión internacional y la expedición de esta norma. De un lado, se habilitaron los escenarios para mejorar las posibilidades de hacer negocios, y de otro lado, la intensidad de la presión por las violaciones a los derechos humanos también disminuyó. Esta situación es expuesta por el mismo Senador Cristo:

"Desde el principio del proceso, Santos entendió perfectamente el significado de la ley en el escenario internacional y el impacto positivo en la percepción del país y en su propia imagen. Para consolidar su liderazgo en el concierto latinoamericano y colocarse como interlocutor privilegiado con Estados Unidos y los países de la Unión Europea, no podía existir un mejor issue que el impulso a una ley de víctimas y restitución de tierras de esa magnitud en un país que en los últimos años se había dedicado a tramitar leyes de beneficios a los victimarios como la de Justicia y Paz, que suscitó tanta crítica y cuestionamiento en el exterior.” (Cristo, 2012, p. 141).

Significó esto un cambio de actitud importante de los demás países de la región y del mundo frente a Colombia mediante el impulso a los Tratados de Libre Comercio Económico y la disminución de apoyo a las organizaciones defensoras de los derechos humanos. Así lo expresan sus líderes:

"Creo que la reacción de la comunidad internacional fue inmediata, un respaldo total, un apoyo, de hecho tan inmediata que eso se tradujo en una falta de apoyo precisamente a las ONGs, a las organizaciones que antes hablábamos de las violaciones a los derechos humanos. La comunidad 
internacional lo que ha hecho es desde ese entonces decir que el país está cambiando, que el país ya no tiene esas problemáticas de derechos humanos que se tenían antes. La comunidad internacional ha respaldado el discurso del gobierno nacional." (Entrevista 18).

Así las cosas, la presión internacional, impulsada por el trabajo de denuncia realizado por las organizaciones defensoras de derechos humanos durante varios lustros, parecer haber dado resultados en gran parte por el interés de un nuevo gobierno que entendió que una de las mejores formas de mejorar su posición comercial en el concierto internacional era cambiar su imagen y la del país generando una política sólida de derechos humanos en el país.

En síntesis, fueron varios elementos de la estructura de oportunidades políticas que se involucraron en la habilitación de oportunidades para que fuese posible el reconocimiento de las Víctimas de Estado. Elementos que fueron reconocidos en su momento por los actores y que se fueron alterando en la sucesión de hechos durante la contienda y que determinaron que fuese posible un resultado en una serie de ganancias parciales. La inestabilidad en las alineaciones de las élites, la existencia de una multiplicidad de centros de poder pese a la prevalencia de un conflicto armado y la presencia de aliados influyentes en un primer momento, más un giro inesperado en la misma alineación de poderes y el ingreso al juego de la presión internacional como respuesta a un interés específico del nuevo mandatario en un segundo momento, se conjugaron finalmente para hacer posible el resultado aquí estudiado.

\subsubsection{Los Mecanismos y los Procesos}

Al tiempo que algunos elementos de la estructura de oportunidades políticas habilitaban las condiciones para avanzar en el desarrollo de los eventos que culminarían con la producción del hito acá analizado, los actores en contienda interpretaban el contexto y desarrollaban su lucha por la conquista de los derechos. Estructura y agencia se encontraban produciéndose varios eventos específicos en 
forma de mecanismos que allanarían el camino para el desarrollo de los hechos. A nuestro juicio fueron cuatro los mecanismos que actuaron durante el proceso de contienda y que permiten explicar de qué manera se produjo el resultado: Difusión, Correduría, Formación de coaliciones y Certificación.

\subsubsection{Difusión}

La difusión es una de las tareas por excelencia de los movimientos sociales al iniciar un episodio de contienda. Entendida esta como la capacidad de propagación de una acción contenciosa, de un tema problemático o un marco interpretativo de un lado al otro (Tilly \& Tarrow, 2007, p. 215), la difusión es una de las herramientas más potentes con las que cuenta los movimientos sociales para amplificar sus objetivos, transmitir sus demandas, conseguir adeptos y en general, movilizar a la ciudadanía para generar mayor presión a su oponente.

Esta difusión si bien suele aparecer al principio de una contienda, pude presentarse en diferentes momentos del episodio y por diferentes medios. En el caso estudiado, el tipo de difusión que vendría a operar para la producción del hito hizo su aparición aún antes de que ningún actor en contienda se plantease la idea de construir un estatuto para las víctimas. En realidad, es el resultado de todo el proceso de constitución del Movice y las primeras respuestas a los agravios que dieron paso a su levantamiento.

Mediante la acción colectiva y pública que se desarrolló desde el año 2004 y 2005, el Movice estaba inscribiendo en la memoria colectiva los reclamos esenciales de su lucha política. Reclamos que quedarían instaurados en diversos sujetos colectivos e individuales, nacionales e internacionales que pocos años después serían los encargados de apuntalar las acciones para la consecución del reconocimiento de las víctimas de estado. Una lectura que comparte Iván Cepeda:

"Sin que se hubiese se organizado el movimiento de víctimas de crímenes de estado en esa coyuntura que implicó el surgimiento de la ley de 
justicia y paz, sin ese proceso de organización de las víctimas de crímenes de estado no hubiera podido visibilizarse y tampoco lograr un cierto nivel de reconocimiento público y legislativo. El enfrentamiento con el proceso de desmovilización paramilitar, la movilización del 6 de marzo, la oposición a la extradición a los jefes paramilitares, el buscar en Estados Unidos las confesiones de esos jefes paramilitares, el haber denunciado los falsos positivos, el haber introducido en la discusión el tema de qué es la criminalidad de Estado, el haber reclamado los derechos de las víctimas del genocidio de la Unión Patriótica, sin esos elementos cuando se llegó a la discusión de la ley de víctimas, repito, hubiera sido difícil si no imposible, el reconocimiento de las víctimas de estado. Así que para sintetizar, el movimiento de víctimas ha sido el factor esencial en el reconocimiento de las víctimas de crímenes de estado" (Entrevista 25).

Basta hacer un recorrido por los primeros años de existencia del Movice para comprender que el reconocimiento de las víctimas de crímenes de estado y la reivindicación de los derechos a la verdad, la justicia y la reparación integral, fueron centro de sus planteamientos. La idea de poner el "apellido": de crímenes de estado, a su nombre: movimiento de víctimas, rompe los paradigmas clásicos con los que usualmente se venían organizando las víctimas independientemente del perpetrador. Acá lo que se hace es exponer en un factor identitario la suma de su lucha y dejar en evidencia la capacidad criminal de un Estado que hasta ese momento no había sido ampliamente cuestionado, o por lo menos, no de manera abierta y pública

Se trató de reivindicaciones que pudieron observarse en sus manifiestos y consignas y por el que se construyeron nuevos repertorios como las galerías de la memoria o las jornadas nacionales y regionales de movilización capaces de invocar en la imagen de la víctima y la palabra de sus familias, la imposibilidad de su desconocimiento. De allí que la afirmación de Iván Cepeda resulta comprensible en la medida en que fue precisamente la labor de este movimiento la que permitió que en pocos años no fuera extraño para el Congreso, para el ejecutivo y para la opinión 
pública en general, el debate sobre el reconocimiento de la existencia de víctimas de Estado y la realización de sus derechos.

Esta difusión, además de ambientar con anticipación el debate durante el primer y segundo proyecto, también facilitó que las organizaciones defensoras de los derechos humanos ajenas al movimiento se sintieran comprometidas con un esfuerzo conjunto para velar por estos derechos $\mathrm{y}$ hacer propias sus reivindicaciones. Recordemos cómo, para la Comisión Colombiana de Juristas, la idea de abogar por el reconocimiento de las víctimas de crímenes de Estado se sostenía no solamente en una visión institucional de los derechos, sino además en la proyección de un debate que ya se había consolidado en el ideario de los activistas y que había comenzado a construirse años antes mediante el levantamiento del Movice.

Esto explica que este mecanismo también fuera usado ampliamente por numerosas organizaciones sociales, defensoras de los derechos humanos y de víctimas quienes en diferentes momentos organizaron Foros, invitaron expertos, produjeron documentos, entablaron diálogos con organismos como Naciones Unidas y el Sistema Interamericano de Derechos Humanos, de donde recogieron los principales postulados inoculando el discurso de los derechos de las víctimas en todos los niveles y escenarios de la vida política y jurídica del país.

De esta forma, el movimiento logra ampliar los marcos cognitivos en los que se había movido el movimiento de derechos humanos hasta ese momento, permeando sus discursos y sus repertorios de acción colectiva. Se comprende entonces de qué manera fue posible atraer aliados de diferentes sectores a un propósito particular, en el que se privilegió los postulados de las víctimas de crímenes de Estado sobre otras discusiones también de gran calado parta las víctimas en general.

Este mecanismo además vino a operar durante todo el proceso contencioso, particularmente tras el llamado a las Audiencias convocadas por el Congreso de la República para debatir los proyectos de ley en la que un número amplio de 
organizaciones de víctimas de diferentes sectores y opinión política se reunieron para exponer sus planteamientos alrededor del proyecto en debate. Una vez el Movice conoce la existencia del proyecto de ley activa a todas sus organizaciones y víctimas para comenzar a dialogar sobre las ventajas y desventajas del proyecto anunciado. Ello hizo que en los diferentes territorios donde tienen presencia capítulos del Movice el tema se propagara con inusual rapidez y comenzaran las discusiones y la construcción de propuestas. Acciones que finalmente produjeron un movimiento importante de actores regionales pensando y creando apuestas alternativas de un marco normativo. Es claro que si bien el Movice no siente que estas acciones hayan sido un factor determinante en la elaboración del articulado final, si mantuvo la expectativa y sirvió como dispositivo importante de presión a los cabildantes y congresistas.

\subsubsection{Correduría}

El uso frecuente de intermediarios capaces de conectar actores que previamente no se conocen o entre quienes tienen conexiones muy débiles, resulta ampliamente favorecedor a los intereses de los movimientos sociales en contienda. Este mecanismo, conceptualizado por McAdam, Tarrow y Tilly (McAdam et al., 2005) y posteriormente perfeccionado por Tilly y Tarrow en 2007, resulta bastante apropiado para desenvolver los nudos de eventos que se atan durante una contienda y que resultan decisivos para comprender los resultados que se van obteniendo en el tiempo. En este caso, apelar al mecanismo de la correduría para explicar los conectores y los resultados durante el proceso de reconocimiento de las víctimas de crímenes de estado es también muy útil en la medida en que la relación acciónefecto no fue directa y de alguna forma, llegó a ser parcialmente contraria a los deseos originales de los activistas.

Encontramos dos momentos importantes en los que la correduría opera a favor del Movimiento. Siguiendo el cauce de los acontecimientos, luego de haberse generado un ambiente propicio para las discusiones políticas sobre la existencia de víctimas de estado mediante un lento pero certero proceso de difusión de su ideario, el 
movimiento contó desde muy temprano con actores que pusieron de inmediato sus apuestas más importantes ante el Congreso de la República.

Durante los primeros meses de debate la correduría operó entre el movimiento y la Unidad Técnica legislativa del Senador Cristo y la desarrolló la Comisión Colombiana de Juristas. Este mecanismo rinde sus frutos más importantes en el momento en que se concibe la idea de modificar la redacción del artículo 3 sobre definición de víctimas incluyendo las de agentes del Estado. A esta acción concreta, le siguió un arduo proceso de intercambio de mensajes y comunicaciones donde se transmitía lo que iba sucediendo en el Congreso durante los debates y las reuniones formales e informales que sostenían los congresistas y el gobierno, al movimiento y a las víctimas y se recogían los debates, documentos y posturas que iba produciendo el movimiento en su conjunto.

En poco tiempo numerosas organizaciones defensoras de derechos humanos, la mayoría activas de tiempo atrás en el movimiento de Derechos Humanos, empiezan a buscar interlocuciones entre el Gobierno, el Congreso y las víctimas, generándose múltiples canales de comunicación y de referencia para introducir temas y plantear problemáticas. De esta forma se amplía esta correduría a otros actores y organizaciones no gubernamentales que comenzaron a participar activamente de las discusiones por lo que resultó ser un trabajo en varios frentes y a varias manos.

Un par de años después, tras el cambio de Gobierno y la llegada al Congreso de un representante del Movice por el Partido Polo Democrático Alternativo, esta tarea también es asumida por el recién elegido Representante a la Cámara Iván cepeda, quién con su equipo legislativo sirvió de correaje entre los debates en el Congreso y los acuerdos a los que iban llegando los congresistas y el gobierno con las víctimas aglutinadas en el movimiento social. Si bien finalmente el Polo Democrático y particularmente Iván Cepeda votaron negativamente la ley, su actuación fue protagónica en la medida en que acercó a las bases regionales y locales del movimiento con los diferentes sucesos políticos que se iban dando en el legislativo y el ejecutivo. No en vano en varias ocasiones colaboró para desarrollar encuentros 
entre congresistas y víctimas, presentar propuestas alternativas de articulado y manifestar públicamente sus acuerdos y desacuerdos sobre la ley.

Es importante señalar que la elección de este nuevo representante a la Cámara, además de convertirse en un aliado del Movice en un escenario de poder y servir como intermediario entre este espacio y las víctimas de su movimiento, es a su vez un resultado de la movilización y la difusión del movimiento en todos sus años de existencia. La visibilidad de este suceso muestra la forma en que este movimiento ha ido sumando ganancias parciales en el ámbito político del país, sin que todavía hayan encontrado.

\subsubsection{Formación de Coaliciones}

Al tiempo que los corredores hacían su trabajo, las organizaciones de víctimas y otras organizaciones de presión comenzaron a aglutinarse y organizarse alrededor de la posibilidad de incidir en el Congreso de la República. Uno de los espacios más sobresalientes fue la plataforma de organizaciones llamada Mesa Nacional de Víctimas de Organizaciones sociales liderada por Viva la Ciudadanía, otra organización con gran ascendencia en el tema de víctimas en Colombia, en la que se reunieron diversas organizaciones y movimientos, incluido el Movice, para realizar una acción conjunta y coordinada.

Esta Mesa, entendida como una Formación de Coaliciones mediante la cual se creó una nueva coordinación de reclamos de varios actores existentes previamente pero distintos entre sí (Tilly \& Tarrow, 2007, p. 216) permitió mantener contacto con el Congreso y con la otra gran plataforma convocada por Fundación Social a la que solían acudir con bastante frecuencia los congresistas involucrados, permitiendo que los mensajes y las propuestas generadas por el Movice fueran transmitidas a los actores con decisión.

Durante los meses que duraron los debates en el Congreso este escenario sirvió además para reconocer las diferentes posturas que existían frente a los componentes 
de la ley, informarse y formarse sobre la forma en que se sucedían los trámites en el Congreso, perfeccionar las posturas políticas con elementos técnicos y jurídicos y visibilizar las principales preocupaciones de las víctimas que allí se aglutinaban. Permitió también armar un gran frente en la defensa del reconocimiento de las víctimas de crímenes de Estado y potenciar los mensajes frente a la importancia de que la ley incluyera la responsabilidad del Estado en la existencia del Conflicto armado y la generación de víctimas durante su permanencia.

En el marco de esta plataforma se haría seguimiento a todo el proceso de expedición de la ley y se cuestionaría con recurrencia el trabajo de los congresistas y del gobierno. Es así que en no pocas ocasiones la Mesa manifestó sus desacuerdos con amplios segmentos de los diferentes proyectos que se iban debatiendo, se escribieron documentos y se emitieron comunicados públicos exclamando con vehemencia las preocupaciones de las víctimas alrededor de varios de los temas, al punto de convertirse en uno de los espacios más críticos de la ley y sus impulsores. Sin embargo, resultó ser uno de los espacios más prolíferos en mensajes al Congreso y más interesados en cada uno de los debates que se iban dando allí.

\subsubsection{Certificación}

Mientras los esfuerzos en Colombia se desarrollaban al calor de los acontecimientos y la lectura de oportunidades y obstáculos, a nivel internacional los organismos de las Naciones Unidas, la Corte Interamericana de Derechos Humanos, las organizaciones internacionales de derechos humanos y múltiples misiones diplomáticas, hacían su propio trabajo. El correlato de la Presión Internacional ejercida desde afuera sobre el Gobierno Nacional fue la Certificación de numerosas entidades externas, no solo sobre la legitimidad y valía del movimiento, sino sobre todo de las denuncias y mensajes emitidos por este.

Entendida ésta como las señales de una autoridad externa sobre su disposición a reconocer y apoyar la existencia y las reivindicaciones de un actor político (Tilly \& Tarrow, 2007, p. 215), la Certificación resultó en este caso fundamental, de un lado 
para evitar mayor represión hacia el movimiento, y de otro lado, para enmarcar política y jurídicamente como válidas las reclamaciones del Movimiento.

Esta certificación fue promovida desde diversas fuentes y en distintos momentos; sin embargo una de las más importantes provino de las Naciones Unidas desde el mismo momento fundacional del Movice mediante la participación activa y directa durante el Segundo Encuentro de Víctimas del señor Michael Frühling, Director de la Oficina en Colombia del Alto Comisionado de Las Naciones Unidas para los Derechos Humanos. Esta intervención, en la que manifiesta con amplitud la posición de su oficina respecto al debate de la ley de "Justicia y Paz" y los derechos de las víctimas coincidiendo ampliamente en los argumentos e interpretaciones normativas realizadas por el Movice, plantea con claridad su posición y respaldo al Movimiento. Estas frases extraídas de su intervención así lo sugieren:

"La Alta Comisionada de las Naciones Unidas para los Derechos Humanos y su Oficina en Colombia han estado, están y estarán siempre al lado de las víctimas. Por ello, en cumplimiento de las funciones propias de su mandato han advertido reiteradamente, durante los últimos años, que los procesos de negociaciones para superar el conflicto armado interno deben siempre estar fundados en la verdad, la justicia y la reparación. Sin la verdad no puede haber justicia. Sin la justicia no puede haber reparación. Sin verdad, justicia y reparación son imposibles el establecimiento de la paz y el logro de la reconciliación nacional.” (Frühling, 2005).

Este posicionamiento, junto a otros tantos que se han producido en forma de certificación, devienen por supuesto de un trabajo amplio de cabildeo de las diferentes organizaciones de defensoras de derechos humanos quienes dedicaron numerosos esfuerzos y recursos en crear confianzas y trasmitir sus mensajes a los actores considerados relevantes en la contienda. Se trata de una lista larga de organizaciones e instituciones que lentamente fueron escuchando al Movimiento y uniéndose a su lucha. Nos cuenta uno de sus miembros: 
"En la comunidad internacional ha habido unos aliados muy importantes, están organizaciones de derechos humanos de Estados Unidos, un grupo de parlamentarios norteamericanos del Partido Demócrata que le han estado haciendo seguimiento y que han venido en ocasiones a hacer acompañamiento. Hay organizaciones en Europa, está Amnistía Internacional, está la Federación Internacional de Derechos Humanos la fidh, y Organizaciones nacionales de distintos países aquí en América Latina. Una organización que le ha hecho mucho acompañamiento y que ha hecho una retroalimentación, una actividad mutua, es la Asociación de madres de la Plaza de mayo y organizaciones de Juristas. Digamos que a nivel internacional se han establecido unas alianzas muy importantes que han acompañado al Movice y que lo han apoyado." (Entrevista 18).

Alianzas que se tradujeron en apoyos explícitos al Movimiento y a su causa de tal manera que lograron convertir la Certificación en una Presión Internacional lo suficientemente fuerte capaz de incidir en la toma de decisiones locales a su favor. De esta forma, aunque la certificación se dio en diferentes momentos, particularmente en la coyuntura del cambio de mandato presidencial entre Uribe y Santos ésta resultó clave. La nueva lectura del Ejecutivo entrante, en la que más allá de la guerra intestinal contra las FARC-EP, privilegió una agenda dirigida al mejoramiento de las relaciones internacionales y el fortalecimiento de la economía nacional, hizo que los mensajes internacionales tuvieran mayor eco en las decisiones nacionales y se reconociera la necesidad de aceptar la existencia y los derechos de las víctimas de crímenes de estado.

\subsubsection{A modo de conclusión}

La lucha por el reconocimiento de las víctimas de Estado comienza varias décadas atrás con uno de los proyectos más importantes que organizaciones de derechos humanos hayan emprendido en el País, el proyecto "Nunca Más". Con el tiempo esta iniciativa se iría transformando en un proceso de movilización y denuncia, más allá del ejercicio de memoria y registro de la barbarie del Estado contra sus 
ciudadanos, hasta convertirse en un movimiento social activo y beligerante. Sin embargo, fue el proceso de desmovilización de grupos paramilitares que emprendiera el gobierno de Uribe en su primer periodo presidencial, el tope de los agravios soportados por las víctimas y las organizaciones y el dispositivo que activó la contienda política.

Con el rechazo a lo que el movimiento comprendió como "refinamiento de las formas de impunidad" en el país, comenzó su contienda contra el Estado buscando el reconocimiento de la responsabilidad de éste en los crímenes cometidos y la realización de los derechos de las víctimas. Si bien el artículo 3 de la ley 1448 de 2011 no alcanza a recoger las aspiraciones completas del Movice, podría señalarse que ha sido uno de los logros más importantes que se han obtenido hasta el momento en la medida en que el Estado admite la existencia de estas víctimas y avanza en procesos de reparación. Por supuesto y como lo señalábamos en otro momento, se trata de un logro agridulce por cuanto este reconocimiento va de la mano de otra serie de desconocimientos y pocos avances en la lucha contra la impunidad, que hacen que los derechos de las víctimas de crímenes de Estado sigan siendo limitados y se mantenga un ambiente de rechazo a las actuales políticas de reparación.

Sin embargo, bien vale la pena indagar sobre los eventos que se involucraron en este momento de la historia y que facilitaron que el Estado debiera hacer este primer reconocimiento. Para ello y siguiendo la ruta explicativa propuesta por Tilly y Tarrow (2007), hemos hecho un análisis detallado de los actores que participaron de los hechos y reconstruimos la secuencia de eventos más inmediatos que se desarrollaron meses previos a la generación del impacto analizado.

Particularmente durante este estudio hemos hecho una descripción detallada del surgimiento del Movice, sus principales derroteros políticos, las interpretaciones que han hecho de la violencia en Colombia y el papel del Estado en la generación de víctimas. Aprendimos que el Movice se constituyó sobre fuertes sectores identitarios, muchos de ellos de izquierda, que venían de procesos previos de 
confrontación política con el Estado, otros más que habían hecho de la defensa de los derechos humanos su oficio principal y posteriormente, la forma en que fueron modificados por la llegada de las víctimas de base no organizadas ni politizadas. Describimos su forma de organización y los repertorios que implementaron durante su constitución y consolidación y cómo fueron lentamente ganando aliados en otros sectores de la oposición a nivel nacional y con organismos y agencias de cooperación a nivel internacional, quienes finalmente les dieron oxígeno necesario para continuar su tarea en la lucha contra la impunidad.

De la mano de la historia de este movimiento también hemos recorrido los diferentes momentos de la guerra que ha vivido Colombia y particularmente las fases de la violencia de Estado y sus principales secuelas. Revisamos los datos y las cifras sobre los crímenes de estado y las diferentes maniobras gubernamentales que se han desarrollado para perpetuar estos dispositivos de violencia y la impunidad de los funcionarios y agentes del Estado. Este examen nos permitió además recordar las diferentes políticas públicas sobre las cuales se ha sedimentado la posición de los gobiernos nacionales sobre este tema y la forma en que este Movimiento Social ha buscado su derrocamiento y logramos identificar los principales puntos críticos en relación a la negación de la existencia de los crímenes de Estado, particularmente en los dos gobiernos del Presidente Uribe, quién esgrimió en todo su mandato una línea dura de pensamiento y acción contra la oposición política.

Eventos que generaron repudio y rechazo en algunos sectores de la sociedad colombiana quienes buscaron en la creación de organizaciones y movimientos sociales para la defensa de los derechos humanos, los caminos para contrarrestar tales políticas. Esta tarea si bien rendía frutos importantes mediante la emisión de fallos de la Corte Interamericana condenando al Estado, o sentencias de las Altas Cortes nacionales ajustando a la constitución y al derecho muchas de estas medidas, aún no lograban la inclusión de las víctimas de estado en las políticas de atención y reparación que desde hacía algunos años se encontraban en vigor. 
Explicar de qué manera fue posible este avance requiere delimitar lo que a nuestro juicio fue la cadena de eventos previos a la producción del hito con el objeto de reconocer los actores, la Estructura de Oportunidades Políticas que entraron a jugar y los mecanismos que se desarrollaron durante la contienda. De allí que luego de la descripción densa del Movimiento y las condiciones políticas de su surgimiento, le dimos paso a recordar la forma en que surge la idea de un estatuto para las víctimas y las diferentes vicisitudes que se vivieron en su trámite.

De este estudio podemos concluir que si bien los eventos con los que comienza el proyecto de ley no se derivan directamente de una acción específica del Movice, si devienen de una proceso de largo aliento que este movimiento ha hecho en relación con la visibilizadad de la responsabilidad del Estado y la exigencia por la realización de los derechos de las víctimas a la verdad, la justicia y la reparación. Por tanto, entender por qué en el año 2007 un Senador, víctima de un grupo guerrillero, y una organización de víctimas, la mayoría también de la guerrilla, hace un Foro de Visibilización para señalar las falencias de la ley de Justicia y Paz en relación a sus derechos y que muy prontamente deban incluir en la iniciativa el reconocimiento de las víctimas de Estado, implica una valoración histórica de las luchas de las víctimas en general y de las de crímenes de estado en particular.

Luchas que después se reflejarían en los sucesivos debates que debió cursar el primer proyecto de ley propuesto por Cristo en el Senado y Rivera en la Cámara de Representantes, y que finalmente costarían la vida de la iniciativa. Pero sobre todo, que alimentaron las disputas sobre las comprensiones y los alcances de la norma mostrando con frecuencia sus ventajas y desventajas. Posturas, muchas de ellas antagónicas entre sí, que dejaron ver los mecanismos de disuasión y de concertación que entraron a jugar en el debate político, partidista e institucionalizado sobre el cual se desarrolló la contienda, y las formas en que el Movice logró penetrar sus demandas y exigencias, así como posicionar sus objetivos en relación a su inclusión como beneficiarios de la norma en discusión. Eventos que solo se explican mediante la combinación de una serie de factores que implicaron la acción sostenida de este actor en diferentes escenarios y por diferentes 
medios y la actuación de terceros con intereses, algunos más cercanos a los postulados del Movice y otros más lejanos.

Nos encontramos también con que fue necesario en 2010 un cambio profundo en el contexto político para que volviera a ser debatida la iniciativa legislativa en el Congreso y, tras un fuerte empujón del gobierno nacional, pudiera tener luz verde en un Parlamento del que hay que decir que se encontraba, en aquel momento, altamente cuestionado por parapolítica y en un proceso de reacomodamiento tras la llegada de una nueva élite luego de un gobierno de ocho años en el poder.

Mezcla de situaciones de coyuntura, de estructura y de acción que determinaron un resultado complejo, heterogéneo y con mayores satisfacciones para unos sectores que para otros. En cualquier caso, vale la pena revisar algunos aprendizajes en relación a la forma en que operó la Estructura de Oportunidades y los mecanismos en este caso. En primer lugar es interesante plantear cómo, si bien la inestabilidad de las élites es una fisura invaluable para penetrar en las estructuras del poder, y eventualmente puede ser la mejor manera de conseguir resultados para un movimiento que carece de recursos, esta inestabilidad debe ser identificada y aprovechada en el momento correcto. Es así que fue posible incluir a las víctimas del estado en la redacción del articulado cuando un Senador en medio de un fuerte debate partidista se las juega por buscar consensos entre los demás actores en el escenario. Un “descuido" bienvenido por los proponentes que encuentran por este medio el vehículo para ampliar los consensos y mejorar su posición en la lucha que se había establecido con el gobierno central.

Pero además una inestabilidad que pronto se convirtió en un cambio en las élites y que determinó completamente el camino que siguió la iniciativa. Se hizo observable en este caso el destino que puede seguir un objetivo de un movimiento social una vez este se instala en uno de los actores con poder, convirtiéndose en un objeto intercambiable en medio de los pactos de las élites en el gobierno con las consecuentes alteraciones que esto puede acarrear en el resultado querido. 
También pudimos aprender que los aliados se van constituyendo en medio de las diferentes contiendas y que no pasa necesariamente por la construcción de acuerdos, pactos o convenios, sino que pueden ser producto de las confianzas establecidas en luchas anteriores, aún si ellas han sido perdidas. Pero además, que el mismo movimiento en su cauce político puede generar nuevos aliados en el poder durante la contienda o aún, convertir a sus propios protagonistas en actores dentro de los escenarios de poder que facilitan la propagación de su ideario. En este caso en particular, pudimos ver como Iván Cepeda, fundador del Movice, en medio de la contienda es elegido como miembro del Congreso y desde allí continúa su disputa contra el Estado por los derechos de las víctimas de crímenes de Estado. Hecho que nos recuerda la pregunta ya conocida de si con el tiempo los partidos políticos darán paso a los movimientos sociales para que se representen así mismo en este tipo de escenarios.

La multiplicidad de centros de poder a su vez nos demuestra una vez más el poder que detentan las instituciones en las contiendas propuestas por los movimientos sociales cuando existe un estado de derecho arraigado. El papel crucial que habían jugado las Altas Cortes apenas años antes que comenzaran los cambios constitucionales que predecían la afectación de los derechos de los ciudadanos, fue suficiente para asumir la embestida a la que fueron sometidas en los años uribistas, pero sobre todo, para proteger a las víctimas que encontraron allí el único medio de defensa a su disposición para librar las batallas con el Estado. Unas Cortes que hoy han cambiado en su composición y en su visión de los derechos pero que quedan en la historia reciente del país, como referente principal de la defensa de los derechos.

A esta estructura de oportunidades, es necesario sumar el rol protagónico que en este caso jugaron los actores internacionales. Y en este caso, no solo aquellos sensibilizados por la continua violación a los derechos humanos en el país sino también aquellos con intereses económicos, que presionaron directamente al gobierno nacional para que diera un viraje certero al tratamiento de esta problemática. Todos estos, elementos que no hubiesen sido útiles si el movimiento 
no agenciara diversas acciones que pueden ser observadas en los mecanismos que entraron a operar.

De otro lado la correduría, la formación de coaliciones y la Certificación mostraron su poder en la facilitación de los procesos de incidencia que suministraron la producción del hito. En primer lugar los aliados influyentes operaron como corredores y generaron los espacios de comunicación entre las víctimas y los congresistas donde se permitió que fluyera la información, generándose un ambiente de debate y de intercambio de opiniones y propuestas.

En segundo lugar la capacidad de formación de coaliciones de las organizaciones, le permitió al Movice participar de un bloque amplio de opinión en la que sus objetivos fueron recogidos dándole mayor capacidad de maniobra y de incidencia en un contexto con múltiples intereses y actores diferentes. Plataformas de trabajo que se convirtieron en un referente importante del gobierno y del Congreso y con quién en no pocos momentos se trató de llegar a acuerdos sin mucho resultado. Sin embargo, esta postura al extremo, si sirvió para jalonar temas que finalmente se convirtieron en ganancias sustanciales en la ley, incluyendo el reconocimiento de las víctimas de Estado.

En tercer lugar, la Certificación que acompañó al movimiento en todo su proceso y que sirvió de factor determinante a la hora de modificarse la EOP mediante el cambio de mandato presidencial. La intención del Ejecutivo de mejorar sus relaciones internacionales y el conocimiento previo del respaldo de numerosos organismos a la apuesta por el reconocimiento de las víctimas de estado, inclinaron la balanza a favor del Movice en un contexto en el que éste tenía poca capacidad de maniobra directa en la contienda.

Por último, es necesario resaltar el papel protagónico que jugó el mecanismo de la Difusión durante todo el tiempo que duró el episodio de contienda. El trabajo que hizo el Movice desde su nacimiento mediante los procesos de sensibilización, formación, visibilización y denuncia; las demandas constitucionales; los debates 
por la Ley de Justicia y Paz; los plantones y toda una suerte de repertorios utilizados ampliamente por el movimiento durante sus años de existencia, permitió que se instalara en la opinión pública, en la arena política y en el concierto internacional, la pregunta por la impunidad y los crímenes de Estado. Esta difusión, que se hizo a diferentes niveles y en muy variados escenarios resultó ser el dispositivo estratégico para la consecución del resultado. Así las cosas, a nuestro juicio fueron necesarios el relacionamiento de 5 elementos de la Estructura de oportunidades políticas y 4 mecanismos para que se produjera el reconocimiento de las víctimas de estado tal y como lo conocemos actualmente.

Ilustración 8. Modelo de explicación del Hito en el Episodio de Contienda

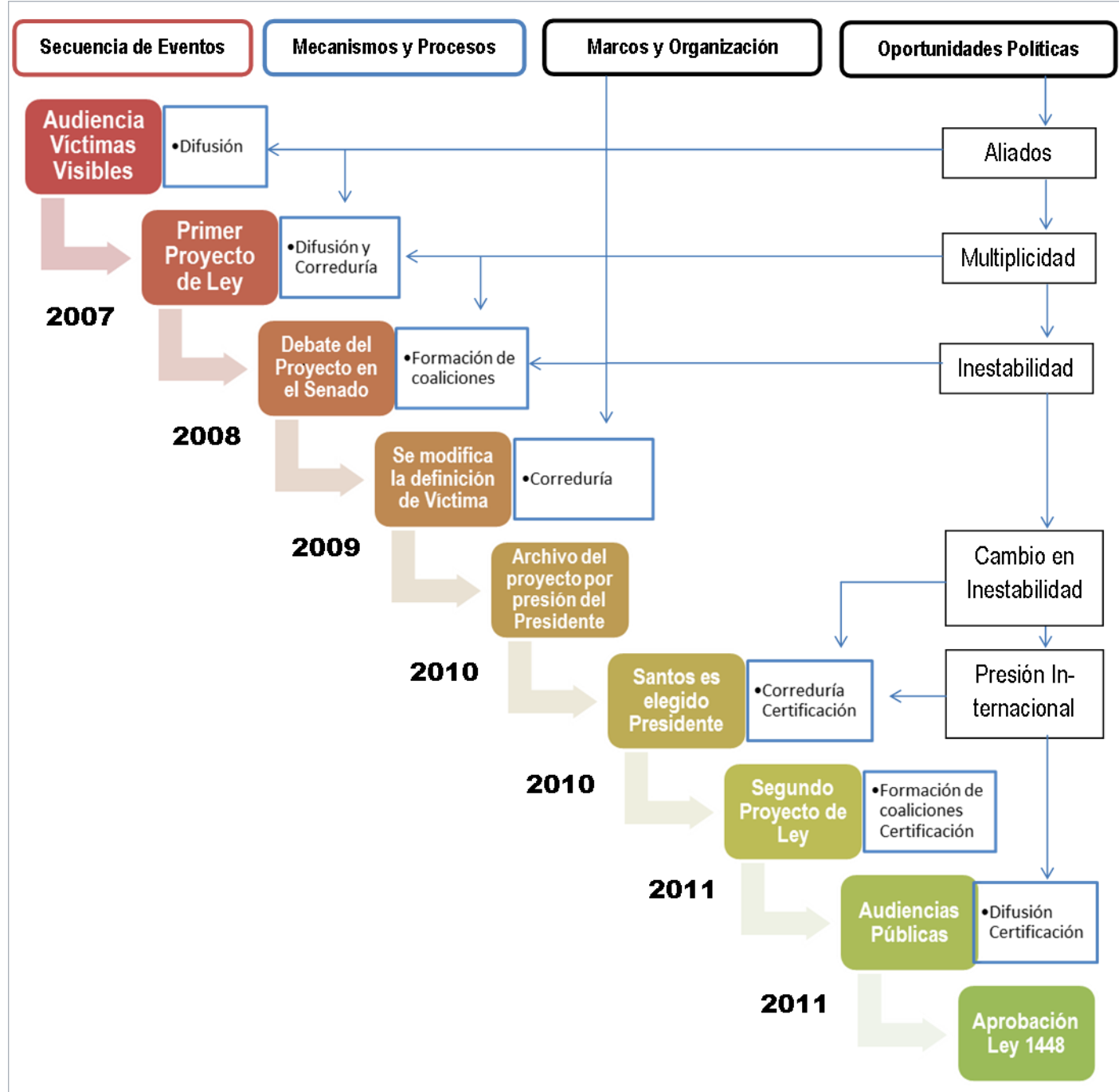

Fuente: Elaboración Propia 


\section{Conclusiones Comparadas y Perspectivas de Investigación}

Podría decirse que en la historia reciente del país, ni los partidos políticos de izquierda ni los movimientos de inconformes, han tenido la visibilidad ni el poder suficiente para imponer la agenda política en Colombia. Si bien durante los últimos años los partidos de izquierda, Polo Democrático Alternativo y Progresistas, se han posicionado en la Alcaldía de Bogotá, sus fuerzas políticas y electorales no les han alcanzado para hacer de este poder algo nacional. Tampoco la promesa revolucionaria que hicieran las guerrillas desde mitad del siglo pasado se llegaron a cumplir. La apuesta militar de la insurgencia colombiana llegó a un punto de no resolución en el que no se pierde la guerra contra el Estado pero tampoco parecen tener las fuerzas suficientes para ganarla. En este contexto, pareciera que los planteamientos liberales y de derecha, incluidos sus aparatos, fueran los llamados a compartirse el poder y/o distribuírselo sempiternamente mediante alternaciones sucesivas, no sin interesantes sobresaltos cargados de los devenires de la guerra, la corrupción, las economías y las presiones internacionales.

Sin embargo en este escenario, donde "parece que todo cambia para que nada cambie", de manera lenta pero progresiva los movimientos sociales se han venido instalando en la arena política local y nacional adquiriendo de manera paulatina la experiencia y conocimientos suficientes para comenzar a desarrollar episodios de contienda contra el Estado Nacional. Se trata de movimientos que, aunque tienen puntos de partida revolucionarios en sus visiones del mundo, han optado por desarrollar una contienda desde la legalidad, menos disruptiva, más tranquila y menos ambiciosa políticamente que la oposición armada más radical.

Por supuesto una mirada desprevenida podría afirmar que estos movimientos no parecieran tener mayor eco en la toma de decisiones políticas de trascendencia. Aún, muchos de sus miembros suelen considerar que sus esfuerzos no desembocan en cambios, que los objetivos siguen estando lejos de ser alcanzados y que la represión y la guerra han impedido un mejor posicionamiento de sus organizaciones. 
Sin embargo, este trabajo pudo mostrarnos que tal debilidad no es del todo cierta. En efecto los movimientos sociales tienen un papel importante y sus acciones pueden llegar a afectar el curso de la acción política y de las decisiones sobre política pública en el país. Se trata de un rol significativo en la medida en que han logrado incorporar parte de sus demandas en las decisiones del Estado, y aunque estas inclusiones se relacionan con un número amplio de factores externos, implican también la agencia de estos movimientos. De allí que consideremos que nuestra hipótesis de partida se confirma.

Recordemos que en ella afirmábamos que: La toma de decisiones sobre politicas públicas es un proceso complejo en el que intervienen mecanismos que van configurando cadenas causales de eventos, las cuales pueden llegar a ser influidas, entre otros factores, por las acciones y las interacciones que los movimientos sociales como actores políticos generan en sus procesos de contienda con otros actores, introduciendo y transformando marcos de interpretación, creando y apropiando estructuras de movilización y atribuyendo y generando oportunidades o amenazas políticas.

Con este estudio fue posible evidenciar que estos movimientos sociales poco a poco han logrado colarse en los más importantes espacios públicos y políticos y lentamente han empezado a permear a los tomadores de decisión; y si bien los cambios de mentalidad y las modificaciones estructurales que desean, aún se encuentran bastante lejos de ser abordados, parte importante de sus mensajes y objetivos han encontrado receptores influyentes que van recogiendo, apropiando y desarrollando sus mensajes.

Esta primera constatación nos hace también un llamado para abordar nuevas formas de estudiar y entender el trabajo de las organizaciones sociales y de base y comprender si los movimientos sociales han tenido logros políticos relevantes y si es así, razonar sobre cómo se produjeron y qué elementos intervinieron para su 
desarrollo, de tal suerte que sea posible identificar, en la experiencia de estos eventos, aprendizajes para la academia y los movimientos sociales.

En este orden de ideas nos parece útil cerrar esta investigación haciendo un ejercicio de comparación entre los resultados estudiados producidos por los movimientos que escogimos para analizar. Con ello esperamos identificar las principales conclusiones que surgieron de la investigación, señalar su utilidad y avizorar nuevos caminos de investigación para aquellos interesados en la materia.

\subsection{Análisis Comparativo}

En las ciencias sociales, incluida la ciencia política, los diferentes enfoques teóricos y metodológicos han generado dos corrientes principales para avanzar en investigaciones comparadas. El método de los sistemas más diferentes y el método de los sistemas más similares. En el primero se pretende, a partir del estudio de numerosos casos, evidenciar todas las variaciones posibles dentro de un conjunto específico. Se trata casi siempre de estudios cuantitativos que tienen por objeto desentrañar un conocimiento más general y abarcador de las preguntas de investigación. De otro lado, el sistema de casos más similares pretende a partir del estudio de dos o algunos pocos casos, aumentar las posibilidades de comparación controlando sus variaciones y haciendo uso de métodos más exhaustivos en el conocimiento de los fenómenos mediante la etnografía y otras técnicas cualitativas (McAdam et al., 2005, p. 88).

Si bien muchos trabajos académicos sobre la movilización se han concentrado en hacer estudios de caso, estos métodos comparados han sido también muy útiles para analizar movimientos sociales o aún, acciones colectivas de gran dimensión como los procesos revolucionarios, los nacionalismos y la democratización. Este es el caso de los autores de la Dinámica de la Contienda Política, libro que nos ha servido de referencia en buena parte de esta investigación, quienes optaron por la estrategia de comparación por parejas de casos muy diferentes para identificar mecanismos o 
procesos similares en contextos ampliamente divergentes (McAdam et al., 2005, p. 90).

Sin embargo nosotros, que no pretendemos por esta vía hacer inferencias causales sino más bien sacar en limpio los hallazgos obtenidos durante la investigación, nos inclinamos por la manera más clásica de hacer la comparación entre casos muy similares con bastantes variables comunes que permanecen constantes a lo largo de los episodios de contienda pero con resultados distintos (Pérez Liñán, 2008); no por su ocurrencia o por la falta de ella sino por la forma y estructuración de cada uno de estos resultados. Esperamos con ello poder identificar en los elementos expuestos, diferencias significativas que nos permitan decir algo nuevo y sugerente de lo que ya hemos expuesto a lo largo de este trabajo sobre el estudio de caso de dos movimientos sociales.

Para ello vamos a hacer uso de la síntesis de los elementos principales de la escuela clásica y la escuela dinámica como posibles ejes de comparación mediante el contraste de los procesos enmarcadores, las estructuras de movilización y los repertorios de acción colectiva en razón de los movimientos sociales estudiados, y de la estructura de oportunidades políticas y los mecanismos, en referencia a los hitos estudiados planteados acá como resultados positivos en políticas públicas.

Es necesario insistir que con este ejercicio comparativo no se pretenden probar hipótesis generales del comportamiento y resultados de los movimientos sociales, ni siquiera en un mismo ambiente o igual periodo histórico; tampoco intentamos plantear posibles caminos seguros que deban recorrer los movimientos sociales para la producción de hitos o resultados positivos. Se trata más bien de identificar elementos similares y diferentes que intervinieron en episodios de contienda paralelos desplegados en Colombia por dos movimientos sociales distintos pero contemporáneos, que se encontraron con obstáculos y oportunidades similares, que desarrollaron sus contiendas de formas diferentes y obtuvieron éxitos parciales por vías diversas dentro del sistema político contemporáneo colombiano. 
El objetivo en este acápite conclusivo es hacer uso de la comparación para saber qué tienen de parecido o de distinto estos dos casos sin que pretendamos decir que los elementos analizados son variables independientes necesarias y/o suficientes o elementos causales del resultado. Recordemos que esta tarea más bien se la hemos asignado a la identificación de los mecanismos y elementos de la EOP que pudieron intervenir en la producción de los hitos y que pueden o no repetirse en diferentes configuraciones en otros casos de contienda.

En este punto nos acercamos nuevamente a los autores de la Dinámica de la Contienda que tienen como objetivo identificar la presencia de mecanismos y procesos en ambientes diferentes, aunque en nuestro caso la pretensión es verificar que tan comunes o diferentes son los elementos estudiados en contextos similares con resultados positivos pero diversos. Para ello haremos un contraste entre los dos movimientos sociales en relación a los elementos combinados de los dos marcos teóricos y metodológicos sobre los que se basó el estudio de los casos, haciendo énfasis en 5 elementos específicos: (a) Episodios y condiciones iniciales, (b) Procesos Enmarcadores (c) Estructuras de Movilización; (d) Repertorios de Acción; (e) Estructura de Oportunidades Políticas: (f) Mecanismos y (g) Resultados

\subsubsection{Cuadro Comparativo}

\begin{tabular}{|l|l|l|}
\hline & $\begin{array}{l}\text { RUTA PACÍFICA DE LAS } \\
\text { MUJERES }\end{array}$ & $\begin{array}{l}\text { MOVIMIENTO DE } \\
\text { VÍCTIMAS DE CRÍMENES } \\
\text { DE ESTADO }\end{array}$ \\
\hline $\begin{array}{l}\text { Episodios y } \\
\text { condiciones } \\
\text { iniciales }\end{array}$ & $\begin{array}{l}\text { Surge en el año 95 con la } \\
\text { primera marcha a Mutatá. }\end{array}$ & $\begin{array}{l}\text { Surge en el año 2004 con el } \\
\text { proceso de desmovilización de } \\
\text { los grupos paramilitares }\end{array}$ \\
$\begin{array}{l}\text { Parte del no reconocimiento } \\
\text { de los daños diferenciados a } \\
\text { las mujeres en el conflicto } \\
\text { armado. }\end{array}$ & $\begin{array}{l}\text { Parte del no reconocimiento de } \\
\text { los derechos a la verdad, la } \\
\text { justicia y la reparación integral } \\
\text { de las víctimas de crímenes de } \\
\text { comienza en 2005 con el } \\
\text { proceso de formación de una } \\
\text { organización miembro de la la } \\
\text { Ruta a mujeres víctimas de } \\
\text { desplazamiento forzado y y cadena causal inmediata }\end{array}$ & $\begin{array}{l}\text { Estado. } \\
\text { comienza en 2007 con la } \\
\text { activación del Interés del } \\
\text { Senador de la República Juan }\end{array}$ \\
\hline
\end{tabular}




\begin{tabular}{|c|c|c|}
\hline & $\begin{array}{l}\text { termina en } 2008 \text { mediante la } \\
\text { expedición del Auto } 092 \text { de } \\
2008 \text {. }\end{array}$ & $\begin{array}{l}\text { Fernando Cristo por parte de la } \\
\text { organización de víctimas de la } \\
\text { guerrilla "Víctimas visibles" } \\
\text { para expedir una ley para las } \\
\text { víctimas y termina en } 2011 \text { con la } \\
\text { expedición de la ley } 1448 \text { de } \\
2011 \text {. }\end{array}$ \\
\hline $\begin{array}{l}\text { Procesos } \\
\text { Enmarcadore } \\
\mathrm{S}\end{array}$ & $\begin{array}{l}\text { Agravios: } \\
\text { experimentadas política y } \\
\text { académicamente ven en la } \\
\text { situación de Urabá de } \\
\text { mediados de los } 90 \text { un } \\
\text { agravio demasiado alto para } \\
\text { no hacer nada. } \\
\text { Objetivos: Buscar una salida } \\
\text { negociada al conflicto } \\
\text { armado como respuesta a la } \\
\text { barbarie contra las mujeres y } \\
\text { el reconocimiento del efecto } \\
\text { diferenciado de la violencia } \\
\text { hacia ellas en el marco del } \\
\text { conflicto armado } \\
\text { Uso frecuente de } \\
\text { simbolismos } \\
\text { comunicarse, transmitir } \\
\text { ideas, hacer la contienda y } \\
\text { ofrecer sororidad. }\end{array}$ & 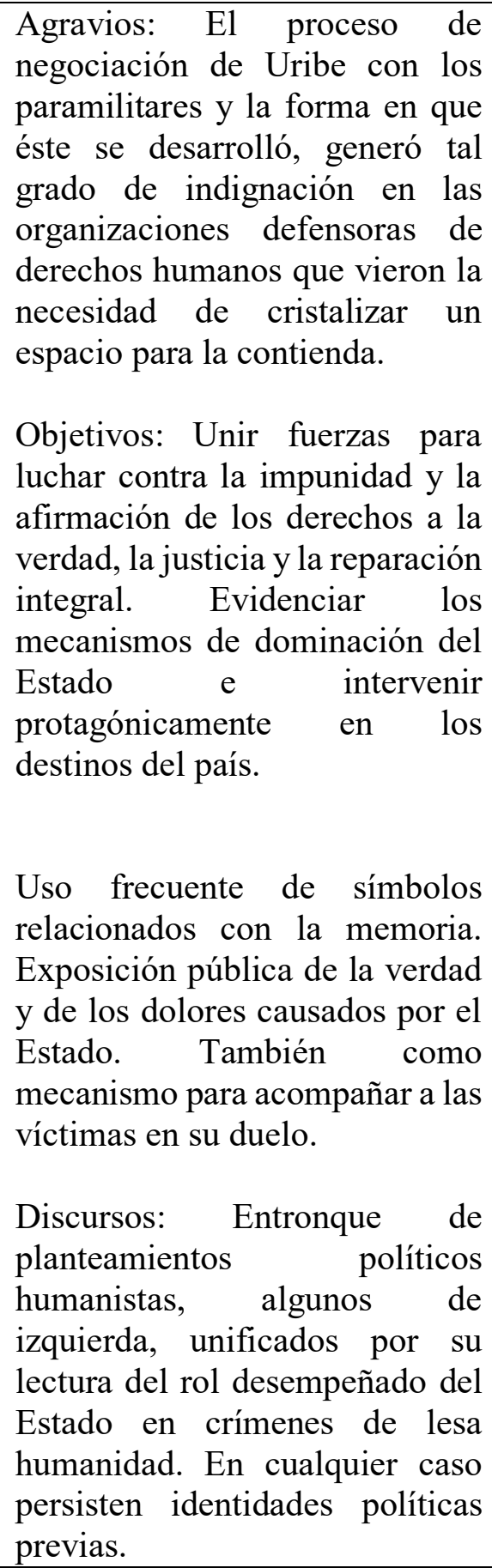 \\
\hline $\begin{array}{l}\text { Estructuras } \\
\text { de } \\
\text { Movilización }\end{array}$ & $\begin{array}{l}\text { Organización } \\
\text { Estructura conformada por } \\
\text { organizaciones de mujeres }\end{array}$ & \begin{tabular}{llll}
\multicolumn{3}{l}{ Organización interna: Estructura } \\
conformada por víctimas \\
crímenes de & estado & y
\end{tabular} \\
\hline
\end{tabular}




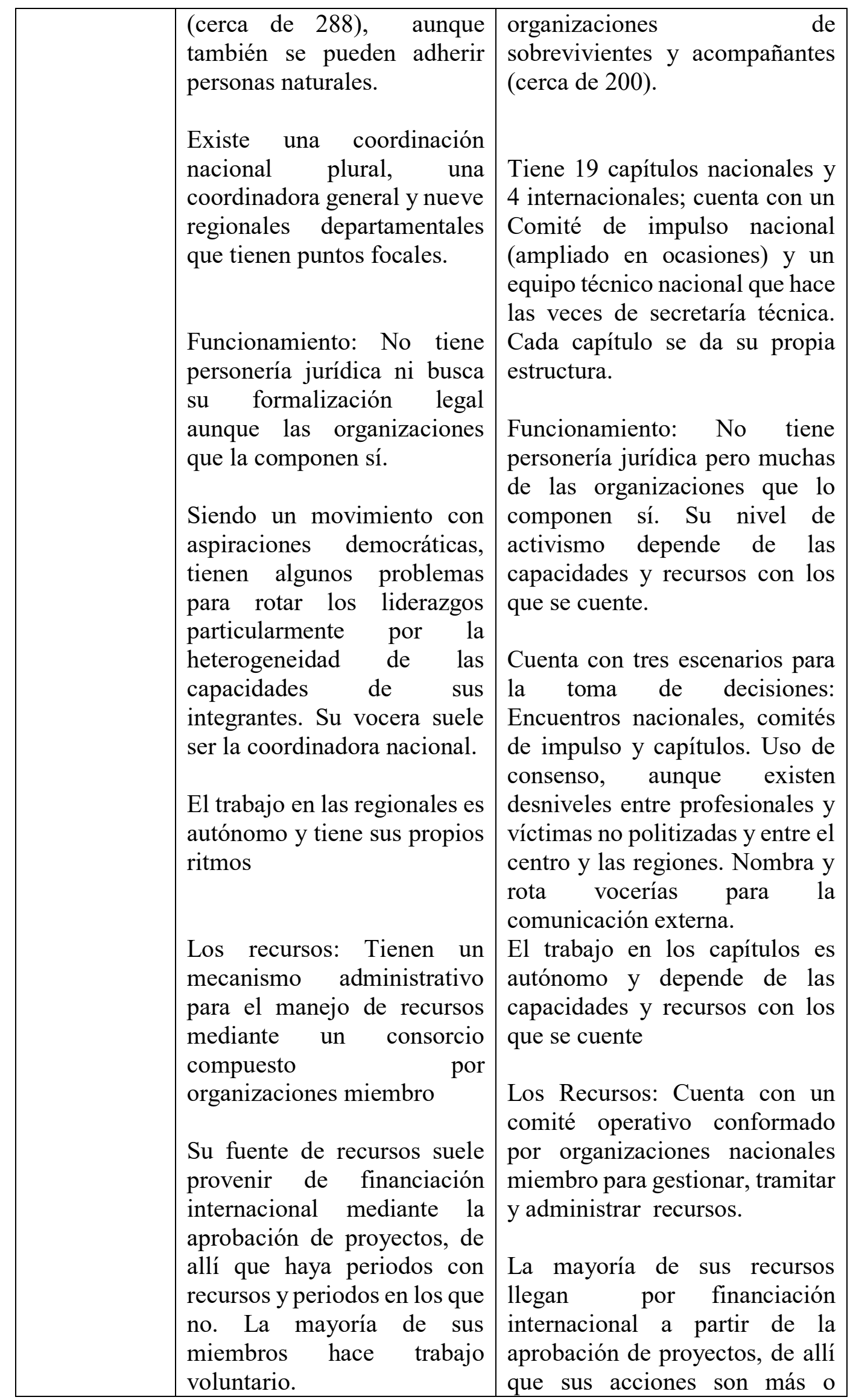




\begin{tabular}{|c|c|c|}
\hline & $\begin{array}{l}\text { Redes y alianzas: Este } \\
\text { movimiento suele trabajar en } \\
\text { colaboración con otros de } \\
\text { manera frecuente y a todos } \\
\text { los niveles }\end{array}$ & $\begin{array}{l}\text { menos potentes dependiendo la } \\
\text { cantidad de recursos con los que } \\
\text { se cuenten. La mayoría de sus } \\
\text { miembros hace trabajo } \\
\text { voluntario. } \\
\text { Redes y alianzas: No hay una } \\
\text { estrategia comprehensiva para la } \\
\text { participación en plataformas } \\
\text { nacionales o internacionales } \\
\text { pero sí se busca el trabajo en } \\
\text { alianza con otras organizaciones. } \\
\text { No hace parte de redes } \\
\text { internacionales }\end{array}$ \\
\hline $\begin{array}{l}\text { Repertorios } \\
\text { de Acción }\end{array}$ & $\begin{array}{l}\text { Movilizaciones } r \text { masivas } \\
\text { callejeras: caravanas } \\
\text { interdepartamentales; Uso de } \\
\text { Rituales y despliegues } \\
\text { simbólicos; } \\
\text { formativos: charlas, talleres, } \\
\text { encuentros, Foros, plantones; } \\
\text { Elaboración de documentos, } \\
\text { investigaciones, folletos, } \\
\text { revistas; Cabildeo y lobby } \\
\text { nacional e internacional; } \\
\text { Acompañamiento a mujeres; } \\
\text { Comunicaciones: página } \\
\text { web, redes sociales, revistas, } \\
\text { publicaciones } \\
\text { Generalidades: } \\
\text { Es un repertorio más } \\
\text { convencional y pacífico que } \\
\text { transgresivo. Llega a ser } \\
\text { disruptivo porque reta a sus } \\
\text { oponentes con su presencia } \\
\text { masiva en territorios de } \\
\text { guerra pero no genera } \\
\text { enfrentamientos. } \\
\text { No se presentan encuentros } \\
\text { violentos físicos con los } \\
\text { oponentes pero si hay grados } \\
\text { de represión mediante } \\
\text { amenazas y victimizaciones. }\end{array}$ & $\begin{array}{l}\text { Acciones de memoria: } \\
\text { audiencias ciudadanas, galerías } \\
\text { de la memoria, ritos de duelo; } \\
\text { Acciones jurídicas: litigio } \\
\text { estratégico, acciones de } \\
\text { inconstitucionalidad, demandas } \\
\text { contra el Estado, etc; } \\
\text { combinación de la acción } \\
\text { jurídica con la movilización } \\
\text { popular; Formación política y en } \\
\text { derechos: capacitaciones, } \\
\text { talleres; Incidencia política y } \\
\text { pública: cabildeo, lobby, } \\
\text { informes, comunicados; } \\
\text { Acompañamiento a víctimas y } \\
\text { otros sectores sociales; } \\
\text { Comunicaciones y campañas: } \\
\text { Página web, redes sociales, } \\
\text { revistas, publicaciones. Alianzas } \\
\text { con medios alternativos. } \\
\text { Generalidades: } \\
\text { Los repertorios se abordan en la } \\
\text { medida de las posibilidades y en } \\
\text { cada capítulo pueden tener una } \\
\text { evolución distinta. Son } \\
\text { expresiones pacíficas pero } \\
\text { vehementes y suele producir } \\
\text { represión posteriormente. } \\
\text { Han ido cambiando y } \\
\text { adaptándose a las oportunidades }\end{array}$ \\
\hline
\end{tabular}




\begin{tabular}{|c|c|c|}
\hline & $\begin{array}{l}\text { El repertorio ha variado con } \\
\text { el tiempo: de las } \\
\text { movilizaciones } \\
\text { interdepartamentales se ha } \\
\text { pasado a acciones de } \\
\text { incidencia e investigación } \\
\text { Su nacimiento coincide con } \\
\text { un aumento de } \\
\text { movilizaciones en general y } \\
\text { en aquellas relacionadas con } \\
\text { asuntos de género y violencia } \\
\text { y aparece convocando la } \\
\text { mayoría de ellas. Estas } \\
\text { movilizaciones además se } \\
\text { concentraron entre 2002 y } \\
\text { 2008, fechas que coinciden } \\
\text { con la llegada de Uribe y el } \\
\text { episodio de contienda } \\
\text { estudiado. }\end{array}$ & $\begin{array}{l}\text { políticas. La interlocución con el } \\
\text { Estado ha cambiado a partir del } \\
\text { cambio presidencial entre Uribe } \\
\text { y Santos. } \\
\text { Adaptan los performance a la } \\
\text { interpretación que hacen del } \\
\text { contexto y su oponente. } \\
\text { Continúan mostrando las } \\
\text { galerías y haciendo algunas } \\
\text { acciones callejeras al tiempo que } \\
\text { están más concentrados en hacer } \\
\text { encuentros, Foros } \\
\text { manifestaciones simbólicas } \\
\text { Su surgimiento coincide con un } \\
\text { aumento importante en el } \\
\text { número de movilizaciones de } \\
\text { víctimas y de manera especial de } \\
\text { las víctimas de crímenes de } \\
\text { estado en relación con víctimas } \\
\text { de la guerrilla. Este pico tiene } \\
\text { lugar en el comienzo del } \\
\text { segundo periodo de Uribe para } \\
\text { comenzar a descender de manera } \\
\text { paulatina los siguientes años en } \\
\text { los que se debate la ley en el } \\
\text { Congreso. }\end{array}$ \\
\hline $\begin{array}{l}\text { Estructura de } \\
\text { Oportunidad } \\
\text { es Políticas }\end{array}$ & $\begin{array}{l}\text { Multiplicidad de centros de } \\
\text { poder: Independencia de los } \\
\text { tres poderes del Estado. La } \\
\text { Corte Constitucional se } \\
\text { mostró como un tribunal } \\
\text { independiente y autónomo } \\
\text { del poder ejecutivo. El } \\
\text { Congreso estaba cuestionado } \\
\text { por paramilitarismo. El } \\
\text { Ejecutivo estaba confrontado } \\
\text { con la Corte Suprema de } \\
\text { Justicia. El gobierno central } \\
\text { era hostil con los defensores } \\
\text { de derechos humanos. } \\
\text { Existencia de la T-025 de } \\
\text { 2004. Obligaciones } \\
\text { internacionales vía Bloque de } \\
\text { Constitucionalidad. }\end{array}$ & $\begin{array}{l}\text { Inestabilidad de las alineaciones } \\
\text { políticas: Búsqueda de } \\
\text { consensos por parte del Senador } \\
\text { Cristo (partido liberal) al interior } \\
\text { del Congreso para recuperar a } \\
\text { antiguos copartidarios y desafiar } \\
\text { a Uribe quién estaba en la } \\
\text { Presidencia. Cansancio de los } \\
\text { liberales con el gobierno de } \\
\text { Uribe a quien aspiran a suceder. } \\
\text { Multiplicidad de centros de } \\
\text { poder: Reconocimiento de } \\
\text { derechos de las Cortes. } \\
\text { Existencia de la T-025 de } 2004 \text {. } \\
\text { Instituciones vigentes pese a la } \\
\text { guerra. Expedición por parte del } \\
\text { congreso de la ley } 975 \text { de } 2005 \text { y } \\
\text { revisión de la Corte } \\
\text { Constitucional mediante la C- }\end{array}$ \\
\hline
\end{tabular}




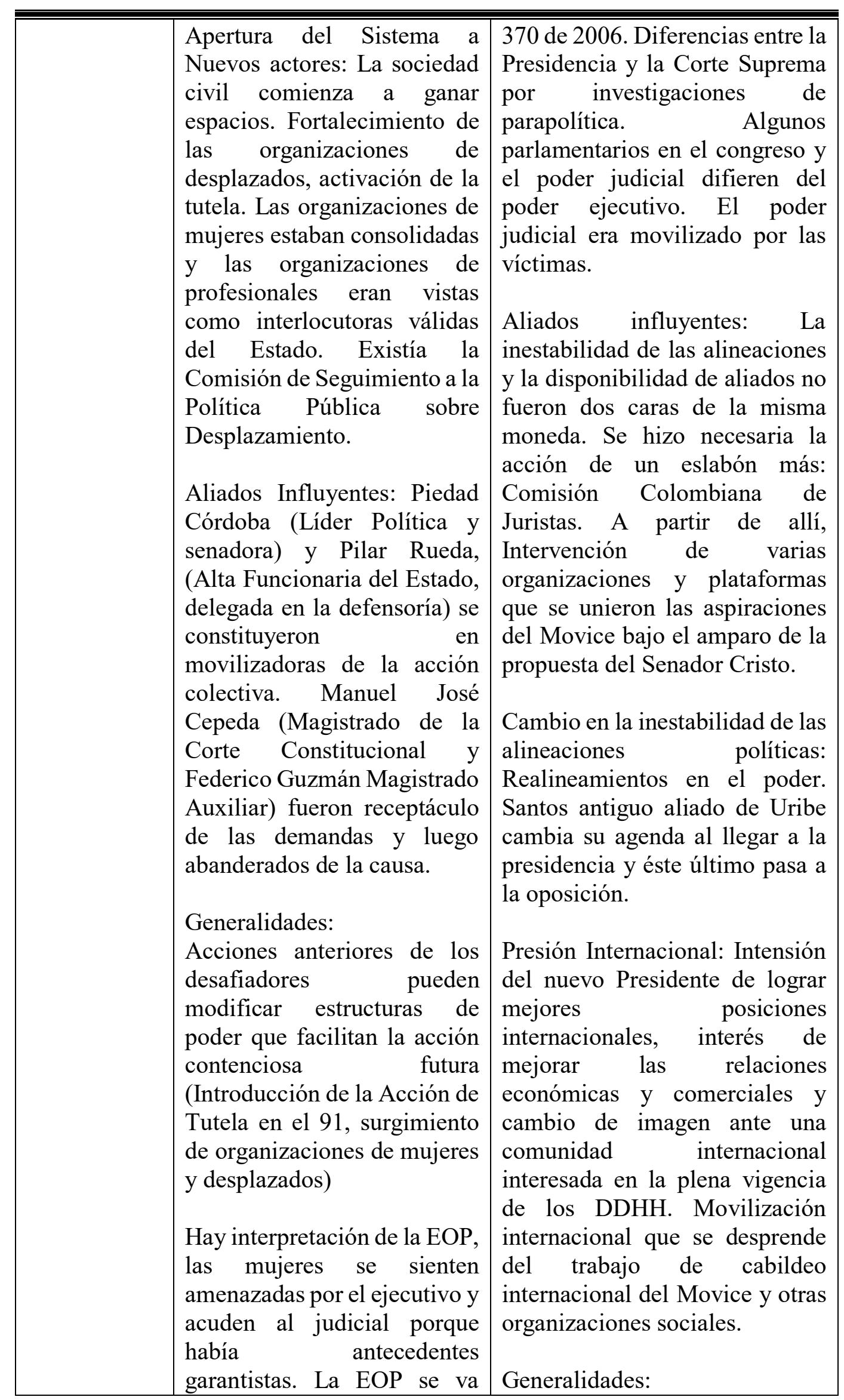




\begin{tabular}{|c|c|c|}
\hline & $\begin{array}{l}\text { construyendo con el tiempo } \\
\text { sobre interacciones } \\
\text { sostenidas de múltiples } \\
\text { actores y éstas se activan } \\
\text { cuando los participantes de } \\
\text { una contiendan la interpretan } \\
\text { así y sacan provecho de ello. } \\
\text { Los aliados fueron } \\
\text { identificados, interpretados y } \\
\text { activados en su momento. }\end{array}$ & $\begin{array}{l}\text { Fue necesario un cambio de } \\
\text { gobierno y de políticas para la } \\
\text { consolidación del hito. Estos } \\
\text { cambios no fueron detectados } \\
\text { tan fácilmente por el Movice } \\
\text { pero si por los aliados y otros } \\
\text { actores que actuaron en } \\
\text { correspondencia. } \\
\text { Muchos de los elementos de la } \\
\text { EOP no pudieron ser } \\
\text { maniobrados por el movimiento } \\
\text { pero si terminaron siendo } \\
\text { aprovechados eventualmente. } \\
\text { Los aliados se construyen en el } \\
\text { tiempo y no necesariamente } \\
\text { actúan con guiones concertados. } \\
\text { Lo hacen como derivación del } \\
\text { convencimiento y relaciones de } \\
\text { confianza previas. }\end{array}$ \\
\hline & $\begin{array}{l}\text { Difusión y cooptación: } \\
\text { Proceso formativo en Bogotá } \\
\text { y cooptación de lideresas, } \\
\text { ampliación de la } \\
\text { comprensión de las } \\
\text { violencias contra las mujeres } \\
\text { líderes. } \\
\text { Constitución de Nuevos } \\
\text { Actores: Mediante la difusión } \\
\text { y la cooptación nace la Red } \\
\text { de Mujeres en Acción hacia el } \\
\text { Futuro como producto del } \\
\text { trabajo de la Casa de la Mujer } \\
\text { la cual pasó a ser miembro de } \\
\text { la Ruta poco tiempo después. } \\
\text { No se sabe de todas las } \\
\text { organizaciones (casa, ruta, } \\
\text { red) quienes activaron mejor } \\
\text { el resultado porque las } \\
\text { mujeres actuaron portando } \\
\text { todas las identidades. } \\
\text { Correduría: Casa de la Mujer } \\
\text { y Piedad Córdoba invitan al }\end{array}$ & $\begin{array}{l}\text { Difusión: } \text { Capacidad de } \\
\text { propagar la necesidad del } \\
\text { reconocimiento de las víctimas } \\
\text { de estado. Se da durante todo el } \\
\text { proceso y comienza en la } \\
\text { constitución del mismo } \\
\text { movimiento, mucho antes de la } \\
\text { cadena causal productora del } \\
\text { hito. } \\
\text { Correduría: la relación acción } \\
\text { efecto no fue directa y los } \\
\text { resultados fueron parcialmente } \\
\text { contrarios a los deseos } \\
\text { originales. En el primer proyecto } \\
\text { ésta la desempeñó la CCJ } \\
\text { modificando la redacción del art } \\
3 \text { para hablar de agentes del } \\
\text { Estado. Posteriormente se } \\
\text { amplía la correduría a otros } \\
\text { actores y organizaciones } \\
\text { gubernamentales. En el segundo } \\
\text { proyecto la hace Iván Cepeda } \\
\text { como Representante a la } \\
\text { Cámara. }\end{array}$ \\
\hline
\end{tabular}




\begin{tabular}{|c|c|c|}
\hline & $\begin{array}{l}\text { magistrado. Estos dos actores } \\
\text { conocían de tiempo atrás las } \\
\text { luchas de las mujeres y la } \\
\text { Corte ya había tenido } \\
\text { experiencia de trabajo con la } \\
\text { sociedad civil. Esta } \\
\text { correduría junta gente muy } \\
\text { distinta entre sí. Mujeres } \\
\text { legas con magistrados } \\
\text { altamente capacitados. } \\
\text { Acción realizada en un } \\
\text { espacio rutinario pero con } \\
\text { vehemencia. } \\
\text { Formación de coaliciones: En } \\
\text { un primer momento y para la } \\
\text { convocatoria al Foro se } \\
\text { coordinaron: Casa de la } \\
\text { Mujer, Red de Mujeres hacia } \\
\text { el futuro, Tribunal de } \\
\text { Mujeres, Marcha Mundial y } \\
\text { Ruta. En un segundo } \\
\text { momento lo hicieron para } \\
\text { recoger información y } \\
\text { preparar la Audiencia. La ruta } \\
\text { activa sus regionales. El } \\
\text { tercer momento fue para la } \\
\text { Audiencia: las } \\
\text { organizaciones se ordenan y } \\
\text { estructuran el guión. Se trató } \\
\text { de una articulación eficiente } \\
\text { debido a la experiencia previa } \\
\text { de trabajo conjunto } \\
\text { Cambio de escala: Cambio de } \\
\text { escala entre el Foro y la } \\
\text { audiencia. Este cambio se da } \\
\text { hacia arriba, aunque } \\
\text { paradójicamente se presenta } \\
\text { de la capital hacia las } \\
\text { regiones periféricas. }\end{array}$ & $\begin{array}{l}\text { Formación de coaliciones: la } \\
\text { acción en la plataforma Mesa } \\
\text { Nacional de víctimas de } \\
\text { organizaciones sociales } \\
\text { (formación de coaliciones) } \\
\text { permite encontrarse con otros, } \\
\text { informarse, formarse, construir } \\
\text { propuestas y visibilizarlas. } \\
\text { Certificación: Correlato de la } \\
\text { presión internacional. Se logra el } \\
\text { respaldo de organizaciones } \\
\text { internacionales que inclinaron la } \\
\text { balanza hacia las pretensiones } \\
\text { del Movice en el cambio de } \\
\text { gobierno cuando Santos } \\
\text { pretende mejorar las relaciones } \\
\text { internacionales. }\end{array}$ \\
\hline Resultados & $\begin{array}{l}\text { AUTO } 092 \text { de } 2008: \\
\text { Providencia de la Corte } \\
\text { Constitucional con órdenes al } \\
\text { Gobierno Nacional basada en } \\
\text { el impacto desproporcionado, } \\
\text { tanto cuantitativo como } \\
\text { cualitativo, que sufren las }\end{array}$ & $\begin{array}{l}\text { ART. } 3 \text { LEY } 1448 \text { de 2011: Ley } \\
\text { de la República mediante la cual } \\
\text { se hace reconocimiento a las } \\
\text { víctimas de infracciones al DIH } \\
\text { y violaciones a los Derechos } \\
\text { Humanos en el marco del } \\
\text { conflicto armado sin importar el }\end{array}$ \\
\hline
\end{tabular}




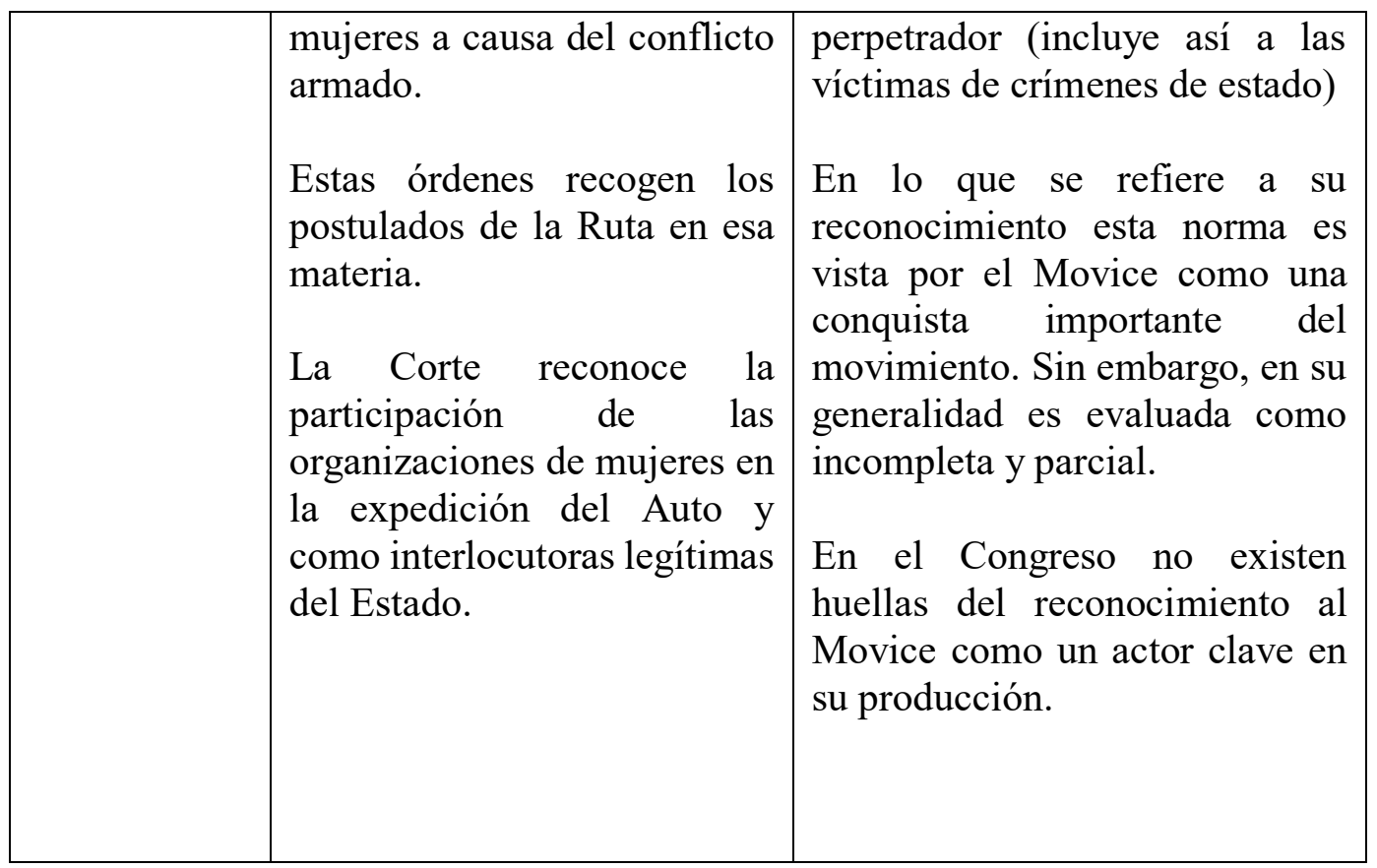

\subsubsection{Episodios y Condiciones Iniciales}

La defensa por los derechos Humanos en Colombia ha sido una tarea de muy largo aliento, de allí que los dos movimientos sociales aquí estudiados emergieran de un proceso más amplio de contienda. Las diferentes fases en que se ha desarrollado el conflicto armado, las violencias socio políticas con las que ha respondido el Estado, los usos de la violencia que pronto comenzaron a desplegar los demás actores armados y el ingreso del narcotráfico como motor económico del conflicto, marcaron en la conciencia de algunos sectores sociales la importancia de plantear una lucha contra el Estado y los actores armados por el reconocimiento de la protección de los civiles en la guerra. Esta es la razón por la que podemos encontrar en Colombia organizaciones defensoras de los derechos humanos desde los años 80s quienes dieron comienzo a un ciclo extenso de contienda que hoy por hoy sigue su curso tras cerca de 40 años de trabajo. Estas organizaciones, englobadas en lo que hoy se conoce como el movimiento de derechos humanos en el país, fueron quienes finalmente habilitaron el espacio y mostraron el camino de la lucha social y política a los movimientos que acá estudiamos. 
Enmarcados en este gran episodio, cada uno de estos Movimientos ha tenido unos antecedentes particulares: el movimiento feminista para la Ruta y los procesos de contestación política y jurídica al Estado marcados desde la izquierda para el Movice, terminan siendo parte de una misma contienda extendida en el tiempo. Un marco de contención de donde fue posible tomar ideas, repertorios, formas de organización y estructuración de redes, que los hizo hábiles y fuertes a la hora de movilizarse y emprender sus propias batallas políticas.

A esta contienda más amplia, regida por el Movimiento de derechos humanos, es posible sin embargo delinearle nuevas fronteras a partir del momento del surgimiento de los movimientos acá estudiados hasta las producciones de los hitos. Estas nuevas delimitaciones nos permiten identificar elementos específicos característicos de las condiciones iniciales que sufren modificaciones radicales durante la contienda. Así las cosas en el caso de la Ruta, el episodio que enmarca nuestro estudio se establece a partir de un estado de cosas caracterizado por un total desconocimiento del Estado y de la ciudadanía en general de la forma en que las mujeres están siendo agredidas en la guerra, y se cierra con el reconocimiento de las afectaciones y riesgos diferenciados de éstas en el conflicto armado. De la misma forma, en el caso del Movice, el episodio que estudiamos comienza con la negación absoluta de la comisión de crímenes por parte del Estado y se cierra con el reconocimiento de la existencia de estas víctimas. En ambos casos se trata de una modificación sustancial en las condiciones iniciales que nos muestras variaciones importantes producidas en medio de la contención pública y política.

Ahora bien, es importante señalar que estamos ante dos movimientos con edades diferentes. Mientras la Ruta emerge a mitad de los años 90, el Movice lo hace casi 10 años después, a mediados de la primera década del siglo XX. Esta diferencia, si bien determina el grado de madurez y complejidad de algunas de sus acciones y dispone formas dispares de su relación con los poderes del Estado en relación a la producción del hito, finalmente no brinda marcos diferenciales contundentes sobre las formas en que se desarrollan las contiendas de nuestro interés. Pero este mismo contraste sí nos permite identificar que, pese a que al interior de los episodios 
estudiados se han presentado numerosos cambios locales y nacionales que van alterando el curso de los acontecimientos y sobre los cuales los movimientos han ido ajustando sus objetivos tácticos y estratégicos, es posible encontrar un hecho particular que profundiza la disputa de los actores sociales y demarca un curso de acción particular para unas luchas específicas.

Nos referimos a la llegada a la presidencia de la República del Álvaro Uribe Vélez, quién abanderando la Política de Seguridad Democrática logra poner sobre aviso al movimiento de derechos humanos, afinando la acción para el surgimiento de uno de los movimientos acá estudiados: el Movice, y construyendo mejores argumentos para el desafío declarado por la Ruta a los guerreros, sus oponentes de antaño. En otras palabras, un cambio en el poder ejecutivo produjo alteraciones suficientes en los movimientos sociales para activar nuevos episodios de contienda en donde fueron posible sus acciones en pro de modificaciones sustanciales sobre las condiciones iniciales. De allí que este sea el escenario con el que comienza la secuencia de eventos en los dos movimientos y determina la producción de los hitos estudiados.

En otras palabras, si bien la contienda en Colombia por los derechos humanos comenzó desde los años 80 , el estudio de los impactos políticos externos específicos (Giugni \& Bosi, 2012) de dos movimientos sociales nos remitió a una mejor delimitación de los eventos mediante la conformación de dos episodios de menor duración (Tarrow y Tilly, 2007), éstos sí más cercanos en el tiempo, 2005 para la Ruta y 2007 para el Movice, de donde pudimos deducir la marcada influencia en su explosión de un cambio en el poder ejecutivo de la Nación.

\subsubsection{Procesos Enmarcadores}

El correlato de esta última afirmación es que si bien para la Ruta y el Movice la concreción en un momento específico de ciertos agravios (McAdam et al., 1999) fue el detonante para la activación que condujo a la producción de ciertos impactos, el surgimiento de los movimientos en sí mismos no fue espontáneo ni ocurrió tras 
la sola identificación de una ofensa; en realidad la activación de estos movimientos son el resultado de un largo proceso de organizaciones, otros movimientos, líderes y lideresas que han recogido banderas anteriores y que se han adiestrado por años en la movilización social. De allí que surgieran con unos objetivos claros, estudiados y validados por sus miembros, los cuales mantienen en el tiempo sin grandes variaciones, si bien los van adaptando a los desafíos del momento y las modificaciones del contexto. Así, mientras la Ruta se esmera en presentarse como un actor neutral en medio del conflicto armado y denuncia en la misma proporción su acción militar, el Movice enfunda su faena en la denuncia y señalamiento de uno de los actores de la guerra: El Estado y su desarrollo paramilitar, como el ente opresor y verdugo de las iniciativas de la oposición.

Esto plantea diferencias importantes en los objetivos y mecanismos de acción colectiva, así como en la forma en que son vistos desde afuera. Mientras la Ruta genera inmovilidad en sus oponentes ante el desconcierto por el uso de simbologías y el enaltecimiento de elementos como el pacifismo, antimilitarismo y feminismo, el Movice suele ser sujeto de retaliaciones más severas al enarbolar discursos desde un espectro ideológico y político determinado, específicamente contra uno de los actores centrales del conflicto armado: el Estado. Al tiempo, mientras los objetivos de la Ruta permanecen en la esfera del deseo por buscar una salida negociada al conflicto y el reconocimiento del efecto que ha causado la guerra en las mujeres, el Movice plantea unos derroteros orientados al poder y su capacidad por desentrañar los crímenes perpetrados por el actor dominante de la guerra.

Ambos movimientos basan además sus interpretaciones en planteamientos de muy hondo calado: el socio-sexo patriarcalismo para el caso de la Ruta, y el develamiento de los mecanismo de dominación del Estado en el caso del Movice. Se tratan los dos, de discursos profundamente revolucionarios que intentan colarse a través de las acciones del movimiento y que, planteados de forma pacífica y por fuera del conflicto, crean una caparazón que impiden ser avasallados por los actores armados. Cabe decir en todo caso que en este propósito la Ruta ha tenido más éxito 
que el Movice, si consideramos el volumen de agresiones contra este último movimiento en relación con el primero en lo que llevan de existencia.

Sin embargo, en el análisis de los elementos enmarcadores de su acción colectiva, puede identificarse una diferencia importante que nos enseña la particularidad de cada movimiento. Nos referimos a la constitución de identidades nuevas y la permanencia y entronque de otras antiguas. Mientras en la Ruta si bien sus miembros suelen llegar con múltiples identidades, el estar allí las condiciona a adoptar una forma específica de entender el mundo: el pacifismo, el feminismo y el antimilitarismo. Hemos visto que hay tantas versiones de estos elementos como mujeres en la Ruta, sin embargo, estas identidades políticas son epicentro de la formación y aspiración ideológica del movimiento, haciendo que todas sus acciones se guíen por estos mandatos y se ajusten a los límites que este les imponen.

Por otro lado el Movice se constituye alrededor de una interpretación única que hacen del oponente fijando su centro identitario en el develamiento de la impunidad de los crímenes cometidos por éste. Si bien son conscientes de las diferencias políticas y organizativas que traen consigo, encuentran a su vez la posibilidad de actuar conjuntamente por provenir de una izquierda con opositores comunes. Esto los anima e invita a mantenerse cohesionados, y les habilita para trabajar conjuntamente en pro de la conquista de sus objetivos, sabiendo que en cualquier caso existen unas identidades políticas previas que los condicionan durante todo el tiempo en que dura la contienda y que posiblemente subsistirá una vez ésta llegue a su fin.

Estas similitudes y diferencias en todo caso nos muestran con claridad cuál es la forma en que interpretan el mundo, qué los anima al cumplimiento de sus objetivos y de qué manera se asemejan y alejan identitariamente, pese a que son dos movimientos que comparten territorios, tiempos históricos y hasta escenarios de acción colectiva. También nos muestra que estas identidades se han ido construyendo y adaptando con el tiempo al contexto y a las vicisitudes de las contiendas a partir de sus disputas internas y en su relación con terceros que, aunque 
no implican modificaciones sustanciales a sus objetivos y el perfil con el que surgieron, si muestran la vivacidad de sus organismos y lo dinámico de sus planteamientos y acciones a lo largo de los episodios (McAdam et al., 2005).

\subsubsection{Estructuras de Movilización}

Estudiar la forma en que los movimientos se organizan resulta funcional en la medida en que nos explica la trayectoria que siguen, los apoyos que encuentran y en general, el grado de legitimidad que tendrán durante la contienda (McAdam et al., 1999). En nuestro caso, también nos enseña mucho sobre la forma en que se vive la política en este país y se distribuyen los poderes económicos y políticos.

Suele decirse que Colombia es un país de regiones y nosotros creemos que en la política y en la guerra es donde esa expresión tiene más sentido. En los territorios es donde se desarrollan las acciones bélicas y se deciden los poderes políticos y económicos locales, se concretan las alianzas y se determinan los enlaces entre la violencia y la arena electoral. Sin embargo, es en el centro donde se toman las decisiones institucionales y se encuentran los poderes supremos; en la Capital es donde el trabajo político genera los impactos más relevantes. De allí que los movimientos sociales en Colombia, y en general las organizaciones políticas, busquen por todos los medios estar presentes en el centro y en las regiones.

Las formas en que los dos movimientos acá estudiados estructuran sus redes y mecanismos de operación basan su estrategia organizativa en la posibilidad de mantener su presencia en el "ámbito nacional", es decir, tener organizaciones o núcleos que los representen en diferentes lugares del país, mientras mantienen su centro de operaciones en Bogotá. Se trata de un formato que, en cualquier caso, tiene un epicentro que determina, impulsa y en muchos momentos, da vida al trabajo regional; pero también es un formato que permite que las individualidades y características particulares de las regiones se expresen mediante procesos autonómicos de acción y de resistencia. Pretende ser además una fórmula elástica que busca amoldarse a la necesidad indeclinable de estar en el centro del poder - 
Bogotá-, y a los requerimientos de las regiones y los territorios donde finalmente se encuentra el corazón de los agravios y de las contiendas.

Esta misma elasticidad ha permeado a sus miembros y a sus criterios de ingreso. En ambos casos si bien la "apropiación" de organizaciones preexistentes y con altas capacidades organizativas fue el mecanismo original de cooptación de sus miembros, con el tiempo esto ha dado paso al ingreso de personas naturales, muchas de ellas sin experiencia política ni organizativa previa, que brindan su tiempo y energías, además de su apoyo voluntario, a la causa. Estos ingresos recientes son absorbidos por los movimientos mediante procesos de formación que les permite a los recién llegados conocer los valores en los que se funda el movimiento, mientras van adquiriendo otra serie de destrezas para el liderazgo.

Esto por supuesto ha traído importantes desafíos a los movimientos quienes constantemente se encuentran en la encrucijada de relevar sus liderazgos para darle aire y dinamismo a la contienda y la necesidad de mantenerlos para evitar que se desdibujen sus objetivos. Al tiempo, ha generado hondos debates sobre el devenir de los Movimientos en relación a la persistencia de algunos de sus líderes y lideresas en los lugares "de poder" dentro de la organización, haciendo que por momentos sean vistos de forma más piramidal que circular.

Ahora bien, en relación a su extensión, si bien difieren en el volumen del número de organizaciones adscritas, estas diferencias son mínimas si se considera que su nivel de acción depende más de su capacidad interna y los recursos de qué dispongan que del número de sus miembros activos. En realidad, mientras la Ruta tiene más organizaciones asociadas y se encuentra en menos lugares del país, el Movice tiene una importante cobertura territorial, incluidos algunos capítulos en el exterior, pero menos organizaciones adscritas. Estas diferencias sin embargo no parecen afectar en gran medida la conquista de objetivos mientras que éstos si se pueden relacionar más con los medios de los que disponga el movimiento en un momento determinado. La capacidad de organización interna y la disponibilidad de 
recursos externos han determinado gran parte de los éxitos y fracasos de sus acciones.

Por ello para estos movimientos la búsqueda de recursos económicos es vital para su existencia. Sin poder sobrevivir exclusivamente con el trabajo voluntario de sus miembros, la gestión de proyectos es una de las tareas permanentes tanto de las oficinas centrales como de las regionales. Esto ha traído como consecuencia que, aunque estos movimientos mantengan un carácter de trabajo en red con las estructuras que los conforman, -menos densa y más porosa-, en temas económicos actúan como una organización no gubernamental con planes y proyectos anuales, así como con administraciones y seguimiento a las ejecuciones como lo haría cualquier corporación, fundación o persona jurídica sin ánimo de lucro. Y en este caso, las similitudes son altas, incluyendo los donantes que suelen provenir de la comunidad internacional que entran a determinar buena parte del curso de las contiendas al aprobar o negar la financiación de ciertos proyectos.

Por último, es notable la diferencia existente entre las dos organizaciones en relación a la importancia que le dan al trabajo en redes y alianzas. Mientras para la Ruta, la universalidad de sus pilares fundamentales las invita a buscar aliadas en otros rincones del mundo, el Movice, concentrado en un oponente inscrito en un territorio y en un periodo histórico, centra sus aspiraciones en el espectro nacional y en lo que allí pueda avanzar, lo cual no significa por supuesto que no tenga y desarrolle el interés de mantener aliados externos.

En cualquier caso, estas formas tan similares de organizarse se relacionan con la dinámica política y social que se ha dibujado en Colombia durante los últimos 30 años, en las que es imposible pensar el país sin darle un protagonismo vital a las regiones pero bajo el reconocimiento de la importancia sempiterna de su capital. Son modelos organizativos que terminan pareciéndose en la medida en que son enfrentados a circunstancias similares, así sus propósitos sean diferentes.

\subsubsection{Repertorios de Acción}


Los repertorios y performance de la Ruta y el Movice tienen varios aspectos en común, y pese a la diferencia de enfoques y objetivos, han vivido variaciones también similares. Un elemento nuclear para resaltar es el carácter pacífico de sus manifestaciones. Pese a que los elementos simbólicos que se usan y el calibre de los mensajes pueden llegar a ser fuertes y vehementes, los dos movimientos sociales han buscado por todos los medios que sus acciones no sean calificadas por el Estado ni por la sociedad como violentas o proclives al enfrentamiento armado o físico. Este interés de alejarse todo lo posible de realizar enfrentamientos de ese nivel tiene que ver particularmente con su deseo de sentar una diferencia con las insurgencias del país, que llevan más de 50 años librando una lucha armada contra la institucionalidad. De allí que los movimientos se interesen permanentemente en marcar una diferencia y crear una imagen alternativa mostrando permanentemente su naturaleza civil.

Estas acciones simbólicas y pacíficas tienen además diferentes connotaciones entre las regiones y los momentos históricos. Cada capítulo o regional adapta a su medida y condiciones los repertorios, innovando a su vez según las necesidades y retos que afronten. Pese a ello, los dos movimientos sociales han escogido un tipo de repertorio que en todo caso han universalizado y que los diferencian de otras expresiones y movimientos sociales. El plantón de las mujeres de negro para la Ruta y las galerías de la memoria para el Movice son elementos estratégicos para conquistar sus objetivos, pero sobre todo para su relacionamiento con los otros movimientos, con el Estado y con la sociedad en general. El empleo de elementos simbólicos, la realización de rituales, las ceremonias, el uso de ciertos colores, imágenes y arengas constituyen un acervo importante de planteamientos políticos y un conocimiento del contexto que les permite identificar qué cosas pueden ser más llamativas e innovadoras en el concierto de las acciones colectivas en el país.

Sin embargo y pese a este carácter pacífico y simbólico, los dos movimientos sociales intentan ser disruptivos y romper la cotidianidad. Se trata de acciones que lejos de pasar desapercibidas buscan hacer una diferencia importante con la rutina 
del entorno por lo que buscan siempre irrumpir, desafiar y oponerse al statu quo. Ya sea que decidan viajar días enteros entre ciudades o interrumpir sesiones en el Congreso con arengas, los dos movimientos están siempre dispuestos a llamar la atención y generar incertidumbre en el oponente.

Pero no solamente los movimientos hacen marchas, plantones o en general acciones callejeras, también estén interesados en un performance más amplio y variado que puede pasar por la investigación, las campañas mediáticas, el cabildeo, la elaboración y presentación de informes y la incidencia política y pública. Esto es así posiblemente por el carácter de los financiadores que aportan recursos económicos, los cuales en muchas ocasiones exigen la presentación de resultados mediante informes y productos, en combinación con el deseo de los movimientos por dejar plasmados sus objetivos e intereses en documentos consultables posteriormente por sus miembros, aliados y oponentes; de allí que los movimientos dediquen parte importante de su tiempo a escribir en revistas y libros sus planteamientos y las novedades que se van presentando en el transcurso de la contienda.

Sin embargo en medio de esta complejidad es posible identificar variaciones en el tiempo, siendo movimientos más explosivos y retadores durante los periodos presenciales de Uribe y un poco menos en los periodos de Santos. Así las cosas, podemos ver cómo los mismos repertorios sufren modificaciones importantes a partir de la experiencia contenciosa que van teniendo los movimientos con sus oponentes, al tiempo que éstos últimos también van cambiando sus métodos y demostraciones de poder. En este caso, una perspectiva desde el Estado más represiva impulsó a los movimientos a ser más belicosos, mientras una visión menos violenta los llevó a mecanismos más discursivos y reposados. Esta variación también es coherente con la delimitación de la cadena causal de análisis para los dos casos, mostrando que en ciertos momentos y contextos, estos movimientos pueden interesarse en buscar mecanismos que desafíen más claramente a su oponente al tiempo que van desarrollando otra variedad de acciones hacia el cumplimiento de propósitos concretos. 
Sobre este punto es importante notar que con el tiempo, de las grandes movilizaciones que se registraron en la primera década del siglo XXI, se ha pasado a acciones más concentradas, menos vistosas y más enfocadas a la investigación y producción de libros: "Paz sin Crímenes de Estado" (2013) del Movice y "La verdad de las mujeres Víctimas del Conflicto Armado en Colombia” (2013) de la Ruta, son una muestra de la forma en que actualmente estos movimientos han decidido continuar la contienda. Vale decir que si bien la elaboración y publicación de un libro no produce la movilización a la que estamos habituados cuando estudiamos repertorios de los movimientos sociales, sí se trata de documentos lo suficientemente explosivos y beligerantes como para ser considerados desafíos reales a sus oponentes.

\subsubsection{Estructura de Oportunidades Políticas}

Es un hecho, y así nos lo muestran los dos casos estudiados, la gran influencia que tiene en la producción de resultados la estructura de oportunidades políticas que existe a la hora de la contienda. Esto se hace aún más evidente cuando estas estructuras se estudian en relación a la atribución de amenazas y oportunidades que les dan los movimientos sociales y los demás actores que se involucran en la contienda. Muestra de ello fueron los tres tipos de oportunidades con que contaron las mujeres de la Ruta y los cinco que acompañaron al Movice durante la producción del hito estudiado. Sin embargo, de todos ellos se destacan dos, que además de ser compartidos por los movimientos, son fiel reflejo de las paradojas políticas que ha vivido Colombia en las últimas décadas.

En primer lugar encontramos la Multiplicidad de centros de poder. La presencia de esta oportunidad política nos muestra las rarezas que puede contener un Estado bastante desigual internamente. En este caso, un país formalmente democrático desde hace dos siglos, con un conflicto armado de cinco décadas, altamente violento y corrupto y con un bajo desarrollo en derechos económicos, sociales y políticos, puede aún tener instituciones lo suficientemente sólidas que permiten mantener un 
cierto equilibrio entre poderes. Esto respondería en parte a una pregunta reciente de la ciencia política y en general de los colombianos interesados. ¿Cómo un Estado débil y fragmentado, que además atraviesa una guerra civil interna, se mantiene en pie y funcional por tanto tiempo?

Parte de la respuesta puede provenir del reacomodamiento que se dio con la Constitución Política en el año 91 que le dio paso a una mayor claridad en la división de poderes y al nacimiento de una Corte Constitucional que sirvió durante dos décadas de válvula de escape para los miles de descontentos que veían sus derechos mermados o desconocidos y que encontraron por allí algún tipo de reconocimiento.

En ambos casos el papel de esta Corte, mediante un mismo pronunciamiento judicial -la Sentencia T-025 de 2004-, sirvió de pilar fundamental para el enmarcamiento de sus luchas venideras. Además de ello, las diferencias entre la Corte Suprema y el Congreso de la República marcaron la pauta para mantener el equilibrio pese a la cercanía de este último con el Ejecutivo. Este conflicto entre poderes, proveniente del descubrimiento de hechos de corrupción y paramilitarismo dentro del Estado, y el rol protagónico que tuvo el poder Judicial en su desenmascaramiento, mantuvo a flote la institucionalidad aún en los momentos más aciagos, produciéndose unos resultados que sirvieron ampliamente a los movimientos estudiados para sacer adelante algunos de sus objetivos.

Además de la multiplicidad de poderes, los movimientos también contaron con la suerte de tener aliados influyentes que inclinaron la balanza a favor de ellos en momentos decisivos. Estos aliados: políticos, activistas, funcionarios públicos y organizaciones no gubernamentales, fueron a su vez vanguardistas en su momento de las luchas sociales y políticas de los sectores menos favorecidos que fueron escalando posiciones de poder y legitimidad, al punto de poder apalancar a los movimientos sociales en los centros de poder y arenas de decisión. Esto también fue posible por los grados de empatía entre los objetivos y los planteamientos 
ideológicos de unos y otros que permitieron en un momento determinado representar los intereses de los movimientos.

La posibilidad de encontrar algunas puertas de salida, y la existencia de unos poderes independientes, permitieron que los movimientos pudiesen desarrollar sus contiendas en medio de la adversidad.

Sin embargo, notemos que existen a su vez elementos diferenciadores entre la EOP de los movimientos estudiados. Esto nos muestra, de un lado, que las Oportunidades Políticas son dinámicas y que estas pueden modificase en poco tiempo. Basta en algunos casos el paso de pocos meses para encontrar variaciones importantes que afectan el curso normal de una contienda; y de otro lado, que estas oportunidades pueden ser leídas y aprovechadas de forma distinta entre los movimientos sociales y allí donde uno encuentra posibilidades de acción, otros ven cerradas las opciones. Estas interpretaciones por su puesto no se basan en ideas puramente subjetivas o aleatorias. Tienen mucho que ver con la experiencia previa y el conocimiento de las reacciones del ponente.

Este es el caso de la apertura del sistema a nuevos actores leído e interpretado como una oportunidad política por la Ruta. El crecimiento en la opinión pública y en los actores del Estado de la importancia de abrir escenarios de diálogo a la población desplazadas, y particularmente a las mujeres víctimas, fue identificado, no solamente como resultado de las luchas de género que se venían estableciendo de tiempo atrás, sino también como una posibilidad de acceder, intervenir e incidir directamente en las arenas decisorias. Sin embargo para el Movice, pese a que se trataba del mismo contexto en el que se animaba la creación de organizaciones de víctimas, estas oportunidades no se abrían de la misma forma. En realidad mientras esto sucedía, el Movice seguía siendo interpretado por el Estado como un enemigo al cual debía acallarse o por lo menos ignorarse. Así, mientras la Ruta, con un carácter neutral y pacifista, leía y aprovechaba sus oportunidades, el Movice debió esperar algún cambio más en la estructura de oportunidades para avanzar en la consecución de nuevos logros. 
La inestabilidad de las alineaciones, un cambio imprevisto en ésta y el efecto que la presión internacional tuvo en el nuevo escenario jugaron ampliamente a su favor, pese a que en este caso para el Movimiento la batalla había comenzado años antes evidenciado la existencia de víctimas de crímenes de estado y planteando su legítimo derecho a la verdad, la justicia y la reparación integral.

Sin embargo fue necesario que se produjera primero una inestabilidad de las alineaciones políticas mediante la fractura entre las toldas liberales y las uribistas para que los primeros decidieran encumbrar las banderas de la defensa de estas víctimas, y luego que hubiese un divorcio entre el nuevo Presidente de la República y el mismo uribismo y un acuerdo político entre el primero y los liberales, para que finalmente Santos asumiera como propia la misma bandera, iniciativa que a todas luces le resultaba supremamente útil para responder a las continuas solicitudes hechas por la comunidad internacional que no mermaba esfuerzos en solicitar modificaciones sobre este tema.

\subsubsection{Mecanismos}

Si bien la Estructura de oportunidades políticas habilitó los escenarios y las condiciones para la producción de los hitos estudiados, fue necesaria la intervención de las Movimientos para que estos tuvieran la forma y el contenido que actualmente tienen. Entender estos resultados, la forma en que se produjeron y los niveles de intervención de los movimientos, es posible a través del análisis de los acontecimientos que alteraron las relaciones entre los diferentes conjuntos de actores, los denominados “mecanismos” por Tilly, Tarrow y McAdam (2005).

Este ejercicio, como puede verse más arriba, nos arrojó una serie de mecanismos que bien vale la pena cotejar entre sí, tratando de revisar, como lo anunciaran los autores previamente enunciados, si se repiten de manera idéntica o por lo menos similar entre diferentes contiendas. 
En efecto, de los mecanismos producidos en cada contienda se destaca que la mayoría para cada caso se repiten. En ambas secuencias de eventos podemos encontrar: Difusión, Correduría y Formación de Coaliciones. Se trata de mecanismos que entraron a jugar de forma importante en cada contienda y que pueden ejemplificar algunos rasgos comunes de la forma en que los movimientos suelen actuar y bajos los cuales se pueden producir resultados positivos. Sin embargo, debe señalarse que estos mecanismos se produjeron en diferentes momentos de la contienda y tuvieron un nivel de protagonismo distinto en la producción del hito.

Así, mientras para la Ruta el trabajo de la correduría fue significativamente más importante para activar la secuencia de eventos que dieron como resultado el hito, para el Movice el mecanismo que determinó la acción fue la difusión. Son mecanismos que por supuesto no trabajan aisladamente sino que se incorporan a un proceso de largo aliento y marcan una diferencia apreciable en la manera en que los resultados se van produciendo. Así, para la Ruta, haber podido contar con aliados influyentes que las conectaran directamente con los tomadores de decisión fue fundamental para lograr el alto nivel de incidencia que finalmente tuvieron en la producción del Auto. Sin esta acción, posiblemente las organizaciones de mujeres no hubiesen tenido la injerencia que tuvieron en este pronunciamiento judicial. Asimismo, sin los grandes esfuerzos en difusión que realizara el Movice años atrás del comienzo de la secuencia de eventos, difícilmente cualquier actor hubiese tenido interés alguno en compartir y representar los intereses de este movimiento cuando se estaba debatiendo la ley en el Congreso.

Pero los mecanismos no solo nos hablan de la activación de la cadena causal, también nos pueden explicar mucho de los contenidos que van adquiriendo los hitos. En el caso de la Ruta la formación de coaliciones y el cambio de escala permitieron que las mujeres de diferentes sectores y regiones entraran en contacto directo con los magistrados pudiendo expresar directamente, de viva voz o mediante informes, sus expectativas frente al pronunciamiento. Esto, y una buena interpretación de las magistrados encargados, hizo posible el Auto reflejara de muy 
buena manera los riesgos y las facetas que habían expuesto las mujeres con sus experiencias de vida durante la contienda. De allí el grado de satisfacción de los diferentes grupos de mujeres frente al contenido del Auto y su posterior utilización como herramienta fundamental de trabajo político en sus organizaciones.

En el caso del Movice por el contrario, una participación indirecta, mediada por la correduría y la formación de coaliciones y casi que arrebatada por los partidos políticos tradicionales y por el ejecutivo, no solo disminuyó la posibilidad de incidencia directa en la elaboración de los contenidos de la ley sino que también generó incertidumbre y desapego con el articulado, al punto de determinar la decisión en el movimiento de no acompañarlo en su versión final, pese al logro de su reconocimiento en uno de sus artículos. La imposibilidad de incidir directamente explica la poca identificación del movimiento con los contenidos del hito, y la distancia que tiene la norma ensimisma, con los objetivos del movimiento.

Por último, existen dos mecanismos que si bien no aparecieron como protagonistas en las contiendas estudiadas, si tuvieron el peso necesario para inclinar la balanza a favor de los movimientos en un momento determinado, mostrándonos que es en la pluralidad de mecanismos y en una adecuada combinación de éstos que se producen resultados significativos. Es el caso de la Constitución de nuevos actores para la Ruta y la Certificación para el Movice.

En relación a la constitución de nuevos actores, si bien el movimiento feminista ya tenía consolidadas muchas organizaciones en toda la geografía nacional y la Ruta ya era un movimiento reconocido, la conformación de una nueva red de mujeres dio oxígeno a la contienda formando los liderazgos que en un momento determinado asumieron como propios los postulados del feminismo en el país. Esta nueva organización, que finalmente terminaría integrándose a la Ruta, fue por unos meses la condensación de las luchas de las mujeres víctimas de desplazamiento al llevar la vocería frente a los tomadores de decisión, quienes optaron por escuchar con atención sus planteamientos. 
Para el Movice, el ingente trabajo de denuncia de las arbitrariedades del Estado colombiano a la comunidad internacional que hiciera todo el movimiento de derechos humanos, y en particular el movimiento en estudio por varios lustros, determinó que cuando se hizo necesario, este movimiento recibiera el respaldo político y el apoyo económico necesario para la contienda. La certificación que obtuviera el movimiento en diferentes momentos y por diversos actores externos evidenció no solo el apoyo y la empatía de otros "calificados" frente a la existencia del movimiento, sino que acompañó particularmente la legitimidad y legalidad de las exigencias del movimiento. De esta manera, el Congreso tendría que reconocer que los derechos reivindicados tenían su correlato en la normatividad internacional y por tanto debían ser examinados y acatados.

Así las cosas, los mecanismos nos mostraron cómo se fueron produciendo los hitos, el nivel de conformismo o inconformismo frente a los mismos y la forma que tomaron sus contenidos.

\subsubsection{Resultados}

De esta manera podemos entender las marcadas diferencias entre los resultados producidos por los dos movimientos sociales. Recordemos que para este estudio los resultados escogidos hacen parte de aquellos impacto externos producidos respecto a derechos legales (Giugni \& Bosi, 2012), los cuáles pueden adoptar a su vez, distintos formatos. Así, mientras para la Ruta éste devino en forma de pronunciamiento judicial de la Corte Constitucional mediante el cual se suministran órdenes de política pública al Gobierno Nacional, para el Movice, éste adopta la forma de Ley de la República como resultado de un proceso complejo y aparatoso en el Congreso de la República. Diferencias que también se trasladan a sus contenidos últimos y que reflejan el proceso y los niveles de intervención de los movimientos en su producción.

Mientras la Ruta y en general el movimiento feminista colombiano logró obtener una decisión basada en el impacto desproporcionado que sufren las mujeres a causa 
del conflicto armado recogiendo integralmente los postulados del movimiento, el Movice, aunque logra mediante el reconocimiento de las víctimas de infracciones al DIH y violaciones a los derechos humanos en el marco del conflicto armado sin importar el perpetrador, su propio reconocimiento, no consigue incorporar todas sus aspiraciones en esta ley. Los actores involucrados, incluyendo sus trayectorias, identidades, formas organizativas, repertorios, tipo de oportunidades y mecanismos involucrados, así como el choque de intereses y consecuencias políticas, económicas y sociales de las reclamaciones, intervinieron para definir el alcance de cada uno de ellos.

De otro lado, bien vale la pena señalar que estos órganos no guardaron similitud a la hora de reconocer el papel jugado por los movimientos para la producción del hito. Hemos dicho durante todo este estudio, que su acción fue necesaria para la producción del hito, sin embargo los mismos promulgadores de las políticas tienen su propia versión. Mientras la Corte identificó y reconoció formalmente el papel del movimiento feminista, de las organizaciones de mujeres desplazadas, y de la Ruta, como uno de los numerosos sectores que hicieron posible la expedición del Auto, algunos congresistas parecen plantear que la ley se hizo menos por la acción del Movice, y casi que "a pesar de la acción de éste", teniendo en cuenta la postura del Polo Democrático Alternativo en las votaciones finales.

Sin embargo estas diferencias también permiten identificar aspectos en común. Uno de ellos es que ninguno de los resultados en política pública provino del Ejecutivo, si bien en el caso del Movice como hemos visto con amplitud, éste jugó un papel protagónico hacia la última parte de la contienda. Y esto es así, no solamente porque el Ejecutivo mantuvo una posición distante de los movimientos, sino porque fungió como opositor permanente de estos. Fue necesaria la imposición de los otros dos poderes, aún sobre el ejecutivo, para que los Movimientos avanzaran en el cumplimiento de sus objetivos. Esto último nos indica que se trata de una contienda que sigue su curso pese a que estos episodios se han cerrado ya. 
Los impactos e implementación de estas políticas quedan aún por estudiar y las luchas que los movimientos han emprendido en estos nuevos escenarios también.

\subsection{Algunos Aprendizajes}

La combinación de la perspectiva integradora y comparativa de los estudios movimientos sociales propuesta por McAdam, McCarthy y Zald (1999) y la perspectiva dinámica de la contienda política de McAdam, Tarrow y Tilly (2005, 2007) nos ha llevado a recorrer caminos sinuosos e interesantes de la vida de estos movimientos sociales y sus impactos. La posibilidad de describir en detalle sus elementos en una perspectiva dinámica, nos permitió entender los diferentes factores que intervinieron en cada una de las decisiones y el tipo de trayectorias que decidieron recorrer los movimientos durante los episodios relatados. Además nos permitió entender los vínculos con el contexto y los demás actores en contienda y nos suministró la posibilidad de plantearnos en una perspectiva histórica de los hechos.

Esta forma de hacer investigación, si bien resulta exigente en la medida en que requiere una descripción detallada de los actores políticos, los escenarios, las instituciones, la cadena de eventos, las oportunidades políticas, los mecanismos y los resultados, permite desentrañar aspectos trascendentales en la producción de los hitos que de otra manera sería casi imposible conocer. El análisis de las entrevistas, las conversaciones informales y extensas con los protagonistas, la lectura cuidadosa de los documentos y las investigaciones, las visitas de campo y a las sedes, y aún, las memorias personales de quien escribe, permitieron hurgar en el corazón de los movimientos y en las realidades nacionales.

Al tiempo, esta combinación metodológica, además de permitirnos avanzar en la descripción densa de estos dos movimientos sociales, nos hizo posible circunscribirlos en un marco histórico más amplio, con profundas raíces en el pasado y expectativas de movilización en el futuro. En este caso pudimos verificar que estos movimientos, más que actores espontáneos puestos en acción tras la 
interpretación de unos agravios, son la extensión de procesos políticos e ideológicos más complejos. Fue durante el recorrido paso a paso por la reciente historia política de Colombia, que pudimos comprender que son los sujetos y actores políticos bien enterados y con amplia experiencia en la contienda, quienes tienen la capacidad de determinar el comienzo de una acción colectiva de largo aliento y, además, de ir alimentando conceptual, filosófica e ideológicamente al movimiento, captando por el camino a más y más adeptos.

Este modelo de trabajo también nos permitió observar lo profundamente ligadas que están las contiendas en Colombia con la política internacional y los intereses transnacionales. Pudimos ver tanto en la Ruta como en el Movice que la intervención de la comunidad internacional es trascendental para la generación de capacidades de los movimientos, especialmente por la vía de la financiación de proyectos. De la misma forma, entendimos cómo el marco normativo internacional no solamente es referente, sino que le implica al Estado colombiano adaptar su legislación interna a estos postulados, convirtiéndose en una camisa de fuerza para la creatividad normativa nacional, y que sus emisarios, comprendidos estos como los representantes de Naciones Unidas y de otras organismos multilaterales, pueden llegar a ser determinantes de la forma que toman las contiendas.

De otro lado fue posible ver cómo los movimientos sociales, pese al conflicto armado y a los altísimos grados de violencia que se experimentan en este país, logran sobrevivir, aun plateándole una contienda política al mismo Estado Nacional. Si bien muchos de sus miembros sufren represión, es cierto que estos movimientos han dado cara a las embestidas de los grupos armados legales e ilegales mediante la adaptación de sus discursos, sus acciones y los lugares que escogen para la lucha política, de tal suerte que evitan su propio aniquilamiento.

En general, la combinación de estos dos enfoques metodológicos nos posibilitó desmarcarnos de la idea clásica de buscar en las frecuencias y en las ausencias y presencias de ciertas características de los movimientos y de las oportunidades políticas las repuestas a las probabilidades de generación de impactos, y con ello, 
deshacernos de los malos augurios sobre las dificultades planteadas en torno a la posibilidad de estructurar los análisis de los movimientos sociales de estas regiones en las teorías clásicas sin tener que perder lo positivo que hay en la descripción densa y estática de los proceso enmarcadores, la estructura de movilización y los repertorios. Al tiempo, el uso de una perspectiva dinámica nos dio la versatilidad suficiente de ir hacia adelante y atrás en el tiempo, indagar por otros actores y sus respuestas y las variaciones de las oportunidades políticas, para poder registrar eventos y situaciones que de otra forma hubiese sido muy difícil identificar. Creemos que con la combinación de estas dos corrientes, hemos logrado sacar lo mejor de cada una de ellas generando mayor integralidad en este estudio.

\subsection{Futuras Investigaciones}

Pero así como este marco teórico y metodológico nos acercó al detalle, nos llevó por los análisis densos y complejos y nos permitió identificar aspectos de los movimientos y de los eventos en un contexto histórico más amplio e intrincado, nos alejó de la posibilidad de hacer contrastes más amplios y abarcadores y de generar conclusiones más generales.

Hemos detectado qué le funcionó a cada movimiento estudiado e identificado las oportunidades políticas y mecanismos que les fueron comunes, pero aún nos falta saber si esto podría ser un patrón explicable para los movimientos en Colombia, o aún, para los movimientos en contextos similares: guerra interna y debilidad institucional. Hacer estudios comparados con otros movimientos sociales al interior de Colombia o en contextos similares seleccionados por la similitud de los hitos, podría ser un avance en este sentido. Interesante también podría ser contrastar estos resultados comparándolos con movimientos en escenarios distintos con hitos y mecanismos similares. Seguramente esto nos permitiría conocer un poco más del comportamiento de los mecanismos dependiendo los ambientes y la forma que toman los hitos. En general, crear estudios comparados que nos permitan conocer más sobre las operaciones que se dan entre actores, mecanismos e hitos podría ser un camino profuso de conocimiento. 
Además de ello, este estudio nos ayudó a identificar temas que podrían ser muy sugerentes para nuevas investigaciones:

a. La intervención de la cooperación internacional en las contiendas domésticas. La injerencia tan alta de la cooperación internacional particularmente mediante recursos financieros, nos permite pensar que se trata de actores con altos intereses en las contiendas que se desarrollan localmente. Su rol en las luchas políticas nacionales, sus intereses y objetivos, el tipo de relación que tejen con sus "socios locales", y la forma en que trasladan la contienda a los escenarios internacionales podrían enseñarnos mucho de la forma que toman las luchas en lo local y de la forma en que se internacionalizan las luchas y se localizan las contiendas.

b. Movimientos sociales vs partidos políticos. Desde hace un tiempo se ha comenzado a estudiar la vocación de poder electoral en los movimientos sociales. La llegada a estos cargos de elección local y nacional de líderes reconocidos de los movimientos sociales podría indicarnos maneras institucionalizadas en las que se pueden empezar a resolver las contiendas. Qué tanto aviva o debilita esta situación a los movimientos sociales, y qué tan efectivo es, en contextos con democracias tan criticadas como la colombiana, el cambio de los repertorios de acciones colectivas a escenarios electorales institucionalizados, podría ser un campo interesante de estudio.

c. Resultados internos y resultados externos. Esta investigación se limitó a hacer un análisis de un tipo de resultado externo determinado por la promulgación de una política pública. Sin embargo, los movimientos producen una serie más amplia de resultados que bien valen la pena ser analizados y contrastados. ¿Qué otros logro han obtenido estos movimientos a nivel cultural, social y político? ¿Cómo son valorados por los movimientos y la sociedad? ¿Se han traducido estos logros en cambios reales para los miembros de los movimientos o para las comunidades por las que se lucha? Son algunas preguntas que pueden ser interesantes para investigaciones venideras. 
En suma, hasta acá hemos avanzado en la presentación detallada del surgimiento y características de dos movimientos sociales colombianos, analizando en particular su participación en la producción de dos impactos en la política pública nacional, a partir del estudio de las oportunidades políticas y los mecanismos que operaron en este proceso. En este ejercicio aprendimos que los movimientos han realizado ingentes esfuerzos por ser escuchados y para que sus reclamaciones sean reconocidas y respondidas, y que en ocasiones obtienen resultados. También pudimos observar que se trata además de movimientos que aspiran a transformaciones políticas estructurales y que se enmarcan en procesos de contienda más amplios en las que seguramente se han producido otra suerte de resultados que valen la pena indagar. Por el momento, creemos que, haber dado cuenta de este relato tal como ha sido narrado en este estudio, facilitará a las nueva generaciones de investigadores interesados en la materia, insumos valiosos para construir nuevas y mejores preguntas de investigación sobre la acción colectiva. 


\section{Bibliografía}

ACNUR. (2004). Algunos indicadores sobre la situación de derechos humanos en la región del Urabá Antioqueño. Recuperado 21 de octubre de 2015, a partir de http://www.acnur.org/t3/uploads/media/COI_675.pdf?view=1

Ajangiz, R. (2002). Política militar y movimientos sociales: el fin de la conscripción en Europa. Universidad del País Vasco, Leioa. Recuperado a partir

de https://www.academia.edu/1606932/Pol\%C3\%ADtica_militar_y_movimie ntos_sociales_el_fin_de_la_conscripci\%C3\%B3n_en_Europa

Alston, P. (2010). Informe del Relator Especial sobre las ejecuciones extrajudiciales, sumarias o arbitrarias. Misión a Colombia. A/HRC/14/24/Add.2. Ginebra, Suiza: Consejo de Derechos Humanos de Naciones Unidas. Recuperado a partir de http://www2.ohchr.org/english/bodies/hrcouncil/docs/14session/A.HRC.1 4.24.Add.2_sp.pdf

Amenta, E., Caren, N., Chiarello, E., \& Su, Y. (2010). The Political Consequences of Social Movements. Annual Review of Sociology, 36(1), 287-307. http://doi.org/10.1146/annurev-soc-070308-120029

Amnistía Internacional. (2004). Colombia: Un laboratorio de guerra. Represión y violencia en Arauca. Amnistía Internacional. Recuperado a partir de http://www.acnur.org/t3/uploads/media/COI_351.pdf?view=1

Arango, L. G., \& Rey, G. (Eds.). (1997). La crisis sociopolítica colombiana: un análisis no coyuntural de la coyuntura. Santafé de Bogotá: Observatorio Socio-Político y Cultural, Centro de Estudios Sociales, Facultad de Ciencias Humanas, Universidad Nacional de Colombia; Fundación Social.

Archila, M. (2003). Idas y venidas, vueltas y revueltas: protestas sociales en Colombia, 1958-1990. ICANH-Inst. Colombiano de Antropología e Historia.

Archila, M., \& Gómez, D. (2005). ¡Las Luchadoras! Recuperado 21 de octubre de 2015, a partir de http://www.semana.com/especiales/articulo/lasluchadoras/75376-3 
Archila, M., \& Pardo, M. (Eds.). (2001). Movimientos sociales, Estado y Democracia en Colombia. Bogotá: Universidad Nacional de Colombia, Centro de Estudios Sociales, Instituto Colombiano de Antropología e Historia.

Bautista Revelo, A. J. (2010). Movilización social de las mujeres para la construcción de la paz: la experiencia de la Ruta Pacífica de las Mujeres en Colombia. Aportes Andinos, 26. Recuperado a partir de http://repositorio.uasb.edu.ec/handle/10644/1058

Borda Guzmán, S. (2012). La administración de Álvaro Uribe y su política exterior en materia de derechos humanos: de la negación a la contención estratégica. Análisis Político, 25(75), 111-137.

Bosi, L., \& Uba, K. (2009). Introduction: The Outcomes of Social Movements. Mobilization: An International Quarterly, 14(4), 409-415.

Campaña «Violaciones y otras violencias: saquen mi cuerpo de la guerra». (2010). Primera Encuesta de Prevalencia: "Violencia sexual en contra de las mujeres en el contexto del conflicto armado colombiano», Colombia 20012009. Bogotá: Campaña «Violaciones y otras violencias: saquen mi cuerpo de la guerra». Recuperado a partir de http://www.humanas.org.co/archivos/1oxfampdf2.pdf

Carreño, E. (2003). Monólogo Gobierno Paramilitares. Presentado en Monólogo Gobierno Paramilitares, Facultad de Derecho, Universidad Nacional de Colombia.

Caviedes, M., \& Caldón, J. D. (2007). Paz y resistencia: experiencias indígenas desde la autonomía. Centro de Cooperación al Indígena CECOIN.

Centro de Investigación y Educación Popular. (2004). Deuda con la humanidad: paramilitarismo de Estado en Colombia 1988 - 2003. Bogotá: CINEP.

Cepeda, I. (2004, enero 7). Paramilitarismo en Colombia: Pacto de lealtades e impunidad. Rebelión. Recuperado a partir de http://www.rebelion.org/hemeroteca/plancolombia/040107cepeda.htm

Cepeda, I. (2007, octubre 31). La lucha por la democracia local. El Espectador. Recuperado 
http://www.elespectador.com/opinion/columnistasdelimpreso/ivan-cepedacastro/columna-lucha-democracia-local

Colombia Herald. (2006). Uribe: «Mientras no estén en la cárcel...» [Video en YouTube]. Bogotá: colombiaherald.wordpress.com. Recuperado a partir de https://www.youtube.com/watch?v=B0qW21fXioo

Comisión Colombiana de Juristas. (2004). En contravía de las recomendaciones internacionales: seguridad democrática, derechos humanos y derecho humanitario en Colombia, agosto de 2002 a agosto de 2004. Bogotá: Comisión Colombiana de Juristas.

Congreso de la República de Colombia. (2011, Junio 10). Ley 1448 de 2011. Por la cual se dictan medidas de atención, asistencia y reparación integral a las víctimas del conflicto armado interno y se dictan otras disposiciones. $\begin{array}{llll}\text { Recuperado } & \text { a } & \text { partir }\end{array}$ http://www.secretariasenado.gov.co/senado/basedoc/ley_1448_2011.html

Corporación Colectivo de Abogados José Alvear Restrepo. (2006, Noviembre 26). San Onofre, Sucre: la comunidad solicita la renuncia del alcalde. Recuperado 24 de octubre de 2015, a partir de http://www.redcolombia.org/oscar/varie/San_Onofre_es.pdf

Corporación Vamos Mujer. (2008). Mujeres de Negro. Ninguna guerra en nuestro nombre. Las mujeres tejemos sueños y esperanzas planetarias. Recuperado a partir de http://vamosmujer.org.co/sitio/images/pdfs/coleccion_editorial/mujeres_de _negro.pdf

Corte Constitucional de Colombia. (2004). Sentencia T-025 de 2004. Declaración de estado de cosas inconstitucional respecto de los derechos fundamentales de las víctimas del desplazamiento forzado por causa del conflicto armado. $\begin{array}{llll}\text { Recuperado } & \text { a } & \text { de }\end{array}$ http://www.corteconstitucional.gov.co/relatoria/2004/t-025-04.htm

Corte Constitucional de Colombia. (2006, Mayo 18). Sentencia C-370 de 2006. Constitucionalidad de la Ley 975 de 2005. Recuperado a partir de http://www.corteconstitucional.gov.co/relatoria/2006/c-370-06.htm 
Corte Constitucional de Colombia. (2008). Auto 092 de 2008. Seguimiento a la Sentencia T-025. Protección de los derechos fundamentales de las mujeres víctimas del desplazamiento forzado por causa del conflicto armado. Recuperado a partir de http://www.corteconstitucional.gov.co/relatoria/autos/2008/a092-08.htm

Corte Constitucional de Colombia. (2009, Enero 26). Auto 011 de 2009. Seguimiento a las medidas adoptadas para superar el estado de cosas inconstitucional sobre el problema del desplazamiento interno. Recuperado a partir de http://www.corteconstitucional.gov.co/T-02504/AUTOS\%202009/118.\%20Auto $\% 20$ del $\% 2026-01-$ 2009.\%20Auto\%20011\%20Habeas\%20Data.pdf

Corte Interamericana de Derechos Humanos. (2010, Mayo 26). Sentencia Caso Manuel Cepeda Vargas vs. Colombia. Recuperado a partir de http://www.corteidh.or.cr/index.php/es/jurisprudencia

Cristo, J. F. (2012). La guerra por las víctimas: lo que nunca se supo de la ley. Bogotá: Ediciones B.

Delgado, J. D. (2007). Perspectivas clásicas y contemporáneas en el estudio de los movimientos sociales: análisis multidimensional del giro hacia la relacionalidad. Revista Colombiana de Sociologia, 28, 47-71.

Departamento Nacional de Planeación. (2003). Plan Nacional de Desarrollo 20022006. Hacia un Estado Comunitario. Recuperado 22 de octubre de 2015, a partir de https://colaboracion.dnp.gov.co/CDT/PND/PND.pdf

El Espectador. (2010, Noviembre 8). Ex diputada española también habría sido víctima de 'chuzadas'. El Espectador. Bogotá. Recuperado a partir de http:/www.elespectador.com/noticias/judicial/ex-diputada-espanolatambien-habria-sido-victima-de-chu-articulo-233776

El Tiempo. (2004, Julio 29). Paras: 120 minutos en el Congreso. El Tiempo. Bogotá. Recuperado a partir de http://www.eltiempo.com/archivo/documento/MAM-1512042

Faciolince, H. A. (2004, agosto 2). Paras en el Congreso. Semana, 1161. Recuperado a partir de http://www.semana.com//portada/articulo/parascongreso/67269-3 
Forero Acosta, J. P. (2009). La construcción de identidades de resistencia contra la guerra en Colombia. Caso de estudio : Ruta Pacífica de Mujeres. Bogotá. Recuperado a partir de http://repository.urosario.edu.co/handle/10336/1087 Frühling, M. (2005, junio 23). Los derechos de las víctimas y los procesos de negociaciones para superar el conflicto armado. Intervención del señor Michael Frühling, Director de la Oficina en Colombia del Alto Comisionado de las Naciones Unidas para los Derechos Humanos En el II Encuentro Nacional de víctimas de crímenes de lesa humanidad y violaciones de los derechos humanos. Recuperado 24 de octubre de 2015, a partir de http://www.hchr.org.co/acnudh/index.php?option=com_content\&view=art icle\&id=303:los-derechos-de-las-victimas-y-los-procesos-denegociaciones-para-superar-el-conflicto-armado\&catid=25:ponencias-deldirector\&Itemid $=41$

Gallón, G. (2014, marzo 17). Ocho años de «Justicia y Paz»: un balance con más sombras que luces. Recuperado 24 de octubre de 2015, a partir de http://www.razonpublica.com/index.php/conflicto-drogas-y-paz-temas30/7446-ocho-a\%C3\%B1os-de-\%E2\%80\%9Cjusticia-ypaz $\% \mathrm{E} 2 \% 80 \% 9 \mathrm{D}$-un-balance-con-m\%C3\%A1s-sombras-que-luces.html

Gamson, W. A. (1990). The strategy of social protest. Belmont, Calif.: Wadsworth Pub. Recuperado a partir de http://www.questia.com/PM.qst?a=o\&d=9698812

García Villegas, M. (2005). Sociedad de emergencia: Acción colectiva y violencia en Colombia. Defensoría del Pueblo, Oficina para la Coordinación de la Atención al Desplazamiento Forzado.

Gaviria Betancur, P., \& Gil Savastiano, L. G. (Eds.). (2010). La agenda de las víctimas en el Congreso 2007-2009: aprendizajes para la incidencia desde la sociedad civil. Bogotá: Fundación Social, Editora Géminis.

Giugni, M. (2008). Political, Biographical, and Cultural Consequences of Social Movements. Sociology Compass, 2(5), 1582-1600. http://doi.org/10.1111/j.1751-9020.2008.00152.x

Giugni, M., \& Bosi, L. (2012). The Impact of Protest Movements on the Stablishment: Dimensions, Models and Approaches. En K. Fahlenbrach 
(Ed.), The Stablishment Respond: Power, Politics and Protest. (pp. 17 - 28). New York: Palgrave Macmillan.

Giugni, M., McAdam, D., \& Tilly, C. (1999). How Social Movements Matter. U of Minnesota Press.

Godàs i Pérez, X. (2007). Política del disenso: sociología de los movimientos sociales. Icaria Editorial.

Gómez López, C., Murad, R., \& Calderón, M. C. (2013). Historias de violencia, roles, prácticas y discursos legitimadores. Violencia contra las mujeres en Colombia 2000-2010. Bogotá: Fondo Interinstitucional. Recuperado a partir de https://www.yumpu.com/es/document/view/23993918/7-violenciacontra-las-mujeres-en-colombia

Gómez Sánchez, G. I. (2011). Between Reconciliation and Justice: The Struggles for Justice and Reconciliation in Colombia. Arizona State University, Arizona. Recuperado a partir de http://repository.asu.edu/attachments/56554/content/Gomez_asu_0010E_1 0538.pdf

Gómez Sánchez, G. I. (2012). Asimetrías del poder, resistencias y derechos de las víctimas frente a los procesos de justicia y paz. Revista Estudios de Derecho, Vol. 69 No. 153. Recuperado a partir de https://aprendeenlinea.udea.edu.co/revistas/index.php/red/article/viewFile/ $14142 / 12502$

Gómez Serrano, H. (2008, junio). La Acción Integral como estrategia de guerra. «365 días de trabajo que hacen la diferencia». Le Monde Diplomatique. Bogotá. Recuperado a partir de https:/elyacare0609.wordpress.com/2008/07/04/la-accion-integral-comoestrategia-de-guerra-365-dias-de-trabajo-que-hacen-la-diferencia/

González, F. E. (2014). Poder y violencia en Colombia. Bogotá: ODECOFICINEP.

González Gil, A. (2006). Acción colectiva en contextos de violencia prolongada. Revista Estudios Políticos, 29, 9-60.

Grupo de Memoria Histórica. (2011). Mujeres y Guerra. Víctimas y Resistentes en el Caribe Colombiano. Bogotá: Taurus. Recuperado a partir de 
http://www.centrodememoriahistorica.gov.co/informes/informes2011/mujeres-y-guerra

Grupo de Memoria Histórica. (2013). ¡Basta ya! Colombia: memorias de guerra y dignidad. Bogotá: Imprenta Nacional. Recuperado a partir de http://www.banrepcultural.org/blaavirtual/memoria-historica-cnrr/basta-ya Gutierrez Arguello, S. (2010, agosto 5). La verdad sobre el proceso de desmovilización paramilitar y su aporte a la paz. Recuperado 24 de octubre de 2015, a partir de http://www.colectivodeabogados.org/cajar_prueba/./?La-verdad-sobre-elproceso-

Ibarra Güell, P. (2005). Manual de sociedad civil y movimientos sociales. Síntesis. Ibarra Melo, M. E. (2011). Mujeres, verdad, justicia y reparación en Colombia. Universitas Humanística, 72(72). Recuperado a partir de http://revistas.javeriana.edu.co/index.php/univhumanistica/article/view/21 54

Ibarra, P., Martí, S., \& Gomà, R. (2002). Creadores de democracia radical: movimientos sociales y redes de políticas públicas. Icaria Editorial.

Jaramillo Londoño, C. (1997). El fracaso de la política social de Samper. Revista Universidad EAFIT, 33(107), 109-131.

Justicia por Colombia. (2010, Noviembre 8). La ex diputada valenciana Isaura Navarro fue espiada por los servicios secretos de Colombia. Recuperado 24 de octubre de 2015, a partir de http://justiciaporcolombia.org/node/277

KienyKe. (2011, Mayo 22). El día en que los paras se tomaron el Congreso. Recuperado 24 de octubre de 2015, a partir de http://www.kienyke.com/historias/el-dia-en-que-los-paras-se-tomaron-elcongreso/

Lewin, J. E., \& Morelo, D. (2015, abril 16). El círculo de Uribe, cada vez más condenado. Recuperado 25 de octubre de 2015, a partir de $\mathrm{http} / / /$ lasillavacia.com/historia/el-circulo-de-uribe-cada-vez-mascondenado-49957 
McAdam, D., McCarthy, J. D., \& Zald, M. N. (1999). Movimientos sociales, perspectivas comparadas: oportunidades politicas, estructuras de movilización y marcos interpretativos culturales. Ediciones Itsmo.

McAdam, D., Tarrow, S., \& Tilly, C. (2005). Dinámica de la contienda política. HACER.

McAdam, D., Tarrow, S., \& Tilly, C. (2008). Methods for Measuring Mechanisms of Contention. Qualitative Sociology, 31(4), 307-331. http://doi.org/10.1007/s11133-008-9100-6

McCarthy, J. D., \& Zald, M. N. (1977). Resource Mobilization and Social Movements: A Partial Theory. The American Journal of Sociology, 82, 1212 $-1241$.

Mesa de Trabajo «Mujer y conflicto armado». (2005). La Tradición, La Semilla y La Construcción. Sistematización de tres experiencias de resistencia de organizaciones de mujeres frente al conflicto armado en Colombia. Bogotá: Fondo de Desarrollo de las Naciones Unidas para la Mujer UNIFEM. Recuperado a partir de http://www.bdigital.unal.edu.co/45484/1/Latradicionlasemillaylaconstrucc ion.pdf

Mesa de Trabajo «Mujer y conflicto armado». (2008). VIII Informe sobre violencia sociopolítica contra mujeres, jóvenes y niñas en Colombia, 2007-2008. Bogotá: Mesa de Trabajo «Mujer y conflicto armado». Recuperado a partir de http://www.calameo.com/read/000360549593d4955644d

Mesa de Trabajo «Mujer y conflicto armado». (2010). X Informe sobre violencia sociopolítica contra mujeres, jóvenes y niñas en Colombia, 2000- 2010. Bogotá: Mesa de Trabajo «Mujer y conflicto armado». Recuperado a partir de http://www.calameo.com/read/000360549593d4955644d

Moncaleano, J., Tenthoff, M., Samudio, V., \& Duarte, M. (2013). Paz sin crímenes de Estado, memoria y propuestas de las víctimas. (J. Giraldo SJ \& F. Andreu, Eds.). Bogotá: Movimiento Nacional de Víctimas de Crímenes de Estado.

Montealegre, D. M., Bautista, A. J., Castaño, A., Betancur Marín, N. C., \& Jaramillo Burgos, A. M. (2011). Verdad, Justicia y Reparación Integral: 
una deuda pendiente con las mujeres víctimas de las violencias. Bogotá: Ruta Pacífica de las Mujeres. Recuperado a partir de http://www.rutapacifica.org.co/descargas/publicaciones/ Verdadjusticiayreparacion.pdf

Morsolin, C. (2005, octubre 17). Duras críticas al proceso de desmovilización en Colombia. Recuperado 24 de octubre de 2015, a partir de http://www.voltairenet.org/article129755.html

Movice. (2004, Mayo 29). Manifiesto por la verdad, la justicia y la reparación integral. Recuperado 24 de octubre de 2015, a partir de http://www.derechos.org/nizkor/colombia/doc/declavictim.html

Movice. (2005, Junio 25). Acta de Constitución del Movimiento Nacional de Víctimas de Crímenes de Estado MOVICE. Recuperado 24 de octubre de 2015 , a partir de http://www.movimientodevictimas.org/versionantigua/index.php?option=c om_k2\&view=item\&id=2584:acta-de-constituci\%C3\%B3n-delmovimiento-nacional-de-v\%C3\%ADctimas-segundo-encuentromovice \& Itemid $=340$

Movice. (2006, Julio 9). Declaración Final Tercer Encuentro Nacional de Víctimas de Crímenes de Estado. Recuperado 24 de octubre de 2015, a partir de http://www.movimientodevictimas.org/versionantigua/index.php?option=c om_k2\&view $=$ item\&id=2586:declaraci\%C3\%B3n-final-tercer-encuentronacional-de-v\%C3\%ADctimas-de-cr\%C3\%ADmenes-deestado\&Itemid $=297$

Movice. (2008a, marzo 8). Declaración política del Cuarto Encuentro del Movimiento Nacional de Víctimas de Crímenes de Estado. Recuperado 24 de octubre de 2015, a partir de http://www.movimientodevictimas.org/versionantigua/index.php?option $=$ com_k2\&view=item\&id=2587:declaraci $\% \mathrm{C} 3 \% \mathrm{~B} 3 \mathrm{n}-\mathrm{pol} \% \mathrm{C} 3 \%$ ADticadel-movimiento-nacional-de-v\%C3\%ADctimas-de-cr\%C3\%ADmenes-deestado-cuarto-encuentro\&Itemid $=340$ 
Movice. (2008b, abril 23). Carta del Movice al Embajador de Costa Rica. Recuperado 25 de octubre de 2015, a partir de http://www.dhcolombia.info/spip.php?article564

Movice. (2008c, noviembre 18). Otra burla más. El Movice rechaza el proyecto de «Ley de víctimas». Recuperado 25 de octubre de 2015, a partir de http://www.movimientodevictimas.org/versionantigua/index.php?option=c om_k2\&view $=$ item\&id $=2141$ :otra-burla-m\%C3\%A1s\&Itemid $=335$

Movice. (2009, Febrero 4). Política Integral de Acción en Derechos Humanos. Una propuesta desde las víctimas de crímenes de Estado. Recuperado a partir de http://www.movimientodevictimas.org/versionantigua/images/stories/pdfs/ Pol-integra\%20en\%20Derechos\%20Hum.pdf

Movice. (s. f.-a). Estructura Organizativa Movimiento Nacional de Víctimas de Crímenes de Estado. Recuperado 25 de octubre de 2015, a partir de http://www.movimientodevictimas.org/?q=content/estructura-organizativa

Movice. (s. f.-b). Historia Movimiento Nacional de Víctimas de Crímenes de Estado. Recuperado 24 de octubre de 2015, a partir de http://www.movimientodevictimas.org/?q=content/historia

Movice. (s. f.-c). Identidad Movimiento Nacional de Víctimas de Crímenes de Estado. Recuperado 25 de octubre de 2015, a partir de http://www.movimientodevictimas.org/?q=content/nuestra-identidad

Movimiento Nacional de Víctimas de Crímenes de Estado, Fundación Comité de Solidaridad con los Presos Políticos, \& Corporación Colectivo de Abogados José Alvear Restrepo. (2009). Sin Justicia y Sin Paz. Verdad Fragmentada, Reparación Ausente. Bogotá: Movimiento Nacional de Víctimas de Crímenes de Estado.

Noticias UNO. (2015, Febrero 8). La «Operación estímulo» del DAS. Recuperado 24 de octubre de 2015, a partir de http:/noticiasunolaredindependiente.com/2015/02/08/ noticias/laoperacion-estimulodel-das/

OPPDH. (2006). Dinámica reciente de la confrontación armada en el Urabá antioqueño. Bogotá: Observatorio del Programa Presidencial para los Derechos Humanos y DIH. Recuperado a partir de 
http://historico.derechoshumanos.gov.co/Observatorio/Publicaciones/docu ments/2010/Estu_Regionales/uraba.pdf

Palau van Hissenhoven, N. (2006). Trámite de la ley de justicia y paz: elementos para el control ciudadano al ejercicio del poder político. Bogota: Fundacion Social.

Pérez Liñán, A. (2008). El Metodo Comparativo: fundamentos y desarrollos recientes. Política Comparada. Recuperado a partir de http://www.politicacomparada.com.ar/material/09/documentos/doctrabajo_n1.pdf

Prensa Rural. (2005, Abril 8). Presentación oficial del Movimiento Nacional de Víctimas de Crímenes de Lesa Humanidad. Recuperado 25 de octubre de 2015, a partir de http://www.prensarural.org/mnv20050408.htm

Proyecto Colombia Nunca Más. (2000). Colombia Nunca Más Crímenes de Lesa Humanidad. Zona 14. (Vols. 1-2). Bogotá: Proyecto Colombia Nunca Más. Proyecto Colombia Nunca Más. (s. f.). Recuperado 24 de octubre de 2015, a partir de

http://movimientodevictimas.org/ nuncamas/index.php?option=com_cont ent\&view $=$ article $\&$ id $=1 \&$ Itemid $=310$

Quintero, B., Rodríguez, A. M., \& Rodríguez, C. (Eds.). (2013). Una mirada a los derechos de las mujeres en Colombia. Informe alternativo presentado al Comité de la CEDAW de Naciones Unidas 2013. Recuperado a partir de http://www.coljuristas.org/documentos/documento.php?id_doc=364\&idio $\mathrm{ma}=\mathrm{es} \&$ grupo $=4$

Ramírez Parra, P. (2009). El movimiento de mujeres frente al conflicto armado en Colombia y la construcción de paz 1998 - 2008. Revista Foro, 67, 31-43.

Ramírez Parra, P. (2010). Efectos de la (des) movilización paramilitar en la vida y el cuerpo de las mujeres en Colombia. Bogotá: Ruta Pacífica de las Mujeres. Recuperado a partir de http://www.bdigital.unal.edu.co/45593/

Romero, F. A. (2003). El movimiento de Derechos Humanos en Colombia. En Boletín $N^{o}$ 5: Emergencia de los Movimientos Sociales en la Región Andina. Quito, Ecuador: Programa Andino de Derechos Humanos, Universidad Andina Simón Bolívar. Recuperado a partir de 
http://portal.uasb.edu.ec/UserFiles/369/File/PDF/

CentrodeReferencia/Temasdeanalisis2/emergenciadelosmovimientossocial es/articulos/floralbaromero.pdf

Romero, M. (Ed.). (2007). Parapolítica: la ruta de la expansión paramilitar y los acuerdos políticos. Bogotá: Intermedio, Corporación Nuevo Arco Iris.

Romero, M. (Ed.). (2011). La economía de los paramilitares: redes de corrupción, negocios y política. Bogotá: Debate, Corporación Nuevo Arco Iris.

Ruta Pacífica de las Mujeres. (2003). La Ruta Pacífica de las Mujeres. No parimos hijos ni hijas para la guerra. Bogotá: Ruta Pacífica de las Mujeres.

Ruta Pacífica de las Mujeres. (2004, Noviembre). Convocatoria: Ruta Pacifica de Mujeres por la Resolución Negociada del Conflicto Armado. Movilización de las mujeres del Chocó para la denuncia sobre el desplazamiento de las comunidades chocoanas. Recuperado a partir de http://www.sindicat.net/dona/ruta_pacifica_de_mujeres_por_la.htm

Ruta Pacífica de las Mujeres. (s. f.-a). Boletín $\mathrm{N}^{o}$ 3. Con pasos de mujer. Recuperado a partir de http:/www.rutapacifica.org.co/sala-deprensa/boletines/159-editorial-verdad-justicia-reparacion

Ruta Pacífica de las Mujeres. (s. f.-b). Boletín N ${ }^{0}$ 7. El feminismo como una opción pacífica de la política. Recuperado a partir de http://www.rutapacifica.org.co/sala-de-prensa/boletines/159-editorialverdad-justicia-reparacion

Ruta Pacífica de las Mujeres. (s. f.-c). Boletín Nº 8. Verdad Justicia Reparación. Recuperado a partir de http:/www.rutapacifica.org.co/sala-deprensa/boletines/159-editorial-verdad-justicia-reparacion

Ruta Pacífica de las Mujeres, Vamos Mujer, Casa de la Mujer, \& Mujeres que Crean. (2008). Informe sobre violencia sexual y feminicidios en Colombia presentado a la Comisión Interamericana de Derechos Humanos. Washington: Comisión Interamericana de Derechos Humanos.

Sala de Situación Humanitaria. (2005). Informe Julio de 2005 (No. Vol. 4 No. 7). Oficina para la Coordinación de Asuntos Humanitarios OCHA. Recuperado a partir de https://www.humanitarianresponse.info/es/system/files/07SSH05ext.pdf 
Sánchez, O. A. (2006). Nuevas formas de resistencia civil. De lo privado a lo público: movilizaciones de la Ruta Pacífica, 1996-2003. Ruta Pacífica de las Mujeres.

Sánchez, O. A. (2008). Las violencias contra las mujeres en una sociedad en guerra. Bogotá: Ruta Pacífica de las Mujeres. Recuperado a partir de http://www.rutapacifica.org.co/publicaciones/227-las-violencias-contralas-mujeres-en-una-sociedad-en-guerra

Semana. (2002, Diciembre 1). Carrera de obstáculos. Semana, 1074. Recuperado a partir de http://www.semana.com/nacion/articulo/carreraobstaculos $/ 55336-3$

Semana. (2004, Octubre 17). Estatuto antiterrorista. Recuperado 24 de octubre de 2015, a partir de http://www.semana.com//on-line/articulo/estatutoantiterrorista/67905-3

Semana. (2006, Diciembre 2). Les voy a pedir a todos los congresistas que mientras no estén en la cárcel, voten... Recuperado 25 de octubre de 2015, a partir de http://www.semana.com//enfoque/frase-de-la-semana/articulo/les-voypedir-todos-congresistas-mientras-no-esten-carcel-voten/82445-3

Semana. (2008a, 22Abril). Mario Uribe pide asilo en Embajada de Costa Rica y víctimas se movilizan. Recuperado 25 de octubre de 2015, a partir de http://www.semana.com//on-line/articulo/mario-uribe-pide-asiloembajada-costa-rica-victimas-movilizan/92289-3

Semana. (2008b, febrero 7). Iván Cepeda: «Queremos que se le rinda un justo homenaje a las víctimas del paramilitarismo». Recuperado 24 de octubre de 2015, a partir de http://www.semana.com//on-line/articulo/ivan-cepedaqueremos-rinda-justo-homenaje-victimas-del-paramilitarismo/90881-3

Semana. (2008c, septiembre 27). ¿Falsos positivos mortales? Recuperado 25 de $\begin{array}{lllll}\text { octubre } & \text { de } & 2015, & \text { a } & \text { partir }\end{array}$ http://www.semana.com//nacion/articulo/falsos-positivos-mortales/956073

Semana. (2010, Febrero 26). Referendo: historia de una causa perdida. Recuperado 25 de octubre de 2015, a partir de 
http://www.semana.com//politica/articulo/referendo-historia-causaperdida/113678-3

Semana. (2011, Febrero 21). Mario Uribe, condenado a siete años y medio de cárcel por «parapolítica». Recuperado 25 de octubre de 2015, a partir de http://www.semana.com//nacion/articulo/mario-uribe-condenado-sieteanos-medio-carcel-parapolitica/235843-3

Smelser, N. J. (1989). Teoría del Comportamiento Colectivo. Fondo de Cultura Económica.

Tarrow, S. (2004). El Poder en Movimiento: Los Movimientos Sociales, la Acción Colectiva y la Política. Alianza.

Tilly, C., \& Tarrow, S. (2007). Contentious Politics. Colorado, USA: Paradigm Publishers.

Verdad Abierta. (2011). Fiscalía formula cargos a tres «paras» por masacre de Barranca. Recuperado 22 de octubre de 2015, a partir de http://www.verdadabierta.com/ imputaciones/570-bloque-centralbolivar/3649-fiscalia-formula-cargos-a-tres-paras-por-masacre-debarranca

Vergel Tovar, C. (2009). Between constitutional jurisdiction and women's rights organizations: women, war and the space of justice in Colombia. Presentado en International Conference on Feminist Constitutionalism, Queens' University - Kingston (Canada).

Weber, M. (2001). Ensayos sobre metodología sociológica. Buenos Aires: Amorrortu. 


\section{Anexo 1. Formatos de Entrevistas}

\section{Formato de Entrevista Movimientos}

\section{Entrevistado:}

Investigadora: Vera Samudio

Director: Salvador Marti i Puig

Esta entrevista contiene las distintas inquietudes que rodean esta investigación y tiene como único destino servir de fuente de información para la misma. Está dividida en dos componentes que pueden ser desarrollados de manera independiente. Las respuestas pueden ser escritas o verbales (mediante grabación de audio). El entrevistado está en plena libertad de omitir temas y respuestas si así lo considera, así como de solicitar el anonimato o uso de seudónimos. La investigadora agradece enormemente el tiempo y disposición para desarrollar esta entrevista.

A. Identificación de Hitos: impactos positivos, percibidos por los movimientos como avances muy relevantes presuntamente producidos por la actividad desplegada por los movimientos.

1. ¿Existe en su criterio algún hito (norma o parte de una norma, sentencia judicial de muy alto impacto, o política pública expedida, implementada o ejecutada desde el Estado), que deba su existencia a una acción o conjunto de acciones que el Movimiento haya desplegado con ese fin?

2. ¿Podría describirnos brevemente de qué se trata este hito? (norma, parte de una norma, sentencia relevante o política pública)

3. ¿En qué medida considera que influyó la acción del Movimiento en la producción de este hito y de qué manera? 
4. ¿Qué grado o tipo de importancia considera que tiene este hito en el cumplimiento de los objetivos del Movimiento?

5. ¿Cuáles son las acciones específicas del Movimiento que considera que incidieron en la producción del hito?

6. ¿Qué otros actores participaron en el proceso de producción del hito?

7. ¿Cuáles elementos del contexto considera que fueron determinantes en el proceso de producción del hito?

8. ¿Cuál respuesta institucional no se ha obtenido a pesar de ser un objetivo del Movimiento y haber desplegado acciones (similares a las que condujeron al hito) para conseguirla?

B. Descripción del Movimiento

Antecedentes:

1. ¿Cuál es la problemática social que motiva el surgimiento del Movimiento?

2. ¿Hay otras problemáticas que sean de interés del Movimiento?

3. ¿Cómo debería ser la situación sin esa problemática?

4. ¿Cómo contribuye la movilización que realiza el Movimiento a la solución?

5. ¿Hay otras formas de buscar esa solución?

Objetivos:

1. ¿cuáles son los objetivos del movimiento?

2. ¿Se han definido objetivos nuevos después del nacimiento del movimiento?

3. ¿Hay procesos de crítica interna sobre los objetivos? ¿Cuáles?

4. ¿Considera que los objetivos de movimiento han sido percibidos por el Estado como una amenaza, o, como una posibilidad?

Perfil Organizativo:

1. ¿Cómo está organizado el Movimiento? 
2. ¿Tiene estructuras organizativas permanentes?

3. ¿Transforma su estructura organizativa frecuentemente?

4. ¿Cómo se producen las decisiones y solucionan los desacuerdos?

Participación en redes:

1. ¿Participa de actividades en red con otros movimientos u organizaciones?

2. ¿En cuáles redes participa?

3. ¿Qué aporta el movimiento a esas redes?

4. ¿Qué aportan las redes al movimiento?

Canales de comunicación

1. ¿Cómo se comunican entre sí los miembros del movimiento sus inquietudes, informaciones, propuestas, etc?

2. ¿Cómo comunican sus ideas, opiniones, informaciones, propuestas exigencias, etc, con otros movimientos o sectores sociales?

Repertorios de acción:

1. ¿Cuáles son las acciones más comunes que realiza el Movimiento?

2. ¿Cuáles otras acciones ha realizado esporádicamente?

3. ¿Hay algún tipo de acción que no realizarían? 


\section{Formato de Entrevista Expertos}

\section{Entrevistada:}

Investigadora: Vera Samudio

Director: Salvador Marti i Puig

Esta entrevista contiene las distintas inquietudes que rodean esta investigación y tiene como único destino servir de fuente de información para la misma. Las respuestas pueden ser escritas o verbales (mediante grabación de audio). El entrevistado está en plena libertad de omitir temas y respuestas si así lo considera, así como de solicitar el anonimato o uso de seudónimos. La investigadora agradece enormemente el tiempo y disposición para desarrollar esta entrevista.

Primera Parte:

El proceso de discusión sobre la necesidad de una ley de víctimas/ Auto de Seguimiento.

1. Definición de la problemática. Cómo se definía la problemática por parte de los diferentes actores? Qué intereses entraban en juego?

2. Actores: Institucionales, políticos, sociales, medios de comunicación. Cómo fue la dinámica de la participación de los diferentes actores?

3. Momentos, tensiones, alianzas. Momentos claves y momentos críticos en la definición de la problemática y la formulación de la política.

Segunda parte: 
Participación directa en el proceso.

1. Cómo fue su participación en el proceso?

2. Qué eventos encuentra relevantes en el proceso?

3. Cómo explica la generación del resultado?

4. Cuál nivel de importancia le da al resultado?

Tercera parte:

Incidencia del Movice / Ruta Pacífica en la inclusión de las "víctimas de agentes estatales" / "reconocimiento de las afectaciones particulares de las mujeres en el conflicto armado".

1. Cómo percibió la actividad y la participación del Movice / Ruta Pacífica durante el proceso y su posible influencia en cuanto a la inclusión de la categoría de "victimas de agentes estatales" en el artículo 3 sobre definición de víctimas / " afectaciones especiales de las mujeres” en el Auto 092

2. Considera que las acciones del movimiento incidieron directa/indirectamente en la producción del resultado? Por qué?

3. Qué elementos externos intervinieron en la producción del hito?

4. El hito podría haberse producido de forma similar ante la ausencia del Movimiento? 


\section{Anexo 2. Listado de Entrevistas}

\section{Ruta Pacífica de las Mujeres}

1. Marina Gallego: Integrante de Dirección Nacional 1. 28 de Noviembre y 7 de Diciembre de 2012.

2. Dunia León Activista de Regional Bolívar. 5 de Diciembre de 2012.

3. Shima Pardo: Responsable Nacional de Comunicaciones. 28 de Enero de 2013.

4. Activista Regional Santander. 28 de Enero de 2013.

5. María Teresa Arizabaleta: Co- coordinadora de Regional Valle del Cauca. 28 de agosto de 2013.

6. Martha Elena Giraldo: Co- coordinadora de Regional Valle del Cauca. 28 de agosto de 2013

7. Socorro Corrales: Coordinadora de Regional Cauca. 28 de Noviembre de 2013.

8. Rosana Jerez: Activista de Bucaramanga.25 de Julio de 2014.

9. Esperanza Ramírez: Activista de Bogotá 1. 19 de Agosto de 2014.

10. Angélica Badillo. Activista de Santander 2. 19 de Agosto de 2014.

11. Olga Amparo Sánchez. Integrante de Dirección Nacional 2. 18 de Septiembre de 2014.

\section{Movimiento Nacional de Víctimas de Crímenes de Estado}

12. Julián Carreño. Integrante de Equipo Técnico Nacional 1. 12 de Diciembre de 2012.

13. Laia Bertran. Integrante de Equipo Técnico Nacional 2. 12 de Diciembre de 2012.

14. Marcela Duarte. Secretaría Técnica Nacional. 15 de Febrero de 2013.

15. Franklin Castañeda. Integrante de Comité de Impulso Nacional 1.7 de Marzo de 2013. 
16. Participación en Encuentro Nacional. 4 de Abril de 2013.

17. Soraya Gutiérrez. Activista de Bogotá 1. 5 de Agosto de 2013.

18. Alfonso Castillo. Activista de Bogotá 2. 8 de Agosto de 2013.

19. Camilo Villa. Activista de Bogotá 3.12 de Agosto de 2013.

20. Rocío Campos. Activista de Santander. 4 de Septiembre de 2013.

21. Jairo Ramírez. Integrante de Comité de Impulso Nacional 2. 18 de Septiembre de 2013.

22. Activista de Nariño. 30 de Septiembre de 2013.

23. Eduardo Carreño. Integrante de Comité de Impulso Nacional 3. 8 de Noviembre de 2013.

\section{Expertos Externos}

24. Ana Jimena Bautista. Consultora en Organizaciones Sociales, Organizaciones No Gubernamentales y Entidades de Cooperación Internacional. 12 de Noviembre de 2013.

25. Iván Cepeda Castro. Senador de la República por el Partido Polo Democrático Alternativo. 22 de Noviembre de 2013.

26. Fátima Esparza. Consultora en Organizaciones Sociales, Organizaciones No Gubernamentales y Entidades de Cooperación Internacional. 23 de Enero de 2014.

27. Osana Medina Bonilla. Funcionaria del Programa "Casas Refugio" de la Secretaría Distrital de Mujer de la Alcaldía de Bogotá. 24 de Febrero de 2014.

28. Cecilia Barraza Morelle. Alta Consejera Presidencial para la Equidad de la Mujer. 3 de Abril de 2014.

29. Gabriel Ignacio Gómez. Docente Universidad de Antioquia. 6 de Abril de 2014.

30. Adriana González Gil. Docente Universidad de Antioquia. 23 de Abril de 2014. 
Anexo 3. Esquema de Codificación para Análisis en Atlas Ti

Códigos para: Estado del Arte y Marco Teórico: EAMT

EAMT-Definición: Definición

EAMT-Impactos : Impactos

EAMT-Metodología : Metodología

EAMT-PE : Procesos Enmarcadores

EAMT-EM : Estructuras de movilización

EAMT-EOP : Estructuras de oprtunidades políticas

Códigos para descripción con conceptos de "Perspectiva Integradora"

EM : Estructuras de Movilización

EOP : Estructura de Oportunidades Políticas

PE : Procesos Enmarcadores

MVCE : Movice

RPM : Ruta Pacífica

MVCE-HITO

MVCE-Otros Impactos

MVCE-EM-ACC : Repertorios de Acción

MVCE-EM-ORG : Forma Organizativa

MVCE-EM-RED : Participación en Redes

MVCE-EOP-AO : Situación de Alianzas y Oposiciones

MVCE-EOP-INT : Presión Internacional

MVCE-EOP-REP : Nivel de Represión

MVCE-EOP-SP : Apertura del Sistema político

MVCE-PE-AGR : Configuración Ideológica: Agravios

MVCE-PE-OBJ : Definición de Objetivos 
RPM-HITO

RPM-Otros Impactos

RPM-EM-ACC : Repertorios de Acción

RPM-EM-ORG : Forma Organizativa

RPM-EM-RED : Participación en Redes

RPM-EOP-AO : Situación de Alianzas y Oposiciones

RPM-EOP-INT : Presión Internacional

RPM-EOP-REP : Nivel de Represión

RPM-EOP-SP : Apertura del Sistema político

RPM-PE-AGR : Configuración Ideológica: Agravios

RPM-PE-OBJ : Definición de Objetivos

\section{Códigos para Análisis DOC (Dinámica de la Contienda)}

\section{Conceptos principales para la descripción}

Descripción-MS-Gobierno

Descripción-MS-Actores-Identidades

Descripción-MS-Bases-Campañas

Descripción-MS-Acciones-Repertorios

Descripción-MS-Eventos-Episodios

\section{Conceptos para la explicación}

Explicación-Condiciones Iniciales

Explicación-Secuencia de eventos

Explicación-Oportunidad-Multiplicidad

Explicación-Oportunidad-Apertura

Explicación-Oportunidad-Inestabilidad

Explicación-Oportunidad-Aliados

Explicación-Oportunidad-Represión

Explicación-Oportunidad-Cambios 
Mecanismos

MVCE-Difusión

MVCE-Polarización

MVCE-Radicalización

MVCE-Atribución de amenaza

MVCE-Atribución de oportunidad

MVCE-Apropiación

MVCE-Correduría

MVCE-Certificación

MVCE-Descertificación

MVCE-Atribución de similitud

MVCE-Formación de identidad

MVCE-Transformación de identidad

MVCE-Constitución de nuevos actores

MVCE-Formación de categorías (Invención, Préstamo, Encuentro)

MVCE-Cambio de objeto

MVCE-Convergencia

MVCE-Coalición

MVCE-Coordinación

MVCE-Imposición repentina de agravios

MVCE-Competencia por el poder

MVCE-Coaliciones transversales

MVCE-Cooptación de intermediarios

MVCE-Emulación

MVCE-Cambio de escala

MVCE-Integración de redes de confianza

MVCE-Activación y desactivación de fronteras

MVCE-Formación de fronteras

MVCE-Cambio de fronteras

MVCE-Deserción 
RPM-Difusión

RPM-Polarización

RPM-Polarización

RPM-Radicalización

RPM-Atribución de amenaza

RPM-Atribución de oportunidad

RPM-Apropiación

RPM-Correduría

RPM-Certificación

RPM-Descertificación

RPM-Atribución de similitud

RPM-Formación de identidad

RPM-Transformación de identidad

RPM-Constitución de nuevos actores

RPM-Formación de categorías (Invención, Préstamo, Encuentro)

RPM-Cambio de objeto

RPM-Convergencia

RPM-Coalición

RPM-Coordinación

RPM-Imposición repentina de agravios

RPM-Competencia por el poder

RPM-Coaliciones transversales

RPM-Cooptación de intermediarios

RPM-Emulación

RPM-Cambio de escala

RPM-Integración de redes de confianza

RPM-Activación y desactivación de fronteras

RPM-Formación de fronteras

RPM-Cambio de fronteras

RPM-Deserción 
Anexo 4. Cifras de Victimización por Año y por Departamento

\begin{tabular}{|c|c|c|c|c|c|c|c|}
\hline DEPARTAMENTO & 1990 & 1995 & 2000 & 2002 & 2005 & 2010 & 2014 \\
\hline Amazonas & 1 & 17 & 48 & 135 & 136 & 93 & 204 \\
\hline Antioquia & $\begin{array}{l}21.06 \\
7\end{array}$ & $\begin{array}{l}68.91 \\
0\end{array}$ & $\begin{array}{l}149.07 \\
4\end{array}$ & $\begin{array}{l}126.46 \\
1\end{array}$ & $\begin{array}{l}68.63 \\
7\end{array}$ & $\begin{array}{l}33.58 \\
7\end{array}$ & $\begin{array}{l}21.50 \\
5\end{array}$ \\
\hline Arauca & 810 & 1.164 & 3.021 & 10.813 & 8.559 & 5.966 & 2.467 \\
\hline Atlántico & 146 & 173 & 1.478 & 2.193 & 2.279 & 455 & 415 \\
\hline Bogotá, D.C. & 185 & 296 & 681 & 1.762 & 1.947 & 967 & 634 \\
\hline Bolívar & 2.159 & 3.582 & 91.715 & 61.809 & $\begin{array}{l}38.97 \\
0\end{array}$ & 5.480 & 5.471 \\
\hline Boyacá & 587 & 576 & 1.461 & 3.507 & 2.479 & 452 & 561 \\
\hline Caldas & 793 & 1.201 & 5.954 & 31.035 & $\begin{array}{l}15.82 \\
5\end{array}$ & 1.013 & 992 \\
\hline Caquetá & 921 & 1.746 & 11.621 & 38.296 & $\begin{array}{l}22.49 \\
2\end{array}$ & $\begin{array}{l}14.06 \\
0\end{array}$ & $\begin{array}{l}12.64 \\
9\end{array}$ \\
\hline Casanare & 479 & 819 & 4.001 & 7.201 & 4.599 & 643 & 897 \\
\hline Cauca & 2.086 & 1.817 & 15.782 & 23.346 & $\begin{array}{l}24.59 \\
1\end{array}$ & $\begin{array}{l}17.76 \\
3\end{array}$ & $\begin{array}{l}22.68 \\
1\end{array}$ \\
\hline Cesar & 2.770 & 5.244 & 32.440 & 61.941 & $\begin{array}{l}33.73 \\
2\end{array}$ & 2.287 & 2.296 \\
\hline Choco & 1.017 & 6.727 & 25.019 & 46.981 & $\begin{array}{l}17.43 \\
2\end{array}$ & 7.185 & $\begin{array}{l}13.57 \\
0\end{array}$ \\
\hline Córdoba & 6.315 & 6.066 & 21.523 & 23.745 & $\begin{array}{l}13.83 \\
1\end{array}$ & $\begin{array}{l}12.95 \\
1\end{array}$ & 6.138 \\
\hline Cundinamarca & 990 & 1.383 & 6.607 & 24.337 & 6.456 & 1.009 & 1.007 \\
\hline Guainía & 27 & 43 & 168 & 306 & 657 & 272 & 206 \\
\hline Guaviare & 380 & 818 & 3.122 & 8.369 & 7.618 & 3.203 & 1.658 \\
\hline Huila & 657 & 877 & 3.647 & 10.755 & 8.426 & 8.166 & 7.791 \\
\hline La Guajira & 520 & 1.437 & 8.174 & 20.840 & $\begin{array}{l}15.81 \\
0\end{array}$ & 3.194 & 1.928 \\
\hline Magdalena & 1.411 & 3.865 & 52.881 & 61.000 & $\begin{array}{l}38.39 \\
3\end{array}$ & 2.699 & 2.996 \\
\hline Meta & 1.664 & 1.873 & 11.702 & 23.920 & $\begin{array}{l}25.13 \\
8\end{array}$ & 6.275 & 3.832 \\
\hline
\end{tabular}




\begin{tabular}{|c|c|c|c|c|c|c|c|}
\hline Nariño & 365 & 859 & 5.450 & 26.219 & $\begin{array}{l}20.45 \\
8\end{array}$ & $\begin{array}{l}26.58 \\
4\end{array}$ & $\begin{array}{l}29.74 \\
7\end{array}$ \\
\hline No definido & 688 & 829 & 14.627 & 4.164 & 6.286 & 180 & 178 \\
\hline Norte De Santander & 1.531 & 2.098 & 15.419 & 46.371 & $\begin{array}{l}15.52 \\
0\end{array}$ & 4.448 & 7.044 \\
\hline Putumayo & 1.122 & 1.408 & 17.198 & 32.507 & $\begin{array}{l}16.70 \\
7\end{array}$ & 8.252 & 7.332 \\
\hline Quindío & 138 & 147 & 605 & 1.470 & 1.350 & 657 & 571 \\
\hline Risaralda & 696 & 1.052 & 4.312 & 5.126 & 4.521 & 790 & 1.459 \\
\hline $\begin{array}{l}\text { San Andrés, Providencia y } \\
\text { Santa Catalina }\end{array}$ & & & 2 & 20 & & & 5 \\
\hline Santander & 2.932 & 3.662 & 14.749 & 14.957 & $\begin{array}{l}10.37 \\
0\end{array}$ & 2.298 & 1.465 \\
\hline Sucre & 1.245 & 3.816 & 30.436 & 33.848 & $\begin{array}{l}19.12 \\
4\end{array}$ & 2.321 & 1.374 \\
\hline Tolima & 980 & 1.854 & 14.704 & 30.303 & $\begin{array}{l}18.97 \\
9\end{array}$ & $\begin{array}{l}10.93 \\
4\end{array}$ & 9.967 \\
\hline Valle Del Cauca & 2.207 & 2.267 & 19.280 & 18.639 & $\begin{array}{l}15.00 \\
5\end{array}$ & $\begin{array}{l}10.02 \\
4\end{array}$ & $\begin{array}{l}28.66 \\
3\end{array}$ \\
\hline Vaupés & 15 & 48 & 487 & 333 & 712 & 230 & 130 \\
\hline Vichada & 33 & 129 & 666 & 1.278 & 1.580 & 801 & 435 \\
\hline
\end{tabular}

Fecha de Corte: 01 oct 2015. Red Nacional de Información Unidad de Atención y Reparación Integral a Víctimas del Conflicto. 